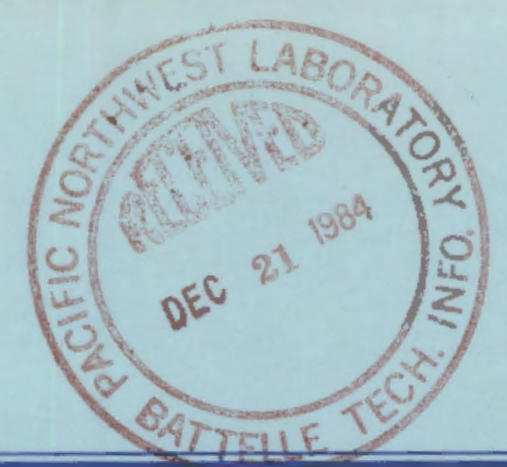

$P N L-5072$ I

NUREG/CR-3681 PNL-5072

\title{
Mitigative Techniques and Analysis of Generic Site Conditions for Ground-Water Contamination Associated with Severe Accidents
}

Draft Report

Prepared by J. M. Shafer, P. L. Oberlander, R. L. Skaggs

Pacific Northwest Laboratory

Operated by

Battelle Memorial Institute

\section{Prepared for}

U.S. Nuclear Regulatory

Commission 


\section{NOTICE}

This report was prepared as an account of work sponsored by an agency of the United States Government. Neither the United States Government nor any agency thereof, or any of their employees, makes any warranty, expressed or implied, or assumes any legal liability of responsibility for any third party's use, or the results of such use, of any information, apparatus, product or process disclosed in this report, or represents that its use by such third party would not infringe privately owned rights.

\section{NOTICE}

\section{Availability of Reference Materials Cited in NRC Publications}

Most documents cited in NRC publications will be available from one of the following sources:

1. The NRC Public Document Room, 1717 H Street, N.W. Washington, DC 20555

2. The NRC/GPO Sales Program, U.S. Nuclear Regulatory Commission, Washington, DC 20555

3. The National Technical Information Service, Springfield, VA 22161

Although the listing that follows represents the majority of documents cited in NRC publications, it is not intended to be exhaustive.

Referenced documents available for inspection and copying for a fee from the NRC Public Document Room include NRC correspondence and internal NRC memoranda; NRC Office of Inspection and Enforcement bulletins, circulars, information notices, inspection and investigation notices; Licensee Event Reports; vendor reports and correspondence; Commission papers; and applicant and licensee documents and correspondence.

The following documents in the NUREG series are available for purchase from the NRC/GPO Sales Program: formal NRC staff and contractor reports, NRC-sponsored conference proceedings, and NRC booklets and brochures. Also available are Regulatory Guides, NRC regulations in the Code of Federal Regulations, and Nuclear Regulatory Commission /ssuances.

Documents available from the National Technical Information Service include NUREG series reports and technical reports prepared by other federal agencies and reports prepared by the Atomic Energy Commission, forerunner agency to the Nuclear Regulatory Commission.

Documents available from public and special technical libraries include all open literature items, such as books, journal and periodical articles, and transactions. Federal Register notices, federal and state legislation, and congressional reports can usually be obtained from these libraries.

Documents such as theses, dissertations, foreign reports and translations, and non-NRC conference proceedings are available for purchase from the organization sponsoring the publication cited.

Single copies of NRC draft reports are available free, to the extent of supply, upon written request to the Division of Technical Information and Document Control, U.S. Nuclear Regulatory Commission, Washington, DC 20555.

Copies of industry codes and standards used in a substantive manner in the NRC regulatory process are maintained at the NRC Library, 7920 Norfolk Avenue, Bethesda, Maryland, and are available there for reference use by the public. Codes and standards are usually copyrighted and may be purchased from the originating organization or, if they are American National Standards, from the American National Standards Institute, 1430 Broadway, New York, NY 10018. 


\section{Mitigative Techniques and Analysis of Generic Site Conditions for Ground-Water Contamination Associated with Sever Accidents}

\section{Draft Report}

Manuscript Completed: January 1984

Date Published: April 1984

Prepared by

J. M. Shafer, P. L. Oberlander, R. L. Skaggs

Pacific Northwest Laboratory

Richland, WA 99352

\section{Prepared for}

Division of Health, Siting and Waste Management

Office of Nuclear Regulatory Research

U.S. Nuclear Regulatory Commission

Washington, D.C. 20555

NRC FIN B2454 


\section{DISCLAIMER}

Use of tradenames is for reader convenience only and does not imply endorsement by the Department of Energy and by Pacific Northwest Laboratory. 
EXECUTIVE SUMMARY.................................... XV

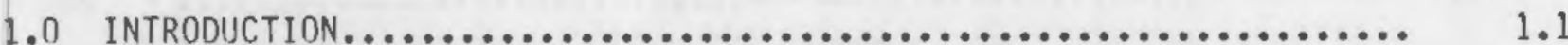

1.1 PURPOSE DF STUDY.................................. 1.1

1.2 ORGANIZATION OF REPORT ........................... 1.2

1.3 BACKGROUND..................................... 1.3

1.4 STUDY OBJECTIVES............................... 1.4

1.5 PROJECT SCOPE.................................. 1.6

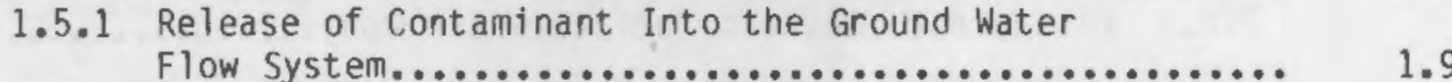

1.5.2 Hydrogeologic Classification of Nuclear Power

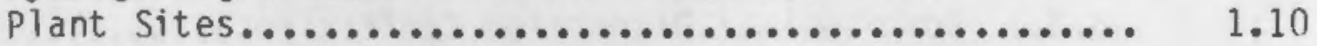

1.5.3 Analysis of Radionuclide Transport in

Ground water.................................. 1.11

1.5.4 Identification and Evaluation of Ground Water

Contaminant Mitigation Techniques................ 1.12

1.5.5 Determination of Feasible Mitigative Techniques

for Specific Hydrogeologic Classifications........... 1.13

1.5.6 Case Study Analysis............................. 1.13

1.6 REALISTIC VERSUS CONSERVATIVE ANALYSES $\ldots \ldots \ldots \ldots \ldots \ldots \ldots \ldots \ldots \ldots$

2.0 DESCRIPTION OF CORE MELT RELEASE OF RADIONUCLIDES $\ldots \ldots \ldots \ldots \ldots \ldots \ldots \ldots$

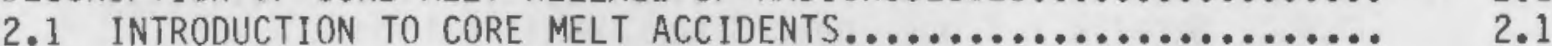

2.1 .1 Definition of Core Melt Accident..................... 2.1

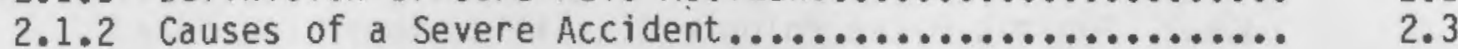

2.1.3 Core Melt Penetration of Reactor Basemat............... 2.5

2.1.4 Chemical Composition of Core Melt Debris............... 2.5

2.1.5 Sump Water Release Following Basemat Penetration...... 2.6

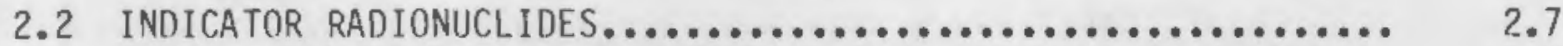

2.2.1 Initial Amount of Indicator Radionuclides in Core..... 2.7

2.2.2 Radionuclide Partitioning....................... 2.7

2.3 CODLING OF THE CORE MELT DEBRIS $\ldots \ldots \ldots \ldots \ldots \ldots \ldots \ldots \ldots \ldots \ldots \ldots \ldots \ldots \ldots$

2.4 CORE MELT DEBRIS LEACH RELEASE...................... 2.10

2.4.1 Introduction to Leach Releases..................... 2.10

2.4.2 Silicic Melts................................... 2.11

2.4 .3 Calcine Melts................................ 2.18

2.5 SUMP WATER RELEASE RATES........................ 2.19 
2.6 CONCLUSIONS CONCERNING RADIONUCLOIDE RELEASES FOLLOWING

A SEVERE ACCIOENT..................................

2.7 REFERENCES.

3.0 GENERIC HYDROGEOLOGIC SITE CLASSIFICATION..................

3.1 CLASSIFICATION SCHEME.............................

3.1.1 Considerations for a Classification Scheme.............

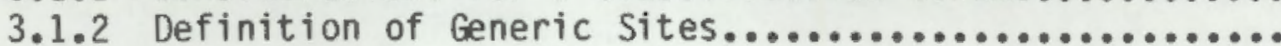

3.2 FLOW PARAMETERS FOR GENERIC SITES ..................... 3.9

3.2 .1 Hydraulic Conductivity............................ 3.9

3.2.2 Effective Porosity.............................. 3.12

3.2.3 Hydrautic Gradient............................... 3.15

3.2.4 Distance to Nearest Surface Water Body.............. 3.20

3.3 TRANSPORT PARAMETERS FOR GENERIC SITES................. 3.20

3.3.1 Longitudinal Dispersion Coefficient.................. $\quad 3.20$

3.3.2 Retardation of Radionuclides by Sorption............. 3.24

3.3.3 Effective Bulk Density.......................... 3.33

3.4 TRANSPORT EQUATIONS FOR ONE DIMENSIONAL SIMULATION......... 3.33

3.4.1 Modeling Objectives for Generic Classifications....... 3.33

3.4.2 Equation for Contaminant Transport in

Ground Water.................................. 3.34

3.5 CONCLUSIONS OF GENERIC HYDROGEOLOGIC SITE CLASSIFICATION..... 3.35

3.6 GENERIC GEOTECHNICAL SITE DATA..................... 3.36

3.6.1 Generic Hydrogeologic Site Classification:

Fractured Consolidated Silicates.................. 3.36

3.6.2 Generic Hydrogeologic Classification: Fractured-

Solutioned Consolidated Carbonates................. 3..37

3.6.3 Generic Hydrogeologic Classification: Porous

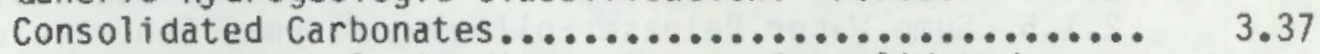

3.6.4 Generic Hydrogeologic Site: Porous Consolidated

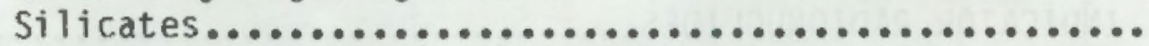

3.6.5 Generic Hydrogeologic Classification: Porous

Unconsolidated Silicates..........................

3.6.6 Generic Hydrogeologic Classification: Fractured

Consolidated Silicate........................... 3.40

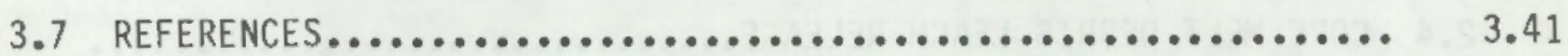

4.0 GROUND-WATER CONTAMINANT MITIGATION TECHNIQUES............... 4.1

4.1 TYPES OF MITIGATION TECHNIQUES....................... 4.1

4.1.1 Static Ground-Water Contaminant Mitigation

Technique.................................... 4.1

4.1.2 Dynamic Ground-Water Contaminant Mitigation

Tehchnique................................... 
4.2 FEASIBILITY CRITERIA FOR GROUND-WATER CONTAMINANT

MITIGATION TECHNIQUES..............................

4.2.1 Design Considerations...........................

4.2.2 Construction Considerations.........................

4.2.3 Performance Considerations.........................

4.2.4 Implementation Considerations.......................

4.3 ANALYSIS OF STATIC GROUNO-WATER CONTAMINANT

MITIGATION TECHNIQUES.............................

4.3.1 Grouts.........................................

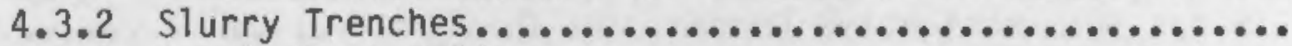

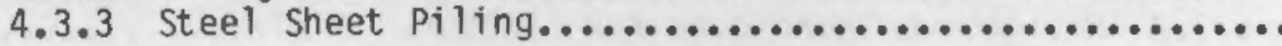

4.4 ANALYSIS OF DYNAMIC GROUND-WATER CONTAMINANT

MITIGATION TECHNIQUES...........................

4.4.1 Ground-Water Withdrawal for Potentiometric

Surface Adjustment (Aquifer Dewatering)..............

4.4.2 Ground-Water Withdrawal and/or Injection

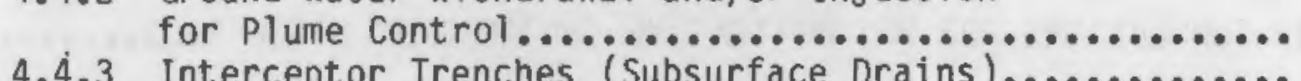

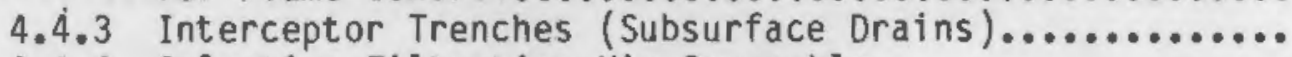

4.4.4 Selective Filtration Via Permeable

4.4 .5 Ground Freezing.................................

4.98

4.103

4.4.6 Air Injection

4.5 U.S. GEOTECHNICAL ENGINEERING CAPABILITY...............

5.0 MITIGATIVE TECHNIQUES FOR GENERIC SITES....................

5.2 GENERIC SITE: FRACTUREED CONSOLIDATED SILICATES -

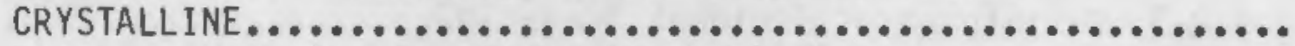

5.2.1 Pre-Mitigative Contaminant Discharge................

5.2.2 Mitigative Techniques for Fractured

Consolidated Silicates...........................

5.3 GENERIC SITE: FRACTURED AND SOLUTIONED CONSOLIDATED

CARBONATES .....................................

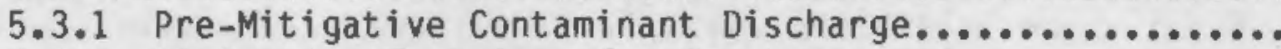

5.3.2 Mitigative Technique for Fractured and

Solutioned Consolidated Carbonates.

5.4 GENERIC SITE: POROUS CONSOLIDATED CARBDNATE..............

5.4.1 Pre-Mitigative Contaminant Discharge.................

5.4.2 Mitigative Techniques for Porous Consolidated

5.5 GENERIC SITE: POROUS CONSOLIDATED SILICATE. 
5.5.2 Mitigative Techniques for Porous Consolidated

Carbonates................................... 5.23

5.6 GENERIC SITE: POROUS UNCONSOLIDATED SILICATES............ 5.27

5.6.1 Pre-Mitigative Contaminant Discharge............... 5.27

5.6.2 Mitigative Techniques for Porous Unconsolidated

Carbonates...................................... 5.30

5.7 GENERIC SITE: FRACTURED CONSOLIDATED SILICATES -

SHALE.................................................. 5.33

5.7.1 Pre-mitigative Contaminant Discharge................. 5.33

5.7.2 Mitigative Techniques for Fractured Shale............. 5.34

5.8 COMPARISON OF PRE-MITIGATIVE CONTAMINANT DISCHARGES......... 5.39

5.8.1 Significant Discharges to Surface Water Bodies........ 5.39

5.8.2 Core Melt Leachate Discharges to Surface Water......... 5.43

5.8.3 Sump Water Discharges to Surface Water............... 5.46

5.9 CONCLUSIONS FOR PRE-MITIGATIVE CONTAMINANT DISCHARGES...$\ldots .5 .48$

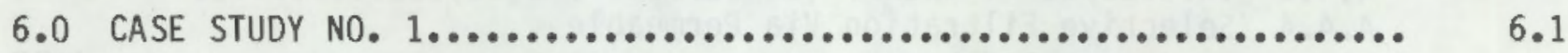

6.1 INTRODUCTION........................................ 6.1

6.1 .1 Case Study 0bjectives............................ 6.1

6.1.2 Relationship of Case Study No. 1 to Generic

Classification - Mitigation Matrix................. 6.1

6.1.3 General Methodology for Evaluation of Mitigative

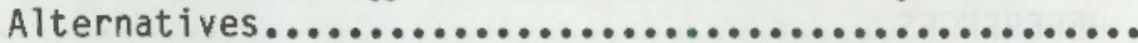

6.1.4 Case Study No. 1 Approach and Limitations..............

6.2

6.3

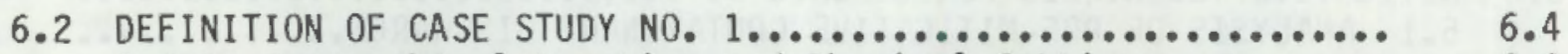

6.2.1 Geographical Location and Physical Setting.............. 6.4

6.2.2 Reactor Design and Plant Configuration................ 6.5

6.2.3 Definition of Accident Scenario..................... 6.7

6.3 REGIONAL ANALYSIS.................................... 6.9

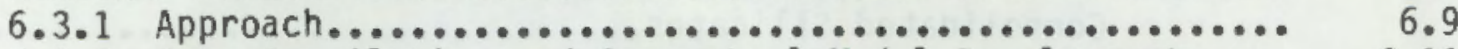

6.3.2 Data Compilation and Conceptual Model Development..... 6.11

6.4 REGIONAL MODEL DEVELOPMENT.............................. 6.44

6.4 .1 Code Selection................................... 6.45

6.4 .2 Initial Regional Model Development.................. 6.46

6.4 .3 Regional Model Calibration........................ 6.46

6.5 LOCAL MODEL DEVELOPMENT................................. 6.55

6.5.1 Local Area Size and Boundary Conditions.............. 6.55

6.6 PRE-MITIGATIVE LOCAL FLOW AND TRANSPORT MODELING............ 6.55

6.6.1 Transport Parameter Estimations...................... 6.59

6.6.2 Pre-Mitigative Local Transport Results............... 6.63 
6.7 EVALUATION OF MITIGATIVE TECHNIQUES..................... 6.69

6.7 .1 Approach........................................ 6.69

6.7 .2 Screening of Mitigative Techniques.................... 6.69

6.7 .3 Assessment of Feasible Alternatives................. 6.72

6.7 .4 Conclusions.................................... 6.87

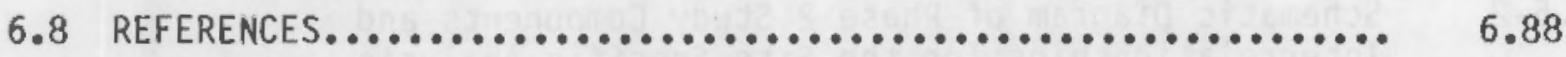


FIGURES

1.5-1 Schematic Diagram of Phase 1 Study Components and

Interrelationships.................................. 1.7

1.5-2 Schematic Diagram of Phase 2 Study Components and

Interrelationships for the Site Specific Analysis........... 1.8

2.1.1-1 Two Possible Configurations of a Severe Nuclear

Accident Involving Failure of the Reactor Basement ......... 2.2

2.4.2-1 Configuration of Solidified Core Debris

for Silicic Melt.

2.4.2-2 Long Term Leach Release Rate for Silicic

Core Metal.

2.4.3-1 Configuration of Solidified Core Debris for

Calcine Melt........................................... 2.19

2.4.3-2 Long Term Leach Rate for Calcine Core Melt................ 2..21

3.1.2-1 Generic Hydrogeologic Classification Scheme

for Nuclear Power Plants in the U.S....................... 3.8

3.2.1-1 LOG 10 Distribution of Hydraulic Conductivity by

Generic Classification............................... 3.11

3.2.1-2 Linear Scale Distribution of Hydraulic Conductivity

by Generic Classification.............................. 3.14

3.2.2-1 $L_{0 G}$ Distribution of Effective Porosity for

Porous Unconsolidated Silicates......................... 3.16

3.2.2-2 Linear Scale Distribution of Effective Porosity

for Porous Unconsolidated Silicate...................... 3.16

3.2.3-1 LOG 10 Distribution of Hydraulic Gradient by

Generic Classification.................................. 3.18

3.2.3-2 Linear Scale Distribution of Hydraulic Gradient by

Generic Classification................................. 3.19

3.2.4-1 Linear Scale Distribution of Reactor Distance

from Surface Water................................. 3.21

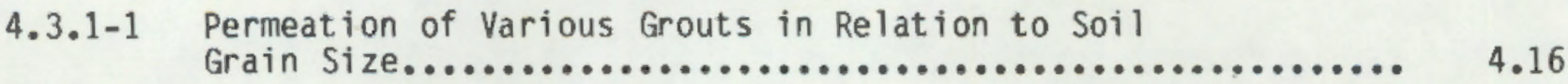

4.3.1-2 Diagram of Downstage Grouting without Packer.............. 4..18 
4.3.1-3 Twenty-Eight Day Permeability of a Typical

Cement Grout........................................ 4.20

4.3.2-1 Schematic Section of Siurry Wall Construction.............. 4.27

4.3.2-2 The Alternate-S1 ot Method.............................. 4.28

4.3.2-3 vibrating-Beam Slurry Wall Construction.................. 4.....

4.3.2-4 Typical Vibrated-Beam (VBT) Injection Set-Up............... 4.31

4.3.2-5 Reversal of Leakage Direction Through Aquitard/Keying Layer as a Result of Pumping Ground Water Within Slurry Wall Confines to a Level Below the Piezometric Surface for the Underlying Aquifer............................ 4.34

4.3.2-6 Permeability of Soil-Bentonite Backfill Related to Fines Content....................................... 4.36

4.3.2-7 Relationship Between the Permeability and Quantity of Bentonite Added to S-B Backfill..........................

4.3.2-8 Schematic Cross Section of S-B Slurry Trench

Cut Wall.............................................

4.3.2-9 Theoretical Relationship Between Wall Permeability and Permeability of Filtercake and Backfill............... 4.... 39

4.3.2-10 Schematic of Filter-Press Test Apparatus................. 4.40

4.3.2-11 Relationship Between the Filtercake Permeability and Cake Formation Pressure and Time........................ 4.41

4.3.2-12 Vertical Leakage of Contaminants........................ 4.43

4.3.2-13 Typical Ground Sequences Where Bentonite Support Has Proved Effective.................................... 4.44

4.3.2-14 Loss of Slurry Water to Unsaturated, Highly Permeable Gravel Zone Leads to Loss of Slurry..................... 4.45

4.3.2-15 Soil Boring and Obseroving Well Locations in the Basin $F$ Area at the Rocky Mountain Arsenal........................

4.3.2-16 Partial Soil Profile Depicted by Borings Around Basin F at Rocky Mountain Arsenal.

4.3.2-17 Boring $\log$ for Hole No. $461 \ldots \ldots \ldots \ldots \ldots \ldots \ldots \ldots \ldots \ldots \ldots \ldots \ldots \ldots \ldots . \ldots . \ldots . \ldots$

4.3.2-18 0-N Relationship for Standard Penetration Test............ 4... 41 
4.3.2-19 The Cell Strength and Shear Modulus of Slurry

as a Function of Time.................................. 4.57

4.3.2-20 The Effect of Slag Replacement on Bleeding................ 4.64

4.3.3-1 Steel Sheet Piling Interlock Designs..................... 4.71

4.3.3-2 Typical Steel Sheet Piling Shapes....................... 4.72

4.3.3-3 In-Place Steel Sheet Piling Cut-0ff Wall................ 4.73

4.4.1-1 Pictorial Representation of Pumping to Lower

Water Table Below Receiving Stream...................... $\quad 4.80$

4.4.1-2 Pictorial Representation of Pumping to Lower

Water Table Below Containment........................... 4.81

4.4.1-3 Pictorial Representation of Pumping to Prevent

Contamination Through a Leaky Confining Layer............. 4.82

4.4.2-1 Pictorial Representation of Extraction/Injection

Contaminant Plume Control.............................. 4.89

4.4.4-1 Schematic Diagram of Permeable Treatment Bed System.......... 4.99

4.4.4-2 Perneable Treatment Bed in Combination with a

Grouted Cut -0 ff..................................... 4.101

4.4.5-1 Frozen Straight Wall Development in Fine-Grained Soil........ 4.109

4.4.5-2 Frozen Straight Wall Development in Coarse-Grained Soil...... 4.110

5.2.1-1 Percentage of Fractured Consolidated Silicates-Crystalline

Sites That Would Discharge Each of the Indicator Radio-

nuclides Prior to 40 Half-Lives of Decay.................. 5.4

5.2.1-2 Discharge Flux of Core Me1t Leachate from Fractured

Consolidated Silicates-Crystalline Sites to Surface

Water for Strontium-90 and Ruthenium-106................. 5.5

5.2.1-3 Discharge Flux of Reactor Sump Water from Fractured

Consolidated Silicates-Crystalline Sites to Surface

Water for Strontium-90, Cesium-137 and Ruthenium-106........

5.3.1-1 Percentage of Fractured and Solutioned Consolidated

Carbonate Sites That Would Discharge Each of the

Indicator Radionuclides Prior to $40 \mathrm{Half}$-Lives of Decay...... 5.10

5.3.1-2 Discharge Flux of Core Melt Leachate from Fractured and

Solutioned Consolidated Carbonate Sites to Surface Water

for Strontium-90 and Ruthenium-90. 
5.3.1-3 Discharge Flux of Reactor Sump Water from Fractured and Solutioned Consolidated Carbonate Sites to Surface Water for Strontium-90, Cesium-137, and Ruthnenium-106...........

5.4.1-1 Percentage of Porous Consolidated Carbonate Sites That Would Discharge Each of the Indicator Radionuclides Prior to $40 \mathrm{Half}$-Lives of Decay.

5.4.1-2 Discharge Flux of Core Melt Leachate from Porous Consolidated Carbonate Sites to Surface Water for Strontium-90 and Ruthenium-106.

5.4.1-3 Discharge Flux of Reactor Sump Water from Porous Consolidated Carbonate Sites to Surface Water for Strontium-90, Cesium-137, and Ruthenium-106...

5.5.1-1 Percentage of Porous Consolidated Silicate Sites That Would Discharge Each of the Indicator Radionuclides

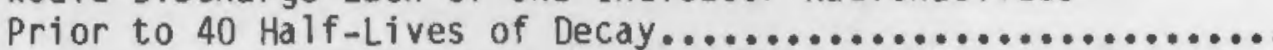

5.5.1-2 Discharge Flux of Core Melt Leachate from Porous Consolidated Silicate Sites to Surface Water for Strontium-90 and Ruthenium-106.

5.5.1-3 Discharge Flux of Reactor Sump Water from Porous Consolidated Silicate Sites to Surface Water for Strontium-90, Cesium-137, and Ruthenium-106...

5.6.1-1 Percentage of Porous Unconsolidated Silicate Sites That Would Discharge Each of the Indicator Radionuclides Prior to $40 \mathrm{Half-Lives} \mathrm{of} \mathrm{Decay....................}$

5.6.1-2 Discharge Flux of Core Melt Leachate from Porous for Unconsolidated Silicate Sites to Surface Water

Strontium-90 and Ruthenium-106....

5.6.1-3 Discharge Flux of Reactor Sump Water from Porous Unconsolidated Silicate Sites to Surface Water Strontium-90, Cesium-137, and Ruthenium-106.

5.7.1-1 Percentage of Fractured Consolidated Silicate-Shale Sites That Would Discharge Each of the Indicator Radionuclides Prior to $40 \mathrm{Half}$-Lives of Decay...

5.7.1-2 Discharge Flux of Core Melt Leachate from Fractured Consolidated Silicate-Shale Sites to Surface Water for Strontium-90 and Ruthenium-106.

5.7.1-3 Discharge Flux of Reactor Sump Water from Fractured Consolidated Silicate-Shale Sites to Surface Water for Strontium-90, Cesium-70 and Ruthenium-106. 
5.8.1-1 Percentage of Nuclear Power Plant Sites in Each Generic Hydrogeologic Classification That Would Discharge

Strontium-90 Prior to 40 Half-Lives of Decay.............. 5.39

5.8.1-2 Percentage of Nuclear Power Plant Sites in Each Generic Hydrogeologic Classification That Would Discharge Cesium-137 Prior to $40 \mathrm{Half-Lives} \mathrm{of} \mathrm{Decay}$

5.8.1-3 Percentage of Nuclear Power Plant Sites in Each Generic Hydrogeologic Classification That Would Discharge Ruthenium-106 Prior to $40 \mathrm{Half-Lives} \mathrm{of} \mathrm{Decay.............} 5.42$

6.2.1-1 STP Site.Location Map.............................. 6.5

$6.2 .2-1$ STP Plant Area................................... 6.6

6.2.3-1 Hypothesized South Texas Plant Leach Release of

Stront ium-90....................................... 6.10

6.3.1-1 Major Steps in Ground-Water Model Applications............. 6.12

6.3.2-1 USGS Topographic Map for the Vicinity of the STP Site....... 6.14

6.3.2-2 Illustration of the Three Basic Porous Media Aquifer Types... 6.18

6.3.2-3 Geohydrologic Cross-Section A-A ' for the STP Site......... 6.20

6.3.2-4 Illustration of Different Aquifer Boundary Types........... 6.21

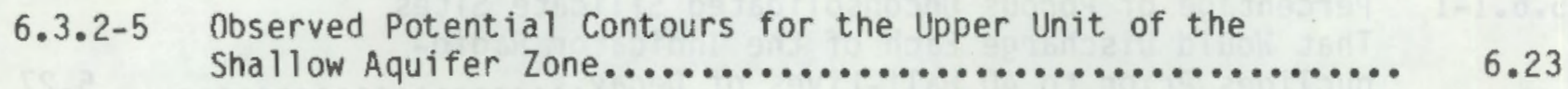

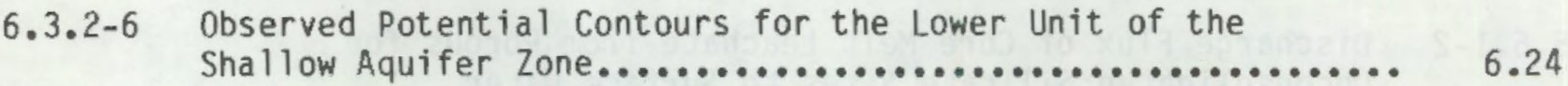

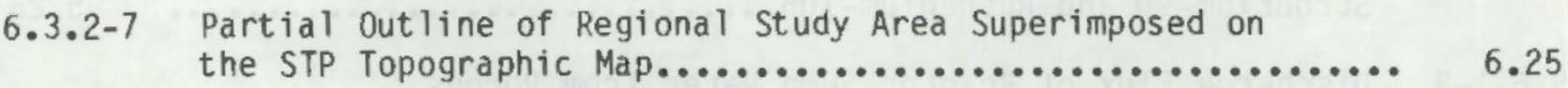

6.3.2-8 Complete Grid for the STP Regional Study Area............ 6.26

6.3.2-9 Observed and Estimated Potential Contours for STP Regional

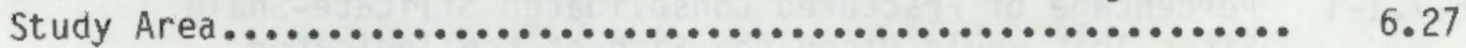

6.3.2-10 Observed Potential Contours for the STP Regional Area....... 6.28

6.3.2-11 Geohydrologic Cross-Sections B-B' and B-B" for the

STP Site........................................ 6.30

6.3.2-12 Locations of the Geohydrologic Cross Section $A-A^{\prime \prime}$ ',

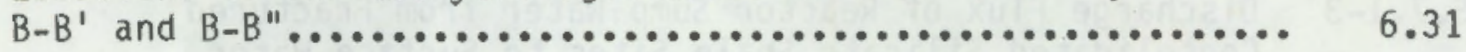


6.3.2-13 Top Elevation Contour and Surface Maps for the Lower Unit of the Shallow Aquifer Within the STP Regional Study Area....

6.3.2-14 Bottom Elevation Contour and Surface Maps for the Upper Unit of the Shallow Aquifer Within the STP Regional Study Area.

6.3.2-15 Overlay of the Top and Bottom Elevations for the Lower Unit of the Shallow Aquifer Within the STP Regional

Study Area..........................................

6.3.2-16 1973 Water Level Observations in the Vicinity of the STP site............................................ 6.39

6.3.2-17 Illustration of the Conceptual Model for the STP Site....... 6.43

6.4.2-1 Potential Contours Simulated by the Initial STP

Region Model.

6.4.3-1 Calibrated Hydraulic Conductivities for the STP Final Regional Model.

6.4.3-2 Calibrated Recharge/Discharge for the STP Final Regional Model.

6.4.3-3 Potential Contours Simulated by the Final STP Regional Model.

6.4.3-4 Observed Potential Surface for the STP Regional Study Area...

6.4.3-5 Final Regional Model Simulation of the Potential Surface for the STP Regional Study Area..........................

6.5.1-1 STP Local Model Study Area............................ 6.56

6.5.1-2 STP Local Area Observed Potential Contours................ 6.57

6.5.1-3 STP Local Model Simulated Potential Contours............... 6.58

6.6.1-1 Illustration of "Random-Walk" Concept Employed by TRANS...... 6.60

6.5.1-2 Field Observations of Longitudinal Dispersivit............ 6.61

6.6.1-3 Stepped Source Leach Rate Curve for Strontium-90......... 6.65

6.6.2-1 Simulated Pre-Mitigation Strontium-90 Concentrations at 100 Years........................................ 6.66

6.6.2-2 Simulated Pre-Mitigation Strontium-90 Concentrations at

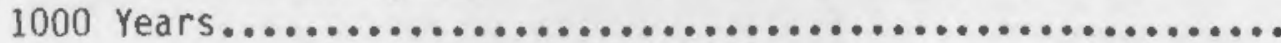


6.6.2-3 Pre-Mitigation Pathline from the STP................... 6.68

6.7.3-1 Location of Down-Gradient Cutoff Wal1.................. 6.73

6.7.3-2 Location of Up-Gradient Cutoff Wall.................... 6.74

6.7.3-3 Pathline from the STP with $2000 \mathrm{ft}$ Up-Gradient Cutoff........ 6.75

6.7.3-4 Simulated Potential Surface: with a $2000 \mathrm{ft}$ Up-Gradient

Cut off .......................................... 6.76

6.7.3-5 Simulated Pathlines from the STP: with Down-Gradient Cut offs......................................... 6.77

6.7.3-6 Simulated Potential Surface: with a $4000 \mathrm{ft}$ DownGradient Cutoff..................................... 6.78

6.7.3-7 Proposed Near-Field Injection Scheme................... 6.81

6.7.3-8 Simulated Pathline from the STP: with the Near-Field Injection Scherne................................... 6.82

6.7.3-9 Simulated Pathline Surface: with the Near-Field Injection scheme............................................. 6.83

6.7.3-10 Proposed Far-Field Injection Scheme.................... 6.84

6.7.3-11 Simulated Pathline from the STP: with the Far-field Injection Scheme................................. 6.85

6.7.3-12 Simulated Potential Surface: with the Far-Field Injection scheme............................................. 
$\underline{\text { TABLES }}$

2.1.4-1 Concrete Compositions................................ 2.6

2.2.1-1 Indicator Radionuclides.............................. 2.7

2.2.2-1 Release Fractions for Indicator Radionuclides.............. 2.8

2.2.2-2 Generic Hydrogeologic and Accident Sequence

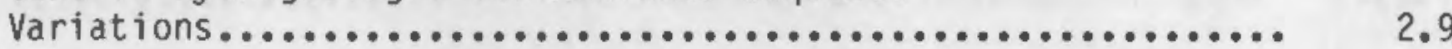

2.4.2-1 Silicic Leach Processes.............................. 2.13

2.4.2-2 Comparison of Long-Term Experimental Data and Silicic Leach Model.......................................... 2.16

2.4.3-1 Estimated Specific Surface Areas for Core Debris............ 2.20 .

3.1.1-1 Percentage of $\mathrm{SiO}_{2}$ and CaO of Common Geologic Units......... 3.4

3.1.1-2 Core Melt and Ground-Water Transport Characteristics

Based on Chemical Rock Type.............................. 3.4

3.1.1.3 Construction Considerations Versus Type of

Geologic Formation..................................... 3.5

3.1.2-1 Generic Site Classification............................. 3.9

3.2.1-1 Comparison of Generic Hydraulic Conductivity.............. 3.13

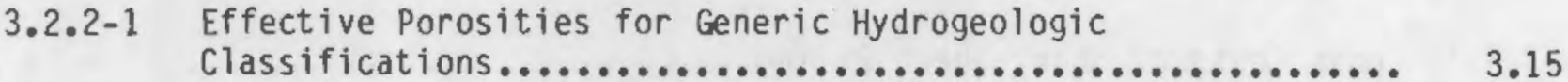

3.2.3-1 Average Hydraulic Gradient for Generic Hydrogeologic Classifications......................................

3.2.4-1 Average Distance to Surface Water Generic Hydrogeologic Classifications.

3.3.1-1 Estimated Dynamic Dispersivity for Various Geologic

Materials............................................ 3.23

3.3.2-1 Equilibrium Distribution Coefficients.................. 3.27

3.3.2-2 Generic Equilibrium Distribution Coefficients.............. 3.30

4.1.1-1 Static Ground-Water Contaminant Mitigation Techniques

Considered for Application to Severe Power Plant

Accidents. 
4,1.2-1 Dynamic Ground-Water Contaminant Mitigation Techniques

Considered for Application to Severe Power Plant

Accidents............................................ 4.3

4.3.1-1 Types of Grouts................................... 4.8

4.3.1-2 Chemical Grouts and Manufacturers........................ 4.14

4.3.1-3 Grout Recommendations Based on Soil Type.................. 4.15

4.3.1-4 Permeability Versus Age of a Portland Cement

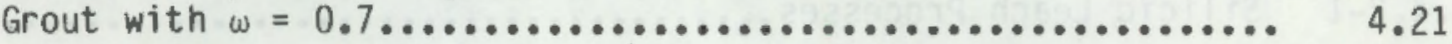

4.3.1-5 Grouting Material Costs (1980\$)......................... 4.24

4.3.2-1 K Values Ranked According to Soil Particle Size............ 4.35

4.3.2-2 Unified Soil Classification System...................... 4..50

4.3.2-3 Determination of Site Characteristics.................... 4.52

4.3.2-4 Quality Control Testing Program During S-B Slurry Wa11

Construction at Gi is on Road Hazardous Site................ 4.55

4.3.2-5 Summary of Slurry Problems and Treatment............... 4.58

4.3.2-6 Common Slurry Materials and Additives................... 4.61

4.3.2-7
Sarious Pollutants $\ldots \ldots \ldots \ldots \ldots \ldots \ldots \ldots \ldots \ldots \ldots \ldots \ldots \ldots \ldots \ldots \ldots \ldots \ldots \ldots$

4.3.3-1 Unit Costs of Steel Sheet Piling...................... 4..76

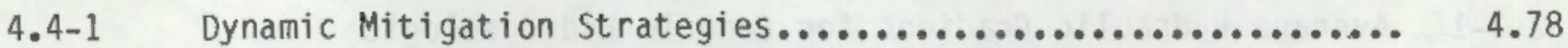

4.4.1-1 Advantages of Aquifer Dewatering Schemes................. 4.86

4.4.1-2 Disadvantages of Aquifer Dewatering Schemes.............. 4.86

4.4.3-1 Unit Costs for Subsurface Drainage Collection

systems......................................... 4.97

4.5-1 U.S. Geotechnical Engineering Capability................ 4.113

5.2.2-1 Mitigative Techniques for Fractured Consolidated

Silicates........................................ 5.9

5.3.2-1 Mitigative Techniques for Fractured and Solutioned

Consolidated silicates................................. 5.15 
5.4.2-1 Mitigative Techniques for Porous Consolidated

Carbonates............................................

5.5.2-1 Mitigative Techniques for Porous Consolidated

Silicates......................................... $\quad 5.25$

5.5.2-1 Mitigative Techniques for Porous Unconsolidated

silicates............................................ 5.31

5.7.2-1 Mitigative Techniques for Fractured Shale................ 5.37

5.8.1-1 Generic Classification Numbering Index.................. 5.40

5.8.1-2 Generic Sensitivity to a Severe Nuclear Accident........... $\quad 5.42$

5.8.2-1 Summary of Pre-Mitigative Core Melt 0ischarges to 5.44

5.8.3-1 Summary of Pre-Mitigative Sump Water Discharges to

Surface Water....................................... 5.47

6.2.3-1 Initial Amounts of Indicator Radionuclides............... 6.8

6.2.3-2 Release Fractions for the Indicator Radionuclides........... 6.9

6.3.2-1 Data Required for Ground-Water Modeling................. 6.13

6.3.2-2 Geologic Description and Water-Bearing Properties of
Stratigraphic Units Forming the Gulf Coast Aquifer.......... 6.16

6.3.2-3 Required Porous Media Hydraulic Properties................ 6.35

6.3.2-4 Aquifer Test Summary............................... 6.36

6.3.2-5 Pump Test Results for Wells in Matagorda County............ 6.36

6.3.2-6 Representative Porosities for Sedimentary Material.......... 6.37

6.3.2-7 Summary of Estimated 1973 Ground-Water Use in the

6.4.2-1 TRANS Input Requirements and Source of Data for Initial

6.6.1-1 Estimated Longitudinal Dispersivity for Various Geologic

Materials........................................... $\quad 6.60$

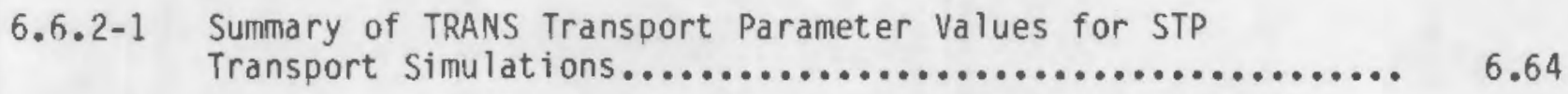


6.7.3-1 Summary of Cutoff Design Evaluations................... 6.79

6.7.3-2 Summary of Injection Scheme Evaluations.................. 6.86 


\section{EXECUTIVE SUMMARY}

Pacific Northwest Laboratory (PNL) has undertaken the study of mitigative techniques and analysis of generic hydrogeologic site conditions for groundwater contamination associated with severe nuclear power plant accidents for the U.S. Nuclear Regulatory Commission. This draft report describes the results of the study as completed through 1983. As a draft issuance of study findings, critical evaluation of report content has been limited to internal review by PNL staff not associated with the project. The authors solicit comments, suggestions, and constructive criticism from individuals and organizations with expertise in hydrogeology and geotechnical engineering. The final report will address, to the extent possible, the comments of respondents.

The purpose of this study is to evaluate the feasibility and desirability of using specific ground-water contaminant mitigation techniques (e.g. constructed barriers to subsurface flow and transport, hydraulic barriers created by ground-water withdrawal and/or injection, etc.) to control radionuclide migration in ground water following a severe commercial nuclear power reactor accident. The objectives of the study are:

1. development of guidelines and supporting information for the determination of the desirability and feasibility of ground-water contaminant mitigation in relation to generic hydrogeologic characteristics of commercial reactor sites in the U.S., and

2. development and demonstration of methodologies for evaluating the desirability and feasibility of designing and implementing groundwater contaminant mitigative strategies on a site specific basis.

The first objective has been met with issuance of this draft report. The second objective is achieved through the conduct of three case studies, one of which has been completed for inclusion in this report.

Core melt releases of radionuclides from the reactor containment are described. Previous studies are employed to characterize the nature of a severe nuclear power plant accident which gives rise to ground-water, and ultimately surface water, contamination. The two types of accidents investigated are: 1) containment basemat penetration of molten core melt debris which slowly cools and leaches radionuclides to the subsurface environment, and 2) containment basemat penetration of contaminated sump water without full basemat penetration by the molten core mass.

Conclusions drawn concerning the release of radionuclides following a severe accident are:

1. chemical composition of the concrete and underlying materials would have a large influence on the leach release rates of core debris. Calcine materials would leach radionuclides at rates approximately two orders of magnitude greater than predominately silicic materials, and 
2. quantities of radionuclides discharged to surface water are highly sensitive to hydrogeologic factors as well as release fractions determined by accident sequences.

Six generic hydrogeologic classifications are developed from an evaluation of reported data pertaining to the hydrogeologic properties of all existing and proposed commercial reactor sites. The six classifications based on geologic unit type are:
1. porous consolidated carbonates,
2. fractured consolidated carbonates,
3. porous consolidated silicates,
4. porous unconsolidated silicates,
5. fractured crystalline silicates, and
6. fractured shale

One-dimensional radionuclide transport analyses are conducted on each of the individual reactor sites to determine the generic and site specific characteristics of a radionuclide discharge to an accessible (i.e., surface) environment. The results are evaluated as generic trends within the six hydrogeologic classifications. Results of the transport analyses indicate that:

1. generic characteristics that would affect (in order of importance) radionuclide transport following a core melt accident are: 1) bedrock chemical type, 2) interstitial versus fracture porosity, 3) sorption, and 4) aquifer hydraulics,

2. the time over which the radionuclides in a sump water release would be discharged into an accessible environment would be site specific, but less than for core melt leachate, which would discharge continuously over hundreds of years,

3. fractured flow systems would be more likely than porous flow systems to discharge contaminants at early times, and

4. peak discharge rates to accessible environments could possibly be one order of magnitude greater for a sump water release versus core melt leaching.

Ground-water contaminant mitigation techniques that may be suitable, depending on specific site and accident conditions, for severe power plant accidents are identified. The techniques which appear most suitable are engineered/constructed barriers such as grout curtains and slurry walls, and dynamic plume control techniques which require ground-water withdrawal and/or injection. Other techniques investigated include subsurface drains, permeable treatment beds, ground freezing, and air injection. Each mitigative strategy or technique is evaluated according to: 1) conceptual design considerations, 2) construction considerations, 3) performance considerations, and 4) implementation considerations. 
Feasible mitigative techniques and associated constraints on feasibility are identified for each of the six hydrogeologic site classifications. The determination of feasibility is based on the generic hydrogeologic properties established for each site and the analysis of the constraints on implementation of each mitigative strategy. The major constraints on the feasibility of ground-water contaminant mitigation are:

1. consolidated geologic media,

2. host geologic material grain size or fissure width,

3. low hydraulic conductivity,

4. high ground-water velocity,

5. surface handling of contaminated ground-water,

6. depth to a basal confining layer, and

7. depth to the contaminant plume.

The first case study was conducted on a site located on the Texas Gulf Coastal Plain and included:

1. a detailed hydrogeologic characterization of a porous coastal plain aquifer,

2. a complete discussion of data requirements and sources for the characterization,

3. development of a two-dimensional ground-water flow and contaminant transport numerical model,

4. a baseline pre-mitigative analysis of radionuclide transport, and

5. an evaluation of the effect of engineered barriers and hydraulic barriers on radionuclide transport.

The first case study concludes that ground-water contaminant mitigation would be necessary at this particular site due to the naturally low hydraulic gradient and associated long travel times. Nevertheless, for demonstration purposes, mitigative strategies are evaluated for their impact on contaminant transport. Results show that the techniques evaluated (i.e., a low permeability cutoff placed up-gradient from the plant, a low permeability cutoff placed down-gradient from the plant, a near-field hydraulic barrier, and a far-field hydraulic barrier) significantly increase ground-water travel times. Increased ground-water travel times resulting from more circuitous travel paths allow for both greater natural decay of radionuclides and increased sorption of radionuclides by the geologic host material. Hydraulic barriers appear to be more effective, in this case, than cutoffs in increasing ground-water travel times to the accessible environment. 


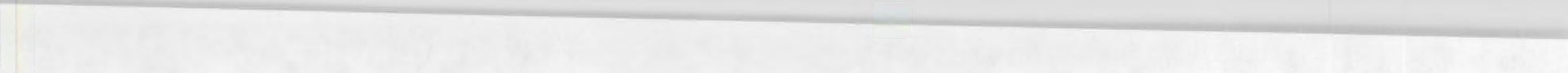




\subsection{INTROOUCTION}

\subsection{PURPOSE OF STUDY}

The purpose of this study is to evaluate the feasibility and desirability of using specific ground-water contaminant mitigation techniques to control radionuclide migration in ground water following a severe commercial nuclear power reactor accident. The evaluation of the necessity and feasibility of mitigative strategies for ground-water contamination resulting from a severe accident is accomplished by two separate levels of analysis. The first level of analysis involves examination of core melt characteristics through an inductive process where a large volume of diverse information is reduced to a small set of generalized (i.e., generic) data concerning broad characteristics of core melt accidents, hydrogeologic properties, and ground-water contaminant mitigative strategies. The second level of analysis is more of a deductive process where insight into site specific ground-water contaminant mitigation is developed through the performance of case studies. These two levels of analyses are complimentary in nature and follow a logical progression in the development of methodology for evaluation of mitigative techniques for core melt accidents.

The generic analysis determines the basic geology and hydrologic factors that affect radionuciide release and transport following a core melt accident. The key hydrogeologic factors are used to classify existing and proposed nuclear power plant sites into generic groups. Evaluation of nuclear power plant sites in a generic manner provides a screening tool that determines:

1. the importance of various hydrogeologic factors related to a core melt accident,

2. the suite of mitigative techniques that are applicable to each generic classification, and

3. the relative environmental sensitivity of a generic classification to a nuclear release.

The second level of analysis determines the site specific aspects of a severe reactor accident and the methodology for evaluating the impact and the response. Case studies are developed to detail the individual characteristics of a site and demonstrate how these characteristics affect the evaluation of mitigative strategies. In addition to demonstration of methodological approaches to the analysis of severe accidents the case studies address:

1. site specific hydrogeologic conditions,

2. development of a conceptual model,

3. selection of mitigative techniques or schemes for evaluation,

4. selection of analytical procedures,

5. design and performance evaluation of mitigative schemes,

6. plant configuration aspects which affect the selection and performance of the mitigative strategies, and

7. validation of generalized results determined by generic analysis. 
The generic analysis is limited by definition, in scope by the requirements for simplifying assumptions and generalizations concerning release and transport of ground-water contaminants. The case studies focus on site conditions and unique factors that affect the design of mitigative schemes. Therefore, the generic examination presents a rough approximation of the relative environmental consequences of a core melt accident and the feasibility of various mitigative techniques that could be used to interdict the resulting contaminants. This information can be used for screening purposes to help plan the necessary elements of a detailed site specific analysis. Detailed design and implementation plans of a mitigative scheme are properly considered only within the framework of a specific site and accident scenario.

The results of the first case study (South Texas Plant in Matagorda County, Texas) are presented in this draft report. The results of the remaining case studies will be presented in the final report.

\subsection{ORGANIZATION OF REPORT}

This draft report is organized into chapters following the logical sequence of performance of this study. A brief description of the contents of each chapter follows:

Chapter 1 - presents an overview of the study including: purpose of study, report organization, study objectives, and the scope of the study with associated limitations.

Chapter 2 - discusses the major types of severe commercial nuclear power reactor accidents considered for this study. Chapter 2 includes discussion of radionuclide release mechanisms and rates expected following a reactor core melt accident.

Chapter 3 - describes the generic hydrogeologic classification scheme and presents the definition of each generic classification. Ground-water flow parameters (e.g., hydraulic conductivity, effective porosity, etc.) and contaminant transport parameters (e.g., longitudinal dispersion, retardation, etc.) are discussed.

Chapter 4 - identifies the various ground-water contaminant mitigation techniques and strategies that may be applicable to groundwater contamination resulting from a severe accident.

Chapter 5 - presents the results of the evaluation of the radionuclide flux for each generic hydrogeologic classification with an assessment of appropriate mitigation measures.

Chapter 6 - discusses the first case study and presents the results of the case study analysis. 
This report is a "draft" issuance of the preliminary results of the study of ground-water contaminant mitigation strategies versus generic hydrogeologic classifications. As such, the report has received limited critical evaluation. However, the final report will reflect the results of a peer evaluation conducted by volunteer reviewers involved in various aspects of geotechnical engineering. The final report will contain the results of two additional case study analyses conducted using the hydrogeologic characterizations and plant configurations of two existing or proposed commercial reactor sites. The final report will also include the results of a review of hydrogeologic site characterization procedures and methodology.

\subsection{BACKGROUND}

Several studies related to this study in purpose and scope have been previously completed. This study draws on these previous studies for basic definitions involving core melt accident types, reactor designs related to radionuclide releases, history of events, and characterization of a core melt accident. The previously completed studies that have influenced the direction and focus of this study are:

1. Niemczyk, S. J. et al. 1981. "The Consequences From Liquid Pathways After A Reactor Meltdown Accident," Nuclear Requlatory Commission, NUREG/CR-1596, USNRC.

2. Office of Nuclear Reactor Regulation. 1981. "Technical Bases for Estimating Fission Product Behavior During LWR Accidents," NUREG-0772, U.S. Nuclear Regulatory Commission, Washington, D.C.

3. Office of Nuclear Reactor Regulation. 1981. "Preliminary Assessment of Core Melt Accidents at the Zion and Indian Point Nuclear Power Plants and Strategies for Mitigating Their Effects," NUREG-0850. Vol. 1, U.S. Nuclear Regulatory Commission, Washington, D.C. This report is alternately referenced as: PACMA 1981.

4. Office of Nuclear Reactor Regulation. 1978. "Floating Nuclear Power Plants," NUREG-0502, U.S. Nuclear Regulatory Commission, Washingt on, D.C.

5. Office of Nuclear Reactor Regulation. 1978. "Liquid Pathway Generic Study," NUREG-0440, U.S. Nuclear Regulatory Commission, Washington, D.C. This report is alternately referenced as: LPGS 1978.

6. U.S. Nuclear Regulatory Commission. 1975. "Reactor Safety Study Appendices VII, VIII, IX, and X, "WASH-1400 (NUREG 75/014), U.S. Nuclear Regulatory Commission, Washington, D.C. This report is alternately referenced as: RSS 1975.

The conclusions of this study are predicated on the results of these previously completed studies of reactor safety and consequences of a severe nuclear power plant accident. 
Throughout this report several terms or phrases are used interchangeably to denote a severe power plant accident (e.g., core melt accident, severe accident, reactor core accident, core meltdown, etc.). The phrase "severe accident" is most encompassing of the conceptualizations of the problem addressed by this study. Within the context of this study a severe accident is considered any extraordinary sequence of events involving the breach from the reactor containment of significant amounts of the reactor core radionuclide inventory which subsequently contact the subsurface environment. This accident definition includes both a molten core melt-through of the containment basemat and/or a significant sump water release through a cracked or otherwise damaged basemat.

\subsection{STUDY OBJECTIVES}

Two principal objectives are accomplished by this study:

1. (Phase 1) evaluation of feasibility and desirability of using groundwater contaminant mitigation techniques for control of radionuclide migration in ground water following a severe nuclear power reactor accident, and

2. (Phase 2) demonstration of methodology for evaluating the feasibility and desirability of implementing ground-water contaminant mitigation strategies via a site-specific case study approach.

These two objectives are accomplished with data from previously published literature and responses from geotechnical engineering firms and government agencies to a letter survey of expertise and experience. Field level studies and primary data collection efforts were entirely beyond the scope of this study.

The intent or purpose of this study is to neither verify nor repudiate previous studies on which this current effort is based. However, judgement is exercised in acceptance of the information provided in previously completed reports. For example, the hydrogeologic classification scheme is based primarily on data provided by S. J. Niemezyk in an unpublished report by Oak Ridge National Laboratory.

Some of the early FSAR's and PSAR's do not contain an extensive review of geologic site conditions. Consequently certain hydrologic parameters had to be estimated. The content of the hydrogeologic data base was reviewed in three respects prior to acceptance for use in this study:

1. a spot check of values was made based on FSAR's available at PNL:

2. hydrologic values were examined for "reasonableness" in the context of the geological classification, and 
3. the ground-water velocities determined from the hydrologic parameters were examined for unrealistic results. In a few cases combined conservative values and/or gradients based on possibly perched water tables resulted in unrealistic ground-water velocities.

In these instances the hydrologic parameters were adjusted with the maximum ground-water velocity restricted to less than $75 \mathrm{~m} /$ day. One site was removed from the data base because all hydrologic parameters were extreme values. In addition, four sites where the core melt would reside in the partially saturated zone above the water table were excluded from analysis. These data, pertaining to the hydrogeologic properties of commercial reactor sites, were considered acceptable for use in a generalized manner in this study for the following reasons:

1. the data were compiled from Preliminary Safety Analysis Reports and Final Safety Analysis Reports that have been reviewed by NRC,

2. limited comparisons of the data with information contained in individual FSAR's indicate the data are reasonable estimates,

3. the data pertain to actual reactor sites in the U.S. Therefore, these data may reflect peculiarities in hydrogeologic properties that may be unique to nuclear power plant sites due to siting restrictions. Such peculiarities would not be evident by simply assuming general properties for various geologic unit types,

4. the data used to develop, from a statistical perspective, generic attributes that can be grouped in a few general categories, and

5. the data represent the most thorough and complete description of hydrogeologic site conditions at nuclear power plant sites in the U.S.

This study is intended to provide U.S. Nuclear Regulatory Commission staff, and other interested parties, guidance in making reconnaissance level estimates for the urgency and necessity of mitigating the effects of a severe nuclear power plant accident on ground-water quality. The study also provides reconnaissance level information on the feasibility and constraints on feasibility of implementing a wide range of potentially applicable ground-water contaminant mitigation schemes.

The first case study analysis is performed on the South Texas Plant located on the Gulf Coastal Plain in Matagorda County Texas. It focuses on the hydrogeologic characterization and conceptual model development for an actual site. Feasible mitigative strategies are screened and several strategies are evaluated in detail. 


\subsection{PROJECT SCOPE}

Because of the multidisciplinary nature of the informational requirements of the project objectives, several independent, but functionally related, tasks were performed in order to provide a thorough and sufficiently detailed analysis. These tasks include:

1. evaluation of contaminant release following a severe nuclear power plant accident,

2. classification of nuclear power plant sites based on the hydrogeologic regime.

3. analysis of radionuclide transport in ground water,

4. identification and evaluation of ground-water contaminant mitigation techniques,

5. determination of feasible mitigative techniques for specific hydrogeologic classifications, and

6. performance of case study analysis of the effectiveness of feasible mitigative techniques.

Only contaminant mitigation schemes that directly affect the long term environmental consequences by active and/or passive interaction with the contaminant are considered in this study. Contaminant mitigation schemes that involve redesign of reactor containment structures or direct manipulation of reactor core materials (e.g., in situ vitrification or core debris removal) are not within the scope of this analysis. In addition, it is assumed that contaminated ground-water supplies would no longer be used.

Figure 1.5-1 shows a schematic diagram of the principal technical elements of the first phase of this study, i.e., the generic analysis. The interactions and interdependencies of the technical elements of the first phase are also presented in the figure. The generic analysis is basically one of decreasing specificity. An intensive review of literature pertaining to postulated core melt features, hydrogeologic site conditions of nuclear power plant sites, and ground-water contaminant mitigative techniques is conducted. Based on the review a vast amount of information is reduced to generalized guidelines concerning hydrogeologic properties of nuclear power plant sites, radionuclide release and transport following a severe accident, and feasible mitigative strategies for resulting ground-water contamination. The generic analysis does not provide sufficient detail required to describe individual sites and such was not the intent of the first phase of this study.

The case study level of analysis, as schematically presented in Figure 1.5-2, compliments the generic analysis. The case studies are designed to highlight differing aspects of site-specific considerations and methodologies that are required to evaluate the necessity and feasibility of implementing ground-water contaminant mitigation following a severe accident. The 


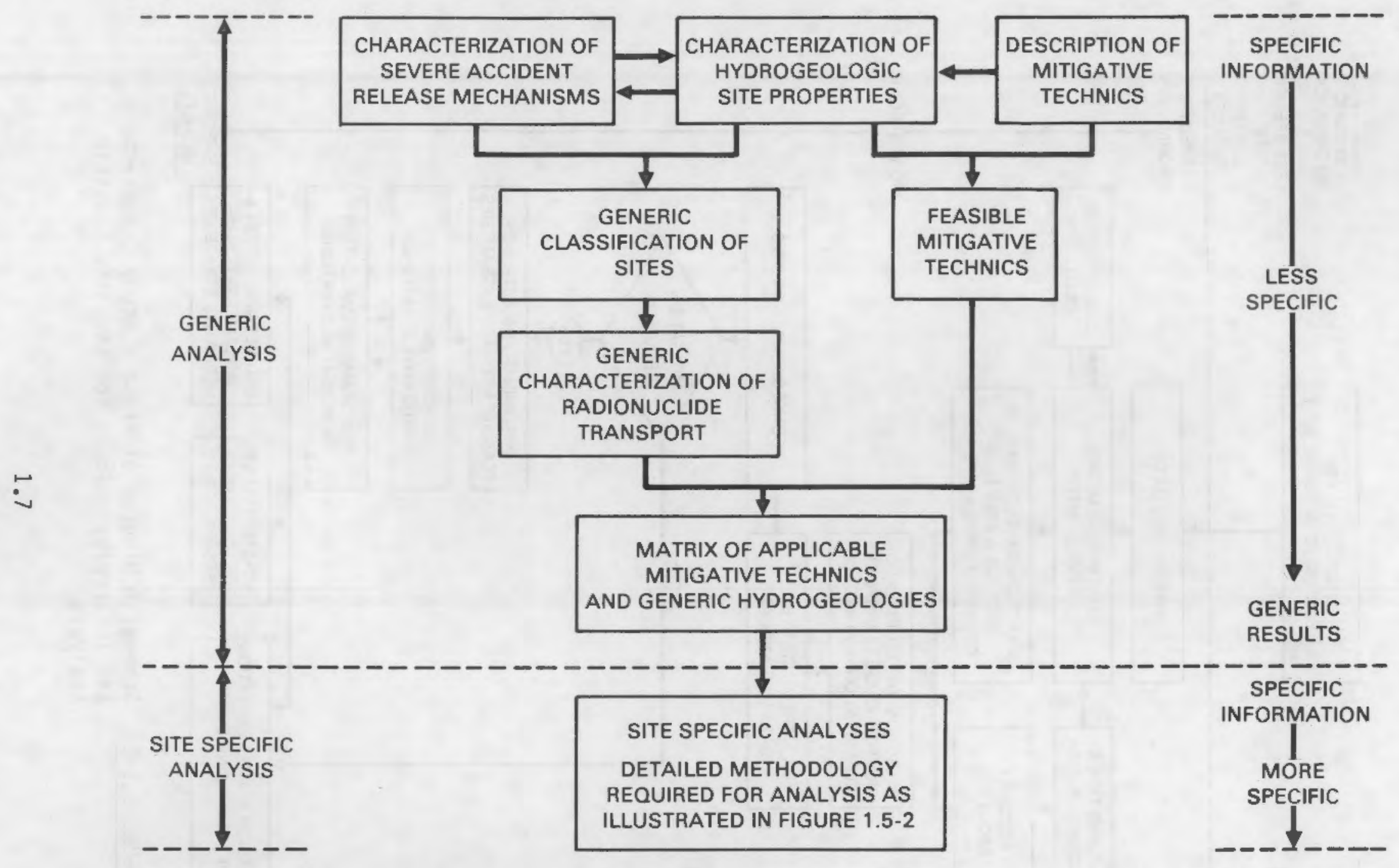

FIGURE 1.5-1. Schematic Diagram of Phase 1 Study Components and Interrelationships for the Generic Analysis 


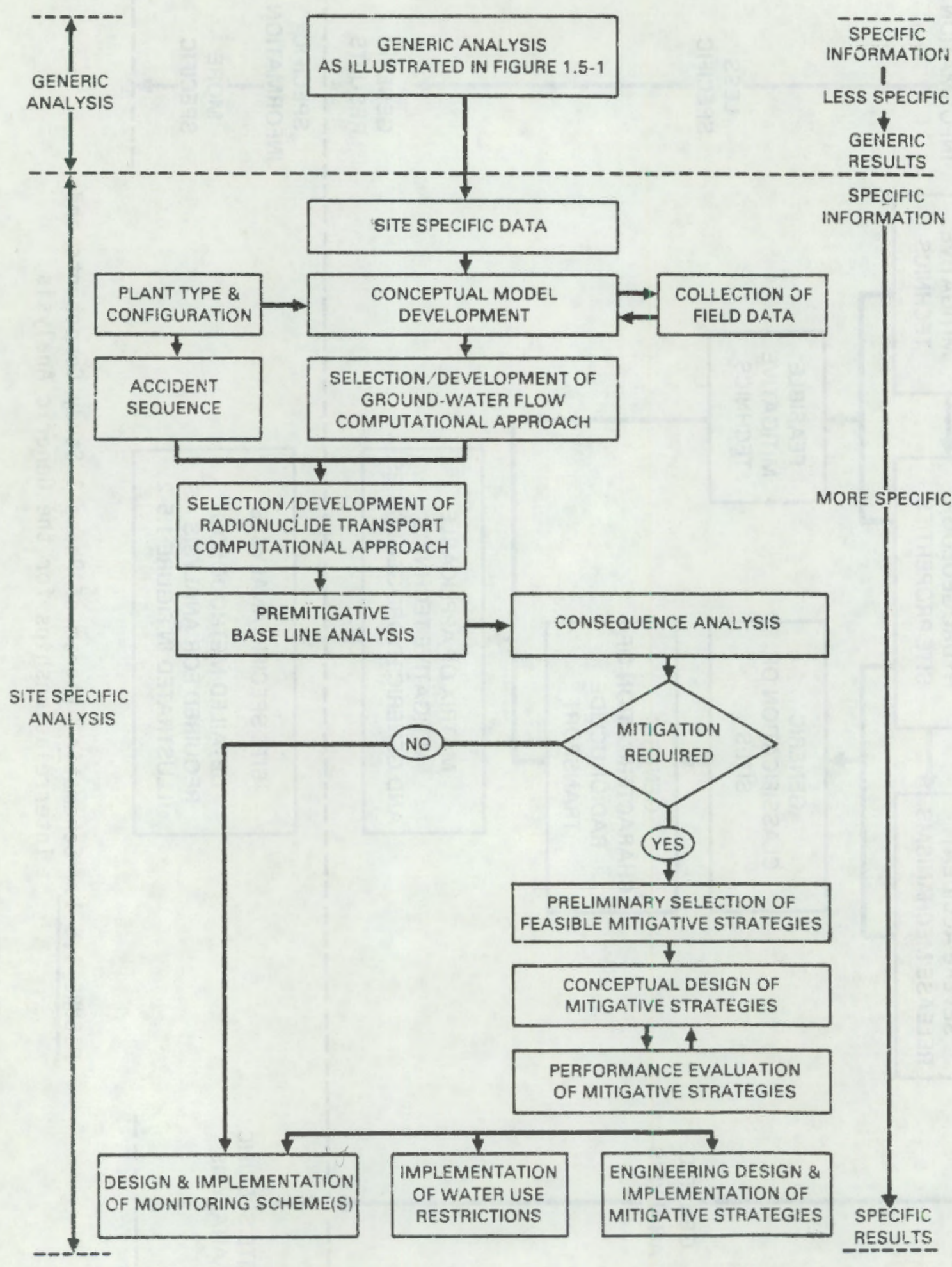

FIGURE 1.5-2. Schematic Diagram of Phase 2 Study Components and Interrelationships for the Site Specific Analysis 
site-specific framework of analysis is one of increasing specificity with increasing detail in the hydrogeologic characterization, radionuclide transport, and evaluation of the performance of mitigative strategies. In summary, the first phase (i.e., generic analysis) of the study is designed to provide broad general information concerning severe power plant accidents and the interdiction of contaminants entering the ground-water pathway. The second phase (i.e., case study analysis) of the study is designed to demonstrate, to the extent possible, methodologies and approaches to the analysis of a severe power plant accident and ground-water contaminant mitigation at a specific site.

\subsubsection{Release of Contaminant into the Ground Water Flow System}

The release of contaminant following a severe nuclear accident is a complicated site and accident specific event. The term "contaminant release" is used in reference to the release of contaminant by leaching, or by flow of reactor sump water into the ground-water system. Contaminant residing below the containment structure in the solid phase of the core debris and not being transported by ground water is not considered to be released.

The release rate, as well as the quantity, is important in characterizing the release of contaminant. This is especially true for accident situations where the environmental consequences are evaluated in terms of the time and spatially dependent concentrations or population doses. The dominant mechanism controlling the time dependent discharge of core melt leachate to surface water is not found in the characterization of transport (i.e., dispersion) but rather in the much greater effect of solid material leaching and hydraulic restrictions of a liquid release. In describing the release of contaminant following a core melt accident the goal is to quantify the major characteristics that control the time dependence of contaminant migration to an accessible environment. Conservative estimates for parameters that govern the release mechanisms allow conservative yet realistic examination of the consequences of a core melt accident.

The release mechanisms that would liberate contaminant to the ground water are not precisely described by basic assumptions and simple processes. There are a host of inner-dependent chemical, hydraulic, thermal and morphological reactions that would control the release rate of contaminant into the groundwater flow system. This study has concentrated on the long-term, far-field effects of a core melt accident and, as such does not address the following:

1. less than full core melt penetration of the containment basemat,

2. partial saturation or resaturation adjacent to the core melt debris,

3. transient thermal effects on melt debris leach release rates and sump water flow rates,

4. less conservative assumptions of core debris morphology (i.e., specific surface area), 
5. multi-component contaminant release mechanisms (i.e., diffusion and corrosion),

6. mixed chemical melt types (e.g., melts composed of partially silicic and partially calcine material), and

7. multi-phase flow of super-heated gases and water away from the core debris.

\subsubsection{Hydrogeologic Classification of Nuclear Power Plant Sites}

The classification of nuclear power plant sites is based on the concept that there are common physical characteristics that control the release, transport, and interdiction of contaminants in ground water. Combining the criteria for classification of contaminant release and contaminant transport with feasible mitigative measures results in a matrix of generic hydrogeologies versus mitigative actions. The classification system serves to define the generic characteristics of a severe accident (i.e., magnitude, transport rates) and the techniques that may be used to achieve a potentially necessary reduction in environmental hazard.

The scope of the generic classification system has been constrained to a workable number of categories such that a representive number of sites are in each category. The deveopment of a generic hydrogeologic classification is limited by the hydrogeologic data base on which the classification scheme is made. The hydrogeologic descriptions are based on data extracted from Preliminary Safety Analysis Reports (PSAR's) and Final Safety Analysis Reports (FSAR's). The extent of the geological/hydrological description of contaminant pathways varies among the reports. This does not, however, imply that the original data or its extraction by other researchers from the safety reports are in error. It should be recognized that the data were compiled for the purpose of conducting generic studies and do not possess the resolution that would be expected from a detailed examination of a specific site. For example, the geologic description portion of the classification scheme is often based on one word descriptions of the materials found beneath the containment structure at a site (e.g., sandstone, clay, limestone). Layered media of different compositions or geologic changes along the contaminant flow path are indiscernible in these circumstances. Consequently, the recognized limitations of the generic hydrogeologic classification scheme are:

1. geological descriptions in the hydrogeologic data base are limited in detail and apply only for the materials under the containment structure, and

2. geology of multi-layered sites are classified based on the predominant unit. Variations in geologic materials can cause unique contaminant transport characteristics and require special or composite mitigative strategies. 


\subsubsection{Analysis of Radionuclide Transport in Ground Water}

For the analysis of radionuclide transport in ground water, a one dimensional transport analysis is conducted for each individual existing and proposed commercial nuclear power plant site in the U.S. The results of the analyses are "lumped" or categorized according to the hydrogeologic regime into generic classifications. Transport analysis on individual nuclear power plant sites when examined as hydrogeologic groups provides considerable insite to the generic factors of a core melt accident. This approach has distinct advantages over an approach based solely on a series of average or representative conditions:

1. hydraulic transport parameters may have a negative correlation (e.g., gradient and hydraulic conductivity) and "average" values may not occur at actual sites,

2. mass transport equations for radionuclides are non-linear and average values may not produce an "average" or representative contaminant discharge to an accessible environment,

3. the range of hydraulic and transport factors can cover several orders of magnitude even in a single generic hydrogeologic classification. Bracketing the feasible range of several key parameters can create more transport scenarios, producing a hroader range in results, than found at actual sites,

4. the variations in contaminant transport that can be expected within each classification are contained within the hydrogeologic data base and can be carried through the analysis,

5. actual site data may contain associations and correlations unique to nuclear power plants due to siting requirements that could be masked by incorporating averaged or assumed data for similar materials existing elsewhere.

In this manner, the generic characteristics of release, transport and discharge to the environment are analyzed. The hydrogeologic data base contains sufficient information for a one dimensional transport analysis at each site.

However, there are certain limitations to this approach. The degree of modeling accuracy is less than if an exhaustive site and modeling study were conducted for each site. The description of spatially dependent hydraulic characteristics (i.e., hydraulic conductivity and effective porosity) by a single representive value permits transport calculations of an approximate nature. The accuracy of the transport analysis is a function of how well each site can be described by single dimensional parameters.

The hydrogeologic data base for nuclear power plant sites used in this study is a combination of measured, extrapolated and estimated parameters. When hydraulic data were unavailable (e.g., effective porosity) conservative values, that is, values that are somewhat biased toward producing more rapid 
contaminant transport were selected. Successive conservative estimates of hydrologic parameters used in transport analyses can produce overly pessimistic results. Specifically, the hydrogeologic transport analysis is limited by:

1. one dimensional, saturated, steady state transport at each site,

2. a single hydrologic unit is considered,

3. the discharge of contaminant is assumed to be at the nearest surface water body,

4. hydrologic conditions are assumed to be the same as when the power plant was constructed,

5. hydraulic spreading of contaminant during sump water release is not considered,

6. data deficiencies (i.e., dispersivities and effective porosities) are filled by estimations based on judgment.

These limitations are most sensitive to the analysis at an individual site. However, when analyzed as a generic group the individual variations are less important and the central tendencies (if present) serve as the generic descriptor. If the analysis results show a broad spectrum of contaminant discharge rates and arrival times at surface water bodies, then the analysis is useful in that it becomes known that the site specific factors (i.e., distance to environmental contact) are more important than generic hydrogeologies.

\subsubsection{Identification and Evaluation of Ground Water Contaminant Mitigation Techniques}

The goal of the identification and evaluation of ground-water contaminant mitigative techniques is to provide a detailed description of feasible methods for controlling and/or reducing ground-water contamination in various geologic environments. Each mitigative measure is described in terms of:

1. design considerations,

2. construction considerations,

3. performance considerations, and

4. implementation considerations.

Information provided in this report serves as a guide to feasible mitigation schemes and discusses their advantages and limitations in comparison with each other and in relation to the geologic medium in consideration. 
Considerations not included in the analysis of mitigative techniques are:

1. multi-layered systems of very different properties requiring a unit by unit evaluation of feasible mitigative measures,

2. complex hydrogeologic environments where spatial changes in material properties require a strategy of multiple mitigative measures,

3. site specific restrictions to access at desired distance from accident site (i.e., topography and existing structures),

4. mitigative measures interacting directly with the core debris (i.e., in situ vitrification, injection of sorbing agents along core debris, or removal of core debris).

The determination of engineering feasibility of the various mitigative schemes requires an indepth evaluation of implementation considerations which include:

1. installation time,

2. construction cost,

3. equipment mobilization,

4. toxicity of chemical treatments, and

5. worker safety.

Unfortunately, these issues are highly site specific and site sensitive; especially worker safety. Thus, great difficulty arises in analyzing these issues in a generic manner. This study identifies these issues and as far as possible, within the generic context of the study, describes their implications in regard to the feasibility of each mitigative technique. To go beyond the level of information provided in this report would be unfounded and potentially misleading and inaccurate within the current scope of the project.

\subsubsection{Determination of Feasible Mitigative Techniques for Specific Hydrogeologic Classifications}

The approach taken for the determination of hydrogeologic sites versus feasibile mitigative techniques is to couple the geohydrologic information pertaining to the generic sites with information compiled on appropriate geologic properties for mitigative technique feasibility. The coupling is based on the range of conditions for which the mitigative technique is designed and the hydrogeologic characteristics describing each generic site. As a result, a practical guide to feasible mitigative techniques with limitations on their feasibility in each generic geological environment is provided.

\subsubsection{Case Study Analysis}

A series of three case studies are planned for the final report. The case studies describe the methodological approach necessary to perform a reconnaissance level assessment of the need and feasibility of implementing mitigative actions at selected commercial reactor sites in the U.S. The case study is not 
intended so much to answer concerns regarding specific courses of action at the selected sites as to develop and demonstrate a methodology for evaluating mitigative alternatives in a site specific manner. The methodology must be broadbased due to the complicated nature of the problem involved in evaluating the suitability of various mitigative techniques. In general, the methodology can be subdivided into two components: 1) the ground-water system which dictates the need for and acceptability of mitigative actions; and 2) the plant configuration and accient scenario which dictate, in a large part, the feasibility of implementing mitigative actions. The case studies are designed to focus attention on different aspects of these two components with hope that in composite they will provide insight into the overall approach necessary for evaluation of the broad range of issues involved in determining the necessity, feasibility, suitability and implementability of mitigative techniques for ground-water contamination following a severe power plant accident.

The results of the first case study are presented in this draft report. The South Texas Plant in Matagorda County, Texas was selected by mutual agreement among NRC and PNL staff. Case study emphasis is focused on charaterization and evaluation of ground-water flow and contaminant transport phenomena in a porous flow environment. The intent of this case study is to determine the methods, procedures, and analyses necessary to evaluate, using available information, the impact of various mitigative strategies on the ground-water flow regime of a specific site. Subsequent case studies will be more heavily involved with issues related to power plant configuration and the trade-offs in performance of various mitigative measures and the trade-offs in performance of various mitigative measures.

\subsection{REALISTIC VERSUS CONSERVATIVE ANALYSES}

The analysis of the consequences of nuclear accidents is often of a conservative nature. Simplifications and estimations are made such that underestimation of the consequences is unlikely. For many aspects of a consequence analysis this approach is valid. However, when a complex series of interrelated events are examined, as in the case of a simulation of a core melt accident, successive estimates that are conservative can affect the realism of the analysis. In extreme cases very conservative analyses produce physically impossible results.

For the analysis of core melt accidents a balance must be made between conservatism and realism. The analysis of the environmental consequences and the need for ground-water contaminant mitigation must be based on a realistic examination of the situations. Over-estimation of the amounts of contaminant. by many orders of magnitude may not provide a proper basis for an evaluation of mitigative measures. At the same time however, it must be recognized that under-estimation of the consequences of a core melt accident is far less desirable than an overestimation of the consequences. This study follows a conservative yet realistic approach, to the degree possible. When phenomena can be simulated at realistic levels of expectation conservative is avoided. However, for analysis of events subject to large uncertainties (i.e., leach rates) conservatism is preserved. 


\subsection{DESCRIPTION OF CORE MELT RELEASE OF RADIONUCLIDES}

\subsection{INTRODUCTION. TO CORE MELT ACCIDENTS}

The accident sequence and the type of nuclear power plant affect the amount of radionuclides that may be released during a severe accident. Commercial nuclear power plants utilize either a pressurized water reactor (PWR) or a boiling water reactor (BWR). Fundamentally, BWR's use one coolant loop with water flowing through the core allowed to boil and flow directly to the turbine-generator. In contrast, PWR's have pressurized water in a double loop incorporating a steam generator. The two reactor types exhibit different characteristics related to core melt accidents. Reactors of either design are capable of undergoing a severe accident in which the reactor core containing nuclear fuel and support materials overheats to the point of melting (RSS 1975). The resulting molten mass could contain sufficient heat to subsequently penetrate (i.e., melt through) the reactor containment structures and enter the geologic strata beneath the power plant (RSS 1975). After sufficient cooling, ground-water flow would contact the core melt debris and initiate the hydraulic transport of radionuclide contaminants away from the site. Pressurized water reactors could also release a significant amount of contaminated water through the melted opening in the containment structure (RSS 1975). The water would originate from reactor cooling water and from the operation of emergency sprays during the accident sequence. The water would be exposed to core materials and would contain a portion of the radionuclide core inventory. This liquid would collect in the reactor sump and could be released as "sump water" during a core melt accident. Severe nuclear power plant accidents of both types (i.e., core melt-through and sump water release) are illustrated in Figure 2.1.1-1. A core melt accident involving the penetration of the containment structure has never occurred. Therefore, the hypothesized sequence and impact of core melt events contain varying degrees of uncertainty related to the size of the radionuclide release, leach rate, and ground-water transport.

\subsubsection{Definition of Core Melt Accident}

In the context of this study an "accident" refers to an unplanned sequence of events which leads to the release of fission products into the ground-water flow system. Although throughout the nuclear fuel cycle there are circumstances which could give rise to the accidental release of radionuclides attention is focused on the class of accidents which result in heating of the reactor core sufficiently to cause some form of breach in the reactor containment. This type of accident is extremely unlikely. However, a core melt accident could be the most catastrophic, in terms of radionuclide release to the environment, of all potential nuclear power plant accidents types. For this reason this investigation is limited to the class of severe nuclear power plant accidents characterized by some form of breach of the reactor vessel and subsequently the containment building basemat.

The characterization of a severe nuclear power plant accident is limited to facilities which employ light-water reactor technology since this technology is the most common for commercial reactors. Specifically, consideration is given to a core melt scenario that would pertain to a reference pressurized 

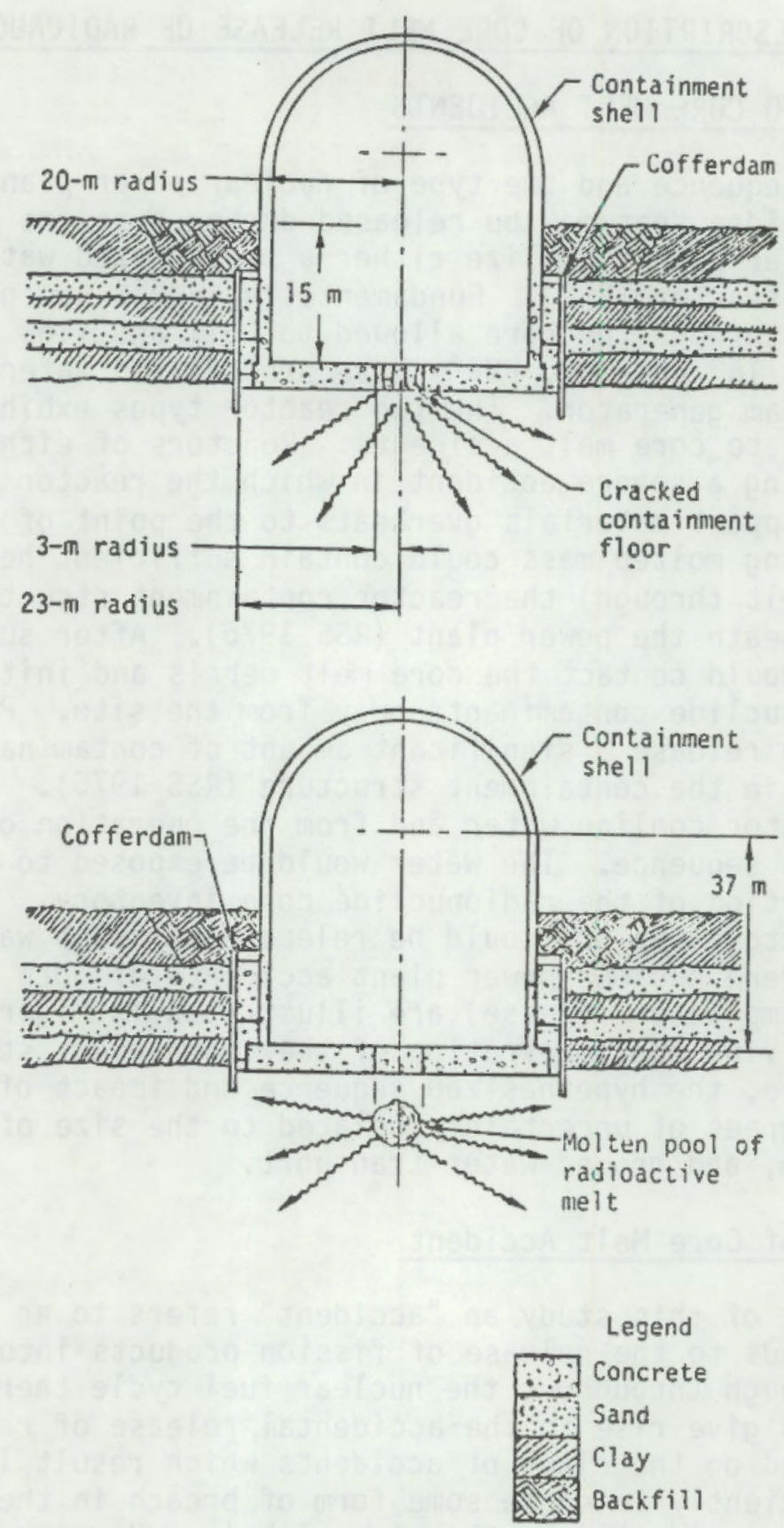

\section{FIGURE 2.1.1-1. Two Possible Configurations of a Severe Nuclear} Accident Involving Failure of the Reactor Basemat (Source: Pitts 1975)

water reactor or a reference boiling water reactor since these design types encompass most of the commercial power reactors either in service or planned in the U.S.

The intent of this discussion is not to provide a detailed assessment of the engineering aspects of a core melt sequence. It is intended, however, to 
outline, in conceptual terms, the possible causes for the initiation of a potential core melt sequence and the subsequent steps leading to the breach of the containment basemat. This outline of a severe accident should provide a common foundation-for the analysis of radionuclide transport and contamination of ground water, determination of hydrogeologic site conditions, and ultimately the assessment of ground-water contamination mitigative techniques.

\subsubsection{Causes of a Severe Accident}

In order for an accident to occur in which the containment is breached there must be sufficient heat generated to cause a loss of integrity of the reactor core by either a melting or partial melting of fuel elements. Overheating of the fuel can occur only if more heat is generated in the fuel than can be removed. This circumstance can be brought about by one of two events. First, a loss of coolant will allow fuel to overheat because of the continued decay of radioactive materials in the fuel after the reactor has been shut down. Second, a heat imbalance can occur if the reactor power is increased beyond the heat removal capability of the cooling system or the cooling system capability is reduced to a level below the generation rate. This study is primarily concerned with the loss of coolant accident which results in the uncovering of the reactor core and subsequent overheating of the fuel.

This class of accident can lead to the initiation of meltdown of the reactor core if there is associated with the loss of coolant failure of the emergency core cooling system (ECCS). The most probable cause of a severe loss of coolant accident is a break in one of the main coolant loop pipes followed by operational failure of the ECCS. In the event of a severe core accident there are specific power plant barriers that must be breached in order for a significant release of fission products and hazardous chemicals to the subsurface environment. The plant barriers that must be breached, in succession, are (RSS 1975):

1. Fuel matrix (U0, pellets in most cases),

2. Fuel cladding (Zircaloy casing or tube for most plants),

3. Reactor vessel and primary system piping, and

4. Containment basemat.

During normal reactor operation the majority of radioactivity remains in the fuel matrix with a small percentage migrating to the gap between the fuel pellets and the cladding. In order for a significant amount of radioactivity to be released to the reactor vessel and primary system piping the fuel cladding must fail thus allowing direct exposure of the fuel pellets. It is assumed that if conditions exist which are severe enough (i.e., high temperature) to cause melting of the fuel cladding then the fuel pellets would also melt causing complete core melting. This assumption is conservative however, due to the higher melting point $\left(\sim 5000^{\circ} \mathrm{F}\right)$ of $\mathrm{UO}_{2}$ than the surrounding metal. Once the above sequence of events has taken place the molten core could melt through the bottom of the reactor vessel (RSS 1975).

It is difficult to predict the physical processes that may occur as a result of a core melting loss of coolant accident. It is considered "likely" 
that sufficient thermal mass would be available to eventually melt through the lower concrete structure (i.e., the basemat) of the containment (RSS 1975). In this study it is assumed that the core melt mass penetrates the basemat and enters the geologic materials under the power plant.

There are several accident sequences for both PWR's and BWR's that could result in a core melt. Each of these accident sequences has a characteristic release of radionuclides. This study assumes that the most probable core melt accident for a PWR or a BWR would occur. The sensitivity of contaminant discharge to the environment to various accident sequences is discussed in Section 2.2.2. The assumed accident sequences are conservative in that: 1) PWR's would partition the radionuclides between core debris and sump water in a ratio that favors early hydraulic release; and 2) BWR's and PWR's would release the maximum amount of radioactivity into the ground-water system rather than the surface or above-ground environment.

The most probable accident sequence for a pressurized water reactor (designated PWR-7 in the Reactor Safety Study 1975) is summarized as follows:

- PWR 7 - This accident sequence involves a core meltdown due to failure in the core cooling systems. The containment sprays would operate, and the containment barrier would retain its integrity until the molten core proceeded to melt through the concrete containment basemat. The radioactive materials would be released into the ground, with some leakage to the atmosphere occurring upward through the ground. Direct leakage to the atmosphere would also occur at a low rate prior to containment vessel melt through. Most of the release would occur continuously over a period of about 10 hours. The release would involve $0.002 \%$ of the iodines and $0.001 \%$ of the alkali metals present in the core at the time of release. Because leakage from containment to the atmosphere would be low and gases escaping through the ground would be cooled by contact with the soil, the energy release rate would be very low.

The most probable accident of a BWR core melt accident (designated BWR-3 in the Reactor Safety Study 1975) is summarized as follows:

- BWR 3 - This release category represents a core meltdown caused by a transient event accompanied by a failure to scram or failure to remove decay heat. Containment failure would occur either before core melt or as a result of gases generated during the interaction of the molten fuel with concrete after reactor-vessel melt through. Some fission-product retention would occur either in the suppression pool or the reactor building prior to release to the atmosphere. Most of the release would occur over a period of about 3 hours and would involve $10 \%$ of the iodines and $10 \%$ of the alkali metals. For those sequences in which the containment would fail due to overpressure after core melt, the rate of energy release to the atmosphere would be relatively high. For those sequences in which overpressure failure would occur before core melt, the energy release rate would be somewhat smaller, although still moderately high. 


\subsubsection{Core Melt Penetration of Reactor Basemat}

In the final stage of a core melt sequence the core of the reactor containing nuclear fuel, steel support structure and piping would liquify (Niemczyk et al. 1981). The molten mass sequently would flow under gravitational force to the bottom of the reactor vessel. The molten mass could then melt through this structure and contact the final barrier - the containment basemat. The basemat is a limestone or silica sand-based concrete approximately three meters in thickness which serves as part of the structural foundation. The decay heat content of the core melt mass would decompose and melt the basemat. Experimental data indicate that the rate of basemat penetration is 3 to $7 \mathrm{~cm} / \mathrm{h}$ (PACMA 1981). During this process the core melt mass would be accreting material from the structures it contacts. The core melt mass may penetrate the basemat and continue to melt into the geologic materials underlying the power plant (PACMA 1981). In reference to an analysis of two PWR's the staff of U.S.NRC concluded that basemat penetration can be precluded only if the core debris is kept separated from the concrete or if the core debris is cooled to temperatures below the penetration threshold for concrete (PACMA 1981). The melt mass would accumulate geologic materials and thus initiate cooling due to convection and conduction. After about one month the melt mass would no longer contain sufficient heat to melt additional material and the core melt debris would begin to solidify (Niemczyk et. al. 1981).

\subsubsection{Chemical Composition of Core Melt Debris}

The physical and chemical properties of core melt debris are, in part, a function of the construction material comprising the basemat and the undisturbed geologic units under the power plant. The precise characterization of a generic core melt debris is not possible due to physical uncertainties, accident dependent factors, and site specific conditions. The melt debris can however be generalized into two basic classifications: 1) core melts into silic materials; and 2) core melts into carbonate materials. The chemical composition, solidified geometries, and release of radionuclides would be fundamentally different in these two melt types. In classification of core melts based on chemical composition of liquified geo-materials there is an assumption that the basemat and the underlying geologic units are chemically similar. In general, this is correct as limestone or silicic aggregate from local sources is used to construct the basemat. The chemical composition of cement produced from silicic and carbonate aggregate is given in Table 2.1.4-1. Core melt masses containing a mixture of silica and carbonate are quite possible and would have physical properties between these two chemical extremes. The two types of chemical melts span the range of feasible debris conditions (Niemczyk et al. 1981).

Silicic materials are more easily melted than carbonates and the molten mass would extend about $11 \mathrm{~m}$ below the basemat (RSS 1975). The idealized configuration of the solidified silicic melt debris is roughly cylindrical. The geometry of the core melt would be determined by the specific heat of silicic material encountered (this may change with depth if a layered geologic unit is penetrated) and the presence of open fractures. The silica melt would 
TABLE 2.1.4-1. Concrete Compositions

(Source: Levine 1977)

\begin{tabular}{|c|c|c|}
\hline Material & $\begin{array}{l}\text { Siliceous } \\
\text { Weight Percent }\end{array}$ & $\begin{array}{c}\text { Carbonate } \\
\text { Weight Percent }\end{array}$ \\
\hline $\mathrm{SiO}_{2}(\mathrm{a})$ & 55.7 & 15.3 \\
\hline $\mathrm{CaCO}_{3}(\mathrm{~b})$ & 0.2 & 64.9 \\
\hline $\mathrm{Ca}(\mathrm{OH})_{2}$ & 21.6 & 12.7 \\
\hline
\end{tabular}

(a) Includes $\mathrm{TiO}_{2}, \mathrm{Na}_{2} \mathrm{O}, \mathrm{K}_{2} \mathrm{O}$

(b) Includes $\mathrm{MgCO}_{3}$

not be a massive block of glass (Niemczyk et al. 1981). Mixing of unmelted materials and some degassing of volatiles would produce a somewhat porous mass along the outer boundary. Fracturing during cooling, especially if cooling was rapid, would greatly increase the surface area and permeability of the debris.

Carbonate materials require an order of magnitude more heat than silicate materials to melt an equivalent volume of rock (Niemczyk et al. 1981). The depth of penetration below the reactor vessel would be less in carbonate materials at about 3 meters as shown in Figure 2.2.2-2. The shape of the solidified melt mass would be strongly influenced by penetration into solution cavities. If the cavities contained water, the melt debris would be rapidly cooled. The core debris would chemically resemble a calcine material and would have a high density due to degassing of carbon dioxide during melting. The degassing of a carbonate melt could also impart a relatively high porosity to the core debris.

\subsubsection{Sump Water Release Following Basemat Penetration}

Pressurized water reactors have a probability of a sump water release in addition to a core melt release of $5 \times 10^{-6}$ per reactor year (RSS 1975). The sump water would originate from cooling sprays used in the accident sequence and would acquire radionuclides from the containment atmosphere. The rate of liquid release is dependent on the permeability of the core melt and surrounding areal position of the water table or perched water tables, size of the basemat penetration, partially saturated flow characteristics, and pressurization of the containment building. The range of variables involved in determining the rate of sump water release indicates that the liquid could slowly leak into the ground-water system over a period of months or could be jetted into the earth in a few hours. A description of the sump water releases is given in section 2.5 . 


\subsection{INDICATOR RADIONUCLIDES}

\subsubsection{Initial Amount of Indicator Radionuclides in Core}

The reactor core contains an inventory of over 75 radionuclides (Niemczyk et al. 1981). These radionuclides are in various quantities and have different half-lives. However, examination of the entire reactor core radionuclide content is not necessary to characterize generic sites. In this study the radionuclides used to indicate the relative severity of an accident have three properties: 1) a long half-life to assure that they do not undergo significant decay prior to surface water discharge; 2) a high initial amount that could cause environmental concern; and 3) a low degree of sorption so that the contaminant would be easily transported by ground water. The three radionuclides meeting these criteria are listed in Table 2.2.1-1.

By examining the transport of these indicator radionuclides, the severity of radionuclide nuclear discharges to the accessible environment can be evaluated. The initial amount of each radionuclide is based on a theoretical reactor of a 3,200. thermal megawatt design (RSS 1975). This reactor size is typical of nuclear power plants in the U.S. which have a design efficiency of $31 \%$ yielding 1,000 electrical megawatts (RSS 1975). The differences in calculation of fuel burnup rates and power densities between PWR's and BWR's is not a sensitive parameter (Niemczyk et al. 1981). The assumption of a single inventory for both reactor types is conservative in respect to the core melt process (Niemczyk et al. 1981).

\subsubsection{Radionuclide Partitioning}

Boiling water reactors would have minor water releases below the containment structure and the radionuclide inventory would reside in the core melt debris. Pressurized water reactors could release a fraction of the core inventory during a core melt accident to the cooling water that collects in the contaminant sump. Release of the sump water through the basemat melt hole or through cracks and fractures in the basemat would also enter the ground-water flow system. The sump water is of note for two reasons: 1) some radionuclides, particularly cesium-137, are concentrated in the sump water; and 2) sump water involves a hydraulic release that could occur over a short period of time thus concentrating and driving contaminant toward the accessible environment. The release fractions of radionuclides are accident and reactor type specific. The core inventory is partitioned into the atmosphere, the core TABLE 2.2.1-1. Indicator Radionuclides

\begin{tabular}{|c|c|c|c|}
\hline $\begin{array}{l}\text { Radionuclide } \\
\text { Nuclide }\end{array}$ & $\begin{array}{l}\text { Initial Amount } \\
\text { (p curies) }\end{array}$ & $\begin{array}{l}\text { Half-Life } \\
\text { (days) }\end{array}$ & $\begin{array}{c}\text { Adsorption } \\
\text { (Relative to Other } \\
\text { Indicator Radionuclides) }\end{array}$ \\
\hline Strontium-90 & $3.71 \times 10^{18}$ & 10519 & Low \\
\hline Cesium-137 & $4.67 \times 10^{18}$ & 11042 & High \\
\hline Ruthenium-106 & $2.48 \times 10^{19}$ & 367 & Intermediate \\
\hline
\end{tabular}


melt debris, and (if it is a PWR) the sump water. The partitioning ratios for this study are given in Table 2.2.2-1 and are taken from the (Niemczyk et. al. 1981).

The assumed accident sequence for the PWR is conservative in that the maximum amount of radioactivity enters the sump water where it can reach the biosphere in the shortest period of time. Radionuclides not in the sump water are assumed to be in the core melt debris where they are leached into ground water over long periods of time.

A core melt accident sequence other than PWR-7 or BWR-3 would release less contaminant into the ground-water flow system than the fractions indicated in Table 2.2.2-1. The magnitude of variations in hydrogeologic parameters are constrasted with variations in documented accident sequences in Table 2.2.2-2. The range of variation in contaminant release fractions due to the occurrence of less probable accident sequences is small in comparison to the large range of core me1t source and hydraulic transport parameters. The amount of contaminant discharged into a surface water body is a much stronger function of generic hydrogeologic conditions than accident sequence.

The effect of radioactive decay exponentially magnifies the variations in the hydraulic and transport characteristics when the radionuclide flux at a distant boundary is evaluated. That is, the large site specific variations in hydrogeologic transport result in even larger variations in amounts of contaminant when discharged into surface water depending on half-life. However, the accident sequence determined release fractions are linearly related to the amount of radionuclides discharged from the ground-water system to a surface water body. The accident sequence is therefore an insensitive parameter in the computation of radionuclide discharge fluxes to a surface water body and the maximum amount is assumed to be released in this study.

\section{TABLE 2.2.2-1. Release Fractions for Indicator Radionuclides}

\begin{tabular}{|c|c|c|c|c|}
\hline $\begin{array}{l}\text { Accident } \\
\text { Sequence }\end{array}$ & Radionuclide & $\begin{array}{l}\text { Airborne } \\
\text { Release }\end{array}$ & $\begin{array}{l}\text { Sump Water } \\
\text { Release }\end{array}$ & $\begin{array}{l}\text { Core Melt Debris } \\
\text { Leach Release }\end{array}$ \\
\hline \multirow{3}{*}{ PWR-7 } & $90_{S r}$ & $1 \times 10^{-4 q}(a)$ & $11 \%$ & $89 \%$ \\
\hline & ${ }^{106} \mathrm{Ru}$ & $1 \times 10^{-4} \%(b)$ & $8 \%$ & $92 \%$ \\
\hline & ${ }^{137} \mathrm{Cs}$ & $1 \times 10^{-3} \%(c)$ & $100 \%$ & $0 \%$ \\
\hline \multirow{3}{*}{$B W R-3$} & ${ }^{90} \mathrm{Sr}$ & $1 \%$ & - & $89 \%$ \\
\hline & ${ }^{106} \mathrm{Ru}$ & $2 q_{0}(\mathrm{~b})$ & - & $92 \%$ \\
\hline & ${ }^{137} \mathrm{Cs}$ & $10 \%(c)$ & - & $0 \%$ \\
\hline
\end{tabular}

(a) Includes Ba.

(b) Includes $\mathrm{Ru}, \mathrm{Rh}, \mathrm{Co}$, Mo, Tc.

(c) Includes $\mathrm{Rb}$. 
TABLE 2.2.2-2. Generic Hydrogeologic and Accident Sequence Variations

\begin{tabular}{|c|c|}
\hline Type of Variation & $\begin{array}{l}\text { Range of Variations within Generic } \\
\text { Classification (given in orders of magnitude) }\end{array}$ \\
\hline $\begin{array}{l}\text { Hydraulic Characteristics } \\
\text { Porosity } \\
\text { Hydraulic Conductivity } \\
\text { Hydraulic Gradient }\end{array}$ & $\begin{array}{l}0-1 \\
3-6 \\
1-2\end{array}$ \\
\hline $\begin{array}{l}\text { Transport Characteristics } \\
\text { Retardation } \\
\text { Distance to accessible } \\
\text { environment }\end{array}$ & $\begin{array}{l}1-3 \\
1-2\end{array}$ \\
\hline Core melt leach rate & 2 \\
\hline $\begin{array}{l}\text { Accident Sequence } \\
\text { Leach release fractions } \\
\text { Sump water release fractions }\end{array}$ & $\begin{array}{l}0-2 * \\
0-2 \star\end{array}$ \\
\hline
\end{tabular}

* Not generically controlled. Includes release categories $\mathrm{Xe}, \mathrm{I}, \mathrm{Cs}, \mathrm{Te}, \mathrm{Sr}$, Ru, and La range of variations are less for indicator radionuclides.

The molten core melt mass would vaporize the ground water in the vicinity of the debris. Other gasses might also form due to volatilization and chemical reactions in the melting of geologic materials. These gasses would contain some of the radionuclides released and may migrate around the basemat or through a ruptured containment structure and enter the atmosphere. This study conservatively assumes that these releases are negligible and the core inventory is available for ground-water transport.

\subsection{COOLING OF THE CORE MELT DEBRIS}

The molten core materials will initially cool by 1) a decrease in decayheat generation, 2) incorporation of cooler geologic materials, 3) degassing of volatiles and 4) convection-conduction processes. The mass of the debris can be estimated to a reasonable degree of certainty based on the heat content of the reactor core and the type of materials penetrated. The shape of the solidified mass is dependent upon the melting point, bulk mass density and water content of the geologic materials as well as the vigor of core melt mixing during penetration. The core melt mass would be roughly cylindrical in form. Liquid core material would flow into any openings or voids (i.e., fractures and solution cavities) encountered during melt penetration. The melt would quench quickly if it encountered a highly transmissive saturated fracture.

The emplacement of the core melt will alter an undetermined zone around the debris. Partial melting and dessication of this zone will change its hydraulic properties. Partial melting may lower the effective porosity and seal existing fractures. Dessication adjacent to the core debris would grade 
into a partially saturated zone and then an undisturbed area. The residual heat of the melt would maintain the dessication zone until temperatures dropped below the boiling point of water. These factors would reduce hydraulic conductivity around the core melt and delay radionuclide transport. The near-field effects of core melt implacenent are not considered further in this study. Transient hydraulic events such as the re-establishment of a flow field around the core debris are conservatively assumed to be instantaneous after core debris cool down.

Ground water contact with the core melt debris will cool the melt at a much faster rate. As ground water cools the outer skin of the melt mass contraction with fracturing along radial and axial patterns is likely. With time, ground-water flows would penetrate deeper into the melt debris until the melt debris became saturated throughout its entire mass. The time period for ground water to fully contact the debris would be on the order of one to two years. In PWR's the liquid sump water could initially reside on top of the core melt mass and hasten cooling by evaporation and condensation inside the containment structure. The top portion of the core melt debris could cool sufficiently to allow sump water to flow around the hot debris about six months after the accident (Niemczyk et a1. 1981). The central portion of the core debris would remain at an elevated temperature after the sump water release. In this study, radionuclides are assumed to enter the ground-water system one year after the accident for core melt leached contaminants and six months after the accident for sump water releases.

\subsection{CORE MELT DEBRIS LEACH RELEASE}

\subsubsection{Introduction to Leach Releases}

The release of contaminant from the core melt debris would be from leaching of radionuclides into the ground-water flow system. Leach releases by ground water are dependent on many factors including:

1. chemical composition of material leached,

2. temperature,

3. ratio of surface area to volume,

4. density,

5. leachate resaturation rate,

6. dominant leach mechanism (i.e., molecular diffusion or matrix corrosion), and

7. amount of core melt debris saturated by ground water.

There are variations and uncertainties associated with all of these factors. The computation of a long-term leach rate for a core melt mass involves parameter estimates and generalizations with greater ranges than those used to calculate ground-water contaminant transport. There is considerable uncertainty in computing a radionuclide leach release rate for a core melt mass.

Leaching results of glasses under laboratory conditions can vary by over an order of magnitude. In addition there are a variety of test methods and reporting formats. Many tests are conducted on powdered or fine-grained 
material at elevated temperatures for short periods of time. The extrapolation of these results to a more massive material at ground temperatures over long time periods is somewhat questionable. The initial state of the surfaces being leached has an important effect on the short-term results. For example, samples with a flame-polished surface are not typical of the bulk of the glass, and leaching of such samples will give different initial results. Fractures or cut surfaces are more typical of the bulk glass surface. Leach tests carried out at room temperature often show high initial leach rates which drop by 2 or 3 orders of magnitude over a few days. Many accelerated leach tests (particularly the Soxhlet test) obscure this initial effect (IAEA 1979). Test of glass leaching are infrequently performed for periods more than a few weeks. Chalk River Laboratory in Canada has a leach test of glass blocks in progress since 1960 (Merrit 1977). The difficulty in determining a long term leach rate has in part, lead to the extremely conservative modeling assumption that the radionuclide release to ground water is instantaneous (LPGS 1978; Niemczyk et al. 1981).

Despite these difficulties the material properties of a silica melt and a calcine melt are recognized as having leach rates that are different by at least one order of magnitude. The leach rate is important when estimates of radionuclide flux over time at a surface water body are used to calculate concentrations and subsequent population doses. Obviously, over estimation of radionuclide release rates by many orders of magnitude (i.e., instantaneous or prompt releases) causes corresponding over estimation of the environmental hazards. In addition, the implementation of contaminant interdiction is predicted by the magnitude and duration of the nuclear release. This study uses conservative yet realistic long-term estimates of leach release rates for silicic and calcine materials.

\subsubsection{Silicic Melts}

\subsubsection{Leach Mechanisms}

For this melt type the geologic materials comprising the basemat and underlying formations are assumed to be predominantly silicon-aluminum-oxides. A glassy (amorphous silica) core melt mixture is calculated by Niemczyk et al. (1981) to contain $86 \%$ silica by weight at the time of solidification. Mixing and degassing would incorporate cavities and particles of rock. Consequently, the core debris would not resemble a solid block of glass. However, the melt material can be chemically characterized as similar to a glass or natural occurring volcanic obsidian. Cooling would subject the debris to thermalinduced stress that would cause fracturing. Experiments conducted on nuclear explosion melt glass indicates that the flow rate of water over the samples did not effect the leach rate (Chapman et al. 1980; Failor et al. 1983). The core melt debris is assumed to be sufficiently porous and/or fractured that it would not form a major hydrualic barrier. The position of the water table is conservatively assumed to be above the top of the core debris.

The mechanism of glass leaching has undergone extensive study due to the feasibility of isolating waste products in glass. The leaching mechanism is described by Barkatt et al (1981) as: 
Early work on silicate glasses containing alkali metal oxides and alkaline earth oxides has shown that the attack of water on the glass starts as a diffusive process through which alkali cations are preferentially leached from the surface layers, leaving behind a porous high-silica layer. As the dealkalized layer becomes thicker, the rate of further diffusion of alkali out of the glass through this layer becomes progressively slower, until silica dissolution at the interface between the dealkalized layer and the solution begins to control the rate of the attack.

After having been exposed for a sufficiently long time, silicate glasses with high durability posses silica-rich films which are dense enough to protect the glass from further rapid attack. In these cases, a transition layer, highly resistant to diffusion, is observed to form between the outer porous gel layer and the solid glass. This is probably due to the replacement of ionized oxygen-alkali bonds by undissociated matrix dissolution. In glasses, the formation of a hydration layer generally occurs simultaneously with the depletion of alkali ions.

A protective gel layer develops more slowly with time and the leach rate is of a parabolic type (Lanza et al. 1980). The growth of the hydration layer may be interrupted by cracking or peeling of the gel. There are two mechanisms that cause disruption of the gel layer: 1) as the glass hydrates the gel layer swells; and 2) the exchange of alkali ions by hydrogen (or $\mathrm{H}_{3} \mathrm{O}^{+}$) ions creates stress along the glass-gel layer due to change in ionic size and bond energies (Barkatt et al. 1981). Exposing fresh glass would restart the leaching process without the protective hydration layer and the leach rate would increase. Mechanical agitation in laboratory tests due to boiling, mixing and handling may cause disruption of the hydration rind. These conditions would occur only in the early stages of core melt cooling and saturation.

Early in the leach process diffusion is noted in glass by the preferential release of the radionuclides strontium-90, cesium-137, and alka1i ions (Barkatt et al. 1981). At longer times ionic diffusion from the glass is hindered by the protective hydration layer. The migration of radionuclides through the hydration layer is retarded by sorption in the insoluble silicic rind. The leaching of radionuclides from glass over long time periods can be summarized as in Table 2.4.2-1.

Leaching of glass over the short term (days) is diffusion controlled. Long-term (decades to a millennium) leach processes, which are important in determining the severity of a long radionuclide release period are controlled by hydration and corrosion of the glass matrix. Leach rates of radioactive high-level waste glass had not reached a constant value at 639 days and demonstrated the combination of release mechanisms (Bradley 1978). Matrix dissolution is an important part of long-term glass leaching (Clark et al. 1979). Matrix dissolution is probably the dominant mechanism at $25^{\circ} \mathrm{C}$ and perhaps as high as $75^{\circ} \mathrm{C}$ (Coles 1981b). 


\section{TABLE 2.4.2-1. Silicic Leach Processes}

1. At early times (days) ionic diffusion process are dominant which become exponentially less important with time.

2. Hydration of outer layer of glass with subsequent loss of akali ions and corrosion of the glass matrix.

3. Following corrosion of the matrix radionuclides and other ions migrate through the hydration layer and are retarded along the pathway.

4. The radionuclide reaches the outer edge of the hydration rind and enters the ground-water flow system.

\subsubsection{Silicic Leach Rate}

The rate of hydration of glass can be estimated by examination of a volcanic glass known as obsidian. These glasses have been exposed to leaching by ground water over thousands of years and provide an example of long term rates. The process of degradation of obsidian forms perlite or hydrated obsidian (Ericson 1981). Obsidian formation is a near surface geologic event and leaching conditions are similar to those of a postulated core melt accident (Ericson 1981). The thickness of the insoluble hydration rind has been correlated with historic and geologic age and is described by Friedman and Long (1976) as:

$$
\ell=K T^{1 / 2}
$$

where:

$$
\begin{aligned}
& \ell=\text { thickness of hydration }(\mu \mathrm{m}) \\
& K=\text { hydration rate }\left[(\mu \mathrm{m})^{2} / 1000 \text { year }\right] \\
& T=\text { time }(y r) .
\end{aligned}
$$

The hydration rate $(K)$ is a function of temperature and chemical composition. In a shallow geologic environment the earth temperature is assumed to be $20^{\circ} \mathrm{C}$. The hydration rate of obsidians in Japan was found to be related to temperature $(T)$ by:

$$
K=\left(6.76 \times 10^{-13}\right) \exp (-8927 / T)
$$

yielding a $K$ of $5 \mu \mathrm{m}^{2} / 1000$ years (Suzuki 1973). This value is in excellent agreement with the hydration rates of obsidian in the western U.S. (Friedman and Long 1976) and (Friedman and Obradovich 1980). The correlation of historical date to thickness of the hydration rind indicates that peeling and loss of the rind due to stress is not a prevalent event at these time periods (i.e., hundreds to thousands of years).

The leach rate of a silica glass is computed by knowing the surface area of the melt and application of Equations (2.2) and (2.3). The geometric surface area of the melt can be computed to a moderate degree of accuracy. The configuration of a silicic core melt is illustrated in Figure 2.4.2-1. The surface area of an actual melt would consist of partially granular to fracture 


\section{SILICIC MELT}

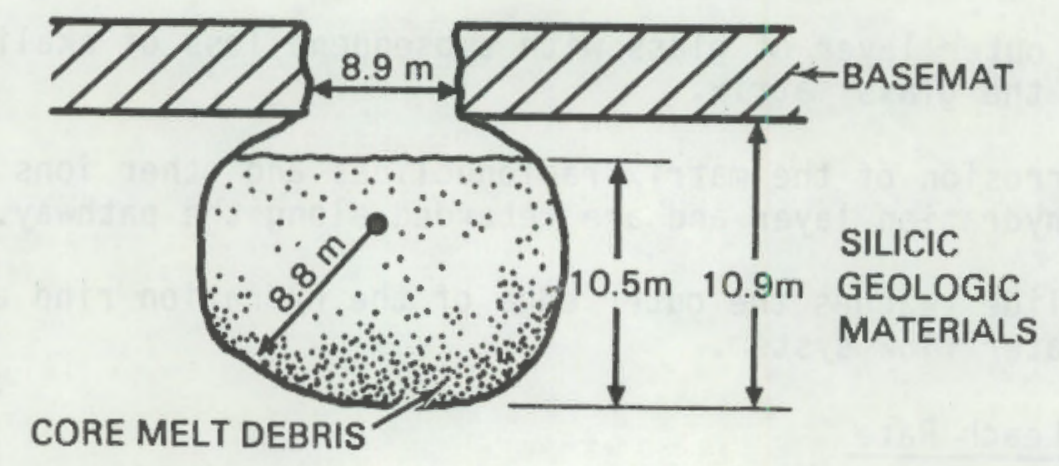

FIGURE 2.4.2-1. Configuration of Solidified Core Debris for Silicic Melt (After: Niemczyk et a). 1981)

surfaces and include irregular fingering into the geologic media. The surface area of a silica melt has been estimated by Niemczyk et al. (1981) to be "at least several times greater than the apparent exterior surfaces". A fractured surface area increase of 1000 over the geometric surface area was considered "more likely" in LPGS (1978). This study will assume a surface area increase factor of 67,000 which corresponds to a very conservative specific surface area of $100 \mathrm{~cm}^{2} / \mathrm{g}(\theta)$ as the upper limit of a silicic melt.

The bulk density $(\rho)$ of the silicic core debris is about $3.01 \mathrm{~g} / \mathrm{cm}^{3}$ including steel and fuel. Assuming a basically cubic fracture pattern the length of a representative fracture surface is computed by

$$
\frac{V}{A}=\frac{N L_{0}^{3}}{N 6 L_{0}^{2}}=\frac{L_{0}}{6}
$$

where:

$$
\begin{aligned}
V & =\text { geometric volume }=2.55 \times 10^{9} \mathrm{~cm}^{3} \\
A & =\text { surface area }=(V \cdot \rho \cdot \beta) \\
N & =\text { number of representative fracture cubes } \\
L_{0} & =\text { length of representative fracture surface }
\end{aligned}
$$

Solving Equation 2.4 for $L_{0}$ gives $1.9938 \times 10^{-2} \mathrm{~cm}$ in the example silicic melt. The amount of silica and dispersed radionuclides leached at time ( $t$ ) then becomes:

$$
M=\frac{Q}{N} L_{0}^{3}-2 L_{0}-H_{t}^{3} N W_{t}
$$


where:

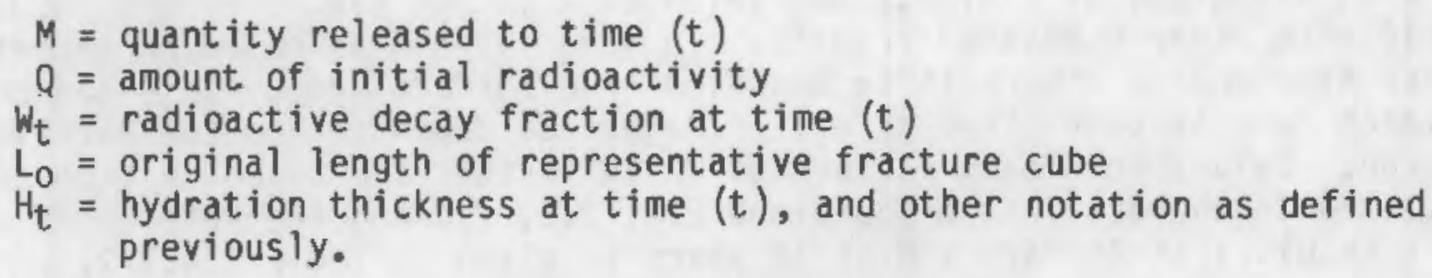

The number of representative fracture cubes (N) cancels in both Equations (2.4) and (2.5). The release of radionuclides from a core melt by this mechanism is conservative in four major respects:

1. the hydration rate would be more rapid in an admixture of silica, steel, fuel and incorporated partially melted geologic materials,

2. the surface area of $100 \mathrm{~cm}^{2} / \mathrm{g}$ is very high and implies extensive fracturing and/or a partially granular material,

3. hydration with subsequent corrosion release of radionuclides would also include the additional time necessary for material to diffuse through the insoluble hydration rind,

4. saturation of core melt is assumed instantaneous after cooling, and

5. the entire core debris is assumed to be below the water table.

These conservative factors of a silicic leach release are judged to be adequate to compensate for the uncertainty in the long-range leach mechanisms not accounted for in the release model. Specifically, there is no method to predict the possible cracking and pealing of the hydration rind and at early times (e.g., days) the hydration rind is not fully formed and diffusion dominates the release of radionuclides.

\subsubsection{Comparison with Experimental Results}

Comparison of this methodology to long-term glass leach data indicates that the results are reasonable. The comparison is based on a leach rate ( $R$ ) in $\mathrm{g} \mathrm{cm}^{-2} \mathrm{~d}^{-1}$ is given as (IAEA 1979):

$$
R=\frac{A_{t}}{A_{0}} \cdot \frac{W_{0}}{S \cdot T}
$$

where:

$$
\begin{aligned}
A_{t} & =\text { amount of "A" }(g) \text { removed in time } t \text { (days) } \\
A_{0} & =\text { initial amount of "A" }(g) \\
W_{0} & =\text { initial weight }(g) \\
S & =\text { surface area }\left(\mathrm{cm}^{2}\right) \\
T & =\text { time (days) }
\end{aligned}
$$


The parameter A can represent the activity of an isotope, however in this case $A$ equals grams of silica. The value of $R$ is not always directly comparable with other published results. In some cases $R$ is based on geometric surface area and in others it is based on true surface area. This can change the leach rate by over three orders of magnitude depending on the material composition. Values for leach rates used in this study are based on true surface area. The leach rate (using Equations 2.4, 2.5, 2.6 and the referenced experimental results) at 45 days and at 14 years is given in Table 2.4.2-2.

The leach rate at 14 years is computed for a standard ground-water temperature of $20^{\circ} \mathrm{C}$ and a lower temperature of $5^{\circ} \mathrm{C}$. The lower leach rate observed at $5^{\circ} \mathrm{C}$ is comparable to measured rates in the cool ground-water $\left(0-5^{\circ} \mathrm{C}\right)$ at Chalk River Laboratory. The hydration rate in near freezing ground water is reduced by over two orders of magnitude. Leach rate calculations for this study were made for ground-water temperatures of $20^{\circ} \mathrm{C}$.

Figure 2.4.2-2 presents the long-term silicic leach release for strontium-90 and ruthenium-106. The release of these two radionuclides is assumed to be congruent and at a rate controlled by the hydration-dissolution of the

TABLE 2.4.2-2. Comparison of Long-Term Experimental Data and Silicic Leach Model

\begin{tabular}{|c|c|c|}
\hline Material & Time & $\left(\mathrm{g} \mathrm{cm}-\mathrm{d}^{-I}\right)$ \\
\hline Rock-Glass (a) & 57 days & $6.6 \times 10^{-8}$ \\
\hline LWR Glass $(a)$ & 45 days & $1 \times 10^{-7}-1 \times 10^{-8}$ \\
\hline NTS Nuclear Explosion Glass(b) & 45 days & $1 \times 10^{-8}-1 \times 10^{-9}$ \\
\hline NTS Nuclear Explosion Glass (c) & $<20$ days & $5 \times 10^{-8}$ \\
\hline Silicic Leach Model(f) & 45 days & $8.3 \times 10^{-8}$ \\
\hline $\begin{array}{l}\text { Chalk River } \\
\text { Glass Blocks (d) }\end{array}$ & 14 years & $5 \times 10^{-11}$ \\
\hline Silicic Leach Model (e) & 14 years & $6.9 \times 10^{-12}$ \\
\hline Silicic Leach Model $(f)$ & 14 years & $7.8 \times 10^{-9}$ \\
\hline
\end{tabular}

(a) Experimental results from IAEA 1979.

(b) Experimental results from Coles and Ramspott 1982.

(c) Experimental results from Failor, Coles, and Rego 1983.

(d) Experimental results from Merrit 1977.

(e) At $5^{\circ} \mathrm{C}$

(f) At $20^{\circ} \mathrm{C}$ 


\section{SILICIC LEACH FUNCTIONS}

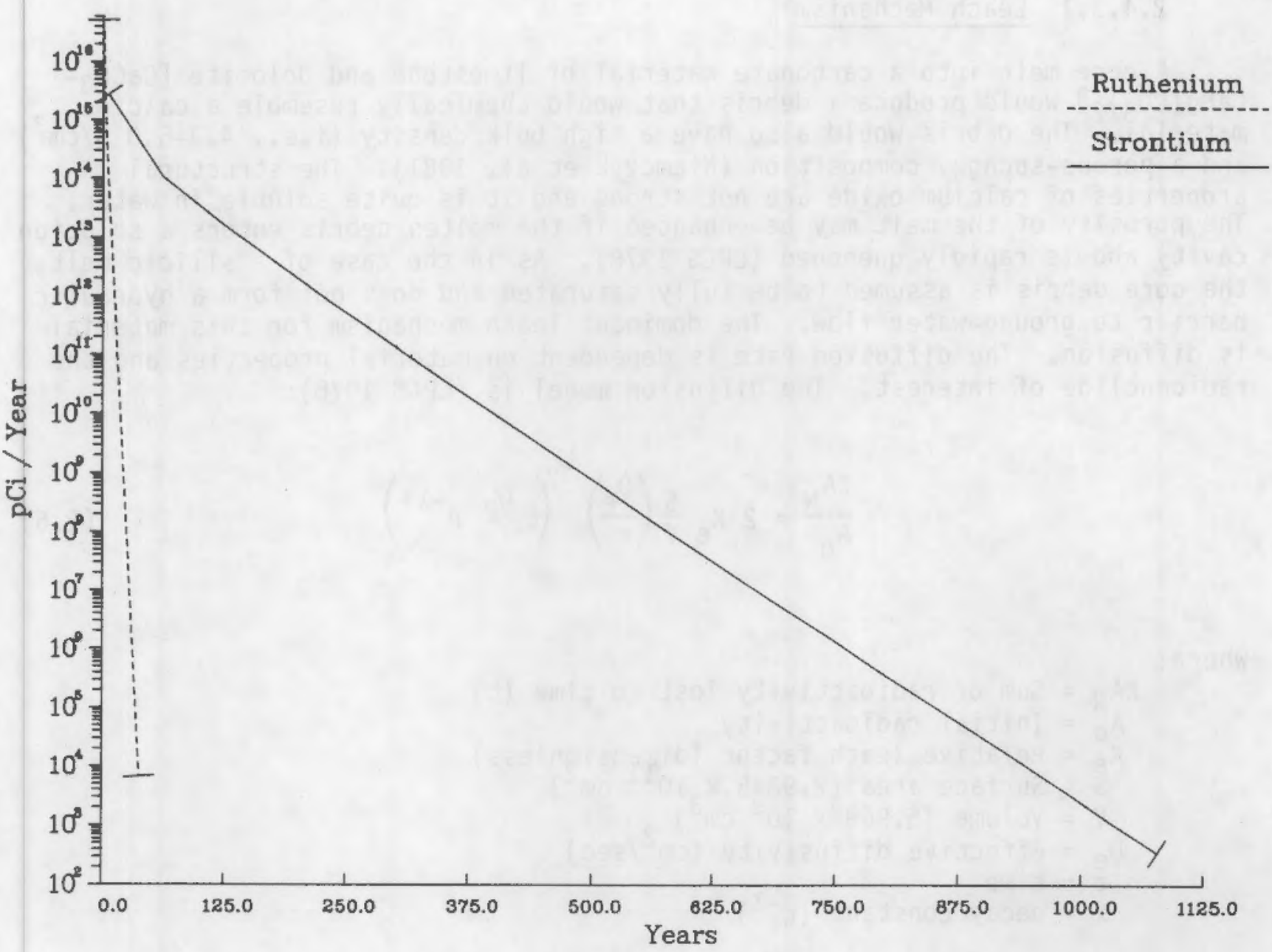

FIGURE 2.4.2-2. Long Term Leach Release Rate for Silicic Core Melt

glass matrix. Obviously, the initial radioactive quantity, release fraction and radioactive decay is included in the calculation. In long-term leach processes individual chemistries of the various elements become less important as a common leach rate is approached as leaching proceeds (Coles 1981a). The decreasing rate of radionuclide release is due to a combination of both the hydration-corrosion model and radioactive decay. Leach rates of nuclear explosion glass have indicated a continued decrease in rate to 420 days and were on a decreasing trend. Steady leach rates were not obtained in these tests (Failor 
et al. 1983). Initial amounts and rates of decay are responsible for the differences in slope of the strontium-90 and ruthenium-106 leach release curves.

\subsubsection{Calcine Melts}

\subsubsection{Leach Mechanism}

A core melt into a carbonate material of limestone and dolomite $\left[\mathrm{CaCO}_{3}-\right.$ $\mathrm{CaMg}\left(\mathrm{CO}_{3}\right)_{2}$ ] would produce a debris that would chemically resemble a calcine material. The debris would also have a high bulk density (i.e., 4.3-5.0 $\mathrm{g} / \mathrm{cm}^{3}$ ) and a porous-spongey composition (Niemczyk et al. 1981). The structural properties of calcium oxide are not strong and it is quite soluble in water. The porosity of the melt may be enhanced if the molten debris enters a solution cavity and is rapidly quenched (LPGS 1978). As in the case of a silicic melt, the core debris is assumed to be fully saturated and does not form a hydraulic barrier to ground-water flow. The dominant leach mechanism for this material is diffusion. The diffusion rate is dependent on material properties and the radionuclide of interest. The diffusion model is (LPGS 1978):

$$
\frac{\Sigma A_{N}}{A_{0}}=2 K_{e} \frac{S}{V}\left(\frac{D_{e}}{\pi}\right)^{1 / 2}\left(t^{1 / 2} e^{-\lambda t}\right)
$$

where:

$$
\begin{aligned}
\Sigma A_{N} & =\text { Sum of radioactivity lost to time }(t) \\
A_{0} & =\text { Initial radioactivity } \\
K_{e} & =\text { Relative leach factor (diqensignless) } \\
S & =\text { Surface area }\left(2.9845 \times 10^{1} \mathrm{~cm}^{2}\right) \\
V & =\text { Volume }\left(5.969 \times 10^{8} \mathrm{~cm}^{3}\right) \\
D_{e} & =\text { Effective diffusivity }\left(\mathrm{cm}^{2} / \mathrm{sec}\right) \\
t & =\text { time } \\
\lambda & =\text { decay constant }\left(\mathrm{t}^{-1}\right)
\end{aligned}
$$

The relative leach factors account for the more rapid release of certain classes of radionuclides. Elements with low valences and/or small ionic radi $i$ are generally leached at the faster rates. The leach rates of strontium-90 and ruthenium-106 are intermediate to alkali metals (i.e., cesium) and the actinide elements (i.e., plutonium) (Moore et al. 1976). The relative leach rate can be reduced by up to three orders of magnitude by inclusion of clay or shale (Moore et al. 1976). Limestone commonly contains thin layers of shale as well as interstitial clay which would reduce the leach rate in comparison to cementitious grouts. Surface area and geometric volume of the melt is based on the calculated core melt geometry presented by Niemczyk et al. (1981). The configuration of a calcine core melt mass is illustrated in Figure 2.4.3-1. Depending upon the rate of carbon dioxide $\left(\mathrm{CO}_{2}\right)$ degassing and the rate of cooling, the bulk density is calculated to be 4.3 to $5.0 \mathrm{~g} / \mathrm{cm}^{3}$. The latter value was chosen to represent the core meit. The surface area of the core debris is subject to large uncertainty. In a ionic diffusion release (Equation 2.7) the 


\section{CALCINE MELT}

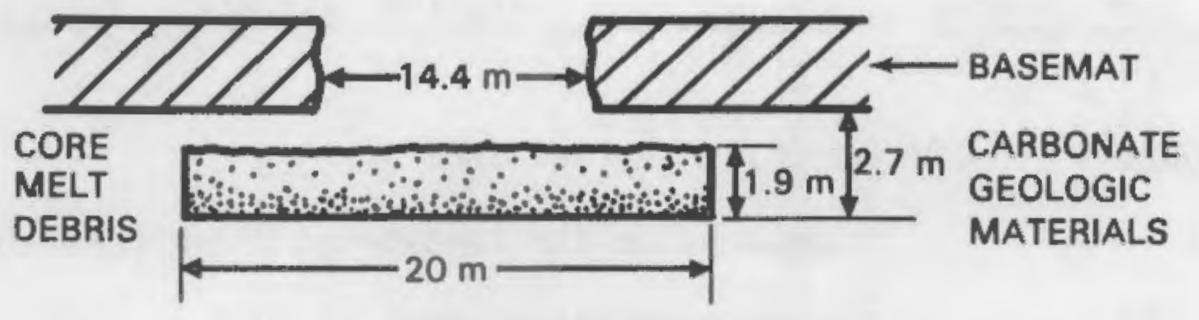

FIGURE 2.4.3-1. Configuration of Solidified Core Debris for Calcine Melt (After: Niemczyk et al. 1981)

accuracy of the leach rate prediction is directly proportional to the accuracy of the estimation of surface area. The core debris surface area can range over two orders of magnitude depending on the chemical composition and water content of the geo-materials under the plant, vigor of the carbonate to calcine reaction and fracturing during post accident cooling. The specific surface area of calcine material is estimated in LPGS (1978) based on geometric surface area and granular particle sizes. The mean diameter of a particle produced by the decomposition of concrete by core debris ranges from 200 to $1000 \mu \mathrm{m}$ (PACMA 1981), These particle sizes correspond to specific surface areas of 60 to $12 \mathrm{~cm}^{2} / \mathrm{g}$, respectively. A summary of these estimates is given in Table 2.4.3-1. A specific surface area of $100 \mathrm{~cm}^{2} / \mathrm{g}$ is considered to be realistic of a calcine material not quenched in standing water.

The effective diffusivity is a fundamental measure of the rate at which a contaminant will be removed from the solid matrix. Experimental work with cementitious grouts (Moore et al. 1976) indicates that the release rate is over 100 times greater than for glass. Based on experimental leaching of strontium-90 from hydrofract grout the effeçtive diffusivity based on geometric surface area is $1 \times 10^{-11}$ to $6 \times 10^{-10} \mathrm{~cm}^{2} / \mathrm{sec}$ (Moore et al. 1976) An effective diffusitivity based on actual surface area is taken as $6 \times 10^{-15} \mathrm{~cm}^{2} / \mathrm{s}$. Figure 2.4.3-2 presents the calcine leach release rate for strontium-90 and ruthenium-106.

\subsection{SUMP WATER RELEASE RATES}

Pressurized water reactors could also release contaminated water used in cooling during the accident sequence. The water would collect in the reactor sump and may be released due to: 1) the flowing through the hole in the basemat formed by the molten core; or 2) flowing through the fractured basemat if the core did not penetrate the containment structure. Therefore, it is feasible to have a contaminated sump water release even if the core melt does not completely penetrate the basemat. The rate of this liquid release would depend on: 
TABLE 2.4.3-1. Estimated Specific Surface Areas for Core Debris

Specific Surface Area

$\left(\mathrm{cm}^{2} / \mathrm{g}\right)$

$0.0025^{(a)}$

Gometric surface area

6.3

Assumes value for land based plant (LPGS-1978)

2.5 (a)

Surface area enhancement of 1000

100 (b) (c)

$1000^{(b)(c)}$

Value less than for water quenched material Particle size minimum of $12{ }^{\mu m}$ for core material
quenched in standing water $(c)^{m}$

(a) Determined for calcine core melt geometry of Niemczyk et. al. (1981).

(b) LPGS (1978) melt geometry more indicative of silicic material.

(c) Particles are assumed to be spherical grains. The range of specific surface areas, in a calcine debris is probably bounded between 10 and $1000 \mathrm{~cm}^{2} / \mathrm{g}$.

1. size of basemat opening,

2. density and viscosity of sump water,

3. hydrogeologic properties of underlying materials, and

4. pressure head.

Assuming that a sump water release occurred at any of the nuclear power plant sites, the liquid release could take place over several days to several months. The sump water release rate and radionuclide release rate used in this study are based on the aquifer properties at each site. There are uncertainty as to the actual conditions that might be present at a core melt accident. Specifically, the permeability of the opening in the basemat (important only when the basemat is fractured and not penetrated) and the pressure head inside the containment building.

If the containment structure ruptured prior to basemat melt-through, the pressure head would consist solely of the hydraulic head difference between the ground water and the fluid inside the containment. The position of the water table at most sites is above the top of the basemat. At these locations if the containment building ruptured prior to melt-through, ground water would flow up through the core melt debris and flood the lower portions of containment. If this ground-water seepage was allowed to equilibrate with respect to the water table the average maximum depth of water inside containment would be 8 to 20 meters (Niemczyk undated). As in the case of water flowing out of the containment structure, the rate would depend upon the site specific conditions as noted above. This water could be pumped from the containment structure as a part of the mitigative procedures. 


\section{CALCINE LEACH FUNCTIONS}

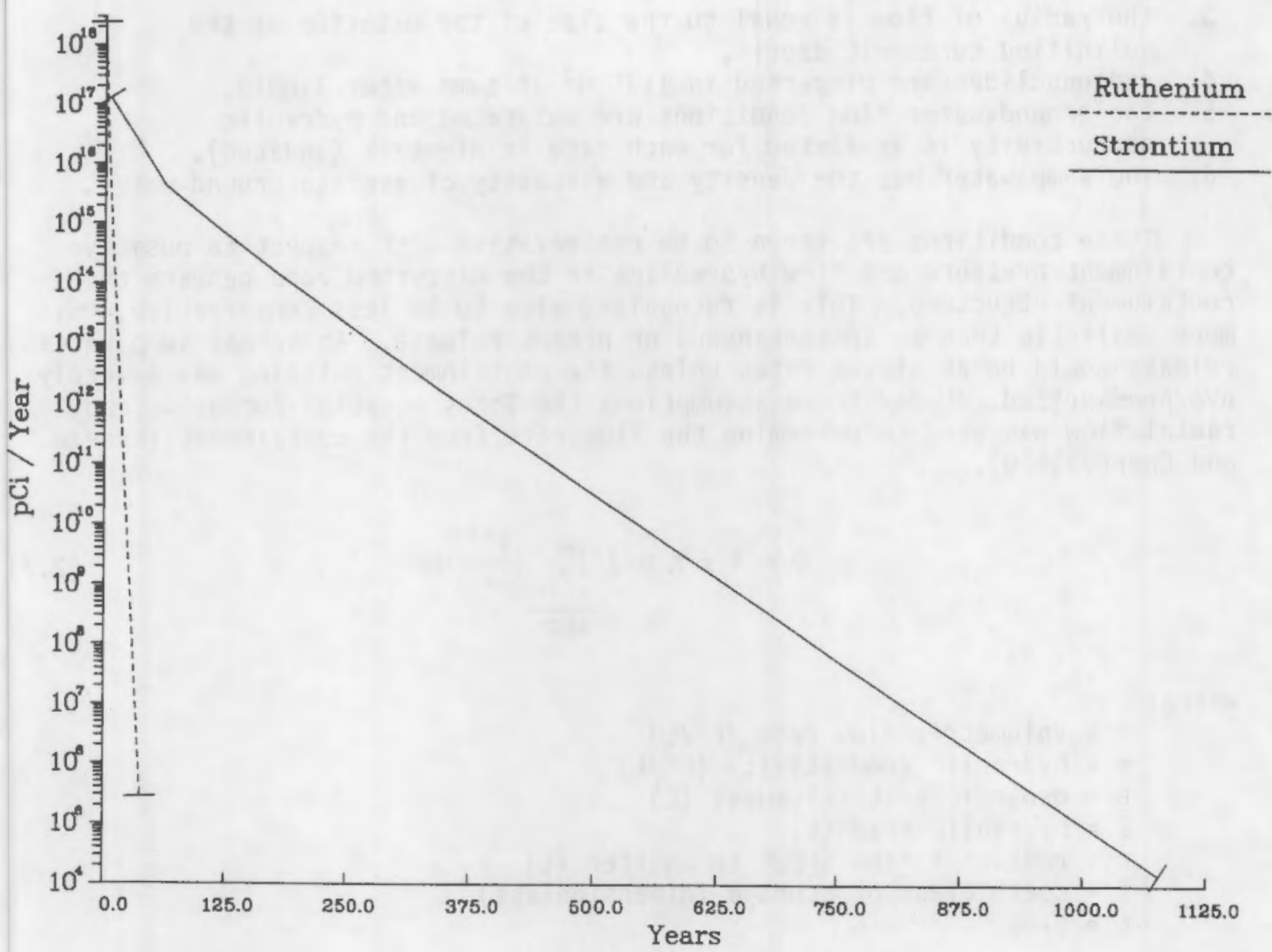

FIGURE 2.4.3-2. Long Term Leach Release Rate for Calcine Core Melt

If the containment structure had not failed and pressure inside the containment was above the ground-water pressure head, sump water would exit the containment. Initially the heat of the core melt mass would prevent sump water from escaping. However, the constant vaporization and condensation of sump water in contact with the melt mass would result in more rapid cooling of the debris. The top of the core melt mass may become sufficiently cool to allow sump water to enter the ground-water system in as little as six months after the accident (Niemczyk et al. 1981). This time period of six months for delay after the accident to time of liquid release is used in this study.

A sump water release is evaluated by making six practical assumptions:

1. the pressure head inside the containment is above the water table 
head by distance from the top of the core melt to the top of the basemat plus 4.5 meters standing water above the basemat,

2. the ground-water flow system is unconfined and the effective porosity as reported in Niemczyk (undated) is equivalent to the effective storage coefficient,

3. the radius of flow is equal to the size of the exterior of the solidified core melt debris,

4. radionuclides are dispersed in $1135 \mathrm{~m}^{3}$ of sump water liquid,

5. the ground-water flow conditions are saturated and hydraulic conductivity is as listed for each site in Niemczyk (undated).

6. The sump water has the density and viscosity of average ground-water.

These conditions are known to be conservative with respect to positive containment pressure and flow hydraulics in the disturbed zone beneath the containment structure. This is recognized also to be less conservative, but more realistic than an instantaneous or prompt release. An actual sump water release would be at slower rates unless the containment building was severely overpressurized. Under these assumptions the Thies equation for non-steady radial flow was used to determine the flow rate from the containment (Freeze and Cherry 1979).

$$
Q=4 \pi K b Z \int_{\frac{r^{2} f}{4 K b t}}^{\infty} \frac{e^{-x}}{x} d x
$$

where:

$$
\begin{aligned}
& Q=\text { volumetric flow rate }\left(L^{3} / \mathrm{t}\right) \\
& K=\text { hydraulic conductivity }\left(\mathrm{L}^{2} / \mathrm{t}\right) \\
& \mathrm{b}=\text { geologic unit thickness }(\mathrm{L}) \\
& \mathrm{Z}=\text { hydraulic head }(\mathrm{L}) \\
& r=\text { radius of flow input to aquifer }(\mathrm{L}) \\
& \mathrm{f}=\text { coefficient of storage (dimensionless) } \\
& \mathrm{t}=\text { time }
\end{aligned}
$$

The rate was averaged over a short period of two hours which allows the peak release rate of radionuclide to be determined. The exponential form of the Thies equation allows an initial flow rate to be rapid with subsequent diminishing of the flow with increasing time. Under these conditions the peak release rate of radionuclides would occur at the beginning of the sump water escape. Therefore, the release rate is modeled as a single valued peak release at each site. The sump water release was not modeled as a time dependent release due to the short period of release from the containment as compared to the travel time to the accessible environment and the uncertainty associated with the volume of water that would be released. The assumptions of the sump water release are reasonable but do not account for site specific factors other than hydraulic conductivity and effective porosity.

The sump water release is designed to properly scale the release of radionuclides based on aquifer hydraulics. Although there is recognized uncertainty 
associated with this methodology it is more realistic than assuming the sump water instantaneously exits. At the least, this method accounts for the gross variations documentated in aquifer hydraulics at the individual commercial nuclear power planit sites. Since each plant site was characterized by a different sump water release rate, there is no standard release rate curve for sump water exiting the containment structure.

\subsection{CONCLUSIONS CONCERNING RADIONUCLIDE RELEASES FOLLOWING} A SEVERE ACCIDENT

1. In the unlikely event of a coremelt accident it is feasible for core debris to degrade and penetrate the containment basemat releasing radionuclides to the ground-water flow system.

2. Chemical composition of the concrete and underlying materials could have a large influence on the physical properties of the solidified core debris. The release of radionuclides from silicic materials is basically a corrosion-dissolution mechanism while calcine materials release contaminants primarily through diffusion processes.

3. The leach release rates could be 100 times greater in calcine materials than in materials that are predominately silicic.

4. Sump water liquid release rates are very site and accident sequence specific. This type of release at a site could occur very slowly or quite rapidly depending on containment pressurization and the hydraulics of the altered zone around the core debris.

5. Radionuclide discharge quantities to surface water are more a func$t$ ion of ground-water transport factor than release fractions determined by accident sequences (e.g., PWR 1-7 and BWR 1-4).

\subsection{REFERENCES}

Barkatt, A., J. H. Simmons, P. B. Macedo. 1981. "Corrosion Mechanisms and Chemical Durability of Glass Media Proposed for the Fixation of Radioactive Wastes," Nuclear and Chemical Waste Management, 2, pp. 3-23.

Bradley, D. J. 1978. "Leaching of Fully Radioactive High-Level Waste Glass," PNL-2664, Pacific Northwest Laboratory, Richland, Washington.

Chapman, N. A., I. G. McKinley, D. Savage. 1980. "Effect of Groundwater Availability on the Release Source Term in a Low Hydraulic Conductivity Environment," In Proceedings of the Workshop on Radionuclide Release Scenerios for GeoTogic Repositories, Conference 8009121, Paris, France.

Clark, D. E., C. G. Putnam, Jr., and L. L. Hench, 1979. Corrosion of Glass, Books for Industry and Glass Industry, New York. 
Coles, D. G. 1981a. "A Continuous-Flow Leach "Testing Method for Various Nuclear Waste Forms," Nuclear and Chemical Waste Management, 2, pp. 245-252.

Coles, D. G. 1981b. "Single-Pass Continuous-Flow Leach Test of PNL 76-68 Glass: Some Selected Bead Leach I Results," In Proceedings of the 1980 Waste-Rock Interaction Technology Program Meeting, Battelle Center, Seattle, Washington.

Coles, D. G., and L. D. Ramspott. 1982. "106 Ru Migration in a Deep Tuffaceous Alluvial Aquifer, Nevada Test Site," Science, 215(4537), pp. 1235-1237.

Ericson, J. E. 1981. "Durability of Rhyolitic Obsidian Glass Inferred from Hydration Dating Research," Natural Analog, 12(4), pp. 283-290.

Failor, R. A., D. G. Coles, J. A. H. Rego. 1983. "Leaching of a Nuclear Melt Glass: Part 1," Lawrence Livermore Laboratory NTIS,PC A05/MF A01,1, Livermore, California.

Freeze, R. A., and J. A. Cherry. 1979. Groundwater, Prentice Hall, Inc, pp. 604.

Friedman and Long. 1976. "Hydration Rate of Obsidian," Science, 191(1), pp. 347-352.

Friedman and Obradovich. 1980. "Obsidian Hydration Dating of Volcanic Events," Quarternary Research, 16, pp. 37-47.

IAEA. 1979. "Characteristics of Solidified High-Level Waste Products," Technical Report Series No. 187, Vienna.

Lanza, F., N. Jacquet-Francillion, and J. A. C. Marples. 1980. "Methodology of Leach Testing of Boro-Silicate Glass in Water," in Radioactive Waste Management and Disposal, R. Simon, ed. Harwood Academic Publishers.

Levine, H. S. 1977. "Non-condensible Gas Evolution," in Core-Meltdown Experimental Review, SAND74-0382 (NUREG-0205 Rev.), Sandia Laboratories, Alabuquerque, New Mexico.

Merrit, W. F. 1977. "High Level Waste Glass: Field Leach Test," Nuclear Technology, 32(1), pp. 88.

Moore, J. G., Godbee, H. W., and Kibbey, A. H. 1976. "Leach Behavior of Hydrofracture Grout Incorporation Radioactive Waste," Nuclear Technology, $32(1), p p .39$.

Niemczyk, S. J. undated. "A Summary of Subsurface Hydrogeological Information for Light Water Nuclear Reactor Sites." Unpublished report. Oak Ridge National Laboratory, Oak Ridge, Tennessee. 
Niemczyk, S. J., et al. 1981. "The Consequences from Liquid Pathways after a Reactor Meltdown Accident," Nuclear Regulatory Commission, NUREG/CR-1596, USNRC.

Pitts, J. H. 1975. "Flow of Radioactive Fluid Through the Soil Surrounding a Power-Reactor Station After a Core Meltdown Accident," Nuclear Technology, $27(10)$, pp. 240.

Suzuki, M. 1973. "Potential of Obsidian Hydration Daling," Jour. Faculty Sci, University Tokyo, Section V, 4:241.

U.S. Nuclear Regulatory Commission. 1975. "Reactor Safety Study," Wash-1400, NUREG-15/014, USNRC. (RSS 1975).

U.S. Nuclear Regulatory Commission. 1978. "Liquid Pathways Generic Study," NUREG-0440, USNRC. (LPGS 1978).

U.S. Nuclear Regulatory Commission. 1981. "Preliminary Assessment of Core Melt Accidents at the Zion and Indian Point Nuclear Power Plants and Strategies for Mitigating Their Effects," NUREG-0850 USNRS. (PACMA 1981). 



\subsection{GENERIC HYDROGEOLOGIC SITE CLASSIFICATION}

\subsection{CLASSIFICATION SCHEME}

\subsubsection{Considerations for a Classification Scheme}

The classification of existing and proposed nuclear power plant sites in the U.S. is based on their respective hydrogeologies. The classification scheme follows the concept that the hydrogeological site conditions will control the ground-water transport mechanisms and will contribute to the determination of appropriate mitigative strategies following a core melt accident. Combining classification criteria for transport with potentially feasible mitigative measures results in a matrix of generic hydrogeologies and the associated mitigative actions. This classification scheme also facilitates the generic study of important ground-water transport characteristics such as travel times and radionuclide discharge rates associated with accessible envi ronments.

The major factors controlling ground-water transport are site geology, hydrology, geochemistry, and geography. These factors are interrelated and strongly affect the overall characterization of a core melt accident. For example, the rock chemistry determines the penetration depth of the core melt mass, the type and rate of leach release and, in part, the retardation of radionuclides in transport. In this case, the geochemistry effects the depth of borings into the contaminated zone, the time scale for project completion, and the necessity for any mitigative action. The selection of specific mitigative techniques is also a function of the hydrogeologic factors at the site. The hydrogeologic site conditions affect the feasibility of a mitigative technique at that location. For example, the construction of slurry walls requires unconsolidated material or very soft consolidated material.

The classification scheme is based on hydrogeologic parameters that are most sensitive in affecting radionuclide transport but are also readily determined for a site. The classification of nuclear power plant sites was limited in scope so that it would not be unwieldy. However, a representative number of sites are included in each generic classification. This is similar in practice to the determination of generic surface water classifications as found in "The Consequences from Liquid Pathways After a Reactor Meltdown Accident," NUREG/CR-1596. Five criteria were used to determine the hydrogeological classification of each nuclear power plant site. These criteria are based on:

1. geologic unit,

2. rock chemistry,

3. consolidation of material,

4. porosity, and

5. ground-water chemistry.

All existing and proposed nuclear power plant sites were reviewed according to the above criteria. The generic site classification scheme was then developed by determining commonalities among the hydrogeologic properties for certain groupings of sites based on the above criteria. Individual generic sites embody these common properties. 
The information needed to classify the nuclear power plant sites is taken from an unpublished report "A Summary of Subsurface Hydrogeological Information for Light Water Nuclear Reactor Sites" by S. J. Niemczyk at Oak Ridge National Laboratory. The hydrogeologic data base presented in the report lists the geologic unit, distance to nearest suface water body and the aquifer properties for each site. The geotechnical data base used to determine the hydrogeologic properties of each power plant site was developed from Niemczyk's report. Portions of the geotechnical data base are presented in Section 3.5 by generic classification.

\subsubsection{Geologic Unit Criterion}

The basemat of the containment structure at nuclear power plants is constructed of concrete up to 3 meters in thickness. Below the basemat and any intervening engineered backfill at each site lay undisturbed geologic materials of various compositions. The geology may consist of massive units or stratified units of various types. When the geologic media are stratified, the hydraulic properties can range over several orders of magnitude between adjacent units. The geotechnical data base used in this study contains 50 sites where stratified deposits were noted. At 29 sites the hydraulic properties of individual units within the stratified materials are known. The determination of which geologic unit was chosen to characterize each stratified site was based on three conditions:

1. position of the water table, (which may be perched),

2. silicate or carbonate rock chemistry, and

3. ground-water hydraulics.

The geologic unit must lie below the water table. The basemat of most nuclear power plants lies below the water table and therefore a core melt accident would directly impact the saturated zone. Fifteen sites have water tables below the basemat. However, the core melt would penetrate into the saturated zone at all but four of these sites. The sites where the core melt would reside in the partially saturated zone are excluded from further study due to extremely slow contaminant transport rates and the complex site specific data and modeling requirements for characterization. Geologic units above the water table or above the top of the core melt were not considered for the purpose of generic classification. A liquid release of sump water from a pressurized water reactor is assumed to flow through and around the core melt mass and into the selected geologic unit.

The geologic materials were classified as being silicates or carbonates. This distinction is necessary because the rock chemistry determines the ultimate depth of the melt and hence controls which geologic units will be in saturated contact with the core melt. There are 47 sites in the geotechnical data base that list a single geologic unit and it was assumed to be the principal unit in contact with the core melt. That geologic unit was then used in the characterization scheme for the generic sites.

When several diverse geologic units contacted the core melt, the third condition, ground-water hydraulics, was considered. For these cases, the 
geologic unit with the highest transmissivity was selected. Some sites list extreme and average hydraulic properties. These sites were characterized by the average hydraulic values.

\subsubsection{Rock Chemistry Criterion}

Geologic materials at nuclear power plant sites can be divided into two generalized chemical classifications: 1) silicates and 2) calcium-magnesium carbonates. The chemical composition of a geologic unit is a result of its formation and any subsequent alteration. Silicic rocks are formed from igneous processes (i.e., granitic intrusions) and occasionally biological processes such as deposits of diatoms radiolaria. Silicates are weathered by physical and chemical actions into unconsolidated sedimentary material such as clay, silt, sand and gravel. Sedimentary silicates (e.g., sandstone and siltstone) are consolidated to competent rock by deep geologic burial. Carbonates are formed primarily by marine organisms and deposited as layered media. Both silicates and carbonates are subjected to a variety of processes that alter their physical form and chemical composition. The percentage of silica and carbonate found in common rock types is given in Table 3.1.1-1.

The reaction of these two chemical rock types to a core melt accident would be markedly different. Silicic materials would be melted to a greater depth below containment structures and would be more resistant to leaching. Carbonitic materials would produce a more shallow melt zone and leach radionuclides into the ground water at a faster rate. The characteristics of a core melt are discussed in Section 2.1 .1 of this report and in NUREG/CR-1596. Details of the chemical controls of leaching processes are discussed in Section 2.2 of this report. Although there is a general distinction between silicate and carbonate melts and leach rates, there is considerable uncertainty involved in assigning either melt type an absolute leach release rate.

The geochemical rock type also has as strong influence on ground-water chemistry and aquifer-nuclide reactions. Table 3.1.1-2 presents a summary listing of melt formation and transport characteristics based on geological rock type.

\subsubsection{Consolidation of Material Criterion}

The selection of mitigative strategies is, in part, a function of the workability of the geologic media. Consolidated materials consist of crystalline and sedimentary units which have become competent rock. Unconsolidated units consisting of clay, silt, sand, and cobbles are characterized as packed particulate material. The engineering properties of consolidated and unconsolidated units are fundamentally different. The competency of geologic materials in many instances influences the feasibility of mitigative measures. For example, a radionuclide release into a consolidated limestone will preclude use of mitigative techniques requiring a deformable geologic media (e.g., sheet piling). The basic construction considerations of consolidated versus unconsolidated materials are listed in Table 3.1.1-3. 
TABLE 3.1.1-1. Percentage of $\mathrm{SiO}_{2}$ and $\mathrm{CaO}$ of Common Geologic Units(a)

\begin{tabular}{|c|c|c|}
\hline $\begin{array}{l}\text { Geologic } \\
\text { Material } \\
\end{array}$ & $\begin{array}{l}\text { Percent } \\
\mathrm{SiO}_{2} \\
\end{array}$ & $\begin{array}{c}\text { Percent } \\
\mathrm{Ca} 0 \\
\end{array}$ \\
\hline clay & 70 & $<2$ \\
\hline silt & 60 & $<10$ \\
\hline till & $60-80$ & $<1$ \\
\hline sand & $70-100$ & $<5$ \\
\hline $\begin{array}{l}\text { limest one } \\
\text { dolomite }\end{array}$ & $\begin{array}{l}<10 \\
<10\end{array}$ & $\begin{array}{l}50 \\
30\end{array}$ \\
\hline $\begin{array}{l}\text { basalt } \\
\text { tuff }\end{array}$ & $50-60$ & $8-12$ \\
\hline $\begin{array}{l}\text { tuff } \\
\text { granite }\end{array}$ & $\begin{array}{c}50-70 \\
>65\end{array}$ & $\begin{array}{r}<6 \\
<15\end{array}$ \\
\hline schist & 60 & $<1$ \\
\hline sandstone & $50-95$ & $<15$ \\
\hline shale & 58 & $<3$ \\
\hline arkose & 77 & 3 \\
\hline graywacke & 66 & 3 \\
\hline
\end{tabular}

(a) Sedimentary units from (Pettijohn 1975) igneous units from (Bowen 1956).

(b) Also contains 30 to $50 \% \mathrm{CO}_{2}$.

TABLE 3.1.1-2. Core Melt and Ground-Water Transport Characteristics Based on Chemical Rock Type

Core Melt and Leach Characteristics

1. Depth of melt below basemat

2. Core melt composition

3. Dominant leach process of core melt

4. Relative leach rate

5. Porosity of core melt

6. Sorption in aquifer type
Silicate

11 meters

Silica melt glass

Hydration-corrosion

Slow

Fracture controlled

More slightly

\section{Carbonate}

3 meters

Calcine material

Diffusion

Fast

Interstitial-Dependent upon degrassing carbon dioxide

Less slightly 
TABLE 3.1.1-3. Generalized Construction Considerations Versus Type of Geologic Formation

Construction Method

Excavation for trenching or disposal

Bore holes as for:

(injection)

(withdrawa 1)

(monitoring)

Sheet pile driving

Ground water freezing

Type of Geologic Formation

Consolidated

Requires special equipment, processes are slow and extensive blasting may be required

Drilling can be slow, bores do not usually require casing

Material enters along fractures and bedding planes

Water is from fractures and interstitital pathways drilling technique may seal fractures

Drilling technique may disturb chemical analysis because of muds used

Not feasible

May not be feasible, karstic limestone with ground water velocities over 1 meter/day Unconsolidated

Common construction equipment, requires support for side walls, limited to practical depths, may require dewatering below water table

Drilling is more difficult, casing and screen required, drilling technique dependent on purpose of bore

Material enters between particles and bedding planes, may cause deformation or lifting of unit

Water is interstitial, screen must be of proper size to avoid removal of fine material, drilling technique may clog formation

Drilling technique may disturb chemical analysis because of muds used

Difficulty dependent on particle size and strength of unit

May cause ground heave and damage to existing facilities

The consolidation of materials criterion also has a bearing on groundwater hydraulics, geochemistry of the radionuclide source term and sorption. These factors are considered as the remaining criteria.

\subsubsection{Porosity Criterion}

Porosity of geologic materials is due to interstitial voids between adjacent grains and openings along joints and fractures. The percentage of interconnected pathways to bulk rock volume is known as the effective porosity. Two major distinctions can be made between fractured and interstitial flow systems. First, interstitial flow occurs in porous media which generally affords a higher percentage of open area and secondly, a larger surface area of rock for the contaminant to contact than in fractured media. 
Interstitial porosity affects the degree of contaminant retardation due to chemical sorption and the average linear ground-water velocity. Sorption of contaminant is dependent upon bulk mass density of the aquifer, porosity, and the equilibrium distribution coefficient. Interstitial porosity normally results in a large aquifer surface area which provides abundant locations for contaminant to be sorbed onto the grains. The average linear velocity of ground water is a function of hydraulic conductivity, hydraulic gradient, and effective porosity. The larger effective porosity of porous media generally results in slower average linear velocities and greater chemical retardation of the transport of contaminants.

Fractured media channels ground water and contaminants preferentially along open joints.. This does not mean that contaminant does not enter the rock matrix, rather that the mass of contaminant will travel along the fracture until hydrodynamic dispersion and/or molecular diffusion forces it into the wall of the aquifer. When the concentration of contaminant in the fracture is less than the concentration in the rock matrix, the contaminant will re-enter the open joint. The aquifer surface area that contaminant contacts is much less in a fractured aquifer. Consequently, less sorption takes place. Secondary mineralization of zeolites or clay filling along the open joints can increase sorption. The effective porosity is relatively lower in fractured rock. When high hydraulic gradients are present in fractured media, the average linear ground-water velocity can be several orders of magnitude greater than in porous media. Rapid flow velocities are more probable when a liquid release occurs such as a reactor sump water release.

\subsubsection{Ground-Water Chemistry Criterion}

Ground-water chemistry is as site specific as ground-water hydraulics. The major effect of water chemistry (i.e., pH and ionic strength) is on the amount of contaminant sorption. Geochemical data are not available for most nuclear power plant sites. This study bases the ground-water chemistry criterion on typical conditions and not on site specific data.

Most categories created by the first four hydrogeologic criteria are assumed to have similar ground-water chemistries. The presence of clay, specifically illite, can strongly affect geochemical processes in the hydrologic unit, especially in regard to sorption/desorption of radionuclides since illite has a specific affinity for cesium.

\subsubsection{Definition of Generic Sites}

Based on the above criteria 16 individual classifications of hydrogeological parameters resulted. However, these 16 classifications produced only six generic sites when applied to the geotechnical data base of existing and proposed power plant sites in the U.S. Some classifications were not filled because of the geologic improbability of occurrence, as in the case of a unconsolidated carbonate aquifer with primarily fracture premeability. Another reason many classifications were empty is due to the limitations of the geotechnical data base. Specifically, the ground-water chemistry at nuclear power plant locations is unavailable. The ground-water chemistry was assumed 
consistant except for the silicic-consolidated-fractured category. In this classification were both fractured crystalline rock (i.e., basalt) and shale which is a fractured sedimentary rock. These rock types would form similar melts and ground-water flow would be mainly contained along fractures. However, the ground-water chemistry of these units is different with the crystalline material having an oxidizing environment and shale a reducing environment. The $\mathrm{pH}$ of both units is acidic. The differing ground-water chemistry contributes to contaminants in shale being more sorbed during transport than for crystalline rock. In addition shale contains the clay mineral illite that can cause irreversible geochemical reactions. An additional classification for shale media was created by this criterion.

A flow chart showing the classification of the sites is given in Figure 3.1.2-1. The final generic classifications are: 1) porous consolidated carbonate, 2) fractured consolidated carbonate, 3) porous consolidated silicate, 4) porous unconsolidated silicate, 4) fractured consolidated silicate in an oxidizing environment (referred to as fractured crystalline silicate), and 6) fractured consolidated silicate in a reducing environment (referred to as shale media). Table 3.1.2-1 presents the generic classification and the associated common aquifer names. Some of the groupings are expected such as fractured limestones and dolomites. An interesting combination of aquifers occurs in the fractured consolidated silicate classification which includes basalt and granite. These geologic units are formed under very different circumstances and can have a large range of hydraulic properties. However, in the near-surface ground-water enviroment they can be expected to have similar transport characteristics. The largest generic classification is porous unconsolidated silicate with 41 sites. This result is not suprising since many nuclear power plants are located adjacent to surface water bodies which are used as a source of cooling water. Many of the surface water bodies are located on alluvial materials. Breaking this classification into further subgroupings was considered. However, flow and transport properties are similar in this classification and further discrimination of generic differences could not be made.

An examination of the generic classifications and associated common aquifers show that the classification scheme is indeed generic. The number of classifications is not excessively large, there is a representative number of sites in each classification, and each classification contains similar hydrogeological characteristics. 


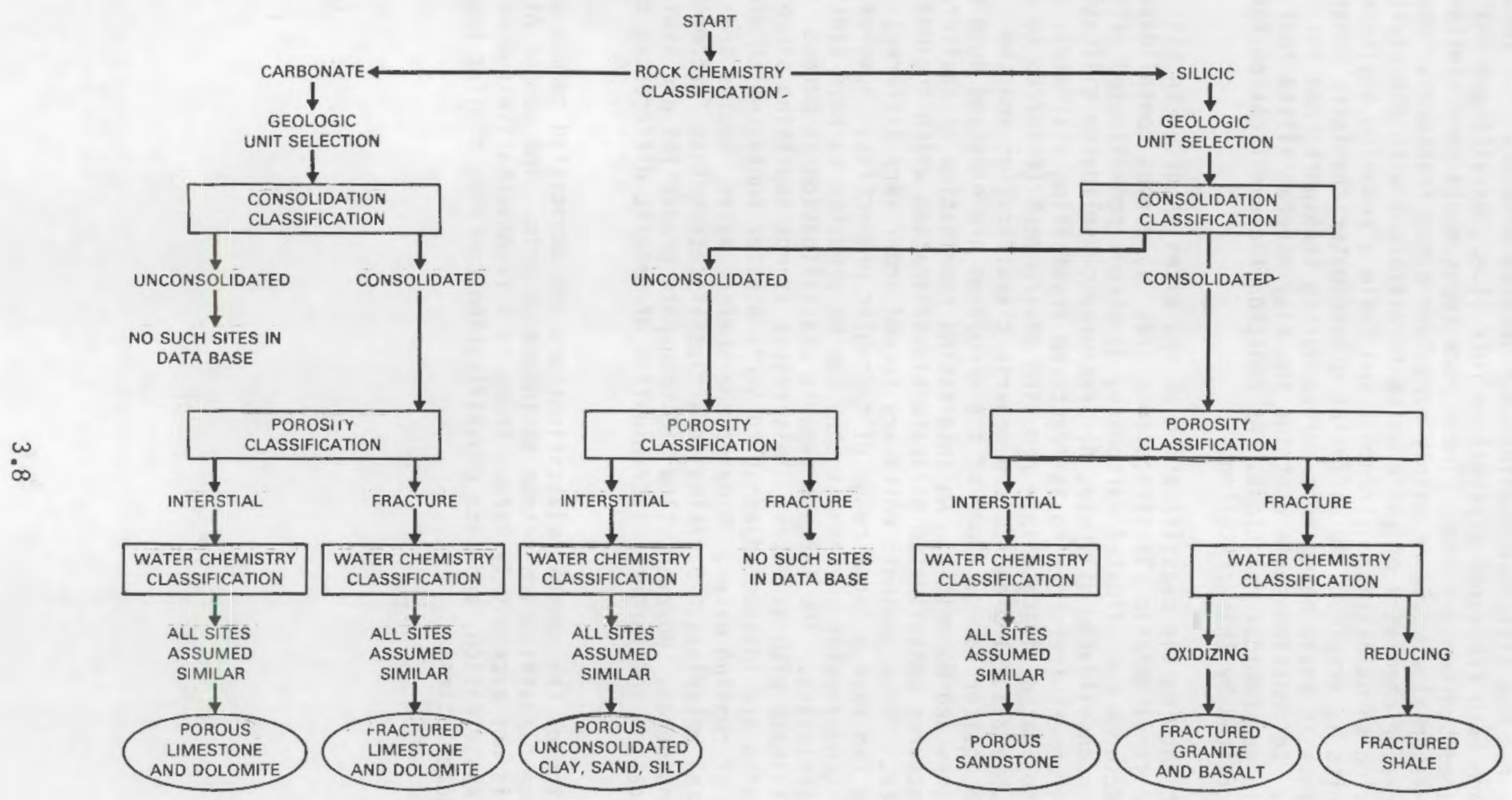

FIGURE 3.1.2-1. Generic Hydrogeologic Classification Scheme for Nuclear Power Plants in the U.S. 
TABLE 3.1.2-1. Generic Site Classification

\begin{tabular}{|c|c|c|}
\hline Generic Classification & Common Aquifers & $\begin{array}{c}\text { Number } \\
\text { of Sites }\end{array}$ \\
\hline $\begin{array}{l}\text { Porous consolidated } \\
\text { carbonate }\end{array}$ & $\begin{array}{l}\text { limestone } \\
\text { dolomite }\end{array}$ & 10 \\
\hline $\begin{array}{l}\text { Fractured consolidated } \\
\text { carbonate }\end{array}$ & $\begin{array}{l}\text { fractured and solutioned limestone } \\
\text { fractured and solutioned dolomite }\end{array}$ & 12 \\
\hline $\begin{array}{l}\text { Porous consolidated } \\
\text { silicate }\end{array}$ & $\begin{array}{l}\text { sandstone } \\
\text { siltstone } \\
\text { claystone } \\
\text { graywacke } \\
\text { arkoses }\end{array}$ & 13 \\
\hline $\begin{array}{l}\text { Porous unconsolidated } \\
\text { silicate }\end{array}$ & $\begin{array}{l}\text { clay } \\
\text { silt } \\
\text { sand } \\
\text { conglomerate } \\
\text { glacial deposits }\end{array}$ & 41 \\
\hline $\begin{array}{l}\text { Fractured crystalline } \\
\text { silicate in oxidizing } \\
\text { environment }\end{array}$ & $\begin{array}{l}\text { igneous rocks } \\
\text { basalt } \\
\text { tuff, granite }\end{array}$ & 16 \\
\hline $\begin{array}{l}\text { Fractured consolidated } \\
\text { silicate in reducing } \\
\text { environment }\end{array}$ & shale & 5 \\
\hline
\end{tabular}

\subsection{FLOW PARAMETERS FOR GENERIC SITES}

\subsubsection{Hydraulic Conductivity}

Hydraulic conductivity is a property of the saturated geologic medium and the fluid that flows through it. Basically, hydraulic conductivity is a measure of the capacity for flow in a unit area of an aquifer. It is defined by Oarcy's Law which states:

$$
q=-K I
$$

where

$q=$ fluid flux rate $\left(L^{3} / L^{2} T=L / T\right)$

$K=$ hydraulic conductivity $(L / T)$, and

$I=$ hydraulic gradient (dimensionless).

Hydraulic conductivity is a spatial parameter which varies in all three dimensions. Inspection of Equation (3.1) shows that hydraulic conductivity has dimensional components of length and time, however this should not be considered ground-water velocity. Hydraulic conductivity at a site is 
determined by testing of core samples in the laboratory or by field testing. The field tests measure a large volume of rock and test results provide a composite hydraulic conductivity. Even at the field scale, hydraulic conductivities may range over thirteen orders of magnitude for differing geologic materials. Coarse porous media such as gravel and solutioned limestone have the highest hydraulic conductivities. Silt, clay, glacial till, are often tightly compacted and exhibit much lower hydraulic conductivities. Crystalline rocks have the lowest hydraulic conductivities because these materials have few flow channels for water movement. For this study, knowing a site hydraulic conductivity within an order of magnitude was considered adequate for generic characterization.

The hydraulic conductivity, for any particular site, may be imprecise. However, within each generic classification, the grouped hydraulic conductivities are characteristic of the geologic materials existing at nuclear power plant sites in the US. The data were fit with a log normal distribution by generic classification and are presented in Figures 3.2.1-1a through 3.2.1-1f. The figures show two standard deviations about the mean of the log hydraulic conductivities. The data transform to log hydraulic conductivities allows a normal probability density function to be fit to the data (Freeze and Cherry 1979). The generic hydraulic conductivities should be examined from two perspectives. First, within each classification, the range of values and the mean value are generically characteristic. Second, comparisons of values among the generic classifications demonstrate which type of site will overall have the highest hydraulic conductivity and the largest expected variations about the mean. The extreme data values from actual nuclear plant sites are indicated by crosses on the left vertical axis. The general ranges of expected hydraulic conductivities for these geologic materials determined for locations not associated with this study (Freeze and Cherry 1979) are given along the right vertical axis for reference purposes.

There is fairly good agreement between the data extremes found at nuclear plant sites and the expected limits. For three classifications (i.e., porous carbonate, porous sandstone, and fractured shale) the site data have values higher than expected. This can be explained as either a possible characteristic of the locations where nuclear power plants have been sited for construction, or is a pessimistic bias in estimation of individual hydraulic conductivity values.

The fractured shale classification contains only five sites and may not be representative of shale media in general. The hydraulic conductivity data are also based on fractured geologic units whereas the expected range of values is given for unfractured shale. This accounts for much of the four orders of magnitude difference between the expected and reported peak values in shale media. The other classifications are within expected limits. None of the classifications have lower than reasonable hydraulic conductivities indicating that the data base is conservative with respect to this parameter.

The highest $\log$ mean values are found, as might be expected, in the fractured-solutioned carbonates. These aquifers can achieve open channel flow, and water movement can be relatively unrestricted due to large flow channels. 

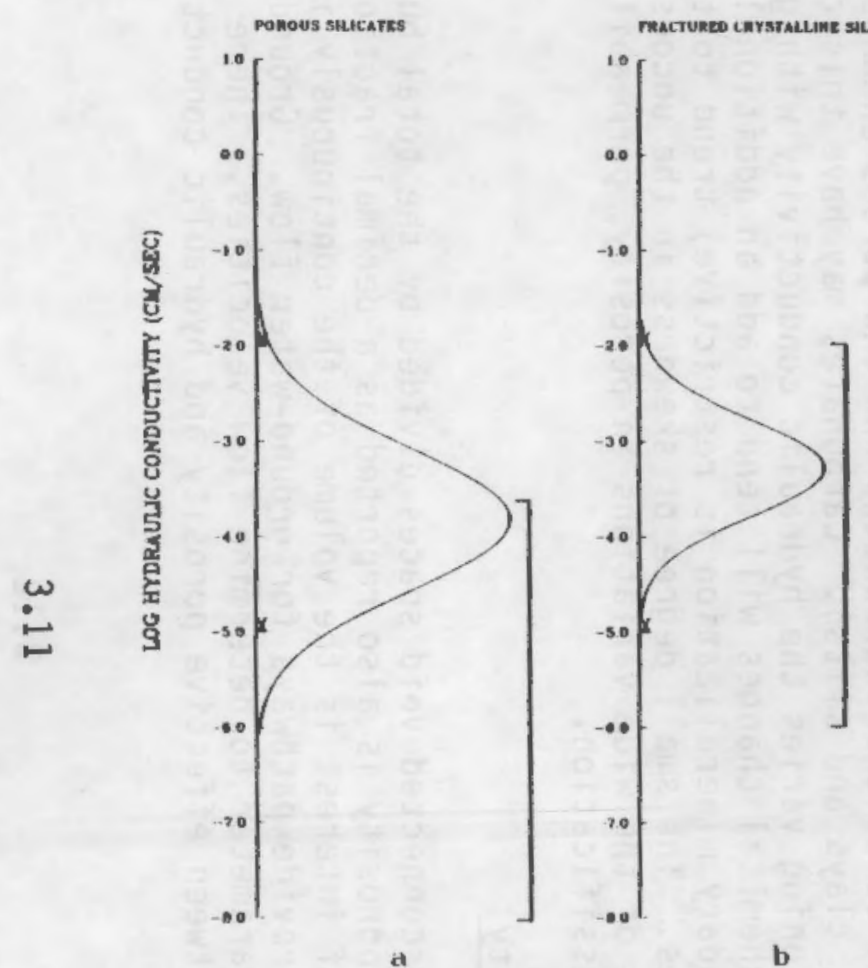

b
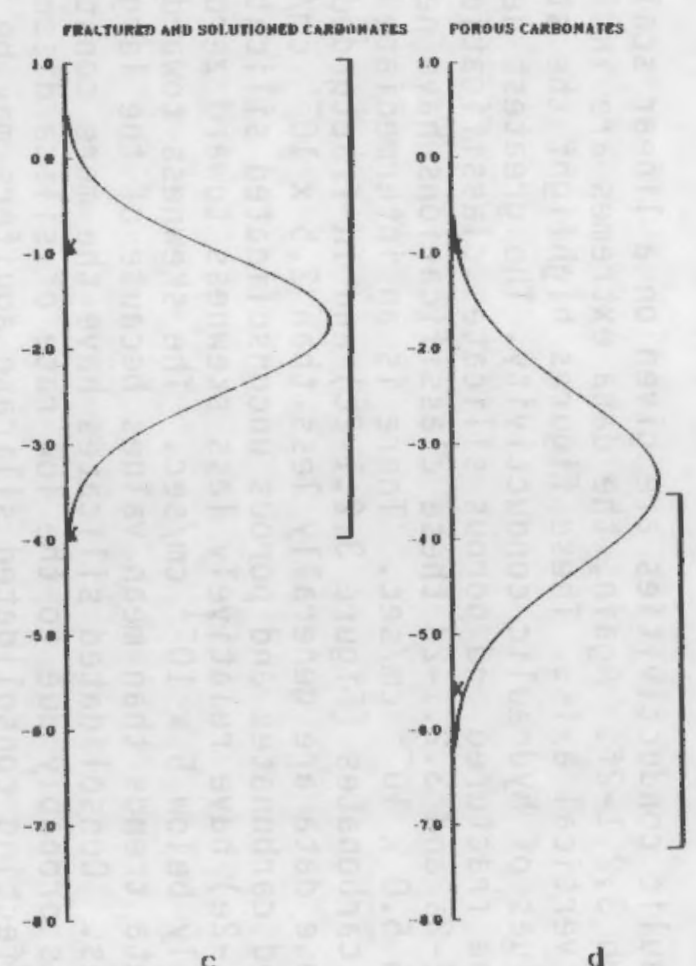

d

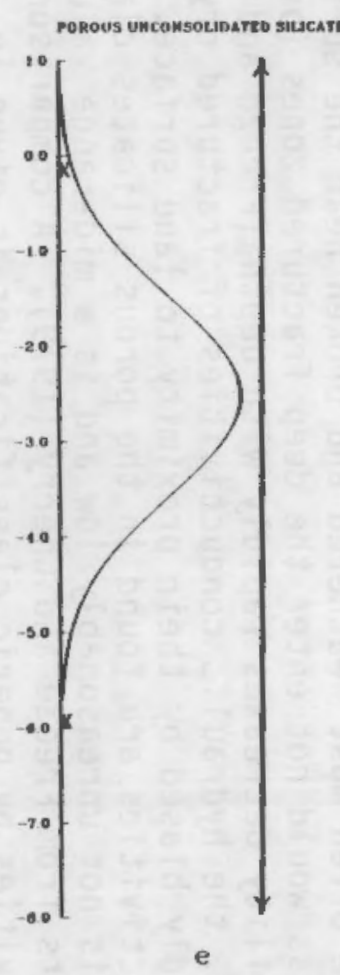

e

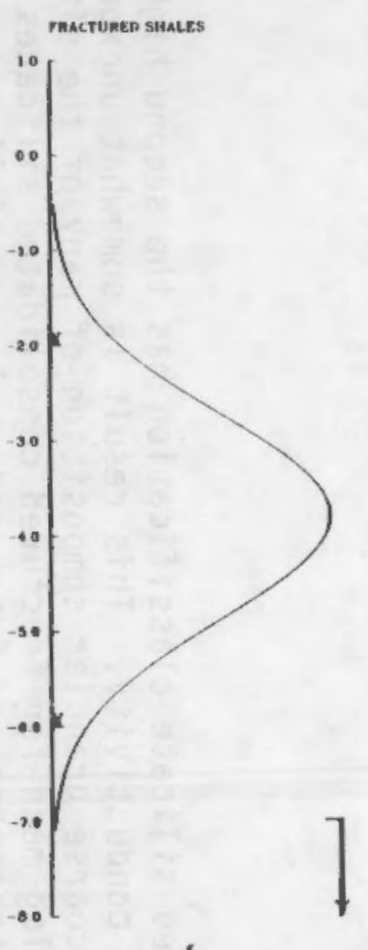

I

FIGURE 3.2.1-1. LOG $_{10}$ Distribution of Hydraulic Conductivity by Generic Classification. Brackets indicate range of values from Freeze and Cherry 1979. 
The porous unconsolidated silicate classification has the second highest log mean value of hydraulic conductivity. This result is somewhat unexpected and is probably due to the coarse granular composition of many of the sites. The hydraulic conductivity log mean for fractured consolidated silicates

(crystalline), porous carbonates and fractured shale are similar in magnitude. Fractured materials are often most weathered and broken near the surface of the land. The coremelt mass would not enter the deep fractured zones (over $50 \mathrm{~m}$ ) where fracture permeability decreases rapidly with depth (Freeze and Cherry 1979). For this study, the hydraulic conductivities of fractured crystalline silicates may be upwardly biased by their proximity to land surface. The lowest hydraulic conductivities are found in the porous silicates classification. The mean value is not unreasonably low and is a mid-range value as compared to expected limits from Freeze and Cherry (1979). A comparison of the log hydraulic conductivities by generic classifications is given in Table 3.2.1-1.

The absolute hydraulic conductivities are given on a linear scale in Figures 3.2.1-2a through 3.2.1-2f. Again, the data extremes are indicated by crosses along the left vertical axis. These figures highlight the strong data skewness toward low values of hydraulic conductivity. The greatest degree of skewness is found in the fractured and porous silicates classifications. Presented in Figures 3.2.1-2a and 3.2.1-2d these classifications have nearly all of the values less than $5.0 \times 10^{-3} \mathrm{~cm} / \mathrm{sec}$. There is an intermediate degree of skewness in the porous carbonates (Figure 3.2.1-2C) and in fracturded shale (Figure 3.2.1-2f). These data are generally less than $2.5 \times 10^{-2} \mathrm{~cm} / \mathrm{sec}$. The fractured and solutioned carbonates and porous unconsolidated silicates (Figures 3.2.1-2b and 3.2.1-2e) have relatiyely less skewness toward zero with the data having values mainly below $5 \times 10^{-1} \mathrm{~cm} / \mathrm{sec}$. The skewness toward zero is more illustrative of data trends than mean values because of the large range of hydraulic conductivities. Consolidated silicates have the more constrained hydraulic conductivities probably due to the low rate of silica dissolutioning. Another factor affecting consolidated silicate aquifers may be the tendency of secondary mineralization along flow channels. The least skewed data are in the fractured and solutioned carbonates and the porous unconsolidated silicates (i.e., sands, clays and silts). Carbonates may have this characteristic because solutioning varies the hydraulic conductivity with geologic time. Therefore, the chemical changes will tend to add an additional nonrestrictive (whereas secondary mineralization is restrictive) trend to the hydraulic conductivities. The small degree of skewness in the unconsolidated silicates is a function of the wide variations in porosity, permeability, and composition of this classification.

\subsubsection{Effective Porosity}

The volume of interconnected void spaces divided by the total bulk volume. The effective porosity is also reported as a decimal fraction. In this case, the volume of interest is the volume of the continuously interconnected yoids which provide pathways for ground-water flow. Ground-water calculations use this parameter to determine flow velocities. There is a positive correlation between effective porosity and hydraulic conductivity. 


\section{TABLE 3.2.1-1. Comparison of Generic Hydraulic Conductivity}

\begin{tabular}{|c|c|c|c|c|c|c|c|}
\hline $\begin{array}{c}\text { Generic } \\
\text { classification } \\
\end{array}$ & $\begin{array}{l}\text { Data Range } \\
\text { in Orders } \\
\text { of Magnitude } \\
\end{array}$ & $\begin{array}{c}\text { Mean } \\
\text { Value, } \mathrm{cm} / \mathrm{s}\end{array}$ & $\begin{array}{l}\text { Mean Log } \\
\text { Value, } \mathrm{cm} / \mathrm{s} \\
\end{array}$ & $\begin{array}{r}\text { Mean Value } \\
\text { Relative to } \\
\text { Generic Classif } \\
\end{array}$ & $\begin{array}{l}\text { (a) } \\
\text { Other } \\
\text { fications }\end{array}$ & $\begin{array}{l}\text { Standard } \\
\text { Deviation About } \\
\text { the Log Mean } \\
\end{array}$ & $\begin{array}{l}\text { Standard Deviation (b) } \\
\text { Relative to Other } \\
\text { Generic Classifications }\end{array}$ \\
\hline $\begin{array}{l}\text { Fractured } \\
\text { crystalline } \\
\text { silicates }\end{array}$ & 3.0 & $1.53 \times 10^{-3}$ & -3.28 & Lower than & average & 0.78 & Smaller than average \\
\hline $\begin{array}{l}\text { Fractured- } \\
\text { solutioned } \\
\text { carbonates }\end{array}$ & 4.0 & $6.42 \times 10^{-2}$ & -1.73 & Higher than & $n$ average & 1.09 & Average \\
\hline $\begin{array}{l}\text { Porous } \\
\text { consolidated } \\
\text { carbonate }\end{array}$ & 4.6 & $1.16 \times 10^{-2}$ & -3.41 & $\begin{array}{l}\text { Slightly lor } \\
\text { average }\end{array}$ & ower than & 1.40 & Average \\
\hline $\begin{array}{l}\text { Porous } \\
\text { consolidated } \\
\text { carbonate }\end{array}$ & 3.0 & $1.79 \times 10^{-3}$ & -3.82 & Lower than & average & 1.13 & Average \\
\hline $\begin{array}{l}\text { Porous } \\
\text { unconsolidated } \\
\text { silicates }\end{array}$ & 5.9 & $5.55 \times 10^{-2}$ & -2.53 & Higher than & average & 1.59 & Larger than average \\
\hline $\begin{array}{l}\text { Fractured } \\
\text { consolidated } \\
\text { silicates-shale }\end{array}$ & 4.0 & $2.4 \times 10^{-3}$ & -3.80 & Lower than & average & 1.64 & Larger than average \\
\hline $\begin{array}{l}\text { (a) Ave } \\
\text { (b) Ave }\end{array}$ & $\begin{array}{l}\text { mean } \\
\text { dard }\end{array}$ & ions ab & re $\log$ & 1.27 . & & & \\
\hline
\end{tabular}



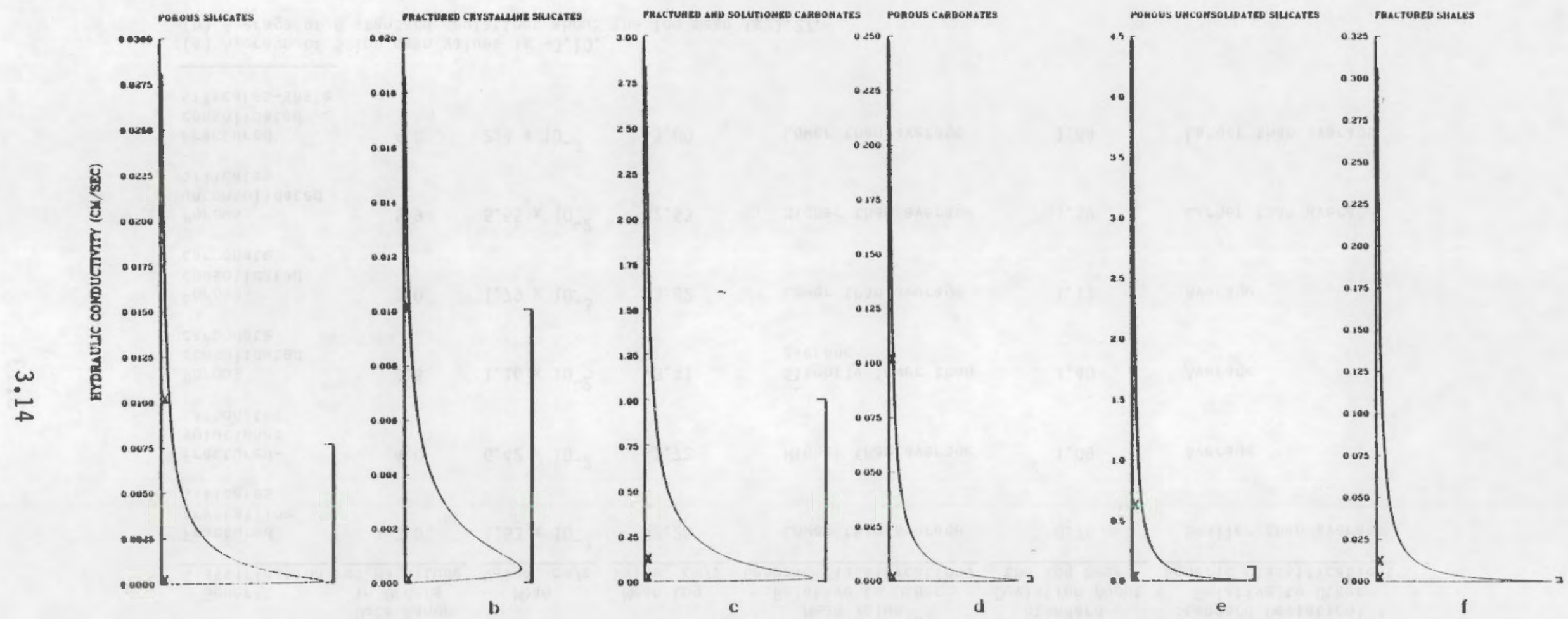

FIGURE 3.2.1-2. Linear Scale Distribution of Hydraulic Conductivity by Generic Classification. Brackets indicate range of values from Freeze and Cherry 1979. 
There are few measured porosities available in the geotechnical data base. At most sites, the effective porosity was estimated by assuming a reasonable value based on geologic rock type. At sites on unconsolidated materials, porosity was estimated for a wide range of geologic materials giving a distribution of values. A statistical analysis on assumed porosities based on a single rock type has little meaning. Representive effective porosities for these generic classifications are presented in Table 3.2.2-1. The effect porosities for unconsolidated silicates are plotted on a log normal distribution in Figure 3.2.2-1 and on a linear scale in Figure 3.2.2-2. Although porosity is not usually considered log-normally distributed this distribution is presented for consistency with other analyses. Also, negative porosity has no meaning which gives credence to a log-normal distribution.

The data extremes in Figure 3.2.2-1 are shown as crosses on the left vertical axis. The effective porosities have a range of about one order of magnitude. The mean $\log$ porosity is 0.10 which is typical of unconsolidated sedimentary deposits. The lowest effective porosity for this generic classification is 0.01 for silt and clay materials. The linear plot of effective porosities shows a definite skewness toward values below the mean. This indicates that most sites are located on deposits with some interstitial silt and clay.

\subsubsection{Hydraulic Gradient}

The hydraulic gradient is the slope of the water table or potentiometric surface. The geotechnical data base used for this study determined the hydraulic gradient by taking the steepest (thus most likely) path along the potentiometric surface from the containment structure to the nearest surface water body. In general, low hydraulic gradients are associated with large hydraulic conductivities and high gradients are found with low conductivities.

TABLE 3.2.2-1. Effective Porosities for Generic Hydrogeologic Classifications

Generic Classification
Fractured crystalline
silicates
Fractured and solutioned
carbonates

Porous carbonates

Porous silicates

Porous unconsolidated silicates

Fractured Shale
Effective Porosity (Dimensionless)

$$
0.01
$$

0.10

0.10

0.01

Average value 0.16

0.01 


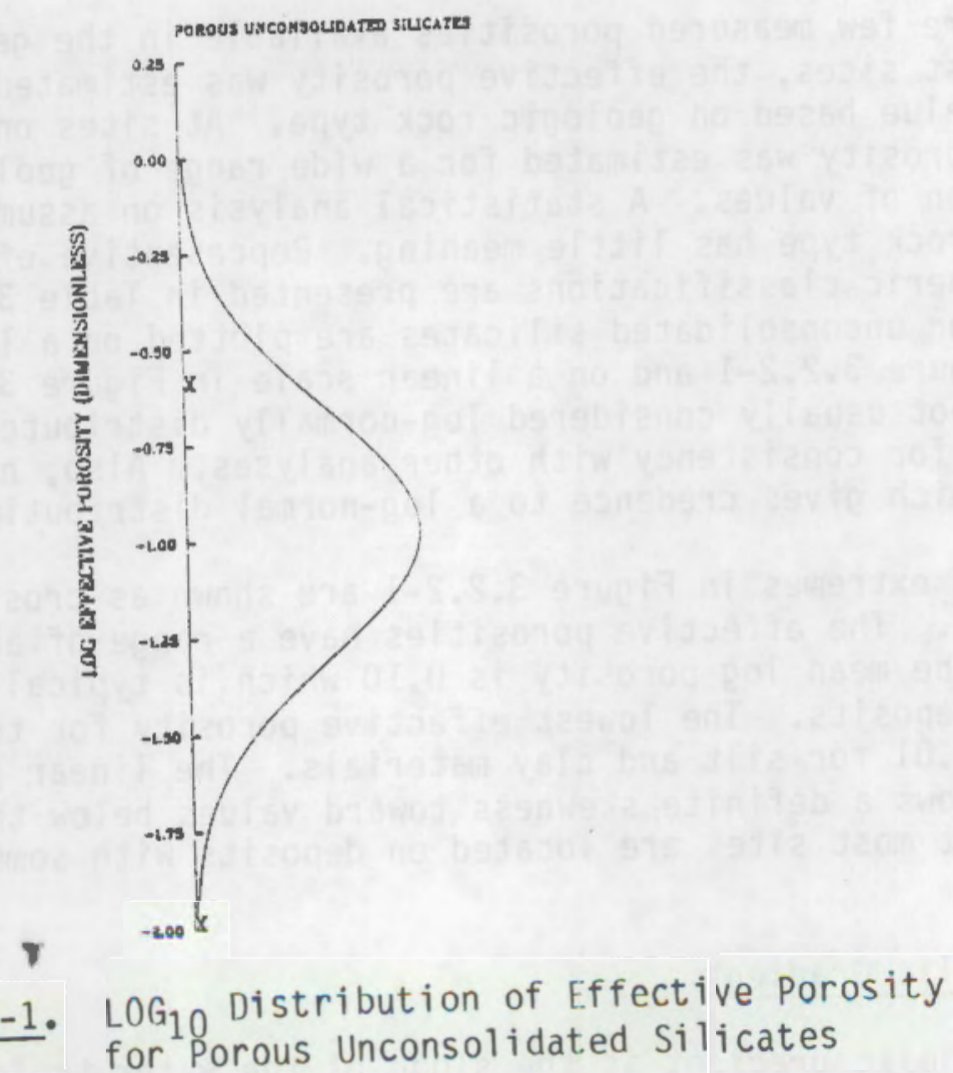

FIGURE 3.2.2-1. for Porous Unconsolidated Silicates

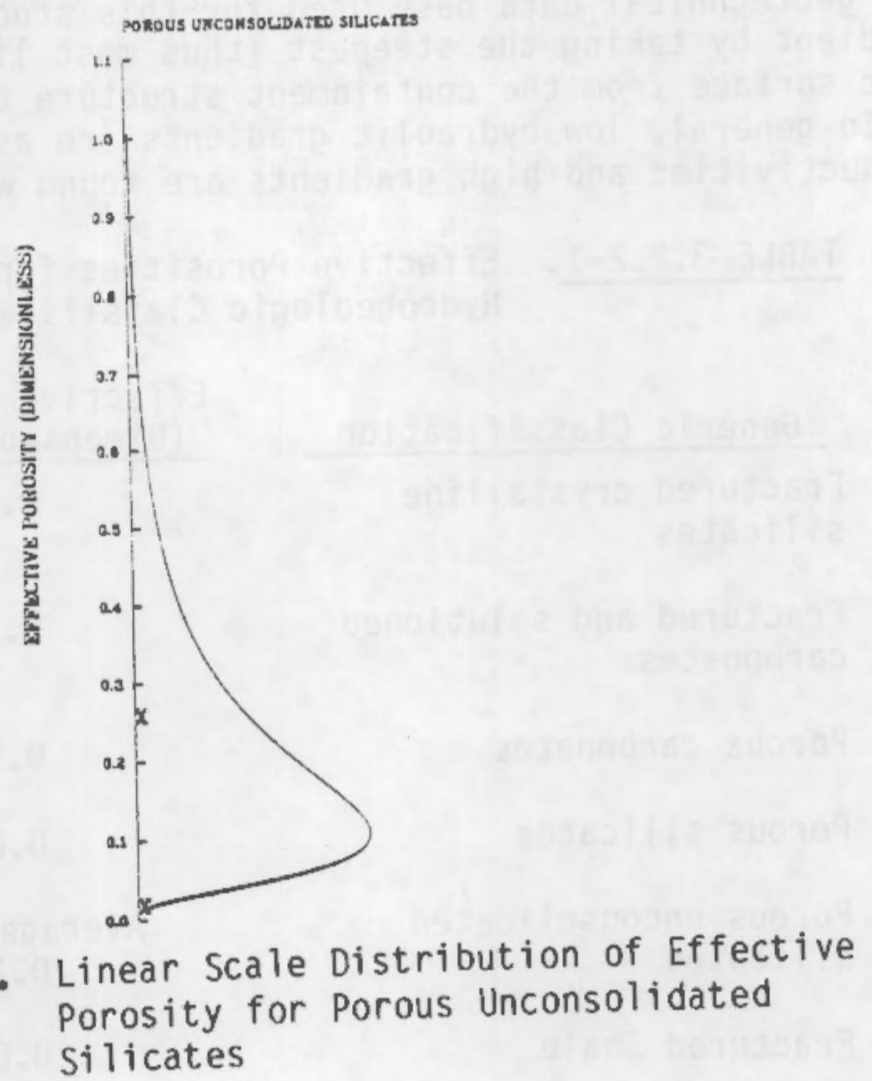


Hydraulic gradients are a function of aquifer properties and location. Local changes in gradient are related to changes in hydraulic conductivity, the presence of hydraulic boundaries and barriers, as well as hydrologic sources and sinks. A hydrologic source is defined as an addition of water to the aquifer through recharge or injection and a hydrologic sink is where water discharges through wells, springs, interaquifer transfer or into surface water bodies. The hydrogeologic gradient in any given aquifer has a strong relationship to the location in the flow field where it is measured.

The log hydraulic gradient is plotted for two standard deviations about the $\log$ mean in Figures 3.2.3-la through 3.2.3-1f. The data limits are shown as crosses on the left vertical axis as in previous figures. The log distributions show that the highest gradients are found in fractured silicate rock. This generic classification also has a relatively small range of values for hydraulic gradients. Fractured shale and froctured silicates have the smallest range of values which indicate a similarity in fracture hydraulics. The lowest gradients are found in porous carbonates. The relatively low value for this classification may also be related to site physiography (i.e., location of plants sites in areas of low relief). The largest spread between data extremes is in the fractured and solutioned carbonate classification. The upper limit is in fair correlation with other classifications, the lower limit is extremely low due to the possibility of karst conditions and open channel flow. A summarized comparison of the hydraulic gradients is given in Table 3.2.3-1.

TABLE 3.2.3-1. Average Hydraulic Gradient for Generic Hydrogeologic Classifications

\begin{tabular}{|c|c|c|c|}
\hline Generic Classification & Mean $\log$ & $\begin{array}{l}\text { Arithmetic } \\
\text { Mean } \\
\end{array}$ & $\begin{array}{l}\text { Data Range } \\
\text { in Orders of } \\
\text { Magnitude }\end{array}$ \\
\hline $\begin{array}{l}\text { Fractured crystalline } \\
\text { silicates }\end{array}$ & -1.2 & 0.070 & 1.2 \\
\hline $\begin{array}{l}\text { Fractured and solutioned } \\
\text { carbonates }\end{array}$ & -2.0 & 0.010 & 2.9 \\
\hline Porous carbonates & -2.2 & 0.007 & 1.5 \\
\hline Porous silicates & -1.8 & 0.015 & 2.3 \\
\hline $\begin{array}{l}\text { Porous unconslidated } \\
\text { silicates }\end{array}$ & -2.1 & 0.009 & 2.5 \\
\hline Fractured shale & -1.9 & 0.012 & 0.9 \\
\hline
\end{tabular}

The hydraulic gradients are presented in Figures 3.2.3-2a through 3.2.3-2f with the vertical axis as a linear scale. The data extremes are again indicated by crosses. The figures show skewness toward lower values in fractured and solutioned carbonates, porous silicates, and porous unconsolidated silicates classifications. The least skew is seen in Figures 3.2.3-2a and 

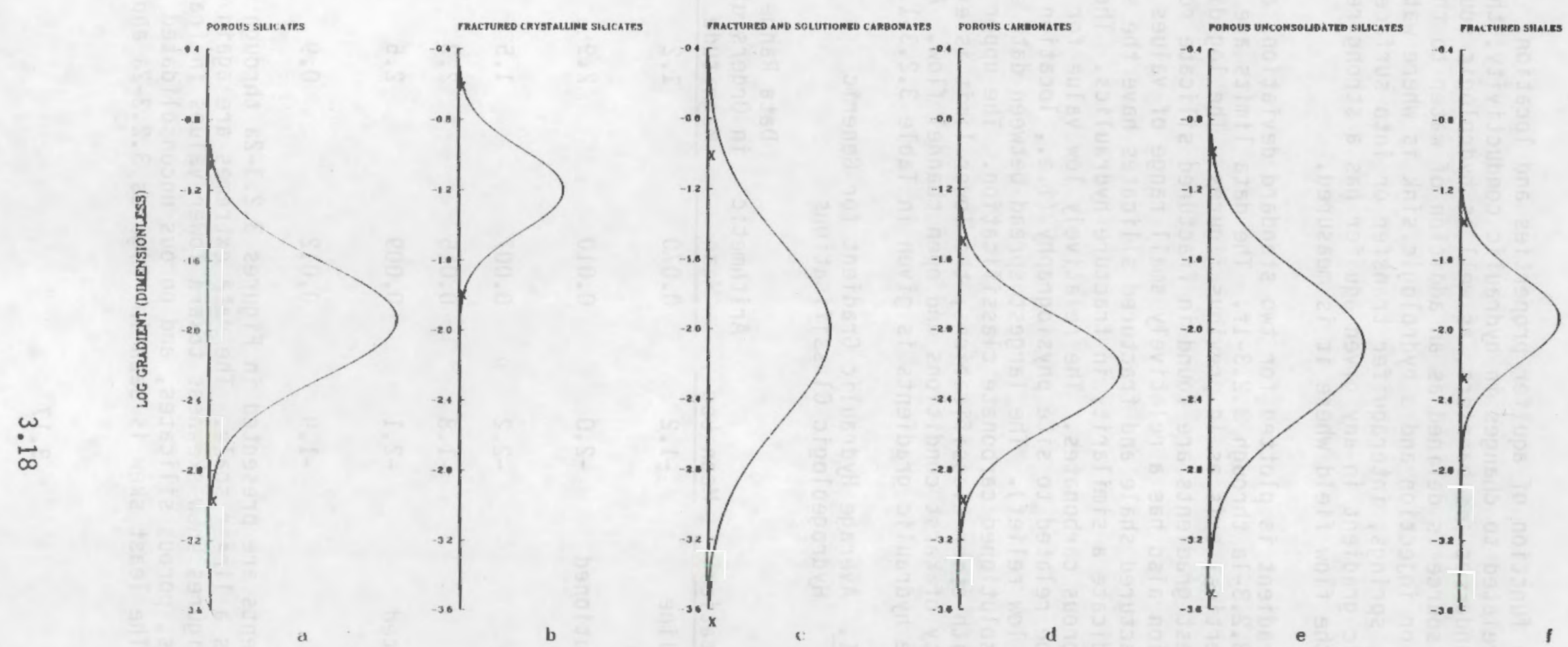
FIGURE 3.2.3-1.
COG $_{10}$ Distribution of Hydraulic Gradient by Generic
Classification 


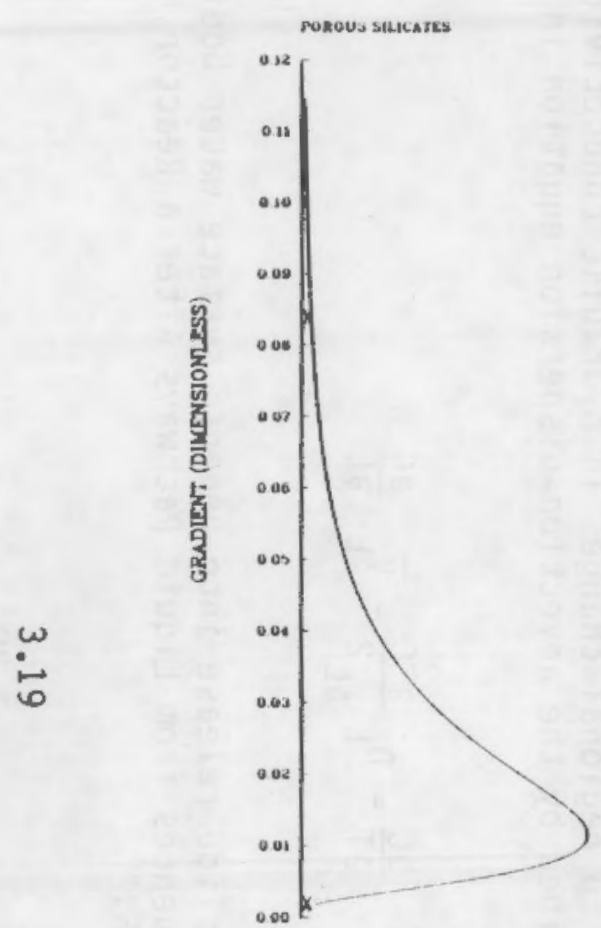

d

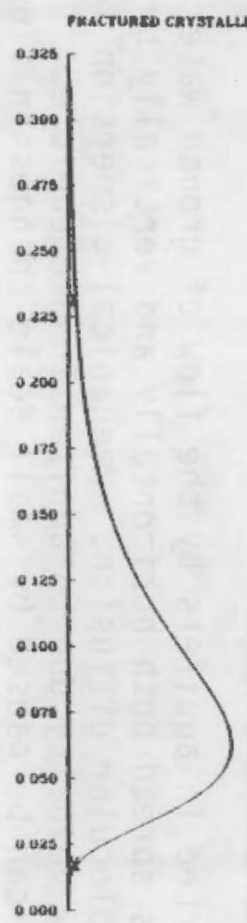

b

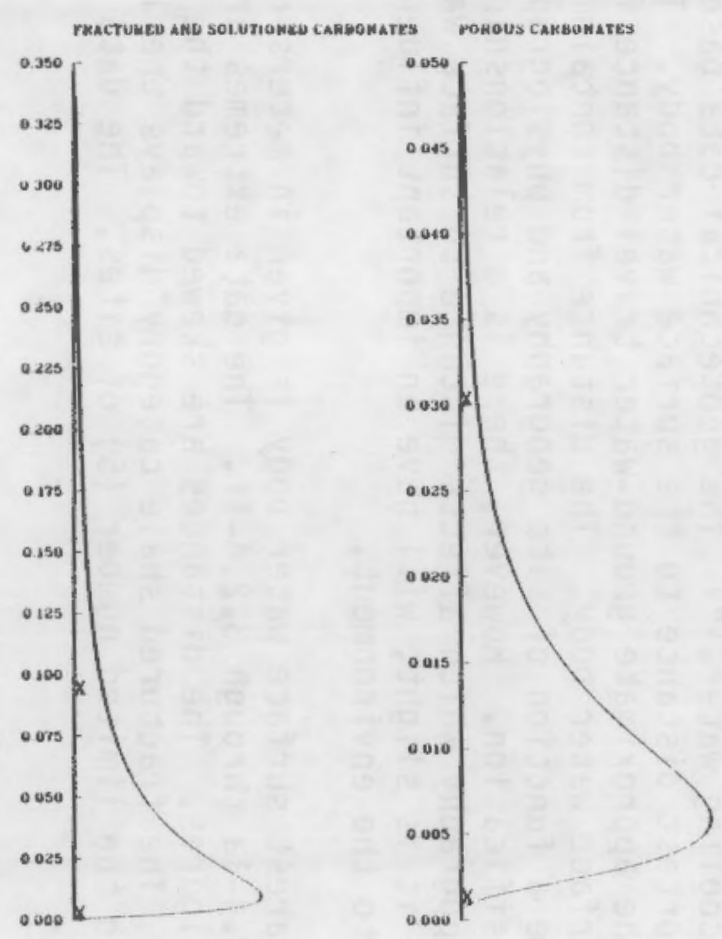

6

d

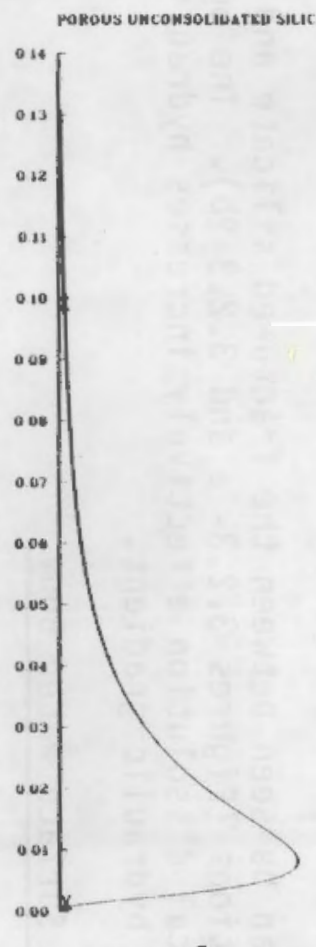

e

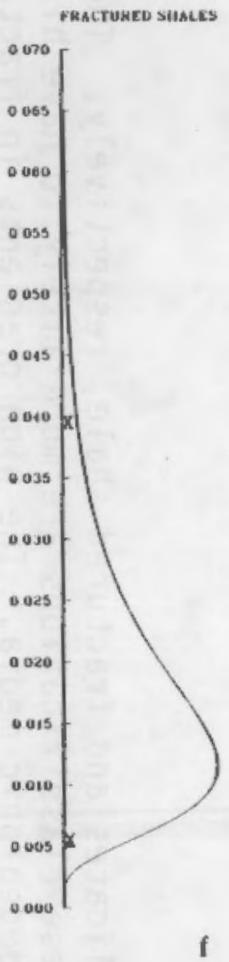

FIGURE 3.2.3-2. Linear Scale Distribution of Hydraulic Gradient by Generic Classification 
3.2.3-2f for fractured silicates and fractured shale, respectively. The hydraulic gradients in these classifications are more likely to have high values than in unfractured geologic media. The high gradients in fractured rock are caused by low aquifer transmissivity.

A clear distinction can be seen between the fractured silicate and fractured carbonate classifications (Figures 3.2.3-2a and 3.2.3-2b). The opening of flow channels via chemical dissolution effectively increases hydraulic conductivity and decreases hydraulic gradient.

\subsubsection{Distance to Nearest Surface Water Body}

Nuclear power plants are usually sited adjacent to surface water bodies which serve as a source of cooling water. (a) The geotechnical data base used for this study lists the shortest distance to the surface water body. This distance is assumed to be the approximate ground-water travel distance from the reactor containment to a surface water body. The distance from containment to a surface water body is more a function of site geography and physiography than of the hydrogeological classification. However, there is a relationship between geology and site topography which affects distance to surface water. Such a relationship even if it is slight, will have an important influence on a release of radionuclides into the environment.

The distance to the nearest surface water body is given in meters on a linear scale in Figures 3.2.4-1a through 3.2.4-1f. The data extremes are plotted as crosses on the figures. The distances are skewed toward the lower values but not toward zero. The fractured shale category displays the least skewness which may be due to the limited number (5) of sites. The data are summarized in Table 3.2.4-1.

\subsection{TRANSPORT PARAMETERS FOR GENERIC SITES}

\subsubsection{Longitudinal Dispersion Coefficient}

Contaminant is transported in aquifers by the flow of ground water. Along the flow path contaminant is spread both horizontally and vertically by mechanical dispersion and molecular diffusion. Mechanical dispersion is a result of variations in flow velocity due to aquifer inhomogeneities. These variations in flow velocity can be caused by small scale changes in flow around an individual sand particle to regional changes in hydraulic conductivity. The dispersive process is described by the advection-dispersion equation in one dimension as:

$$
\frac{\partial C}{\partial T}=D_{L} \frac{\partial^{2} C}{\partial L^{2}}-\bar{V}_{L} \quad \frac{\partial C}{\partial L}
$$

(a) The affects of radionuclide release into generic surface water bodies is covered in "The Consequences from Liquid Pathways After a Reactor Meltdown Accident " NUREG/CR-1596. 


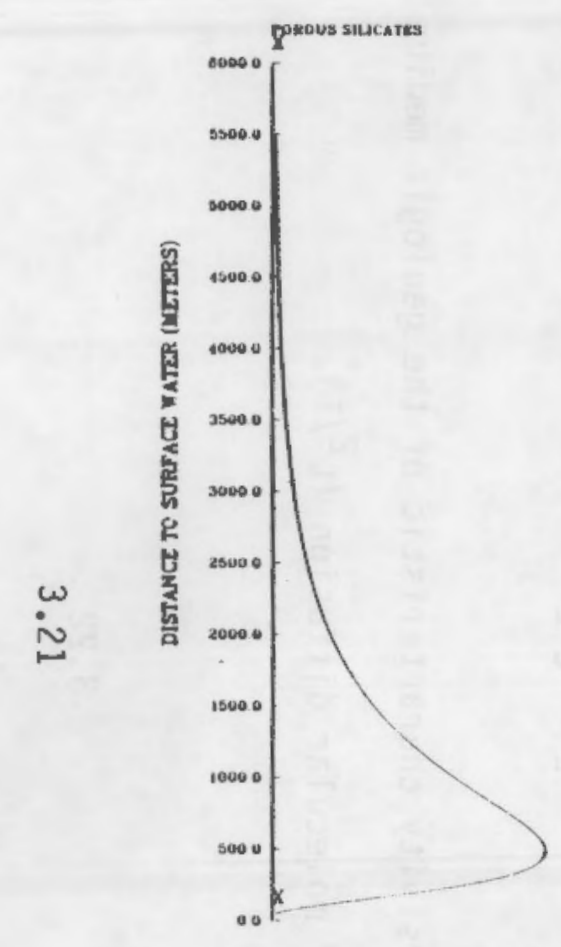

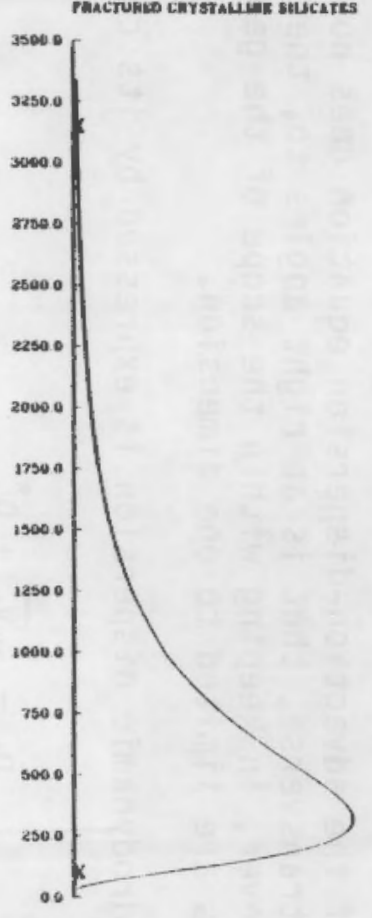

b

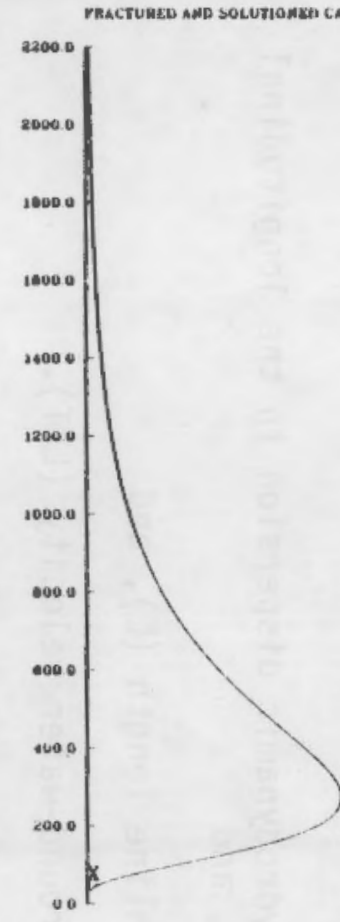

.

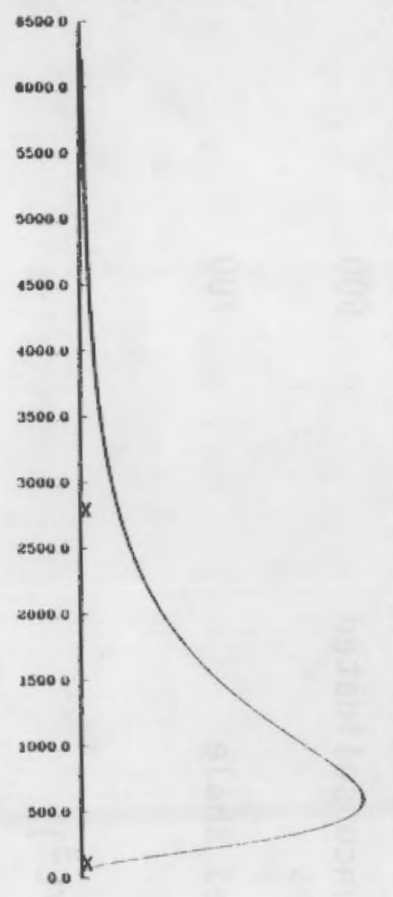

d

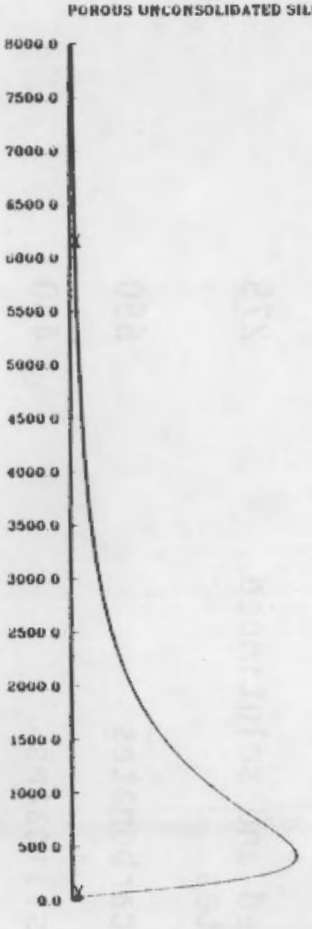

e

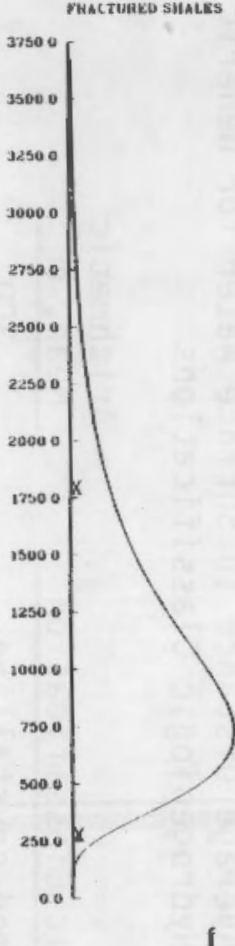

I

FIGURE 3.2.4-1. Linear Scale Distribution of Reactor Distance from Surface Water 
TABLE 3.2.4-1. Average Distance to Surface Water for Generic Hydrogeologic Classifications

\begin{tabular}{|c|c|}
\hline Generic Classification & $\begin{array}{l}\text { Arithmetic } \\
\text { Mean, } m\end{array}$ \\
\hline $\begin{array}{l}\text { Fractured crystalline } \\
\text { silicates }\end{array}$ & 300 \\
\hline $\begin{array}{l}\text { Fractured and solutioned } \\
\text { carbonates }\end{array}$ & 275 \\
\hline Porous carbonates & 650 \\
\hline Porous silicates & 450 \\
\hline $\begin{array}{l}\text { Porous unconsolidated } \\
\text { silicates }\end{array}$ & 500 \\
\hline Fractured shale & 700 \\
\hline
\end{tabular}

where

$$
\begin{aligned}
C & =\text { concentration }\left(M / L^{3}\right), \\
T & =\text { time, } \\
D_{L}= & \text { coefficient } g^{f} \text { hydrodynamic dispersion in the longitudinal } \\
& \text { direction }\left(L^{2} / T\right), \text { and } \\
L & =\text { ground-water pathline length }(L), \text { and } \\
\bar{V} & =\text { average linear ground-water velocity }(L / T) .
\end{aligned}
$$

The one dimensional form of the advection-dispersion equation does not account for contaminant spreading transverse, that is at right angles to, the groundwater flow direction. However, in keeping, within the scope of the geotechnical data base dispersion values are limited to one dimension.

The coefficient of hydrodynamic dispersion is expressed by its components as:

$$
D_{L}=\alpha_{L} \bar{V}_{L}+0^{*}
$$

where

$$
\begin{aligned}
\alpha_{L} \bar{V}_{L} & =\text { dynamic dispersivity characteristic of the geologic medium }(L) \text {, and } \\
D^{*} & =\text { coefficient of molecular diffusion }\left(L^{2} / T\right) .
\end{aligned}
$$


In geologic materials where ground-water velocities are low molecular diffusion is the dominant factor of hydrodynamic dispersion (Freeze and Cherry 1979). Rapid ground-water flow results in dynamic dispersivity being the major factor in dispersion. In this study, molecular diffusion is ignored for two reasons. First, in various geologic media rates of molecular diffusion are uncertain. Values for this parameter can only be estimated within two orders of magnitude. Secondly, molecular diffusion along the flow path is important only when ground-water velocities are slow or when travel distances are long. In these cases, radioactive decay often diminishes the contaminant to very low concentrations prior to surface water discharge. These assumptions provide a realistic yet conservative approach for consideration of this parameter.

There are no measured values of dispersion for nuclear power plant sites. Field tracer tests which inject a nonreactive chemical agent into an aquifer and monitor concentrations at distance are required to determine true dispersion. Few of these long-term tests are conducted in the field and most dispersion data are derived from laboratory experiments involving flow through isolated colurnns. The applicability of these measurements to field situations and the parametric content of the advection-dispersion equation are currently undergoing critical review by several researchers (Matheron and DeMarsily 1980; Gelhar et al. 1979; Simmons 1982; Molz et al. 1983).

The dynamic dispersivity was estimated for each site based on the geologic materials. Estimates of dynamic dispersitivity are presented in Table 3.3.1-1.

TABLE 3.3.1-1. Estimated Dynamic Dispersivity for Various Geologic Materials (Source: Yeh 1981)

$\begin{array}{lc}\text { Geologic Material } & \begin{array}{c}\text { Estimated Dynamic } \\ \text { Dispersivity, m }\end{array} \\ \text { Clay-Silt } & 1 \\ \text { Silty Clay } & 5 \\ \text { Silty Marl } & 10 \\ \text { Sandy Silt } & 25 \\ \text { Sand } & 50 \\ \text { Porous Consolidated (a) } & 50 \\ \text { Fractured (a) } & 100\end{array}$

(a) Estimated by authors. 


\subsubsection{Retardation of Radionuclides by Sorption}

\subsubsection{Definition of Sorptive Process}

The concentration of contaminant can be altered by chemical reactions along the ground-water flow path. The chemical reactions among the contaminant, native ground-water and aquifer material are complex and interrelated. Possible reactions include: adsorption, fixation, complexing, colloid formation, precipitation, solutioning and ion exchange. These processes tend to alter contaminant concentrations by retarding transport with respect to groundwater velocity, that is causing the contaminant to move at a different rate than the ground water. The reactions may change in time and space as the contaminant moves away from the source. The vigor of these reactions depends upon the chemical species present, ionic strengths, pH (acidity) and Eh (oxidation potential) of the ground water and the type of minerals in the geologic unit. Description of these processes by coupled geochemical ground-water transport models is in the early stages of development by researchers.

Site specific ground-water chemistry is lacking for most nuclear power plant sites. The most basic measure of ground-water chemistry is $\mathrm{pH}$ and this parameter is available for less than half of the sites. Most sites have measured or estimated ground-water $\mathrm{pH}$ values between 7.0 and 8.5 which is slightly alkaline (Niemczyk et a1. 1981).

Sorption is a process by which chemical reactants are adsorbed or adhere as a thin film onto the surfaces of solids and then by desorption re-enter the ground-water flow field. The mechanism of retardation is a result of contaminant not being transported during the time it is sorbed onto the rock matrix. The process is modeled by assuming that reactions are instantaneous, in equilibrium and reversible. The partitioning of contaminant between solid phases and liquid in a porous medium is described by the equilibrium distribution coefficient known as $k_{d}$. Aquifer properties of porosity and bulk mass density are also parameters in the determination of retardation by sorption.

When more than one chemical species is present, which would most likely be the case for a core melt accident, each species has an individual value of the equilibrium distribution coefficient and the contaminant stream becomes chemically segregated. The retardation by sorption is described by:

$$
R_{d}=\frac{V}{v_{c}}=1+\frac{\rho_{b} K_{d}}{n_{e}}
$$

where

$R_{\mathrm{d}}=$ retardation factor expressed as a ratio of the ground-water velocity to the radionuclide species velocity.

$\mathrm{V}=$ ground-water velocity $(\mathrm{L} / \mathrm{t})$,

$V_{C}=$ contaminant velocity $(\mathrm{L} / \mathrm{t})$,

$\rho_{b}=$ mass bulk density $\left(M / L^{3}\right)$,

$\mathrm{K}_{\mathrm{d}}=$ equilibrium distribution coefficient $\left(\mathrm{L}^{3} / \mathrm{M}\right)$, and

$n_{\mathrm{e}}=$ effective porosity expressed as a fraction. 
The value of the equilibrium distribution is empirically determined in the laboratory by batch (static) experiments or dynamic experiments in which the contaminant flows through a column of aquifer material. The batch laboratory tests give a representative value for the $k_{d}$ of the chemical species while column experiments can measure the retardation directly. Field tests for this parameter are less numerous. Comparison between laboratory batch and column experiments indicate that values can range over an order of magnitude for similar geologic materials. Ground-water chemistry changes as mentioned above can induce additional large scale variations in $K_{d}$ values.

Equation (3.4) is valid for granular porous media where there is a large surface area for contaminant to be sorbed. The presence of very fine grained material such as clay enhances the sorption process. By contrast in fractured aquifers the surface area of rock that the contaminant contacts with is much less. The contaminant is largely confined to the fractures until matrix diffusion forces it into the interior of the rock. Therefore contaminant transport and retardation have two fundamental differences in fractured rock. First, the contaminant is hydraulically confined to the fracture for much of its transport. Second, there is much less surface area onto which the contaminant can be sorbed. The texture of the fracture surface and any secondary mineralization are also factors which affect contaminant transport under these conditions.

Examination of Equation (3.4) shows that if typical fractured aquifer parameters are input, the low value of porosity and high value of mass bulk density will cause a large computed retardation. Clearly this approach is incorrect because conceptually less retardation should occur on fracture surfaces. A better description of retardation in fractured systems than given by Equation (3.4) is needed to describe the sorptive process.

When radionuclide transport in fractured rock occurs over long time periods, molecular diffusion of contaminant into the rock matrix is an important factor in retardation (Neretnieks 1980). Diffusion would continue to carry radionuclides into low velocity zones as long as a concentration gradient existed between the fracture and the rock matrix. The net effect would be an equilibrium distribution coefficient that increases with time as observed in tests of retardation of strontium and cesium in granite (Allard et al. 1978). In these tests the contaminant concentration was found to be related to the $\log$ of the square root of time. These processes are not considered by $\mathrm{K}_{\mathrm{d}}$ mechanisms which assume that reactions are instantaneous, in equilibrium and reversible. Applying $K_{d}$ values to geologic media and not considering diffusion over long times can lead to an under-estimation of retardation. An equilibrium distribution coefficient based on fracture hydraulics has been proposed (Burkholder 1976) which requires a description of the fracture geometry. Knowledge at this level of detail of the hydrologic characteristics is beyond this study and most other studies on fractured aquifers. In some instances where fracturing is extensive the retardation is computed with Equation (3.4) by assuming that on a regional scale the fracture system performs as an equivalent porous media. The fracture systems in the geotechnical data base for this study do not meet this requirement in that the porosities are much below those found in porous media. 
At the present time there is no standard method or accepted means for computing retardation factors in fractured media. However, not accounting for sorption in fractured media is undesirable because: 1) sorption is known to take place in fractures, 2) zero retardation is unduly conservative and would result in unrealistically high rates of contaminant discharge, and 3 ) it would not allow for the gross variations in sorption among the generic classifications. In keeping with the "order of magnitude" approach of this generic analysis, a contaminant velocity is determined by applying a correction factor to laboratory $K_{d}$ data. In developing this methodology it was also recognized that the ground-water velocities predicted by the hydrogeologic data base may already be biased toward high values by conservative estimates of hydraulic parameters. Therefore, computation of a retardation factor for fractured media was accomplished with the understanding that it only provided a means of scaling the known differences in retardation among various geologic environments.

A retardation factor in fractured aquifers is determinedd by computing the $K_{d}$ value based on a mass value by correcting for the fraction of the aquifer exposed to contaminant. To accomplish this, the equilibrium distribution coefficients determined from laboratory results with crushed rock are divided by the ratio of fracture porosity over crushed rock porosity. The $k_{d f}$ value is defined as:

$$
K_{d f}=\frac{K_{d} \cdot \text { fracture porosity }}{\text { crushed rock porosity }}
$$

where

$K_{d}=$ granular media equilibrium distribution coefficient, e.g.,

(crushed rock porosity $=0.25$ )

(fractured porosity $=0.01$ ).

Therefore, the resulting $K_{d f}$ in this example is 25 times less than the $K_{d}$ value for porous media of the same rock type.

\subsubsection{Values of Equilibrium Distribution Coefficients}

The values of equilibrium distribution coefficients were determined by an extensive literature search for previous test results for the radionuclides strontium-90, cesium-137 and ruthenium-106.

The choice of these radionuclides to characterize a core melt is detailed in Section 2.3.1. Each generic hydrogeological classification is discussed separately below and summary Table 3.3.2-1 provides a list of representative equilibrium distribution coefficients for each radionuclide.

\section{Fractured Crystalline Silicates}

Most references for this rock type are based on tests in granite or gneiss. These reports give data for strontium and cesium but not ruthenium. Erdal et al. (1979); Tschurlovits (1979); Skagius et al. (1982); Landstrom (1978); Torstenfelt et al. (1982); and Walton et a1. (1982) have conducted the 


\section{TABLE 3.3.2-1. Equilibrium Distribution Coefficients}

\begin{tabular}{|c|c|c|}
\hline Reference & $\begin{array}{l}\text { Radio- } \\
\text { nuclide }\end{array}$ & $\underline{K}_{d}(m \ell / g)$ \\
\hline Erdal et al. (1979) & $\begin{array}{l}90-S r \\
137-C s\end{array}$ & $\begin{array}{l}12 \\
300\end{array}$ \\
\hline Tschurlovits (1979) & $\begin{array}{l}90-S r \\
137-C s\end{array}$ & $\begin{array}{l}2-15 \\
60-2500\end{array}$ \\
\hline Torstenfelt et al. (1982) & $\begin{array}{l}90-S r \\
137-C s\end{array}$ & $\begin{array}{l}7-30 \\
100-400\end{array}$ \\
\hline Skagius et al. (1982 & $\begin{array}{l}90-\mathrm{Sr} \\
137-\mathrm{Cs}\end{array}$ & $\begin{array}{l}7 \\
10-15\end{array}$ \\
\hline
\end{tabular}

most recent work on silicate materials. For strontium the $K_{d}$ 's range from 2-15 ml/g and cesium $K_{d}$ 's range from $60-2500 \mathrm{m \ell} / \mathrm{g}$. The equitibrium distribution coefficients are listed by source in Table 3.3.2-1. A clear understanding of retardation of ruthenium is given in Onishi et al. (1981) which demonstrates that ruthenium is mobile mainly in cases of disposal of fuel reprocessing wastes containing high nitrate. In natural environments with neutral $\mathrm{pH}$ and not excessive nitrate concentrations the element ruthenium should not be ground-water coincident. An estimated reasonable value of $k_{d}$ for ruthenium is $50 \mathrm{ml} / \mathrm{g}$.

\section{Fractured and Porous Consolidated Carbonates}

These two generic classifications have the same rock chemistry and are discussed as one group. Fractured and solutioned carbonate equilibrium distribution coefficients are corrected for a lower porosity to differentiate them from porous carbonates. There are few references for $k_{d}$ values in this rock type. In non-saline ground-water conditions $K_{d}$ values that are most probable are 1.4 to $20 \mathrm{ml} / \mathrm{g}$ for strontium and $1.3-2000 \mathrm{ml} / \mathrm{g}$ for cesium from: Maclean et al. (1979); Seitz et al. (1979); Serne et al. (1977); Relyea et al. (1979); and Relyea and Serne (1979). There are no references for ruthenium in this generic rock type and a reasonable estimated value of $50 \mathrm{ml} / \mathrm{g}$ is used for this study.

\section{Porous Consolidated and Unconsolidated Silicates}

Consolidated and unconsolidated silicates are considered together because they have similar rock chemistries. A distinction is made in determining equilibrium distribution coefficients between geologic materials that are described as "dirty" and "clean". Geology literature often refers to aquifers that contain significant quantities of clay and silt as "dirty" (e.g., a dirty sandstone). The inclusion of these fine particles in an aquifer provides a larger surface area and more locations for sorption to take place. A "clean" sandstone does not have interstitial clay or silt and less sorption is expected. For cesium the references are: Baetsle et al. (1964); Barney, and 
Anderson (1979); Barney and Brown (1980); Berak (1963); Coles et al. (1980); Dosch, and Lynch (1978); Erdal et al. (1979); Erdal et al. (1980); Harwell (1980); Janzer et al. (1962); Meyer et al. (1978); Meyer (1979); Meyer (1980); Nork and Fenske (1970); Nork et al. (1971); Relyea et al. (1978); Relyea et al. (1979); Rhodes (1957); Routson (1973); Schmal (1972); Tamura (1972); and Wilding and Rhodes (1963). The cesium Kd values for porous silicates ranged from $0-100 \mathrm{ml} / \mathrm{g}$ for clean aquifers and $70-3000 \mathrm{ml} / \mathrm{g}$ for dirty aquifers.

The equilibrium distribution coefficient for strontium was determined by examining the following references: Baetsle and Dejonghe (1962); Baetsle et a1. (1964); Barney and Anderson (1970); Barney and Brown (1980); Berak (1963); Cerrai et al. (1969); Dosch (1980); Dosch and Lynch (1978); Duursma et al. (1974); Erdal et al. (1979); Erdal et al. (1980); Francis and Bondietti (1980); Gardner and Skulberg (1964); Harwell (1980); Nork and Fenske (1970); Nork et al. (1971); Relyea et al. (1978); Relyea et al. (1979); Rhodes (1957); Routson (1973); Schmal (1972); and Wilding and Rhodes (1963). The strontium $K_{d}$ values range from $1-30 \mathrm{ml} / \mathrm{g}$ for a clean porous silicate to $50-2000 \mathrm{ml} / \mathrm{g}$ for a dirty porous silicate.

Ruthenium equilibrium distribution coefficients were examined for cases not involving fuel reprocessing wastes. These wastes contain high levels of nitrate which mobilize ruthenium. At the Nevada Test Site ruthenium migration was observed in an alluvial aquifer flowing through an underground atomic bomb melt glass About one percent of the total inventory of ruthenium was migrating at the velocity of the ground-water (Coles and Ramspott 1982). The following references were used: Aston and Duursma (1973); Collet et al. (1968); Duursma (1973); Gardner and Skulberg (1964); Kepak (1966); Rhodes (1957b); Schell et al. (1979); Schell et al. (1980). The range of expected $K_{d}$ values for a clean porous silicate could not be reasonably determined from the ruthenium references. There are too few measurements to state with certainty what the expected range of $\mathrm{K}_{d}$ 's might be. Certainly the range of values covers more than an order of magnitude. A $K_{d}$ of $50 \mathrm{ml} / \mathrm{g}$ is a reasonable estimate for ruthenium sorption in a clean porous silicate. In a dirty porous silicate there are sufficient tests to set the range of ruthenium $K_{d}$ values at $200-$ $700 \mathrm{ml} / \mathrm{g}$.

\section{Shale Media}

Laboratory tests on crushed shale samples have a wide range of results. The references for equilibrium distribution coefficients are: Barney and Grutzeck (1977); Barney and Anderson (1979); Tewhey et al. (1978); and Erda 1 et al. (1979). Laboratory tests on shale report $K_{d}$ values ranging from $17-156 \mathrm{ml} / \mathrm{g}$ for strontium, $183-8000 \mathrm{ml} / \mathrm{g}$ for cesium, and $300-438 \mathrm{ml} / \mathrm{g}$ for ruthenium.

\section{Selected Equilibrium Distribution Coefficient}

Judgment was used to select a representive $k_{d}$ value for each radionuclide for each generic site classification. Porosity corrections for fractured media were applied to $K_{d}$ 's determined from crushed rock samples. The resulting $K_{d}$ values are more realistic than applying a single $k_{d}$ for each radionuclide to 
all geologic environments. Equilibrium distribution coefficients used in this study and in previous reports on core meit accidents are presented in Table 3.3.2-2.

\subsubsection{General Comments on Geochemistry and Sorption}

The geochemical effects on sorption are assumed uniform within each generic classification. At a site where mitigative measures would be needed the ground-water chemistry would be an important consideration in the choice of chemical treatment methods and predictions of sorption. We can make several observations as to the effect of ground-water chemistry on sorption that applies to all sites. These are listed below for the three radionuclides of concern (i.e., strontium-90, cesium-137, and ruthenium-106).

Variations in Equilibrium Distributions Coefficients

Laboratory values for $K_{d}$ 's can be subject to wide variations as noted in Section 3.3.2.2. The range of $k_{d}$ values for equivalent rock samples was documented by an interlaboratory comparison of batch tests (Relyea and Serne 1979). In these tests cesium and strontium sorption on linestone showed over an order of magnitude variation in resultant $K_{d}$ values. There was much less variation in test results for cesium and strontium sorption on silicate (basalt). The mechanisms responsible for the wide range of values have been attributed to a strong dependence of sorption to concentration (Seitz et al. 1978, and Anderson et al. 1981). Diffusion of contaminant into the rock matrix was considered as the mechanism for variations in $K_{d}$ values by Neretniek's reinterpretation of the data in Seitz et a1. (1978) (Neretnieks 1980).

The size of the rock particle has also been observed to effect $K_{d}$ values. Tests of cesium sorption on carbonate showed that $K_{d}$ was proportional to particle surface area for large particles (diameter $>0.2 \mathrm{~mm}$ ), but proportional to mass for smaller particles (Rancon 1967). A diffusion mechanism was also believed to be responsible for these $K_{d}$ variations. The diffusion of contaminant into the rock over time is just as important as the sorption equilibrium values in determining retardation (Neretnieks 1980). Not accounting for diffusion in time plus concentration dependent experiments may be responsible for some of the reported range in values. Incorporation of time dependent $k_{d}$ values into ground-water transport calculations is in the early stages of development.

In summary five general statements can be made concerning computational time-concentration dependent retardation:

1. Retardation mechanisms are not presently parametrically defined and $K_{d}$ values are emperically determined. These values have a wide range of reported results for a single nuclide in similar geologic materials.

2. Time-concentration dependence is observed in long-term laboratory tests. Cesium is noted for this characteristics possibly because cesium has a high diffusivity. This would support the diffusion 
TABLE 3.3.2-2. Generic Equilibrium Distribution Coefficients

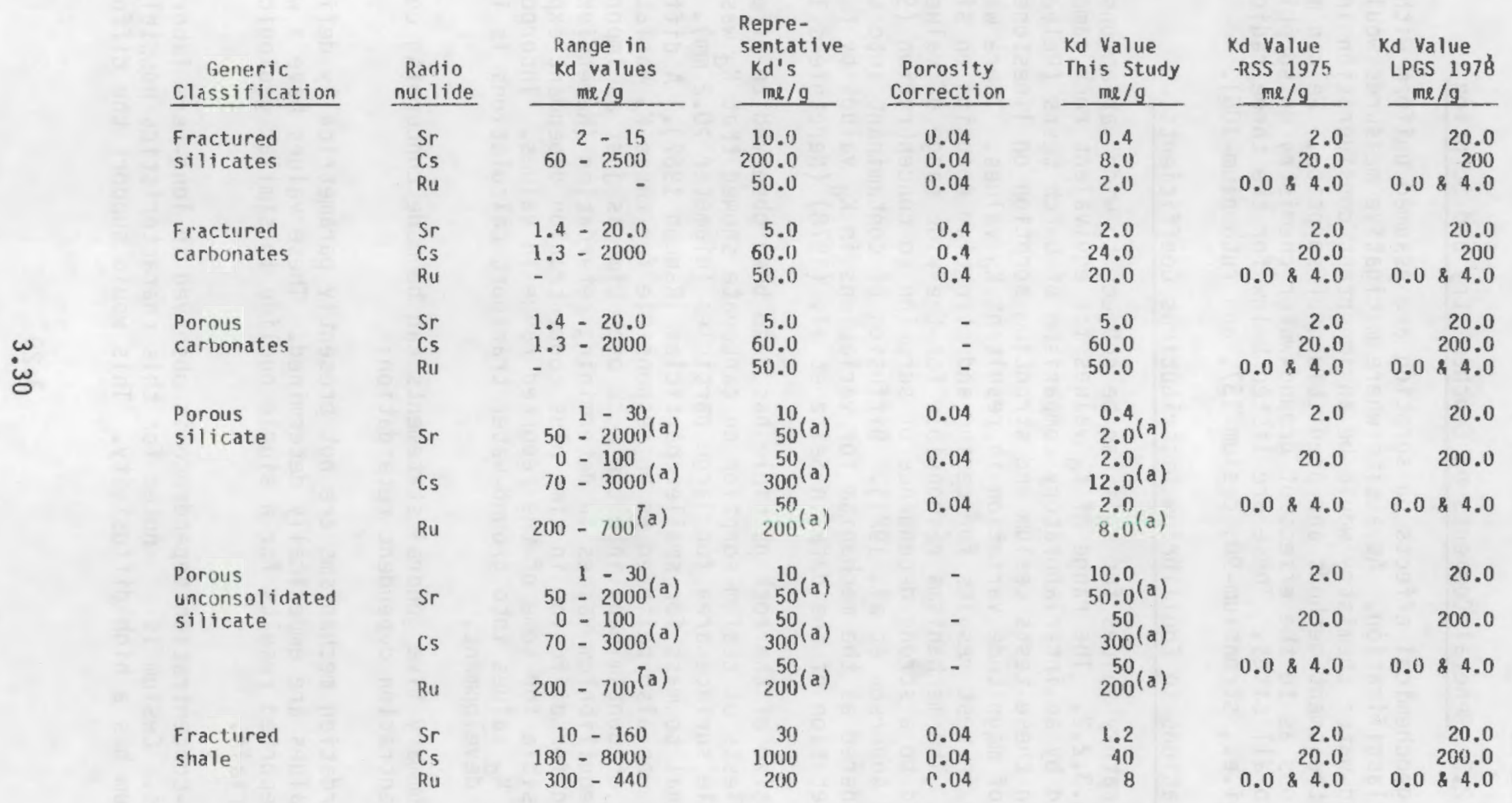

(a) Geologic Materials Containing Clay and Silt 
mechanism as the cause of time dependent $k_{d}$ values. Diffusion rates for contaminant entering the rock matrix would be greater than the rates for contaminant leaving the matrix because of the difference in concentration gradients.

3. Coefficients for these mechanisms and their interrelationships have not been experimentally determined. Measurement of the depth and number of micro fractures as well as surface area have been shown to be important (Neretnieks 1980).

4. The dominant mechanisms for retardation are related to the site specific geochemical environment. Geochemical processes that alter contaminant mass transport will vary among geologic sites.

5. Ground-water contaminant transport codes do not describe the ever increasing surface area exposed to contaminant for either granular or fractured media.

\section{$\mathrm{pH}$ Effects}

When the $\mathrm{pH}$ is constrained between values of 5 to 10 the rock matrix will not be dissolved at an appreciable rate and the sorption of strontium and cesium will not be altered. This lack of sensitivity to $\mathrm{pH}$ is caused by the fairly simple aqueous chemistry of strontium and cesium. They remain simple cations $\mathrm{Sr}^{2+}$ and $\mathrm{Cs}^{+}$in ground water at these $\mathrm{pH}$ values. Ruthenium adsorption versus $\mathrm{pH}$ is more complicated. Ruthenium aqueous chemistry suggests that at $\mathrm{pH}$ values 5 to 8 there is high adsorption, below pH 5 there would be lower adsorption. Above pH 9 adsorption also decreases because ruthenium solution species favor anionic forms which do not readily adsorb onto geologic media. The following references were used: Baetsle et al. (1964); McHenry (1954, 1955, 1958); Rhodes (1957); Rhodes and Nelson (1957); and Prout (1958, 1959).

\section{Eh Effects}

Eh does not affect adsorption of strontium and cesium. As ground water becomes more reducing (i.e., contains less dissolved oxygen) it is predicted that ruthenium adsorption would increase as the oxidized forms of ruthenium $\mathrm{RuO}^{4-}$ and $\mathrm{RuO}_{4}{ }^{2-}$ would convert to $\mathrm{Ru}^{4+}$ and $\mathrm{Ru}^{3+}$ (Relyea and Washburne 1980; Onishi et al. 1981).

\section{Temperature Effects}

Between $4^{\circ}$ and $60^{\circ} \mathrm{C}$ cesium-137 adsorption seems to drop slightly (a factor of 2 to 3) with increasing temperature. Between these two temperature ranges strontium-90 adsorption is not affected significantly. The thermal effects on sorption of ruthenium-106 are not mentioned in the literature reviewed. The following references were used: Ames et a1. (1981, 1982, 1983a, 1983b); Ames and McGarrah (1980a, 1980b); Barney (1982); Daniels et al. (1981); Erdal (1979, 1980); Mckinley and Greenwood (1980); Mckinley and West (1981a. 1981b); and Salter et al. (1981a, 1981b). 


\section{Ionic Strength}

Both strontium-90 and cesium-137 adsorption are directly affected by increases in ionic strength. As competing cations $\left(\mathrm{Na}^{+}, \mathrm{K}^{+}, \mathrm{Ca}^{2+}, \mathrm{Mg}^{2+}\right)$ increase both elements show diminished adsorption. In salt brines, $\mathrm{Sr}$ and $\mathrm{Cs}$ adsorption is essentially zero. This is due to cation competition for positive exchange sites on the rocks and clays. For limestone and dolomite rock, the high ionic strength (high $\mathrm{Ca}^{2+}$ ) can cause precipitation of more calcitedolomite and thus some retention of strontium-90 by co-precipitation processes. In general; ruthenium-106 adsorption is not affected by increases in salt content from (distilled water to seawater). Ruthenium-106 sorption is not controlled by a cation exchange process.

\section{Unique Properties of Rocks}

Carbonate-based rocks such as limestone and dolomite can enhance, via precipitation, strontium removal when compared to silicic rocks. High cation exchange capacity is ohserved in sediments and in shale, which is a high adsorber. Also, illite-clay-bearing sediments and rocks such as shale, are very good adsorbents. Cesium fits between the plate crystal structures and gets "locked in". Precipitation without subsequent dissolution would deposit a radionuclide permanently in the rock matrix. The following references were used: Coleman et al. (1963); Lomenick et al. (1967); Sawhney (1964); Jacobs (1962); Tamura (1963a, 1963b); Tamura and Jacobs (1960, 1961).

\section{Dissolved Organics}

In general, strontium-90 and especially cesium-137 are little affected by dissolved organics. They form very weak soluble organic complexes. Most of the strontium-90 and cesium-137 remain $\mathrm{Sr}^{2+}$ and $\mathrm{Cs}^{+}$thus organics do not interfere with adsorption. There are only a few studies on ruthenium-106 adsorption in the presence of organics. The studies split equally between claiming increased adsorption and decreased adsorption. Many of the authors used very high concentrations of organics $\left(10^{-4} \mathrm{M}\right.$. These concentrations are at least 100 times greater than any expected ground-water concentrations. The following references were used: Amy (1972); Bovard et al. (1968); Essington et al. (1965); Essingt on and Nishita (1966); Kilikov (1968); Kilikov and Molchanava (1972); Schell et al. (1980); and Wilding and Rhodes (1963).

\section{Effect of Inorganic Ligands}

Inorganic ligands $\left(\mathrm{Cl}^{-}, \mathrm{SO}_{4}{ }^{2-}, \mathrm{HCO}_{3}^{-} / \mathrm{CO}_{3}{ }^{2-}, \mathrm{NO}_{3}^{-}\right.$and $\left.\mathrm{PO}_{4}{ }^{3-}\right)$ do not affect $\mathrm{Cs}$ adsorption and only slightly affect $\mathrm{Sr}$ adsorption. If the concentrations of sulfate, carbonate or phosphate become quite high, $\mathrm{Sr}$ adsorption increases because of precipitation of gypsum $\mathrm{CaSO}_{4} \cdot 2 \mathrm{H}_{2} \mathrm{O}$, calcite $\mathrm{CaCO}_{3}$ and apatite $\mathrm{Ca}_{3}\left(\mathrm{PO}_{4}\right)_{2}$. Strontium can substitute for cafcium in some of the crystal lattices?

Complexes of ruthenium-106 nitrate are very strong and can keep ruthenium mobile. Reprocessing wastes are very high in nitrate and at Hanford Washington ruthenium migration is observed. In normal ground waters nitrate levels should 
not be high enough, even in organic rich sediments, to impact ruthenium adsorption. The following references were used: Ames and Rai (1978) and Rai and Serne (1978).

\subsubsection{Effective Bulk Density}

The retąrdation equation [Equation (3.4)] requires a known mass bulk density $\left(M / L^{3}\right)$ for each nuclear power plant site. This information is not contained in the geotechnical data base and was estimated for each site. In consolidated formations the effective bulk density was estimated by Equation 3.6:

$$
\rho_{b}=\rho_{m}\left(1-\eta_{e}\right)
$$

where

$$
\begin{aligned}
& \rho_{\mathrm{b}}=\text { effective bulk density, } \\
& \eta_{\mathrm{e}}=\text { effective porosity, and } \\
& \rho_{\mathrm{m}}=\text { average mass density of rock }\left(2.65 \mathrm{~g} / \mathrm{cm}^{3}\right) \text {. }
\end{aligned}
$$

Unconsolidated deposits were assigned a bulk density based on the sand, silt and clay content. Sandy units were given a value of $1.4 \mathrm{~g} / \mathrm{cm}^{3}$, silty units were assumed to have a bulk density of $1.6 \mathrm{~g} / \mathrm{cm}^{3}$ and clay units were assumed to have a value of $1.8 \mathrm{~g} / \mathrm{cm}^{3}$ as suggested by Yeh (1981). The mass bulk density of an aquifer can be estimated to a fair degree of accuracy and this is not considered a sensitive parameter.

\subsection{TRANSPORT EQUATIONS FOR ONE DIMENSIONAL SIMULATION}

\subsubsection{Modeling Objectives for Generic Classifications}

The geotechnical data base, given in Section 3.5, was used to simulate the transport of radionuclides in the ground-water flow system from each of the nuclear power plant sites to their respective nearest surface water body. The purpose of this modeling effort is to determine the generic hydrogeological characteristics of a radionuclide release into surface water. The single valued parameters contained in the geotechnical data base dictate that simple mathematical models be used. There is little to be gained by applying a complex multi-dimensional model to a single dimensional data set under steady state ground-water conditions. At the same time it must also be recognized that simple modeling, in this case one dimensional, does not produce the same degree of accuracy that would result from an extensive site specific field and modeling study.

The modeling approach is centered around the determination of what constitutes a generically characteristic radionuclide release to a surface water body. Simply using average or median hydraulic characteristics for each generic classification to evaluate transport would have produced unacceptable results for four reasons. First, hydraulic parameters at a site may have a negative correlation (e.g., gradient and hydraulic conductivity) and thus average parameters may not occur simultaneously at actual sites. Second, mass transport equations of radionuclides are non-linear and average values would 
not necessarily produce an "average" radionuclide discharge to surface water. The third reason is that even within a generic hydrogeologic classification the hydraulic parameters cover several orders of magnitude. Average parameter values would not represent the range of feasible radionuclide discharges. The variations in radionuclide discharges are generically contained in the geotechnical data base and should be carried through the analysis. Fourth, the actual site data may contain associations and correlations that are unique to nuclear power plant sites which should also be carried through the analysis.

The generic hydrogeologic characteristics of a radionuclide release were determined by modeling each power plant site and presenting the results by generic classification. The rational of this modeling approach is that consideration of actual sites (with subsequent analysis as a generic group) is more beneficial than simply analyzing aquifer properties with assigned average values. The modeling results for 97 nuclear power plants are presented by generic classification and not as individual nuclear plant sites.

\subsubsection{Equation for Contaminant Transport in Ground Water}

The transport of radionuclides was simulated using the computer code AT123D (Yeh 1981). The code represents an analytical transient model of radionuclide transport and can be applied in one, two, or three dimensions. For this study the one dimensional option was appropriate. A simplified form of the transport equation [Yeh 1981, equation (7)] can be written as:

$$
\frac{\partial C}{\partial t}=\nabla \cdot(\bar{R} \cdot \nabla C)-\nabla \cdot \overrightarrow{U C}-\lambda C+\frac{\dot{M}}{\eta_{e} R_{d}}
$$

where

$$
\begin{aligned}
C & =\text { dissolved concentrations of contaminant }\left(M L^{-3}\right), \\
t & =\text { time }(t), \\
\nabla & =\text { gradient operator, } \\
K & =\text { retarded dispersion tensor } D_{L} / R d\left(L^{2} T_{-1}\right), \\
U & =\text { retarded flow velocity }(L / T) \\
\lambda & =\text { radionuclide decay constant }\left(T^{-1}\right), \\
R_{d} & =\text { retardation factor, } \\
M & =\text { rate of contaminant mass release }\left(M L^{-3} T^{-1}\right), \text { and } \\
\hat{e} & =\text { effective porosity (dimensionless). }
\end{aligned}
$$

This equation is also subject to a series of boundary conditions that are not detailed in this report. The retarded flow velocity (U) is defined as:

$$
U=\frac{K \cdot I}{R_{d} \cdot n_{e}}
$$

where

$$
\begin{aligned}
R_{d} & =\text { retardation factor }(E q \cdot 3.4) \\
K & =\text { hydraulic conductivity }(L / T),
\end{aligned}
$$




$$
\begin{aligned}
I & =\text { hydraulic gradient (dimensionless), and } \\
n_{e} & =\text { effective porosity (dimensionless). }
\end{aligned}
$$

A continuous release of contaminant is further simplified to:

$$
C(X, Y, Z, t)=\int_{0}^{t} \frac{\dot{M}}{h_{e} R d} F_{i j k}(x, y, Z, t ; \gamma) d y
$$

where

$(X, Y, Z, t ; Y)=$ the space and time coordinants, and

$F_{i j k}=$ the integral of Green's Function in three dimensions.

In a one dimensional solution of a release from a point source the integral of Green's Function is expressed as:

$$
F_{i}=4 \pi K_{x x}^{1}(t-\tau) \exp \left[-\frac{\left(x-x_{s}\right)-U(t-\tau)^{2}}{4 K_{x x}(t-\tau)}-\lambda(t-\tau)\right]
$$

where

$$
\begin{aligned}
x & =\text { distance from source down the hydraulic gradient, } \\
K_{X X} & =x \text { component of the retarded dispesion tensor, } \\
X_{S} & =x \text { coordinate of point source, } \\
Y & =\text { total time of release, }
\end{aligned}
$$

and the other parameters as previously defined.

The release of nuclear mass from the core melt (M) is described for sump water and the core mass in Section 2.2 .

The model AT123D determines concentrations at a point. These values were converted to a radionuclide flux $(M / T)$ in order to effectively judge the potential environmental impacts of a core melt release.

\subsection{CONCLUSIONS OF GENERIC HYDROGEOLOGIC SITE CLASSIFICATION}

1. A hydrogeologic classification scheme for nuclear power plants must consider not only basic hydrogeologic transport factors, but also the geologic properties that affect the radionuclide source term and the feasibility of mitigative techniques.

2. Parameters contained in the hydrogeologic data base have values that tend to produce relatively rapid ground-water velocities. These values are not unrealistic, but rather represent conservatism in parameter selection and/or properties characteristic of nuclear power plant sites.

3. Simulation of ground-water transport by a one dimensional-homogeneous model may not produce extremely accurate results. However, in consideration of the large differences in contaminant release and transport rates among the generic classifications this methodology is 
adequate to describe the relative characteristics of severe nuclear power plant accidents in various geologic environments.

3.6 GENERIC GEOTECHNICAL SITE DATA ${ }^{(a)}$

The following sections list the individual reactor site hydrogeologic properties by generic classification. These data were used in the preceding equations to establish the probable range in the hydrogeologic properties for each generic classification. The results of the generic hydrogeologic analyses are presented with the applicable mitigative techniques in Section 5 .

\subsubsection{Generic Hydrogeologic Site Classification: Fractured Consolidated Silicates (Crystalline)}

Total Number of Sites: 16

\begin{tabular}{|c|c|c|c|c|}
\hline $\begin{array}{l}\text { GENERIC SURFACE } \\
\text { WATER CLASSIF. }\end{array}$ & $\begin{array}{l}\text { HYORAULIE } \\
\text { CONOUCTIVITY }\end{array}$ & $\begin{array}{l}\text { EFFECTIVE } \\
\text { POROSITY }\end{array}$ & $\begin{array}{l}\text { AYDRAULIC } \\
\text { GRAOIENT }\end{array}$ & $\begin{array}{l}\text { OISTANCE } \\
\text { SURFACE }\end{array}$ \\
\hline - & $(C M / S)$ & - & - & (METERS) \\
\hline 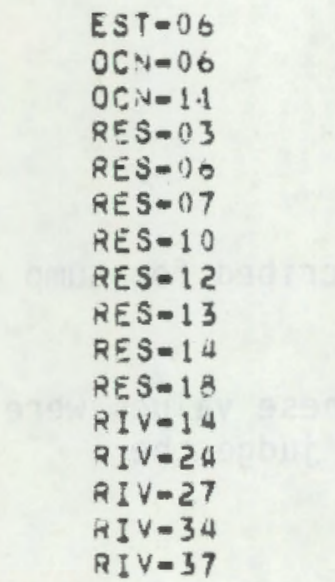 & $\begin{array}{l}0.10 E=02 \\
0.10 E=02 \\
0.47 E=02 \\
0.25 E=03 \\
0.17 E=02 \\
0.87 E=03 \\
0.10 E=02 \\
0.19 E=03 \\
0.10 E=02 \\
0.35 E=04 \\
0.10 E=01 \\
0.10 E=02 \\
0.110 E=02 \\
0.53 E=113 \\
0.50 E=04 \\
0.10 E=04\end{array}$ & $\begin{array}{l}0.01 \\
0.01 \\
0.01 \\
0.01 \\
0.05 \\
0.01 \\
0.01 \\
0.01 \\
0.01 \\
0.01 \\
0.01 \\
0.30 \\
0.01 \\
0.01 \\
0.01 \\
0.01\end{array}$ & $\begin{array}{l}0.120 \\
0.025 \\
0.060 \\
0.075 \\
0.025 \\
0.144 \\
0.220 \\
0.042 \\
0.060 \\
0.150 \\
0.033 \\
0.040 \\
0.043 \\
0.015 \\
0.070 \\
0.229\end{array}$ & $\begin{array}{r}76 . \\
122 . \\
3125 . \\
762, \\
198 . \\
457 . \\
320 . \\
360 . \\
183 . \\
76 . \\
91 . \\
152 . \\
976 . \\
1129 . \\
1829 . \\
107 .\end{array}$ \\
\hline
\end{tabular}

(a) These data are taken from: Niemczyk, S. J., unpublished, "A Summary of Subsurface Hydrogeological Information for Light Water Nuclear Reactor Sites," Oak Ridge National Laboratory, Oak Ridge, Tennessee. A discussion of this data base is provided in Section 1.4 . 
3.6.2 Generic Hydrogeologic Classification: Fractured-Solutioned Consolidated Carbonates

Total Number of Sites: 12

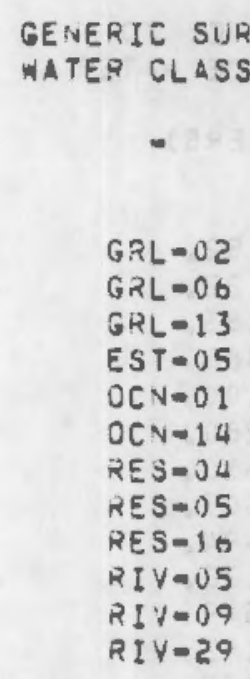

\begin{abstract}
HYOAAULIC
CONDUCTIVITY

\section{EFFECTIVE POROSITY}

$(C M / S)$

$0.28 E-02$

$0.10 E-02$

$0.10 E+00$

$0.10 E=0 ?$

$0.03 E-111$

$0.10 E+00$

$0.10 E-03$

$0.10 E+00$

$0.10 E+00$

$0.10 E+00$

$0.10 E+0 D$

$0.10 E+03$

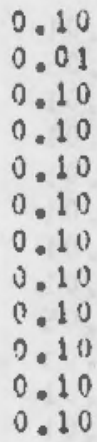

HYORAULIC GRADIENT

-
DISTANCE TO

SURFACE MATER

(METERS)

0.006
0.007
0.006
0.092
0.001
0.000
0.020
0.085
0.023
0.009
0.008
0.051

61.

229.

122.

133.

010.

183.

701.

122.

229.

2927.

549.

198.

3.6.3 Generic Hydrogeologic Classification: Porous Consolidated Carbonates

Total Number of Sites: 10

\begin{tabular}{|c|c|c|c|c|}
\hline $\begin{array}{l}\text { GENEPI I SURFACE } \\
\text { WATER CLASSIF. } \\
\text { - }\end{array}$ & $\begin{array}{l}\text { HYOQAULIC } \\
\text { CONDUCTIVITY } \\
\text { (CM/S) }\end{array}$ & $\begin{array}{l}\text { EFFECTIVE } \\
\text { POROSITY } \\
\text { - }\end{array}$ & $\begin{array}{c}\text { HYDRAULIC } \\
\text { GRAOIENT } \\
\text { - }\end{array}$ & $\begin{array}{l}\text { DISTAPICE TO } \\
\text { SURFACE NATER } \\
\text { (METERS) }\end{array}$ \\
\hline $\begin{array}{l}G R L=04 \\
G R L=05 \\
O C V=07 \\
E S T=01 \\
R E S=09 \\
\text { RES }=11 \\
R E S=? 0 \\
R I V=-1) 8 \\
R I V=17 \\
R I V=40\end{array}$ & $\begin{array}{l}0.10 E-J 2 \\
0.38 E=02 \\
0.10 E=01 \\
0.10 E=02 \\
0.97 E=04 \\
0.10 E=03 \\
0.23 E=05 \\
0.10 E+00 \\
0.10 E=03 \\
0.10 E=04\end{array}$ & $\begin{array}{l}0.10 \\
0.10 \\
0.10 \\
0.10 \\
0.00 \\
0.01 \\
0.01 \\
0.10 \\
0.10 \\
0.02\end{array}$ & $\begin{array}{l}0.001 \\
0.003 \\
0.002 \\
0.009 \\
0.004 \\
0.030 \\
0.016 \\
0.004 \\
0.006 \\
0.019\end{array}$ & $\begin{array}{r}732 . \\
61 . \\
793 . \\
2744 . \\
133 . \\
1067 . \\
244 . \\
457 . \\
2287 . \\
1998 .\end{array}$ \\
\hline
\end{tabular}


3.6.4 Generic Hydrogeologic Site: Porous Consolidated Silicates

Total Number of Sites: 13

\begin{tabular}{|c|c|c|c|c|}
\hline $\begin{array}{l}\text { GENERIC SURFACE } \\
\text { WATER CLASSIF. }\end{array}$ & $\begin{array}{l}\text { HYORAULIC } \\
\text { CONDUCTIVITY }\end{array}$ & $\begin{array}{l}\text { EFFECTIVE } \\
\text { POROSITY }\end{array}$ & $\begin{array}{l}\text { HYORAULIC } \\
\text { GRADIENT }\end{array}$ & $\begin{array}{l}\text { DISTANCE TO } \\
\text { SURFACE WATEQ }\end{array}$ \\
\hline - & $(C M / S)$ & - & - & (METERS) \\
\hline $\begin{array}{l}G R L=07 \\
G R L=10 \\
O C N=02 \\
R E S=17 \\
R I V=04 \\
R I V-10 \\
R I V=12 \\
R I V-20 \\
R I V=2 Z \\
R I V=23 \\
R I V=32 \\
R I V=36 \\
R I V=30\end{array}$ & $\begin{array}{l}0.10 E=04 \\
0.10 E=01 \\
0.10 E=02 \\
0.10 E=03 \\
0.10 E=04 \\
0.10 E=04 \\
0.10 E=04 \\
0.21 E=03 \\
0.10 E=01 \\
0.10 E=02 \\
0.15 E=03 \\
0.10 E=04 \\
0.72 E=03\end{array}$ & $\begin{array}{l}0.01 \\
0.05 \\
0.01 \\
0.01 \\
0.01 \\
0.01 \\
0.01 \\
0.01 \\
0.05 \\
0.05 \\
0.01 \\
0.01 \\
0.05\end{array}$ & $\begin{array}{l}0.010 \\
0.020 \\
0.083 \\
0.031 \\
0.003 \\
0.010 \\
0.001 \\
0.050 \\
0.007 \\
0.013 \\
0.010 \\
0.006 \\
0.014\end{array}$ & $\begin{array}{r}152 . \\
122 . \\
183 . \\
488 . \\
6100 . \\
1280 . \\
610 . \\
305 . \\
1494 . \\
122 . \\
549 . \\
183 . \\
1829 .\end{array}$ \\
\hline
\end{tabular}




\subsubsection{Generic Hydrogeologic Classification: Porous Unconsolidated Silicates}

Total Number of Sites: 41

\begin{tabular}{|c|c|c|c|c|}
\hline $\begin{array}{l}\text { GENERIC SURFACE } \\
\text { WATEA CLASSIF. } \\
\text { - }\end{array}$ & $\begin{array}{l}\text { HYORA:JLIL } \\
\text { CONDUCTIVITY } \\
\text { (CH/S) }\end{array}$ & $\begin{array}{l}\text { EFFECTIVE } \\
\text { POROSITY } \\
\text { - }\end{array}$ & $\begin{array}{l}\text { HYDRAULIC } \\
\text { GRADIENT }\end{array}$ & $\begin{array}{l}\text { DISTANCE TO } \\
\text { SURFACE AATER } \\
\text { (METERS) }\end{array}$ \\
\hline 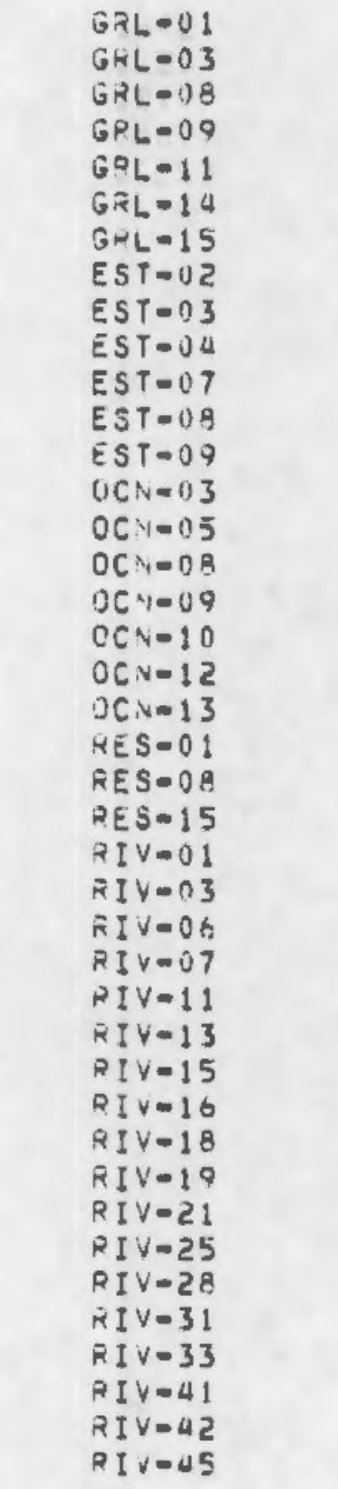 & $\begin{array}{l}0.21 E=01 \\
0.10 E=04 \\
0.10 E=02 \\
0.10 E=02 \\
0.17 E=02 \\
0.30 E=03 \\
0.10 E=02 \\
0.19 E=01 \\
0.14 E=01 \\
0.94 E=02 \\
0.94 E=02 \\
0.35 E=02 \\
0.10 E=04 \\
0.94 E=01 \\
0.95 E=01 \\
0.94 E=01 \\
0.33 E=01 \\
0.13 E=01 \\
0.70 E=01 \\
0.30 E+00 \\
0.10 E=02 \\
0.10 E=05 \\
0.10 E=01 \\
0.23 E+00 \\
0.97 E=03 \\
0.10 E=04 \\
0.20 E+00 \\
0.10 E=01 \\
0.10 E+00 \\
0.12 E=03 \\
0.10 E=02 \\
0.10 E+00 \\
0.10 E=04 \\
0.10 E=05 \\
0.50 E=04 \\
0.19 E+00 \\
0.00 E+00 \\
0.30 E=02 \\
0.10 E=04 \\
0.12 E=01 \\
0.35 E=01\end{array}$ & $\begin{array}{l}0.05 \\
0.05 \\
0.25 \\
0.25 \\
0.25 \\
0.01 \\
0.25 \\
0.25 \\
0.05 \\
0.05 \\
0.05 \\
0.05 \\
0.01 \\
0.25 \\
0.25 \\
0.25 \\
0.25 \\
0.05 \\
0.25 \\
0.25 \\
0.25 \\
0.20 \\
0.05 \\
0.25 \\
0.05 \\
0.05 \\
0.25 \\
0.25 \\
0.25 \\
0.25 \\
0.05 \\
0.25 \\
0.01 \\
0.02 \\
0.02 \\
0.25 \\
0.25 \\
0.25 \\
0.01 \\
0.25 \\
0.25\end{array}$ & $\begin{array}{l}0.020 \\
0.018 \\
0.040 \\
0.050 \\
0.003 \\
0.050 \\
10003 \\
0.010 \\
0.012 \\
0.021 \\
0.021 \\
0.005 \\
0.003 \\
0.001 \\
0.001 \\
0.001 \\
0.024 \\
0.010 \\
0.004 \\
0.000 \\
0.001 \\
0.098 \\
0.021 \\
0.002 \\
0.004 \\
0.050 \\
0.028 \\
0.017 \\
0.003 \\
0.002 \\
0.004 \\
0.054 \\
0.011 \\
0.026 \\
0.029 \\
0.010 \\
0.003 \\
0.002 \\
0.012 \\
0.002 \\
0.030\end{array}$ & $\begin{array}{r}244 . \\
152 . \\
6098 . \\
183 . \\
92 . \\
183 . \\
183 . \\
168 . \\
640 . \\
274 . \\
152 . \\
2043 . \\
489 . \\
366 . \\
457 . \\
2287 . \\
61 . \\
76 . \\
488 . \\
823 . \\
122 . \\
122 . \\
91 . \\
213 . \\
793 . \\
3963 . \\
152 . \\
76 . \\
1341 . \\
5183 . \\
335 . \\
107 . \\
6098 . \\
274 . \\
13 . \\
183 . \\
2690 . \\
4268 . \\
1768 . \\
3659 . \\
335 .\end{array}$ \\
\hline
\end{tabular}


3.6.6 Generic Hydrogeologic Classification: Fractured Consolidated Silicate (Shale)

Total Number of Sites: 5

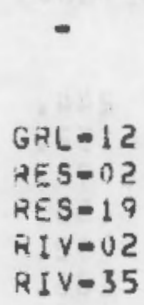

$G R L-12$

NE $5=02$

RES -19

$R ! V=02$

RIV $=35$

$0.10 E=U S$
$0.10 E=02$
$0.10 E=02$
$0.10 E=194$
$0.10 E=01$

0.01
0.01
0.01
0.01
0.01

AYORAULIC GRADIENT

DISTANCE TO

SURFACE WATER

-

(METERS)

0.005
0.005
0.014
0.015
0.039

396.

251.

915.

1708.

1250 . 


\subsection{REFERENCES}

Allard, B., H. Kipatsi, and B. Torstenfelt. 1978. "Adsorption of Long Lived Radionuclides in Clay and Rock, Part 2," Chalmers University of Technology, KBS Technical Report 98.

Ames, L.L. and J. E. McGarrah. 1980a. "Basalt-Radionuclide Distribution Coefficient Determinations FY-1979 Annual Report," PNL-3146, Pacific Northwest Laboratory, Richland, Washington.

Ames, L. L. and J. E. McGarrah. 1980b. "Investigation of Basalt-Radionuclide Distribution Coefficients: Fiscal Year 1980 Annual Report," RHO-BWI-C-108, Rockwell Hanford Operations, Richland, Washington.

Ames, L. L., J. E. McGarrah and B. A. Walker. 1981. "Basalt-Radionuclide Reactions: FY-1981 Annual Report," RH0-BW-CR-127P, Rockwell Hanford Operations, Richland, Washington.

Ames, L. L., J. E. McGarrah, B. A. Walker, and P. F. Salter. 1982. "Sorption of Uranium and Cesium by Hanford Basalts and Associated Secondary Smectite," Chem. Geol., 35, pp. 205-225.

Ames, L. L., J. E. McGarray, B. A. Walker, and P. F. Salter. 1983a. "Uranium and Radium Sorption on Amorphous Ferric Oxyhydroxide," Chem. Geol., 40, pp. 135-148.

Ames, L. L., J. E. McGarrah, and B. A. Walker. 1983b. "Radionuclide SorptionDesorption Kinetics on Umtanium Basalt and Associated Minerals: FY-82 Annual Report," RHO-BW-CR-192P, Rockwell Hanford Operations, Richland, Washington.

Amy, J. P. 1971. "Contribution to the Study of the Migration of Ruthenium-106 in Soils," RFP-Trans-140.

Andersson, K., B. T. Torstenfelt, and B. Allard. 1982. "Sorption Behavior of Long-Lived Radionuclides in Igneous Rock," IAEA-SM-257/20 International Atomic Energy Agency, Vienna.

Astgn, S. R. and E. K. Duursma. 1973. "Concentration Effects on ${ }^{137} \mathrm{Cs},{ }^{65} \mathrm{Zn}$, ${ }^{60} \mathrm{C}$, and ${ }^{106} \mathrm{Ru}$ Sorption by Marine Sediments with Geochemical Implications," Neth. J. of Sea Res. 6, pp. 225-240.

Baetsle, L. and P. Dejonghe. 1962. "Investigations on the Movement of Radioactive Substances in the Ground Part III: Practical Aspects of the Program and Physiocochemical Considerations," in: Ground Disposal of Radioactive Wastes. TID-7628, pp. 198-210.

Baetsle, L. H., P. Dejonghe, W. Maes, E. S. Simpson, J. Souffriau, and P. Staner. 1964. "Underground Radionuclide Movement," EURAEC-703. 
Barney, G. S. 1982. "FY 1981 Annual Report: Radionuclide Sorption on Basalt Interbed Materials," RHO-BW-ST-35P, Rockwell Hanford Operations, Richland, Washington.

Barney, G. S. and P. D. Anderson. 1979. "The Kinetics and Reversibility of Radionuclide Sorption Reactions with Rocks - Progress Report for 1978," in Task 4 Second Contractor Information Meeting, Vol. II (R. J. Serne editor), PNL-SA-7352 Vol. II, Pacific Northwest Laboratory, Richland, Washington, Pp. 161-218.

Barney, G. S. and G. E. Brown. 1980. "The Kinetics and Reversibility of Radionuclide Sorption Reactions with Rocks," in Task 4 Third Contractor Information Meeting Vol. II, edited by J. F. Relyea, PNL-SA-8572, Pacific Northwest Laboratory, Richland, Washington, pp. 261-308.

Barney, G. S. and M. W. Grutzeck. 1977. "The Kinetics Reversibility of Radionuclide System Reactions with Rocks," RHO-ST-4 Rockwell Hanford Operations, Richland, Washington 99352.

Berak, L. 1963. "The Sorption of Microstrontium and Microcesium on the Silicate Minerals and Rocks," UJV-528-63.

Bovard, P., A. Grauby and A. Saas. 1968. "Chelating Effect of Organic Matter and Its Influence on the Migration of Fission Products," IN: Isotopes and Radiation in Soil Organic Matter Studies. CONF-680275, pp. 471-495.

Bowen, N. L. 1956. The Evolution of Igneous Rocks, Dover Publication, Inc., New York.

Cerrai, E., M. G. Mezzadri and C. Triulzi. 1969. "Sorption Experiments of Strontium, Cesium, Promethium, and Europium on Marine Sediment Samples," Energia Nucleare. 16(6), pp. 378-385.

Coleman, N. T., R. J. Lewis, and D. Craig. 1963. "Sorption of Cesium by Soils and its Displacement by Salt Solutions," Soil Science Society of America, Proceedings, pp. 290-294.

Coles, D. G., H. C. Weed and J. D. Tewhey. 1980. "Geochemical Studies of Sorption and Transport of Radionuclides in Rock Media," in Task 4 Third Contractor Information Meeting, Vol. 1, edited by J. F. Relyea, PNL-SA-8572, Pacific Northwest Laboratory, Richland, Washington, pp. 357-434.

Coles, D. C., and L. D. Ramspott. 1982. "Migration of Ruthenium in a Nevada Test Site Aquifer: Discrepancy Between Field and Laboratory Results," Science. 215(4537), pp. 1235-1236.

Collet, M., R. Maushart and P. Spaander. 1968. "Accumulation of Radioactive Materials by River Silt," In: Radiation Protection. Pt-2, W. S. Snyder et al. (eds), pp. 1343-9. 
Daniels, W. R., et al. 1981. "Laboratory Studies of Radionuclide Distributions Between Selected Groundwaters and Geologic Media, October 1, 1979-September 30, 1980," LA-8586-PR, Los Alamos Scientific Laboratory, Los Alamos, New Mexico.

Dosch, R. G. 1980. "Assessment of Potential Radionuclide Transport in SiteSpecific Geologic Formations," SAND 79-2468. Sandia National Laboratory, Alburquerque, New Mexico.

Dosch, R. G. and A. W. Lynch, 1978. "Interaction of Radionuclides with Geomedia Associated with the Waste Isolation Pilot Plant (WIPP) Site in New Mexico," SAND 78-0297. Sandia National Laboratory, Albuquerque, New Mexico.

Duursma, E. K. 1973. "Concentration Effects of ${ }^{137} \mathrm{Cs},{ }^{65} \mathrm{Zn},{ }^{60} \mathrm{Co}$, and ${ }^{106} \mathrm{Ru}$ Sorption by Marine Sediments with Geochemical Implications," Neth. J. of Sea Res. 6, pp. 225-240.

Duursma, E. K., P. Parsi and G. Statham. 1974. Fixation of Radionuclides with Time by Marine Sediments, IAEA-163. pp. 107-108.

Erda1, B. R., et al. 1979. "Laboratory Studies of Radionuclide Distributions Between Selected Ground Waters and Geologic Media," in Task 4 Second Contractor Information Meeting Vol. II, edited by R. J. Serne, PNL-SA-7352 Vol. Il, Pacific Northwest Laboratory, Richland, Washington, pp. 4-160.

Erdal, B. R., et al. 1980. "Laboratory Studies of Radionuclide Distribution Between Selected Ground Waters and Geologic Media," in Task 4 Third Contractor Information Meeting Vol. 1, edited by J. F. Relyea, PNL-SA-8571, Pacific Northwest Laboratory, Richland, Washington, pp. 435-525.

Erdal, B. R., et al. 1979. "Sorption-Desorption Studies on Argillite," LA-7455-MS Los Alamos Scientific Laboratory, Los Alamos, New Mexico.

Erdal, B. R., et al. 1979. "Sorption-Desorption Studies on Granite," LA 7456-MS, Los Alamos Scientific Laboratory, Los Alamos, New Mexico.

Essington, E. H. and H. Nishita. 1966. "Effect of Chelates on the Movement of Fission Products Through Soil Columns," Plant and Soil, 24, pp. 1-23.

Essington, E. H., H. Nishita and A. J. Steen. 1965. "Release and Movement of Radionuclides in Soils Contaminated with Fallout Material from an Underground Thermonuclear Detonation," Health Physics, 11, pp. 689-698.

Francis, C. W. and E. A. Bondietti. 1980. "Sorption of Long-Lived Radionuclide Species on Geologic Media FY79 Annual Report," in Task 4 Third Contract or Information Meeting, Vol. 1I, J. F. Relyea editor, PNL-SA-8572, Pacific Northwest Laboratory, Richland, Washington, pp. 81-133. 
Freeze, R. A. and J. A. Cherry. 1979. Ground Water, Prentice Hall, Inc. pp. 604 .

Garder, K. and 0. Skulberg. 1964. "Sorption Phenomena of Radionuclides to Clay Particles in River Water," Intern. J. Air Water Pollution. 8, pp. 229-41.

Gelhar, L. W., A. L. Gutjahr and R. J. Naff. 1979. "Stochastic Analysis of Macrodispersion in a Stratified Aquifer," Water Resources Res., 15(6), pp. 1387-1397.

Harwel1, M. A. 1980. "Reference Site Initial Assessment for a Salt Dome Repository," PNL-2955, Vol. 1, Pacific Northwest Laboratory, Richland, Washington.

Jacobs, D. G. 1962. "Cesium Exchange Properties of Vermiculite," Nuclear Sci. Eng., 12, pp. 285-292.

Jacobs, D. G. and T. Tamura. 1960. "The Mechanisms of Ion Fixation Using Radioisotopes Techniques," IN: 7th International Cong. of Soil Sci. II: 206-214.

Janzer, V. J., M. C. Goldberg, C. G. Angelo and W. A. Beetem. 1962. "Summary of Distribution Coefficients for Fission Products Between Ground Water and Rocks from Project Gnome," In: Hydrologic and Geologic Studies for Project Gnome. Part IV, U.S.G.S.

Kepak, F. 1966. "Sorption of the Radioisotopes ${ }^{35} \mathrm{~S},{ }^{131_{\mathrm{I}} \text { and }{ }^{106} \mathrm{Ru} \text { on }}$ Hydrated Oxides in Laboratory Columns," Collection Czechoslov. Chem. Commun. 31, pp. 3500-3511.

Kulikov, N. V. 1968. "Influence of Certain Complexons on Radioisotope Sorption by Soil," Tr. Inst. Ekol. Rast. Zknivotn. 61, pp. 21-5 (in Russia)

Kulikov, N. V. and I. V. Molchanova. 1972. Radioisotopes in the Soil Solution System. INIS-MF-887-3-, pp. 2-13 (in Russian).

Landstrom, 0. 1978. "In Situ Experiments on Nuclide Migration in Fractured Crystalline Rocks," KBS Technical Report 110 Stockholm, Sweden.

Lomenick, T. F., D. G. Jacobs and E. G. Struxness. 1967. "The Behavior of Strontium-90 and Cesium-137 in Seepage Pits at ORNL," Health Physics, 13, pp. 897-905.

Maclean, S. C., et al. 1979. "The Measurement of Sorption Ratios for Selected Radionuclides on Various Geologic Media," in Waste Isolation Safety Assessment Program, Task 4 Second Contractor Information Meeting, PNL-SA-7352 Vol. 1, pp. 187-230, edited by R. J. Serne. 
Matheron, G. and G. De Marsily. 1980. "Is Transport in Porous Media Always Diffusive?" Water Resources Res., 16(5), pp. 901-917.

McKinley, I. G. and J. M. West. 1981a. "Radionuclide Sorption/Desorption Processes 0ccurring During Groundwater Transport: Progress Report Detober 1979-December 1980," ENPU 81-6, Environmental Protection Unit, Harwel1 Laboratory, England.

Mckinley, I. G. and J. M. West. 1981b. "Radionuclide Sorption/Desorption Processes 0ccurring During Groundwater Transport: Progress Report JanuaryJune 1981," ENPU 81-14, Environmental Protection Unit, Harwell Laboratory, England.

McHenry, J. R. 1954. "Adsorption and Retention of Cesium by Soils of the Hanford Proj3ect," HW-31011, Hanford Works, Richland, Washington.

McHenry, J. R. 1955. "Adsorption and Retention of Strontium by Soils of the Hanford Project," HW-34499, Hanford Works, Richland, Washington.

McHenry, J. R. 1958. "Ion Exchange Properties of Strontium in a Calcareous Soil. Soil Science Society America, Proceedings," 22, pp. 514-518.

Meyer, R. E., et al. 1978. "Systematic Study of Nuclide Sorption on Select. Geologic Media," in Waste Isolation Safety Assessment Program Task 4 Contractor Information Meeting Proceedings, R. J. Serne editor, PNL-SA-6957, Pacific Northwest Laboratory, Richland, Washington, pp. 343-369.

Meyer, R. E. 1979. "Systematic Study of Metal Ion Sorption on Selected Geologic Media," in Task 4 Second Contractor Information Meeting Vol. 1, edited by R. J. Serne, PNL-SA-7352, Vol. 1, Pacific Northwest Laboratory, Richland, Washington, pp. 231-329.

Meyer, R. E. 1980. "Systematic Study on Nuclide Adsorption on Selected Geologic Media," in Task 4 Third Contractor Information Meeting Vol. II, J. F. Relyea editor, PNL-SA-8571, Pacific Northwest Laboratory, Richland, Washington, pp. 1-79.

Neretnieks, I. 1980. "Diffusion in the Rock Matrix: An Important Factor in Radionuclide Retardation?" Journal of Geophysical Research, 85, pp. 4379-4387.

Niemczyk, S. J. Unpublished. "A Summary of Subsurface Hydrogeological Information for Light Water Nuclear Reactor Sites," Oak Ridge National Laboratory, Oak Ridge, Tennessee.

Molz, F. J., 0. Güven and J. G. Melville. 1983. "An Examination of ScaleDependent Dispersion Coefficients," Ground Water, 21(6), pp. 715-725. 
Nork, W. E. and P. R. Fenske. 1970. "Radioactivity in Water - Project Rulison," NV0-1229-131.

Nork, W. E., E. J. Forslow and E. H. Essington. 1971. "Radioactivity in Water, Central Nevada Test Area," NVO-1229-175.

Onishi, Y., et al. 1981. "Critical Review: Radionuclide Transport, Sediment Transport, and Water Quality Mathematical Modeling; and Radionuclide Adsorption/Desorption Mechanisms." PNL-2901, Pacific Northwest Laboratory, Richland, Washington.

Pettyjohn, F. J. 1975. Sedimentary Rocks," Third Edition Harper \& Row, New York.

Prout, W. E. 1958. "Adsorption of Radioactive Wastes by Savannah River Plant Soil," Soil Science. 86, pp. 13-17.

Prout, W. E. 1959. "Adsorption of Fission Products by Savannah River Plant Soi1," DP-394, DuPont, Savannah River, South Carolina.

Randon, D. 1967. "Mechanisme de la Contamination Radioactive des Roches Consildees Impermeable ou tres peu Permeable," Disposal of Radioactive Wastes into the Ground. Proceedings of a symposium, Vienna IAEA, p. 179.

Relyea, J. F. and R. J. Serne. 1979. "Controlled Sample Program Publication Number 2 Interlaboratory Comparison of Batch Kd Values," PNL-2872, Pacific Northwest Laboratory, Richland, Washington.

Relyea, J. F., R. J. Serne, D. Rai and M. J. Mason. 1978. "Batch Kd Experiments with Common Minerals and Representative Ground Waters," in Waste Isolation Safety Assessment Program Task 4 Contractor Information Meeting Proceedings, R. J. Serne editor, PNL-SA-6957, Pacific Northwest Laboratory, Richland, washington, pp. 125-150.

Relyea, J. F., et a1. 1979. "Batch Kd Experiments with Common Minerals and Representative Ground Waters," in Task 4 Second Contractor Information Meeting Vol. II, R. J. Serne editor, PNL-SA-7352, Vol. II, Pacific Northwest Laboratory, Richland, Washington, pp. 259-330.

Rhodes, D. W. 1957. "The Effect of pH on the Uptake of Radioactive Isotopes from Solution by a Soil," Soil Science Society of America, Proceedings. 21, pp. 389-392.

Rhodes, D. W. and J. L. Nelson. 1957. "Disposal of Radioactive Liquid Wastes from the Uranium Recovery Plant," HW-54721, Hanford Works, Richland, Washington.

Routson, R. C. 1973. "A Review of Studies on Soil-Waste Relationship the Hanford Reservation from 1944 to 1967," BNWL-1464, Battelle-Northwest, Richland, Washington. 
Sawhney, B. L. 1964. "Sorption and Fixation of Microquantities of Cesium by Clay Minerals: Effect of Saturating Cations," Soil Science Society America, Proceedings, 28, pp. 183-186.

Schell, W. R., T. H. Sibley, A. Nevissi and A. Sanchez. 1979. "Distribution Coefficients for Radionuclides in Aquatic Environments. Il. Studies on Marine and Freshwater Sediment Systems Including the Radionuclides 106-Ru, 137-Cs and 241 Am," Second Annual Research Progress Report, NUREG/CR-0802. (a)

Schell, W. R., T. H. Sibley, A. Sanchez and J. R. Clayton, Jr. 1980. "Distribution Coefficients for Radionuclides in Aquatic Environments, III. Adsorption and Desorption Studies of ${ }^{106} \mathrm{Ru},{ }^{137} \mathrm{Cs}, 241_{\mathrm{Am}},{ }^{85} \mathrm{Sr}$ and $237 \mathrm{Pu}$ in Marine Freshwater Systems," NUREG/CR-0803.'(a)

Seitz, M. G., et al. 1978. "Studies of Nuclear-Waste Migration in Geologic Media," Annual Report October 1977-September 1978. ANL-79-30. Argonne National Laboratory, Argonne, Illinois.

Seitz, M. G., et a1. 1979. "Transport Properties of Nuclear Waste in Geologic Media," in Waste Isolation Safety Assessment Program," Task 4 Second Contractor Information Meeting, PNL-SA-7352 Vol. 1 pp. 405-508, edited by R. J. Serne.

Serne, R. J. and J. F. Relyea. 1981. "The Status of Radionuclide SorptionDesorption Studies Performed by the WRITE Program," in The Technology of High-Level Nuclear Waste Disposal. P. L. Hofmann, Editor D0E/TIC-4621 TVol. 1). Technical Information Center, Springfield, Virginia.

Serne, R. J., et al. 1977. "Batch Kd Measurements of Nuclides to Estimate Migration Potential at the Proposed Waste Isolation Pilot Plant in New Mexico," PNL-2448, Pacific Northwest Laboratory, Richland, Washington.

Skagius, K., et al. 1982. "A Study of Strontium and Cesium Sorption on Granite," Nuclear Technology (59), pp. 302-313.

Simmons, C. S. 1982. "A Stochastic-Convective Transport Representation of Dispersion in One-Dimensional Porous Media Systems," Water Resources Res. 18(4), pp. 1193-1214.

Tamura, T. 1972. "Sorption Phenomena Siginificant in Radioactive - Waste Disposal," In: Underground Waste Management and Environmental Implications, T. D. Cook (ed.). Am. Assoc. Petrol. Geol. pp. 318-330.

(a) Schmalz, B. L. 1972. "Radionuclide Distribution in Soil Mantle Lithosphere as a Consequence of Waste Disposal at the National Testing Station," ID0-10049. 
Tamura, T. 1963. "Cesium Sorption Reactions as Indicator of Clay Minerals Structures," IN: Proc. Nat1. Conf. Clays, Clay Minera1s, 10, pp. 389-398.

Tamura, T. 1963. "Selective Ion Exchange Reactions for Cesium and Strontium by Soil Minerals," Colog. Intern. Retention Migration Ions Radioactifs Sols, Saclay, pp. 95-104.

Tamura, T. 1964. "Reactions of Cesium-137 and Strontium-90 with Soil Minerals and Sesquioxides," ORNL-P-438, Oak Ridge National Laboratory, Oak Ridge, Tennessee.

, and D. G. Jacobs. 1960. "Structural Implications in Cesium Sorption," Hea th Phys., 5, pp. 149-154.

, and 1961. "Improving Cesium Selectivity of Bentonites by Heat Treatment," Health Physics, 5, pp. 149-154.

Tewhey et al. 1978. "Studies of Radionuclide Availability and Migration at the Nevada Test Site Relevant to Radioactive Waste Disposal," in Task 4 Second Contractor Information Meeting, Vol. I, R. J. Serne editor, PNL-SA-7352 Vol. I, Pacific Northwest Laboratory, Richland, Washington, Pp. 187-231.

Torstenfelt, B., et a1. 1982. "Sorption of Strontium and Cesium on Rocks and Minerals," Chem. Geol. 36(1/2), pp. 123-137.

Tschurlovits, M. 1979. "Laboratory Investigations on the Retention of Fission Products by Granites," in Proceedings of the Workshop on the Migration of Long-Lived Radionuclides in the Geosphere Brussels 29-31 Jan 1979 pp. 225-231 Published by OECD, Paris, France.

Walton, F. B., et al. 1982. "The Determination of Nuclide-Geologic Media Reaction Kinetics Using Mixing - Cell Contactors," Chem. Geol. 36(1/2), pp. 155-178.

Wilding, M. W. and D. W. Rhodes. 1963. "Removal of Radioisotopes from Solution by Earth Materials from Eastern Idaho," ID0-14624.

Yeh, G. T. 1981. "AT123D: Analytical Transient One-, Two-, and ThreeDimensional Simulation of Waste Transport in the Aquifer System," ORNL-5602, Oak Ridge National Laboratory, Oak Ridge, Tennessee. 


\subsection{GROUND-WATER CONTAMINANT MITIGATION TECHNIQUES}

\subsection{TYPES OF MITIGATION TECHNIQUES}

There are two general classes of ground-water contaminant mitigation alternatives that may be appropriate, in individual cases, for application to ground-water contamination resulting from a severe commercial nuclear power plant accident. These two classes are: 1) static or passive techniques, and 2) dynamic or active strategies. The individual techniques or schemes that comprise each class are designed to interact directly with ground-water flow and consequently contaminant transport to achieve an acceptable level of contaminant mitigation. Indirect ground-water contaminant mitigation schemes that involve redesign of reactor containment structures or manipulation of reactor core material (e.g., in situ vitrification) are not considered.

\subsubsection{Static Ground-Water Contaminant Mitigation Techniques}

Static or passive mitigation techniques are typically engineered/constructed barriers to ground-water flow and consequently contaminant transport. The primary objective of a constructed barrier is to redirect the ground-water flow away from potentially accessible surface environments (e.g., surface water bodies, production well fields, etc.). Achievement of this objective usually results in ground-water being forced to follow more circuitous routes with longer travel times. The longer travel times provide longer time for the natural decay of radionuclides. Also, there may be additional benefits to longer travel times through increased opportunity for contaminant retardation.

Constructed barriers are considered static ground-water contaminant mitigation technqiues because once in-place they are not readily adaptable to changing conditions of ground-water contamination. Barriers are also considered passive rather than active because they do not directly influence the ground-water contaminant concentrations as, for instance, pumping of ground water for surface treatment would directly infleunce contaminant concentrations. Engineered/constructed barriers do not normally require a significant amount of maintenance. When properly designed and constructed these types of barriers (except steel sheet piping) are considered, from a practical viewpoint, to be permanent. However, constructed barriers do not last indefinitely. Barriers tend to be more costly than other mitigation alternatives and the time for construction can be significant.

Three basic types of constructed barriers were analyzed for their feasibility and suitability as mitigation measures for ground-water contamination resulting from a severe power plant accident. The barriers considered are grout curtain cut-off walls, slurry trench cut-off walls, and steel sheet piling. Table 4.1.1-1 provides a further breakdown of the static ground-water contaminant mitigation techniques. Only steel sheet pilings are considered because other materials (such as wood or reinforced concrete) are not capable of forming a watertight seal to an effective depth. Reinforced concrete pilings are not normally placed to depths that would allow complete vertical 
TABLE 4.1.1-1. Static Ground-Water Contaminant Mitigation

Techniques Considered for Application to

Severe Power Plant Accidents

1. Grout curtain cut-off walls

1a. Particulate grouts: Cement-based grouts

1b. Non-particulate grouts: Chemical-based grouts

2. Slurry trench cut-off walls

2a. Soil-bentonite slurry trenches

2b. Cement-bent onite slurry trenches

2c. Lean concrete slurry trenches

2d. Vibrating beam slurry trenches

3. Steel sheet piling

cut off of ground-water flow. Each of the ground-water flow barriers listed in Table 4.1.1-1 are analyzed in detail as to their engineering feasibility for specific applications.

Extensive monitoring is required during and following construction in order to verify performance characteristics of constructed barriers.

\subsubsection{Dynamic Ground-Water Contaminant Mitigation Techniques}

Dynamic or active ground-water contaminant mitigation techniques are primarily conceptual strategies for actively (i.e., directly) influencing the state of ground-water contamination. Active influence is accomplished by either changing the ground-water flow regime by pumping and/or injection, directly treating the contaminated ground-water or combinations of both approaches. Active ground-water contaminant mitigation schemes are generally better able to respond to changes in the state (i.e., contaminant plume velocity, concentration, etc.) of ground-water contamination than constructed barriers. However, typicallily associated with dynamic schemes are relatively high maintenance costs. Also extensive monitoring feedback is usually recommended to insure adequate performance.

The dynamic ground-water contaminant mitigation schemes may be applicable as temporary mitigation measures while permanent measures are being designed and constructed. Also, several of the dynamic schemes may be most effective in combination with permanent barriers. The design of a dynamic mitigation scheme may necessarily require surface handling of contaminated ground water. This circumstance may cause significant safety problems related to handling, transporting, treating, and disposing of contaminated ground water.

The dynamic ground-water contaminant mitigation schemes analyzed for their feasibility and applicability to mitigate the effects of ground-water contamination following a severe power plant accident are presented in Table 4.1.2-1. 
TABLE 4.1.2-1. Dynamic Ground-Water Contaminant Mitigation Techniques Considered for Application to Severe Power Plant Accidents

1. Ground-water withdrawal for potentiometric surface adjustment

1a. Prevent discharge to receiving stream

1b. Prevent saturated contact with core melt mass

1c. Prevent contamination of leaky aquifers

2. Ground-water withdrawal and/or injection for contaminant plume control

2a. Withdrawal and injection

2b. Withdrawal without injection

2c. Withdrawal with surface treatment and recharge

2d. Injection only

3. Subsurface drains

4. Selective filtration via permeable treatment beds

5. Ground freezing

6. Air injection

\subsection{FEASIBILITY CRITERIA FOR GROUND-WATER CONTAMINANT MITIGATION TECHNIQUES}

There are several important considerations for determining the suitability of mitigative techniques for ground-water contamination resulting from a severe power plant accident. These considerations encompass: 1) design, 2) construction, 3) performance, and 4) implementation issues related to each mitigation measure. These issues are addressed in specific detail for each of the mitigation alternatives. A brief overview of each issue follows.

\subsubsection{Design Considerations}

Design considerations include the variations in specific types of techniques (e.g., particulate versus non-particulate grout), appropriate host geologic media, size, location, and orientation of the various mitigation measures and design limitations. Passive ground-water barriers (i.e., slurry trenches, grout curtains, and steel sheet piling cut-offs) have better defined engineering design considerations than typically do dynamic ground-water contaminant mitigation strategies which are more conceptual in design (i.e., less rigorously defined from an engineering standpoint).

\subsubsection{Construction Considerations}

Construction considerations are a major concern in determining the feasibility of specific mitigation strategies. Construction considerations include appropriate methods of installation, limitations of construction methods, 
equipment required for construction, etc. Several of the mitigation strategies (i.e., slurry trenches, subsurface drains, and permeable treatment beds) require extensive excavation. Trenching is realistically feasible only in unconsolidated media and soft, easily ripped semi-consolidated media. The strategies requiring extensive trenching are not practically feasible in a consolidated medium such as a crystalline silicate medium, for example.

Several of the dynamic mitigation strategies require well construction. The type of well system developed (i.e., well point versus deep well) can have a significant impact on the overall performance of a particular mitigation alternative.

Grouting and ground freezing operations require special expertise and equipment which may not be readily available. Permeable treatment beds require a permeable material with high ion exchange capacity. Naturally occurring glauconite greensands have been recommended but suitable deposits of glauconite may exist only in the Mid-Atlantic region of the U.S. This may preclude application (because of transportation costs) in other regions of the U.S.

Similar to design considerations, construction considerations are a function of the mitigation technique itself, the physical properties of the site, and the accident scenario.

\subsubsection{Performance Considerations}

Performance considerations include permeability reduction (if appropriate to the technique), durability, continuity, and contaminant compatibility. In a practical sense, the performance is related to how well the strategy can achieve and maintain an acceptable level of ground-water quality at predetermined locations. Embodied in this philosophy is the protection of accessible environments such as surface water bodies or producing ground-water well fields.

All of the performance considerations (e.g., permeability reduction) vary with time. For instance, steel sheet piling may be expected to corrode significantly in approximately 40 years thus reducing its effective performance. Durability is closely related to permeability reduction and maintenance requirements. How long a barrier will perform as designed is a function of quality control during construction and ground-water chemistry. For example, cement-based constructed barriers will lose their integrity more rapidly in a saltwater environment or if exposed to freeze/thaw cycles. Also, sulphate attack on concrete can lead to a loss of integrity. Most, if not all, of the dynamic mitigation strategies are temporary and their design with respect to the overall mitigation plan should reflect this condition.

\subsubsection{Implementation Considerations}

In determining the engineering feasibility of ground-water contaminant mitgation schemes implementation considerations play a key role. The implementation considerations include: 
1. Installation/construction time,

2. Cost,

3. Equipment mobilization,

4. Toxicity (some chemical grouts are highly toxic), and

5. Safety of workers.

Difficulty arises in analyzing these issues in a generic sense however, because of their site-specific and site dependent nature. Unit values for the estimated time required to perform a specific task (e.g., well drilling) and associated cost are provided as available. The EPA has estimated the total cost of hypothetically designed mitigation schemes involving several of the techniques analyzed herein. EPA's estimates are included for comparison of alternative methods. In other instances, only very general time for installation, relative to other techniques, is provided.

Equipment mobilization requirements are not only dependent on the mitigation strategy employed but also on the site configuration and geographical location of the site. Standard excavating and/or drilling equipment is used to construct most ground-water contaminant mitigation measures but specialty equipment is required for grouting and ground freezing. Unobstructed right-ofway must be provided for drilling and excavating equipment and subsurface obstacles such as utility services must be avoided by mitigation techniques involving trenching or extensive drilling.

Worker safety during the installation and maintenance of a ground-water contaminant mitigation scheme is of primary concern. However, worker exposure to radiation resulting from atmospheric releases or diffusion of vapor through the unsaturated soil column would be extremely site sensitive and accident specific. Meteorological conditions at the time of the atmospheric release of radiation would greatiy influence transport and deposition rates of atmospheric contaminants in the vicinity of the plant. Due to the (in general) several orders of magnitude higher transport properties of airborne contaminants versus ground-water transport of contaminants a time delay from the occurrence of an accident and the implementation of a ground-water contaminant mitigation scheme may enhance worker safety without sacrificing mitigation performance. In most cases however, the closer to the contaminant source the mitigation scheme is implemented, in general, the more cost effective the scheme will be. A sitespecific thorough investigation of ground-water flow and contaminant transport should be conducted in relation to the accident scenario to determine the time delay that can be tolerated in implementing a ground-water contaminant mitigation strategy if one is necessary.

Another safety issue involves the safe handling, treatment, and disposal of contaminated ground water. Several of the mitigation schemes require above ground handling of contaminated ground water thus requiring special care to insure the safety of workers and integrity of the surface environment. A related concern is the secondary contamination of drilling and pumping equipment in prolonged contact with contaminated ground water.

In summary, the implementation considerations for ground-water contaminant mitigation schemes are extremely important in the overall assessment of the 
applicability of each measure. However, these issues are also highly sensitive to specific and individual site characteristics ranging from the physical plant configuration, to local meteorological conditions at the time of the accident, to the time history of events of the accident itself. Therefore it is difficult, if not impossible, to address these issues in a generic manner. In the analysis of individual mitigation techniques each implementation issue (if relevant) is addressed to a level of detail consistent with the generic nature of this study.

\subsection{ANALYSIS OF STATIC GROUND-WATER CONTAMINANT MITIGATION TECHNIQUES}

The static mitigation techniques analyzed for their applicability to mitigate the effects of a severe power plant accident on ground-water quality are constructed barriers to ground-water flow. The primary differenes among these interdiction techniques are their method of construction and composition. They all divert ground-water flow in a similar passive manner.

The three barriers to ground-water flow analyzed are grout curtain cutoffs, slurry trenches, and sheet piling cut-offs. The fundamental purpose of each technique is to redirect ground-water flow and consequently contaffinant transport (if placed down-gradient from the contaminant source) away from accessible surface environments of concern. From an engineering standpoint these barriers, except sheet piling cut-offs, are considered permanent even though over time their performance (i.e., imperviousness) will deteriorate. Their ability to redirect ground-water flow becomes increasingly impaired as their permeability increases.

of the static ground-water contaminant mitigation techniques considered, grouting is the most generally applicable across all generic hydrogeologic site classifications. However, grouting operations can be expensive and time consuming plus special expertise and equipment is necessary for construction of grout curtain cut-offs. Slurry trench construction requires excavation which limits application to unconsolidated media or soft, semi-consolidated media and also limits the depth to which a slurry trench can be installed. Sheet piling application is also limited to unconsolidated host materials.

Constructed barriers to ground-water flow placed transverse to the direction of flow have the propensity to "backing-up" water in unconfined aquifers. A low permeability barrier may cause a "bathtub effect" immediately up-gradient from the barrier under certain flow and ground-water recharge and conditions. Depending on the specific circumstances giving rise to the "bathtub effect" pumping may be required to control the ground-water mounding. If the barrier is placed up-gradient from the contaminant source uncontaminated water may be forced to the surface but cause little concern. However, if a "bathtub effect" causes contaminated water to rise to the surface, then a ground-water dewatering scheme (Section 4.4.1) should be implemented. In confined flow situations, a constructed barrier may cause an increase in the hydraulic head immediately up-gradient from the barrier. The increased head may cause increased vertical leakage downward with the potential from contaminating lower aquifers. In this instance a reduction in head through ground-water withdrawal maybe advisable. In any event, the creation of a 
"bathtub effect" resulting from an engineered barrier and the potential consequences would be an integral part of the site-specific analysis of the performance of the mitigative strategy. Control or reduction of ground-water mounding would depend on site-specific factors including level of contamination, degree of mounding, ground-water discharge opportunities, and the plant configuration. As a final note, even if the contaminant source was totally contained, the potential for ground-water mounding would exist from local precipitation percolating to the water table.

\subsubsection{Grouts}

Grouting is the process of filling soil voids and/or rock cavities and fissures with some type of stabilizing material which acts as a sealing agent and thereby reduces soil/rock permeability. The stabilizing material, or grout, is injected into the geologic medium in the liquid phase by various mechanisms and, upon curing, results in the increased strength of the host material. Permeability reduction is achieved by consolidation and densification of the grouted material.

There are many grouting mechanisms and a wide variety of grouts exhibiting varied in-place mechanical properties. The choice of grout penetration mechanisms depends largely on the properties of the host material and the purpose of the treatment. Within the context of this study, the grout treatment purpose is to develop ground-water cut-offs to control the lateral movement of radionuclides through the geologic medium under consideration. Structural stability and strength of the resulting soil-grout complex are of lesser importance. The choice of grout material is dependent on its rheological behavior, particularly viscosity, rigidity, and granular state (Harris et al. 1982a).

\subsubsection{Grout Penetration Mechanisms}

There are five basic grouting mechanisms (Attewell and Farmer 1976):

1. Permeation Grouting - Even injection into soil or rock pore spaces resulting in a series of cylinders around the grout sources. Successive grout applications (i.e., primary, secondary, tertiary, etc.) result in the formation of a reduced permeability ground-water cut-off. Applicability - pervious sands or gravels; porous rock

2. Fissue Grouting - Well-dispersed, water-cement grout injection into fissures. High pressures are often used to slightly enlarge (i.e., widen) the fissures to facilitate passage of the grout. Subsequent deposition of cement particles is relied upon to "silt up" the fissures. Applicability - fissured rock and layered soils having a low intrinsic permeability.

3. Fracture Grouting - Hydrofracture in vicinity of grout injection source to increase penetration rates. Applicability - low or variable permeability rocks and soils 
4. Compaction Grouting - High pressure injection of grout with high solids content with high penetration characteristics. Compaction grouting is also referred to as consolidation grouting. Applicability - Loose, unconsolidated soils or sands.

5. Bulk Grouting - Stabilization of large cavities such as caves or abandoned mine works. Applicability - large subterranean cavities and voids.

Grouts are designed to penetrate through the void space of the host material. Penetration grouting requires grouts composed of portland cement or finegrained clays such as bentonite or non-particulate, synthetic chemicals. Cement-based grouts are used primarily for grouting very coarse sands and gravels. Non-particulate grouts may be used to penetrate fine-grained host material (Dunn et al. 1980).

\subsubsection{Types of Grouts}

Grouts are normally dividied into two groups: 1) particulate grouts, and 2) non-particulate grouts. Particulate grouts are subdivided into cement grouts and clay grouts. Non-particulate grouts (often referred to as chemical grouts) are subdivided into silicate grouts and organic polymers (Attewell and Farmer 1976).

The most important properties of grouts related to their flow and consequently permeation of the host material are (Attewell and Farmer 1976):

1. Size of particles,

2. Viscosity, and

3. Shear strength.

Once the grout has been successfully injected its set properties become important considerations. Grout set properties relate to permeability reduction, strength and durability. There is of ten a relationship between strength and viscosity of grouts within particular subcategories. A grout with a high strength is usually denser and more viscous as a fluid than is a lower strength grout (Attewell and Farmer 1976). Table 4.3.1-1 presents a summary of the major types of grouts currently in use.

TABLE 4.3.1-1. Types of Grouts (Source: Attewell and Farmer 1976)

\begin{tabular}{lll} 
Group & Type & Composition \\
\hline Cement & Cement Suspension & water, cement (ratio $>1)$ \\
Grouts & Cement slurry & water, cement (ratio $<1)$ \\
& Sand-cement & water, cement, sand \\
& Flyash-cement & water, cement, flyash \\
& Clay-cement & water, cement, bentonite \\
& Alum-cement & water, cement, aluminium \\
& & sulphate
\end{tabular}


TABLE 4.3.1-1. (Cont ' $d$ )

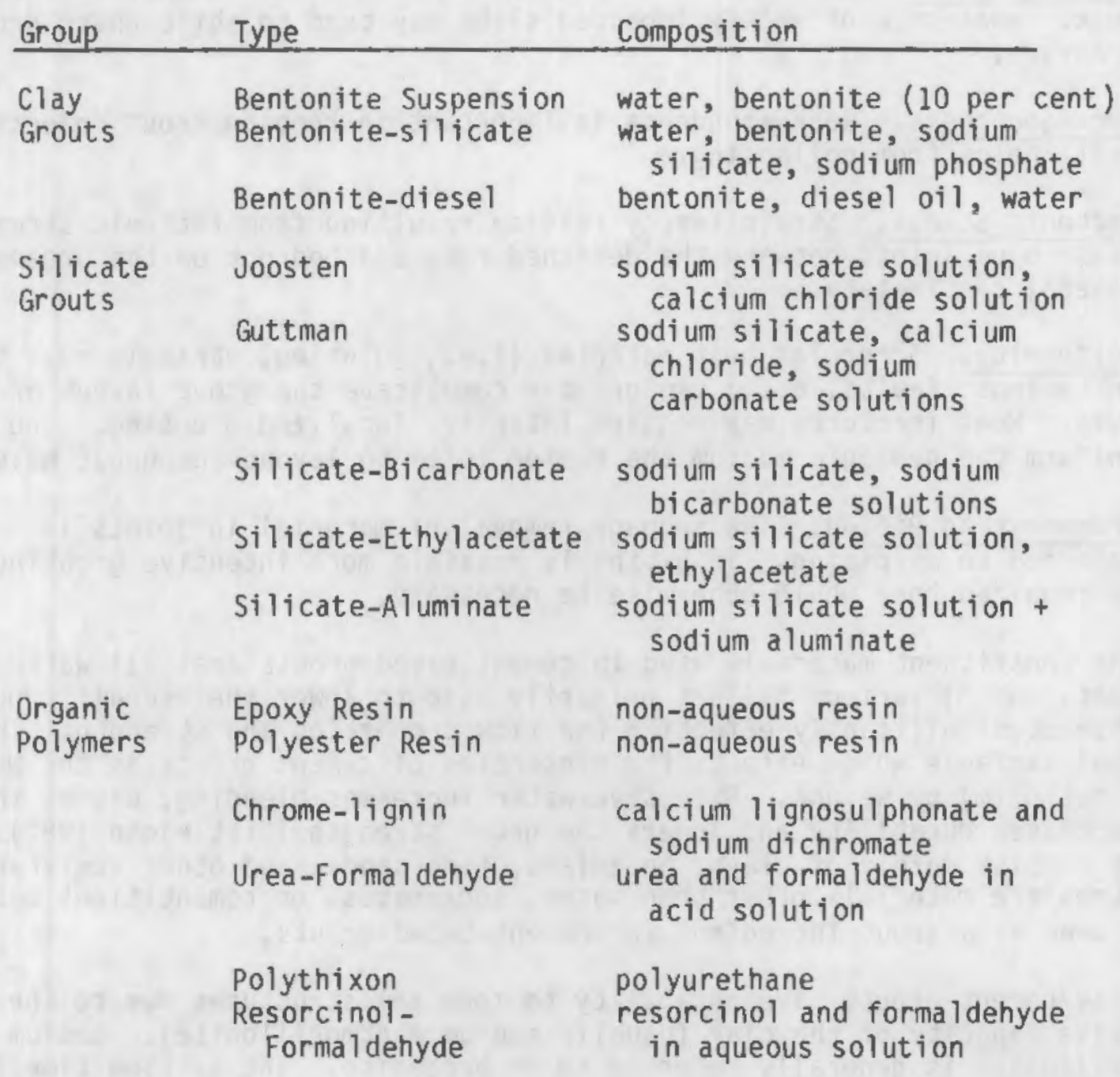

4.3.1.3 Design Considerations for Particulate (Cement and Clay) Grouts

The physical properties of the host geologic medium play a major role in the design and construction of cement grout cut-offs. Houlsby (1982a) lists eight effects of geology on cement grouting:

1. Spacing of Open Joints. Widely spaced joints make grouting easier while close spacing can lead to surface leaks and patchy grouting.

2. Size of Open Joints. Joints wider than $2 \mathrm{~mm}$ assist grout penetration. Joints wider than $6 \mathrm{~mm}$ inhibit proper tightening to grout refusal. Conversely, joints tighter than $0.5 \mathrm{~mm}$ make penetration difficult.

3. Direction of Open Joints. An average dip between $30^{\circ}$ and $60^{\circ}$ is easiest to intercept by vertical grout holes and is less likely to permit rock movement than a more vertical or horizontal dip. 
4. Rock Strength. Rock should be massive, tough and well-anchored to bedrock. Weak rock or weakly imbedded slabs may tend to shift under grouting pressure.

5. Rock Soundness. Rock soundness is important in keeping grout injection drill holes from collapsing.

6. Tectonic Stress. Strain energy release resulting from tectonic stress can cause open joints between the detached rock and bedrock on the order of several centimeters.

7. Uniformity. Irregular host material (i.e., jointing, variable rock types, intrusions, faults, etc.) can greatly complicate the grout layout procedure. Weak fractures may require intensive localized grouting. The more uniform the geologic medium the easier it is to layout the grout holes.

8. Proneness to piping. The seepage removal of material in joints is referred to as piping. If piping is possible more intensive grouting may be required than would otherwise be necessary.

The constituent materials used in cement-based grouts are: 1) water, 2) cement, and 3) various fillers primarily used to lower the overall grout cost without significantly effecting the flow properties and strength. The principal variable which effects the properties of cement grouts is the water/ cement ratio $(\omega)$ by weight. Excessive water increases bleeding, causes shrinkage, decreases durability and lowers the grout strength (Littlejohn 1982). Fillers consist mainly of clays, pozzolans, fine sands, and other admixtures. Admixtures are materials other than water, aggregates, or cementitious materials, used as a grout ingredient for cement-based grouts.

Clay/cement grouts have an ability to form gel structures due to the absorptive capacity of the clay (usually sodium montmorillonite). Sodium montmorillonite is generally referred to as bentonite. The setting time for bentonite/cement grouts is not well-defined and strength development is slow (Littlejohn 1982). Normally within 24 hours the clay/cement grout sets up to a strength of soft to firm clay (Harris et al. 1982a). In clay/cement grouts where high proportions of clay are used (e.g., 50 percent clay content) the clay filler increases the volume yield per unit weight of material thus reducing the cost in relation to low clay/cenent ratio grouts with lower volume yields per unit weight.

Pozzolans such as naturally occurring finely ground shale, pumicite, and diatomite or artificially produced flyash and ground blast furnace slag are not cementitious but react with free lime cement (in the presence of water) to form a cementitious compound (Littlejohn 1982). Pozzolans are primarily used as cheap bulk fillers for large cavity grouting where strength may not be of great concern.

Sand fillers are used in grouts requiring high frictional shear strength. These grouts typically have a low water content. Sand/cement ratios are usually limited to a maximum of three parts sand to one part cement to maintain 
particle suspension (Littlejohn 1982). Occasionally admixtures are combined with grouts to alter their flow, or set properties. They should not be used indiscriminately however, and are not a substitute for good grout practices (Littlejohn 1982).

\subsubsection{Design Considerations for Non-Particulate Grouts}

Non-particulate grouts (i.e., chemical grouts) normally consist of solutions of two or more chemicals which react to form a gel. The reaction causes a decrease in fluidity and facilitates solidification and subsequent formation of occulusions in fill voids of the host material (U.S. Army Office of the Chief of Engineers 1973). The viscosities of chemical grouts tend to be very low and generally (except for fillers that are sometimes added) contain no particulate matter. Chemical grouts can therefore be injected into materials with voids small enough to limit penetration of cement-based grouts. Chemical grouts have been used primarily in fine granular material and to seal fine fissures in fractured rock (U.S. Army Office of the Chief of Engineers 1973).

Most chemical grouts belong to one of the following four groups:

1. Sodium silicate grouts

2. Acrylamide grouts

3. Lignin grouts

4. Epoxy and polyester resins grouts

Each grout exhibits certain characteristics that make it suitable for certain applications. For several chemical grouts the speed of the chemical or physicochemical reaction limits the radius of grout penetration. Other factors affecting grout penetration include: 1) concentrations of constituent chemicals, 2) permeability of the material being grouted, 3) grouting pressure, and 4) continuity of injection technique (U.S. Army Office of the Chief of Engineers 1973).

\section{Sodium Silicate Grouts}

Sodium silicate is the chemical basis of a variety of silicate grouting processes. Sodium silicate forms a gel in the presence of specific reactants. The gel fills voids and binds particles together when injected into granular material. Several reactants can be used and the choice is based on desired gel time, strength and permanence requirements, and cost.

The chemical reaction occurs when sodium silicate (an alkaline) is mixed with an acidic material. A gel is formed if the silica concentration in the silicate solution is greater than one or two percent by volume. Acidic mixers commonly used are: chlorine, ammonium salts, bisulfates, bicarbonates, sulfur dioxide, and sodium silicofluoride (U.S. Army Office of the Chief of Engineers 1973).

Sodium silicate is injected in either a two-solution process or as a single solution. The two-solution (termed "two-shot method") process consists of the injection of a solution of sodium silicate followed by a second separate 
injection of the reactant chemical(s). The reaction between the silicate and the reactant solution is almost instantaneous thus allowing the sealing of water bearing strata with moderate ground-water velocities and pressure heads. Disadvantages of the two solution process include limited grout radii due to the speed of the reaction and uncontrolled mixing of the solutions in the host material (U.S. Army Office of the Chief of Engineers 1973).

The one solution process consists of injection of the sodium silicate with the reactant in a single solution. Prior to mixing, the reactant(s) are diluted with water and introduced into the aggitated sodium silicate solution. The one-solution process allows more complete grout penetration and better control of the grout radius. However, sodium silicate grouts placed with the two-shot technique tend to have greater strength (U.S. Army Office of the Chief of Engineers 1973).

\section{Acrylamide Grouts}

The most widely used acrylamide grout has been composed of acrylamide and methylene bisacrylamide mixed in proportions the produce stiff gels from dilute water solutions (U.S. Army Office of the Chief of Engineers 1973). Gel time can be controlled within the range of a few seconds to several hours by varying the proportions of the constituent materials. The viscosity of acrylamide grouts approaches that of water and they maintain a low viscosity for roughly 95 percent of their fluid life. If allowed to dry the acrylamide gel will lose water and shrink. However, if allowed to continue drying the gel will slowly re-swell to its original volume. Excessive drying will destroy the gel (U.S. Army Office of the Chief of Engineers 1973).

Acrylamide grouts have been used to construct grout curtains and to grout jointed and fissured rock to control water seepage. The principal use has been to stop saturated and partially saturated ground-water flow. Acrylamide grouts can penetrate materials with a grain size of $0.01 \mathrm{~mm}$ (silt size range) and have been used in fissured rock with fissures up to 10 to $15 \mathrm{~cm}$ in width (U.S. Army Office of the Chief of Engineers 1973).

Prior to early 1978 three acrylamide grouts and one acrylamide-based grout were commercially available in the U.S. However, with the recognition of acrylamide as a neurotoxin and subsequent cases of acrylamide poisoning, U.S. manufacturing of AM-9 (trade name of acrylamide) was discontinued. The Japanese and the French marketed acrylamide-based grouts in the U.S. in 1979 but they also withdrew from the U.S. market. Terrage1॰, Q-Seal®, and PWG are a11 distributor trade names for $\mathrm{AM}{ }^{\circ}$ and are no longer marketed in the U.S. (Karol 1982a).

\section{Lignin Grouts}

Lignin is a by-product of the paper making sulfite process that forms an insoluble gel when combined with a chromium compound. Viscosities of various lignin solutions vary over a wide range making lignin grouts suitable for injection into voids of fine sand to coarse silts (U.S. Army Office of the Chief of Engineers 1973). 
Lignin grouts consist of materials that are rapidly soluble in water. The gel in normal grout concentrations (i.e., the weight ratio of water to lignosulfonate of $4: 1$ to $5: 1$ ) has a rubbery consistency and is practically impermeable to water. If protected against drying and freezing the grout ordinarily does not deteriorate (U.S. Army Office of the Chief of Engineers 1973).

Lignin grouts are used primarily in fine granular material. They have also been successfully used to grout fine fissures in fractured rock. The U.S Army Office of the Chief of Engineers (1973) does not recommend lignin grouts for use in soils containing an appreciable amount of material finer than the No. 200 (0.0029 in.) sieve. A dilute solution of lignosulfonate can be used to grout fine, nonargillaceous sands for permeability reduction.

\section{Epoxy and Polyester Resin Grouts}

Epoxy and polyester resins are organic compounds comprising two-component systems made of a resin base and a hardener. Epoxy resins are resistant to acids, alkalies, and other organic chemicals and they cure without volatile byproducts thus preventing formation of bubbles or voids. Epoxy resins are also compatible with various thickening agents (e.g., bentonite). Epoxy resins are thermosetting (i.e., they will not liquify once they have hardened even when heated) (U.S Army Office of the Chief of Engineers 1973). This property may be important for applications in close proximity to a core melt accident where ground-water temperatures may be significantly higher than surrounding ambient temperatures.

Polyester resins are also two-component systems that have been used to stabilize or strengthen fractured rock. Polyester resins are low viscosity, thermosetting liquid plastics that chemically cure to a solid. Polyester resins do not bond as well to moist rock as due epoxy resins. Also, they are more brittle and exibit greater shrinkage than epoxy resins (U.S. Army office of the Chief of Engineers 1973).

The four categories of non-particulate grouts discussed above are not allencompassing of chemical grouts, although they encompass the most frequently used non-particulate grouts. Other chemical grouts include (U.S. Army office of the Chief of Engineers 1973):

1. Cationic organic - emulsions utilizing diesel oil as a carrier

2. Resorcinol - formaldehyde

3. Epoxy - bitumen

4. Calcium acrylate

5. Aniline - furfural

6. Aluminum octoate compounds

7. Urea - formaldehyde

8. Polyphenolic polymors

These additional grouting compounds and systems are all classified as Newtonian low viscosity grouts. A complete listing of chemical grouts and their trade name and manufacturer is included in Table 4.3.1-2. 
TABLE 4.3.1-2. Chemical Grouts and Manufacturers (Source: U.S. Army Office of the Chief of Engineers 1973)

\begin{tabular}{|c|c|c|}
\hline Type & Trade Name & $\begin{array}{c}\text { Manufacturer, Producer, } \\
\text { or Distributor } \\
\end{array}$ \\
\hline Acrylate & $A C-400(a)$ & -- \\
\hline Acrylamide Pre-polymer & Injectite $80(a)$ & -- \\
\hline Resin & Cyanaloc & Cynamid International \\
\hline Resin & Herculox & $\begin{array}{l}\text { Ha1liburton } 0 i 1 \text { Well } \\
\text { Cementing } \mathrm{Co} \text {. }\end{array}$ \\
\hline Silicate & Injectrol-G & $\begin{array}{l}\text { Halliburton } 0 i 1 \text { Well } \\
\text { Cementing } \mathrm{Co} \text {. }\end{array}$ \\
\hline Silicate & Siroc & $\begin{array}{l}\text { Raymond International } \\
\text { Inc. }\end{array}$ \\
\hline Silicate & Geloc-4 ${ }^{(b)}$ & - \\
\hline Silicate & Terraset $(b)$ & -- \\
\hline Silicate & Hardener $600^{(b)}$ & -- \\
\hline Lignin & $B 10 x-A 11$ & $\begin{array}{l}\text { Halliburton } 0 \text { il Well } \\
\text { Cementing } \mathrm{Co} \text {. }\end{array}$ \\
\hline Lignosulfonate & Terra Firma & Concrete Chemicals Co. \\
\hline Epoxy resin & -- & George W. Whitesides Co. \\
\hline Polyester resin & -- & Cyanamid International \\
\hline Polyphenolic polymer & Terranier & Rayonier, Inc. \\
\hline Resorcinol-formaldehyde & CR-726 & Catalin Corp. of America \\
\hline Phenoplast or resorcin-formal & -- & Soletanche \\
\hline Aluminum octoate & Firmgel & Byron Jackson, Inc. \\
\hline Cationic organic-emulsion & SS-13 & Brown Mud $\mathrm{Co}$. \\
\hline Aminoplasts or urea-formols & -- & -- \\
\hline Epoxy-bitumen & -- & -- \\
\hline Calcium acrylate & -- & -- \\
\hline Aniline-furfural & -- & - \\
\hline Polyurethane & TACSS & -- \\
\hline Polyurethane & $\mathrm{CR} 250^{\star}$ & -- \\
\hline
\end{tabular}

(a) Identified by Karol 1982 .

(b) Identified by Baker 1982 . 


\subsubsection{Choice of Grouts}

The choice of grout is made so as to allow effective penetration of the host material and provide the necessary reduction in permeability with acceptable duration. The effect of ground water on the various grouts also influences the choice of the grout. Ground water can dissolve some soluble elements of a grout and can cause certain chemical and physicochemical changes in the grouts. According to Caron (1982) these two effects may result in a reduction of the imperviousness of a grout that is variable among the differing types of grouts.

Soil penetration by a grout is primarily by impregnation and occasionally by fracturing-impregnation for most applications to control ground water and contaminant movement via grouted cut-off walls. Impregnation grouting (i.e., permeation grouting) requires grouts that are adopted to the size of the voids of the host material in order to penetrate the soil voids. Thus a wide range of grouts, both particulate and non-particulate, are potentially applicable (Caron 1982).

In most cases cement-based grouts are suitable for fissured coherent soils. In granular soils there is a filtration of cement-based grouts as grainsize decreases. Chemical grouts may be more suitable because of lower viscosities and lack of particulate matter as the host material becomes more fine. The criteria of grainsize distribution $\left(\mathrm{d}_{10}\right)$, permeability $(\mathrm{K})$, and specific surface (S) can be used to recommend types of grouts appropriate to each type of granular soil (Caron 1982). Table 4.3.1-3 lists three soil types and the recommended grout.

Caron (1982) suggests that the limit between chemical grouts and cementbased grouts is fairly well-defined. When cement-based grouts can only proceed by fracturing because of the fineness of the host material, chemical grouts become more suitable. The limit between gels and resins, however, is not as well-defined because the only significant difference in preset properties is viscosity.

The permeation characteristics of both particulate grouts and chemical grouts are limited by increasing shear resistance of the interface between the grout and the host soil (Attewell and Farmer 1976). Figure 4.3.1-1 shows the soil size limitations on grout permeation.

\section{TABLE 4.3.1-3. Grout Recommendations Based on Soil Type}

(Source: Caron 1982)

\begin{tabular}{|c|c|c|c|}
\hline Soil Type & $\begin{array}{c}\text { Grain Size } \\
\text { Distribution (mm) }\end{array}$ & $\begin{array}{c}\text { Permeability } \\
(\mathrm{cm} / \mathrm{sec})\end{array}$ & $\begin{array}{c}\text { Specific } \\
\text { Surface }(1 / \mathrm{cm})\end{array}$ \\
\hline 1. Coarse-grafined & $d_{10}>0.05$ & $x>10^{-1}$ & $S>1 / 10$ \\
\hline 2. Medfum-grained & $0.02<d_{10}<0.05$ & $10^{-3}<k<10^{-1}$ & $1 / 1000<s 1 / 1000$ \\
\hline 3. Fine-gratned & $d_{10}<0.02 \mathrm{~mm}$ & $k<10^{-3}$ & $s<1 / 1000$ \\
\hline
\end{tabular}

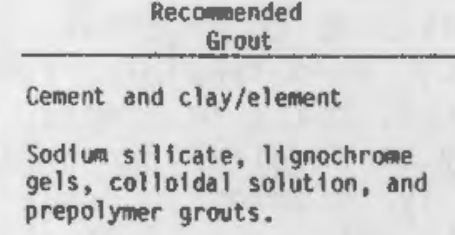

Acrylamide-based grouts and other pore solution grouts 


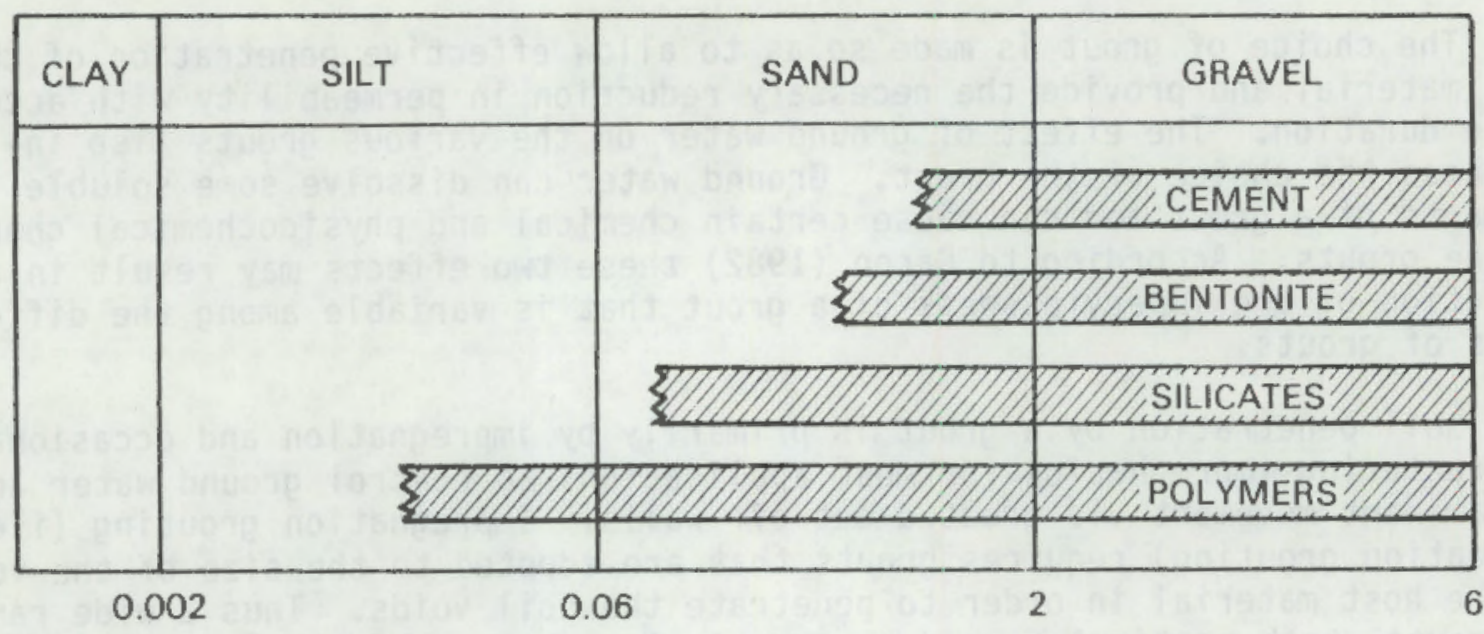

GRAIN SIZE, mm

FIGURE 4.3.1-1. Permeation of Various Grouts in Relation to Soil Grain Size (Source: Attewell and Farmer 1976).

Baker (1982) states that the initial permeability of the host soil material is the overall key to determining the groutability of the soil mass. Host materials with permeabilities ranging from $10^{-1} \mathrm{~cm} / \mathrm{sec}$ to $10^{-3} \mathrm{~cm} / \mathrm{sec}$ are "easily groutable". Permeabilities in the range $10^{-3} \mathrm{~cm} / \mathrm{sec}$ to $10^{-4} \mathrm{~cm} / \mathrm{sec}$ are "moderately groutable", while material permeabilities between $10^{-4} \mathrm{~cm} / \mathrm{sec}$ and $10^{-5} \mathrm{~cm} / \mathrm{sec}$ are marginal with respect to practical ability. Host materials with permeabilities less than $10^{-5} \mathrm{~cm} / \mathrm{sec}$ are considered ungroutable.

\subsubsection{Grout Curtain Construction Considerations}

The process of constructing a grout curtain to function as a barrier to ground-water flow involves several steps. These steps include:

1. Geohydrologic investigations,

2. Layout,

3. Drilling grout holes,

4. Grout mixing, and

5. Grout injection.

Site investigations for grouting may involve geological or geotechnical methods normally used for any geohydrological site characterization. These studies should be conducted sufficiently to avoid any unsuspected major surprises as to host material properties, ground-water flow characteristics, etc. When feasible, test grouting is recommended to determine rates of grout takes, suitable pumping pressures, and estimates of the volume of grout that may be required for a particular grouting operation (Albritton 1982). Normally, volumetric grout requirements are estimated from the porosity of the host material. Typical groutable material has an effective porosity between 0.25 percent and 0.45 percent (Baker 1982). 
Layout

Penetration grout curtains are constructed in a series of primary, secondary, tertiary, etc. grout applications. This construction process, termed "split-spaced injection staging", refers to multiple grouting episodes in the same zone or area. Primary grouting is the initial grouting of a previously ungrouted area. Individual grout cylinders or "bulbs" are not in contact or overlap only slightly. Secondary and tertiary grouting successively fills the ungrouted areas remaining in the same zone. Grout pipe spacing is designed to locate primary and secondary grout injection points. The secondary locations are usually at the midpoint between primary injection points (Baker 1982).

Project costs are highly sensitive to grout pipe spacing. Pipes spaced too close to each other (i.e., less than $0.5 \mathrm{~m}$ ) will result in excessive costs for drilling. Pipes spaced too far apart (i.e., more than $2.5 \mathrm{~m}$ ) will result in long pumping times and loss of control of the grouting process due to uncertainty about the location of the grout front. Most grouting operations have a pipe spacing between $0.8 \mathrm{~m}$ and $1.5 \mathrm{~m}$ (Baker 1982). The U.S. Army Corps of Engineers suggests that the proper spacing for the "split-spaced method" primary grout holes should be rarely less than 3.0 m (Albritton 1982).

There are four basic stage grouting methods (Houlsby 1982a):

1. Downstage without packer,

2. Downstage with packer,

3. Upstage, and

4. Circuit grouting downstage.

For high standard grouting (which would be required to assure control of radionuclide migration following a severe power plant accident) Houlsby (1982a) recommends downstage grouting without packer (Figure 4.3.1-2). The steps involved in downstage grouting require repeated drilling/grouting operations at successively greater depths in the same grout hole. The advantages of this procedure are proving of upper grouted stages and automatic handling of material weaknesses as they exist (Houlsby 1982a).

Grout Hole Drilling.

Minimum diameters as small as $38 \mathrm{~mm}$ have been successfully used for grout hole specifications. However, for deep or inclined grout holes larger diameters are recommended because the stiffness of the drill rods will result in straighter boring. Also, distribution of grouting pressures in the host medium is affected by the diameter of the boreholes. Smaller holes require greater pressures to achieve the same relative results compared to larger holes with less pressure (Albritton 1982).

Both rotary drilling and percussion drilling with water are acceptable means for grout hole boring. Caution must be exercised to insure that no premature plugging of fine fissures by dry rock flour, drilling mud, or clay 
THE STEPS WHEN WORKING

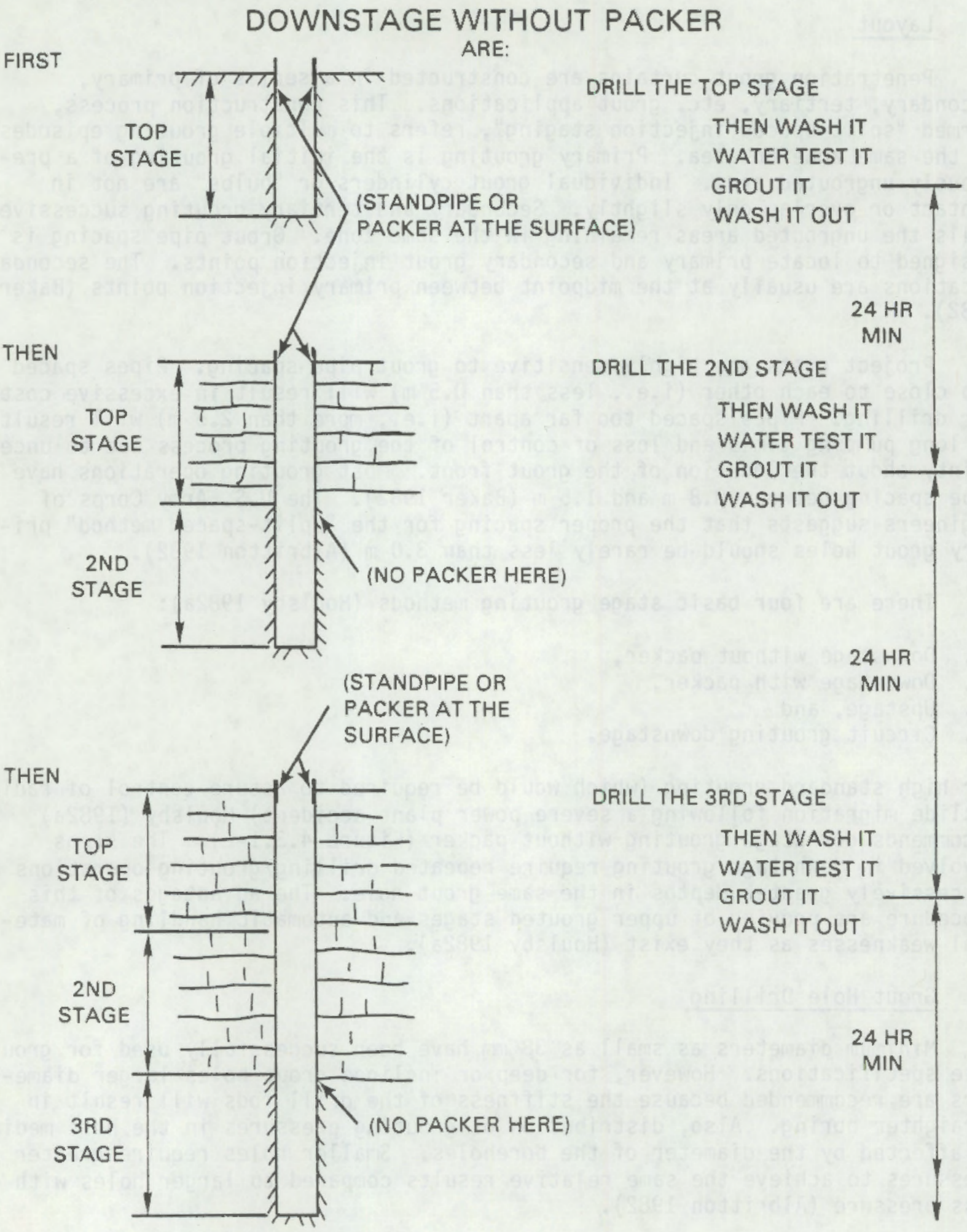

AND SO ON FOR THE REMAINDER OF THE HOLE

FIGURE 4.3.1-2. Diagram of Downstage Grouting without Packer (Source: Houlsby 1982a)

$$
4.18
$$


slurry occurs. The U.S. Army Corps of Engineers normally requires water, as opposed to air, for a drilling fluid. However, water may occasionally cause caving, erosion, and/or bit binding. Grout holes should be flushed of all drill cuttings and turbidity prior to grout injection (Albritton 1982).

\section{Grout Mixing}

For penetration grouting, high speed mixing of cement grouts is essential. Cement grouts mixed at high speeds usually penetrate well due to the absence of conglomerations of cement grains. High speed mixing facilitates complete and thorough wetting of cement grains thus allowing thorough hydration. High speed mixers operate at speeds in the range 1500 to 2000 revolutions per minute. High speed mixing may require as little as 15 seconds per mixing cycle enabling rapid feed to a "fast" hole (Houlsby 1982a).

The U.S. Army Corps of Engineers indicates that starting with a thin water/cement ratio mix (i.e., $5: 1$ or $6: 1$ ) may be preferable to a thicker starting grout, even if eventually a thick grout is required. By starting with a thin grout fine fractures may be successfully grouted that otherwise would have been plugged by a thicker grout (Albritton 1982). However, sedimentation of cement grains increases with increasing water/cement ratios. A 6:1 water/ cement mix may experience up to 60 percent sedimentation in two hours. Sedimentation may be lowered by adding bentonite in small amounts (Deere 1982).

Mixing of chemical-based grouts is specific to and dependent on the grout employed. For some two-shot processes mixing (of multiple constituents) is not necessary; mixing essentially takes place in the grouted medium.

\section{Grout Injection}

Penetration grouting requires a moderate injection pressure that does not cause excessive disturbance of the host medium. Normal penetration grout pressures do not exceed 0.4 bar per meter of depth. Allowable pressures increase as the depth of stage increases with rule-of-thumb injection pressures of 0.23 bars per meter of depth for average to weak host materials. The rule-of-thumb injection pressure can be doubled for sound material. Regardless of the sustained injection pressure the build-up of pressure should be gradual (Houlsby 1982a).

Grout injection should continue until absolute grout take refusal. Once refusal has been reached it is advised to hold the pressure for approximately 15 minutes. For grouting wide cracks (i.e., $0.3 \mathrm{~cm}$ to $0.6 \mathrm{~cm}$ ) second injections after a one to two day delay may be advisable (Houlsby 1982a).

\subsubsection{Grout Performance and Durability}

The two most important issues related to the suitability of grout curtains as barriers to ground-water contaminant migration resulting from a severe power plant accident are the long-term permeability of the grout barrier and the durability of the barrier. Quality control should be maintained throughout the 
grouting operations. Variations (i.e., non-uniformity of final grout curtain properties) result from three causes (Littlejohn 1982):

1. Inadequate/improper mixing of grout,

2. Variations in grout material (both quality and quantity), and

3. Apparent variations from the testing procedure.

The assurance of acceptable quality requires rigid engineering supervision of all grouting operations.

\section{Grout Curtain Permeability}

For cement-based grouts the cured permeability is a function of the original water/cement ratio $(\omega)$. For fresh or aging cement grouts the permeability is related to the age of the grout. Figure 4.3.1-3 shows the relationship between water/cement ratios and 28 day permeability for a typical cement-based grout. Table 4.3.1-4 shows the permeability increase with age for a Type I (ordinary porland cement) grout.

Chemically grouted cut-off walls can achieve the same relative permeability reduction as cement-based grout curtains. Permeability testing in fine, medium, and coarse grained sands indicate that permeabilities as low as $5 \times 10^{-9} \mathrm{~cm} / \mathrm{sec}$ can be achieved with acrylate grouts such as $\mathrm{AC}-400^{\oplus}$ (Clarke 1982). The U.S. Army Corps of Engineers states that sands with ungrouted permeabilities in the range of $1 \mathrm{~cm} / \mathrm{sec}$ to $1 \times 10^{-3} \mathrm{~cm} / \mathrm{sec}$ were grouted with a $10 \%$ acrylamide solution to permeabilities of $2 \times 10^{-10} \mathrm{~cm} / \mathrm{sec}$ (U.S. Army Office of the Chief of Engineers 1973).

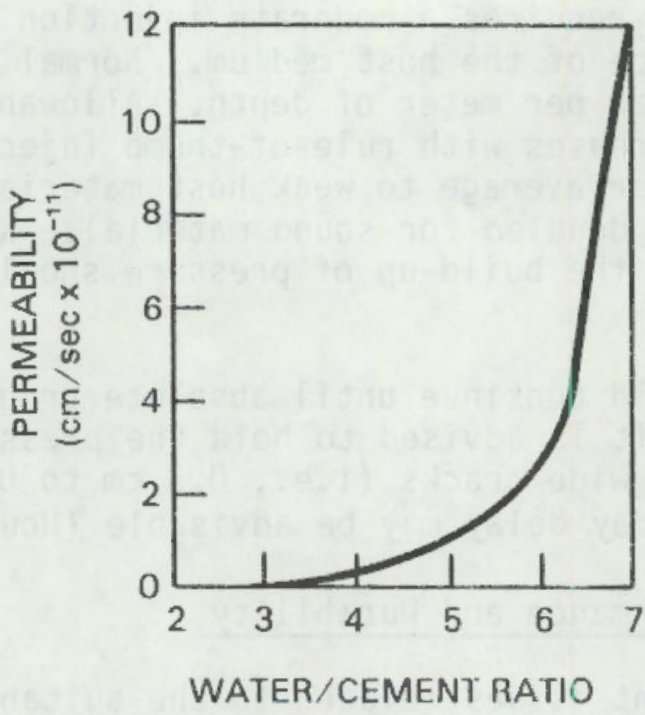

FIGURE 4.3.1-3. Twenty-Eight Day Permeability of a Typical Cement Grout (Source: Littlejohn 1982) 
TABLE 4.3.1-4. Permeability Versus Age of a Portland Cement Grout with $\omega=0.7$ (Source: Littlejohn 1982)

\begin{tabular}{cc} 
Age (days) & Permeability $(\mathrm{cm} / \mathrm{sec})$ \\
\cline { 1 - 2 } Fresh & $2 \times 10^{-4}$ \\
5 & $4 \times 10^{-8}$ \\
6 & $1 \times 10^{-8}$ \\
8 & $4 \times 10^{-9}$ \\
13 & $5 \times 10^{-10}$ \\
24 & $1 \times 10^{-10}$ \\
U1timate & $6 \times 10^{-11}$ \\
(Estimated) &
\end{tabular}

Test grouting of alluvial sands with silicate-based grouts indicate that under field conditions permeability reductions of one to two orders of magnitude lower than the untreated permeability can be realized. Laboratory tests with the same grout material achieved permeability values averaging $4.8 \times$ $10^{-7} \mathrm{~cm} / \mathrm{sec}$ or two to three orders of magnitude lower than the field-grouted sand (Davidson and Perez 1982).

In general, chemically grouted sands exhibit permeability reductions of approximately three to six orders of magnitude lower than the original ungrouted sand (Baker 1982).

\section{Grout Curtain Durability}

Grout durability and grout compatibility with the surrounding environment are closely related. The durability (i.e., maintenance of permeability reduction) of cement-based grouts is effected primarily by the chemistry of the ground water in contact with the set grout. Deterioration of cement grouts can be caused by high concentrations of dissolved sulphates or acids in ground water, large-scale temperature fluctuations causing freeze/thaw cycles, and prolonged exposure to sea water (Littlejohn 1982).

Littlejohn (1982) recommends a water/cement ratio of 0.4 for grouts subjected to freeze/thaw cycles. Increased resistance to chemical breakdown of cement grouts can be achieved by using higher cost aluminous cements.

Silicate-based chemical grouts with silicate concentrations of $35 \%$ or more by volume tend to resist deterioration by freeze/thaw and by episodes of wetting and drying. Silicate grouts containing less than $30 \%$ silicate by volume should be used only for temporary applications. Repeated freezing and thawing will cause deterioration of acrylamide-type grouts because of the rupture of gel particle bonds. Laboratory tests indicate however, that for host materials grouted below the water table no significant deterioration of acrylamide-type grouts occurred in 15 years (U.S. Army Office of the Chief of Engineers 1973). 


\subsubsection{Effects of Ground Water on Grouting}

The effect of ground water on grouting operations and the resulting grouted barrier is twofold. First, there are mechanical impacts associated with the ground-water pressure head and the velocity of the moving ground-water chemistry. Second, there are influences on the durability of the in-place grout caused by variations in ground-water chemistry.

As grouting closes drainage pathways, up-gradient ground-water elevations will rise thus causing increased pressure head on the grout itself. These higher pressures, caused by the placement of the grout, may cause the grout to be pushed out of the seepage zones and result in reopening of the flow pathways. Karol (1982b) recommends injecting grout near the end of treatment at pressures higher than the maximum anticipated future ground-water head.

Because ground water will be flowing in contact with the grout curtain there is a continuous potential for weakening of the grout. If grouts with high water/cement ratios are used, loss of most of the effectiveness of the barrier can occur as early as one year after construction (Houlsby 1982b). Uneven grouting may be caused by instability and mixing at the grout/groundwater interface. If the grout viscosity is greater than the viscosity of the water being displaced mixing will be reduced (Attewell and Farmer 1976).

For chemical grouts, the flow of the grout will be reversed due to their low viscosity as soon as the pumping injection pressures are eliminated. To avoid reverse flow pumping pressures should be maintained until the grout has developed some set strength (Attewell and Farmer 1976).

As long as the mechanical and chemical effects of ground water are considered in the design and installation of the barrier grouting can be successfully performed above and below the water table. Some precautions need to be exercised, however. For instance, ground water with a high pH can lead to premature deterioration of silicate-based grouts by inhibiting initial gellation. Conversely, low pH ground water may accelerate gellation of silicate grouts while preventing the setting of acrylate grouts. It is also necessary to determine if perched water exists in the grout zone and to establish the presence of any artesian pressures (Baker 1982).

\subsubsection{Grouting Implementation Considerations}

The five key issues related to implementation of grout barriers to mitigate ground-water contamination resulting from a severe power plant accident are:

1. Construction time,

2. Cost,

3. Toxicity of grout material,

4. Equipment mobilization, and

5. Worker safety. 


\section{Construction Time}

The time required to construct a grout barrier to ground-water flow is highly variable and site specific. Construction time is a function of:

1. Size and orientation of barrier,

2. Grout hole spacing,

3. Grouting method,

4. Lithology of host material

5. Drilling method, and

6. Grout take rates and setting time.

Since each job is unique or customized there are no adequate unit timings for the various procedures comprising a grouting operation. Compared with other techniques, however, most grouting operations are significantly slower

(Harris et al. 1982a). Several months may be required for a complete grouting operation.

\section{Cost}

The total cost of a grouting operation is a function of (U.S. Army Office of the Chief of Engineers 1973):

1. Initial cost of materials,

2. Location of job site,

3. Ouantities and types of grout to be used,

4. Volume of material to be placed,

5. Labor,

6. Overhead,

7. Equipment rental, and

8. Drilling cost.

Of the total cost, direct contractor costs for supply of labor and plant may typically range from $40 \%$ to $55 \%$. Site preparation, maintenance, and supplies costs may be expected in the range from $25 \%$ to $30 \%$ of the total cost. Finally, design and engineering costs may typically range from $20 \%$ to $30 \%$ of the total project cost (Fox and Jones 1982). The actual cost is highly variable from job to job and may not breakdown into the above ranges in every case.

Chemical grouts are commercially available at prices ranging from $\$ 0.13$ to $\$ 2.64$ per liter. Sample grout material cost data are presented in Table 4.3.1-5. While grouting material costs may vary 20 to 1 the overall inplace costs typically vary from 3 to 1 because the cost of grout placement is a major cost factor in the overall cost of the job (Karol 1982a).

Additional costs related to radiation protection should also be considered. 
TABLE 4.3.1-5. Grouting Material Costs (1980\$)

(Source: EPA 1982)

$\begin{array}{lc}\text { Grout Material } & \text { Unit Cost }(\$ / 1 \text { iter }) \\ \text { Portland Cement } & 0.25 \\ \text { Bentonite } & 0.33 \\ \text { Silicate } & \\ 20 \% & \\ 30 \% & 0.46 \\ 40 \% & 0.55 \\ \text { Lignochrome } & \\ \text { Acrylamide } & 0.41 \\ \text { Urea Formaldehyde } & 1.76\end{array}$

\section{Toxicity}

Most cement-based and clay/cement-based grouts are considered non-toxic although they are skin irritants. However, certain types of chemical grouts are highly toxic and manufacture of some otherwise very useful grouts, has been stopped due to their toxic behavior.

Sodium silicate grouts are considered non-toxic and non-corrosive and consequently do not pose any health threats. However, some of the reactant compounds used with silicate gels may be toxic and thus require a certain measure of care when handling (Karol 1982a).

Acrylamide grouts have been found to be neurotoxins and their manufacture has been discontinued in the U.S. Only the powders and solutions are toxic, however. The gel does not exhibit toxic behavior. An acrylate polymer grout (AC-400) ${ }^{\circledR}$ was made commercially available in 1980 as a replacement to acrylamide grout. $A C-400^{\circ}$ possesses much of the same properties as the discontinued AM-9® grout with approximately $1 / 100$ the toxicity of AM-9® (Clarke 1982).

Lignosulfonate grouts containing a hexavalent chromium compound are extremely toxic. The resulting gels formed by these grouts may leach toxic materials into the ground water (Karol 1982a).

Grouts containing phenol or formaldehyde and an alkaline base represent potential health hazards. Grouts using urea solutions are also toxic and corrosive because of formaldehyde concentrations (Karol 1982a). 


\section{Equipment Mobilization}

Many different pieces of equipment are necessary to complete a grouting operation. Drilling equipment is required for grout hole development and selection of a clear, continuous drilling right-of-way of several meters width should be part of the layout process.

Based on the size of the job (i.e., amount of grout to be placed) a variety of equipment component types may be suitable. Basic equipment requirements include mixer, agitator, pump, circulation line, and control fittings. These items can be individual components or in some cases combined into single units. For very large jobs the machinery can be installed in a central mixing and pumping station with circulation lines to particular site locations (Houlsby 1982a). This approach may be particularly conducive to grout curtain construction after a severe accident since the majority of heavy equipment could be placed in relatively "safe" areas on the site. Circulation lines up to two miles return have been successfully used. For most power plant sites grouting equipment mobilization would not exclusively preclude a grouting operation.

\section{Worker Safety}

Worker safety and protection from radiation exposure would be a serious implementation issue. The grouting should be automated and streamlined as much as practically possible in order to minimize the size of work crews. Consolidation of equipment in relatively safe zones should also be considered. The layout of the grout curtain should consider opportunities for placement of the curtain upwind from the prevailing wind direction if possible.

\subsubsection{Slurry Trenches}

Slurry trenches or cut-off walls are engineered/constructed barriers that may be appropriate for use in protecting local water supplies from contaminated ground water resulting from a severe power plant accident.

A slurry trench is a ground-water barrier that penetrates vertically through pervious layers of soil. It is keyed (i.e., built) into an underlying soil layer that is impervious to local ground-water flow. A gel like slurry mixture of bentonite clay and water is normally used to support a trench excavated for development of the slurry wall. The slurry supports the trench sidewalls and prevents collapsing of the excavation.

The slurry is either replaced with a backfill material, or with the direct addition of cement the slurry itself will harden to form the cut-off wall. Slurry walls are designed to specifications that are made on a site-specific basis. The wall must be sufficiently impervious to ground-water flow, resistant to degradation by the ground-water contaminants, and relatively permanent.

Slurry wall construction originated in Europe, but is now used extensively in the U.S. Over seventy slurry walls were built in the U.S. during the two year period before 1980 (D'Appolonia 1980). They have been used in subways, 
mine shafts, and building construction for structural stability, in dams to control seepage, at waste disposal sites for isolating contaminated ground water, and at construction sites for dewatering.

Slurry cut-off walls have several advantages over other types of groundwater barriers. They generally cost less than other methods. Also slurry walls can key into the underlying impervious layers without interlocks that are necessary for steel sheet piling. There is also no need to estimate overlap as in grouting. Finally, homogeneity and continuity can be tested by sampling excavation cuttings. Sampling insures that the wall will be placed to the appropriate depth (Miller 1979).

\subsubsection{Design and Construction Considerations for Slurry Trenches}

There are four general types of slurry walls. Each has its own set of advantages and disadvantages that require consideration on a site-specific basis.

\section{Soil-Bentonite (S-B) Slurry Wall}

The soil-bentonite slurry wall, sometimes referred to as the American method, is the most deformable and plastic slurry wall. Construction starts with marking and leveling the area where the trench is to be excavated. A backhoe usually begins the excavation by digging several feet along the planned trench alignment. A slurry mixture is then continuously added to the trench to prevent the sidewalls from caving during excavation. The slurry is a viscous mixture of bentonite clay and water. Bentonite is a high sodium montmorillonite clay that expands when wetted. It is prepared using a mixing technique best suited for the time and space restrictions at the project site.

Backfilling begins when the maximum trench depth has been reached over a portion of the wall length. The sides and bottom of the trench should be cleared of sediments by scraping them with excavation tools. Soundings of the trench depth, and cuttings or samples from the trench bottom are sometimes made to insure that the entire trench bottom is open and cleared (Miller 1979). If the sediments encountered are less permeable than the backfill their removal is usually not required and will only add cost and time to the project

(D'Appolonia 1980).

Some construction companies use mechanical desanders or sedimentation methods to clean the slurry before backfilling. D'Appolonia (1980) states that these methods are useless and do not increase the performance of a slurry wall.

The backfill is usually mixed at the side of the trench. Either excavated soil or soil imported to the site is sluiced with the slurry, and then mixed by tracking and blading with a bulldozer. It is recommended (D'Appolonia 1980) that the slurry, to be used in the backfill, be taken directly from the trench. This slurry is thicker than freshly mixed slurry and contains a higher level of suspended particles. These two properties of the slurry that was used during the excavation process tend to decrease the permeability of the completed wall when the slurry is used as a constituent in the backfill. 
Mechanical batchers and pugmills have been used to mix the backfill at sites that do not have enough room to use a bulldozer or where backfill materials are costly (D'Appolonia 1980). The backfill is placed initially in the bottom corner of the trench with clamshells, or pumped there through pipes that extend to the trench bottom. Placement continues until the backfill reaches ground level. Additional backfill is bulldozed into the trench causing downward slough over the initially placed backfill. Excavation, cleaning of the trench bottom, and backfilling occur simultaneously as pictured in

Figure 4.3.2-1 until the wall is complete.

To finish construction a compacted clay cap, two to three feet thick, is usually placed over the trench.

\section{Cement-Bentonite (C-B) Slurry Wall}

In the construction of a cement-bentonite slurry wall, there is no need for backfilling. Cement is added to the bentonite-water slurry right before it is placed in the trench. The slurry itself hardens and forms the ground-water barrier. The wall has a relatively high strength and is not deformable like the S-B wall.

The alternate-slot method is usually used for deep trenches or for trenches passing through unstable soils. As shown in Figure 4.3.2-2, trench sections between 3 and 6 meters (10 and $20 \mathrm{ft}$ ) long are dug with the same length of unexcavated ground between them. The primary panels are formed when the C-B slurry hardens in the initially excavated trenches. The slots between panels are then excavated and filled with slurry to form the secondary panels (Harris et al. 1982b).

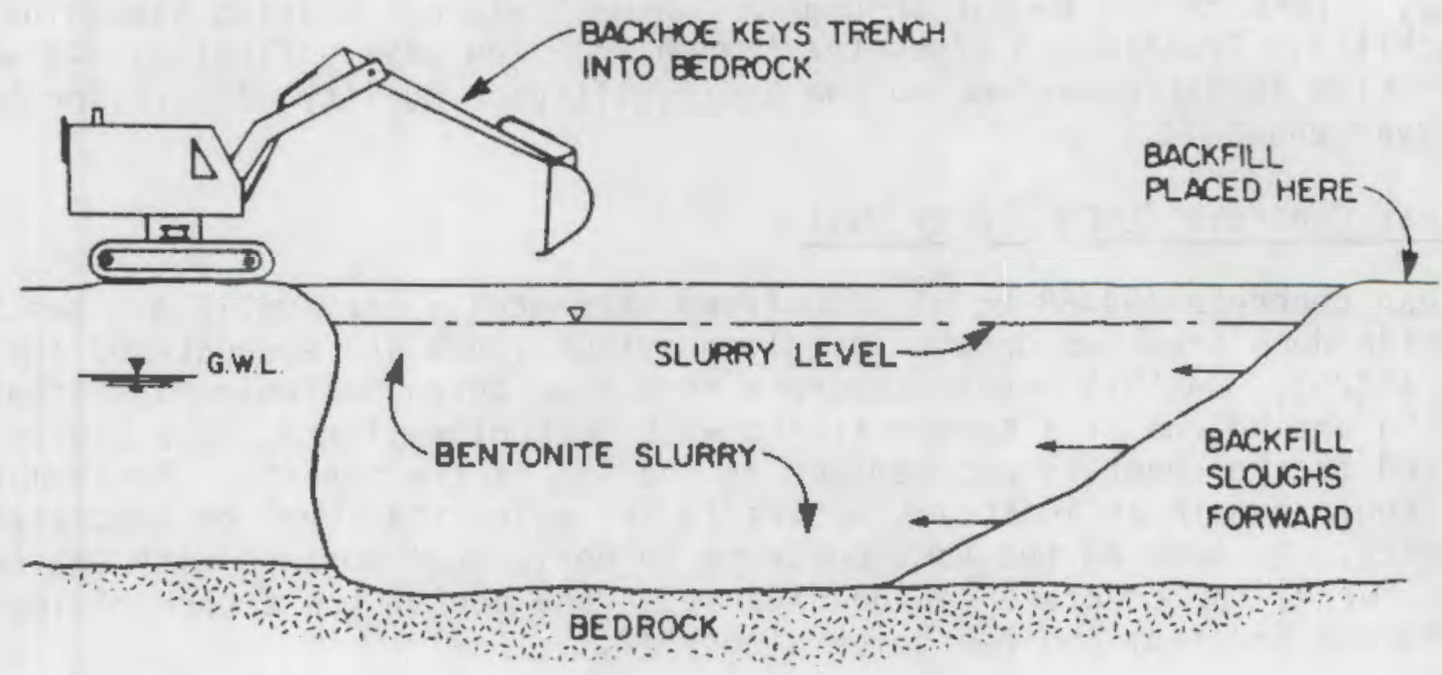

FIGURE 4.3.2-1. Schematic Section of Slurry Wall Construction (Source: Ayres et al. 1983) 


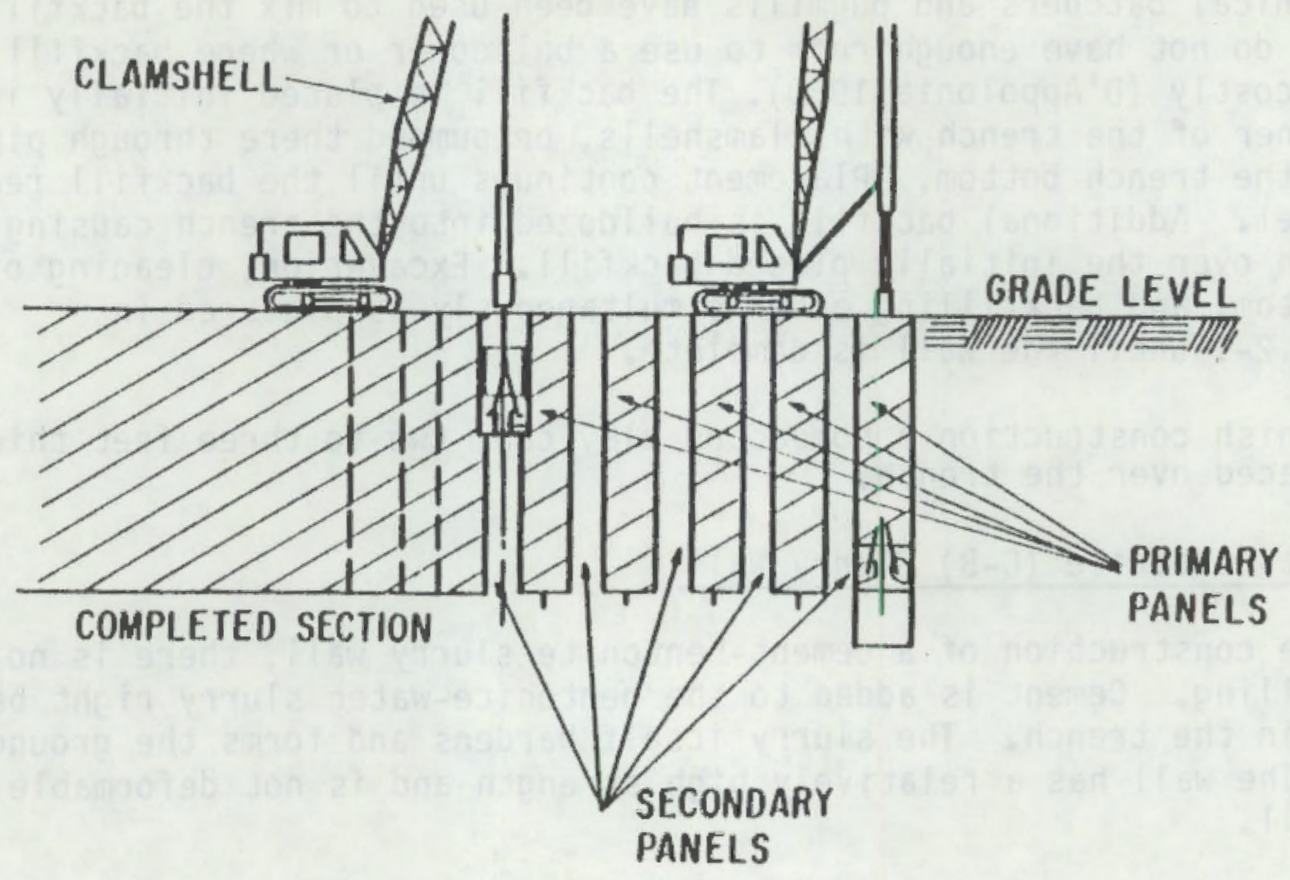

FIGURE 4.3.2-2. The Alternate-Slot Method

(Source: Harris et a1. 1982b)

Cement-bentonite slurry walls have several advantages over S-B slurry walls. There is less length of open trench during construction of a $\mathrm{C}-\mathrm{B}$ wall. The shorter trench length coupled with a faster slurry hardening time, stabilizes the ground and leaves less chance for trench failure. In the event of a failure, repairs are easier because the slurry mixture hardens relatively quickly. Trenches can be cut through a $\mathrm{C}-\mathrm{B}$ wall without causing sloughing of the backfill. Traffic can cross the trench in a few days. Finally, C-B wall construction is not dependent on the avalability or quality of soil for backfill (Ryan undated).

\section{Lean-Concrete (L-C) Slurry Wall}

Lean concrete $\left(34-68 \mathrm{~kg} / \mathrm{m}^{2}\right.$ unconfined strength) slurry walls are best suited for deep trenches or when highly pervious zones are encountered (Harris et a1. 1982b). In this method concrete is pumped through tremie pipes that extend to the bottom of a trench filled with bentonite slurry. The slurry is displaced by the concrete and removed at the top of the trench. The tremie pipes should remain at least 1.5 meters $(5 \mathrm{ft}$ ) below the level of concrete in the trench. Ry keeping the same concrete in horizontal contact with the bentonite slurry, the concrete can be cleaned at the top of the trench of impurities transferred from the bentonite slurry (a).

(a) Information from advertising brochure of Bencor Corporation of America, Dallas, Texas. 
To prevent discontinuities in the completed wall, some contractors will desand before concreting begins. One desanding method requires sucking the slurry out of the trench through a pipe. The slurry is then sent through a vibrating screen to sift out large particles and subsequently through a fine grain desander. Sand can also be removed from the slurry by reducing the power of suspension of the slurry by adding sodium tripolyphoshpate. The sand that falls to the bottom can be removed with a clamshell.

The alternate slot method is used during construction. One tremie pipe per 4.6 meters (15 feet) is standard procedure (Millet and Perez 1981). To ensure the continuity of the wall, the ends of the primary panels are shaped by using end-pipes or wide-flanges. These ends are filled in when the secondary panels are tremied in.

\section{Vibrating-Beam Thin (VBT) Slurry Wall}

This technique was brought to the U.S. from Europe in $1975^{(a)}$. There exists some controversy vibrating-beam slurry wall effectiveness as a groundwater barrier because they are very thin; usually no more than $10 \mathrm{~cm}(4 \mathrm{in}$.) wide.

A special crawler crane equiped with vibrator, leads, and injection beam repeatedly injects a C-B slurry into the soil forming a continuous impervious wall (Figure 4.3.2-3). The slurry is made in a mixer, pumped to the injector and forced into the soil; no backfilling is necessary. Slurry systems states that the VBT method accurately keys into the bottom impervious layer, increases the homogeniety of the wall, and uses slurry that is less contaminated than backfilled trenches $(\mathrm{b})$.

Slurry Systems follows specific procedures when mixing $C-B$ slurry (Schmednecht undated). Bentonite is augered into a stream of water and pumped through a centrifugal pump for approximately six minutes. Cement is added and a centrifugal pump mixes it for roughly 3 additional minutes. The slurry is then stored for a limited time or is pumped directly to the vibrating beam injection rig.

The mixed slurry is jetted into the ground with the aid of an injection beam driven by a vibrating pile-hammer (Figure 4.3.2-4). The injection beam is a standard wide flange section. Wear tips are welded to the end of the injection beam to adjust the width of the slurry wall. The lead on the crane can be adjusted laterally and vertically to assure plumbness on uneven or loose ground. There is a vertical hydraulic support ram with a bearing pad on the bottom of the lead for stability.

(a) Information from advertising brochure of Slurry Systems, a division of Thatcher Engineering Corporation, Gary, Indiana.

(b) Letter from Frank Zlamal, Slurry Systems Division of Thatcher Engineering Corporation, to John Shafer, PNL. 


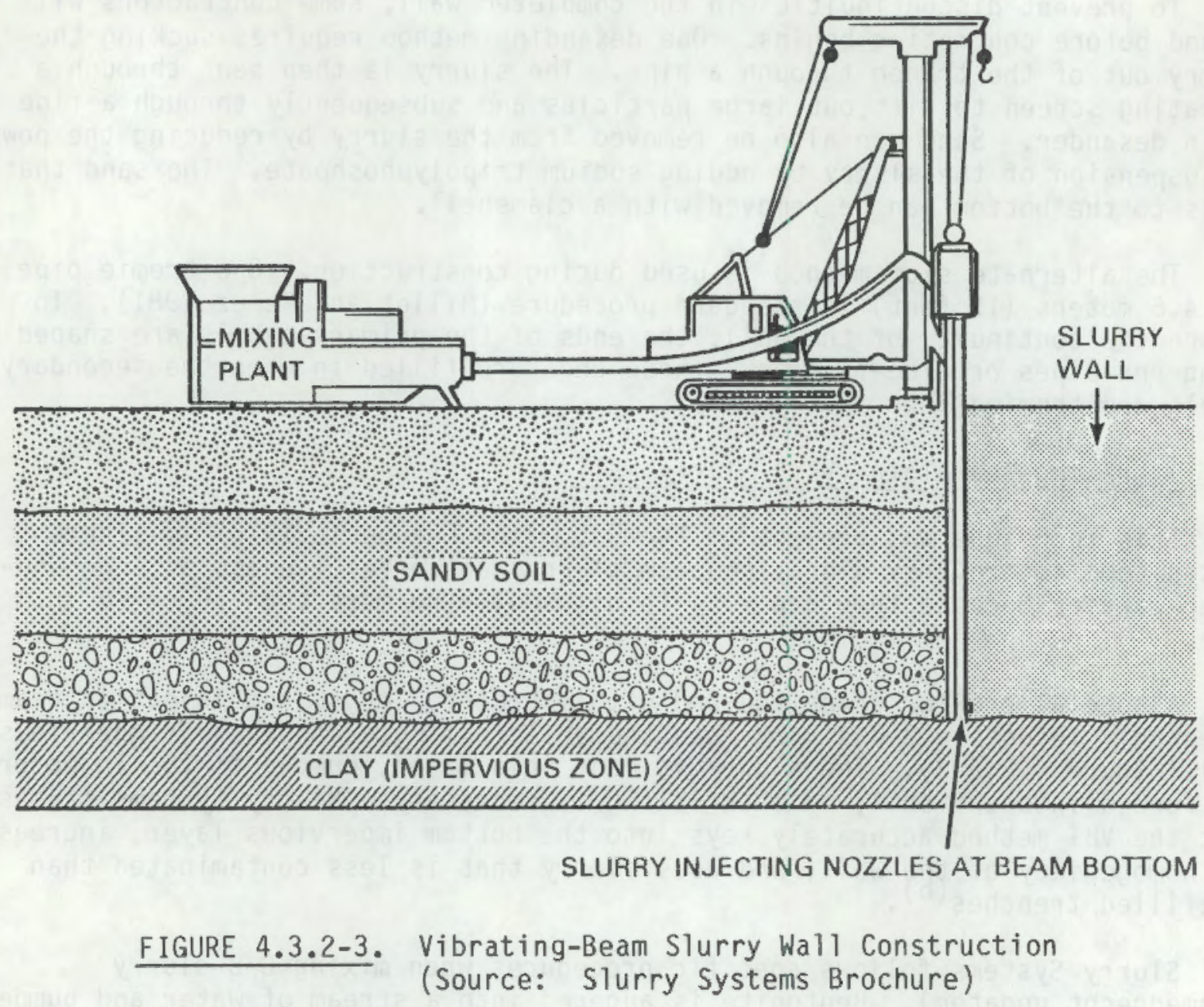

While the injection beam is removed from the ground, the C-B slurry is jetted under pressure into the depression. The slurry wall is constructed by successive injections of slurry into the ground.

The main problem with the VBT method is assuring continuity at depth between adjacent passes. Calculations must be done at each site to make sure the vibrator is powerful enough to force the beam into the soil. The VBT technique works best in sandy type soils which are easy to penetrate. Keying-in to consolidated underlying layers is not possible (Schmednecht undated).

There are several advantages to the VBT method. Construction is not dependent on the quality of on-site soil for backfill as in the S-B method, and mixing can be done at a distance from the trench. The cement in the backfill makes for a quick set. The VBT method uses less materials and time than other slurry wall methods. 


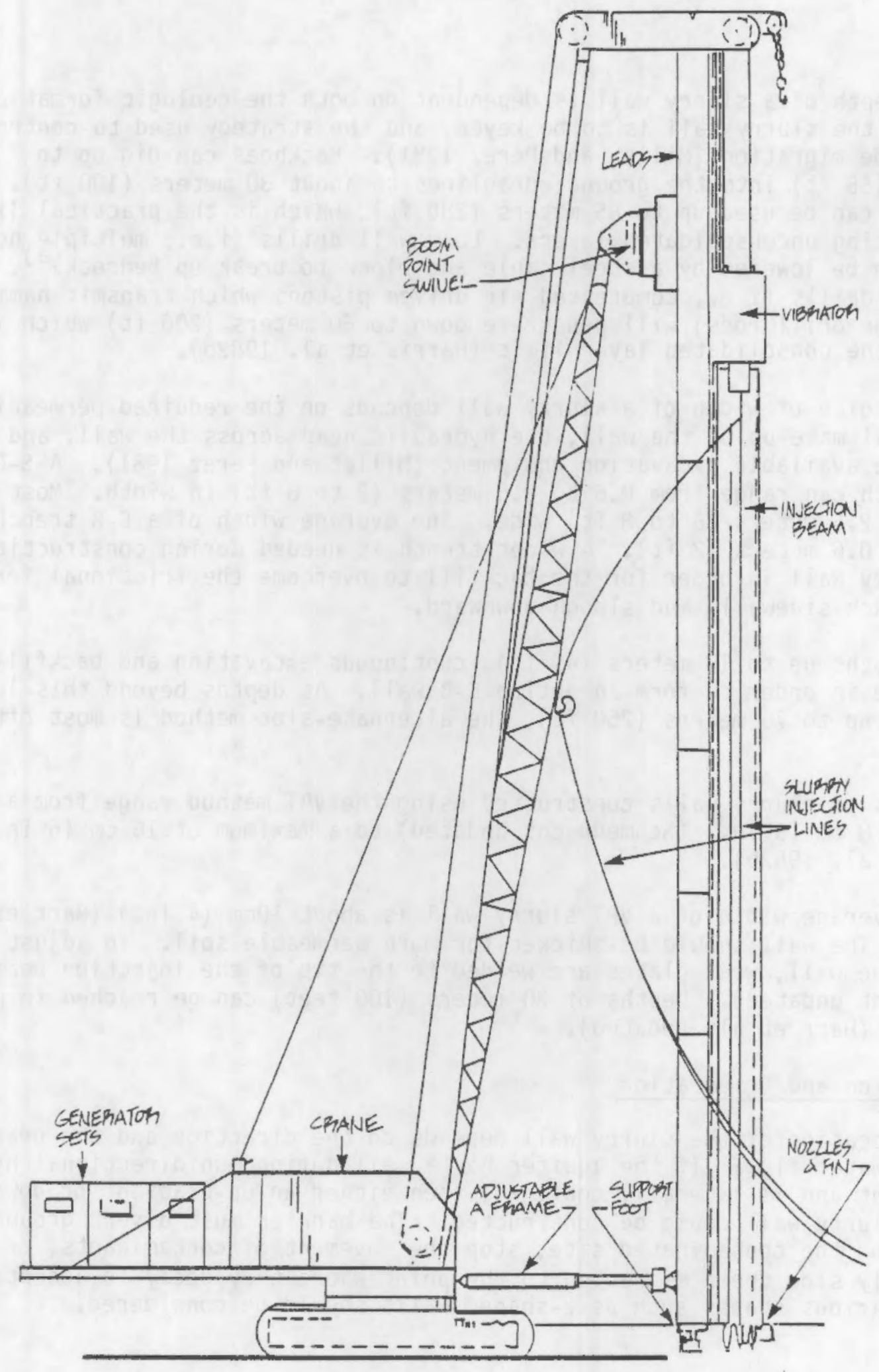

FIGURE 4.3.2-4. Typical Vibrated-Beam (VBT) Injection Set-Up (Source: Schmednecht undated) 
Size

The depth of a slurry wall is dependent on both the geologic formations into which the slurry wall is to be keyed, and the strategy used to control radionuclide migration (Millet and Perez 1981). Backhoes can dig up to 17 meters ( $55 \mathrm{ft}$ ) into the ground; draglines to about 30 meters (100 ft). Clamshells can be used up to 85 meters $(280 \mathrm{ft})$, which is the practical limit for excavating unconsolidated layers. Long wall drills (i.e., multiple head drills) can be lowered by a steel cable and block to break up bedrock (a). Percussion drills (i.e., compressed air driven pistons which transmit hammer blows to the drill rods) will penetrate down to 60 meters (200 ft) which is therefore the consolidated layer limit (Harris et al. 1982b).

The choice of width of a slurry wall depends on the required permeability, the material make-up of the wall, the hydraulic head across the wall, and the size of the available excavation equipment (Millet and Perez 1981). A S-B trench width can range from 0.6 to 2.5 meters $(2$ to $8 \mathrm{ft}$ ) in width. Most are built 2 to 2.5 meters (6 to $8 \mathrm{ft}$ ) wide. The average width of a $\mathrm{C}$ - $\mathrm{B}$ trench is narrower: 0.6 meters $(2 \mathrm{ft})$. A wider trench is needed during construction of a S-B slurry wall in order for the backfill to overcome the frictional forces of the trench sidewalls and slough downward.

At depths up to 15 meters (49 ft), continuous excavating and backfilling can be done in order to form an entire C-B wall. At depths beyond this lower limit, and up to 75 meters $(250 \mathrm{ft})$, the alternate-slot method is most often used.

Widths of slurry walls constructed using the VBT method range from a minimum of $8 \mathrm{~cm}(3 \mathrm{in.)}$ (Schmednecht undated) to a maximum of $16 \mathrm{~cm}(6 \mathrm{in.})$ (Harris et al. 1982b).

The average width of a VBT slurry wall is about $10 \mathrm{~cm}$ ( $4 \mathrm{in}$.) (Harr et al. undated). The wall should be thicker for more permeable soil. To adjust the width of the wall, wear plates are welded to the tip of the injection beam (Schmednecht undated). Depths of 30 meters (100 feet) can be reached in permeable soils (Harr et al. undated).

\section{Location and Orientation}

The location of the slurry wall depends on the direction and the gradient of ground-water flow. If the aquifer has a well-defined unidirectional hydraulic gradient and is laterally confined, then either an up-gradient or downgradient slurry wall could be constructed. The barrier must divert ground water around the contaminated site, stop the movement of contaminants, or sufficiently slow their migration to the point where they decay to acceptable levels. Various shapes such as L-shaped walls should be considered.

(a) Information from advertising brochure of Bencor Corporation of America, Dallas, Texas. 
A wall placed up-gradient from the power plant may effectively divert local ground water around the contaminated area. The wall may even divert ground water below the contaminant source without being keyed into a low permeability soil layer. A slurry wall placed down-gradient may sufficiently retard or stop the contaminated leachate (EPA 1982). Contaminated ground water that reaches the wall could be pumped to temporary storage for treatment and subsequent recharge.

Another strategy to prevent contaminated ground water from migrating, is to completely surround the plant with the barrier. This type of barrier is best suited to areas where the direction of ground water may reverse, such as tidal areas and near major rivers (EPA 1982). Surrounding the site with a barrier may have two advantages: 1) uncontaminated ground water is effectively diverted around the contaminant source, and 2) the barrier will isolate the site from the regional hydraulic gradient which would considerably reduce contaminant transport.

As discussed in the section on key-in integrity, there is a possibility that contaminants may vertically leak through irregularities in the keying layer and out of the slurry wall confinement area. Pumping water out of the slurry wall confine can be used to mitigate this downward leakage. As shown in Figure 4.3.2-5, when the fluid level in the slurry wall confinement area is kept at a lower level than the surrounding ground water, flow will be into the confined area, and no contaminants will escape (D'Appolonia undated).

Water should be pumped until a balance in the hydrostatic pressures inside and outside of the contained area directs flow inward. Additional pumping may be needed to maintain this balance, although the slurry wall will greatly reduce the required pumping volume by slowing down the movement of ground water into the confinement site. Pumping to create an inward flux of ground water might not be economical at sites where leakage is great (Harris et al. 1982b).

Care must be taken to avoid hydrofracturing of the slurry wall when pumping. This occurs when the ground-water pressure exceeds the gel strength of the slurry. Blowout tests on slurry samples can be done to determine the hydraulic gradient at which a failure may occur (Harris et al. 1982).

\subsubsection{Performance Considerations for Slurry Trenches}

The effectiveness of slurry walls in restricting ground-water flow depends on several factors. These factors include ground-water conditions, soil limitations, and keying layer restrictions (Harris et al. 1982b). Low permeability is the most important performance criterion that must be met. However, deformability, strength, and durability of the wall should also be considered.

Permeability

Typical values for the coefficient of permeability $(K)$ for several soil types are presented in Table 4.3.2-1. 


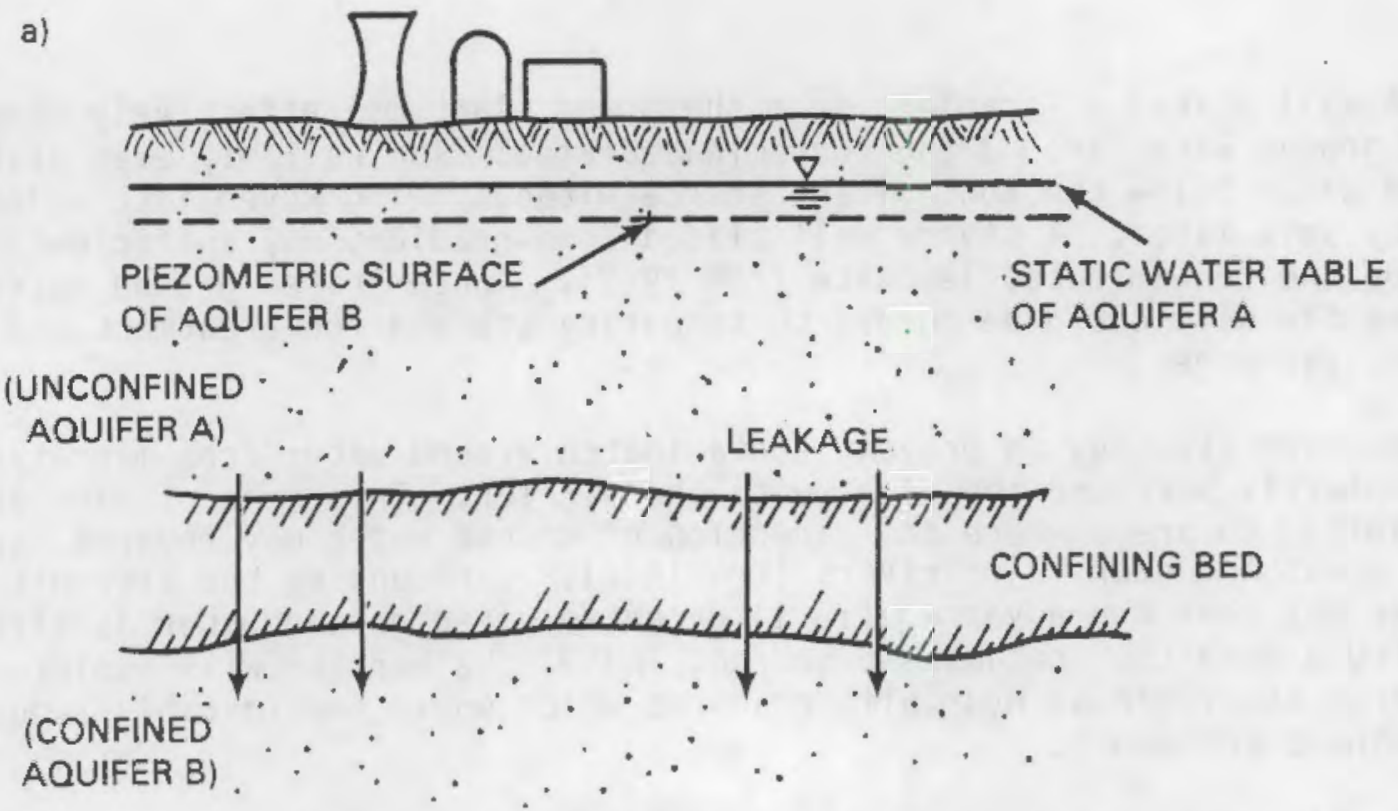

a) PRIOR TO SLURRY WALL INSTALLATION

b)

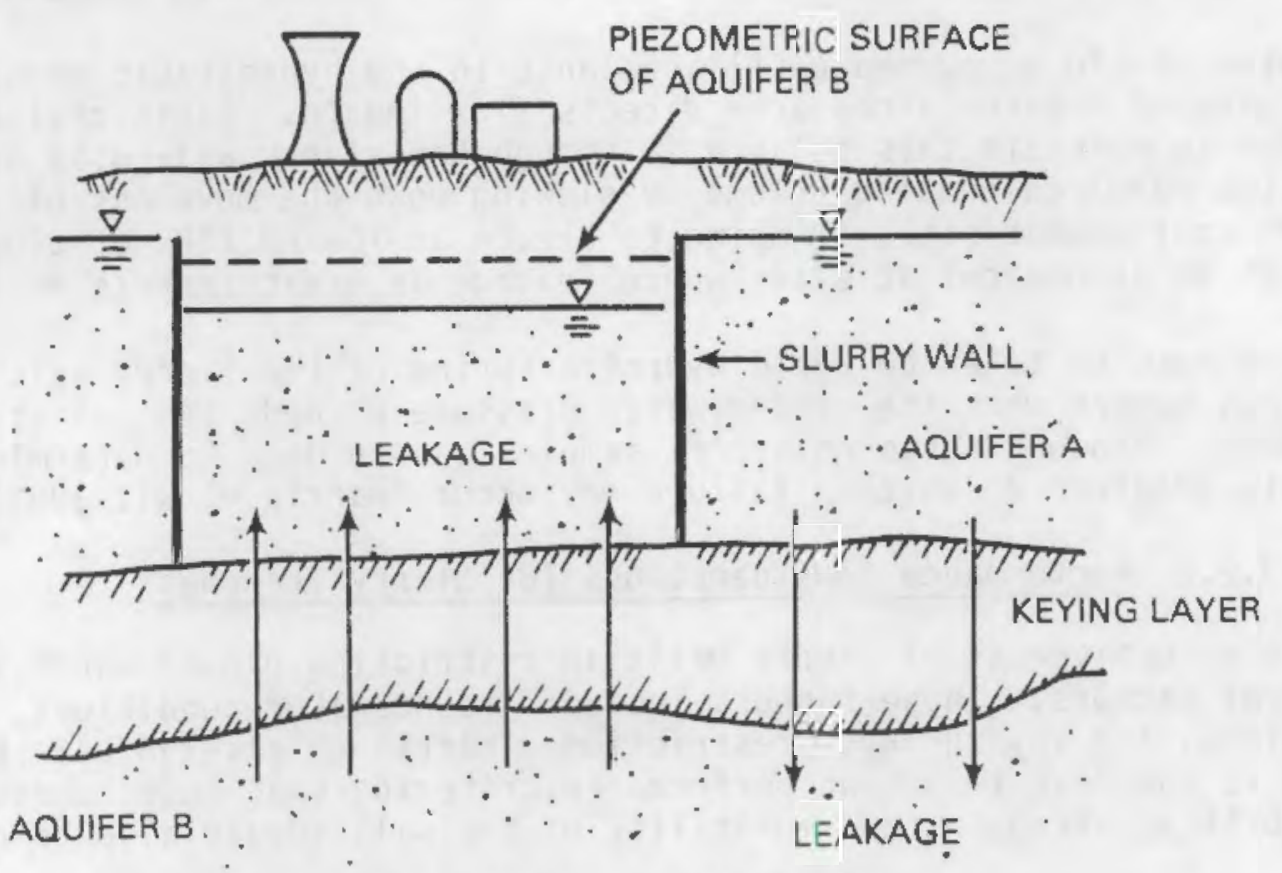

b) AFTER INSTALLATION OF SLURRY WALL

FIGURE 4.3.2-5. Reversal of Leakage Direction Through Aquitard/Keying Layer as a Result of Pumping Ground Water Within Slurry Wall Confines to a Level Below the Piezometric Surface for the Underlying Aquifer (Source: Harrris et al. 1982b) 


\section{TABLE 4.3.2-1. K Values Ranked According to Soil Particle Size.}

(Source: Attewell and Farmer 1976)

$$
\begin{aligned}
& \text { Clay: } k<10^{-7}(\mathrm{~cm} / \mathrm{s}) \\
& \text { Silts: } 10^{-7}<k<10^{-5}(\mathrm{~cm} / \mathrm{s}) \\
& \text { Fine sands: } 10^{-5}<\mathrm{k}<10^{-3}(\mathrm{~cm} / \mathrm{s}) \\
& \text { Coarse sands: } 10^{-3}<\mathrm{k}<10^{-1} \mathrm{~cm} / \mathrm{s} \\
& \text { Gravels: } 10^{-1}<\mathrm{km} / \mathrm{s}
\end{aligned}
$$

\section{Variance of Permeability With Particle Size}

As is shown in Table 4.3.2-1, there is a relationship between particle size and the coefficient of permeability. This is important when considering the proportions of fine and coarse grade particles to be used in the S-B backfill mixture.

Figure 4.3.2-6 plots the permeability of S-B backfill as a function of soil gradation (the bentonite content is held constant at $1 \%$ ). The gradation is classified by the percentage of material that passes through a standard No. 200 mesh sieve. For both plastic and non-plastic fines the smaller the soil particle, the less permeable the backfill. Therefore soil types near the top of the table in Table 4.3.2-1 (clay, silt, and fine particles) will decrease the permeability of the backfill. By using mixes that contain over $30 \%$ plastic fines, a low permeability wall can be made (D'Appolonia undated).

The amount of bentonite clay used, also has an effect on permeability. In Figure 4.3.2-7 the amount of bentonite is plotted against the permeabilities of backfills containing various grades of soils. Permeability is shown to decrease as increasing percentages of bentonite are used. However, a mix containing a high bentonite concentration is seldom used for the reasons pointed out in the following example.

Performance criteria specifying the limits on the gradation of the backfill mix are often required of the contractor building the slurry wall. At a hazardous waste disposal site located in Nashua, New Hampshire (Ayres el al. 1983), the backfill material was required to contain over $5 \%$ bentonite and over $30 \%$ fines. The desired permeability of $10^{-7} \mathrm{~cm} / \mathrm{s}$ for the completed slurry wall could have been achieved with the addition of bentonite alone. The silt size fines were used instead because they were less expensive, improved the consistency of the backfill, and were found to degrade less in the presence of leachate from the dumpsite. 


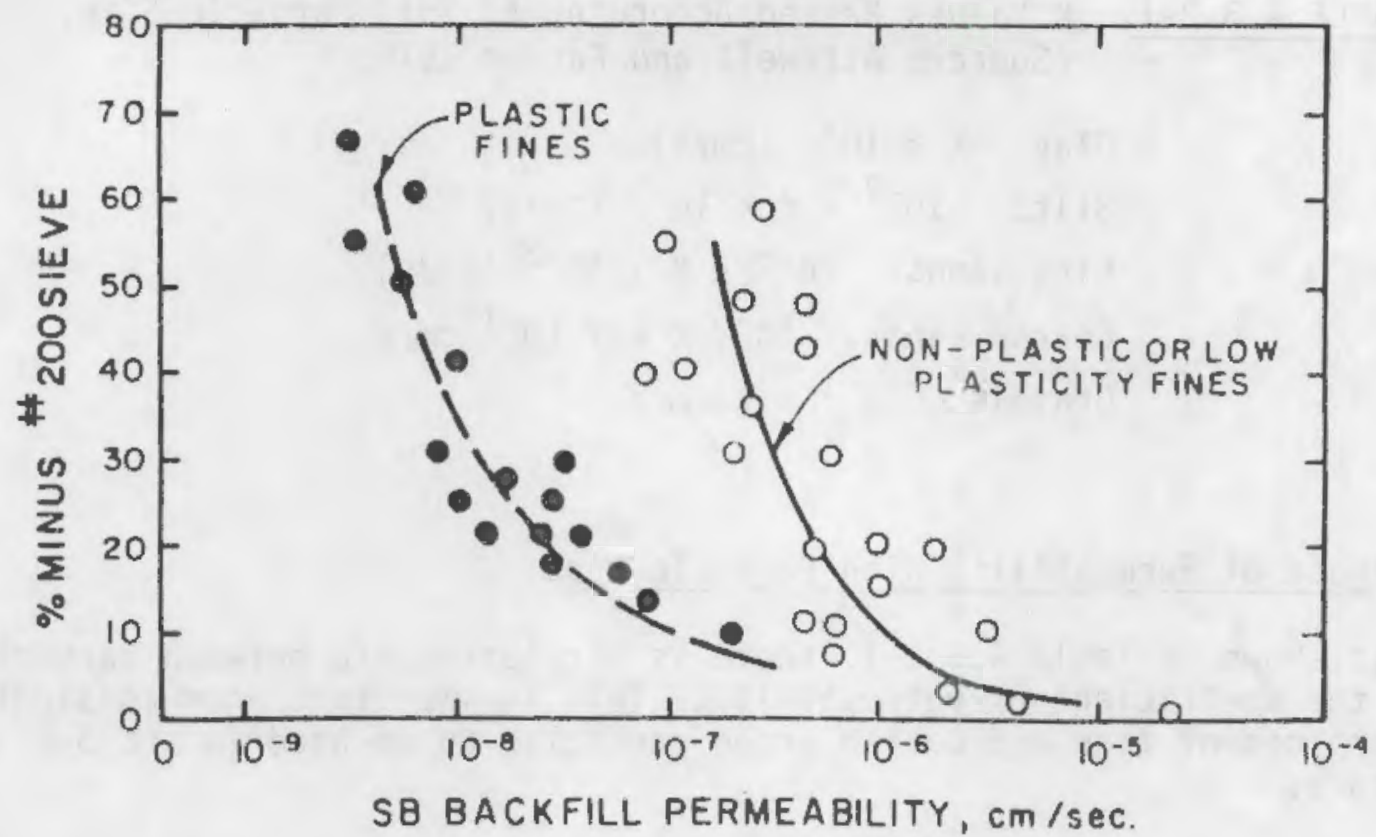

FIGURE 4.3.2-6. Permeability of Soil-Bentonite Backfill Related to Fines Content (Source: D'Appolonia undated)

The grade of the bentonite used has an effect on the permeability of a slurry wall. Bentonite of higher grade has a greater swelling potential and will be less pervious (Ayres et al. 1983).

\section{Filtercake Versus Backfill Permeability}

As shown in Figure 4.3.2-8 there are two phases for a S-B slurry wall. First there is an outer filtercake layer formed by the seeping of the slurry through the walls of the trench. The bentonite penetrates through the sidewalls to a distance dependent on the surrounding soil permeability and on the viscosity and gel strength of the bentonite suspension (Harris et al. 1982b). This thickness ranges from less than a meter to a meter. (a) Seepage stops when the filtercake thickness limits any more flow (Ryan undated).

The inner phase of the cut-off wall is made up of the backfilled material ( $S-B$ method), concrete ( $L-C$ method), or the hardened slurry ( $C-B$ and VBT methods). The down-gradient side of the filtercake is often ruptured by seepage forces and extruded into the trench sidewall (D'Appolonia 1980). The upgradient side usually stays intact. Separate permeability tests on the filtercake and the backfill of C-B slurry walls have been carried out (Harr et al. undated).

(a) Information from advertising brochure of Bencor Corporation of America, Dallas, Texas. 


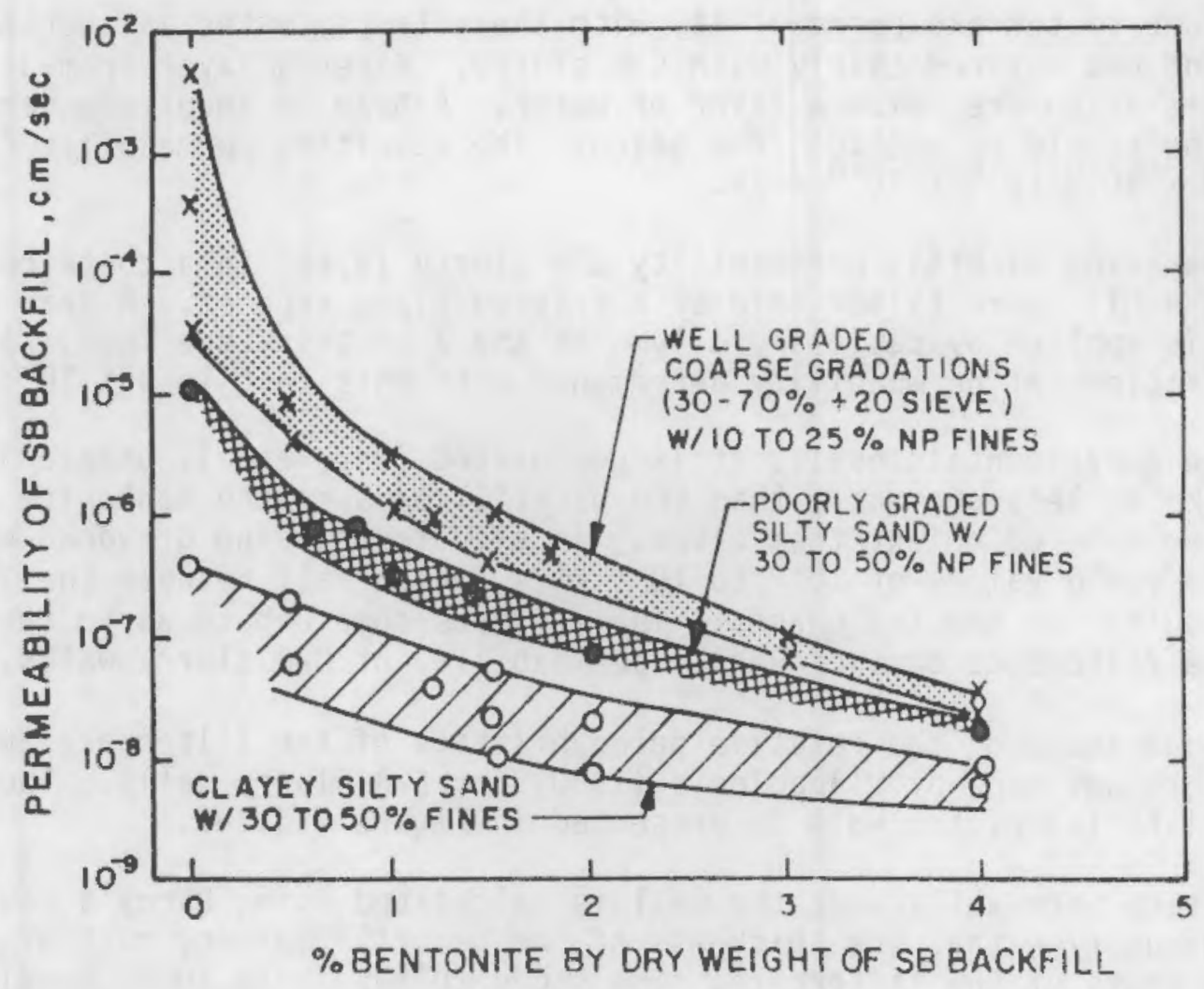

FIGURE 4.3.2-7. Relationship Between the Permeability and Quantity of Bentonite Added to S-B Backfill (Source: D'Appolonia undated)

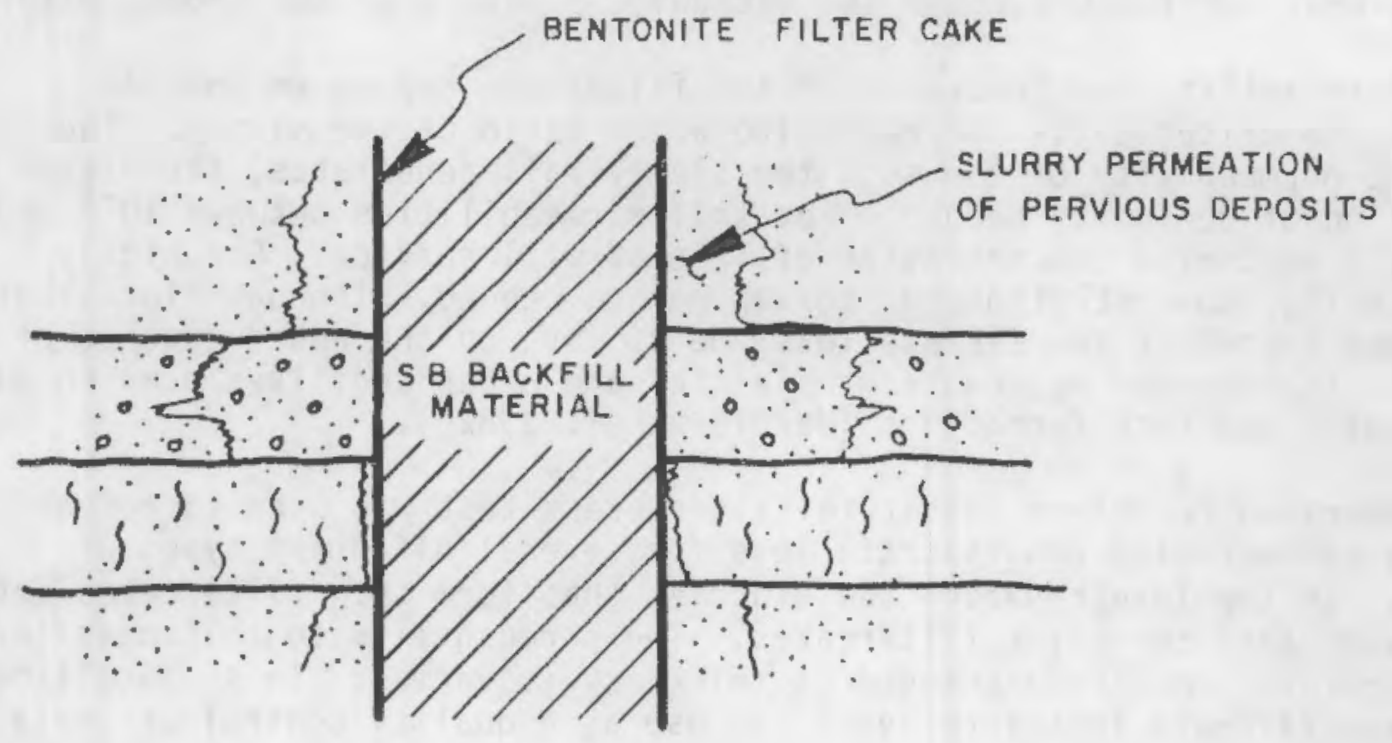

FIGURE 4.3.2-8. Schematic Cross Section of S-B Slurry Trench Cut Wall (Source: D'Appolonia undated) 
To measure filtercake permeability with these tests, water is suctioned through a sand bed covered thinly with C-B slurry. After a layer from 3 to $4^{\circ} \mathrm{mm}$ forms, it is covered with a layer of water. A head of about 9 meters is applied to the sample by suctign from below. The resulting permeability values range from $3 \times 10^{-8}$ to $5 \times 10^{-8} \mathrm{~cm} / \mathrm{s}$.

When measuring backfill permeability the slurry is put in a container in contact with a Millipore filter held by a fritted glass support. A head of about $30 \mathrm{~cm}$ is applied by capillary column on the $3 \mathrm{~cm}$ thick specimen. A typical coefficient of permeability determined with this test is $3 \times 10^{-6} \mathrm{~cm} / \mathrm{s}$.

From the experimental results it is postulated (Harr et al. undated) that the filtercake is less permeable than the backfill because the bentonite particles have more time to orient themselves. In situ tests using drawdown methods in test wells yield values of $10^{-6}$ to $10^{-7} \mathrm{~cm} / \mathrm{s}$, which fall between the laboratory test results for the two phases. There exists some debate as to the effect of the filtercake on the overall permeability of C-B slurry walls.

A thorough study of the relative permeabilities of the filtercake and backfill layers was done by D'Appolonia (1980) for S-B slurry walls. The average permeability (K) of the wall is presented in Figure 4.3.2-9.

The average permeability of the wall is calculated using Darcy's Law and making the assumption that the thickness of the backfill is very much greater than the thickness of the filtercake. The study (D'Appolonia 1980) concluded that the overall permeability of the slurry wall is controlled by the backfill when the backfill permeability is low. However, when the backfill permeablity is high the filtercake is the controlling factor. Furthermore, due to the low permeability of the filtercake, the upper limit of the wall permeability is on the order of $10^{-6} \mathrm{~cm} / \mathrm{s}$. This figure is accurate assuming that the up-gradient filtercake does not rupture under the hydraulic pressure of the ground water.

The permeability and thickness of the filtercake depend on several criteria. One criterion is the bentonite-water ratio of the slurry. The greater the permeability of the soil the slurry wall penetrates, the higher the concentration of bentonite needed. For soil permeabilities between $10^{-1}$ and $10^{-2} \mathrm{~cm} / \mathrm{s}$, a bentonite concentration of 4 to $6 \%$ will suffice. For highly permeable soils, concentrations up to $12 \%$ may be needed, although flocculants can be added to reduce the fitrate loss and to save on the added expense of the bentonite. Lightweight aggregate or plastics are other additives used to plug fissured soils and rock formations (Harris et al. 1982b).

The American Petroleum Institute filter press test was used to compare filtercake permeability and filtrate loss for several different types of bentonite. In the investigation the slurries that form thin filtercakes were less pervious than the thick filtercakes. The permeability to thickness ( $k / t)$ ratio, therefore, remains unchanged as thickness is varied. This cancelling effect makes filtrate loss irrelevant for use as a quality control criteria. 


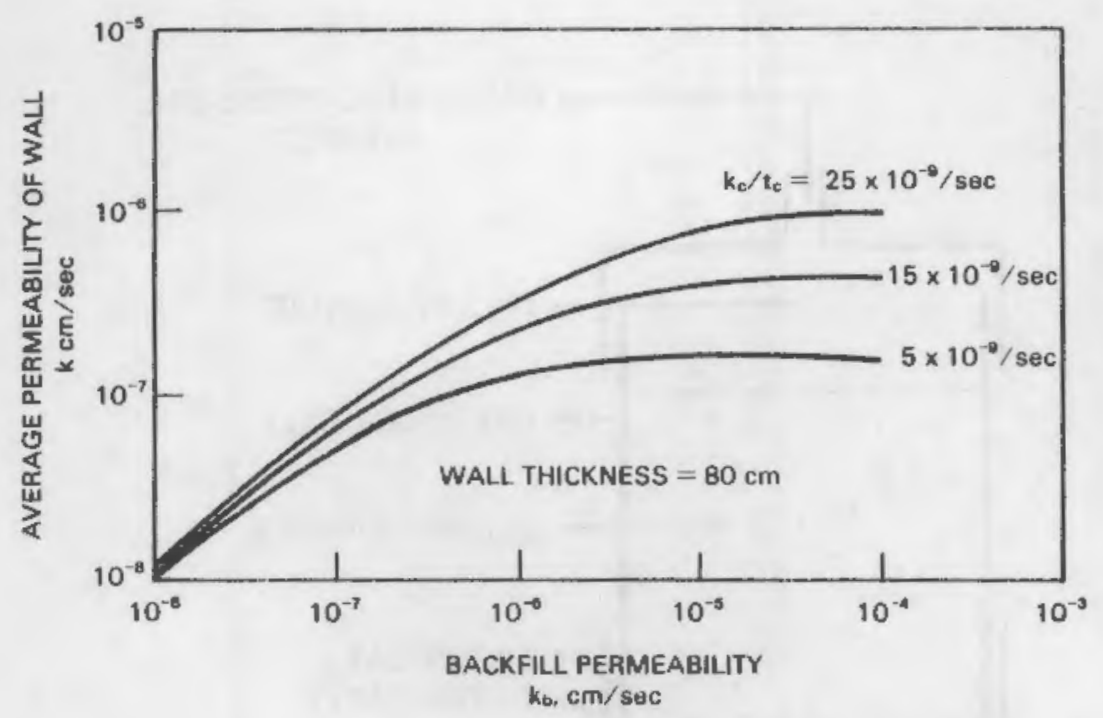

FIGURE 4.3.2-9. Theoretical Relationship Between Wall Permeability and Permeability of Filtercake and Backfill (Source:

D'Appolonia 1980) b = backfill, $c=$ filtercake, $t_{C}=$ thickness of filtercake)

The Marsh Funnel Test is commonly used to determine viscosity. The test involves simply recording the time it takes for a slurry to run through a funnel of standard size. This amount of time is referred to in "Marsh-seconds". D'Appolonia (1980) found the viscosity of the slurry to have little effect on filtercake permeability if it is measured greater than about 38 Marsh seconds.

The time it takes for the filtercake to form and the difference in head between the slurry and the pore fluid in the soil also have an effect on the filtercake (D'Appolonia 1980). In a filter press test, using the apparatus shown in Figure 4.3.2-10, permeability $(\mathrm{K} / \mathrm{t})$ is measured by the flow rate of water through the filtercake layer, divided by the head and area of the sample.

In an experiment done by D'Appoplonia (1980) cake permeability is plotted against the head applied to the sample for four varying lengths of time (Figure 4.3.2-11). The four seperate curves plotted from the data imply that the filtercake permeability is more dependent on the formation time than on the pressure applied to it. Lower permeabilities were found for filtercakes formed over greater periods of time. Letting a slurry with a viscosity of over 40 Marsh seconds sit in the trench for 24 hours before backfilling allows a filtercake of a sufficiently low permeability to form.

Soil Permeability Limits for Slurry Wall Use

A typical soil-bentonite slurry wall containing $10-20 \%$ fine particles (No. 200 standard sieve) and $2-4 \%$ bentonite clay hy weight will have a 


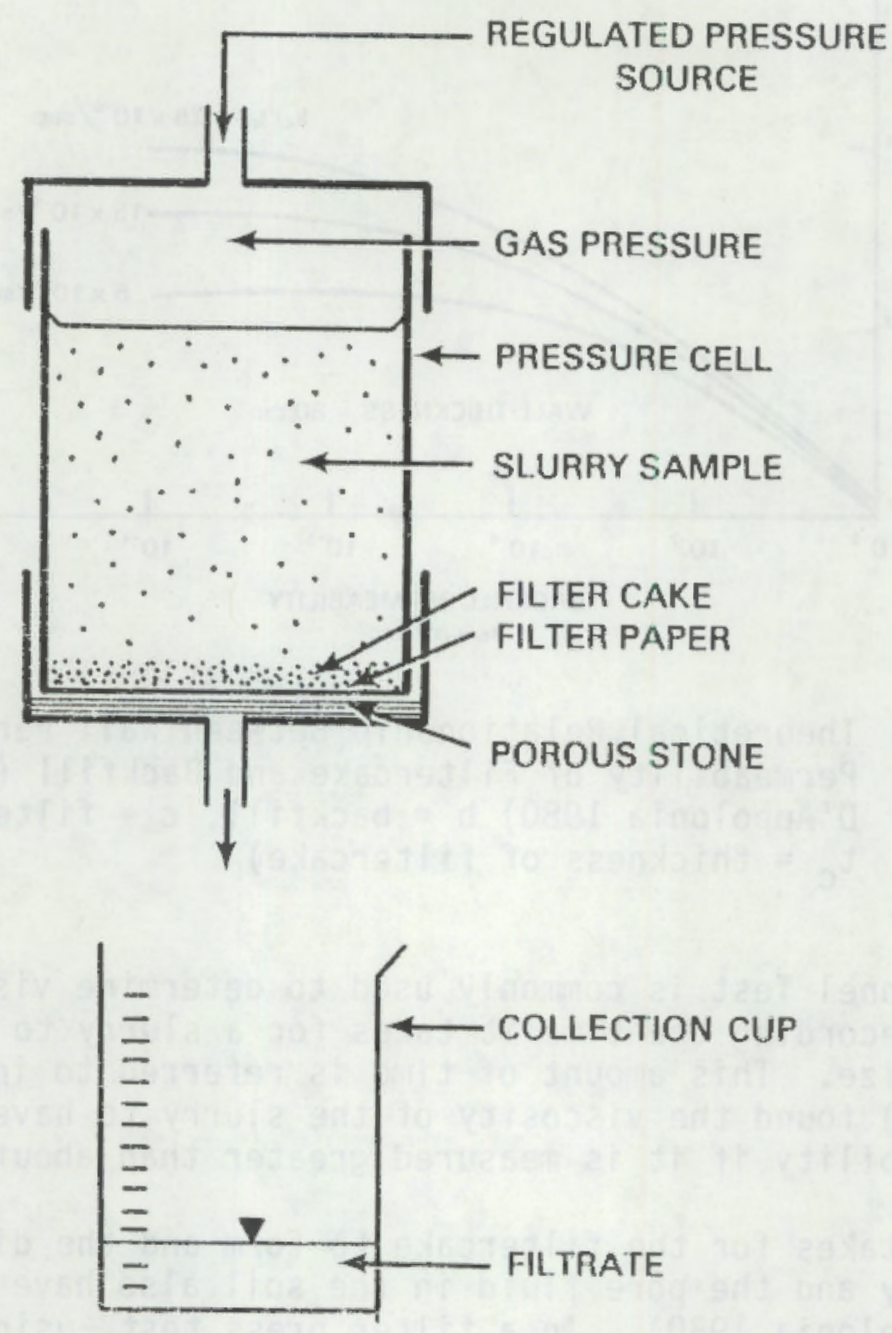

FIGURE 4.3.2-10. Schematic of Filter-Press Test Apparatus (Source: D'Appolonia 1980)

permeability of about $10^{-7} \mathrm{~cm} / \mathrm{sec}$ (Millet and Perez 1981). Darcy $\mathrm{K}$ factors between $10^{-6}$ and $10^{-7} \mathrm{~cm} / \mathrm{sec}$ are found with field measurements for cementbentonite slurry walls (Harr et al. undated). This range in permeability values encompasses that of clay (shown in Table 4.3.2-1). A slurry wall, therefore, placed in a clay medium would not decrease the flow velocity of contaminated ground water through that area; the wall would be a redundant feature. The wall would be helpful if there were highly fissured zones within the relatively impervious soil, or if a less permeable slurry wall was used. New]y developed $C-B$ slurry mixes are reaching Darcy $K$ values between $10^{-9}$ and $10^{-10} \mathrm{~cm} / \mathrm{s}$ (Harr et al. undated). 


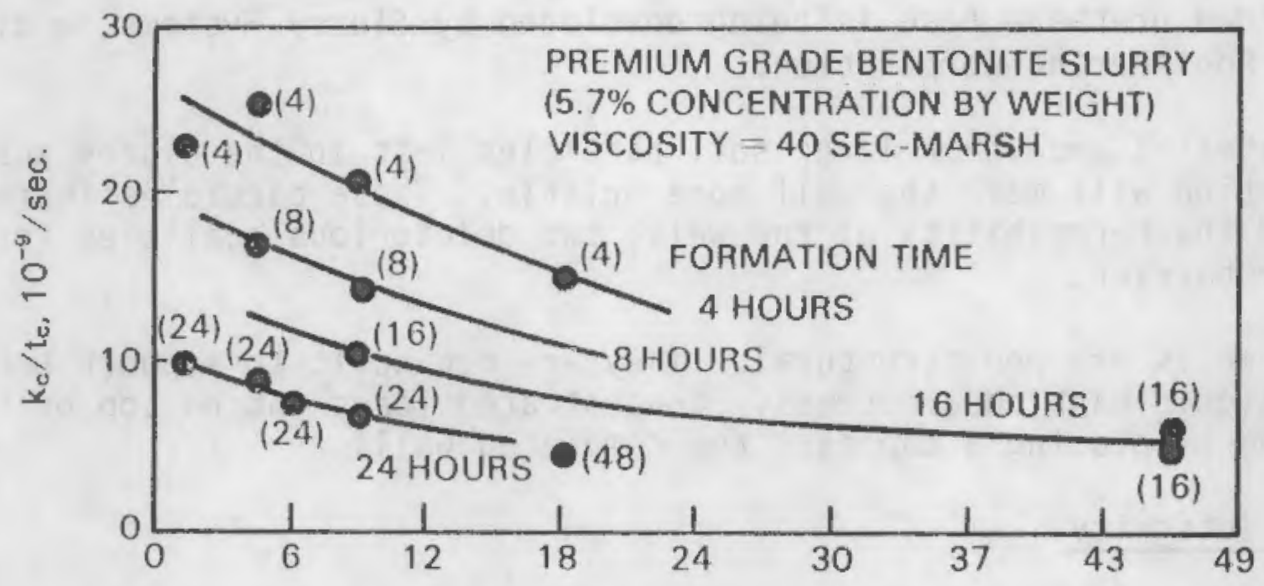

CAKE FORMATION PRESSURE, meter OF WATER

FIGURE 4.3.2-11. Relationship Between the Filtercake Permeability and Cake Formation Pressure and Time (Source: D'Appolonia 1980)

When seepage velocities are above $5 \mathrm{~cm} / \mathrm{s}$ the bentonite particles in the soil-bentonite slurry cannot layer themselves to form filtercake on the trench sidewalls. The slurry will seep through highly permeable soils and will not fulfill its function of stabilizing the trench. Plastics or light-weight aggregate can be used to slow slurry losses through rock, gravel, and other very permeable layers (Harris et al. 1982b).

In summary, the utilization of slurry walls is limited to soils having Darcy $K$ values greater than $10^{-6} \mathrm{~cm} / \mathrm{s}$ and ground-water velocities less than $5 \mathrm{~cm} / \mathrm{s}$. This range is sujtable for most soils, since their permeability range averages from $10^{-2}$ to $10^{-3} \mathrm{~cm} / \mathrm{s}$.

\section{Continuity}

A slurry wall must be continuous and have good integrity to maintain low permeablility. Often times C-B slurry walls and L-C slurry walls are constructed in sections. The connections between the sections must be good to avoid cold joints or windows through which ground water could leak. Retarders can be used to slow the hardening process and permit better contact between panels (Millet and Perez 1981).

A high level of plasticity will permit the healing of cracks caused by the ground shifting or other pressures put on the wall. A S-B slurry wall is similar to a slowly thickening gelatin. The slurry migrates toward the point of higher liquid flow. This expansion tends to repair seal deformations and fissures in the wall.

C-B slurry walls are not considered infinitely plastic. Although they can withstand compressive strains of several percent under in-situ conditions without cracking. A new slurry wall construction method having elastic properties 
and an extended urethane base is being developed by Slurry Systems, a division of Thatcher Engineering Corporation.

Sand material and other large soil particles left in the slurry suspension after excavation will make the wall more brittle. These particles increase the strength and the permeability of the wall; two deleterious qualities for a ground-water barrier.

Slurry walls are non-structural. They are not built to support bending moments of significant shear stress. Concentrated loads put on top of the wall are mitigated by placing a cap over the completed wall.

\section{Key-ir. Integrity}

To insure low permeability, contaminated ground water must be stopped from flowing under the slurry wall. The slurry wall should penetrate through all pervious zones, such as desiccation cracks, and make a good connection (i.e., have high keying-in integrity) with a highly impervious layer beneath it.

If the underlying stratum is clay, the wall should be keyed from $0.5 \mathrm{~m}$ to $1.0 \mathrm{~m}$ ( $2 \mathrm{ft}$ to $3 \mathrm{ft}$ ) into the layer. When bedrock is the keying layer, the slurry wall is usually built directly over it (EPA 1982). Percussion drilling to excavate the trench through the bedrock is expensive and can cause the rock to fracture. In this case the bottom of the trench is cleaned thoroughly to insure that unwanted sediments (i.e., those of higher permeability than the surrounding soil) that could cause pervious voids are not caught between the bedrock and the slurry wall.

Discontinuities in bedrock or gaps in soil can be filled by grouting. The grouting method consists of pumping a $\mathrm{C}-\mathrm{B}$ slurry into the ground under pressure to seal any voids beneath the slurry wall.

Contaminants can travel vertically through a leaky keying layer in several ways (Harris et al. 1982b). Figure 4.3.2-12a shows a slurry wall which has been keyed into a layer of low permeability. The contaminated ground water seeps through this layer to the main aquifer below. In Figure 4.3.2-12b the slurry wall is keyed into sufficiently impervious geological strata with good integrity. The contaminants, though, leak through a permeable window inside the contained area. A similair problem exists in Figure 4.3.2-12d where contaminants leak through an undetected permeable zone. Grouting has been used in Figure 4.3.2-12c to seal voids around the bottom of the slurry wall. Leakage still occurs through cracks in the soil strata. Pumping can mitigate the downward flow of contaminated ground water, although it is more economical to avoid this situation by carrying out proper tests during design.

\subsubsection{Appropriate Geologic Media}

Typical ground sequences where slurry cut-off walls have been succesfully used are shown in Figure 4.3.2-13. It is important to consider variances in soil types, and the depth at which they occur in the implemenation area for 

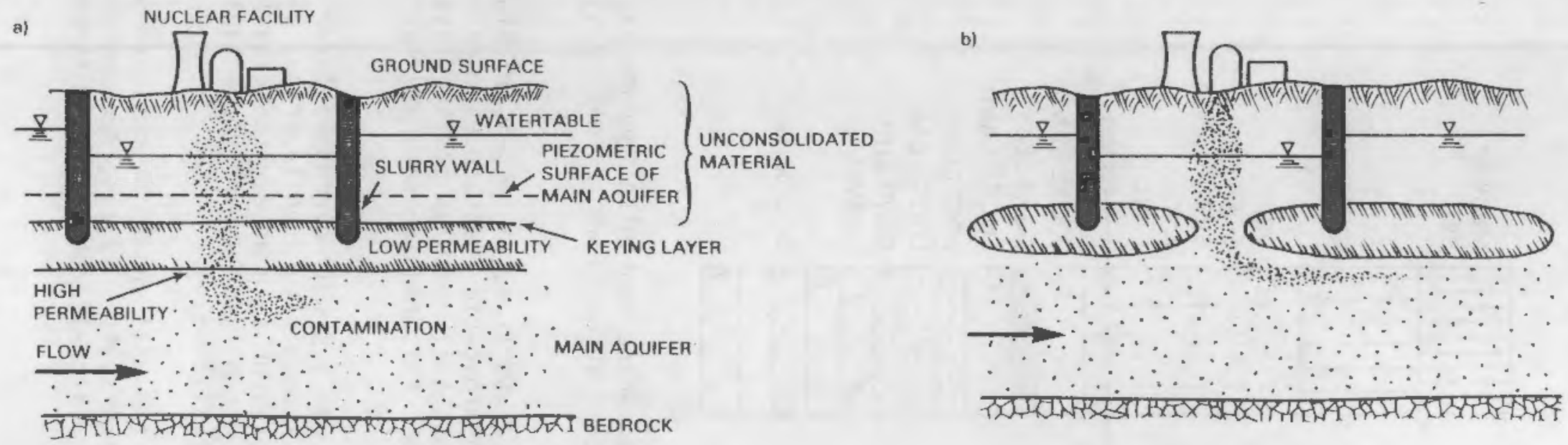

$\stackrel{+}{\omega}$
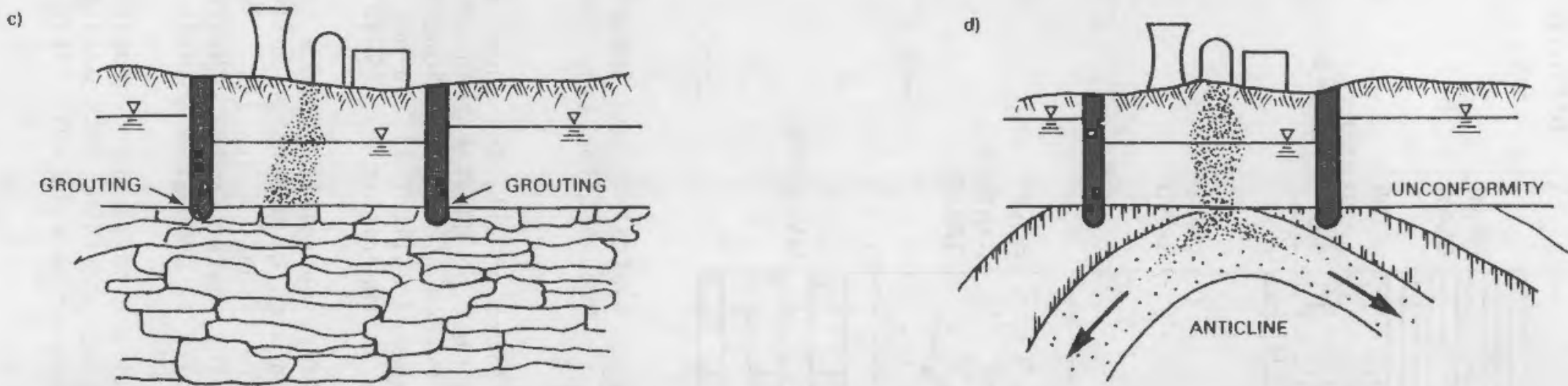

FIGURE 4.3.2-12. Vertical Leakage of Contaminants [through: (a) area of high permeability in aquitard layer, (b) opening in discontinuous clay lenses, (c) secondary openings in limestone or dolomite, (d) undetected geological structures (Source: Harris et al. $1982 \mathrm{~b})]$ 


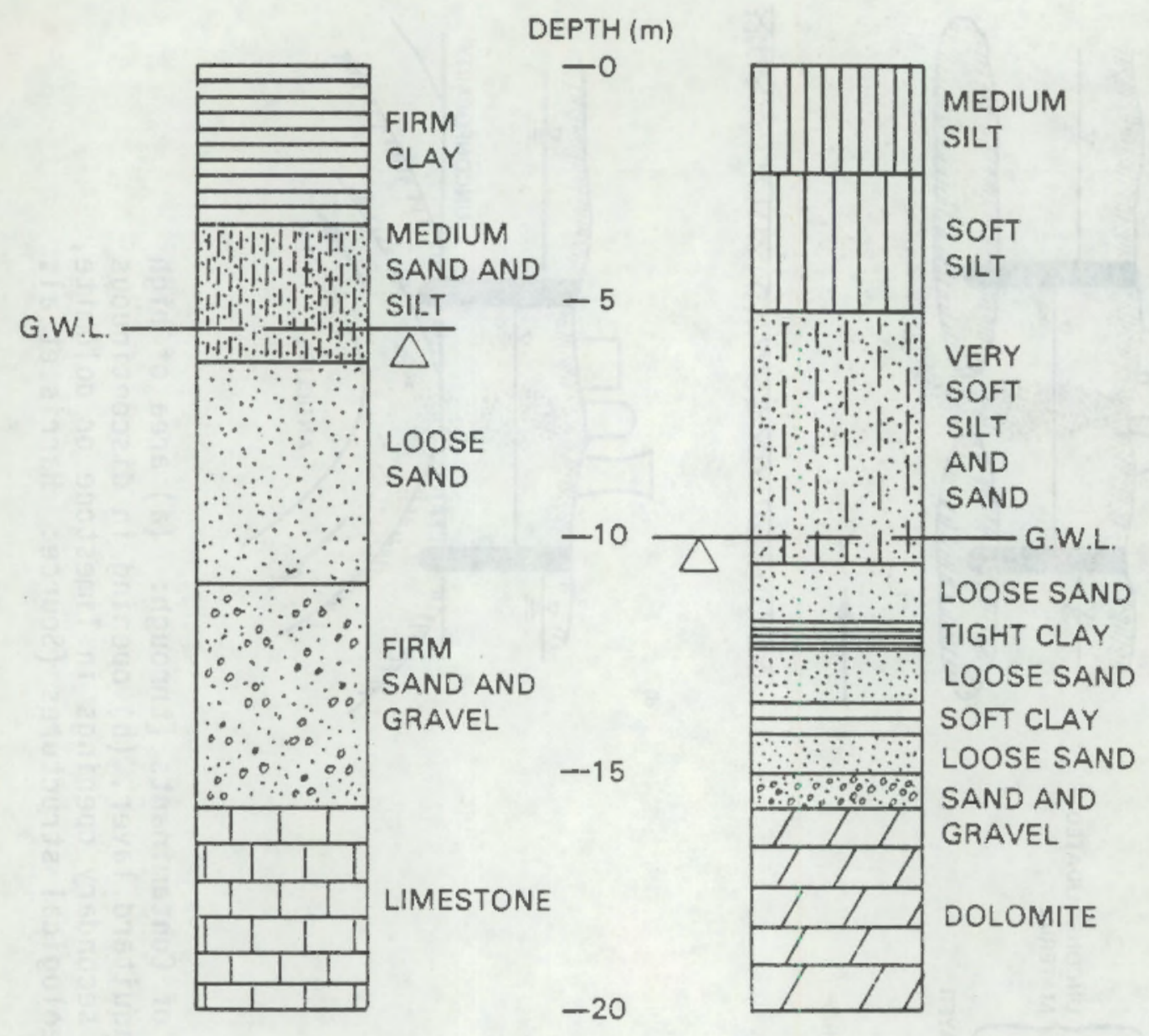

FIGURE 4.3.2-13. Typical Ground Sequences Where Bentonite Support Has Proved Effective (Source: Attewell and Farmer 1976)

several reasons. First of all, the shear strength (i.e., internal friction) of each soil layer must be greater than the hydrostatic pressure exerted by the slurry on the trench sidewalls. Some loose soils such as marine clays, alluvium, and fresh hydraulic fill, do not meet this requirement, and may cause the trench to cave in (Harris et al. 1982b).

Seepage of slurry out of the trench through a highly permeable layer such as gravel, combined with ground-water inflow from a saturated layer may also cause trench failure (Figure 4.3.2-14). To prevent such an event, tests for permeability, density, water content, hydrologic pressures, and porosity for each soil type should be conducted (Harris et al. 1982b).

If loose soils are an expected problem, the wall should be designed as straight as possible. Draining with well-point systems is also recommended in some cases to decrease the soil void ratio and increase the shearing strength. 


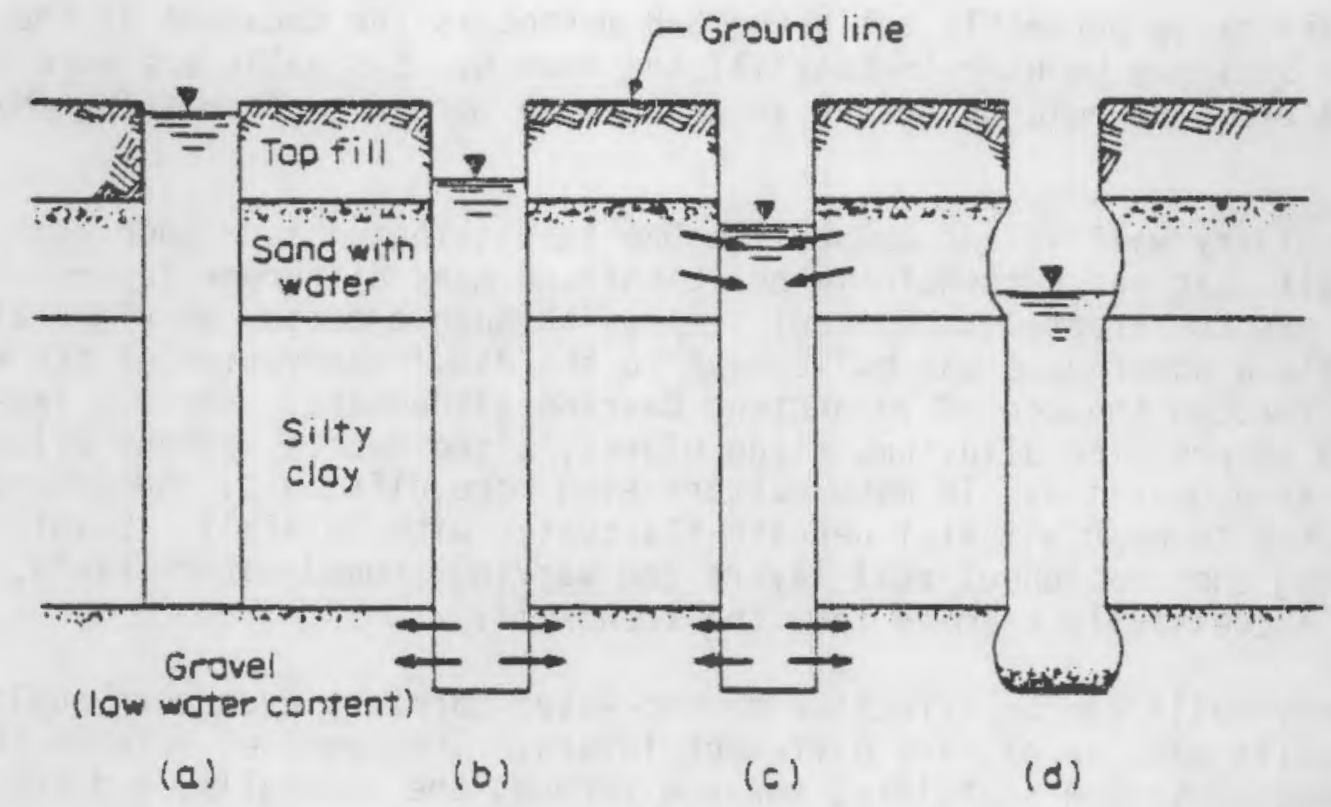

FIGIIRE 4.3.2-14. Loss of Slurry Water to Unsaturated, Highly Permeable Gravel Zone Leads to Loss of Slurry (Source: Harris et al. 1982b)

A dense array of well-points may be needed to draw water from soft soils which have low permeabilities. The likelihood of trench collapse can also be lessened during construction by excavating smaller panels and backfilling them appropriately.

The type of geological media encountered is a factor in choosing the type of slurry wall. Compact soils have greater shear strengths and exert less pressure against a slurry, whereas loose and soft soils would tend to collapse in the trench. A C-B slurry may be the best choice in soils prone to trench failure. A C-B slurry wall is more viscous than the S-B slurry, provides more physical strenghth when hardened, and is easier to repair if a failure does occur (Harris et al. 1982b).

A C-B slurry may be the best choice in very permeable soils such as sands. Due to its high viscosity and density, there would be less slurry loss by seepage through the trench walls.

The saturated loose type soils are best for the VBT method because less force is needed to penetrate these soils (Schmednecht undated). The beneficial qualities of a $C-B$ slurry (i.e., viscous and self-hardening properties) also exist for a VBT slurry in loose soils, because they are basically the same mixtures.

The L-C wall is most appropriate in deeper trenches that pass through coarse gravel and boulder zones (Harris et a1. 1982b). A C-B slurry wall might ordinarily be effective in highly permeable zones except it might set before the excavating depth is reached. 
In mid-range permeable soils the $S-B$ method is the cheapest if the excavated soil can be used to backfill the trench. S-B walls are more elastic and could prove to hold up better in areas with more ground shifting (Miller 1979).

The slurry wall at the Bonneville Dam in Washington is a good example of a slurry wall that was successfully built through many different layers of soils. The wall was constructed to control seepage through a bottom pervious alluvium layer while a powerhouse was built next to the dam. Excavation of the trench was made through the toe of an ancient Cascade slide mass. Various layers consisted of preslide alluvium, slide blocks, slide debris, recent alluvium, and deep sand deposits. To make matters even more difficult, the ground-water level in the topmost alluvial deposit fluctuates with rainfall. Despite the challenging combination of soil layers and varyjng ground-water levels, a L-C wall was successfully tremied into the trench ${ }^{(a)}$.

Slurry walls can be effective ground-water barriers even when built through soils made up of many different layers. The combined effects these layers have on trench stability, seepage through the sidewalls, and the soil needed for backfill ( $S-B$ wall), should be thoroughly studied while designing and choosing the type of slurry wall to be used. The geological history of the area and boring tests are good sources of this information.

\section{Preconstruction Testing}

Soil characteristics important in designing a slurry trench cut-off wall for a specific site are: permeability, the amount of soil stratification, and the depth and nature of the impervious layer.

Many techniques are used to gather this information. At the Rocky Mountain Arsenal (Miller 1979), located in Denver, Colorado, test boring holes were made around a contaminated basin (Figure 4.3.2-15). The results were used to determine the depth to bedrock and the orientation of subsurface materials to be penetrated by the slurry wall.

In Figure 4.3.2-16, four borings depict a two-dimensional vertical cut into the ground. Table 4.3.2-2 shows the Unified Soil Classification used in the boring profile. The horizontal line that approximately bisects the profiles divides the top most clay soils from the sandy soils below. The shale key-in layer is shown by the lower line. Rock quality designation (RQD) indices and qualitative hardness are sometimes used to characterize the bedrock to determine ripability. It was decided that the slurry wall was to be keyed into the shale layer by at least 0.6 meters

The borings were made by a hollow stem auger. Split spoon samples were taken at $1.5 \mathrm{~m}$ increments of change in stratum. Tests results from these samples for boring profile \#461 can be seen in Figure 4.3.2-17. The table

(a) Information from advertising brochure of Bencor Corporation of America, Dallas, Texas. 


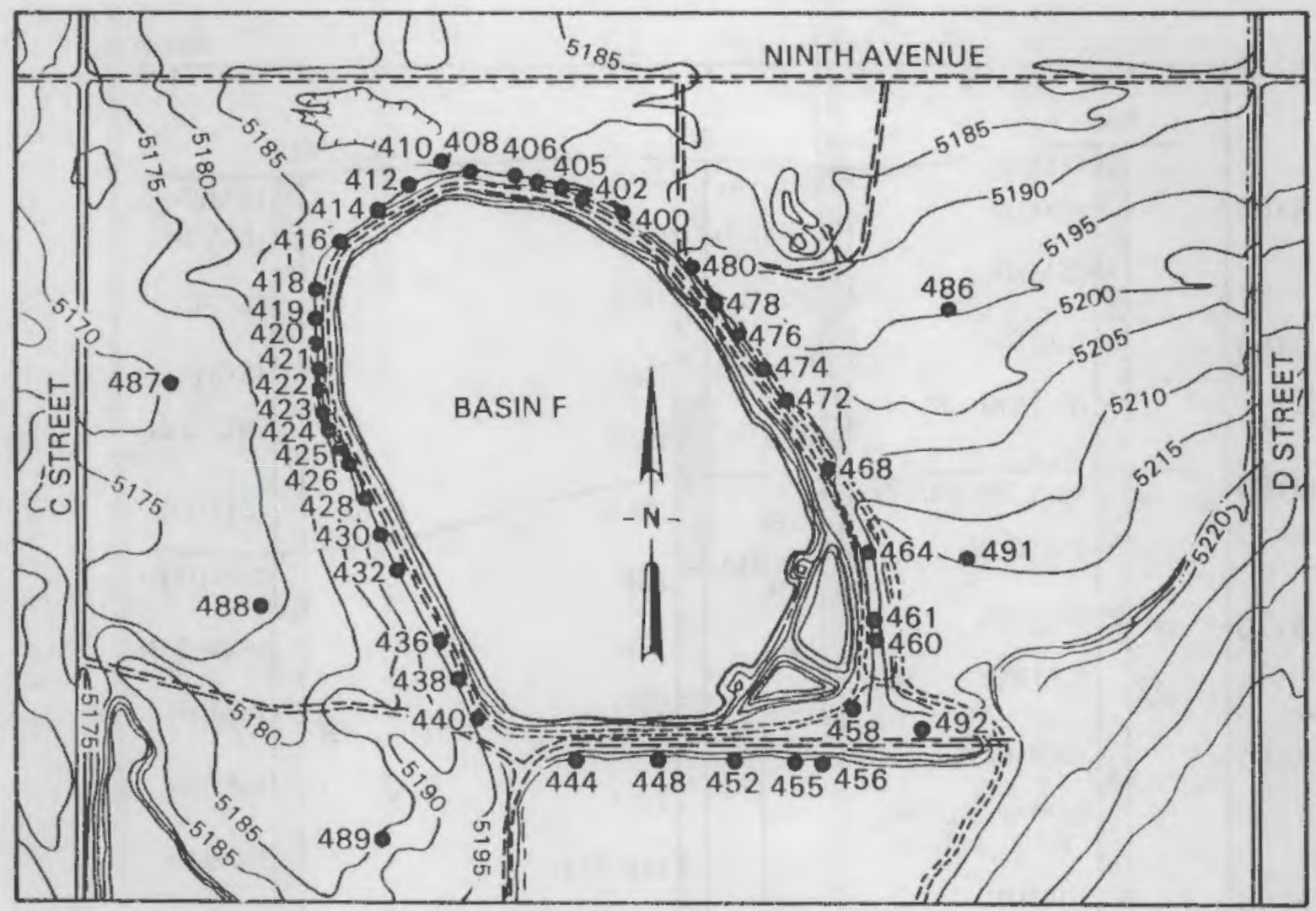

FIGIIRE 4.3.2-15. Soil Boring and Dbserving Well Locations in the Basin F Area at the Rocky Mountain Arsenal (Source: Warner 1979)

directly next to the boring shows the blows per foot, or $N$ value, a measure of the relative density of the soil. These values were estimated from Standard Penetration Test results (Figure 4.3.2-18). This test is fairly reliable for sands, but is a crude measurement for clays (Peck 1953).

The water content naturally occuring in the soil types is indicated by an unfilled circle in Figure 4.3.2-17. The dark dots mark the Atterberg plastic state limits which define the effect of exchangeable ion composition and are sketched for only the clay minerals. The minimum moisture content at which a clay exibits plasticity is the plastic limit. The liquid limit is the point at which the clay begins to flow (Attewell and Farmer 1976). Specific gravities, and estimated values of density, strengths, and porosities are also tabulated.

At the Nashua, New Hampshire site (Ayres et al. 1983), gradation tests were done using on-site soils and soils brought in from elsewhere. Hydraulic conductivity tests on S-B mixtures using both short term, high gradient and 


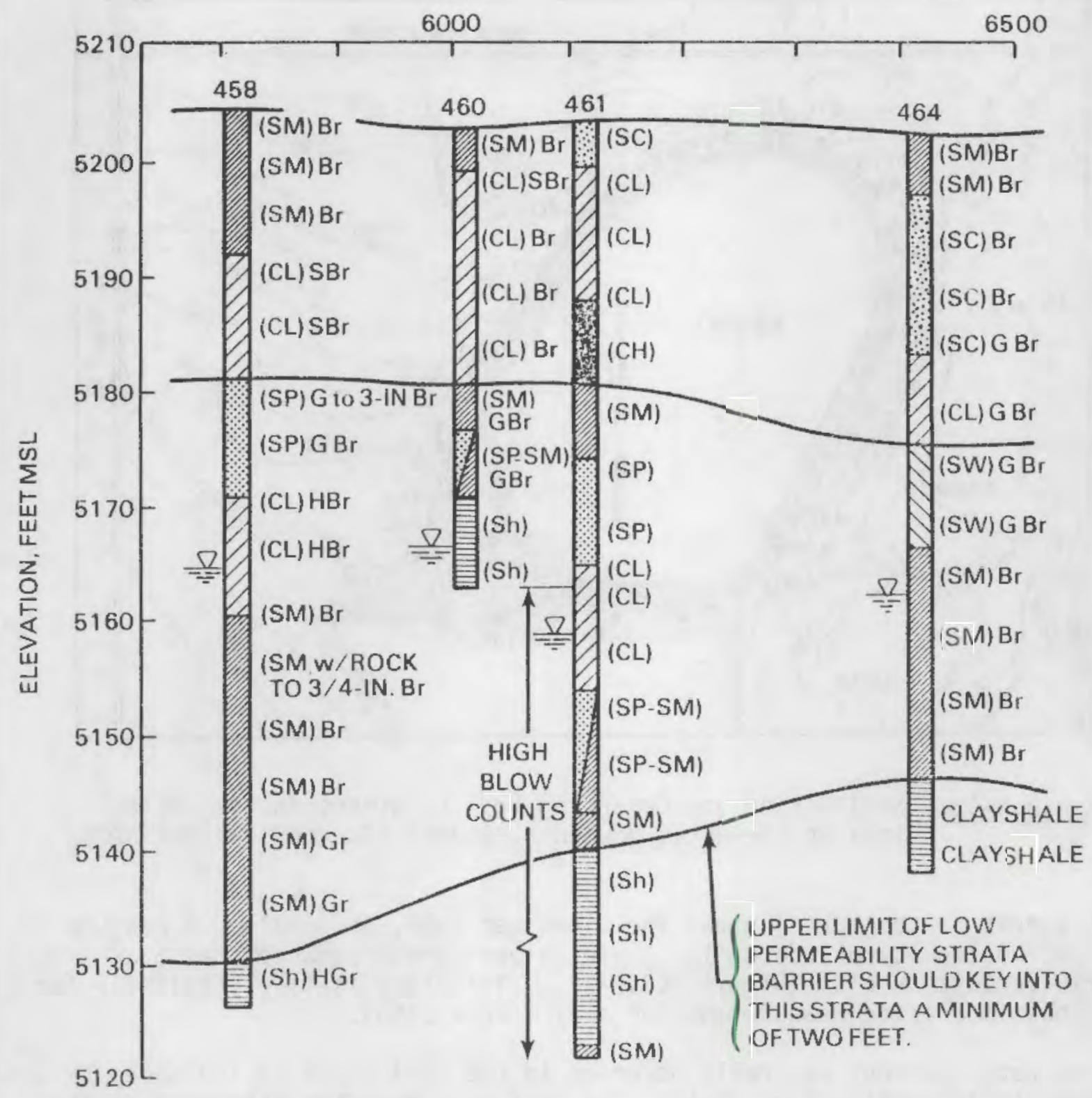

FIGURE 4.3.2-16. Partial Soil Profile Depicted by Borings Around Basin F at Rocky Mountain Arsenal (Source: Warner 1979)

long terin, low gradient methods along with $x$-ray diffraction tests, of samples permeated with the contaminated leachate, were used to set limits on the amount of fine grained borrow and bentonite additives to be used.

Other preconstruction testing includes hydrogeologic investigations to determine the depth, flow rate, direction, and chemical characteristics of ground water. These characteristics need to be known to prevent caving in of 


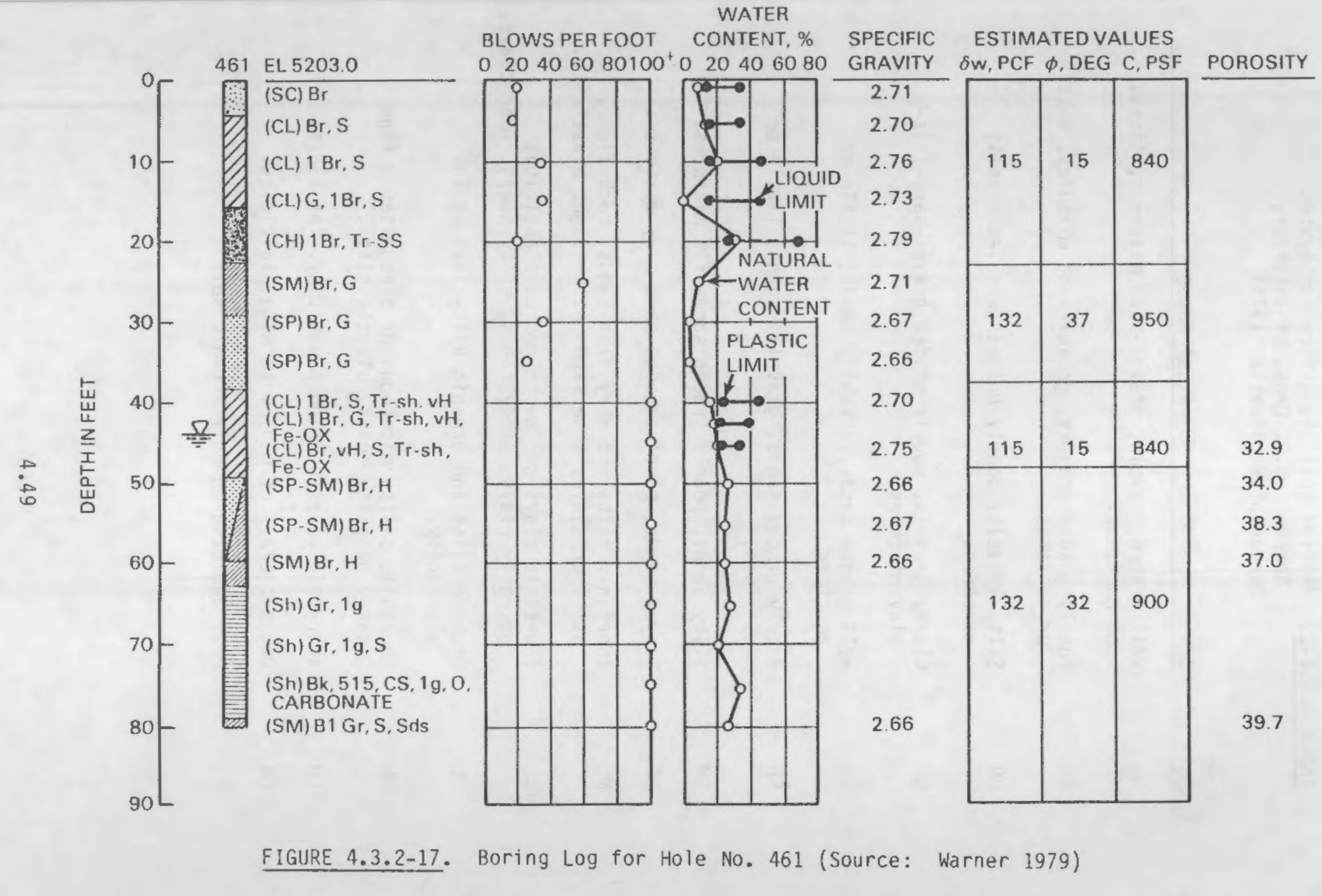


TABLE 4.3.2-2. Unified Soil Classification System (Source: U.S. Dept. of Interior, Bureau of Reclamation 1974)

Group

Symbols Typical Names

GW Well graded gravels, gravel-sand mixtures, little or no fines.

GP Poorly graded gravels, gravel-sand mixtures, little or no fines.

GM Silty gravels, poorly graded gravel-sand-silt mixtures.

GC Clayey gravels, poorly graded gravel-sand-siltclay mixtures.

SW Well graded sands, gravelly sands; little or no fines.

SP Poorly graded sands, gravelly sands; little or no fines.

SM Silty sands, poorly graded sand-silt mixtures.

SC Clayey sands, poorly graded sand-clay mixtures.

ML Inorganic silts and very fine sands, rock flour, silty or clayey fine sands with slight plasticity.

CL Inorganic clays of low to medium plasticity, gravelly clays, sandy clays, silty clays, lean clays.

OL Organic silts and organic silt-clays of low plasticity.

$\mathrm{MH}$

Inorganic silts, micaceous or diatomaceous fine sandy or silty soils, elastic silts.

$\mathrm{CH}$ Inorganic clays of high plasticity, fat clays.

$\mathrm{OH} \quad$ Organic clays of medium to high plasticity.

P Peat and other highly organic soils. 


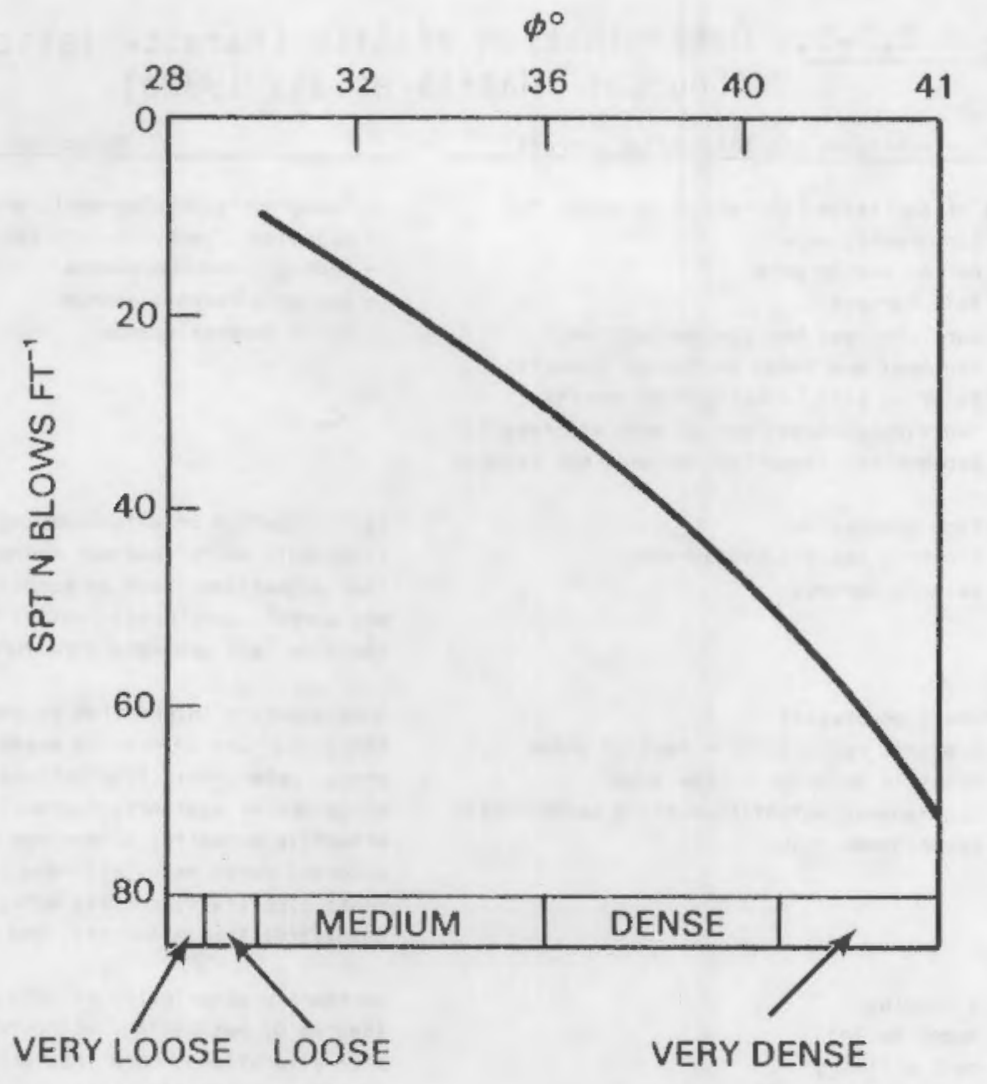

\section{FIGURE 4.3.2-18. 0-N Relationship for Standard Penetration Test} (Source: Attewell and Farmer 1976)

the trench due to high hydrostatic pressures, and to predict the direction and velocity of contaminants reaching the wall.

Water quality information from past monitoring programs and test results from observation wells give information on artesian pressures, ground-water levels, springs, and seasonal variations in ground-water conditions. It should also be determined whether man-made recharge areas (e.g., cooling resevoir) exist at the site (Millet and Perez 1981).

The tests carried out to aid in the design of a cut-off wall can be divided into three groups: surface and subsurface reconnaissance, in-situ tests, and laboratory tests. These tests and their objectives are outlined in Table 4.3.2-3.

\subsubsection{Quality Control Considerations}

\section{Clay Mineralogy}

Clay minerals can be divided into three major groups: montmorillonites, illites, and kaolinites. Montmorillonites that have their surface charge 


\section{Table 4.3.2-3. Determination of Site Characteristics (Source: Harris et al. 1982b)}

Techniques and Informetion Sources

Surface and Subsurface Reconnaissence

In $-\mathrm{s} 1$ tu 5 Site Characterl zation

- Topographle maps

- Morlal photographs

- Soll surveys

- Surficial and bedrock geologle maps

- Reglonal and local geological reports

- Existing site Investigation reports

Surfoce gecphysics

- Electric rasistivity surveys
Use of avellable information provided in:

- Hydrologic investigation maps and reports

- Geophysical Investigation meps and reports

- Selsaic surveys

Borehole geaphysles

- Electrlic resistivity - neutron probe

- Acoustic velocity - flou mater

- Spontaneous potentlal - fluld conductivity

- Gamme-ganme probe

Weil logging

- Auger Doring

- Well drllling

- Spllt-spoon sampling

Soll surveys

- Standard penetration test

- Core penetration test

- Fleld sampling and description

- Auger boring, corlings test plts, etc.

Geologlc surveys

- Site survey

Hydrologic surveys

- In-situ permeability tests

- Field pumping tests

- Piezometric level surveys

Grain-s!ze analysis

- Sieve

- Hydrometer

Laboratory perneablilly tests

Chemlcal analysis--soll and water

- Soluble salts

- $\mathrm{pH}$

- Organle matter

- Chemical contamlnants

- Clay analysis
Objective

- Topograohic/phys lographic analysis

- Hydrologic/geohydrologic reconnalssance

- Geologie reconnaissance

- Geologíc reconnalssance

- Solis reconnelssance

Identifleation of water-bearing formations; If thologic units; bedrock contacts; physlcal, rock properties, such as porosity, fluid content, and lestic constants; faults; fractures; cavlties; and geologlc structures.

Supplementary Informetion to corling and hydrologic samplling. Can used to anslyze perched water and annual water table fluctuatlons; stratigraphy and structure of aqulfers; hydraulle conductivlty: effective porosity; mineralogy of consolldated and unconsolldated materlal; rate of groundwater movement; dipersivlty coofflelents; groundweter chemlstry; transmlsslvity, and storage coefflclents.

Systematic descrlption of soll or rock materlal (degree of weatherling, mi erostructure, color gralnsize altaretlon); core fracturing; dlscontinuity; spacing, horlzontal distribution and extent of the different soll strata; poroslty.

Description of soll-grain size, plasticlty, relative oenslty, undralned shear strength, locetion, and extent of soli units.

Detalled site survey to map topographlc, gecmorphlc, geologlc, and hydrologlc features such as slumpling solis, swamey solls, springs, steep slopes, subsidence, faults, otc., that may have been overlocked during prelliminary site Investigation or that were noted during slte reconnolssance.

Groundwater levels, seasonal fluctuations, rate of $f l$ ow of confined and uncontined ground water, reglonal and local groundwater flow patterns, leakage of contined aquiters, Identitication of aqulfers, permeablilitles.

Slurry/groundwater conoatlblilities, permeablilities, porositles, dispersivity coefflelents; sultablility of borrow and backflll meterlal. 
balanced by the sodium ion, are of particular interest for their use in slurry mixtures. These clays are referred to as sodium bentonite, sodium montmorilIonite, or because they are found and mined principally in Wyoming, they are called Wyoming bentonite.

A combination of tetrahedral and octahedral sheets form a lattice structure for sodium bentonite. The tetrahedral layer is composed of units of one silicon atom surrounded by four oxygen atoms. The octahedral layer has units of one multivalent cation and several hydroxyl ions $(\mathrm{OH}-)$. These layers form clay particles that are flat and flake-shaped (Jepsen undated).

Compared to illite clay, there is much less replacement of $\mathrm{Si}^{+4}$ by $\mathrm{Al}^{+3}$ in the tetrahedral layers of bentonite clay. This causes the total cationic charge between the structural units to decrease and, subsequently, expansive tendencies are not held back. A net charge imbalance is set up in bentonite by about $20 \%$ of the $\mathrm{Al}^{+3}$ ions being replaced by $\mathrm{Mg}^{+2}$ ions in the octohedral layer. In sodium bentonite clays this imbalance is satisfied by a sodium ion at the surface of the unit. These sodium ions are held loosely and readily exchange for other cations, especially those of higher valence (Jepsen undated).

Sodium bentonite has a large surface area of up to $800 \mathrm{~m}^{2} / \mathrm{gram}$ when fully hydrated (Jepsen undated). This characteristic coupled with its high ionic exchange tendency gives it a cationic exchange capacity between 80 and 150 meq/100 grams. Compared with the cationic exchange capacities of kaolinite and illite, which range from 3 to $15 \mathrm{meq} / 100 \mathrm{grams}$ and 20 to $40 \mathrm{meq} / 100 \mathrm{grams}$, respectively, the range of values for sodium bentonite clay is very high. This high ionic exchange capacity causes bentonite to expand 10 to 15 times its dry size upon hydration. When water is added to bentonite attractive forces set up between the water and the clay. The flake-shaped clay particles separate as a thin film of water forms between them, which acts like a lubricant to disaggregate them further. This phenomenom accounts for bentonites high swelling property and its use as a soil sealant (Jepsen undated).

When bentonite is mixed with water it becomes a thixotropic gel (i.e., it becomes fluid when agitated and rethickens when left stationary). The viscosity of hydrated bentonite increases over time as the clay particles orient themselves. When bentonite is mixed with the right quantity and sizes of particulate matter it forms an effectively impervious barrier.

\section{Slurry Properties}

The primary function of a slurry in the construction of cut-off walls is to support the sides of the trench during excavation. In order to fulfill this requirement, the slurry must be sufficiently dense. Although if it is too thick it will impede the excavation, backfilling, and trench cleaning operations. A low filtrate loss is also needed to ensure that the slurry remains in the trench and does not seep through the sidewalls. Another variable slurry property is viscosity. A thick slurry is needed to suspend loose soils and prevent them from accumulating at the base of the trench. Conversely, the 
slurry must be thin enough to facilitate pumping and circulating during construction operations (Harris et al. 1982b).

By controlling the viscosity, specific gravity, and filtrate loss, an optimal slurry can be made. The pH of a slurry should fall between 6.5 and 10. A deflocculating agent may be required for a pH greater that 10.5 (Millet and Perez 1981).

Repeated testing during construction will insure that quality controls are met. Table 4.3.2-4 outlines the quality control testing done at a hazardous waste disposal site located in Nashua, New Hampshire. The types, frequency, and desired values from the tests are tabulated. Many of these procedures are defined in the API specification RP-13B.

\section{Viscosity}

Viscosity is the primary property tested to determine the usability of a slurry. It is a measure of the ability of a fluid to resist shearing and depends largely on the extent of hydration of the bentonite clay (Ryan undated).

The Marsh Funnel test is commonly used to determine viscosity. Acceptable values for both $S-B$ and $C-B$ slurry range from 30 to 80 Marsh-secs at $20^{\circ} \mathrm{C}$, with an optimum value of about 40 Marsh-secs. Changes in the slurry viscosity during excavation may be due to differences in batches of slurries mixed and added to the trench, changes in the underground environment, and the time the slurry is left sitting in the trench. In order to return the slurry to optimum consistency, new slurry may be added to the trench (Ryan undated).

The development of gel strength may be more important in making an efficient slurry wall than the apparent viscosity. Many problems are encountered, though, when measuring gel strength. Ultrasonic pulse velocity techniques have been used to circumvent some of these problems. These tests give shear modulus data, G, by measuring the pulse velocity for a shear wave moving through the gel.

\section{Filtrate loss}

Filtrate loss is the loss of water from a slurry when put under pressure. A high filtrate loss wastes slurry and causes a concentration of slurry in the filtercake. Filtrate loss is irrelevant as a quality control criterion. Despite this finding, many contractors measure the extent of hydration of the bentonite slurry by this property.

A filter press test (such as API Test PP131B) simulates the formation of filter cake on the trench walls. Filtercake is the slurry and soil combination resulting from electrokinetic and seepage forces that push the slurry through the sides of the trench. The test predicts how much slurry will be lost during 
Table 4.3.2-4. Quality Control Testing Program During S-B Slurry Wall Construction at Gilson Road Hazardous Site (Source: Ayres et a1. 1983)

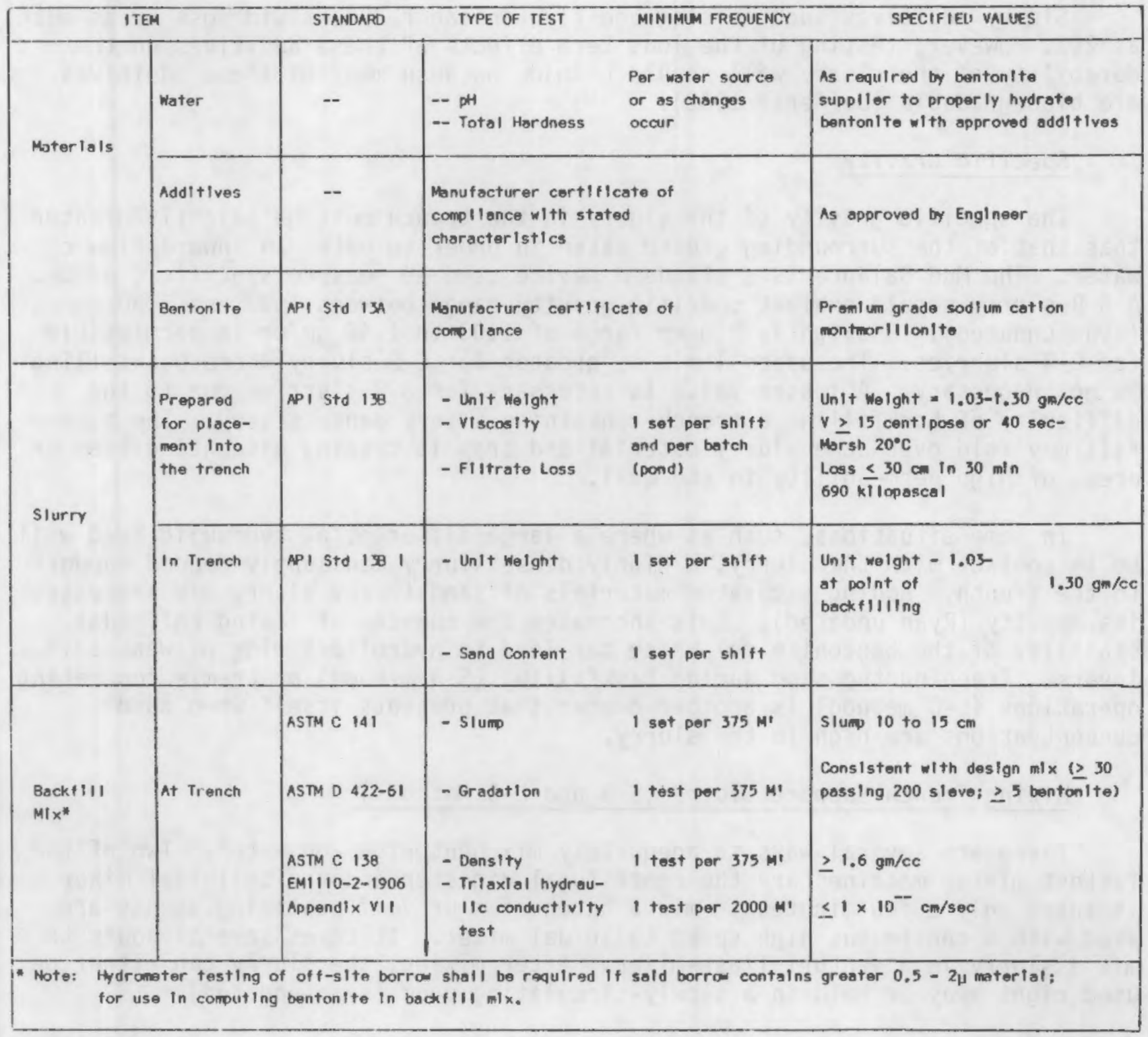


excavation and, also, how fast the cake will form or reform if disturbed. For a C-B slurry the normal range of filtrate loss is from 100 to $180 \mathrm{ml}$ in 30 minutes (Millet and Perez 1981). For a S-B slurry the filtrate loss should measure less than $30 \mathrm{ml}$ in 30 minutes (Ryan undated).

Slurry additives such as slag and fly ash can reduce fluid loss by as much as $20 \%$. However, testing of the long term effects of these additives on the durability of the slurry wall should be made because many of these additives are biodegradable (Jefferis 1982).

\section{Specific Gravity}

The specific gravity of the slurry in the trench must be slightly greater than that of the surrounding ground water in order to deter an inward flow of water. The Mud Balance is a standard device used to measure specific gravity. A S-B slurry should exhibit specific gravity range between 1.03 and $1.30 \mathrm{gm} / \mathrm{cC}$ (Ryan undated). A slightly higher range of 1.03 to $1.40 \mathrm{gm} / \mathrm{cc}$ is permissible for C-B slurries. The upper limit is greater for C-B slurry where backfilling is not necessary. A lesser value is necessary for $S-B$ slurries due to the difficulty of backfilling a trench containing a very dense slurry. The backfill may fold over some slurry material and trap it causing discontinuities or areas of high permeability in the wall.

In some situations, such as where a large differential hydraulic head will be in contact with the slurry, a highly dense slurry can supply needed support to the trench. Adding excavated materials of sand to the slurry may increase its density (Ryan undated). This increases the chances of losing colloidal stability of the bentonite gel which can lead to hydrofracturing of weak soil layers. Trapping the sand during backfilling ( $S-B$ method) or tremie concreting operations ( $L-C$ method) is another danger that presents itself when sand concentrations are high in the slurry.

\section{Mixing Trench Support Slurry (S-B and L-C Methods)}

There are several ways to adequetely mix bentonite and water. Two of the fastest mixing machines are the centrifugal digester and the colloidal mixer. It takes only a few minutes to mix a batch of slurry if peptizing agents are used with a continuous high speed colloidal mixer. It takes several hours to mix a slurry in a venturi flash-mixer. After mixing, the slurry can either be used right away or held in a slowly-circulating pond (Ryan undated).

The circulating time and the mixing time greatly effect the gel strength and viscosity of a slurry. The viscosity of a slurry increases over time and does not tend toward an equilibrium value. Tests (Jefferis 1982) conducted on four different types of bentonite found positive evidence for this hypothesis.

An increase in the gel strength of slurry over time was tested. The data points are plotted in Figure 4.3.2-19. The rate of gel strength increase is controlled by the time from original mixing. Gel strength values should not be determined by extrapolation before a few days time has elapsed. The sharp curve in the graph would cause higher than true values to be calculated. 


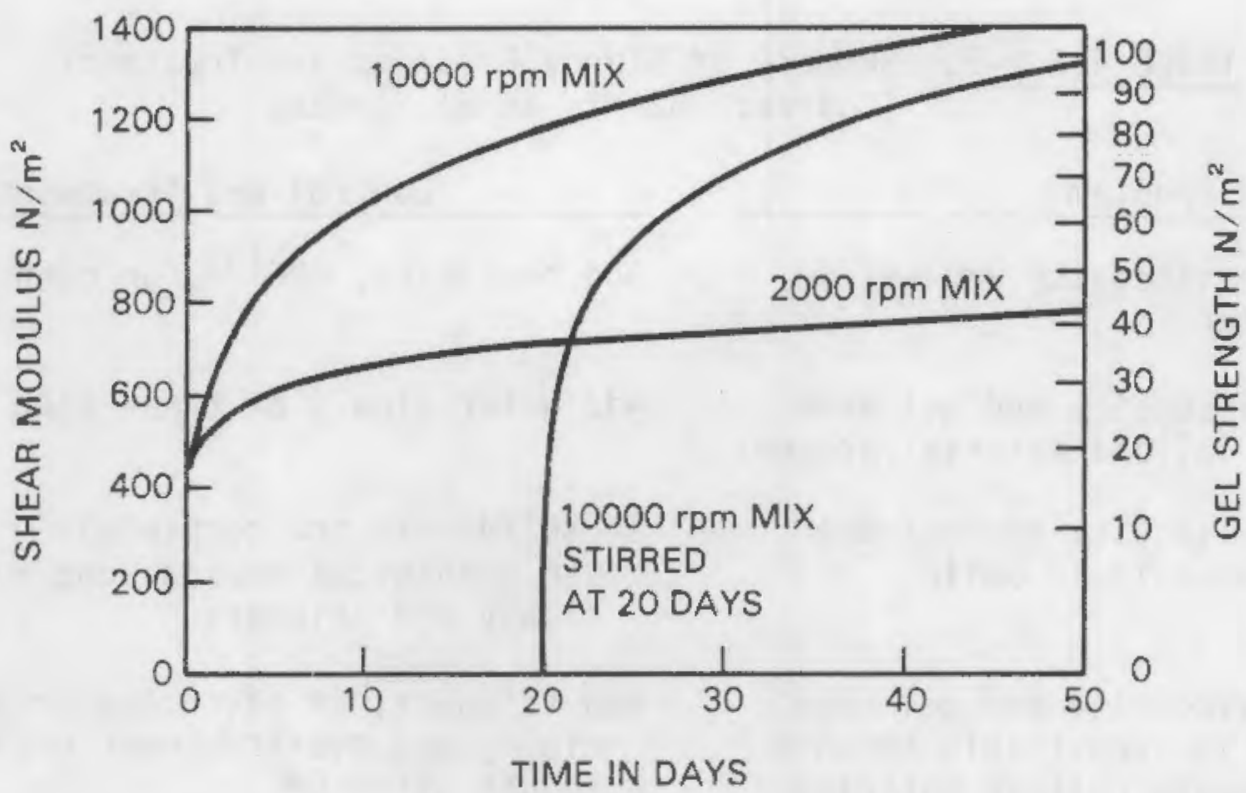

FIGURE 4.3.2-19. The Cell Strength and Shear Modulus of Slurry as a Function of Time (Source: Jefferis 1982)

There are several reasons why viscosity and gel strength increase over time. One reason is that delamination, the process of swelling and separation of the clay sheets that form the clay particles, continues with time. Water seeps between the clay layers and new smaller clay particles are formed. Viscosity and gel strength both increase as the quantity of these particles rises. Another reason may be that the clay particles change their orientation with respect to one another over time and form stronger interparticle bonds (Jefferis 1982).

Assuming that delamination and reorientation of the clay particles increases the gel strength and viscosity of a slurry, decreased particle size should lower the permeability of the slurry wall. Secondly, time and mixing will not necessarily decrease filtrate loss. If a decrease in filtrate loss is desired, a thicker filtercake can be make by adding dispersing agents to the slurry (Jefferis 1982).

\section{Treatment of Slurry Problems}

During construction quality control testing might show the need to alter the composition of the slurry. Table 4.3.2-5 lists problems encountered in the field and gives techniques used to solve them.

Water quality parameters that may prevent slurry problems include: $\mathrm{pH}$ of 7 (+ or - 1), hardness less than $500 \mathrm{ppm}$, and oil, organics, or other potentially harmful substances limited to $50 \mathrm{ppm}$ each (Miller 1979). The groundwater chemical composition also has effects on slurries. The calcium content 
TABLE 4.3.2-5. Summary of Slurry Problems and Treatment

(Source: Harris et al. 1982b)

\section{Problem}

To increase viscosity and gel in fresh water

To reduce viscosity and gel when adequate colloid material present

To reduce viscosity and gel due to high noncolloid solid content

To reduce viscosity and gel when dilution is inadvisable because of inadequate colloid material or weight reduction

To increase viscosity and gel due to high colloid solid content (sand)

To decrease density

To reduce filtration rate and thickness, i.e., reduce fluid loss

To handle large volumes of entrained sand and cuttings

To control salt flocculation in offshore drilling and excavation in salt formations

To permit trench excavation in sand and gravel (sand will increase density, decrease viscosity, and aggravate tendency toward lost circulation
Control and Treatment

Add bentonite, $\mathrm{CMC}^{(\mathrm{a})}$, or both

Add water slowly or treat with thinners

If solids are not completely dispersed, use mechanical separation; add water slowly and thinners

Add thinners; if viscosity drops appreciably and overtreatment occurs, adjust using $\mathrm{CMC}$

Remove solids by mechanical separation; add bentonite or CMC

Recirculate fluid to remove solids by mechanical separation or by allowing them to settle; do not add water, but adjust flow properties if required after the density is decreased

Add bentonite and CMC; if viscosity
becomes too high, treat with FCL $(b)$ or other thinners

Use mechanical dispersion; avoid adding water and chemicals

Stabilize solution through the protective action of CMC or use thinners

Provide adequate initial gel strength to keep sand in suspension; build good filter cake and film to keep fluid loss low; use higher bentonite concentrations and add CMC 


\section{TABLE 4.3.2-5. (cont'd)}

Problem

To permit trench excavation in clay

To permit trench excavation in shale

To permit excavation in erratic formulations

To reduce lost circulation

To control contamination with cement

To control contamination with organic matter and sewage

(a) Sodium carboxymethyl cellulose

(b) Ferrochrome lignosulfonate

\section{Control and Treatment}

Keep viscosity and gel low; use thinnest suspension colloidally stable; use thinners

Reduce filtration rate to prevent hydrous disintegration or sloughing of formation; add bentonite and CMC; monitor slurry level to control sudden loss of fluid

Base selection of slurry on most critical formation; make periodic adjustments

Use lost-circulation materials; maintain minimum safe slurry weight

Add FCL or other thinning agents; if restoration is not achieved, reject slurry; use pretreated bentonites

Avoid peptized brands; use natural bentonite and monitor slurry closely 
of hard waters has a flocculating effect on the slurry. High concentrations of sodium and alkali salts will decrease the swelling of bentonite. Thorough testing of the slurry in the presence of the on-site ground-water chemistry should be conducted to guard against any decrease in swelling which could potentially increase the permeability of the wall.

\section{Slurry Additives and Processes}

The complication and cost involved in the use of slurry additives has restricted their use. Additives such as fluid-loss control agents, contamination resistant agents, and peptizers of polyelectrolytes to improve colloidal stability have been used in the past (Harris et al. 1982b). A more extensive list is outlined in Table 4.3.2-6.

Slurry wall contractors have developed a number of processed (and patented) slurry mixes. ASPEMIX ${ }^{\circledR}$ is a cold asphalt emulsion developed by Slurry Systems to withstand chemicals that bentonite-based slurry can not due to cation-exchange and clay degration. Slurry Systems is also presently developing a slurry having elastic properties $(\mathrm{a})$.

The Environmental Products Division of the American Colloid Company has developed two chemical treatment processes that produce slurries that are more contaminant resitant. Saline Sea ${ }^{\circledR}$ is used to resist contamination in excess of $100,000 \mathrm{ppm}$ TDS. Ultra Gel ${ }^{\circledR}$ is for use where high viscosity slurries are required. It contains peptized bentonite and restricts flocculation in strong ionic solutions $(\mathrm{b})$. The American Colloid Company has patented a process that increases the swell potential of sodium bentonite. In this process water soluble polymers disaggregate the clay particles and increase the clay surface area available for hydration. A contaminant resistant sodium montmorillonite was also developed. This slurry was initially made to resist environments of high salt concentrations. It was later discovered to hold up against other leachate constituents that decrease the swelling ability of the slurry by both cationic exchange and water of hydration crowding (Jepsen, undated).

\section{Consistency}

Slump Tests are used to determine the consistency and fluidity of the S-B backfill, the C-B slurry, and the concrete used in a L-C wall. A conical mold is filled with material and inverted on a flat surface. The drop in hejght below the mold height is measured and labeled the slump of the material (B).

The S-B backfill slides down into the trench at a slope determined by the slump of the backfill and the gradation of the material in the mixture. The higher the slump and more uniform the gradation, the flatter the slope will

be. The lower the slump and the coarser the grade material, the steeper the

(a) Information from advertising brochure of Slurry Systems, a division of Thatcher Engineering Corporation, Gary, Indiana.

(b) Lapedes, Daniel N., ed. 1974. McGraw-Hill Dictionary of Scientific and Technical Term 2nd ed. McGraw-Hill Book Co. New York. 
TABLE 4.3.2-6. Common Slurry Materials and Additives

(Source: Harris et al. 1982b)

\section{Purpose}

Weight materials

Colloid materials

Thinners and dispersing agents

Intermediate-sized particles

Flocculants and

polyelectrolytes

Fluid loss-control agents

Lost-circulation materials
Type

- Barite (barium sulfate) or soil (sand)

- Bentonite (Wyoming, Fulbent, Aquagel, Algerian, Japanese, etc.), basic freshwater slurry constituent

- Attapulgite, for saltwater slurries

- Organic polymers and pretreated brands

- Quebracho, organic dispersant mixture (tannin)

- Lignite, mineral lignin

- Sodium tetraphosphate

- Sodium humate (sodium humic acid)

- Ferrochrome lignosulfonate (FCL)

- Nitrophemin acid chloride

- Calcium lignosulfonate

- Reacted caustic, tannin (dry)

- Reacted caustic, lignite (dry)

- Sodium acid pyrophosphate

- Sodium hexametaphosphate

- Clay, silt, and sand

- Sodium carboxymethyl cellulose (CMC)

- Salts

- Starches

- Potassium aluminate

- Aluminum chloride

- Calcium

- CMC or other flocculants

- Pregelatinized starch

- Sand in small proportions

- Graded fibrous or flake materials; shredded cellophane flakes, shredded tree bark, plant fibers, glass, rayon, graded mica, ground walnut shells, rubber tires, perlite, timesetting cement, and many others 
slope. Slopes average between 5:1 and 10:1. With steeper slopes (low slump) there is a greater possibility of trapping unwanted materials such as sediment, partially excavatęd material, or fluid slurry in the wall. With flatter slopes (high slump) excavating problems may arise. The results of a slump test should range between 10 and $15 \mathrm{~cm}$ ( 4 and $6 \mathrm{in.)}$ for S-B backfill (Millet and Perez 1981).

A slump range of 18 to $23 \mathrm{~cm}$ ( 7 to $\mathrm{g}$ in.) is appropriate for concrete that is to be tremied into a slurry trench to form a L-C wall. Too stiff of a mix may lead to voids and open honeycombs in the panels (Millet and Perez 1981).

Deformability and Strength

Slurry walls are non-structural; they are not built to support bending moments or significant shear stres5. Concentrated loads put on top of the wall are mitigated by placing a cap over the completed wall. S-B walls are generally assumed to be infinately plastic for construction purposes (Ryan undated), although functionally they need to achieve the strength of the surrounding host material. The actual plasticity of a S-B slurry wall is a function of the amount of fines in the backfill. The strength is a function of internal friction which is controlled mainly by consolidation stress (D'Appolonia 1980).

A soil-bentonite wall will be sufficiently plastic and resistant to cracking if its slump is between 10 and $15 \mathrm{~cm}$ ( 4 and $6 \mathrm{in.}$ ), and there is reasonable gradation of coarse to fine material. A coarse gradation and a low slump makes for a rigid wall (Millet and Perez 1981).

The higher the cement-water ratio in a C-B slurry or a concrete mix ( $L-C$ method) the stiffer and less deformable the slurry wall will be. Strain at failure increases when the cement-water ratio is increased. Conversely, the higher the bentonite-water ratio, the more flexible the wall becomes (Millet and Perez 1981).

The brittleness and low deformability resulting from high cement concentrations can be detrimental to the performance of a slurry wall. A high cement concentration can be beneficial by protecting the wall from erosion by ground water and reducing seepage of slurry through permeable soils (Schmednecht undated). Processes combining the benefits of a high cement ratio and eliminating the brittleness associated with this type of mix are being developed. For example, Slurry Systems is developing a slurry wall construction method having elastic properties with an extended urethane base.

To specify the required structural strength of the concrete used to form a L-C wall, American Concrete Institute specifications can be used. Although all slurry walls should be designed as if they had zero strength (Harr et al. undated).

Vane Shear and Swedish Fall Cone measurements of shear strength of usual slurry mixes used for VBT slurry walls produced shear strength values of about $171 \mathrm{~kg} / \mathrm{sq}$. meter (35 psf) within a week of preparation. The strength of the slurry was found to double after a month. Very high strengths on the order of 
$4882 \mathrm{~kg} / \mathrm{sq}$. meter ( $1000 \mathrm{psf}$ ) can be made by doubling the usual cement content. The increased strength is gained at the expense of permeability, which rises significantly (Harr et al. undated).

\section{Mixing C-B Slurry}

There are essentially three different ways (Jefferis 1982) to mix cement, bentonite, and water to form a material that is suitably impervious to ground water. In the dry mixing method bentonite and cement are mixed together and then hydrated in a mixer. The bentonite particles do not disperse because of reactions between the cement and water, so a low water to cement ratio is obtained. With this type of slurry mix bentonite is not present for its swelling capabilities. It is added to enhance the flow and cohesiveness of the slurry. This mix achieves high strength upon hardening, and it is used mainly for injection grouts.

In another mixing method the bentonite alone is hydrated and then the cement is added. The mix stiffens suddenly when the cement is first added and then becomes fluid again shortly after. This is due to negatively charged bentonite particles flocculating with positively charged particles in the solution. When the bentonite particles surround the cement particles, the floc structure breaks and the slurry becomes more fluid. The slurry becomes more viscous as calcium and other ions are released by the cement and flocculate the bentonite.

Finally, a slurry can be made by wetting the cement first. Cement grains often bunch together and become encapsulated by the bentonite when added to the slurry. By wetting the cement before the addition of bentonite, a more homogeneous mix is produced. These cement nodules can also be broken apart by high shear mixing or by mixing for longer periods of time.

Cement nodules incorporated into a slurry wall act as high stress points which decrease its strength and act as pervious material which increases its permeability. A low shear mixing rate produces a less homogeneous mix that tends to be more weak and plastic. High shear mixing, on the other hand, produces a homogeneous mix that is stronger, more brittle, and less pervious (Jefferis 1982).

When very low permeability is a quality control criteria, pre-wet cement and high shear mixing can prove to be effective. For high strain capabilities (and less expense), dry cement and low shear mixing are the best choices (Jefferis 1982).

Filtrate loss of slurry through the trench sidewalls increases markedly with the addition of cement (Ryan undated). Adding fine material such as ground granulated blast furnace slag and fly ash to C-B slurries can control bleeding (Jefferis 1982). Unlike cement they do not react with bentonite by releasing ions into solution which causes the bentonite gel to bleed. They work by making the slurry more viscous and less likely to seep through the sidewalls (Figure 4.3.2-20). 


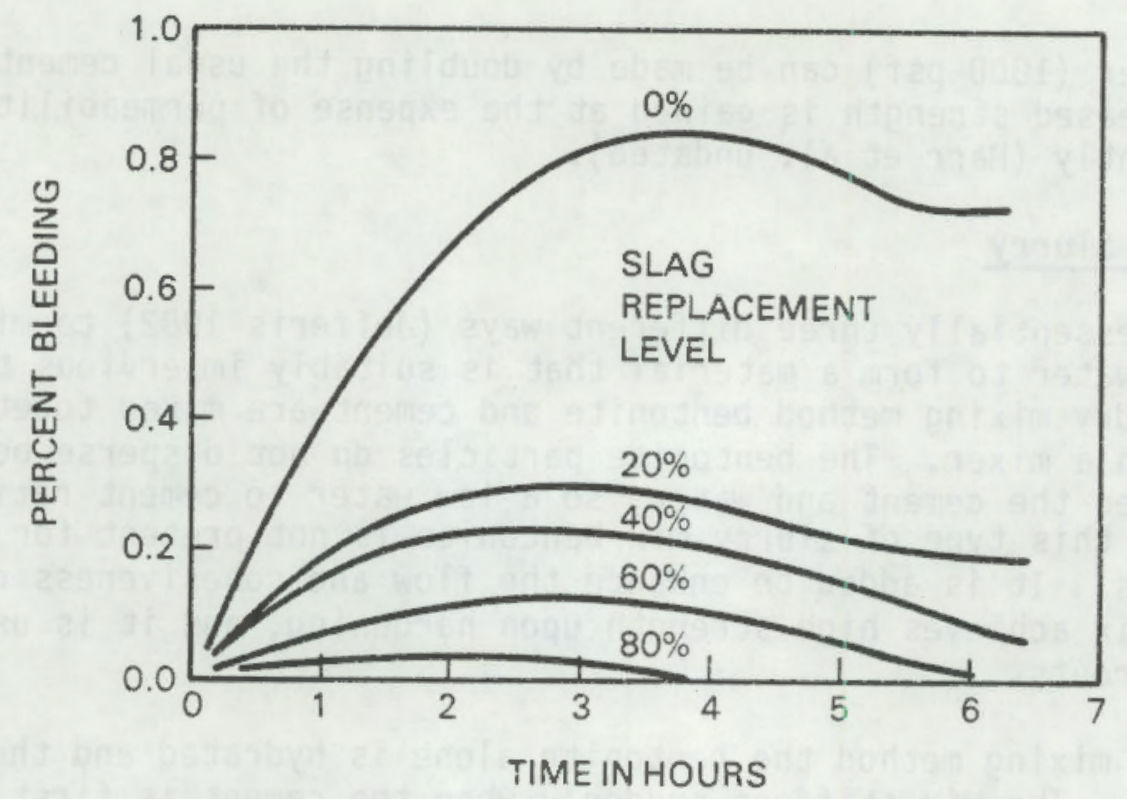

MIX: $150 \mathrm{~kg}$ CEMENT, $50 \mathrm{~kg}$ BENTONITE TO $930 \mathrm{~kg}$ WATER

FIGURE 4.3.2-20. The Effect of Slag Replacement on Bleeding (Source: Jefferis 1982)

Up to $95 \%$ of the cement can be replaced by slag. A slurry with this concentration of slag will be very fluid and easy to mix. Consequently, the mix will be homogeneous and will form into a strong, brittle, and highly impervious barrier. Fly ash produces a less brittle wall than slag. No more than $50 \%$ of the cement can be replaced by fly ash or the slurry takes too long to set (Jefferis 1982).

\subsubsection{Contaminant Compatibilty of Slurry Trenches}

Cut-off walls used to contain contaminated ground water following a severe power plant accident must be designed so as not to increase in permeability when in contact with the contaminated ground water. There are two ways (D'Appolonia undated) in which a contaminated liquid can increase the permeability of a slurry wall.

First, the soil minerals in the wall may be soluble in the permeant. A loss of solids in the wall increases its pore volume allowing more liquid to pass. Second, pore fluid substitution may reduce the double layer of partially bound water surrounding the hydrated bentonite or other clay particles in the wall. This would lower the effective size of the clay particles that clog the pore space between the soil grains, again allowing more room for liquid to pass through the barrier. Organics adsorped onto the bentonite surface decrease the swelling potential of the slurry by lowering the area available for water to react (Harris et al. 1982b).

The sodium ions in bentonite clay are easily and rapidiy replaced by multivalent cations (e.g., calcium, magnesium, and heavy metals) transported in 
the ground water. This leads to the smaller double layer described above and decreases the swelling of the hydrated bentonite. When sodium ions of bentonite exchange with an equivalent number of ions in the contaminant, steady state conditions prevail, and the permeability reaches a constant but higher level (D'Appolonia undated). The ion exchange capacity may offset the effects of increased permeability through adsorption of the radionuclide onto the clay minerals.

The magnitude of the permeability increase of a slurry wall depends on the difference in chemistry between the initial and final pore fluid and the sensitivity of the clay to the pore fluid chemistry change. Sodium bentonite is the most sensitive of the montmorillonite clays. Alluvial or lucustrine clays are less sensitive and undergo less change when leached with a contaminant. The particular type of sodium bentonite does not seem to change the permeability level increase due to leaching with contaminants (D'Appolonia undated).

Backfill that is contaminated with the leachate will increase in permeability less than if uncontaminated soil were used. Therefore, contaminated soil excavated from the trench can be used to increase the durability of the slurry wall (Millet and Perez 1981).

Table 4.3.2-7 shows the effects of various pollutants on a soil-bentonite slurry wall.

\subsubsection{Implementation Considerations for Slurry Trenches}

\section{$\underline{\text { Cost }}$}

S-B and C-B walls range from about $\$ 43$ to $\$ 75 / \mathrm{sq}$. meter ( $\$ 4$ to $\$ 7 / \mathrm{sq}$. ft) of vertical cut-off wall (Warner 1979). The price differs somewhat between contractors and increases with soil depth. The usual trend is that S-B walls are the least expensive, followed closely by $C-B$ walls, and $L-C$ walls being the most expensive. The ICOS Corporation of America prices S-B walls at $\$ 32$ to $\$ 65 / \mathrm{sq}$. meter ( $\$ 3$ to $6 / \mathrm{sq}$. ft), C-B walls at $\$ 54$ to $\$ 108 / \mathrm{sq}$. meter ( $\$ 5$ to $10 / \mathrm{sq}$. ft), and L-C walls at $\$ 161$ to $\$ 323 / \mathrm{sq}$. meter ( $\$ 15$ to $\$ 30 / \mathrm{sq}$. ft) (Harris et al. 1982b).

The cost of a C-B wall depends largely on the type of soil available for backfill. Cost increases with the transportation costs of soils brought to the site. Much slurry is wasted during excavation when constructing a C-B wall. The entire trench must be filled with slurry, and much of it leaks through the sides of the trench. If on-site soil can be used in the backfill of a S-B wall, holding all other variables constant, it would be less expensive than the C-B method (Harris et al. 1982b).

The cost of a slurry wall increases with the difficulty of excavating the trench. The maximum depth penetrated by a S-B wall at a site in Nashua, New Hampshire is 33 meters $(108 \mathrm{ft})$. The estimated cost through overburden was 
TABLE 4.3.2-7. S-B Permeability Increase Due to Leaching with Various Pollutants (Source: D'Appolonia 1980)

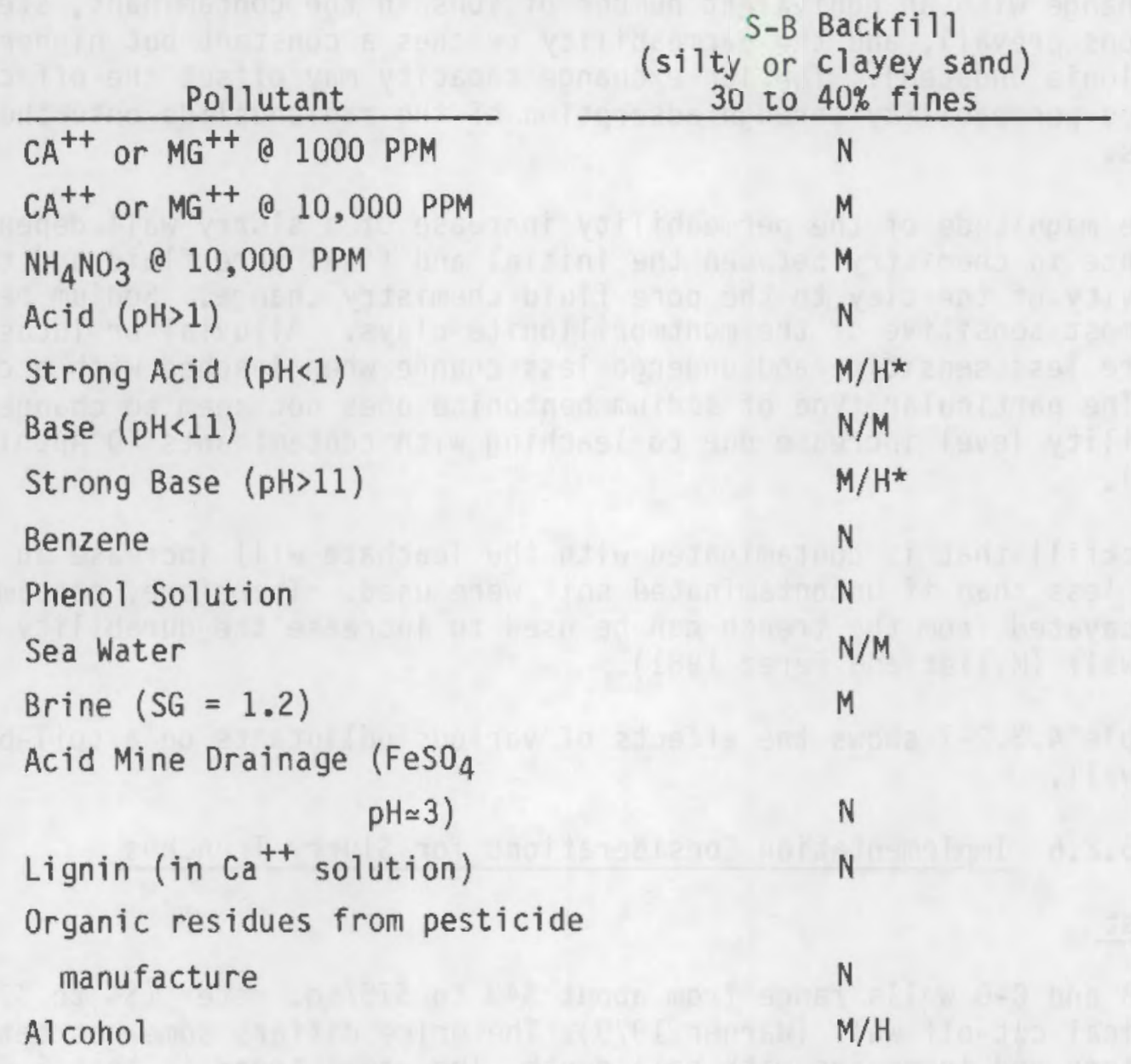

\footnotetext{
N - No significant effect; permeability increase by about a factor of 2 or less at steady state.

M - Moderate effect; permeability increase by factor of 2 to 5 at steady state.

$\mathrm{H}$ - Permeability increase by factor of 5 to 10 .

* - Significant dissolution likely.
} 
$\$ 50 / \mathrm{sq}$. meter $(4.50 / \mathrm{sq}$. ft) and increased to $\$ 1500 / \mathrm{sq}$. meter $(\$ 150 / \mathrm{sq}$. ft) through bedrock (Ayres et al. 1983).

Spencer, White, and Prentis, Inc. claims that the VBT method is inherently quicker, therefore there is economy of labor and equipment. VBT walls are also thin which keeps material costs low $(a)$.

\section{Construction Time}

Excavation time is a function of equipment used, soil conditions, and the depth of excavation. A C-B wall takes either the same amount of time or less to construct than a S-B wall, and a $L-C$ wall takes the most amount of time to complete. The ICOS Corporation of America approximates S-B and C-B construction time at $280 \mathrm{sq}$. meters/day; and for L-C walls, 30 to $70 \mathrm{sq}$. meters/day. Similar quotes are given by Geo-Con Inc. with average construction times, for S-B and C-B walls, between 280 and 370 sq. meters/day (Harris et a1. 1982b).

Construction time varies with depth. Engineered Construction International, Inc. estimates an average time of $370 \mathrm{sq}$. meters/day for a 12 meter depth. Raymond International, Co. estimates an average time of $140 \mathrm{sq}$. meters/day for a 9 meter depth. These figures are for 8 hour shifts. Construction time could be decreased by employing 3 eight hour shifts per day (Harris et a1. 1982b).

Time could also be saved by using the proper equipment. Clamshell excavation takes 2 to 3 times longer than with a backhoe. A backhoe is faster than either a dragline or a clamshell. Also the type of mixer used can greatly hasten operations. For example, no time is needed for bentonite hydration if an $1800 \mathrm{rpm}$ mixer is used (Harris et al. 1982b).

\section{The Timing of Several Case Studies}

At a site in Nashua, New Hampshire, the excavation, transport, and compaction of 190,000 cubic meters $(250,000 \mathrm{cu}$. yds) of soil, and backfilling of the trench, were completed in 8 weeks. The cap or cover system was then placed over the S-B slurry wall bringing the total construction time to 3 months (Ayres et al. 1983).

A C-B wall encompasses the Tilden Tailings Disposal System in Gribben Basin, Michigan. The wall was built through soil strata at about $1200 \mathrm{sq}$. meters/day. When bedrock was reached, the production rate dropped to less than $750 \mathrm{sq}$. meters/day. The maximum depth was 25 meters (80 ft) (Harris et al. $1982 b)$.

An un-reinforced lean concrete cut-off wall was used for dewatering at Bonneville Dam in Washington. Excavation averaged $16 \mathrm{sq}$. meters/day (170 sq. $\mathrm{ft} /$ day) up to a depth of 46 meters (150 ft) (Harris et a1. 1982b).

(a) Information from advertising brochure of Spencer, white, and Prent is, Inc. 
In Warsaw, Missouri, the VBT method was used to construct a slurry wall for excavation dewatering. In 40 working days $9290 \mathrm{sq}$. meters $(100,000 \mathrm{sq}$. $\mathrm{ft.}$ ) of slurry wall was placed to a depth of 14 meters ( $45 \mathrm{ft}$ ) (Harr et al. undated).

\section{Equipment Mobilization}

Following a severe power plant accident, atmospheric releases may limit work near the site. Additional time may be needed to mobilize special equipment to be used under these conditions (Harris et al. 1982b). Construction workers must be informed of and protected from radiation exposure, and difficulty may be experienced in organizing work crews.

\section{Bentonite Supply}

Sufficient quantities of bentonite would be available for slurry wall construction in the event of an accident. Although bentonite may have to be acquired from several suppliers in order to obtain a sufficient amount on short notice. Quality control would be made more difficult by mixing different types of bentonite.

\section{Site Restrictions}

Above ground obstacles such as man-made structures or vegetation must be removed where the wall is to be constructed. Underground obstacles such as subsurface piping (e.g., utility service) must be located to insure avoidance.

The amount of space available for construction at the site should be considered. The choice of a S-B wall may be eliminated if the site is small. S-B walls are relatively wide and space is needed next to the trench to mix the backfill, unless it is specially prepared elsewhere and transported to the trench (adding expense to the project).

For locations where ground-water levels are high, a difference in hydrostatic pressure in and outside the trench can be induced by pumping. In order for the filtercake layer to form, the hydrostatic pressure in the trench must be greater than the external hydrostatic pressures. For this condition to exist, the slurry level in the trench must be about 1.3 meters ( $4 \mathrm{ft}$ ) above the ground-water level. A berm built along the trench alignment can be used to raise the ground level and increase the amount of slurry above the ground-water level (Harris et al. 1982b).

Near coastal regions, the tide may increase the hydrostatic pressure on one side of the trench. In this case hydrostatic pressure of the slurry on the trench sidewalls can be increased by either increasing the height of the berm or the density of the slurry (Harris et al. 1982b).

\section{Weather Constraints}

Rain or snow can stop slurry wall construction temporarily. Although, the mixer used in the construction of a C-B wall makes it easier to continue con- 
struction during the rain. A mixing plant could be used during S-B wall construction to mitigate changes in the bentonite-water ratio due to rain water infiltration (Harris et al. 1982b).

Freezing temperatures can halt slurry wall construction. The delivery of materials to the site may be hampered by poor road conditions. Slurry freezes at about $-1{ }^{\circ} \mathrm{C}\left(28^{\circ} \mathrm{F}\right)$ and regains its original properties when thawed. Slurry walls may fracture at the 1.2 meter frost line after installation (Harris et al. 1982b).

\section{Environmental Effects}

The slurry has minor impacts on the environment. The migration of slurry into the soil surrounding the trench is relatively low. It is not probable that the small amounts of chemical additives sometimes used in slurries will leach from the wall into the local ground water (Harris et al. 1982b).

The greatest environmental effect will be on the local ground-water flow. An increase in the up-gradient hydraulic head, due to ground-water flow impeded by the slurry wall, can have effects on the rate of vertically moving water. The local water table may rise creating a "bathtub effect" (EPA 1982). Areal ground water modeling can be used to analyze the effect of a slurry wall on ground-water flow and changes in water table elevations (Miller 1979).

\subsubsection{Steel Sheet Piling}

Sheet piling, along with grout curtains and slurry trenches, can be used to form static barriers to ground-water movement. Various materials can be used to construct sheet piles (e.g., wood, precast concrete, and steel) but steel is the most effective and widely used as a ground-water cut-off. A steel sheet piling ground-water barrier consists of interlocking steel piles driven into the ground via a pile driver. The piles are typically driven from ground surface or from pre-dug trenches (EPA 1982).

\subsubsection{Sheet Piling Design Considerations}

Steel sheet pilings are typically hot rolled steel sections $1.25 \mathrm{~m}$ to $12.2 \mathrm{~m}$ in length (i.e., vertical) and $0.4 \mathrm{~m}$ to $0.8 \mathrm{~m}$ in width (i.e.., horizontal direction of cut-off wall). The shapes of individual piling sections are higly varied and manufacturer dependent. Many manufacturers have also developed their own piling interlocking designs and all manufacturers of steel sheet piling make special corner sections and "T" connections (EPA 1982).

The effectiveness of steel sheet piling as a ground-water barrier is a function of the integrity of the interlocking system (Harris et al. 1982a). The cut-off effectiveness can be lost if sections of the wall become unlocked allowing seepage through the resulting gap. If out of interlock, an individual sheet can stray more than a meter out of position without detection. 
Steel sheet piling is applicable only to unconsolidated host materials, except in very rare situations where the piles may be hard driven through consolidated material. Steel sheet piling is usually not even considered suitable for use in very rocky soils because of the difficulty in driving the piles through cobbles and boulders and the resulting damage to the piles themselves (EPA 1982).

Steel sheeting is most effective as a ground-water flow barrier when anchored (i.e., driven into) in a low permeability bed of firm clay (Harris et al. 1982a). When first placed in the ground the permeability of steel sheet piling cut-offs is quite high even with an impermeable key because the interlocks, which are loose to facilitate placement, allow significant seepage. However, as time passes, the permeability is reduced due to the siltation of fine soil particles in the interlock seams. The rate of sealing depends of ground-water flow rates and the adjacent soil properties (EPA 1982).

The three most important design considerations for steel sheet piling cutoffs are the (Harris et al. 1982a):

1. Interlock,

2. Shape of pile cross-section, and

3. Material.

Examples of various types of interlocking systems are presented in Figure 4.3.3-1. The pilings are assembled before being driven to facilitate a positive lock. Good interlocks are relatively soil tight, however none are completely water tight.

The cross-sectional shape of pilings is designed to facilitate resistance to bending of the resultant wall. In addition to bending strength the pilings must be suitable for driving into soil to appropriate depths. The shapes of cross-sections are also designed to provide required stiffness (Harris et al. 1982a). Figure 4.3.3-2 shows examples of typical sheet piling cross-sectional shapes. Generally, steel sheet piling shapes are divided into two main types: 1) U-type sections, and 2) Z-type sections. The U-type sections are commonly referred to as arch web types (see Figure $4,3.3-2$ ). Steel sheet piling typically weighs between $73 \mathrm{~kg} / \mathrm{m}^{2}$ and $78 \mathrm{~kg} / \mathrm{m}^{2}$ of wall area with $0.6 \mathrm{~cm}$ to $2.25 \mathrm{~cm}$ of thickness (Harris et al. 1982a).

For purposes of mitigating ground-water contamination from severe power plant accidents only steel sheet piling is being considered. Pilings made of other materials are not as effective in controlling ground-water seepage (EPA 1982; Harris et al. 1982a; Lee 1949). Steel can withstand the force of driving during installation and thus can be used in more resistant strata than other materials; timber in particular). The steel piling design specifications, particularly the amount of steel in the cross-section and the quality of the steel, are determined primarily by the soil resistance to be overcome in driving the pilings (Harris et al. 1982a). 

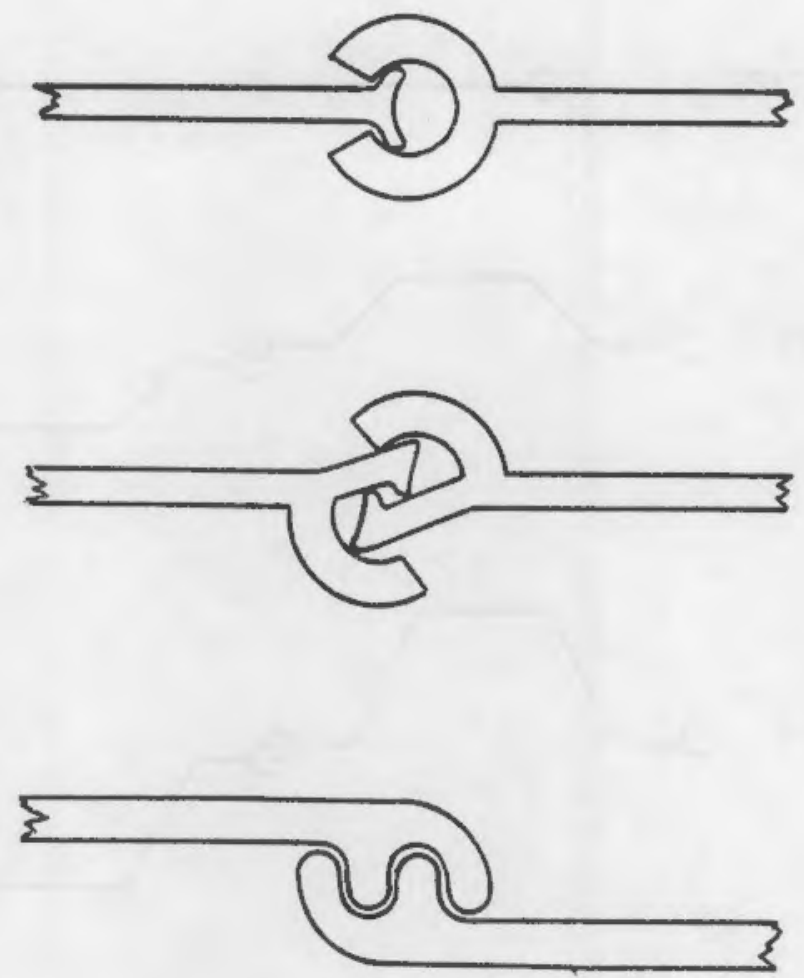

FIGURE 4.3.3-1. Steel Sheet Piling Interlock Designs (Adapted from: Merriman and Wiggin 1947)

\subsubsection{Sheet Piling Construction Considerations}

Sheet piling is forced into place in pairs, with a pneumatic or steam driven pile driver or a drop hammer. Steel sheet piles usually drive outward and tend to creep in the direction in which the cut-off wall is being driven. In order to prevent outward movement of the pilings they are pitched and driven to part penetration. The piles are driven a meter or so at a time over the entire length of the wall until all the piles have been driven to the desired depth (Figure 4.3.3-3) (EPA 1982, Lee 1949).

For driving steel sheeting in cohesive soils the recommended ratio of the weight of the hammer to the weight of the sheeting being driven is 2.0 . For less cohesive, granular, soils a double acting steam hammer is recommended because the rapidity of hammering results in vibration of the subsoil which greatly facilitates penetration (Lee 1949).

Heavy equipment is usually preferable to lighter weight equipment for faster driving and prevention of damage to the piles. Often a cap block or driving head is used to prevent damage to the top edge of the sheeting (EPA 1982). Hammering should be temporarily suspended when an obstruction or sudden resistance is encountered in order to save damaging the toe of the piles and 

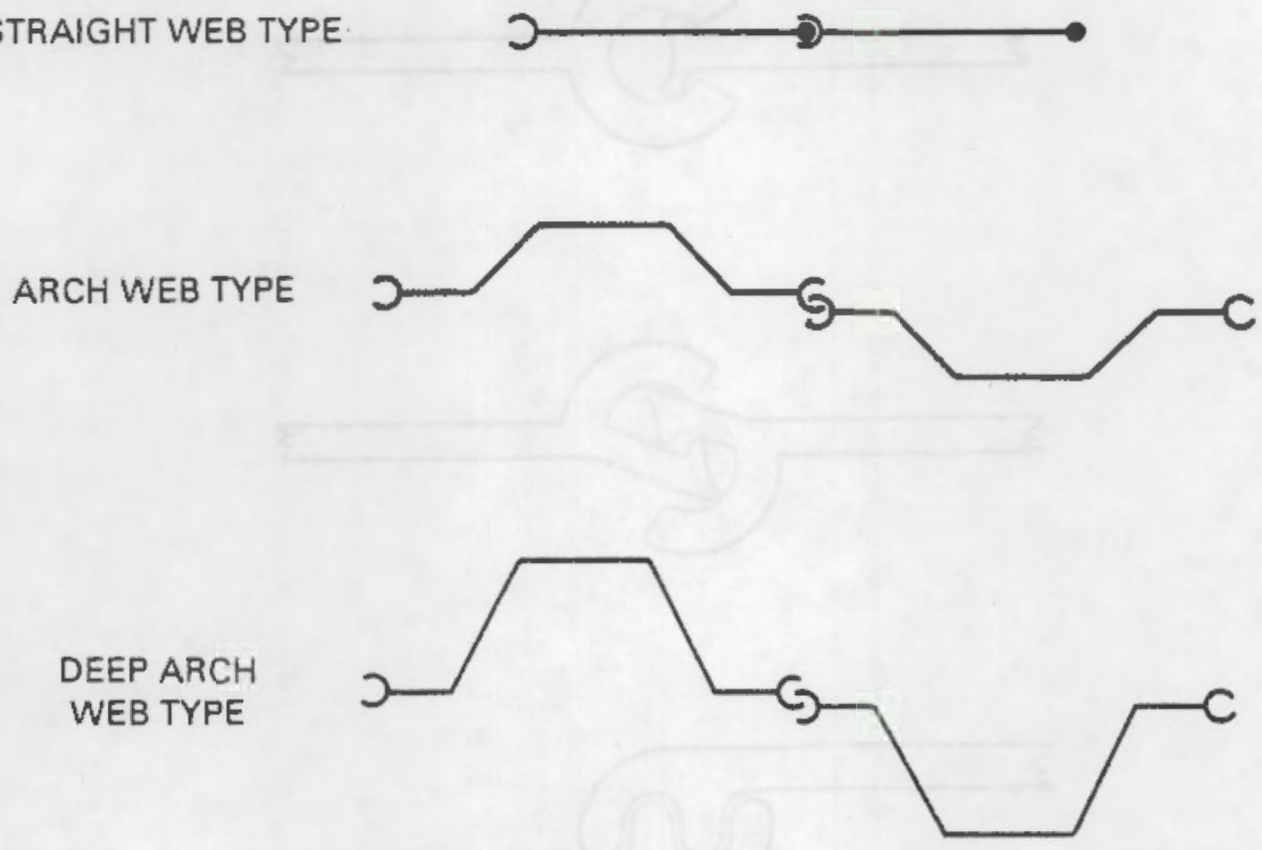

Z-TYPE
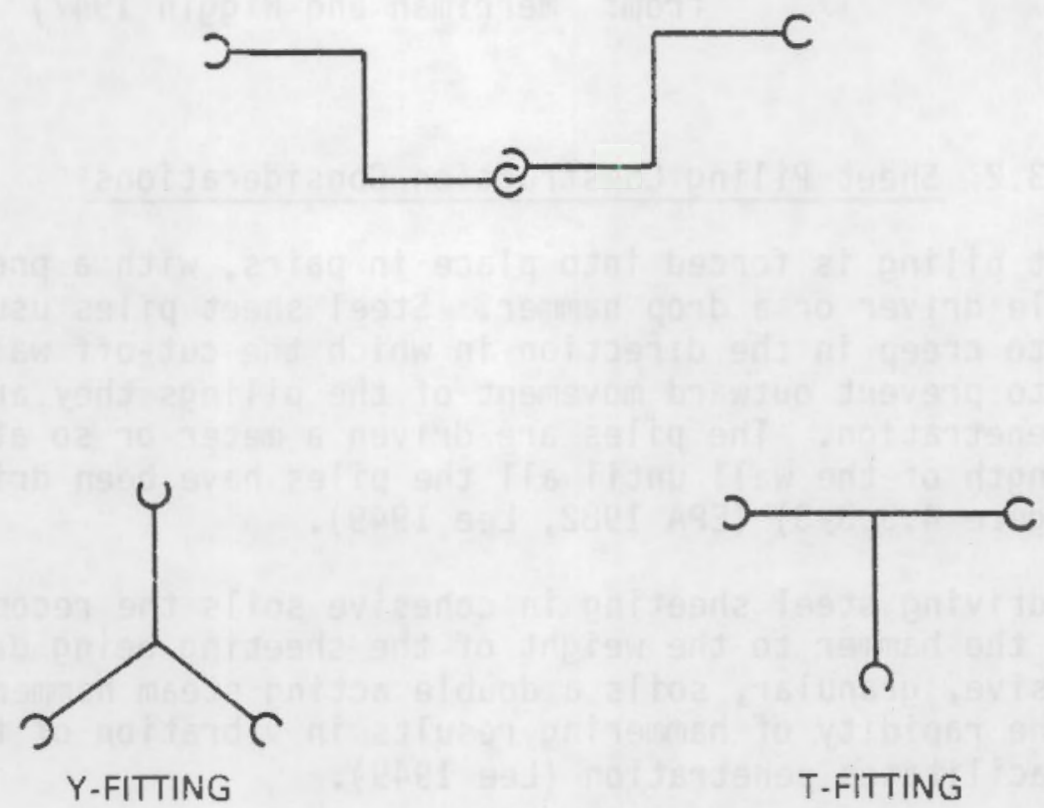

T-FITTING

FIGURE 4.3.3-2. Typical Steel Sheet Piling Shapes (Source: EPA 1982) 


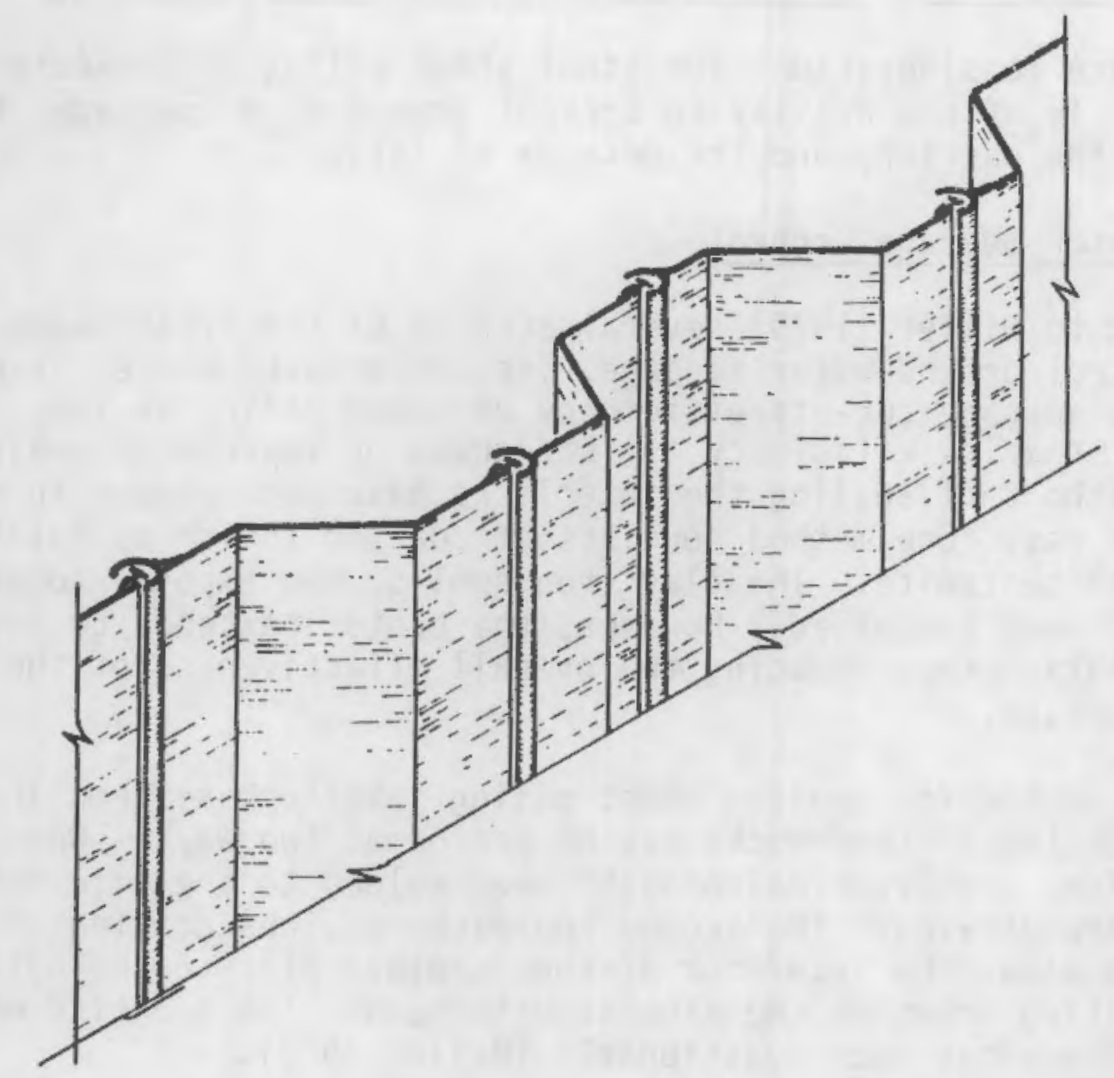

FIGURE 4.3.3-3. In-Place Steel Sheet Piling Cut-off Wall (Source: Miller 1979)

possibly opening the interlock. Hammer bounce indicates when an obstruction or stiff resistance has been encountered. If only stiff resistance is considered the cause of the bounce a heavier hammer may be required for continued penetration. Conversely, if an obstacle has been met hammering of adjacent piles may free the snagged sheet (Lee 1949).

A pile frame is often used with a pile hammer since the frame helps alignment of the sheets. When steel sheeting is driven without a pile frame timber walings are used to support the sheeting during installation (Harris et al. 1982a; Lee 1949). Some types of steel sheet piling are delivered interlocked in pairs offering a significant time savings. Also, for installation in stiff cohesive soil the bottom edge of the sheets are occasionally reinforced by bolting or welding steel strips thereby reducing the skin friction higher on the pile (Lee 1949).

The play in most interlock systems allows for a significant degree of curvature in the constructed cut-off wall. However, the strength of the interlock and its watertightness are inversely related to the swing properties of the interlock (Lee 1949). 


\subsubsection{Performance Considerations for Steel Sheet Pilings}

Performance considerations for steel sheet piling ground-water barriers consist primarily. of the ability to control ground-water seepage, the durability of the barrier, and the methods of failure.

\section{Ground-Water Seepage Control}

According to Miller (1979) several studies of the effectiveness of sheet piling to control ground-water seepage, including instrumented studies, have shown that the seepage cut-off efficiency of sheet piling is low. The principal reason for the low efficiency is inadequate or improperly sealed interlocks. Two methods of sealing the interlocks have been used with varying degrees of success. One method consists of coating (prior to driving) the interlocks with bentonite. The clay then swells when exposed to water after the piles have been installed. However, the bentonite tends to scrape off during installation thus reducing the overall effectiveness of the coating in controlling seepage.

A second method for sealing sheet piling interlock systems involves grouting. Grouting of interlocks can be performed two ways. One way consists of grouting after installation through tubes welded to the pile interlock area installed before driving. The second approach requires driving or jetting the injection pipe along the interlock of the in-place pile to the bottom of the pile and injecting grout as the pipe is withdrawn. The grouting methods are costly and success has been questionable (Miller 1979).

Another reason for the possible reduction in performance of sheet piling as a ground-water cut-off is broken interlocks caused by hard or improper driving. Related to this problem is also the concern over adequate sealing of the piles in an impervious key-in strata or foundation. Both of these problems are difficult to detect for in-place pilings (Miller 1979). If the pilings have to be driven hard to obtain sufficient penetration in an impervious layer the sheets may buckle causing damage to the interlock. Because of the damaged interlock the succeeding sheet may be forced out of the lock causing potentially significant leakage through the gap (Lee 1949).

Where effective seals (i.e., little or no leakage) can be maintained both for interlocks and the key-in, sheet piling provides an essentially continuous impermeable barrier. In practice sheet piling cut-off walls have been constructed in soils ranging from well-drained sand to impervious clay (EPA 1982).

Steel Sheet Piling Durability

Steel corrodes under typical ground conditions at a maximum rate of 2 to $5 \mathrm{mils} /$ year for the first few years and then the rate declines (Miller 1979). Steel also corrodes faster in a sea-water environment than a fresh-water environment (Lee 1949). Depending on the conditions of the soil and the groundwater chemistry the performance life of a steel sheet piling wall may be between 7 and 40 years (EPA 1982). 
Typically, a sheet piling cut-off wall is in contact with three subsurface environments (Miller 1979):

1. Relatively dry soils above the water table,

2. Alternatively wet and dry soils in the transition zone from the vadose zone to the saturated zone, and

3. Continuously wet soil in the saturated zone below the water table.

The transition environment ( $\# 2$ above) is the most corrosive and could potentially have a corrosion rate in excess of 10 mils/year (Miller 1979). Some measure of protection against corrosion can be obtained by using hot-dip galvanized or polymer-coated steel pilings. Cathodic protection has also been proposed for corrosion protection of submerged pilings (EPA 1982). However, corrosion protection will not indefinately extend the life of a steel sheet piling cut-off wall.

Because of the relatively short life of a sheet piling cut-off compared to grouts and slurry trenches this ground-water interdiction techniques should most probably be considered as a temporary or short-term corrective measure while more long-term or permanent solutions are studied and/or implemented.

\section{Causes of Sheet Piling Wall Failure}

Failure of steel sheet piling walls can usually be attributed to: 1) insufficient penetration of the piling toe causing the wall to tilt and then possibly slide forward, and 2) ineffective anchorage also resulting in tilting of the wall and subsequent sliding forward. Ineffective anchorage may be in the form of inadequate or improper bolting of walings to pilings, the walings themselves, the tie rod and end fixings, or the anchors themselves (Harris et al. 1982a; Lee 1949). Also anchorages may fail because they are placed too near the wall. Failure of sheet piling walls by overstressing the sheeting in bending are rare (Lee 1949).

\subsubsection{Steel Sheet Piling Implementation Considerations}

There are certain advantages and disadvantages of steel sheet piling walls in comparison with other engineered (i.e., constructed) barriers. The advantages of steel sheet piling ground-water cut-offs are (EPA 1982):

1. Materials and construction expertise are readily available,

2. Relatively easy to install,

3. Relatively inexpensive, and

4. Low maintenance requirements.

There are major disadvantages using steel sheet piling include (EPA 1982):

1. Cannot be used in consolidated medium,

2. Cannot be used effectively in rocky unconsolidated medium,

\subsection{5}


3. Limitations on the maximum depth of installation,

4. Initially not waterproof and without secondary sealing of joints may not achieve required levels of watertightness, and

5. Relatively short-lived.

Considerations for implementing or installing a steel sheet piling cut-off wall are: 1) installation time, 2) cost, 3) equipment mobilization, and 4) differential water levels, and 5) worker safety.

Installation Time

As with grout curtains and slurry trenches the time required to install a steel sheet piling cut-off is both a function of the specifications of the wall and the location of construction. Consequently, the construction time is highly job-specific. In general, the installation time per lineal meter of wall is greater for sheet piling than a similar depth slurry wall and less time per lineal meter than for a grouted curtain cut-off assuming no grouting of the sheet piling interlocks.

\section{$\underline{\text { Cost }}$}

As is the case with construction time, installed sheet piling costs are job specific. Unit steel pricing can be used to estimate the materials cost, however the cost of driving the piles depends on the size, length, and type of section used, the nature of the soil, the amount of piling used, local labor conditions, and the method of driving. The EPA (1982) suggests guidelines to estimate the unit cost of a steel sheet piling wall. Table 4.3.3-1 contains estimates for materials and installation.

Once the total area of the wall to be constructed has been determined an adjustment factor of 1.6 is normally used to account for the area of the interlocking device. The adjusted area (i.e., the required area multiplied by 1.6)

\section{TABLE 4.3.3-1. Unit Costs of Steel Sheet Piling}

(Source: EPA 1982)

\begin{tabular}{|c|c|}
\hline Commodity & Cost/Unit \\
\hline Black Steel & $\begin{array}{l}\$ 1,139 / \text { metric ton } \\
\text { (assumed } 1980 \text { dollars) }\end{array}$ \\
\hline $\begin{array}{l}\text { Hot-dipped } \\
\text { Galvanized Steel }\end{array}$ & $\begin{array}{l}\$ 1,296 / \text { metric ton } \\
\quad \text { (assumed } 1980 \text { dollars) }\end{array}$ \\
\hline Installation & $\begin{array}{l}\$ 231 / \text { metric ton } \\
\text { (assumed } 1979 \text { dollars) }\end{array}$ \\
\hline
\end{tabular}


can then be multiplied by the weight per area of the type of steel to be used which results in the total weight of the wall. The unit costs in Table 4.3.3-1 can then be used to estimate the total cost of the wall (EPA 1982).

There are several manufacturers of steel sheet piling in the IJ.S. as well as in Japan, West Germany; France; Britain; Luxenborg; the USSR and some eastern European countries (Harris et a 1. 1982a). U.S manufacturers of steel sheet piling include Bethlehem, U.S. Steel, and Jones and Laughlin Company.

\section{Equipment Mobilization}

The majority of the heavy equipment necessary to install a steel sheet piling cut-off consists of the pile driving apparatus. A derrick or a pile frame is sometimes used to support the hammer and, in the case of the frame, to align the pilings. A drop hammer is preferred for clay or marl and a doubleacting hammer for non-cohesive soils (Lee 1949). Cranes are also used to suspend leaders and raise and lower hammers. Sufficient clearance must be provided to maneuver the crane or pile frame along the course of the wall; and because the sheeting is typically delivered to the job site via flatbed tractor-trailer rigs there is also a limit to the one piece length of sheeting that can practically be delivered.

\section{Differential Water Levels}

Because the sheet piling acts as a barrier and redirects the ground-water flow there is potential for different water levels on each side of the wall, hence differential hydrostatic pressure on the sheet piling wall (harris et al. 1982a). Where this pressure gradient exists across the wall the potential for seepage under the wall increases. If seepage occurs (due to inadequate key-in of the toe of the piling) the seepage flow will increase the effective unit weight of the soil on the up-gradient side of the wall and decrease the effective unit weight of the soil on the down-gradient side of the wall. The likelihood of increased pressure differentials due to differential water levels across the wall should be factored into the design of the wall. If such differentials are expected to be high, as might be the case with a heavy rainstorm over a local up-gradient recharge area which could cause a rapid rise in the water table, the design of the wall and anchorage system should accomodate the additional load (Harris et a1. 1982a).

\section{Worker Safety}

The same worker safety issues arising for grout curtain construction and slurry trench development apply to steel sheet piling placement. However, steel sheet piling does not require opening of a trench as is the case with slurry wall construction. Thus the potential radiation exposure associated with trenching below the water table is avoided by sheet piling.

\subsection{ANALYSIS OF DYNAMIC GROUND-WATER CONTAMINANT MITIGATION STRATEGIES}

Dynamic and quasi-dynamic mitigation alternatives influence the state of the contaminated ground-water in an active manner. These alternatives are 
better characterized as "mitigation strategies" rather than "interdictive tẹchniques" which refers more to passive, engineered/constructed barriers. Dynamic mitigation strategies offer a wide range of potentially feasible (depending on the accident scenario and geohydrologic conditions of the particular site) approaches to containing, diverting, and/or treating groundwater contamination.

Dynamic strategies tend to be energy intensive and require some level of maintenance as opposed to the static barrier techniques (e.g., slurry trenches). For this reason, and others discussed under each strategy, dynamic strategies tend to be temporary corrective actions. However, even though most of these strategies are temporary they are not necessarily short-lived. Also, the dynamic strategies are more conceptual in design than the constructed barriers and often a complete mitigative course-of-action will comprise several of the individual strategies presented herein.

The dynamic mitigation methods are primarily concerned with active means to manipulate the ground-water flow regime in order to intercept the contaminant plume to remove it, treat it in-place, remove and treat it, or divert it. Many of the methods are only feasible in shallow aquifers in unconsolidated media. Other techniques are theoretically feasible in any geologic setting. However, certain practicalities prohibit application in some circumstances. The underlying philosophy of the dynamic mitigation schemes is one of concentration reduction to acceptable levels, not total contaminant removal. Several of the strategies require handling of the contaminated ground water. Safety issues are important since the potential radionuclide concentrations are substantial.

Many of the dynamic mitigation strategies are combinations of pumping and injection or re-injection schemes designed to lower the water table or through gradient control contain the contaminant plume. Two barrier construction techniques are also included in the dynamic strategies category because their maintenance is energy intensive. Table 4.4-1 contains a list of the dynamic

\section{TABLE 4.4-1. Dynamic Mitigation Strategies}

1. Ground-water withdrawal for potentiomnetric surface adjustment.

2. Ground-water withdrawal and/or re-injection for contaminant plume control.

3. Subsurface collection with recovery drains.

4. Selective filtration via permeable treatment beds.

5. Ground freezing.

6. Air injection. 
mitigation strategies considered for mitigation of ground-water contamination resulting from a severe power plant accident.

\subsubsection{Ground-Water Withdrawal for Potentiometric Surface Adjustment (Aquifer Dewatering)}

Ground-water withdrawal to lower the water table in a predefined region can be an effective means of mitigating ground-water contamination resulting from a severe power plant accident. Lowering the water table via ground-water pumping can produce three consequences that are favorable in reducing the concentration of radionuclides in ground-water or their flux to an accessible environment. The three consequences of ground-water withdrawal as applied to ground-water contaminant mitigation are (EPA 1982):

1. Lowering the water table sufficiently to prevent the contaminated ground-water from discharging to a receiving stream that is in hydraulic contact with the unconfined aquifer,

2. Lowering the water table so that it is not in direct contact with the solidified core mass, and

3. Lowering the water table to preclude leaky aquifers from contaminating other aquifers.

Figures $4.4 .1-1,4.4 .1-2$ and $4.4 .1-3$ pictorially represent these three schemes.

Figure 4.4.1-la shows the possible pre-drawdown condition of contaminated ground water being discharged to a down-gradient surface stream. Pumping can be implemented to create a cone of depression that extends to the streamaquifer interface and, if sufficient, reduces or eliminates ground-water discharge to the stream (Figure 4.4.1-1b). Figure 4.4.1-2a shows a possible situation wherein the containment basemat is below the water table elevation. A breach of the basemat would allow direct contact of the sumpwater with the saturated ground-water flow system thus allowing immediate down-gradient transport of the radionuclide concentration in the sumpwater. However, with groundwater dewatering below the basemat (Figure 4.4.1-2b) a partially-saturated zone is created between the basemat and the water table. Radionuclide transport in this partially-saturated region would be slowed and oriented vertically downward especially in the case of a leaching solidified core mass as opposed to a sumpwater release. The third application of ground-water pumping to mitigate the effect of a severe power plant accident is shown in Figure 4.4.1-3. A situation might exist where the aquifer in which ground-water contamination arises is in leaky contact with another uncontaminated aquifer. Creation of a drawdown area in the overlying aquifer (Figure 4.4.1-3b) near the contaminant source may reduce or preclude contamination of previously uncontaminated aquifers.

The first two applications of ground-water pumping to lower water table elevations are best suited for shallow unconfined aquifers. However, piezometric heads in a confined aquifer can also be lowered by pumping until water 
a) BEFORE PUMPING

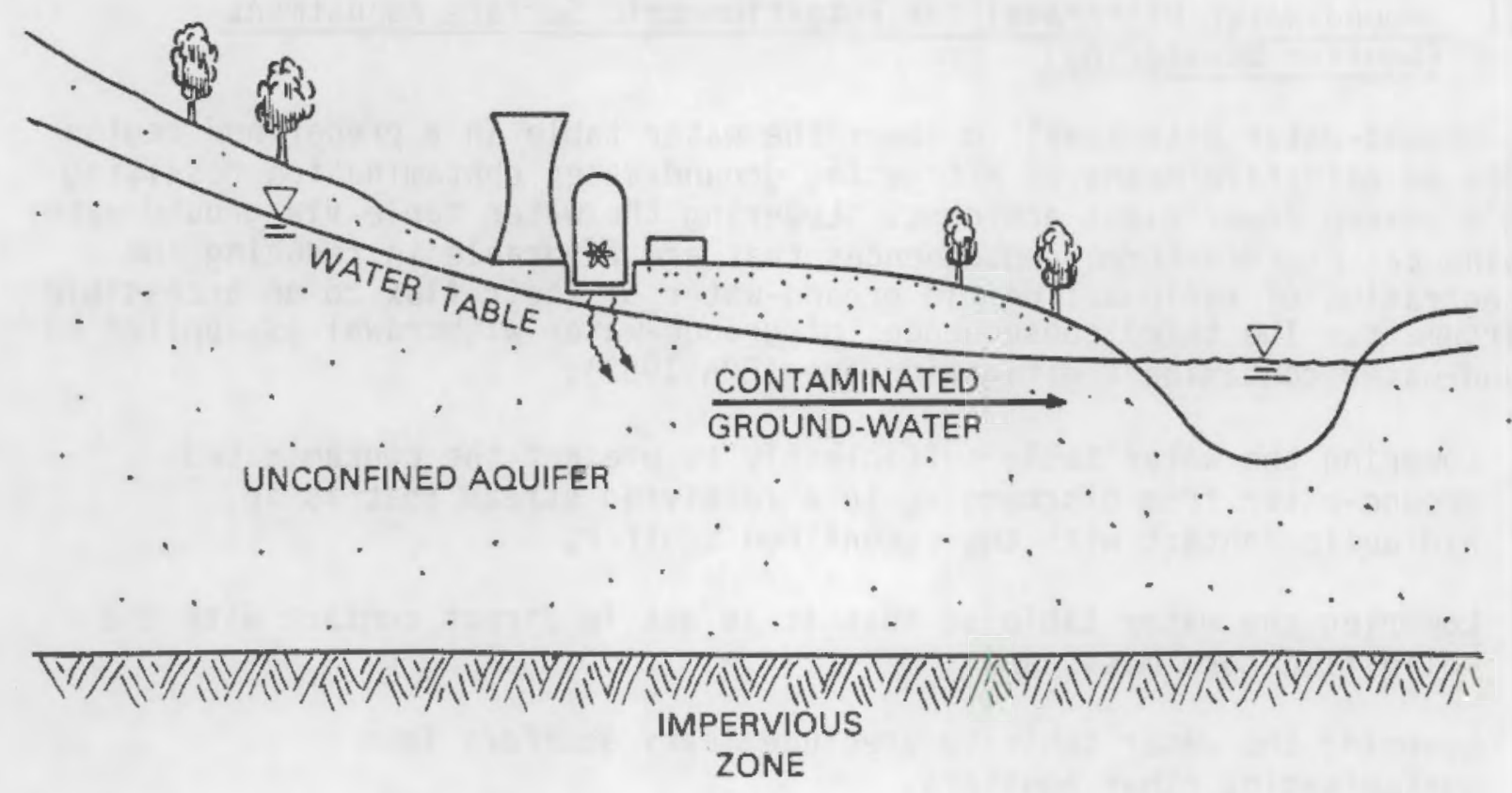

b) AFTER PUMPING

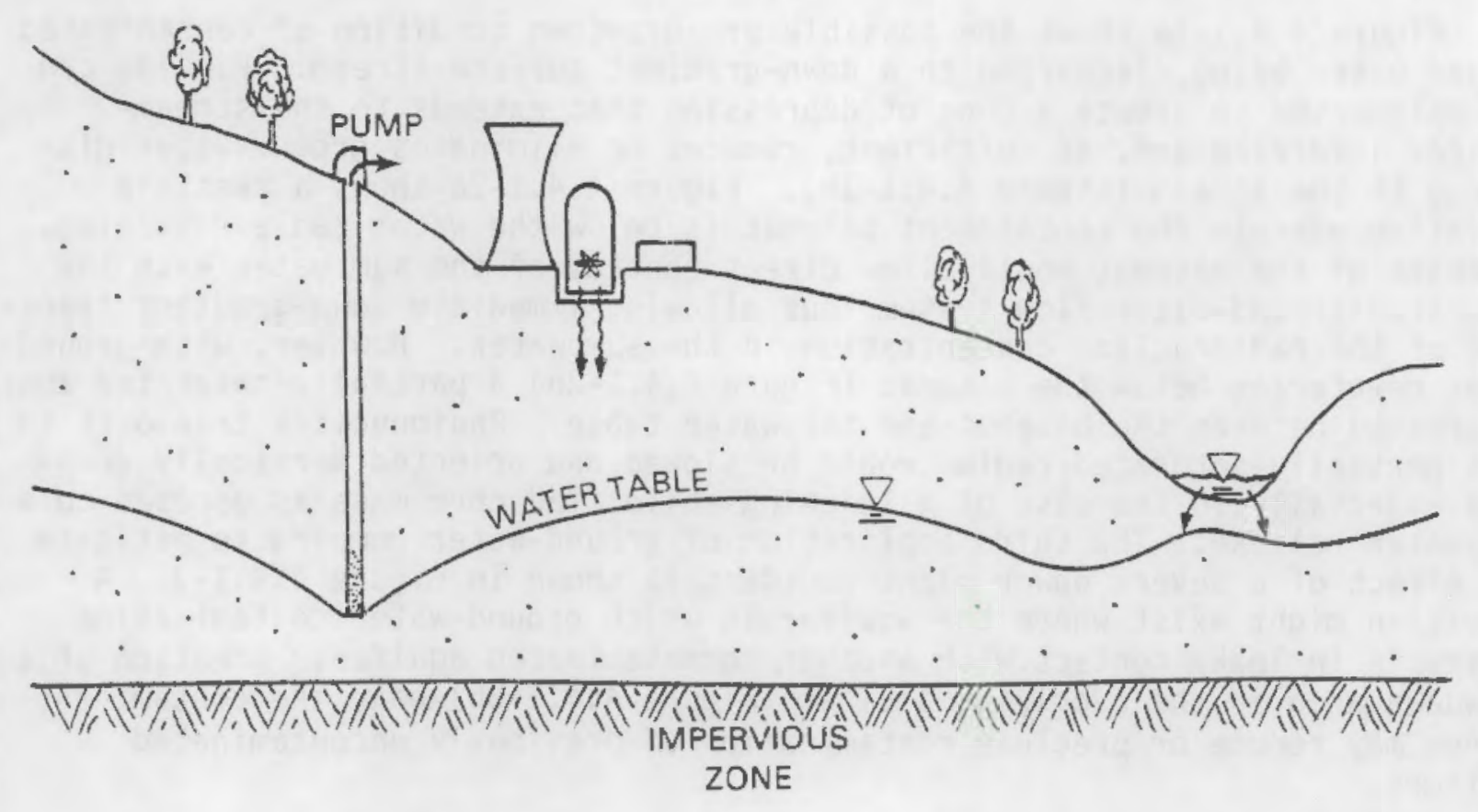

FIGURE 4.4.1-1. Pictorial Representation of Pumping to Lower Water Table Below Receiving Stream (After: EPA 1982). 


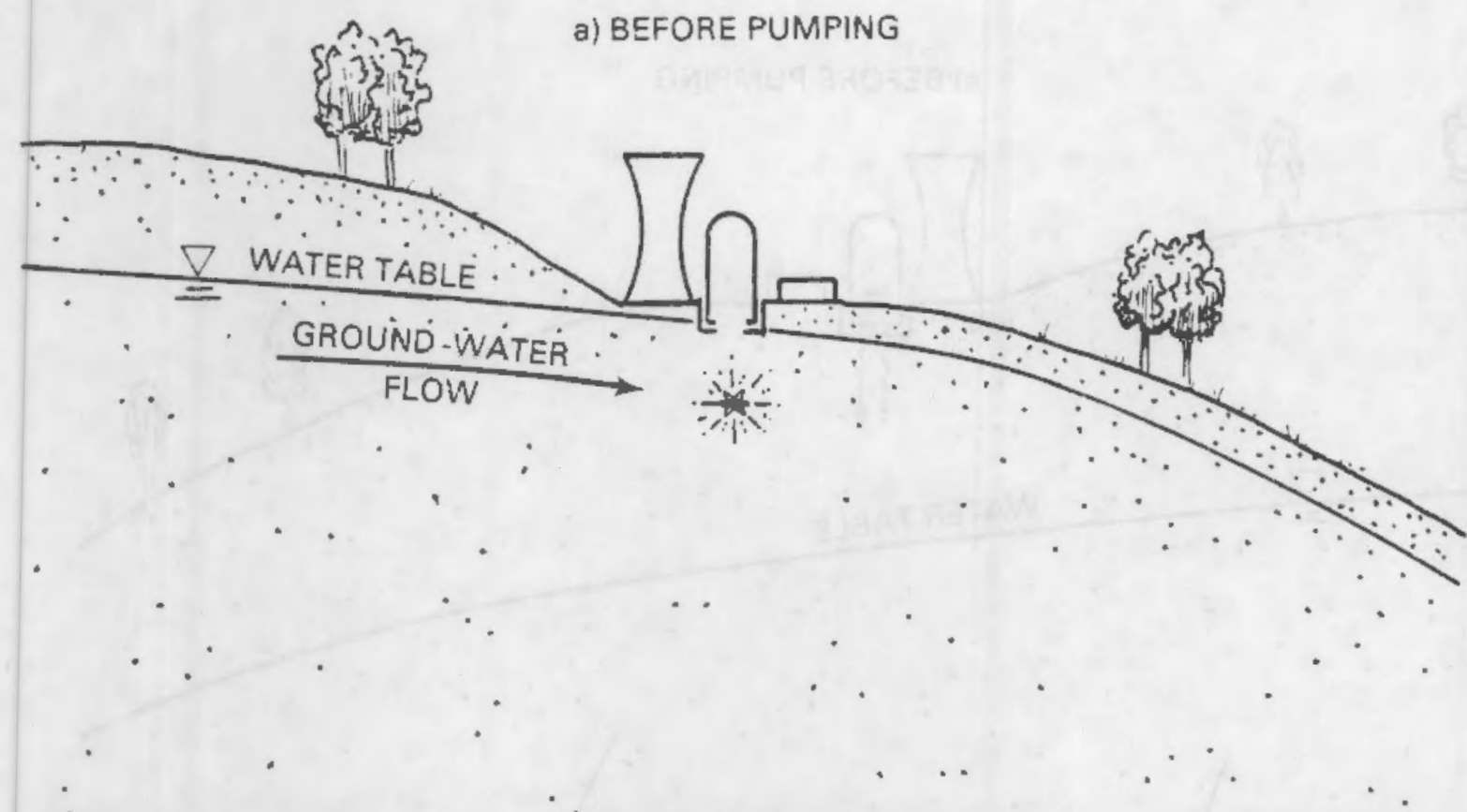

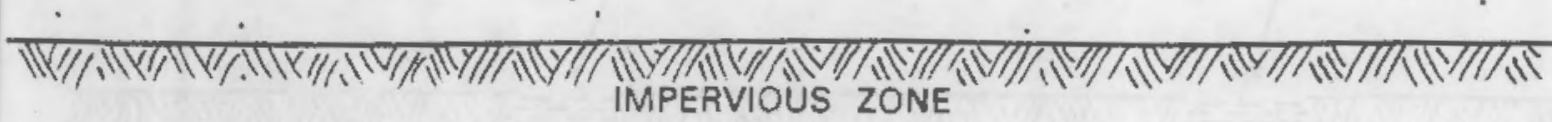

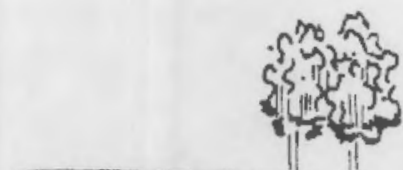

b) AFTER PUMPING

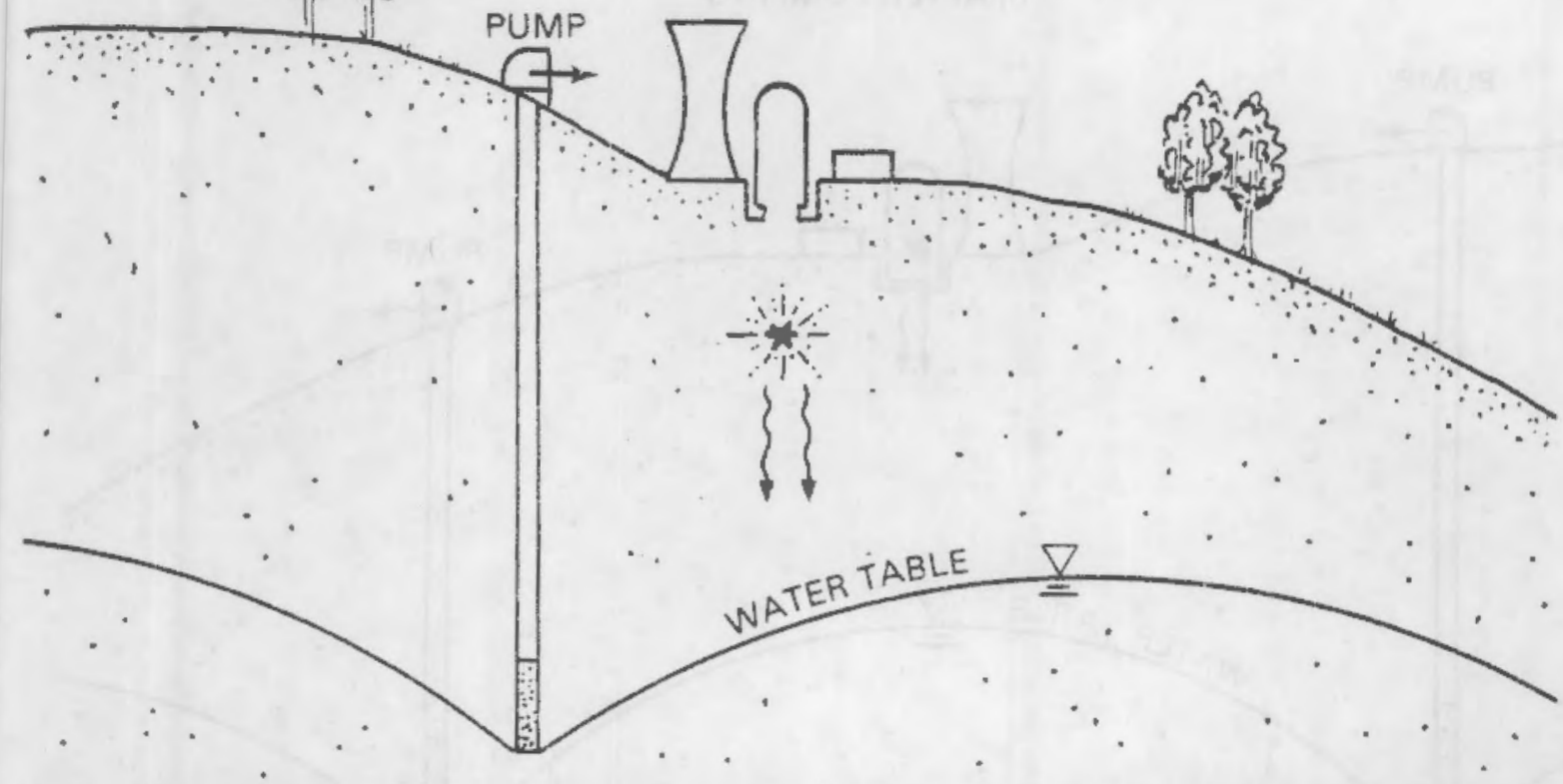

(V/I) IMPERVIOUS ZONE

FIGURE 4.4.1-2. Pictorial Representation of Pumping to Lower water Table Below Containment (After: EPA 1982) 


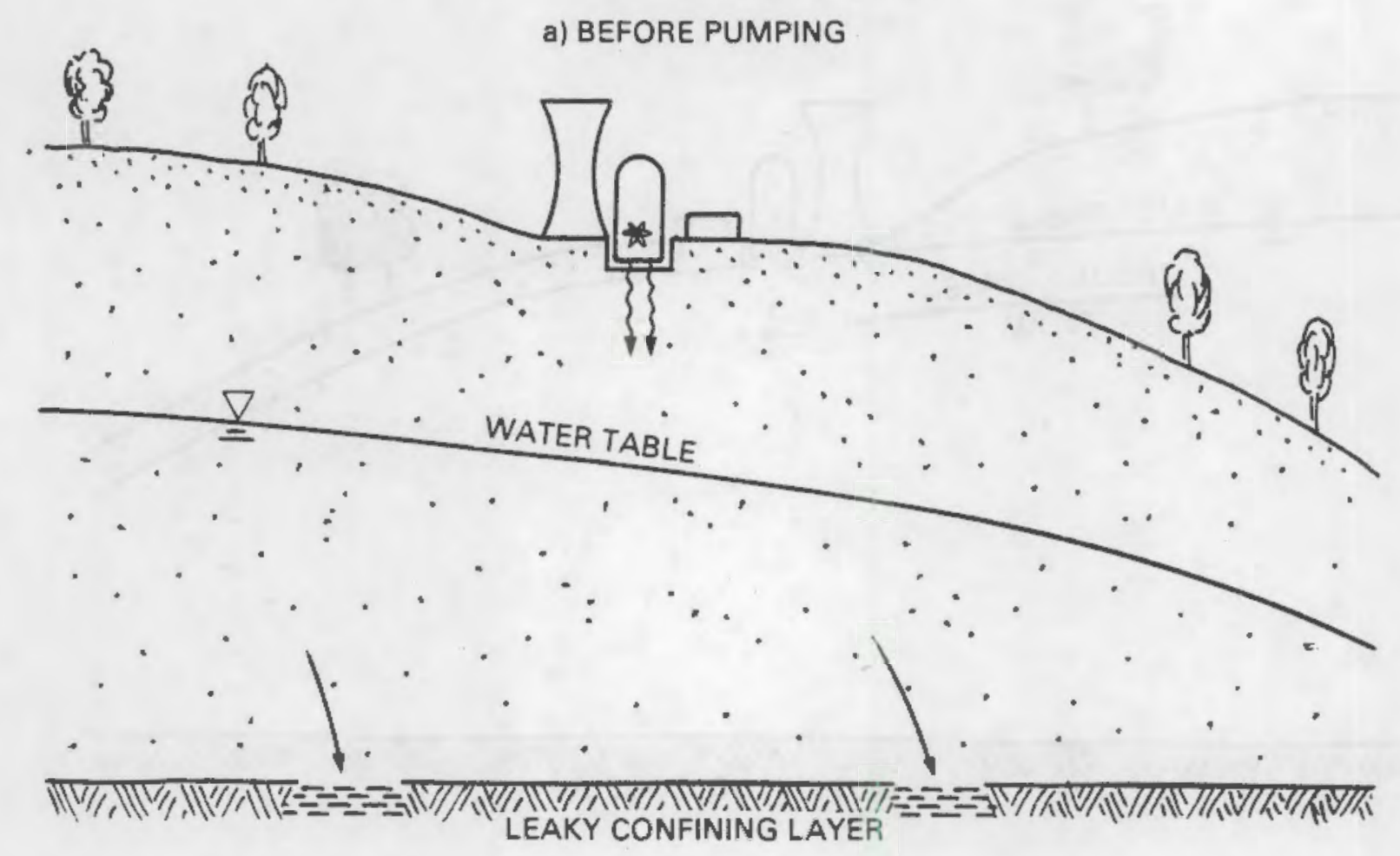

b) AFTER PUMPING

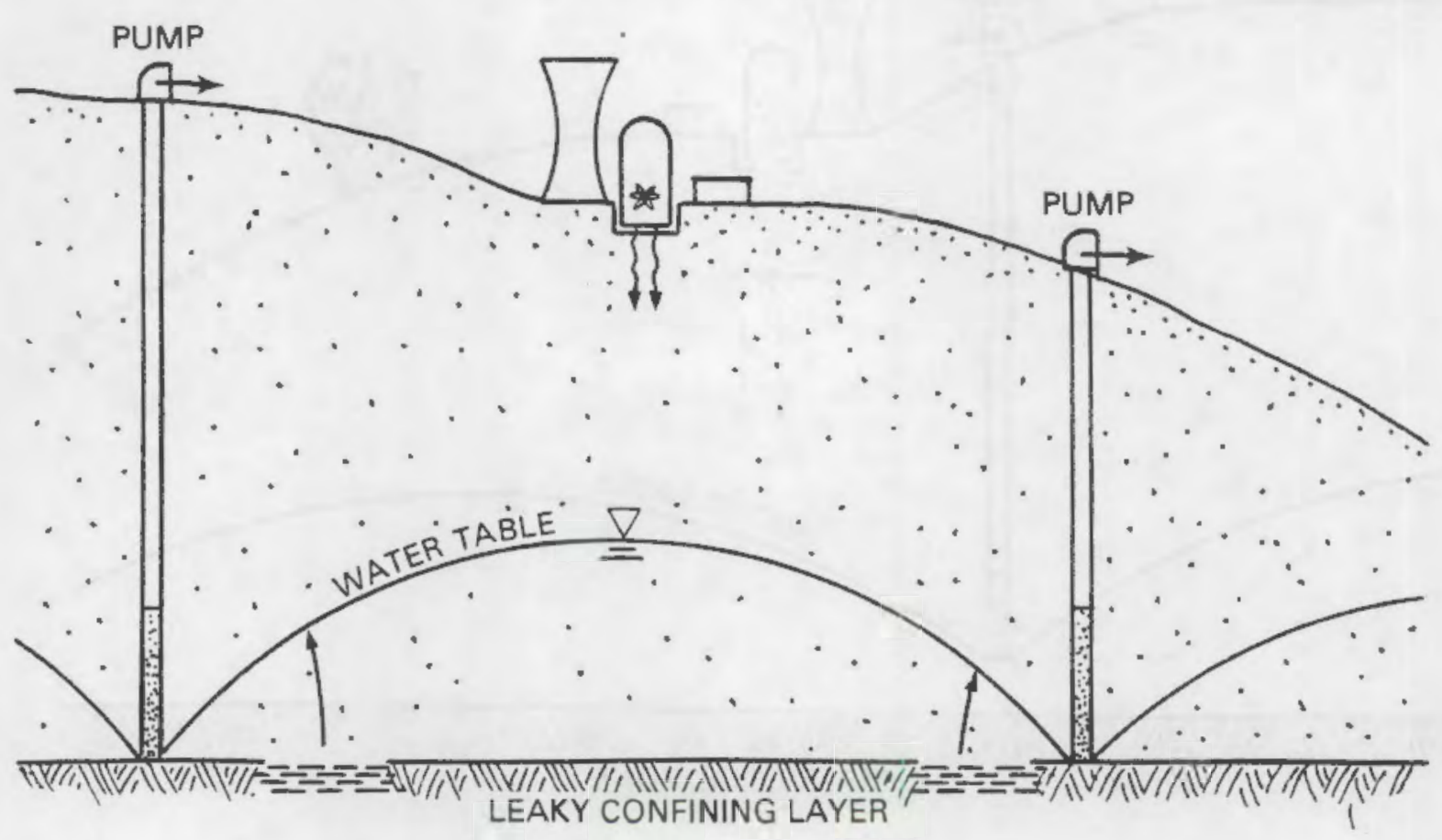

FIGURE 4.4.1-3. Pictorial Representation of Pumping to Prevent Contamination Through a Leaky Confining Layer. (After: EPA 1982). 
table conditions exists. The third application is feasible for both confined and unconfined ground-water systems. All three applications may result in contaminated water being pumped to the surface. This situation may necessitate expensive and/or difficult handling procedures for the well discharge.

\subsubsection{Design Considerations for Ground-Water Withdrawal for Water Table Adjustment}

The following discussion is provided in order to present certain considerations for the design of dewatering systms. Within the context of this study, design refers to a conceptual development of dewatering strategy not the engineering design of a specific application. Detailed site analyses are necessary for the engineering design of dewatering systems.

Lowering of the water table necessarily requires the pumping of ground water by either using a well point dewatering system or a deep well system. A well point system is typically composed of a header pipe connecting a series of closely spaced wells which are pumped by suction centrifugal pumps, submersible pumps, or jet ejector pumps depending on the volume pumped and the depth of pumping. A separate pump may be used for each well point or a central pump may be used for several well points (EPA 1982).

Deep well systems are required for consolidated geologic formations where the water table is too deep for suction lifts. Each well is equipped with its own pump and can dewater at greater depths than a well point. The cost of a deep well system is generally higher than a well point system (Harris et al. 1982a).

Regardless of which well system (i.e., well point or deep well) is used the proper design of a ground-water dewatering scheme requires an understanding of well hydraulics and the hydrogeologic properties of the aquifer. The radius of influence of a well systern must be determined for various pumping rates in order to estimate the extent of the cone of depression. The drawdown and total radius of influence for a well is a function of (EPA 1982):

1. Pumping rate,

2. Hydraulic-conductivity and saturated thickness of aquifer,

3. Ground-water recharge,

4. Regional and local flow boundary conditions, and

5. Length of time pumping continues.

The drawdown at various distances from the well field can be estimated using the above information. These estimates are best produced by representing the aquifer and well field in a mathematical ground-water flow model and solving for the drawdown at various distances. Well point spacing is based on the composite radii of influence required to achieve the necessary drawdown. 
According to the EPA (1982) designs for well point dewatering systems are highly variable and depend on the depth to which drawdown is required, the transmissivity and storativity of the aquifer, the depth at which the contaminant arises, and the depth of the aquifer. Well points are normally installed by jetting down, driving in-place, or in open holes (Harris et al. 1982a; EPA 1982).

There are special situations which may require design modifications. Fine-grained soils (e.g., silts) with low permeabilities cannot be easily drained by well point systems. These soils can be partially drained with well points that are gravel-packed from the bottom of the hole to within a meter of the surface with the remainder sealed with bentonite or similar sealant. This system requires closely spaced well points, and pumping capacity is reduced. For stratified soils, vertical sand drains may be used along with well points to facilitate drainage. The drains are installed in the reduced permeability layers that require dewatering and extended to underlying higher permeability layers where the well points are located. Separate well point systems may be required for dewatering multiple permeable layers separated by impervious zones (EPA 1982). Similar analyses of aquifer response (i.e., drawdown) due to pumping are required to design a deep well dewatering system.

\subsubsection{Construction Considerations for Ground-Water Withdrawal for Water Table Adjustment}

Depths for well points are a function of the depth to which the water table must be lowered. The depth for the well points subsequently determines the type of pump that would be most efficient and the size (i.e., diameter) of the well points (EPA 1982).

For situations where the water table is relatively near the ground surface and maximum drawdown of 5 or 6 meters is required a well point system with a centrifugal suction pump may be adequate (Harris et al. 1982a; EPA 1982). Because in practice (primarily due to friction losses) suction pumping is limited to about 5 meters a deep well system, a multistage well point system, or a combination of deep wells and well points is required for pumping lifts greater than 5 or 6 meters.

Well point pipe sizes are normally determined from experience and site conditions. Recommended sizes vary depending the properties of the host material. For fine-grained material (e.g., silts) well points with a $11 / 2$ inch $(3.8 \mathrm{~cm})$ diameter are suitable. For material with higher permeabilities well point diameters as large as 6 inches $(15.2 \mathrm{~cm})$ may be required. Riser pipe sizes usually vary between 1 inch and $31 / 2$ inches in diameter depending on the well point diameter (EPA 1982).

Well point spacing depends on the radius of influence of each well and the required composite radii of influence. The normal range for well point spacing is 1 to 3 meters depending on ground-water velocities, host material properties, and the time available for dewatering (Harris et al. 1982a). Narrower spacing (i.e., 1 to 2 meters) may be required for stratified or fine-grained soils. 
A typical well point system will yield between 40 liters per minute and 100 liters per minute per well point (Harris et al. 1982a). Greater yields can sometimes be achieved by using larger diameter well points. A hydrogeologic study of the aquifer characteristics in the site area is required to accurately estimate the yields and subsequent drawdown from a well point system or a deep well system.

Deep well construction involves the selection of the size of pump to be used which dictates the minimum diameter of well casing and screen (Harris et a1. 1982a, EPA 1982). A 4-inch submersible pump can be used for well discharge rates less than 375 liters per minute. A 6-inch pump can be used for discharges between 500 and 1500 liters per minute (EPA 1982). Drawdowns in excess of 12 meters can be achieved by deep well systems (Harris et al. 1982a).

There are certain geologic conditions that favor filter packing of deep wells. These conditions are (EPA 1982):

1. Fine uniform soils where filter packing would allow larger slot openings in the weil screen,

2. Thick confined aquifers where filter packing would allow screening the entire thickness,

3. Loosely cemented sandstone where filter packing would allow larger slot openings in the well screen, and

4. Thinly bedded formations where the thickness of each strata is not known.

Depending on the geologic conditions of the host material, the spacing for wells in a deep well system can be on the order of 15 meters (Harris et al. 1982a).

\subsubsection{Performance Considerations for Ground-Water Withdrawal for Water Table Adjustment}

Ground-water dewatering schemes are temporary measures for mitigating the effects of a severe power plant accident. However, depending on the accident scenario and resulting magnitude of the potential ground-water contamination, dewatering of the permeable geologic units may be an efficient and cost effective means of minimizing the impact of the accident. Specific advantages of aquifer dewatering schemes are listed in Table 4.4.1-1.

There are also certain disadvantages to water table adjustment schemes. one of the more serious is the problem of safely handling, processing, and/or disposing of contaminated ground water discharged from the wells. Additional disadvantages of this mitigation alternative are presented in Table 4.4.1-2. 
IABLE 4.4.1-1. Advantages of Aquifer Dewatering Schemes (Source: Harris et a1. 1982a, EPA 1982)

- Construction methods are relatively simple and there is a high degree of design flexibility.

- Construction costs are typically lower than for engineered barriers and construction times are less than for a grout curtain or sheet piling cut-off.

- Highly site adaptable and responsive to changes in contaminant plume migration - system can be easily disassembled.

- For well point systems, many wells can be discharged with a single pump.

- Systems are reliable if properly monitored.

TABLE 4.4.1-2. Disadvantages of Aquifer Dewatering Schemes

(Source: Harris et al. 1982a, EPA 1982)

- Inadequate performance of well point systems in fine silty soils. Design flexibility is significantly reduced in this manner.

- Ongoing maintenance and operational costs escalate with time.

- Continous need for utility service.

- For well point systems, supervision is required to detect any breaks in the vacuum throughout the system.

- Consolidation and subsidence may cause problems in the vicinity of the drawdown.

\subsubsection{Implementation Considerations for Ground-Water Pumping for Water Table Adjustment}

As is the case with constructed barriers the implementation considerations for dewatering of a geologic unit are construction time requirements, cost, equipment mobilization and worker safety.

Installation Time

The construction time for installation of a well point system or a deep well system is dependent on the hydrogeologic site conditions, the size of the area to be dewatered, the depth of dewatering, and the work load. For development of a well point system four wells per day can be installed with one drilling rig working one shift. Two deep wells (i.e., 15 to 18 meters) per day can 
be drilled with one rig working one shift. These estimates assume average drilling conditions and extensive geologic-contaminant sampling was omitted during construction (Harris et a1. 1982a). These estimates are very optimistic. If more drilling rigs are used and/or extra shifts are worked construction time can be reduced.

The well installation time is only one component of the overall time required to achieve a dewatering objectıve. Engineering design and equipment mobilization increase front-end time. Once dewatering (i.e., pumping) begins significant drawdown is not instantaneous. Depending on pumping rates and aquifer hydrogeologic conditions it may take several weeks or more to obtain satisfactory potentiometric adjustment.

$\underline{\operatorname{Cost}}$

The cost of a dewatering scheme is highly site specific. Cost are a function of (Harris et al. 1982a):

1. design and layout,

2. mobilization of equipment,

3. well pretesting and pump test analyses,

4. system installation,

5. operation and maintenance costs (i.e., labor, materials, energy), and

6. monitoring costs.

The EPA (1982) estimated the cost of a hypothetical well point dewatering system at $\$ 240,000$. (a) The cost is for a system of 2 inch diameter well points placed approximately every 2 meters with the total number of well points equalling 416. The total length of header pipe is 762 meters with one centrifugal pump with a 5 meter lift. Included in the design are two high capacity wells with 4-inch submersible pumps. The water table is expected to be drawn down about 4 meters. Three monitoring wells with centrifugal pumps are also included in the cost.

\section{Equipment Mobilization}

Equipment mobilization should not pose any significant restrictions on ground-water dewatering. Standard drilling techniques are used and no specialty equipment is normally required. The contractor would require a certain amount of time to move equipment onsite, however. Unobstructed access for drilling equipment would be a necessity and drilling must be clear of overhead and subsurface utility services. A reliable power source for pump operation must be reachable from the site.

\section{Worker Safety}

An issue of critical concern is the safe handling of any contaminated water that may be pumped from the aquifer. Depending on retardation of radio-

(a) Assumed 1980 dollars. 
nuclides by the host material, initial source concentrations, the pumping rate, and the distance the wells are from the contamination source variable concentrations of radionuclides may be in the pump discharge. Such contaminated discharge would require safe handling and disposal. Also, pumping contaminated ground-water could cause secondary contamination of well system equipment thus posing an additional safety problem.

\subsubsection{Ground-Water Withdrawal and/or Injection for Plume Control}

Ground-water withdrawal, with or without injection, for contaminant plume containment is a dynamic mitigation technique that has been used successfully to control saltwater intrusion in coastal areas. Plume containment may also be appropriate in certain instances for controlling radionuclide contamination from severe power plant accidents. Like ground-water dewatering, plume control via ground-water withdrawal is a conceptual approach to ground-water contaminant mitigation. There are four general pumping schemes that can be used for contaminant plume containment. These are (Harris et al. 1982a; EPA 1982).

1. A series of withdrawal and injection wells (often in pairs) that extract contaminated ground water for surface treatment and subsequent re-injection,

2. Ground-water withdrawal without recharge,

3. Withdrawal and surface treatment of contaminated ground water with recharge through recharge basins, and

4. Injection to reverse the hydraulic gradient.

Figure 4.4.2-1 shows the basic extraction/injection scheme for contaminant plume containment. The effect of withdrawal without recharge and recharge via recharge basins can also be visualized from Figure 4.4.2-1. Withdrawal without recharge may be feasible only for cases where small quantities of ground-water are being pumped because pumping large volumes may alter the potentiometric surface and direction of flow within a confined aquifer. Recharge is necessary when the withdrawal would adversely impact the regional ground-water flow regime (EPA 1982). Finally, water injection can be used to create a gradient barrier to force contaminated ground water to flow away from a given area of concern (Harris et al. 1982a).

\subsubsection{Design Considerations for Contaminant Plume Control}

Well design considerations for contaminant plume containment are the same as those for ground-water dewatering schemes. Both well point systems and deep well systems (depending of contaminant concentrations and hydrogeologic conditions) are applicable to plume containment. The approach is based on locating wells and establishing pumping rates that incorporate the plume within the radius of influence of an extraction well. Therefore, the effect of injection and withdrawal on ground-water flow and contaminant transport must be well 


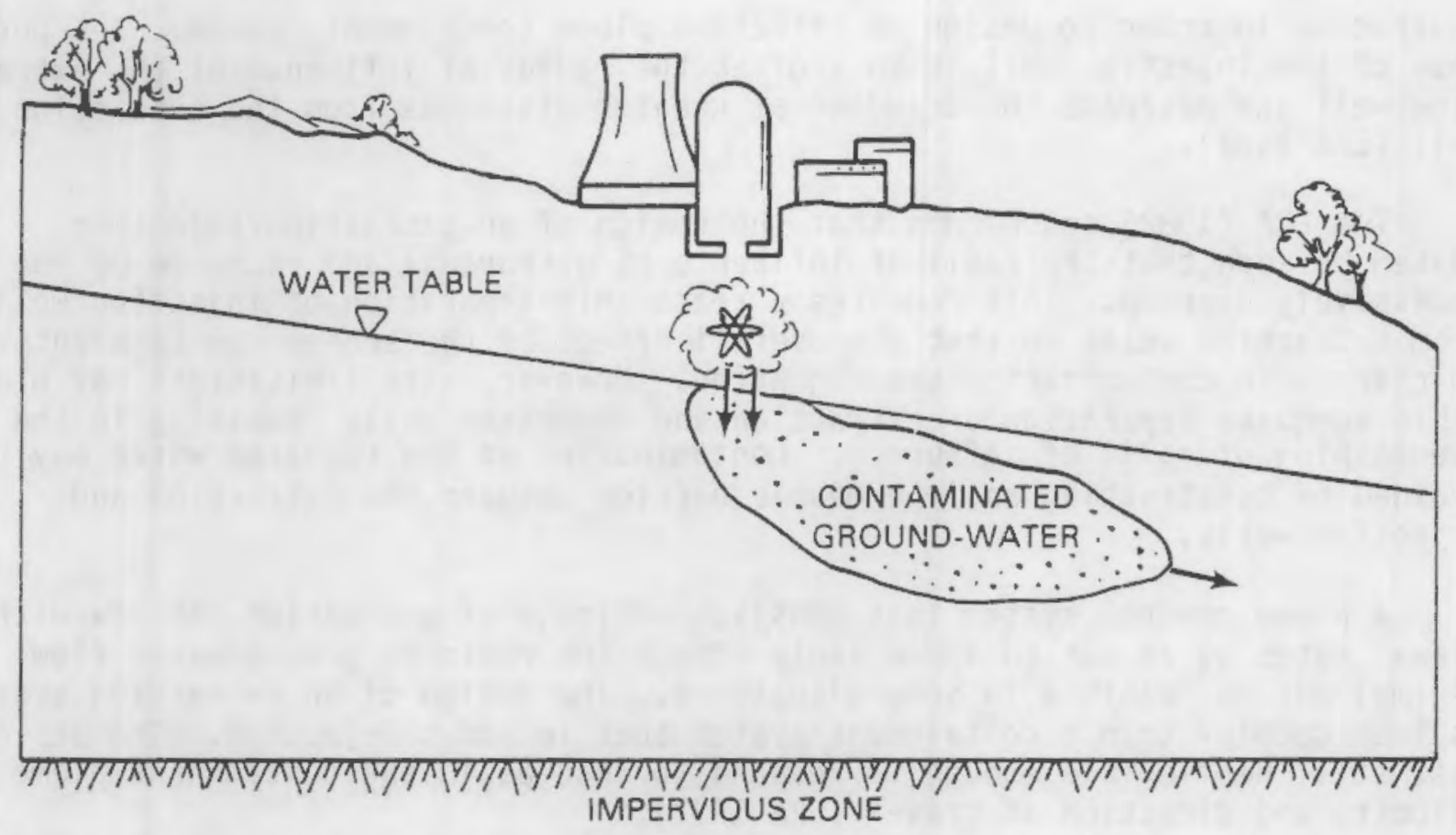

\section{A. BEFORE PUMPING}

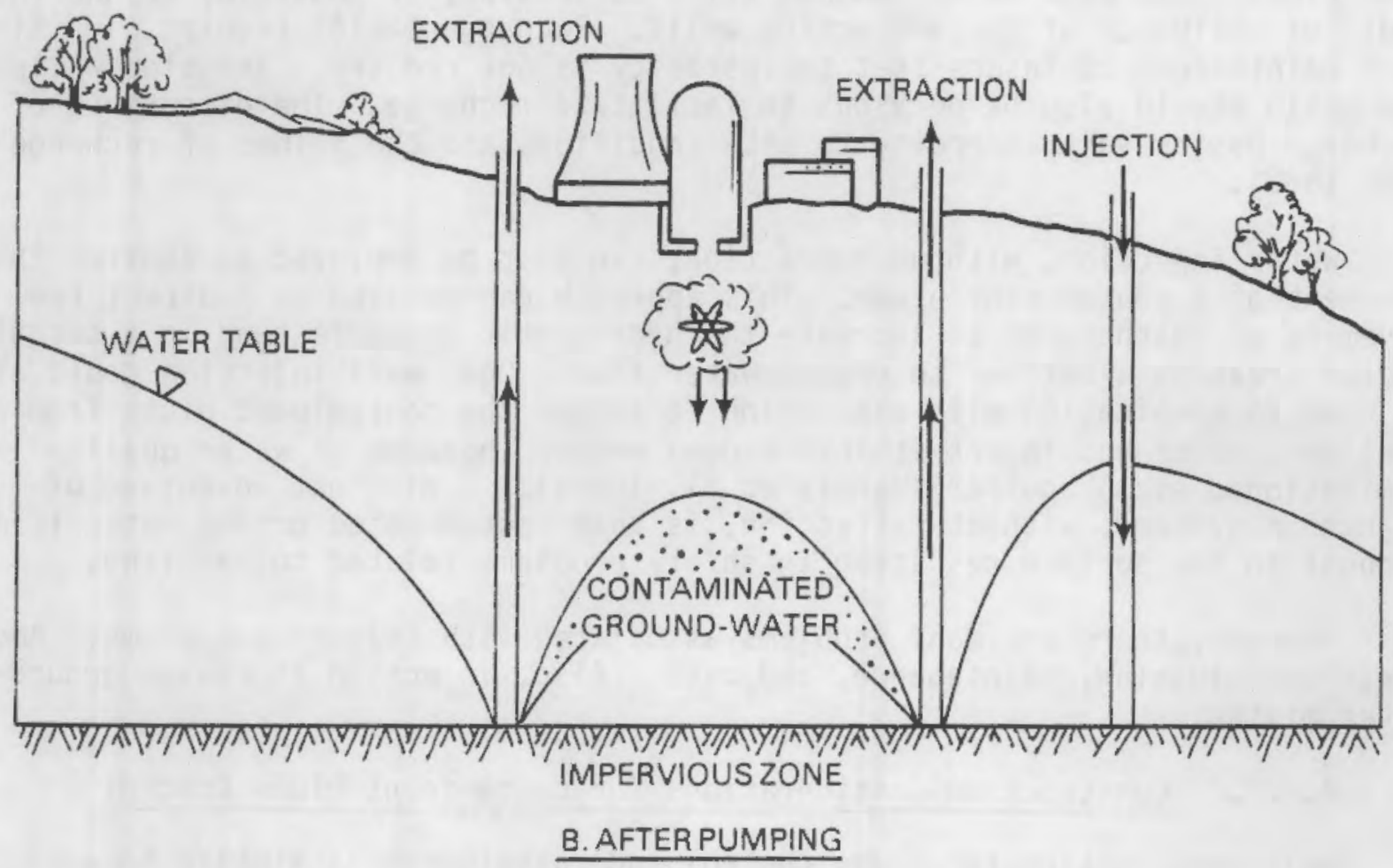

FIGURE 4.4.2-1. Pictorial Representation of Extraction/Injection Contaminant Plume Control (After: EPA 1982) 
understood in order to design an effective plume containment system. The purpose of the injection well is to shorten the radius of influence of the extraction well and decrease the drawdown at greater distances from the extraction well (EPA 1982).

The EPA (1982) recommends that the design of an extraction/injection system be such that the radii of influence of withdrawal and recharge do not excessively overlap. This requires a reasonable separation of injection wells from extraction wells so that the overall effect of the scheme can be adaptive to changes in contaminant plume migration. However, site limitations may prohibit adequate separation of extraction and injection wells resulting in the overlapping of radii of influence. Contamination of the recharge water may be avoided by constructing an impermeable barrier between the extraction and injection wells.

A plume control system that consists entirely of extraction (at low withdrawal rates so as not to appreciably effect the regional ground-water flow regime) may be feasible in some situations. The design of an extraction system is less complex than a containment system that includes injection. The design must still be flexible enough to respond to changes in the contaminant plume velocity and direction of travel (EPA 1982).

For cases that require recharge to replenish local ground-water supplies but do not necessarily require injection for plume control, recharge basins may be cost effective means of recharging ground water where permitted by geologic conditions. Recharge basins should still be located, if possible, beyond the radii of influence of the extraction wells. Recharge basins require significant maintenance to insure that the porosity is not reduced. The side walls of the basin should also be pervious to facilitate recharge. The dimensions of recharge basins vary according to site conditions and the volume of recharge (EPA 1982).

Water injection, without extraction, can also be employed to control the movement of a contaminant plume. This approach can be used to redirect the movement of leachate or to increase the hydrostatic pressure head in a certain region creating a barrier to ground-water flow. Deep well injection could also be used in combination with extraction to remove the contaminant plume from a shallow aquifer and inject it into a deep unused (because of water quality limitations, etc.) aquifer (Harris et al. 1982a). A distinct advantage of injection systems, without extraction, is that contaminated ground water is not brought to the surface resulting in safety problems related to handling.

However, there are many problems associated with injection systems. Among these are clogging, maintenance, and cost. Also, injection increases groundwater mixing.

\subsubsection{Construction Considerations for Contaminant Plume Control}

Well construction for plume control and containment is similar to well construction for ground-water dewatering schemes (Section 4.4.1). Well point systems will be adequate for shallow aquifers and are recommended because of 
their flexibility if sufficient capacities can be achieved. Otherwise, high capacity wells must be installed (EPA 1982).

Water injection is more difficult than extraction. Injection wells are susceptible to clogging and recharge water containing suspended solids and other matter can reduce the efficiency of water injection. Filtration of injection water is usually required to insure effective recharge.

\subsubsection{Performance Considerations for Contaminant Plume Control}

Theoretically, contaminant plume containment via pumping and injection is feasible in any water bearing medium. Practical limitations related to the amount of water that can be pumped and/or injected, the ground-water velocity, and the physical dimensions of the plume determine on a site by site basis the actual effectiveness of plume containment as a mitigation technique. Twodimensional or preferably three dimensional ground-water flow and contaminant transport simulations of the site should be conducted to determine the feasibility of this approach and estimate well locations and pumping rates.

Like most dynamic mitigation schemes plume containment is a temporary alternative that might preceed or be implemented in conjunction with a permanent barrier. Because of the ability to control withdrawal and injection rates this approach is highly flexible and adaptive to changes in plume velocity and size. For this reason plume control may be very important in the early stages of ground-water contamination because of the limited ability to "steer" the contaminant plume away from potentially dangerous locations.

The main advantage of ground-water withdrawal and injection for plume control is that the depth of the contaminant plume does not deter successful implementation of this mitigation scheme. Plume control via withdrawal and/or injection provides a positive means of reducing the velocity or changing the direction of the spread of a contaminant plume. It may be most appropriate in situations where a constructed barrier is not feasible or would result in excessive costs as would be the case in a crystalline bedrock aquifer (Harris et al. 1982a). Other advantages of plume containment are low cost compared to constructed barriers, design flexibility, and operational flexibility which facilitates adaptation to changes in contaminant plume migration (EPA 1982).

There are also several disadvantages to plume containment via pumping and injection. These include (Harris et al. 1982a; EPA 1982):

1. Operation and maintenance costs that significantly exceed 0 \& $M$ costs for other mitigation alternatives,

2. Injection water availability,

3. Suitability of host medium for injection,

4. Plume volume and characteristics are time dependent and may vary with climate conditions and site conditions, 
5. Extensive monitoring is required to detect excursions beyond the control boundaries, and

6. In areas where the water table is near ground surface a high differential head may not be achievable.

\subsubsection{Implementation Considerations for Contaminant Plume Control}

The implementation considerations for contaminant plume control are the same as those for aquifer dewatering schemes (Section 4.4.1.4) and other mitigation alternatives. These considerations are time of installation, cost, equipment mobilization and worker safety. An additional implementation consideration is monitoring of the performance of a containment scheme.

\section{Installation Time}

As with strict dewatering schemes, the time required to install a plume containment system is site specific. It is dependent on the hydrogeologic properties of the site and the size and velocity of the contaminant plume. Roughly two deep wells (i.e., 15 to 18 meters) can be drilled per day with one drilling rig working one shift (Harris et al. 1982a). If deeper wells are to be installed the installation time would be increased accordingly.

\section{$\underline{\operatorname{Cost}}$}

The EPA (1982) has estimated the cost of a hypothetical plyme containment system (excluding operation and maintenance costs) at $\$ 272,400$. (a) This cost represents a system of 18 extraction and injection wells and four monitoring wells. The wells are 6 in. diameter wells approximately 10.5 meters deep. The plume dimensions are roughly $610 \mathrm{~m}$ long, $230 \mathrm{~m}$ wide, and $10 \mathrm{~m}$ deep. Water is extracted by seven pumping wells and injected, after surface treatment, through seven injection wells. Four injection wells are held in reserve in case of clogging in an active injection well. Each well is designed for a 4 in. submersible pump. The extraction wells and injection wells are approximately $300 \mathrm{~m}$ apart to avoid overlap of radii of influence. This system also requires over $1500 \mathrm{~m}$ of $8 \mathrm{in}$. steel pipe to connect the extraction system with the treatment system and subsequently to the injection system.

The total cost (i.e., \$272,400) was computed using the following unit costs (EPA 1982):

1. Construction and installation of uncased wel1 =

$$
\$ 8.20 \text { per } \frac{\text { inch diameter well }}{\text { meter of depth }}
$$

2. 6 in. PVC casing $=\$ 21.32 /$ meter

3. 4 in. submersible pump $=\$ 1,175.00$

4. 8 in. steel pipe $=\$ 150.92 /$ meter

(a) Assumed 1980 dollars. 
By far the most expensive component of the system is the network of steel piping linking the extraction wells with the treatment system and injection

wells. This component accounts for $\$ 230,000$ of the total cost. The cost does not include the development of the treatment system or energy costs related to system operation.

\section{Equipment Mobilization}

No specialty equipment is required to implement a plume containment system. Standard well drilling equipment can be used for installation. The system layout should consider any buried or overhead obstacles such as utility services which may obstruct drilling. In some cases temporary roads may have to be constructed or drill rigs pulled to the site via bulldozers. On site access of drilling equipment must also be considered. A reliable power source must also be assured along with an injection water supply of acceptable quality.

Safety in handling contaminated ground water that is brought to the surface is also important. If surface treatment is to be used safety precautions must be invoked to insure that uncontaminated areas do not become contaminated thus compounding the problem.

\section{Monitoring}

Careful monitoring of the extent of the contaminant plume and any changes in plume configuration is a necessity if a plume containment scheme is to be successful. Because pumping and injection schemes are highly adaptive, containment system operation can be adjusted to respond to changes in plume characteristics that if undetected would result in loss of control of the plume.

\subsubsection{Examples of Existing Plume Containment Systems}

\section{Rocky Mountain Arsenal, Denver, Colorado}

To control the migration of contaminants leaching from a surface storage basin a combination plume containment/impermeable barrier system has been installed at the Rocky Mountain Arsenal. The system consists of a series of extraction wells up-gradient from an impermeable barrier and a series of injection wells down-gradient from the barrier. Approximately thirty-three 8 in. extraction wells remove contaminated ground water which is treated and injected through forty 16 to $18 \mathrm{in}$. injection wells. The total system is $5200 \mathrm{ft}$ long and handles a flow of $443 \mathrm{gpm}$ (EPA 1982, Miller 1979).

\section{Palo Alto, California}

A series of extraction/injection wells is being used to create a barrier to further salt-water intrusion in a multiple aquifer ground-water system in the bayfront area of Palo Alto, California. Nine extraction/injection well doublets with a total capacity of 7.6 million liters per day comprise the system. In addition, three types of monitoring wells (i.e., shallow, middepth, and deep) were designed and installed to serve as both monitoring points 
and test holes for hydrogeologic site characterization. The bid price for the system was $\$ 400,000$ (assuming 1975 dollars) (Sheahan 1977).

\subsubsection{Interceptor Trenches (Subsurface Drains)}

Interceptor trench or recovery drain systems are quasi-dynamic groundwater contaminant mitigation techniques that may be appropriate for radionuclide contamination of a shallow, unconfined ground-water aquifer (Harris et al. 1982a). However, handling and disposal of the recovered contaminated ground water may pose significant safety problems. Subsurface drains are gravel or sand-filled trenches with plastic or ceramic drain title. The trenches can be placed either up-gradient or down-gradient from the contaminant source and intercept (in the up-gradient case) uncontaminated water that was destined to become contaminated or (in the down-gradient case) contaminated water for treatment depending on location.

Subsurface drains are most suitable for application in clay or silty clay soil where the permeability of the drain can be made significantly greater than that of the host material (EPA 1982). Recovery drains may not be feasible where deep frost zones exist.

\subsubsection{Design Considerations for Interceptor Trenches}

The design of a subsurface collection system is dependent on the volume of contaminated ground water (for down-gradient systems), or the volume of uncontaminated ground water (for up-gradient systems), to be intercepted. The quantity of ground water to be drained can be used to estimate the performance requirements for the drains (EPA 1982). The design of the collection system is based on the estimate of the quantity of intercepted ground water.

To effectively convey ground water, the drain must be more permeable than the soil being drained. The envelope material (i.e., backfill material) should be roughly twenty-five times more permeable than the host material (i.e., material being drained) (Harris et a1. 1982a). Also, the drain should be below the water table to a depth that is adequate to intercept the contaminant plume. Consequent1y, a limiting factor in the design of a subsurface drainage system is the operational limits of trenching equipment.

According to the EPA (1982) subsurface drains should have a slight slope. Grades provide velocities sufficient to keep the drains clean during discharge and increase speed of drain emptying when discharge has stopped. Slopes accurately excavated of 0.1 percent are feasible with current trench digging equipment.

An important design consideration for subsurface drains is the resistance to flow in the drain. Because of the small area of inflow for most drains significant resistance to flow is sometimes encountered. The resistance depends on (EPA 1982):

1. The hydraulic conductivity of the material surrounding the drain pipe, 
2. The geometric flow characteristics, and

3. The distribution and orientation of openings in the wall of the conveyance pipe.

The type of drain pipe is usually less critical to performance than the resistance of approach properties of the envelope material (EPA 1982).

Once the drain has been designed, the removal system can be designed. The removal system usually consists of one or more sump basins or wetwells. The entire system should be located as close to the contaminant source as practically possible in order to maximize the collection of contaminants while minimizing the collection of uncontaminated ground water (Harris et al. 1982a; EPA 1982).

\subsubsection{Construction Considerations for Interceptor Trenches}

Typically, subsurface drainage systems are constructed by excavating a trench and placing plastic or ceramic drain tile end to end along the bottom. The trench is backfilled with a suitable envelope material (e.g., gravel, sand, etc.) to a certain thickness above the drain pipes and then capped with soil or clay (EPA 1982). Slit trenches excavated by backhoe may be suitable where seasonal fluctuations in the water table are minimal and the site soil is relatively cohesive. When overburden material is less cohesive and water table elevations are deep, trenching becomes more complex and expensive (Harris et al. 1982a).

In some cases a synthetic, impermeable liner can be placed at the downgradient side of the interceptor trench in order to prohibit contaminated ground water from flowing through the trench. The liner may be necessary if the envelope material has a relatively high permeability (EPA 1982). Also, after the trench is backfilled with the envelope material it may be necessary to wrap the material with a pervious fabric to prevent clogging of the gravel and drain with soil particles. The EPA (1982) suggests a strongly woven fabric called Typlar@ which allows water to pass but prevents soil from entering the granular envelope.

The construction of interceptor trenches is limited by encounter with impermeable soil layers and the operational limits of trenching machinery. While theoretically trenches can be excavated to considerable depths, the practical economic constraints become prohibitive. Hydraulic backhoes can excavate to depths on the order of 17 meters. For greater depth excavations a crane and clamshell apparatus can be used (EPA 1982).

\subsubsection{Performance Considerations for Interceptor Trenches}

The performance of subsurface drains is a function of design, accident scenario, and local climate conditions, all of which are site specific. The primary advantages of subsurface drains as a ground-water contaminant mitigative technique are (Harris et a1. 1982a; EPA 1982): 
1. Active removal of contaminated ground water,

2. Considerable design flexibility and adaptation to dynamics of groundwater contamination,

3. High reliability because of extensive monitoring,

4. Relatively low maintenance requirements.

As is the case with other mitigative techniques that actively remove contaminated ground water (e.g., recovery wells, permeable treatment beds, etc.) a serious problem may exist for the safe handling and disposal of contaminated ground water recovered via subsurface drains. Other disadvantages to subsurface drains are (Harris et a1. 1982a; EPA 1982):

1. Poorly suited for low permeability soils,

2. Limited to areas of shallow ground water in unconfined aquifers,

3. Location in close proximity to contaminant source, and

4. Continuous monitoring required.

Monitoring is extremely important in assessing the performance of subsurface drains since the opportunity exists for the contaminated ground water to breach the drainage system. An auxilliary or back-up system, perhaps a dewatering scheme, should be available in the event of a failure of the drainage system.

\subsubsection{Implementation Considerations for Interceptor Trenches}

Time of constructioin, cost, equipment mobilization, and safety of workers are the most important implementation issues for interceptor trenches.

\section{Time of Construction}

Construction time is dependent on the length and depth of the trench and the properties of the overburden. If shoring of the trench walls is not required, subsurface drains can be developed fairly quickly, especially in relation to other constructed mitigative techniques. However, if extensive shoring and/or dewatering requirements are associated with the trench excavation the

\section{$\underline{\text { Cost }}$}

The cost of interceptor trenches is site specific and dependent on the final design. Unit costs for such items as excavation, drainage tile, crushed stone, etc. can be used to approximate the total cost of a subsurface drainage system. The EPA (1982) gathered data pertaining to the unit costs of several items required for the developed of a drainage system. These costs are presented in Table 4.4.3-1. Maintenance costs are estimated by Harris et al. (1982) to be approximately $\$ 1,600(a)$ per year.

(a) Assumed 1978 dollars. 
TABLE 4.4.3-1 Unit Costs for Subsurface Drainage Collection Systems (Source: EPA 1982)

\section{Item}

Excavation;

$6 \mathrm{~m}$ deep, $1.2 \mathrm{~m}$ wide

hydraulic backhoe

Crushed stone; $3 / 4$ inch

Cost to buy, load, haul

$5 \mathrm{Km}$, place, and spread

Tile Drainage

Vitrified clay (Standard bel]

and spigot)

$$
\begin{aligned}
& \text { 4" } \\
& 6 \text { " } \\
& 8^{\prime \prime} \\
& \text { perforforated }
\end{aligned}
$$

Percast concrete manholes

$48^{\prime \prime} \times 3^{\prime}$

$48^{\prime \prime} \times 4^{\prime}$

Concrete wetwells

Sewer piping;

Concrete; nonreinforced;

extra strength

6" diameter

8 " diameter

Bituminous fiber

4" diameter

Sewer piping, PVC

4 "

6"

$8^{\prime \prime}$

Backfilling:

Spread dumped material by dozer

4" Submersible pumps

installed; to $55 \mathrm{~m}$

$2 \mathrm{HP} ; \mathrm{B} 40$ - 1440GPH

$5 \mathrm{HP} ; 1302$ - $1494 \mathrm{GPH}$;

Holding tank;

Horizontal cylindrical glass

fiber reinforcement phthalic

resin tanks

$$
\begin{aligned}
& 37,850 \text { l } \\
& 75,700 \text { l }(20,000 \mathrm{gal}) \\
& (20,000 \mathrm{gal})
\end{aligned}
$$

Unit Cost (a)

$\$ 1.30 m^{3}$

$\$ 10.85 \mathrm{~m}^{3}$

$\$ 7.00 \mathrm{~m}$ installed

$\$ 8.60 \mathrm{~m}$ installed

$\$ 14.20 \mathrm{~m}$ installed

$\$ 180.59$

$\$ 215.73$

$\$ 6,500.00$

$\$ 12.90 \mathrm{~m}$

$\$ 14.10 \mathrm{~m}$

$\$ 6.70 \mathrm{~ms}$

$\$ 5.70 \mathrm{~m}$

$\$ 9.50 \mathrm{~m}$

$\$ 15.10 \mathrm{~m}$

$\$ 0.86 \mathrm{~m}^{3}$

$\$ 1,700$

$\$ 2,375$

(a) Assumed 1978 dollars.

$\$ 6,354$ installed

$\$ 14,164.50$ installed 


\section{Equipment Mobilization}

No specialty equipment is required for the construction of interceptor trenches. Readily available trenching or excavation equipment is required to open a suitable trench for placement of drain tile. Site access is required for heavy equipment and subsurface obstacles must be avoided for continuity of the drain. Envelope material, particularly crushed stone, is generally available throughout the U.S.

\section{Safety of Workers}

Implementation of any ground-water contaminant mitigation scheme necessarily involves consideration of potential radiation exposure of construction workers in the vicinity of the power plant. However, potential exposure levels are dependent on the accident scenario, local meteorological conditions, and other site-dominated factors, as well as the time lag between the occurrence of the accident and the implementation of the mitigation strategy. Subsurface drains perform more efficiently the closer they are located to the contaminant source. Depending on the structural configuration of the power plant and the local ground-water flow regime design of an effective subsurface drain system could require work in close proximity to the containment building with relatively little elapsed time from commencement of the accident.

\subsubsection{Selective Filtration Via Permeable Treatment Beds}

In-place ground-water treatment through selective filtration is a technique that is conceptual yet potentially applicable to the mitigation of a severe power plant accident contaminating an unconsolidated shallow groundwater aquifer. Selective filtration using permeable treatment beds of highly sorptive material has the advantage of significantly reducing the down-gradient concentration of certain radionuclides in solution without appreciably altering the local ground-water flow regime. The "bathtub effect" of ground-water backing up behind an impervious barrier is no longer a problem as the unmitigated ground-water flow regime is maintained even though portions of the flow pass though or are channelled through the permeable treatment bed.

Selective filtering is a temporary ground-water contaminant mitigation technique because of the finite effective life of the filtration material. Once the effective ion exchange capacity of the filtration material has been exhausted the material must be reactivated or replaced with new material. Removal from the treatment bed, transportation, and disposal of the contaminant filtration material could present safety problems. However, where the influx of radionuclide concentrations in ground water may be high but relatively short-lived, as might be the case for a core sumpwater radionuclide release, a permeable treatment bed may be a very effective means of satisfactorily reducing contaminant concentration levels. Selective filtering may be capable of wholly mitigating the effects of a sumpwater release but conversely only be suitable as a temporary mitigative measure for a leach-type accident scenario. 


\subsubsection{Design Considerations for Permeable Treatment Beds}

In-place contaminant treatment is a conceptually sound method of reducing the spread of radionuclide contaminant plumes that may occur in shallow unconsolidated aquifers. However, since the treatment bed has a finite ability to treat (through sorption) the radionuclide contaminated ground water this mitigative technique should be considered temporary in most instances. The technique has not been implemented to any extent and therefore design considerations (and even more so for construction considerations) have not developed to the point of standard engineerinig practice.

Few materials can be feasibly employed to control contaminant concentrations in ground water (EPA 1982). This is especially true for radionuclide contaminants. The filter material must be highly sorptive yet exhibit a controllable permeability. The filter material also must not itself contaminate the ground water. Natural occurring materials with high clay mineral content such as glauconitic greensand or synthetically produced resins with high ion exchange capacities are potentially good radionuclide filter materials.

Conceptually, a permeable treatment bed system consists of an excavated trench oriented so as to intercept the contaminant plume. The trench is backfilled with the filter material and then capped (EPA 1982). Figure 4.4.4-1 shows a schematic diagram of a permeable treatment bed.

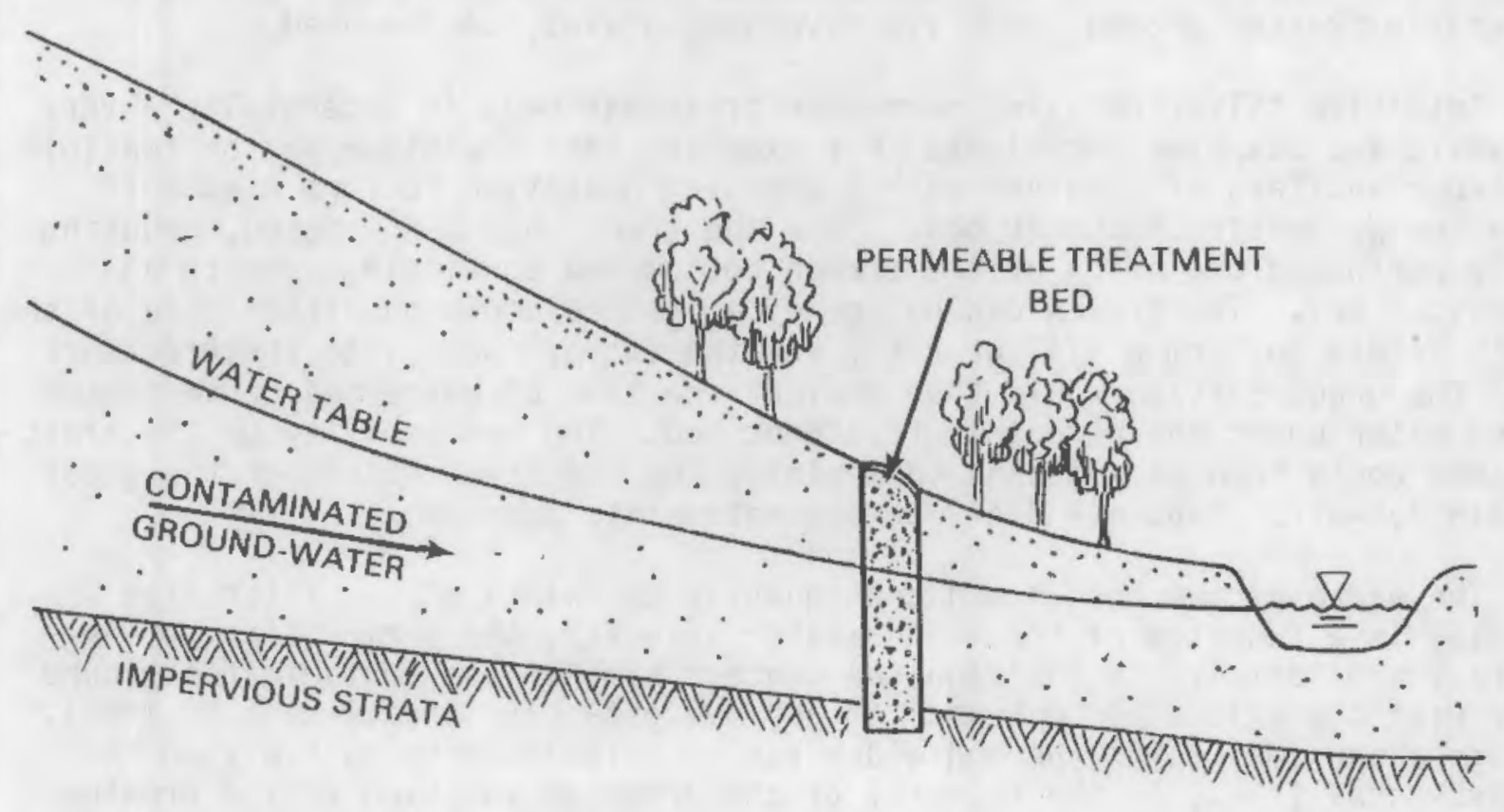

FIGURE 4.4.4-1. Schematic Diagram of Permeable Treatment Bed System (After: EPA 1982) 
The design considerations associated with permeable treatment beds are (EPA 1982):

1. Selection of suitable filtration material,

2. Location of the treatment bed in relation to the regional and local ground-water flow regime,

3. Length (perpendicular to general direction of flow),

4. Width (in the direction of the flow), and

5. Depth, must be keyed to impervious strata or barrier.

In most cases it would be advisable to place the treatment bed reasonably close to the contaminant source. Dispersion of the contaminant plume decreases closer to the source thereby reducing the overall dimensions of the treatment bed and consequently its cost. However, close proximity to the contaminant source may not be feasible because of inability to adequately anchor the filter in an impervious layer or the contaminant plume has migrated a considerable distance prior to design and construction of the treatment bed. The length of the treatment bed may be reduced with a fractional increase in width or thickness if highly permeable converging ground-water flow channels (e.g., gravel drains, etc.) are used to intercept contaminated ground water and divert it to the filter. Down-gradient from the treatment bed a similar arrangement for dispersing treated ground water via diverging drains, can be used.

Selective filtering using permeable treatment beds is potentially a very versatile and adaptive technique. For example, this technique may be feasible in deeper aquifers if combined with a grouting operation to form a cut-off below the permeable treatment bed. Once the trench has been opened, grouting can be performed beginning at the trench bottom and continuing down to an impervious key. The trench can be opened a limited depth on either side of the grout curtain to form a sill or a key for the cut-off wall into the treatment bed. The grout curtain would then prevent the flow of untreated contaminated ground water under the permeable treatment bed. The permeability of the treatment bed could then be adjusted to minimize the "bathtub" effect of the grout curtain cut-off. Figure 4.4.4-2 demonstrates this approach.

The width of the trench and consequently the width of the filtration material is a function of the ground-water velocity, the permeability of the filtration material, and the required contact time of the contaminated ground water with the filtration material to achieve effective treatment (EPA 1982). A rough approximation of the bed width can be calculated by multiplying the highest local (i.e., in the vicinity of the proposed location of the treatment bed) ground-water velocity by the required contact time. The determination of the effective contact time requires knowledge of both the radionuclide concentration in the ground water, and sorptive properties of the radionuclide species, and the filtration material being considered. Disturbance to the 


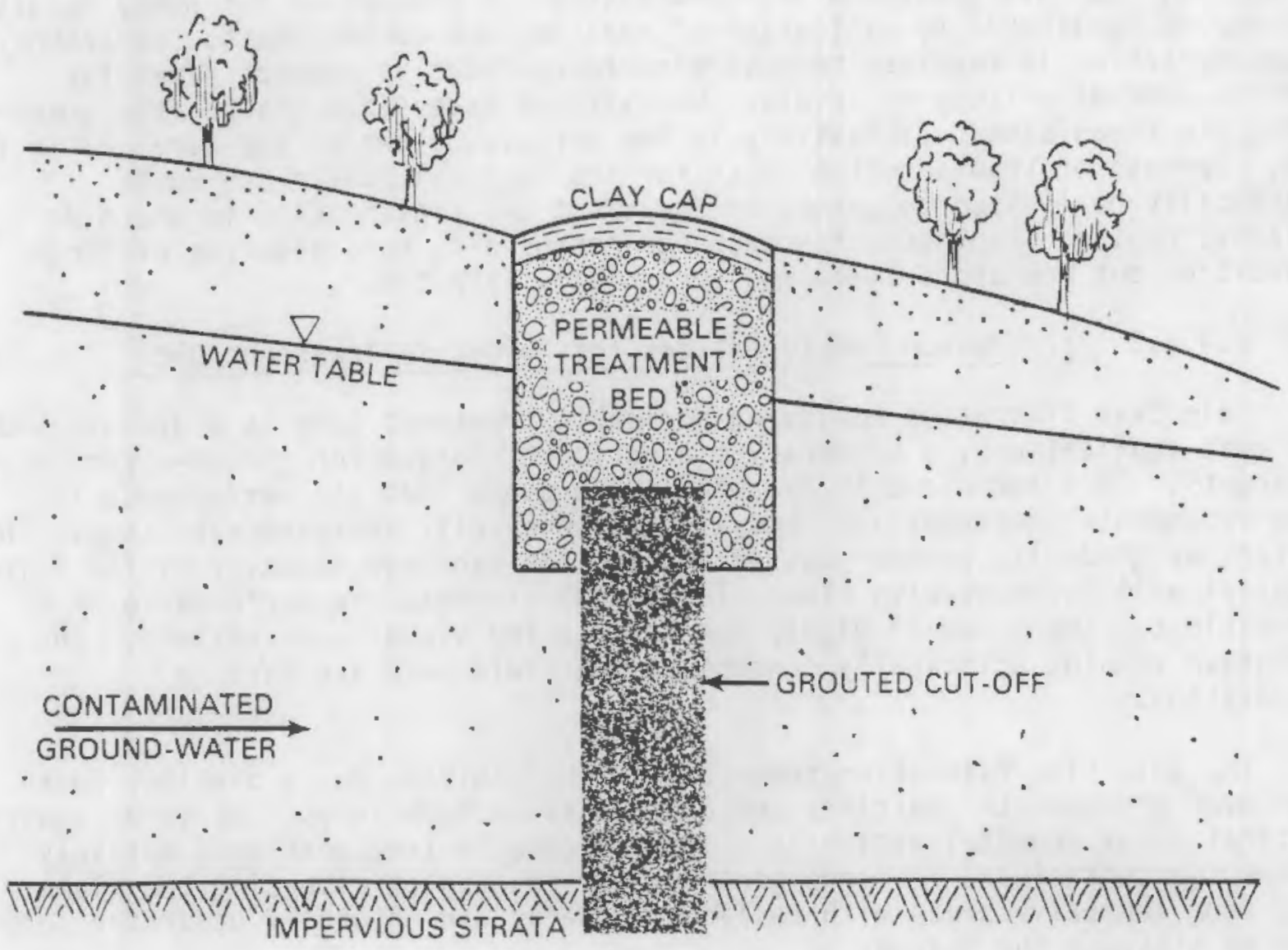

FIGURE 4.4.4-2. Permeable Treatment Bed in Combination with a Grouted Cut-Off

general ground-water, and flow regime can be minimized by adjusting the permeability of the treatment bed to approximate the permeability of the surrounding aquifer (EPA 1982).

\subsubsection{Construction Considerations for Permeable Treatment Beds}

Permeable treatment beds are only practically applicable to unconsolidated host media because of excavation requirements. Consequently, excavation normally requires shoring (e.g., sheet piling). The trench will intersect the water table thus requiring dewatering of potentialy contaminated ground water. Trenches are dug in a manner similar to the construction of interceptor trenches. Backhoes or clamshells would ordinarily be used for the excavation. The trench borrow material can be used for a compacted cap or, if inadequate, a suitable cap of compacted clay can be placed over the trench once the filter material is in-place.

Natural materials or synthetic resins with high ion exchange capacities must be used for the filter material. The radionuclides sorb onto the skeletal framework of the material thereby reducing their concentration in the ground 
water. Glauconitic greensand has good adsorption properties for heavy metals and may be applicable to mitigation of radionuclide contaminants. Laboratory experimentation is required to determine representative contact times for various removal efficiency levels. Deposits of accessible glauconitic greensands are found almost exclusively in New Jersey, Delaware, and Maryland in the U.S. Because of transporation costs for the materia1, their use would practically be limited to permeable treatment bed construction in the MidAtlantic region. Synthetic ion exchange resins also have high ion exchange capacities but are short-lived and very costly (EPA 1982).

\subsubsection{Performance Considerations for Permeable Treatment Beds}

Selective filtration employing permeable treatment beds is a dynamic and, for most applications, a temporary mitigation technique for ground-water contaminants. This technique is dynamic in the sense that its performance is time-dependent. Radionuclide removal efficiency will decrease with time. The filter may gradually become plugged and the ion exchange capacity of the filter material will decrease with time. The acutal time-history performance of a permeable treatment bed is highly specific to individual applications. The technique remains principally conceptual and field data are rare or nonexistent.

The selective filtration technique, when feasible, has a distinct advantage over ground-water barriers and other passive techniques. It is an aquifer restoration or remedial action strategy. Permeable treatment beds actively remove the contaminant from the ground water instead of diverting the plume away from sensitive areas with reliance on decay and naturally occurring sorption to mitigate the hazard.

\subsubsection{Implementation Considerations for Permeable Treatment Beds}

There are important implementation considerations for permeable treatment beds. Among these are construction time, cost, equipment mobilization, disposal of spent filtering material and worker safety. Permeable treatment beds can be constructed very rapidly assuming adequate site access and no additional site work (e.g., grouting or drainage construction) is required. No sophisticated equipment is necessary, consequently little lead-time is required for equipment mobilization. Backhoes can be used for trench excavation and common sheet piling can be used for shoring of open trenches. The most time consuming aspect of permeable treatment bed construction may be the quarrying and hauling of the filter material.

If glauconitic greensands are to be used as the filter material, the client's contractor may have to negotiate the purchase of land overlying an accessible deposit because there are few or no comnercial producers of glauconitic greensands. The contractor would have to excavate the filter material and haul it to the site thus greatly increasing the total cost of the permeable treatment bed (EPA 1982). 
The EPA (1982) has estimated the cost(a) of a permeable treatment bed based on approximations for unit costs of various activities. The costs are broken into trench excavation costs, materials costs, and installation costs. Trench excavation costs include:

1. Excavation $\cong \$ 0.76 /$ cubic meter ( $\$ 1 /$ cubic yard)

2. Spreading of borrow $\cong \$ 0.50 /$ cubic meter $(\$ 0.66 /$ cubic yard)

3. Well point dewatering $\cong \$ 23.00 / 1$ ineal meter $(\$ 75.00 / 1$ ineal foot $)$

4. Sheet piling:

Sheeting $\approx \$ 0.53 /$ square meter $(\$ 5.70 /$ square foot)

Walers and struts $\simeq \$ 95.25 /$ metric ton

Materials and installation costs are difficult to estimate, especially for glauconite bearing deposits, because possible land purchase and transportion are significant cost items that cannot be unit priced. Synthetic ion exchange resins are very expensive with costs estimated by the EPA (1982) at more than $\$ 10.00$ per kilogram $(\$ 5.00 / 1 \mathrm{~b})$. For comparison of the effect of the type of filter material on total project costs, the EPA (1982) estimated the costs for a permeable treatment bed approximately $300 \mathrm{~m}$ long, $1.2 \mathrm{~m}$ wide, and $6 \mathrm{~m}$ deep. If the filter material is crushed limestone, the total cost is $\$ 485,000$. If activated carbon is used for the filter material, the cost is $\$ 4,531,000$. The difference in cost is nearly an order of magnitude.

In summary, there are particular advantages and disadvantages of glauconitic permeable treatment beds (EPA 1982). The advantages include potentially high removal efficiencies, good residence time properties thus reducing the volume of material needed, and good permeability. Disadvantages of glauconitic treatment beds are unknown saturation characteristics, application practically limited to Mid-Atlantic Region, bed plugging may occur, may reduce ground-water $\mathrm{pH}$, and removal efficiencies of constituents at high concentrations is unknown. The technique is feasible however, and additional experimentation and analysis will define limits of performance and ranges of feasible application.

\subsubsection{Ground Freezing}

Ground freezing is a technique whereby, depending on soil particle size and ground-water velocity, ground-water flow can be significantly reduced. A frozen subsurface wall a few meters thick is created in much the same manner as a grout cut-off. Ground freezing is an energy intensive dynamic interdiction technique that may provide temporary mitigation while more permanent measures are implemented.

(a) Assumed 1982 dollars. 


\subsubsection{Design Considerations for Ground Freezing}

The mechanical properties of frozen soil are such that in many cases they have relatively higher strengths than similar soils treated with other geotechnical procedures. Because of the increase in strength of frozen soils groundwater freezing can, in some cases, prevent ground-water flow (Attewell and Farmer 1976). Although full saturation of the host material pore space is not required for this method to be effective, a minimum moisture content is necessary. The minimum required moisture content is a function of the material grain size and distribution (Harris et al. 1982a).

According to Sanger (1968) frozen ground engineering requires a great deal of field experience and engineering judgement. There are only a few commercial contracting companies and much of their information on design and construction of frozen barriers (especially soil properties) is proprietary. However, the design of a frozen barrier must necessarily include considerations of the structural stength and deformation of the frozen soil and the thermal properties of the soil.

The strength that frozen soil exhibits is derived from the bonding of soil particles and ice. Clay soils which adsorb a large amount of water develop less ice and weaker bonds than quartz-type soils which adsorb very little water. This phenomenon is due to the lower freezing point of the water adsorbed onto the surface of clay minerals than the surrounding free water. Conversely, quartz-based soil particles adsorb very little water thus allowing more free water ice to form.

A continuous ground-water barrier is achieved in much the same manner as a grouted cut-off is developed. Cylinders of frozen soil are formed around freeze pipes through which a suitable coolant is circulated. The radii of the frozen cylinders increase until adjacent cylinders intersect. Continued cooling then increases the frozen wall thickness until the design thickness is reached (Attewell and Farmer 1976). The process involves two stages (Attewell and Farmer 1976; Sanger 1968):

1. Stage I - A solid (frozen) soil cylinder is forming around the freeze 2. Stage II - The cylinders have merged and the wall thickens.

During Stage I (the transient stage) the rate of advancement of the ice front is a function of the thermal diffusivity and the moisture content. The rate of advancement of the freeze zone decreases with increasing radius from the freeze pipe. Once Stage II (steady state) has been reached, the heat outflow is a function of the thermal conductivity of the soil (Attewell and Farmer 1976).

In theory, ground freezing can be applied to almost any geologic medium in which freeze pipes can be installed and suitable moisture exists. However, both Stage I and Stage II freezing are affected by ground-water flow. Consequent ly, ground-water velocities are important considerations in determining the feasibility and subsequent design of a frozen barrier. The method is not 
feasible for ground-water velocities that are not relatively slow. Sanger (1968) states that most experienced contractors consider $0.9 \mathrm{~m} /$ day to $1.2 \mathrm{~m} /$ day the maximum ground-water velocity that can be successfully tolerated. At higher ground-water velocities the resulting frozen wall may be practically $(99+\%)$ impervious over solid portions but contain small windows that will not close regardless of the amount of refrigeration.

Small windows may also be present in frozen soil that was unsaturated. Consequently, freezing should not be considered for host material with $<10 \%$ saturation (Harris et al. 1982a). Also, because of lower freezing points, ground freezing is not normally feasible in strata bearing heavily contaminated ground water.

Harris et a1. (1982a) polled four ground freezing contractors (FrontierKemper Constructors; More Trench; Geofreeze Corp.; and ECI). They state that there are no depth limitations for a frozen wall although thermal erosion under warm ambient conditions must be considered. Recommended temperatures for suitable strength of frozen walls are $-7^{\circ} \mathrm{C}$ for sand and $-29^{\circ} \mathrm{C}$ for soft clay (Harris et al. 1982a).

\subsubsection{Construction Considerations for Ground Freezing}

Construction of a frozen wall requires the vertical installation in the host medium of a series of steel refrigeration or freeze pipes. Once the freeze pipes are in-place to the desired depth, a refrigerant is circulated through the pipes which causes heat removal from the host material. Continued heat removal causes an expanding frozen cylinder to form around each freeze pipe. As the cylinders intercept each other a continuous frozen wall develops (Harris et al. 1982a).

A wide variety of equipment can be used to construct a subsurface frozen wal1. However, basic equipment requirements include a freeze plant for the refrigerant, a system of surface pipes and pumps to distribute the refrigerant to the freeze pipes, the freeze pipes, and instrumentation pipes which are also inserted in the ground to monitor soil temperature.

The freezing plants for cooling of the refrigerant are normally composed of one or more mobile refrigeration machines. Circulating cooling systems are used except in rare emergencies when, because of strict time limitations, expendable coolants (i.e., liquid nitrogen or liquid carbon dioxide) are used in a non-circulating open system. Expendable refrigerant systems are not recommended because of difficulty in field control and expense. Normal ground freezing operations employ a brine (e.g., calcium chloride) which is cooled by the freezing plant and circulated to the freeze pipe. Brine circulating systems require greater time in comparison to cryogenic liquid systems but are easier to control and less expensive. Circulating systems can also be run for longer periods of time (Harris et al. 1982a). For permanent refrigeration systems, an alcohol solution (e.g., ethylene glycol) is used for a coolant (Sanger 1968). 
Refrigeration procedures are important considerations in ground freezing. The refrigeration sequence is comprised of an initial period with peak refrigeration load followed by the maintenance period for temperature and consequently wall thickness. During the Stage I period, 24 hour monitoring is recommended for quality assurance (Harris et al. 1982a). The lowest feasible brine temperature will require the least amount of time to complete the wall but will result in the heaviest refrigeration load. Refrigeration loads are computed as tons of refrigeration per foot of pipe with 1 ton representing 200 Btu per minute. Both refrigeration load and temperature may require adjustment during the freezing process to accomodate changing needs (Sanger 1968). The two primary considerations in constructing a frozen subsurface barrier are the insulation of the above-ground system to minimize heat leakage and the specifications and placement of the freeze pipes. Sanger (1968) states that proper insulation of above-ground piping by closed-cell foamed plastic can significantly reduce the heat loss of the above-ground system. Such insulation should be protected from weather and construction damage and painted with white or aluminum paint. To combat open air convection and solar radiation, any exposed frozen surfaces should be covered. Natural ground cover should not be disturbed, if possible. Plastic membranes can sometimes be used to protect the surface area directly above the wall.

Freeze pipes are typically composed of an open-ended inner feed pipe, through which the brine is injected, inside a closed-end freeze pipe for brine recovery. The coolant (brine) is pumped down the open-ended inner feed pipe. As the brine rises in the annular space between the feed pipe and the freeze pipe it absorbs heat from the surrounding host material. The brine eventually returns to the refrigeration plant for recooling and recirculation. The feed pipe usually has a diameter of 1-1/2 in. $(4 \mathrm{~cm})$ to $2 \mathrm{in.}(5 \mathrm{~cm})$ and is approximately half a meter shorter than the closed-end freeze pipe. These pipes are usually ordinary steel, however, plastic feed pipes have also been used (Sanger 1968).

The initial cost of the piping can be expensive creating a tendency to use small pipe with large spacing. However, the radial expansion of the frozen cylinders around the freeze pipes slows down quickly enough to cause excessive time requirements if piping and spacing are not properly designed. Freeze pipes are usually between $4 \mathrm{in} .(10 \mathrm{~cm})$ and $6 \mathrm{in} .(15 \mathrm{~cm})$ in diameter and are placed $1.0 \mathrm{~m}$ to $2.0 \mathrm{~m}$ apart. The larger the diameter the better the alignment control during placement (Sanger 1968).

Much like grouting, multiple rows of freeze pipes can be installed to construct a thick frozen wall. Also, for a frozen ground-water cut-off it is important to insure penetration of the freeze pipes into an impervious soil or rock strata. The host material will ordinarily freeze below the pipe to a depth of approximately 0.4 times the average wall thickness. Sanger (1968) recommends a $3 \mathrm{~m}$ penetration of the freeze pipe into the impervious layer for a satisfactory waterstop. 


\subsubsection{Ground Freezing Performance Considerations}

All characteristics of a subsurface frozen cut-off are strongly dependent on temperature. When complete freezing is achieved and no windows exist, a frozen ground-water barrier is essentially impervious. However, problems of windowing have occurred with single-row walls, thus requiring a double row wall. Ground-water freezing in fissured and fractured rock can be especially difficult because of the lack of adequate means to estimate the amount of water in the fissures. While the overall rock material may be frozen, a window at a large fissure may remain open (Sanger 1968).

The determination of initial wall closure (i.e., end of Stage I) is sometimes difficult. Thorough monitoring is necessary to track the freezing process. A surface heave pattern may indicate the progress of Stage I but temperature sensors provide more reliable information in most cases, especially in sands. However, temperature measurements may be misleading in fine-grained material such as clays and silts because the effective freeze temperature of water is below $0^{\circ} \mathrm{C}$. Also, dissolved salts can lower the freeze point, thus a brine leak posses a potentially serious problem (Sanger 1968). Ground freezing within the influence of a salt-water/fresh-water interface would very seldom be practical because of lower freeze temperatures of the salt water.

Ongoing maintenance is required for frozen ground-water flow barriers. The Stage II temperature of the cut-off must be held at a suitable temperature if the wall is to maintain its integrity. Because of the necessity to hold a particular temperature, the maintenance of a frozen wall is energy intensive. The freeze plant may be only operated periodically during Stage II but it must be serviced and available.

\subsubsection{Ground Freezing Implementation Considerations}

Like most of the potentially feasible mitigative techniques for groundwater contamination resulting from a severe power plant accident, the key implementation considerations for ground freezing are: 1) installation time, 2) cost, 3) equipment mobilization; and 4) worker safety. Ground-water freezing must also consider the location of the thermal plume and its heat content. A frozen ground-water barrier may be placed under severe thermal stress when encountered by ground water with temperatures significantly above ambient temperatures. As is also the case with other mitigative techniques ground freezing implementation considerations are highly site specific and site sensitive.

\section{Installation Time}

Data are not readily available concerning the actual times required to close a frozen wall. However, once Stage I begins (i.e., freeze pipes are installed and refrigeration commences) the time for closure is roughly exponentially proportional to the relative spacing of the freeze pipes. The closer the pipes the shorter the time required to achieve closure (Harris et al. 1982a). 
Sanger (1968) presents two figures (Figure 4.4.5-1 and Figure 4.4.5-2) showing the results of the development of two straight frozen walls; one in a fine-grained soil and the other in a coarse-grained soil. The time for closure (i.e., Stage I) in the fine-grained soil was 38 days while it only took 21 days for closure in the coarse-grained soil. The time requirements for Stage II are also presented in the figures. The specifications of the freezing operation were (Sanger 1968):

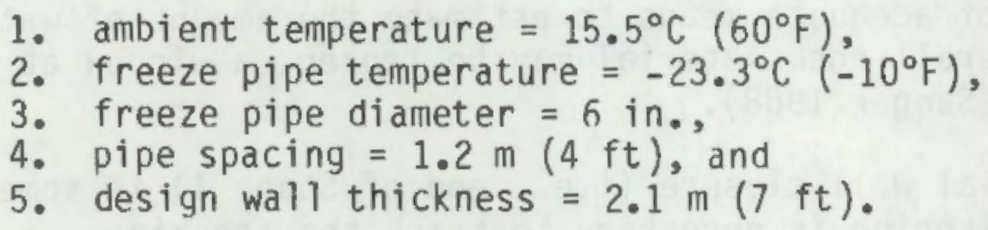

Prior to initiating freezing, however, the freeze pipes must be installed in the host material. They are placed in pre-drilled holes with strict vertical alignment tolerances. Fractured and fissured rock and unconsolidated material containing large cobbles or boulders decrease drilling accuracy and require longer drilling time. Equipment mobilization may take a minimum of one week or longer while the drilling of holes and subsequent installation of freeze pipes may require six weeks or more (Harris et al. 1982a).

Equipment Mobilization

Surface access must be provided for drilling rigs and there must not be any subsurface drilling obstructions (e.g., gas pipelines, etc.). Standard industry drilling equipment is readily available and would pose no constraint to the overall constuction of a frozen cut-off.

The freeze plants are combinations of portable refrigeration machines and do not require a foundation. However, substantial electrical service is necessary because the refrigeration plants are normally powered by electricity. According to Harris et al. (1982a) electric motors of fer greater reliability and less maintenance than gasoline or diesel powered engines. Without the availability of sufficient commercial power (300 kVA to 1000 kVA) freezing is not feasible.

\section{Cost}

Because of high costs, ground freezing is not competitive with other barrier-type methods of interdicting ground-water flow and contaminant transport. Although costs cannot be generalized, some rule-of-thumb figures (a) suggest: $\$ 35$ to $\$ 45$ per cubic meter for freezing costs for cut-off walls; and $\$ .90$ to $\$ 3.80$ per square meter of wall area per week for refrigeration maintenance costs (Harris et al. 1982a). Drilling costs represent a substantial addition to the project cost, and potentially can cost as high as $35 \%$ to $50 \%$ of total construction cost (Harris et al. 1982a).

(a) Assumed 1982 dollars. 


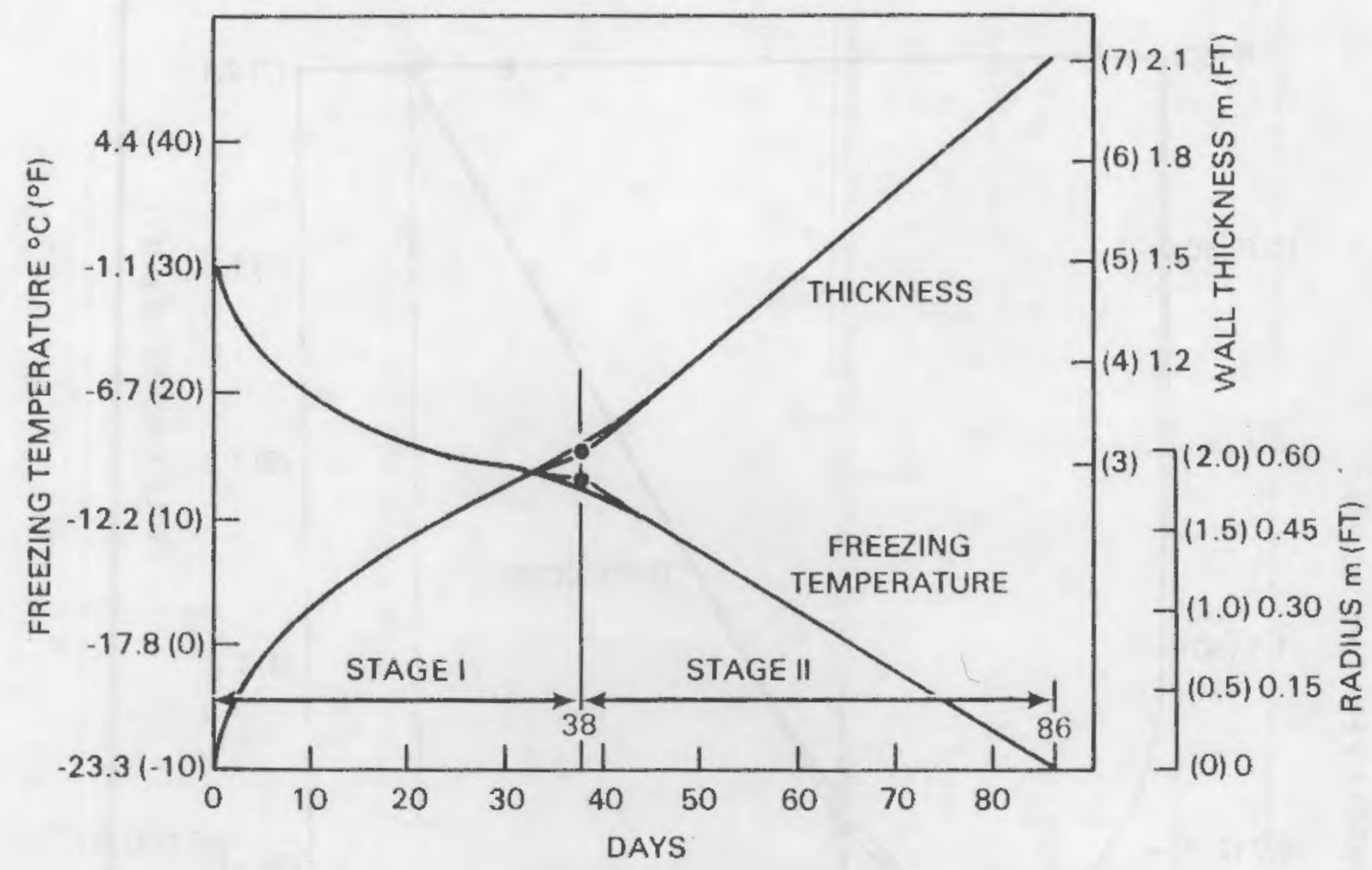

FIGURE 4.4.5-1. Frozen Straight Wall Development in FineGrained Soil (Source: Sanger 1968)

Artificial ground freezing is expensive and is not feasible for long-term closure. Also, experience is limited to a few contracting companies and is highly dependent on qualified and experienced personnel. Sanger (1968) states that ground freezing is usually considered as a last resort.

\section{Worker Safety}

The same considerations for worker safety requirements for other mitigation alternatives are also required for ground water freezing operations.

\subsubsection{Air Injection}

Air injection below the water table has been studied as a possible mechanism for the retardation of the movement of fluid borne contaminants (Nelson 1966). Although few data exist on the practical engineering and installation aspects of air injection, this interdictive technique is, in theory, feasible in certain situations. Air injection into the very permeable strata below the water table is capable of retarding flow or expanding flow into longer, lower permeability, flow paths. Air injection may be suitable as an emergency control measure in porous unconsolidiated and some porous consolidated saturated media. 


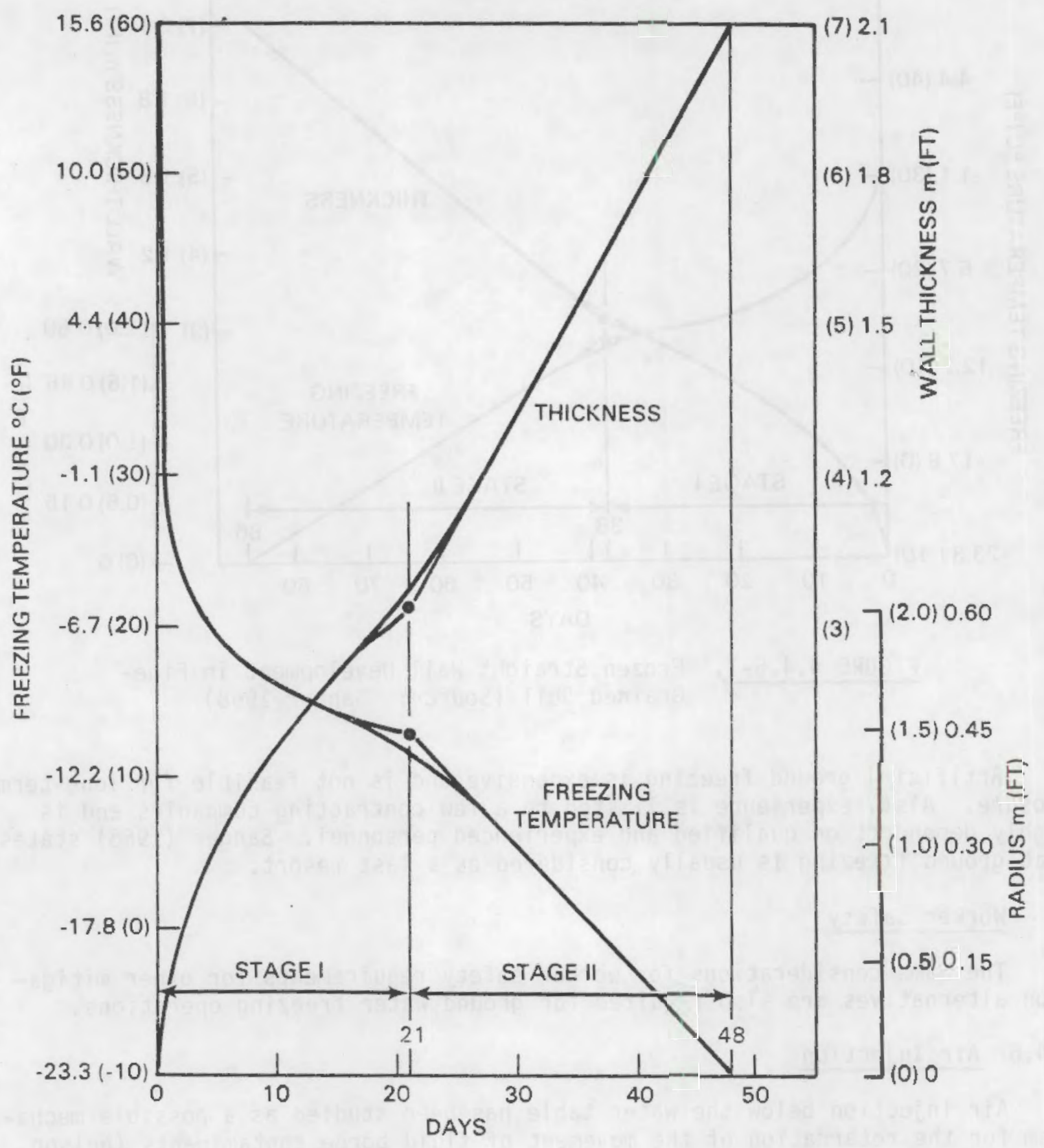

FIGURE 4.4.5-2. Frozen Straight Wall Development in CoarseGrained Soil (Source: Sanger 1968) 
The physical phenomenon of air retarded ground-water flow in a porous media relates to the energetics of adsorption and surface tension which constrain the water to the smaller (and sometimes less conductive) pore spaces. More particularly, through air injection a multiphase or partially saturated flow system is induced. The significant reduction in hydraulic conductivity with greater capillary pressure brings about the slowing and spreading of the flow system. The larger and more conductive parts of the pore channels are reserved for air flow. As the air pressure is increased, the capillary pressure increases causing the air-water interface to retreat to smaller and smaller pores. By significantly increasing the air pressure, the effective water premeability of the material can be reduced to near zero (Nelson 1966).

\subsubsection{Design and Construction Considerations for Air Injection Systems}

The most important issues concerning air injection feasibility as a ground-water interdiction strategy are (Nelson 1966):

1. Required air injection pressures,

2. Quantities of air flow,

3. Types of injection configurations, and

4. Effects of variations in host material properties.

These four items can be determined using traditional multiphase fluid flow models.

Nelson (1966) reports that greater than a thousand fold reduction in the velocity of water borne contaminants can be achieved with air injection pressures of $1.4 \mathrm{~kg} / \mathrm{cm}^{2}$ to $1.8 \mathrm{~kg} / \mathrm{cm}^{2}$ and air flow rates between 0.14 and $0.23 \mathrm{~m}^{3} / \mathrm{min} /$ per approximately $9.0 \mathrm{~m}^{2}$ of area. It is suggested that to be most effective in retarding or diverting ground-water flow air should be injected into the most permeable material in the saturated zone within which the radionuclides are traveling. Although air injection in less permeable strata may reduce air flow rates it is not as effective in reducing ground-water flow.

The installation of an air injection system requires a layout similar to that required for grouting or ground freezing. Holes must be drilled to the required depth of injection and appropriate injection apparatus installed. Readily available construction grade air compressors can be used thus eliminating expensive mobilization of special purpose equipment.

\subsubsection{Implementation Considerations for Air Injection Systems}

There is little field experience in utilizing air injection to retard the movement of ground water through a porous media and the technique is energy intensive. Air injection pressures must be maintained if the reduction in water permeability is to be maintained. As is the case with other ground-water interdictive techniques, implementation considerations include time to install a system, its corresponding cost and worker safety. This technique is very competitive with other mitigative approaches because of the lack of need for special and/or deliverable materials (e.g., grouting compounds). Also, no special equipment is required for air injection systems (Nelson 1966). Long- 
term maintenance of the reduced water permeability does require a moderate energy consumption for compressor operation for continuous air injection. In comparison with the time necessary to develop a frozen cut-off air injection provides an almost immediate influence on the movement of ground water in the region affected by the air flow. Air injection may only be suitable as a temporary emergency strategy to quickly divert ground-water flow away from a sensitive area or permanent barrier construction site. There is a safety consideration associated with air in contact with the contaminant. The air may capture some of the radionuclides. This portion of the contaminants may then be returned to the surface as the aquifer de-aerates along the fringe of the air barrier and/or when the system is terminated.

\subsection{U.S. GEOTECHNICAL ENGINEERING CAPABILITY}

The following table (Table 4.5-1) of U.S. geotechnical engineering capability was developed from a review of geotechnical engineering literature and a letter survey of geotechnical design and construction firms identified in trade journals. The list of firms is not complete but it is representative of the experience and capability of U.S. firms related to implementation of the various ground-water contaminant mitigation techniques. 


\section{TABLE 4.5-1. U.S. Geotechnical Engineering Capability}

I. Hydrogeologic Site Investigation (a) II.

1. Dames and Moore, Inc.

Los Angeles, California

2. Donohue and Associates, Inc. Sheboygan, Wisconsin

3. Geraghty and Miller, Inc. Syosset, New York

4. Grout Water Associates, Inc. Westerville, Ohio

5. Hayward Baker Company Odenton, Maryland

6. James M. Montgomery, Inc. Pasedena, California

7. JRB Associates, Inc. McLean, Virginia

8. SCS Engineers, Inc. Long Beach, California

9. STS Consultants, Ltd. Northbrook, Illinois

10. Sverdrup and Parcel, Inc. St. Louis, Missouri

11. TAMS

New York, New York

12. Woodward-Clyde Consultants San Francisco, California

13. D'Appolonia Pittsburgh, Pennsylvania

14. Metcalf and Eddy, Inc. Boston, Massachusetts

15. $\mathrm{CH} 2 \mathrm{M}-\mathrm{Hill}$

Portland, Oregon
Grout Curtains

1. American Cyanamid Company Princeton, New Jersey

2. Burgess and Niple, Inc. Columbus, Ohio

3. Cementation Company of America, Inc.

Tucson, Arizona

4. Diamond Chemicals

Cleveland, Ohio

5. Halliburton Company Duncan, Oklahoma

6. Hayward Baker Company Odenton, Maryland

7. Layne New York Company Pittsburgh, Pennsylvania

8. Mitsubishi International Corporation

Chicago, Illinois

9. Mueser, Rut ledge, Johnston and Desimone

New York, New York

10. Pressure Grout Company Doly City, California

11. Raymond International Builders, Inc. Pennsauken, New Jersey

12. Stang - Cofor, Inc. Crange, California

13. STS Consultants, Ltd. Northbrook, Illinois

14. W. G. Jaques Co. Des Moines, Iowa 
III. Slurry Trenches

1. American Colloid Company Skokie, Illinois

2. Bencor Corporation of America Dallas, Texas

3. Case International Company Chicago, Illinois

4. Engineered Construction Internationa 1, Inc. Pittsburgh, Pennsylvania

5. GE0-CON, Inc. Pittsburgh, Pennsylvania

6. ICOS Corporation of America New York, New York

7. International Minerals and Chemical Corp. Mundelein, Illinois

8. Moretrench American Corp. Rockaway, New Jersey

9. Mueser, Rutledge, Johnston, and Desimone

New York, New York

10. Raymond International Builders, Inc. Pennsauken, New Jersey

11. Soletanche and Radio, Inc. McLean, Virginia

12. STS Consultants, Ltd. Northbrook, Illinois

13. Thatcher Engineering Corp. Gary, Indiana

14. White, Morrison-Knudson, Mergantine Newton, Massachusetts

(a) There are many competent geotechnical consulting firms throughout the U.S. that can perform hydrogeologic site investigations. This list presents several representative firms.

4.114
IV. Steel Sheet Piling

Most heavy construction companies throughout the U.S. are experienced with the design and construction of steel sheet piling cut-offs.

V. Well Design/Drilling

The 1983 National Water Water Well Association Membership Directory lists several hundred well drilling contractors and equipment suppliers.

VI. Ground Freezing

1. Cementation Company of America, Inc. Tucson, Arizona

2. Engineered Construction International, Inc. Pittsburgh, Pennsylvania

3. Frontier-Kemper Constr.

4. Geofreeze Corp.

5. Moretrench American Corp. Rockaway, New Jersey 


\subsection{REFERENCES}

Albritton, J. A. 1982. "Cement Grouting Pratice U.S. Army Corps of Engineers." In Proceedings of the Conference on Grouting in Geotechnical Engineering, (W. H. Baker, ed.), ASCE, New York, Pp. 264-278.

Alves, Jr., E., and D. B. Hunt. 1969. "Alamitos Barrier Project Report 68-68." Los Angeles County Flood Control District, Los Angeles.

Attewel1, P. B., and I. W. Farmer. 1976. Principles of Engineering Geology. Chapman and Ha11, New York.

Ayres, J., et al. 1983. "The First EPA Superfund Cut off Wall Design and Specifications." Presented at Third Symposium on Aquifer Restoration and Ground-Water Monitoring, National Water Well Association, Columbus, Ohio.

Baker, W. H. 1982. "Planning and Performing Structural Chemical Grouting." In Proceedings of the Conference on Grouting in Geotechnical Engineering, (w. H. Baker, ed.), ASCE, New York, pp. 515-539.

Bear, J. 1979. Hydraulics of Groundwater. McGraw-Hill Book Co., New York.

Caron, C. 1982. "The State of Grouting in the 1980's." In Proceedings of the Conference on Grouting in Geotechnical Engineering, (W. H. Baker, ed.), ASCE, New York, pp. 346-358.

Clarke, W. J. 1982. "Performance Characteristics of Acrylate Polymer Grout." In Proceedings of the Conference on Grouting in Geotechnical Engineering, (w. H. Baker, ed.), ASCE, New York, pp. 418-432.

Committee on Grouting. 1980. "Preliminary Glossary of Terms Relating to Grouting." ASCE Journal of the Geotechnical Engineering Division, 106(GT7), pp. 803-815.

D'Appolonia, D. J. Undated. "Slurry Trench Cut-Off Walls for Hazardous Waste Isolation." Engineered Construction International, Inc., Pittsburgh, Pennsylvania.

D'Apppolonia, D. J. 1980. "Soil-Bentonite Slurry Trench Cut-Offs." ASCE

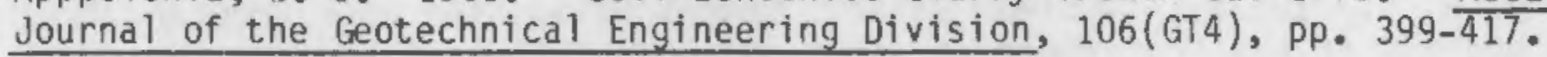

Davidson, R. R., and J. Y. Perez. 1982. "Properties of Chemically Grouted Sand at Locks and Dam No. 26. In Proceedings of the Conference on Grouting in feotechnical Engineering, (W. H. Baker, ed.), ASCE, New York, Pp. 433-449.

Davis, S. N., and R. J. M. DeWiest. 1966. Hydrogeology. John Wiley and Sons, New York. 
Deere, D. U. 1982. "Cement-Bentonite Grouting for Dams." In Proceedings of the Conference on Grouting in Geotechnical Engineering, (W. H. Baker, ed.), ASCE, New York, pp. 279-300.

Department of Water Resources, State of California. 1975. "Ground Water Basin Protection Projects: Fremont Salinity Barrier." Bulletin No. 147-2, Sacramento, California.

Dunn, I. S., L. R. Anderson and F. W. Kiefer. 1980. Fundamentals of Geotechnical Analysis. John Wiley and Sons, New York.

Environmental Protection Agency. 1982. "Handbook for Remedial Action at Waste Disposal Sites." EPA-625/6-82-006, Municipal Environmental Research Laboratory, USEPA, Cincinnati, Ohio.

Fox, R. C., and M. C. Jones. 1982. "Remedial Drilling and Grouting of Two Rockfill Dams." In Proceeding of the Conference on Grouting in Geotechnical Engineering, ( $W$ H. Baker, ed.), ASCE, New York, pp. 136-151.

Gourlay, A. W., and C. B. Carson. 1982. "Grouting Plant and Equipment." In Proceedings of the Conference on Grouting in Geotechnical Engineering, (W. H. Baker, ed.), ASCE, New York, pp. 121-135.

Harr, M. E., et al. Undated. "Vibrated-Beam Placed Thin Slurry Walls for Construction Dewatering, Water Conservation, Industrial Waste Ponding, and Other Applications." M. E. Harr Enterprises, Inc., West Lafayette, Indiana.

Harris, V. A., et al. 1982a. "Accident Mitigation: Alternative Methods for Isolating Contaminated Groundwater." Draft Report, Division of Environmental Impact Studies, Argonne National Laboratory, Argonne, Illinois.

Harris, V. A., et al. 1982b. "Accident Mitigation: Slurry Wall Barriers." Division of Environmental Impact Studies, Argonne National Laboratory, Argonne, Illinois.

Houlsby, A. C. 1982a. "Cement Grouting for Dams." In Proceedings of the Conference on Grouting in Geotechnical Engineering, ( New York, pp. 1-84.

Houlsby, A. C. 1982b. "Optimum Water: Cement Ratios for Rock Grouting." In Proceedings of the Conference on Grouting in Geotechnical Engineering, (W. H. Baker, ed.), ASCE, New York, pp. 317-331.

Hvorslev, M. J. 1951. "The Log and Soil Permeability in Ground-Water Observations." Bulletin No. 36, Waterways Experiment Station, U.S. Army Engineer Waterways Experiment Station, Vicksburg, Mississippi.

Jefferis, S. A. 1982. "Effects of Mixing on Bentonite Slurries and Grouts." In Proceedings of the Conference on Grouting in Geotechnical Engineering (w. H. Baker, ed.), ASCE, New York, pp. 62-76. 
Jepsen, C. P. Undated. "Clay Mineralogy and Importance when Utilizing Clay as a Soil Sealant." Environmental Products Division, American Colloid Company, Skokie, Illinois.

Karol, R. H. 1982a. "Chemical Grouts and Their Properties." In Proceedings of the Conference on Grouting in Geotechnical Engineering ( $W . H$. Baker, ed.), ASCE, New York, Pp. 359-377.

Karol, R. H. 1982b. "Seepage Control with Chemical Grout." In Proceedings of the Conference on Grouting in Geotechnical Engineering ( $W$. H. Baker, ed.), ASCE, New York, pp. 564-575.

Karol, R. H. 1968. "Chemical Grouting Technology." ASCE Journal of the Soil Mechanics and Foundations Division, 94(SM1), pp. 175-204.

Kaufman, W. J. 1973. "Notes on Radionuclide Pollution of Groundwaters." Sanitary Engineering Research Laboratory, University of California, Berkeley, California.

Lee, D. H. 1949. Sheet Piling Cofferdams and Caissons. Concrete Publications Limited, London.

Littlejohn, G. S. 1982. "Design of Cement Based Grouts." In Proceedings of the Conference on Grouting in Geotechnical Engineering, (W. H. Baker, ed.), ASCE, New York, pp. 35-48.

Markewicz, F. J., and S. Ladding. 1975. "Glauconite." In Industrial Minerals and Rocks, (S. J. Lefond, edidor-in-chief), American Insi itute of Mining, Metallurgical and Petroleum Engineers, Inc., New York, pp. 679-688.

McWhorter, D. B., and D. K. Surada. 1977. Ground Water Hydrology and Hydraulics. Water Resources Publications, Fort Collins, Colorado.

Merriman, T., and T. H. Wiggin (eds.). 1947. American Civil Engineers' Handbook. John Wiley and Sons, Inc., New York.

Miller, S. P. 1979. "Geotechnical Containment Alternatives for Industrial Waste Basin F, Rocky Mountain Arsenal, Denver, Colorado; A Dualitative Evaluation." Technical Report GL-79-23, U.S. Army Engineer Waterways Experiment Station, Vicksburg, Mississippi.

Millet, R. A., and J. Y. Perez. 1981. "Current USA practice: Slurry Wall Specifications." ASCE Journal of the Geotechnical Engineering Division, 107(GT8), pp. 1041-1055.

Nelson, R. W. 1966. "Air Injection Below the Water Table to Retard Movement of Liquid Contaminants: A Preliminary Analysis." Scientific Programming and Analysis Department, Computer Sciences Corporation, Richland, Washington. 
Niemczyk, S. J., et al. 1981. "The Consequences from Liquid Pathways After a Reactor Meltdown Accident." Nuclear Regulatory Commission, NUREG/CR-1596, USNRC.

0lson, R. E., and D. E. Danial. 1981. "Measurement of the Hydraulic Conductivity of Fine-Grained Soils." In Permeability and Groundwater Contaminant Transport, (T. F. Zimmie and C. D. Riggs, ed.), STP746, ASTM, PhiladeTphia, pp. 18-64.

Peck, R. B., W. E. Harrison and T. H. Thornburn. 1953. Foundation Engineering. John Wiley and Sons, New York.

Rishel, H. L., et al. 1982. "Costs of Remedial Response Actions at Uncontrolled Hazardous Waste Sites." SCS Engineers, Long Beach, California.

Robson, S. G. 1981. "Computer Simulation of Movement of DIMP-Contaminated Groundwater Near the Rocky Mountain Arsenal, Colorado." In Permeability and Groundwater Contaminant Transport, (T. F. Zimmie and C.0. Ri ggs, eds.), STP746, ASTM, Philadelphia, pp. 209-220.

Ryan, C. Undated. "Slurry Cut off Walls Design and Construction." GEO-CON, Inc., Pittsburgh, Pennsylvania.

Sanger, F. J. 1968. "Ground Freezing in Construction." ASCE Journal of the Soil Mechanics and Foundations Division. 94(SM1), pp. 131-158.

Schmednecht, F. C. Undated. "Vibrated Beam Technique for Cut-off Wall Construction." Slurry Systems, A Division of Thatcher Engineering Corporation, Gary, Indiana.

SCS Engineers. 1981. "Manual for Upgrading Existing Disposal Facilities." Long Beach, California.

Sheahan, N. T. 1977. "Injection/Extraction Well System - A Unique Seawater Intrusion Barrier." Ground Water, 15(1), pp. 32-50.

Tolman, A. L., et al. 1978. "Guidance Manual for Minimizing Pollution from Waste Disposal Sites." EPA-600/2-78-142, Municipal Environmental Research Labortory, USEPA, Cincinnati, Ohio.

Tsang, C. F., et al. 1973. "A Study of Contaminant plume Control in Fractured-Porous Media." Earth Science Division, Lawrence Berkeley Laboratory, Berkeley, California (mimeographed).

Urquhart, L. C. (ed.). 1950. Civil Engineering Handbook. McGraw-Hill Book Co., New York.

U.S. Army Office of the Chief of Engineers. 1973. "Chemical Grouting: Engineering and Design." Engineer Manual EM 110-2-3504, Washington, D.C. 
U.S. Department of the Interior, Bureau of Reclamation. 1974. Design of Small Dams. U.S. Government Printing Office, Washington, D.C.

Warner, J. W. 1979. "Digital-Transport Model Study of DIMP Ground-Water Contamination at the Rocky Mountain Arsenal, Colorado." Open File Report 79-676, USGS, Lakewood, Colorado.

Williams, D. W. 1977. "The Dashte-Naz Ground-Water Barrier and Recharge Project." Ground Water, 15(1), pp. 23-31.

Williams, E. B. 1982. "Contamination Containment by In Situ Polymerization." Presented at Second Symposium on Aquifer Restoration and Ground-Water Monitoring, National Water Well Association, Columbus, Dhio. 



\subsection{MITIGATIVE TECHNIQUES FOR GENERIC SITES}

\subsection{ANALYSIS OF PRE-MITIGATIVE CONTAMINANT DISCHARGE}

The release of radionuclides and subsequent transport to an accessible environment without mitigative action are discussed in this section. The release of strontium-90, cesium-137 and ruthenium-106 following a severe accident are used as indicators of the severity of contamination via the groundwater pathway. Existing and proposed nuclear power plant sites are individually characterized by one dimensional transport analysis and the results are presented in composite by generic hydrogeological classification. The nomenclature adopted in this report uses the term "release" in reference to leach or sump water release of radionuclides from the core melt debris, the term "discharge" is used in reference to radionuclides discharged from the ground-water flow system to an accessible environment.

The analysis of pre-mitigative discharge fluxes for the generic classifications is intended to provide a generic representation of the data trends and extremes that are anticipated in the event of a severe accident. Individual sites are discussed only as examples of generic liquid pathway responses to a core melt accident. The reader is cautioned that this generic analysis is not intended to provide precise transport results of any specific site. The radionuclide activities and first contaminant discharge times at specific sties may be in error by an order of magnitude or more due to simplifying leach rate assumptions, geohydrologic data base estimates, and one-dimensional contaminant transport analysis limitations.

The purpose and value of the pre-mitigative analysis of radionuclide discharges is to demonstrate in a generic fashion the general time constraints and activity magnitudes of contaminanted ground-water discharges that are possible following a core melt accident. Knowledge of the generic range of contaminant arrival times and activities at the nearest downstream surface water body provides a screening to determine, in general, the necessity of contaminant interdiction for one hydrogeoloic classification versus another. Analysis of a specific site for the evaluation of the need of mitigative measures can only be properly addressed in a case study format. A description of the pre-mitigative discharge fluxes is provided for each generic site classification.

The generic characteristics of a hydrologic nature (i.e., effective porosity, hydraulic gradient, etc.) determine the average linear ground-water velocity for each site. The indicator radionuclides (i.e., strontium-90, cesium-137 and ruthenium-106) have individual decay rates and individual degrees of retardation by sorption. Hence, the amounts and respective ratios of the indicator radionuclides and radionuclides discharged to accessible environments via the ground-water pathway demonstrate the generic nature of a contaminant release for each hydrogeologic classification. If generic groupings 
or central tendencies are not observed in the transport results, the analysis indicates that site specific conditions (i.e., travel distance) are more important than generic hydrogeology.

Important to the pre-mitigative analysis are the questions: 1) does the contaminant decay to insignificant levels prior to discharge? 2) when does the first contaminant arrive at an accessible environment? 3 ) how long does contaminant continue to be discharged? and 4) when does the discharge attenuate to low levels? The first question in the analysis focuses on what constitutes a significant radionuclide release. A release into a ground-water system will always be a part of the hydrologic cycle and eventually reach a surface water body or other accessible environment. The time necessary to transport the contaminant can be as short as a few weeks to time periods measured in hundreds of thousands of years. Long transport times allow decay processes to reduce the radionuclide activity to virtually background levels. Therefore, a time limit is useful to discriminate between immediate releases of appreciable quantities of radionuclides and late arrivals of insignificant quantities.

In this study, a particular radionuclide discharge is considered significant if it occurs prior to 40 half-lives of decay. The time period of 40 halflives allows radioactive decay to reduce the initial activity by a factor of $9.09 \times 10^{13}$. The 40 half-life time period of indicator radionuclides is also a long enough time span in which a detailed hydrologic investigation could be completed before first discharge to surface water. For the radionuclides of interest, the 40 half-life time periods are: 1,128 years for strontium-90, 1,209 years for cesium-137, and 40.4 years for ruthenjum-106. For example, if the entire core inventory of strontium-90 $\left(3.71 \times 10^{18} \mathrm{pCi}\right)$ is instantaneously released into the ground water, the strontium-90 activity after 40 half-lives would be $3.37 \times 10^{6} \mathrm{pCi}$. If the entire remaining amount of the initial inventory were discharged instantaneously to a surface water body, (assuming no mechanical dispersion or molecular diffusion) the resulting activity would be within the limits of Title 10 of the Code of Federal Regulations, Part 20 of $300 \mathrm{pCj} / \ell$ if the volume of the water body was greater than $1.12 \times 10^{4} \&(3.97 \times$ $\left.10^{2} \mathrm{ft}^{3}\right)$. This minimum volume of water needed to dilute the strontium-90 activity to permissible levels is comparable to a small pond even under very conservative assumptions of release and transport. The purpose of setting the 40 half-lives limit for a significant release is to screen sites from consideration that do not require activities to mitigate imminent environmental consequences of a core melt accident. The indicator radionuclides were selected for mobility and long halflives, therefore they would be the first to be discharged at the highest activities. After 40 half-lives of decay, the necessity of mitigative action is dependent on site specific characteristics of the accessible environment and associated human factors. The percentage of sites for each generic classification where over 40 half-lives occur prior to surface water discharge is presented as the first level of analysis in Sections 5.2 through 5.7 .

The next key characteristic of the generic examination is the first arrival time of contaminant. This time is important as it represents the maximum time available for the implementation of a mitigative technique. If the first arrival of contaminant is shortly after release, there may be 
insufficient time to implement adequate and/or cost effective mitigative measures. Conversely, a long delay for arrival of the first contaminant provides greater time for site studies of plume migration and local

hydrogeologic conditions before initiating mitigation activities. The spread time or time over which contaminant continues to arrive at the accessible environment is also a factor in mitigation. Long spread times of hundreds of years require mitigative measures that possess durability and performance characteristics sufficient to continue the mitigative technique for as long as release rates are above acceptable limits. Long spread times are associated with leaching of core melt masses. Short spread times, as might be the case for sump water releases, will concentrate the contaminant in space and time. Mitigative techniques for this type of release would be spatially dependent on current plume location in contrast to a core melt leachate plume which would extend continuously from the source to the accessible environment.

Another key characteristic of this generic study is the radionuclide discharge rate to accessible environments, particularly surface water. The capacity for mixing and dilution of a surface water body is an important consideration when evaluating the severity of an accident. The generic discharges to surface water are given in flux units (i.e., pci/yr) so that the magnitude of a release can be examined in relation to the size and uses of the receiving water body.

The radionuclide fluxes are given for both leaching of the solid core melt mass and liquid sump water releases. A core melt mass may be expected to release radionuclides by leaching for both boiling water reactors (BWR) and pressurized water reactors (PWR). Liquid release of sump water used in emergency cooling is expected to be important primarily for PWR's. Therefore, accidents at BWR sites are described, in general, by release from the core melt mass. Although there may be liquid releases from BWR's, PWR accidents may have both a sump water and core melt mass component. This study examines the effects of a sump water and core debris leach release at each site regardless of reactor type. A discussion of leach and sump water releases to ground water is presented in Section 2.0.

\subsection{GENERIC SITE: FRACTURED CONSOLIDATED SILICATES - CRYSTALLINE}

\subsubsection{Pre-Mitigative Contaminant Discharge}

\subsubsection{Significant Radionuclide Discharge}

The first level of analysis of the pre-mitigative contaminant discharge involves determination of the percentage of fractured consolidated silicates sites where a discharge to surface water is calculated to occur prior to a 40 half-life time limit. The three radionuclides used as indicators of contaminant discharge (i.e., strontium-90, cesium-137 and ruthenium-106) travel in the ground-water flow system at different rates and have individual rates of decay. Therefore, not all of the radionuclides would discharge to surface water prior to 40 half-lives of decay. The percentage of individual sites with a calculated significant release is presented in Figure 5.2.1-1. In the fractured consolidated silicate-crystalline classification, $94 \%$ of the sites have a 


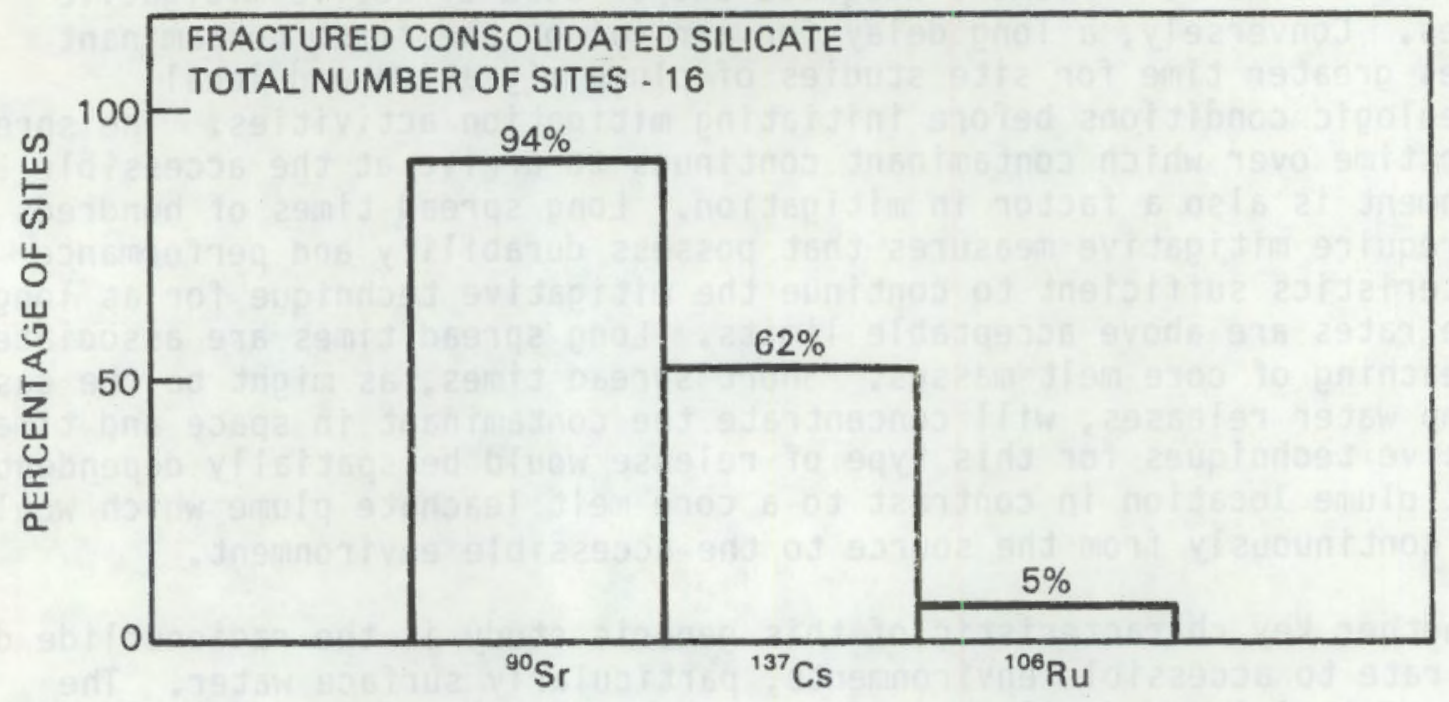

FIGURE 5.2.1-1. Percentage of Fractured Consolidated Silicates-Crystalline Sites That Would Discharge Each of the Indicator Radionuclides Prior to $40 \mathrm{Half}-\mathrm{Li}$ ves of Decay

significant strontium-90 discharge while only $5 \%$ experience a significant ruthenium-106 discharge. The difference in these two percentages is, in part, due to the longer half-1ife of strontium-90 (28.1 years) as compared to a halflife of 1 year for ruthenium-106. For ruthenium-106 to be discharged at so few sites before 40 half-lives have occurred indicates short contaminant travel times are feasible at only a limited percentage of sites in this generic classification.

Although cesium-137 has a somewhat longer half-life than strontium-90, sorption delays cesium migration about 20 times more effectively in this generic classification. Cesium-137 is discharged before 40 half-lives at $62 \%$ of the sites. As compared to all other generic hydrogeologic classifications, fractured consolidated crystalline silicates exhibit the second highest percentage of calculated significant radionuclide discharges.

\subsubsection{Core Melt Leachate Discharge to Surface Water}

The leaching of the core melt mass would release radinouclides into the ground-water flow system where they would be transported toward a surface water body. The flux of radionuclide activity at the point of contact with a surface water body is given in Figure 5.2.1-2. The time scale in years represents the time after the beginning of core melt leaching. The heat generated in the core melt mass is expected to delay ground-water contact with the core melt for up to one year as discussed in Section 2.1.1. Strontium-90 has a slower rate of decay than ruthenium-106 and hence, retains its activity over a longer span of time. The first arrival of contaminant is indicated by the left most line perpendicular to flux/year curve. The flux/year curve is not extended past a lower limit of $1 \mathrm{pCi} / \mathrm{yr}$ as a plotting convenience. 


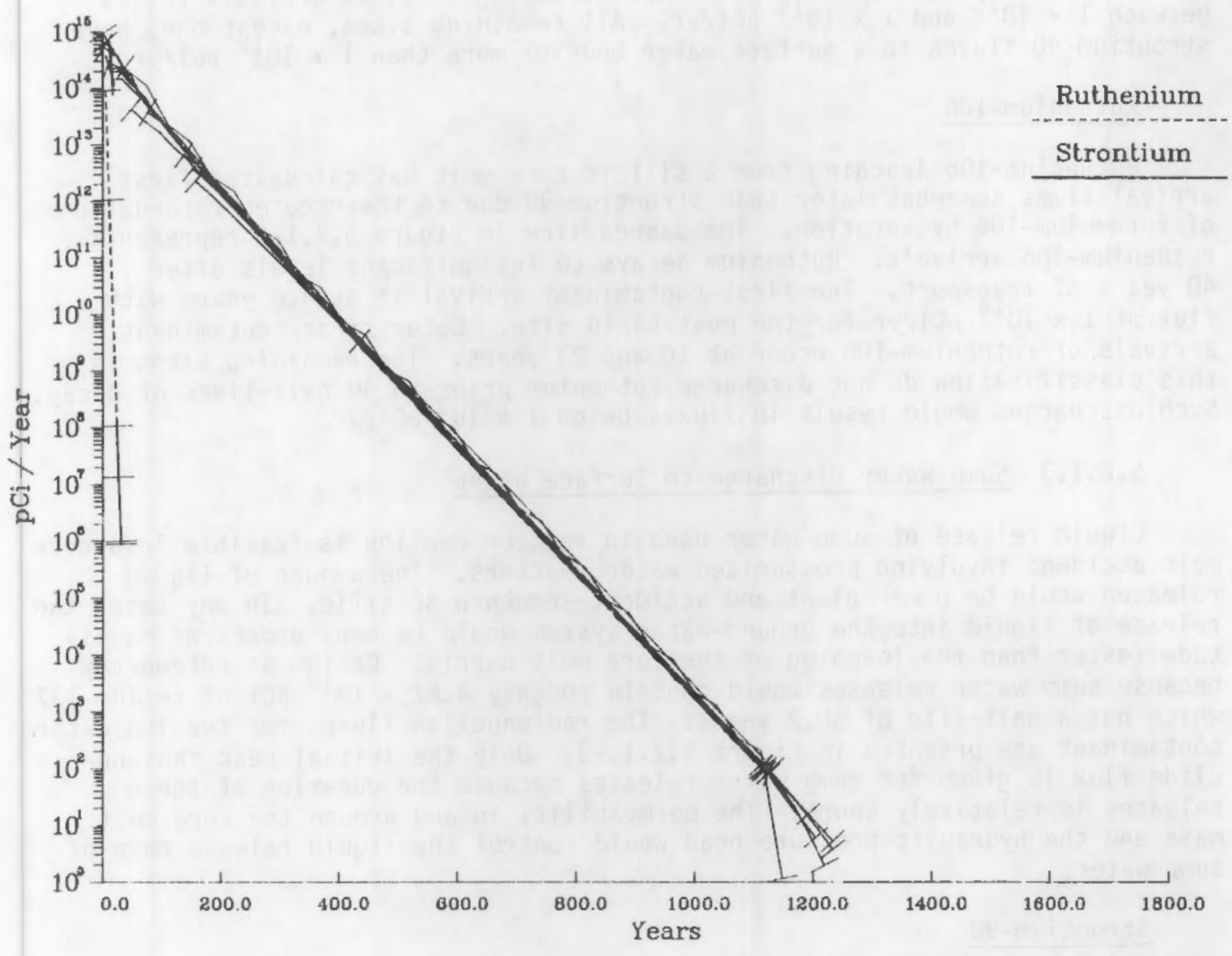

FIGURE 5.2.1-2. Discharge Flux of Core Melt Leachate from Fractured Consolidated Silicates-Crystalline Sites to Surface Water for Strontium-90 and Ruthenium-106

\section{Strontium-90}

The first calculated arrival times for strontium-90 are spread between 0.9 years and 150 years. Une site has an extreme first arrival of contaminant at the nearest surface water at 430 years. The fractured consolidated silicate-crystalline classification exhibits a major grouping of strontium-90 arrival times at about 10 years. This result is not unexpected in a fractured flow system where sorption is hindered and hydraulic conductivities and effective 
porosities favor contaminant transport. The remaining sites not contained in the major grouping have calculated first arrival times scattered between 20 and 150 years.

The strontium-90 flux for the major grouping of first arrivals ranges between $1 \times 10^{15}$ and $1 \times 10^{14} \mathrm{pCi} / \mathrm{yr}$. All remaining sites, except one, have strontium-90 fluxes to a surface water body of more than $1 \times 10^{12} \mathrm{pCi} / \mathrm{yr}$.

\section{Ruthenium-106}

Ruthenium-106 leaching from a silicic core melt has calcualted first arrival times somewhat later than strontium-90 due to the greater retardation of ruthenium-106 by sorption. The dashed line in Figure 5.2.1-2 represents ruthenium-106 arrivals. Ruthenium decays to insignificant levels after 40 years of transport. The first contaminant arrival is at 4.6 years with a flux of $1 \times 10^{14} \mathrm{pCi} / \mathrm{yr}$ for the most rapid site. Later first contaminant arrivals of ruthenium-106 occur at 10 and 23 years. The remaining sites in this classification do not discharge ruthenium priog to 40 half-lives of decay. Such discharges would result in fluxes below $1 \times 10^{3} \mathrm{pCi} / \mathrm{yr}$.

\subsubsection{Sump Water Discharge to Surface Water}

Liquid release of sump water used in reactor cooling is feasible in a core melt accident involving pressurized water reactors. The amount of liquid released would be power plant and accident-sequence specific. In any case, the release of liquid into the ground-water system would be many orders of magnitude faster than the leaching of the core melt debris. Cesjum is noteworthy because sump water releases would contain roughly $4.67 \times 10^{10} \mathrm{pC} i$ of cesium-137 which has a half-life of 30.2 years. The radionuclide fluxes for the indicator contaminant are prsented in Figure 5.2.1.-3. Only the initial peak radionuclide flux is given for sump water releases because the duration of these releases is relatively short. The permeability in and around the core melt mass and the hydraulic pressure head would control the liquid release rate of sump water.

\section{Strontium-90}

The discharge fluxes calculated for strontium-90 show a cluster of arrival times at 0.9 to 40 years which includes $60 \%$ of the sites. The remaining sites have first arrival times spread out over 400 years after release. The fluxes are greater than anticipated for the core melt mass which would be a characteristic of sump water releases. The maximum flux of the sites is $6 \mathrm{x}$

$10^{16} \mathrm{pCi} / \mathrm{yr}$. The lowest value in the clustered data is $2.5 \times 10^{15} \mathrm{pCi} / \mathrm{yr}$. The remaining strontium discharges range from $1 \times 10^{10}$ to $3 \times 10^{15} \mathrm{pCi} / \mathrm{yr}$. Other than the clustering of points at times less than 40 years there is no trend or generalization evident in the data except for the decreasing flux with time due to radioactive decay. 


\section{FRACTURED CRYSTALLINE SILICATE - SUMP WATER}

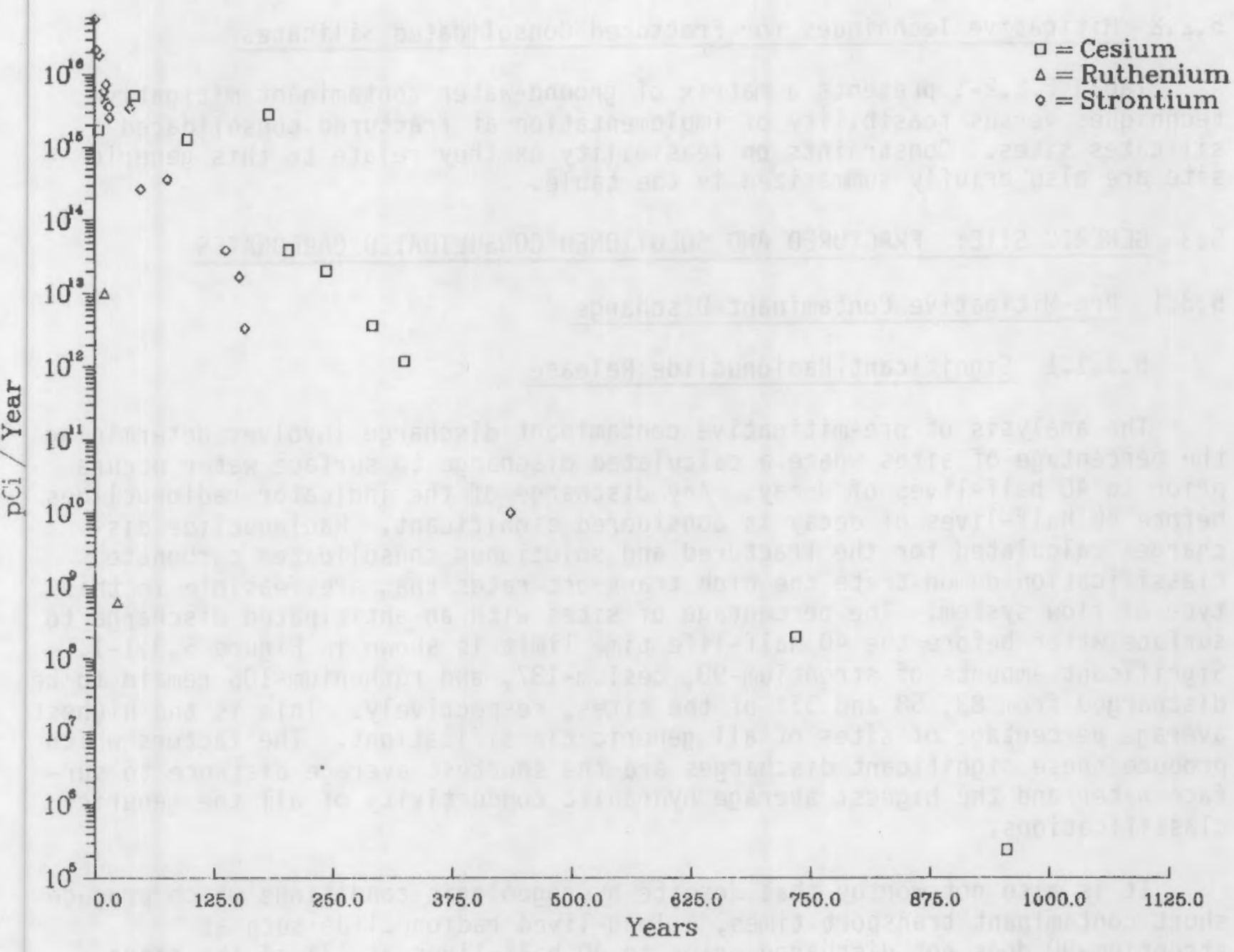

FIGURE 5.2.1-3. Discharge Flux of Reactor Sump Water from Fractured Consolidated Silicates-Crystalline Sites to Surface Water for Strontium-90, Cesium-137 and Ruthenium-106

\section{Cecium-137}

Cesium is more strongly retarded than the other indicator radionuclides and arrives at the surface water body last in the contaminant stream. The arrival times do not. group but follow a linear trend from 18.4 to 950 years. Peak flux is $1 \times 10^{17} \mathrm{pCi} / \mathrm{yr}$ at 18.4 years. Generally, the cesium fluxes are greater than those of strontium when travel times to the surface water body are greater than 50 years. The sump water discharge of cesium-137 exhibits the greatest flux value in the fractured consolidated silicates classification. 


\section{Ruthenium-106}

Ruthenium-106 decays to low levels before discharge into a surface water body at most of the sites in this generic classification. The peak flux is $1 \times$ $10^{13} \mathrm{pCi} / \mathrm{yr}$ or about 3.5 orders of magnitude less than strontium-90.

\subsubsection{Mitigative Techniques for Fractured Consolidated Silicates}

Table 5.2.2-1 presents a matrix of ground-water contaminant mitigative techniques versus feasibility of implementation at fractured consolidated silicates sites. Constraints on feasibility as they relate to this generic site are also briefly summarized in the table.

\subsection{GENERIC SITE: FRACTURED AND SOLUTIONED CONSOLIDATED CARBONATES}

\subsubsection{Pre-Mitigative Contaminant Discharge}

\subsubsection{Significant Radionuclide Release}

The analysis of pre-mitigative contaminant discharge involves determining the percentage of sites where a calculated discharge to surface water occurs prior to 40 half-lives of decay. Any discharge of the indicator radionuclides before 40 half-lives of decay is considered significant. Radionuclide discharges calculated for the fractured and solutioned consolidated carbonate classification demonstrate the high transport rates that are feasible in this type of flow system. The percentage of sites with an anticipated discharge to surface water before the 40 half-life time limit is shown in Figure 5.3.1-1. Significant amounts of strontium-90, cesium-137, and ruthenium-106 remain to be discharged from 83,58 and $33 \%$ of the sites, respectively. This is the highest average percentage of sites of all generic classifications. The factors which produce these significant discharges are the shortest average distance to surface water and the highest average hydraulic conductivity of all the generic classifications.

It is also noteworthy that despite hydrogeologic conditions which produce short contaminant transport times, a long-lived radionuclide such as strontium-90 does not discharge prior to 40 half-lives at $17 \%$ of the sites.

This demonstrates that within generic classifications that are favorable to rapid contaminant discharge, there are individual sites that do not have the potential for concentrated radionuclide discharges to surface water.

\subsubsection{Core Melt Leachate Discharge to Surface Water}

The contact of ground water with the core melt debris would initiate leaching and release of contaminant to the ground-water flow system. Carbonate rock when melted forms a calcine material that leaches at a faster rate than a silica melt. Therefore, this generic classificaiton (i.e., fractured and solutioned carbonates) has the chemical and hydraulic potential for the largest radionuclide fluxes from core melt leaching. The flux of the indicator radionuclides is given in Figure 5.3.1-2. As previously described, the initial 
TABLE 5.2.2-1. Mitigative Techniques for Fractured Consolidated Silicates

Mitigative Technique

1. Grouting:

1a) Particulate/ Cement-based

1b) Non-particulate/ Chemical

2. Slurry Trenches:

2a) Soil bentonite $(S-B)$

2b) Cement bentonite $(C-B)$

2c) Lean concrete (L-C)

2d) Vibrating beam (VBT)

3. Steel Sheet Piling

4. Ground-Water Withdrawal for Potentiometric Surface Adjustment:

4a) Prevent discharge to receiving stream

4b) Prevent water table contact $w /$ core melt mass.

4c) Prevent contamination of leaky aquifer
5. Ground-Water Withdrawal and/or Injection for Contaminant Plume Control:

5a) Withdrawal and injection

5b) Withdrawal without injection

5c) Withdrawal and recharge

5d) Injection
Feasibility

Fissure grouting

Fracture grouting

Infeasible

Infeasible

Marginally feasible

Feasible

- Definition of fracture system required.

- Drilling costs may be high.

- Ground-water system response may be prohibitively slow due to relatively low hydraulic conductivity.

- Detailed hydrogeologic studies of complex flow system required to determine feasibility.

- Fracture system may enhance performance by concentrating contaminants. 


\section{TABLE 5.2.2-1. (contd)}

- Proper handling required for contaminated water brought to the surface.

6. Interceptor Trenches

7. Permeable Treatment Beds

8. Ground Freezing

9. Air Injection
Infeasible

Infeasible

Marginally feasible
- Excavation prohibited by competent rock.

- Excavation prohibited by competent rock.

- Drilling costs may be high.

- Very expensive and energy intensive.

- Thermal erosion may preclude implementation.

- 0.9-1.2 m/day maximum groundwater velocity.

- Surface piping insulation required.

- Host material saturation $>10 \%$.

Marginally feasible
- Little engineering expertise or implementation experience.

- Saturated conditions required.

- Drilling costs may be high.

- Energy intensive.

- Air bleeding of contaminants.

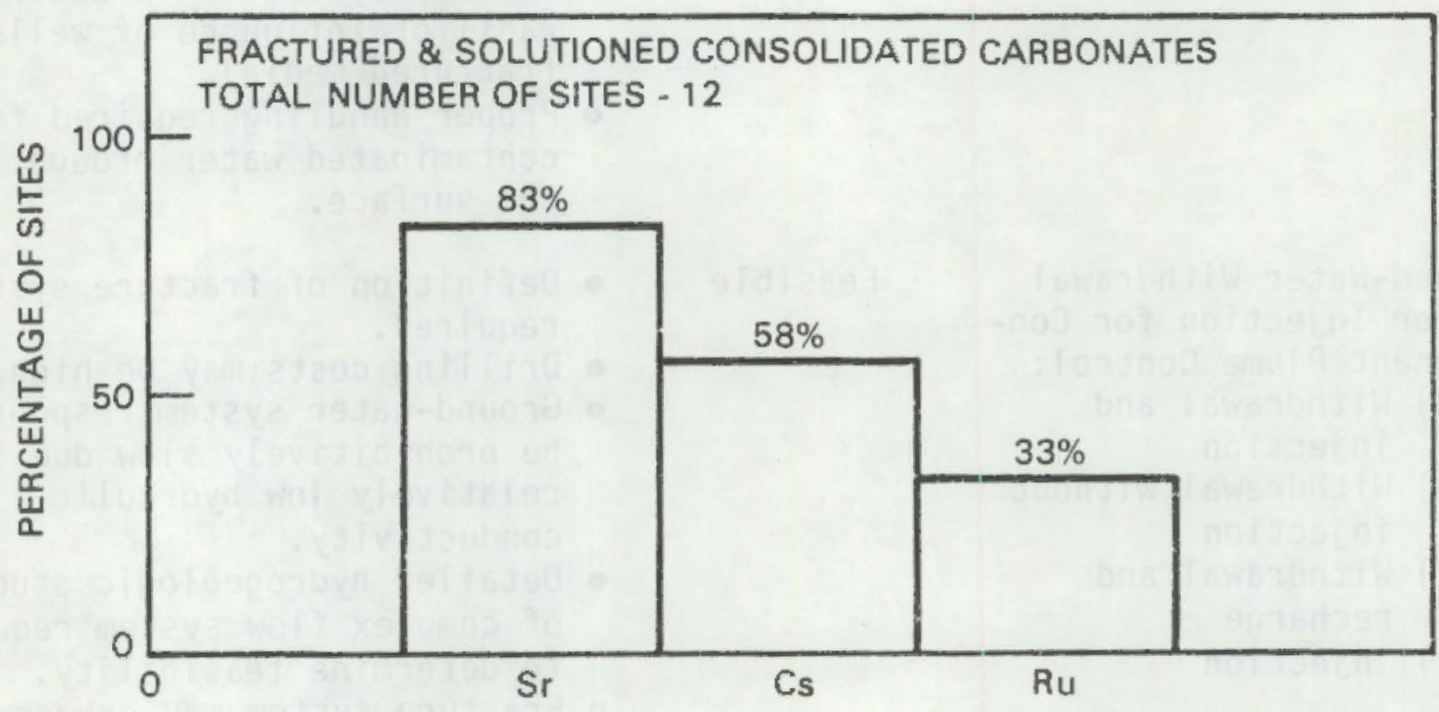

FIGURE 5.3.1-1. Percentage of Fractured and Solutioned Consolidated Carbonate Sites That Would Discharge Each of the Indicator Radionuclides Prior to $40 \mathrm{Half}$-Lives of Decay 


\section{FRACTURED CONSOLIDATED CARBONATES - CORE MELT}

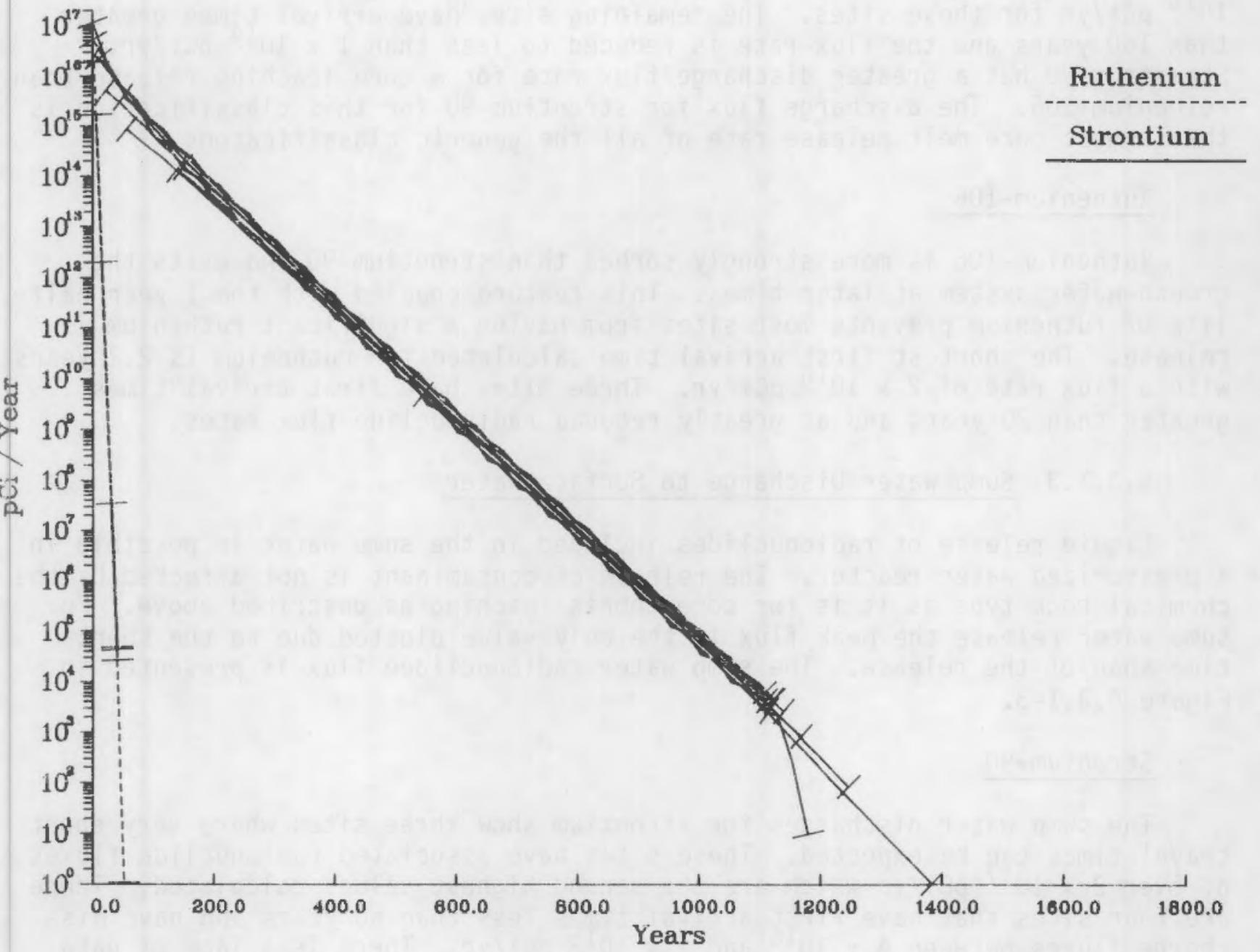

FIGURE 5.3.1-2. Discharge Flux of Core Melt Leachate from Fractured and Solutioned Consolidated Carbonate Sites to Surface Water for Strontium-90 and Ruthenium-106

contact of contaminant with surface water is indicated by a perpendicular line at the start of the flux/year curve. The flux rates are plotted to a lower limit of about $1 \mathrm{pCi} / \mathrm{yr}$. Amounts below this level are considered insignificant.

\section{Strontium-90}

The calculated first arrival times of this contaminant are nearly all between 0.6 and 140 years. One site has a first contaminant arrival at 
540 years. Of interest is the number of sites that have arrival times that are very shgrt. Four sites have short arrival times and also have flux rates of $1 \times 10^{17}$ to $1 \times 10^{16} \mathrm{pCi} / \mathrm{yr}$. There are three sites where contaminant is expected to reach the accessible environment prior to 60 years after the accident. The flux rate for strontium-90 is relatively high at about $1 \times$ $10^{15} \mathrm{pCi} / \mathrm{yr}$ for these sites. The remaining sites have arrival tjmes greater than 160 years and the flux rate is reduced to less than $1 \times 10^{14} \mathrm{pCi} / \mathrm{yr}$. Strontium-90 has a greater discharge flux rate for a core leaching release than ruthenium-106. The discharge flux for strontium-90 for this classification is the largest core melt release rate of all the generic classificatons.

\section{Ruthenium-106}

Ruthenium-106 is more strongly sorbed than strontium-90 and exits the ground-water system at later times. This feature coupled with the 1 year halflife of ruthenium prevents most sites from having a significant ruthenium release. The shortest first arrival time calculated for ruthenium is 2.2 years with a flux rate of $2 \times 10^{16} \mathrm{pCi} / \mathrm{yr}$. Three sites have first arrival times greater than 20 years and at greatly reduced radionuclide flux rates.

\subsubsection{Sump Water Discharge to Surface Water}

Liquid release of radionuclides included in the sump water is possible in a pressurized water reactor. The release of contaminant is not affected by the chemical rock type as it is for core debris leaching as described above. For sump water release the peak flux is the only value plotted due to the short time span of the release. The sump water radionuclidee flux is presented in Figure 5.3.1-3.

\section{Stronium-90}

The sump water discharges for strontium show three sites where very short travel times can be expected. These sites have associated radionuclide fluxes of over $2 \times 10^{17} \mathrm{pCi} / \mathrm{yr}$ which are the second highest values calculated. There are four sites that have first arrival times less than 60 years and have discharge fluxes between $4 \times 10^{16}$ and $2 \times 10^{15} \mathrm{pCi} / \mathrm{yr}$. There is a lack of data clustering for all radionuclides in this classification which precludes generalization.

Cesium-137

Radionuclide discharge flux reaches the overall highest calculated value for a cesium-137 sump water release in fractured and solutjoned carbonates. The peak flux occurs at 2.6 years with a value of $2.5 \times 10^{17} \mathrm{pCi} / \mathrm{yr}$. The next arrival time of cesium is at 7.1 years at a flux rate of $1.7 \times 10^{17} \mathrm{pCi} / \mathrm{yr}$. The remaining sites lie along a generalized decay curve without a clustering of data values. 


\section{FRACTURED CONSOLIDATED CARBONATE - SUMP WATER}

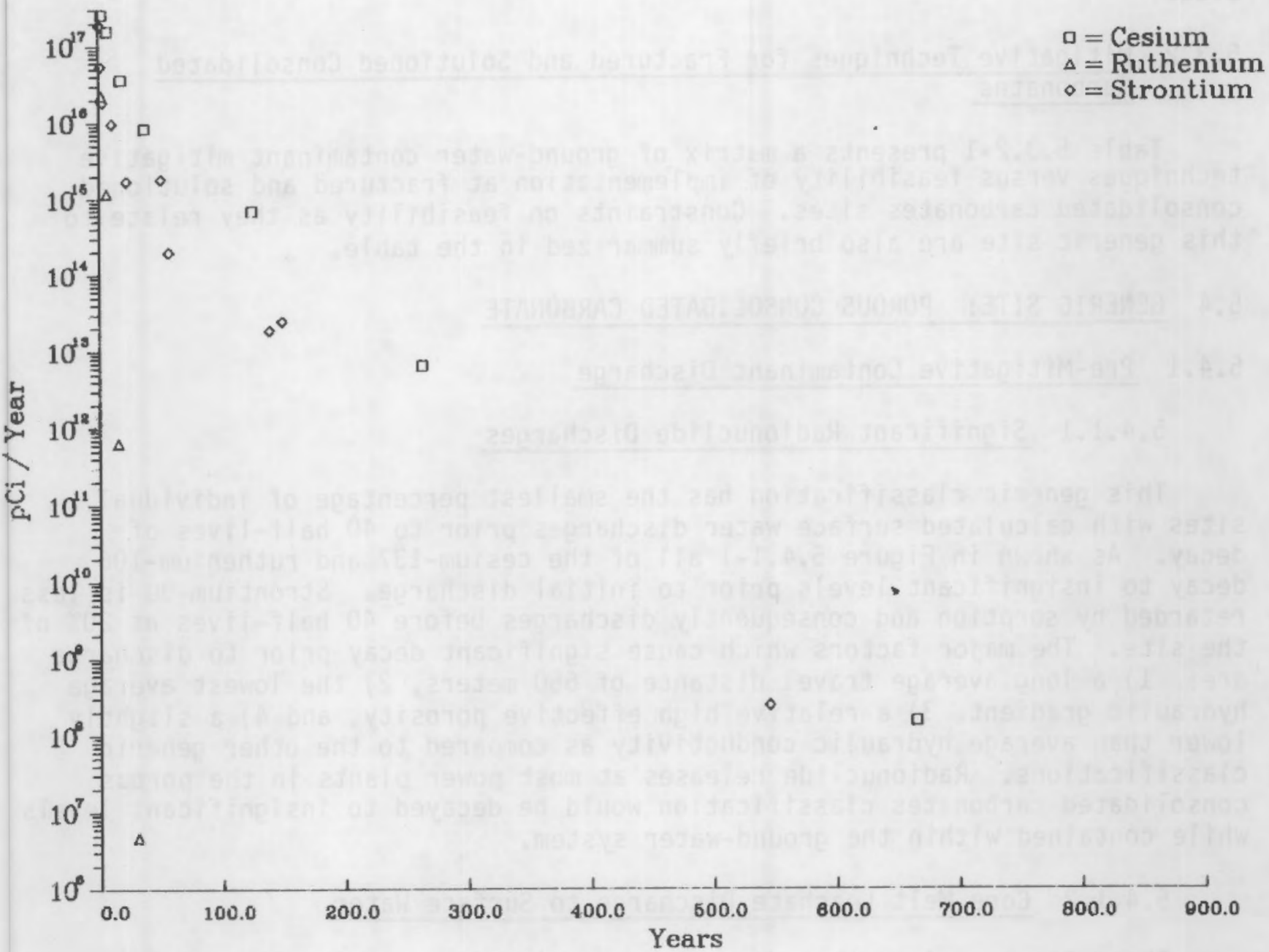

FIGURE 5.3.1-3. Discharge Flux of Reactor Sump Water from Fractured and Solutioned Consolidated Carbonate Sites to Surface Water for Strontium-90, Cesium-137, and Ruthenium-106 


\section{Ruthenium-106}

The ruthenium-106 flux levels are also greatef than average for this generic classification. The peak value is $2 \times 10^{16} \mathrm{pCj} / \mathrm{yr}$ occurring at 2.2 years. Ruthenium-106 flux levels are below $1 \times 10^{15} \mathrm{pCi} / \mathrm{yr}$ for most sites.

\subsubsection{Mitigative Techniques for Fractured and Solutioned Consolidated Carbonates}

Table 5.3.2-1 presents a matrix of ground-water contaminant mitigative techniques versus feasibility of implementation at fractured and solutioned consolidated carbonates sites. Constraints on feasibility as they relate to this generic site are also briefly summarized in the table.

\subsection{GENERIC SITE: POROUS CONSOLIDATED CARBONATE}

\subsubsection{Pre-Mitigative Contaminant Discharge}

\subsubsection{Significant Radionuclide Discharges}

This generic classification has the smallest percentage of individual sites with calculated surface water discharges prior to 40 half-lives of decay. As shown in Figure 5.4.1-1 all of the cesium-137 and ruthenium-106 decay to insignificant levels prior to initial discharge. Strontium-90 is less retarded by sorption and consequently discharges before 40 half-lives at $20 \%$ of the site. The major factors which cause significant decay prior to discharge are: 1) a long average travel distance of 650 meters, 2) the lowest average hydraulic gradient, 3 ) a relative high effective porosity, and 4) a slightly lower than average hydraulic conductivity as compared to the other generic classifications. Radionuclide releases at most power plants in the porous consolidated carbonates classification would be decayed to insignificant levels while contained within the ground-water system.

\subsubsection{Core Melt Leachate Discharge to Surface Water}

There are two sites that demonstrate a significant core melt debris leachate discharge but only for strontium-90. The discharges are plotted versus time in Figure 5.4.1-2. The discharged flux of strontium-90 indicates that at one of these sites discharge fluxes are elevated with a value of $4 \times$ $10^{15} \rho \mathrm{Ci} / \mathrm{yr}$ arriving at 44 years. The gther site has a calculated first arrival at time of 204 years at $2 \times 10^{13} \rho \mathrm{Ci} / \mathrm{yr}$. There are an insufficient number of calcualted significant core melt releases to form any trends.

\subsubsection{Sump Water Discharge to Surface Water}

Sump water release in this generic classification is similar to core melt leachate because the only radionuclide to reach the surface water environment prior to 40 half-lives of decay is strontium-90. The peak sumpwater discharge 
TABLE 5.3.2-1. Mitigative Techniques for Fractured and Solutioned Consolidated Carbonates

Mitigative Technique

1. Grouting:

1a) Particulate/ Cement-based

2a) Non-particulate/ Chemical

Feasibility
Permeation
grouting
Fissure
grouting
Fracture
grouting
Bulk
grouting

2. Slurry Trenches:

2a) Soil bentonite (S-B)

2b) Cement bentonite ( $C-B)$

2c) Lean concrete ( $L-C)$

2d) Vibrating beam (VBT)

3. Steel Sheet Piling

4. Ground-Water Withdrawal for Potentiometric Surface Adjustment:

4a) Prevent discharge to receiving stream

4b) Prevent water table contact $w /$ core melt mass.

4c) Prevent contamination of leaky aquifer

Infeasible

Infeasible

Marginally feasible
Constraints on Feasibility

- Rapid contaminant travel time.

- Joint gaps between $0.5 \mathrm{~mm}$ and $6.0 \mathrm{~mm}$ for cement-based grouts.

- Major cavities may be encountered requiring massive bulk grouting.

- Fissure width up to $10 \mathrm{~cm}$ $15 \mathrm{~cm}$ can be grouted w/acrylamide-based grouts.

- High ground-water velocities may prohibit grouting or require bulk fill material.

- Excavation prohibited by competent rock.

- Because of relatively high hydraulic conductivity sufficient drawdown may not be achieved; and large withdrawal volumes may be required.

- Definition of possibly complex fracture system is necessary

- Detailed hydrogeologic studies required to determine feasibility (i.e., difficulty arises in determining radii of influence of wells in fractured media).

- Proper handling required for contaminated water brought to the surface. 
TABLE 5.3.2-1. (contd)

5. Ground-Water Withdrawal and/or Injection for Contaminant Plume Control:

5a) Withdrawal and injection

5b) Withdrawal without injection

5c) Withdrawal and recharge

5d) Injection
Feasible

- Shallow aquifers preferable.

- Definition of possibly complex fracture system required.

- Detailed hydrogeologic studies required to determine feasibility.

- High hydraulic conductivity may require pumping of large quantities of water.

- Fracture system may enhance performance by concentrating contaminants.

- Proper handling required for contaminated water brought to the surface.

\section{Interceptor Trenches}

7. Permeable Treatment Beds

8. Ground Freezing

9. Air Injection
Infeasible

Infeasible

Marginally feasible

Marginally feasible
- Excavation prohibited by competent rock.

- Excavation prohibited by competent rock.

- Very expensive and energy intensive.

- Thermal erosion may preclude implementation.

- 0.9-1.2 m/day maximum groundwater velocity.

- Surface piping insulation required.

- Host material saturation $>10 \%$.

- Little engineering expertise or implementation experience.

- Saturated conditions required.

- Energy intensive.

- Air bleeding of contaminants. 


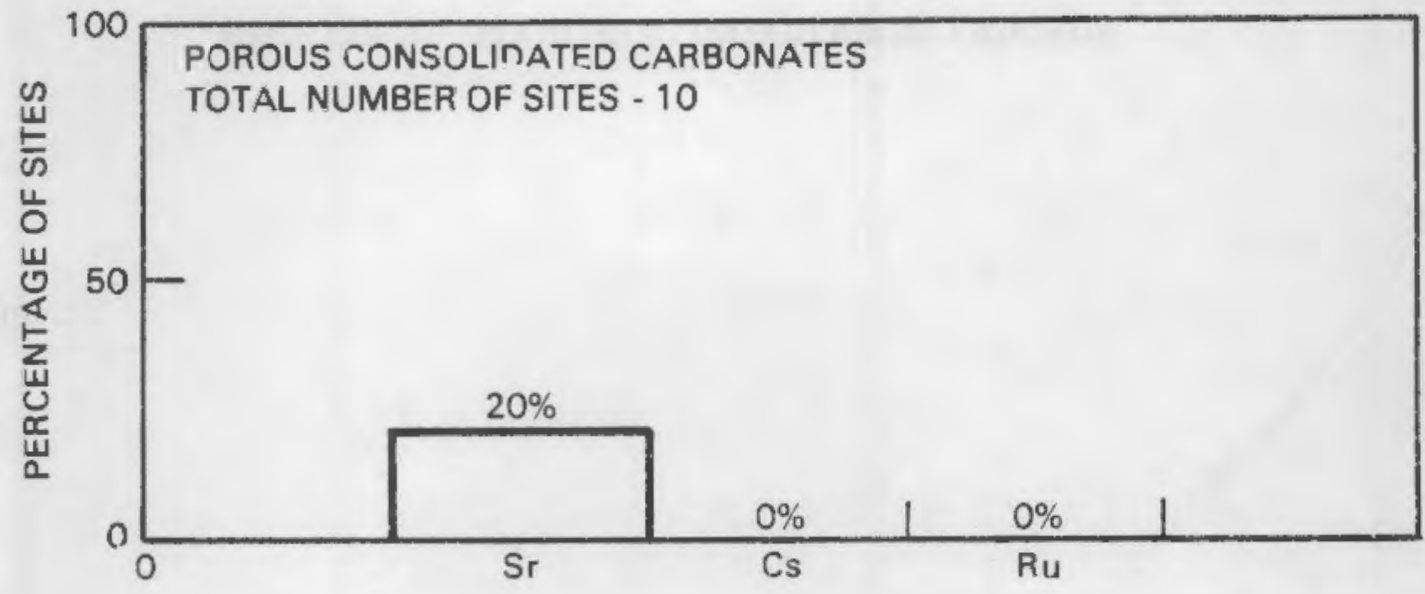

FIGURE 5.4.1-1. Percentage of Porous Consolidated Carbonate Sites That Would Discharge Each of the Indicator Radionuclides Prior to $40 \mathrm{Half}-\mathrm{Lives}$ of Decay

flux is given in Figure 5.4.1-3. The first arrival times are similar to arrivals from the core melt lechate. Flux levels are $1.2 \times 10^{15} \mathrm{pCi} / \mathrm{yr}$ for the shortest arrival time of 44 years.

\subsubsection{Mitigative Techniques for Porous Consolidated Carbonates}

Table 5.4.2-1 presents a matrix of ground-water contaminant mitigative techniques versus feasibility of implementation at porous consolidated carbonates sites. Constraints on feasibility as they relate to this generic site are also briefly summarized in the table.

\subsection{GENERIC SITE: POROUS CONSOLIDATED SILICATE}

\subsubsection{Pre-Mitigative Contaminant Discharge}

\subsubsection{Significant Radionuclide Discharges}

The percentage of sites in this generic hydrogeologic classification where radionuclides are calculated to discharged to a surface water body before 40 half-lives of decay is shown in Figure 5.5.1-1. Strontium-90 and cesium-137 are discharged at $38 \%$ and $31 \%$ of the sites, respectively. Ruthenium-106 decays to insignificant levels for nearly all sites indicating a moderately long average ground-water travel time. The amounts of sorption for the indicator radionuclides are less in a silicate aquifer versus a carbonate aquifer. Therefore, strontium-90 and cesium-137 are not strongly sorbed and are discharged at significant amounts at nearly the same percentage of individual sites. 


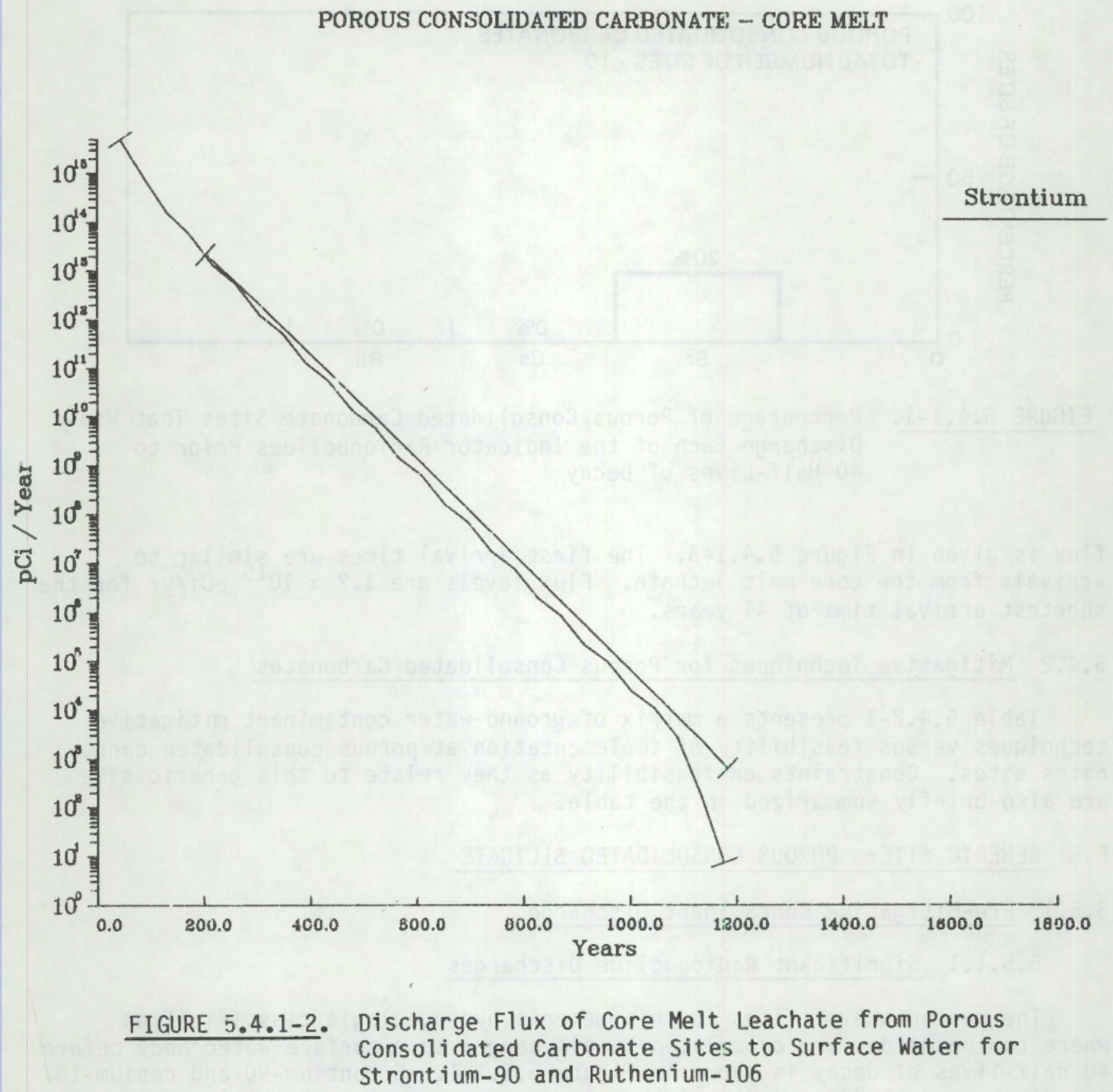




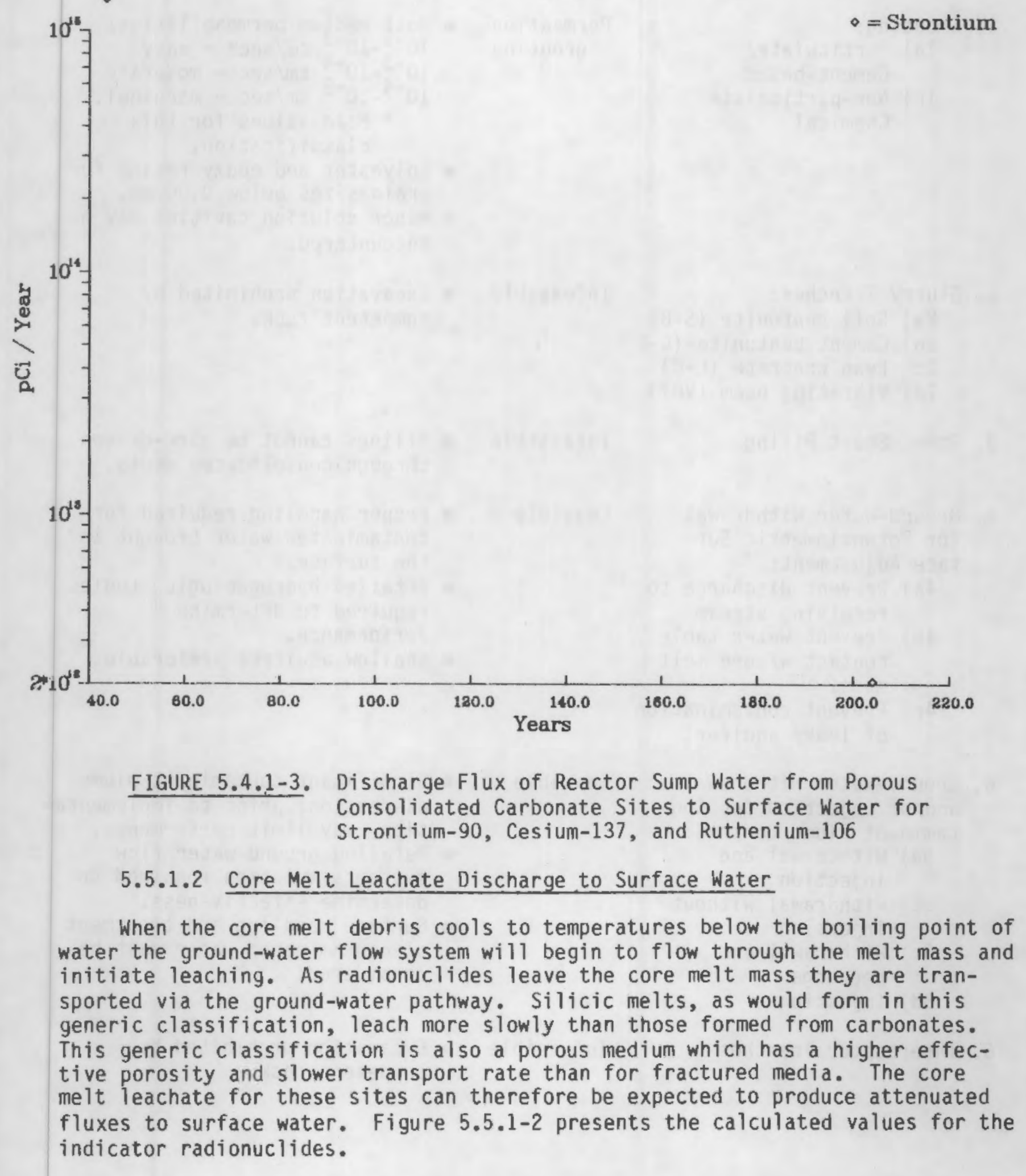


TABLE 5.4.2-1. Mitigative Techniques for Porous Consolidated Carbonates

Mitigative Technique

1. Grouting:

la) Particulate/ Cement-based

1b) Non-particulate/ Chemical
2. Slurry Trenches:

2a) Soil bentonite (S-B)

2b) Cement bentonite ( $C-B)$

2c) Lean concrete ( $L-C)$

2d) Vibrating beam (VBT)

3. Steel Sheet Piling

4. Ground-Water Withdrawal for Potentiometric Surface Adjustment:

4a) Prevent discharge to receiving stream

4b) Prevent water table contact $w /$ core melt mass.

4c) Prevent contamination of leaky aquifer.

5. Ground-Water Withdrawal and/or Injection for Contaminant Plume Control:

5a) Withdrawal and injection

5b) Withdrawal without injection

5c) Withdrawal and recharge

5d) Injection

6. Interceptor Trenches
Feasibility Constraints on Feasibility

Permeation grouting

Infeasible

Infeasible

Feasible

- Proper handling required for

Feasible
- Significant contaminant plume dispersion, prior to implementa- tion, may limit performance.
- Detailed ground-water flow system simulation required to determine effectiveness.
- Surface handling and treatment of contaminated water must be considered.

Infeasible contaminated water brought to the surface.

- Detailed hydrogeologic studies required to determine performance.

- Shallow aquifers preferable.

- Host medium permeabilities: $10^{-1}-10^{-3} \mathrm{~cm} / \mathrm{sec}^{\star}=$ easy $10^{-3}-10^{-4} \mathrm{~cm} / \mathrm{sec}=$ moderate * Mear values for this classification.

- Polyester and epoxy resins for

- Minor solution cavities may be encountered.

Excavation prohibited by through consolidated media.

- Excavation prohibited by competent rock. 


\section{TABLE 5.4.2-1. (contd)}

7. Permeable Treatment Beds Infeasible

8. Ground Freezing

9. Air Injection
Feasible

Marginally feasible
- Excavation prohibited by competent rock.

- Very expensive and energy intensive.

- Thermal erosion may preclude implementation.

- 0.9-1.2 m/day maximum groundwater velocity.

- Surface piping insulation required.

- Host material saturation $>10 \%$.

- Little engineering expertise or implementation experience.

- Saturated conditions required.

- Energy intensive.

- Air bleeding of contaminants.

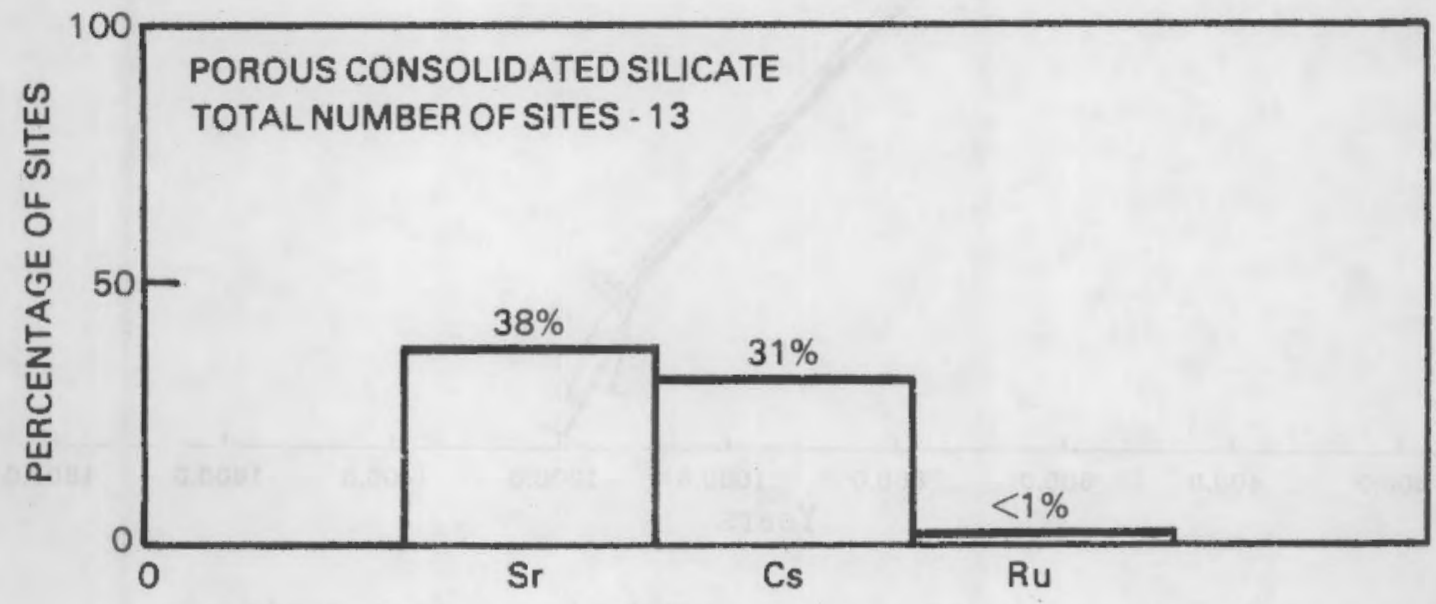

FIGURE 5.5.1-1. Percentage of Porous Consolidated Silicate Sites That Would Discharge Each of the Indicator Radionuclides Prior to $40 \mathrm{Half}$-Lives of Decay 


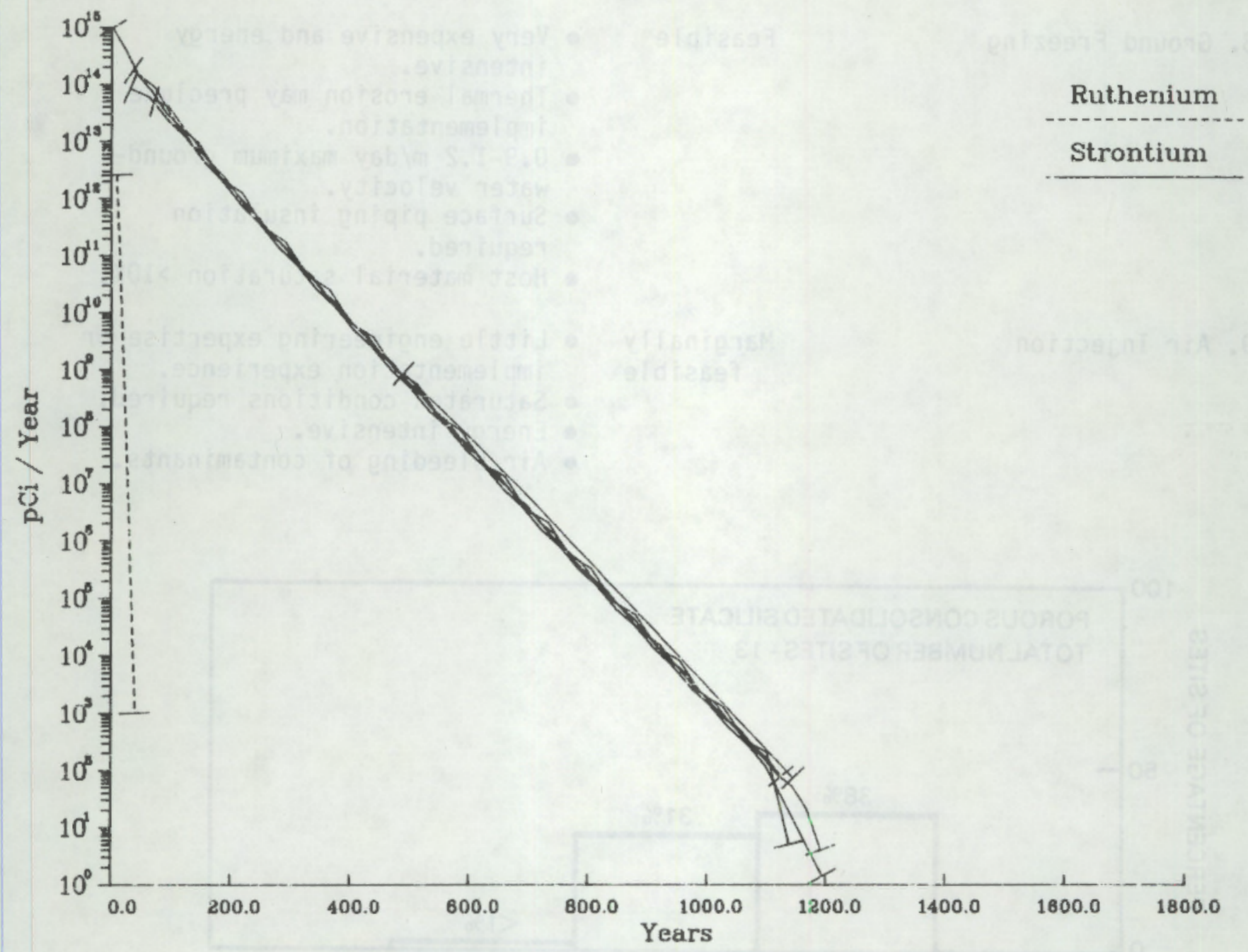

FIGURE 5.5.1-2. Discharge Flux of Core Melt Leachate from Porous Consolidated Silicate Sites to Surface Water for Strontium-90 and Ruthenium-106 


\section{Strontium-90 and Ruthenium-106}

Calculated first discharge of core melt strontium-90 arrives at 2 years after release at a flux level of $1 \times 10^{15} \rho \mathrm{Ci} / \mathrm{yr}$. Three sites are clustered about a first contaminant arrival time of about 50 years at a flux of $8 \times 10^{13}$ $\rho C i / y r$. A single site has a first arrival at 475 years with a corresponding flux of $5 \times 10^{8} \rho \mathrm{Ci} / \mathrm{yr}$.

Ruthenium-106 arrives in signifjçant amounts for only one site. This site is for 9.8 years at a flux of $2 \times 10^{12} \rho \mathrm{Ci} / \mathrm{yr}$.

\subsubsection{Sump Water Discharge to Surface Water}

Liquid release of sump water is possible for pressurized water reactors. The sump water would contain dissolved portions of the melt mass that would enter the ground-water system over a short time span. Flux values for the sump release of the indicator radionuclides are given in Figure 5.5.1-3. Sump water release rates are independent of the chemical composition of the core melt mass.

\section{Stront ium-90}

Strontium-90 is the first radjonuclide to discharge with an arrival time of 2 years at a flux level of $410^{10} \rho \mathrm{Ci} / \mathrm{yr}$. There is a cluster of first contaminant arrivals at about 50 years. The sump water flux for these arrivals is approximately $1 \times 10^{15} \mathrm{pCi} / \mathrm{yr}$ which is one order of magnitude greater than the associated core melt discharge.

\section{Cesium-137}

The highest flux rate in this generic classjfication is for a cesium-137 sump water discharge. The peak level is $8 \times 10^{16} \mathrm{pCi} / \mathrm{yr}$ with a first arrival time of 10 years. The remaining cesium discharges arrive at times greater than 150 years and flux levels less than $2 \times 10^{14} \mathrm{oCi} / \mathrm{yr}$.

\section{Ruthenium-106}

Ruthenium arrives in significant activities at a surface water body for a single site which is also the case for coremelt leachate. The first arrival time is 9.8 years at a flux rate of $3.510^{13} \mathrm{\rho Ci} / \mathrm{yr}$.

\subsubsection{Mitigative Techniques for Porous Consolidated Silicates}

Table 5.5.2-1 presents a matrix of ground-water contaminant mitigative techniques versus feasibility of implementation at porous consolidated silicates sites. Constraints on feasibility as they relate to this generic site are also briefly summarized in the table. 


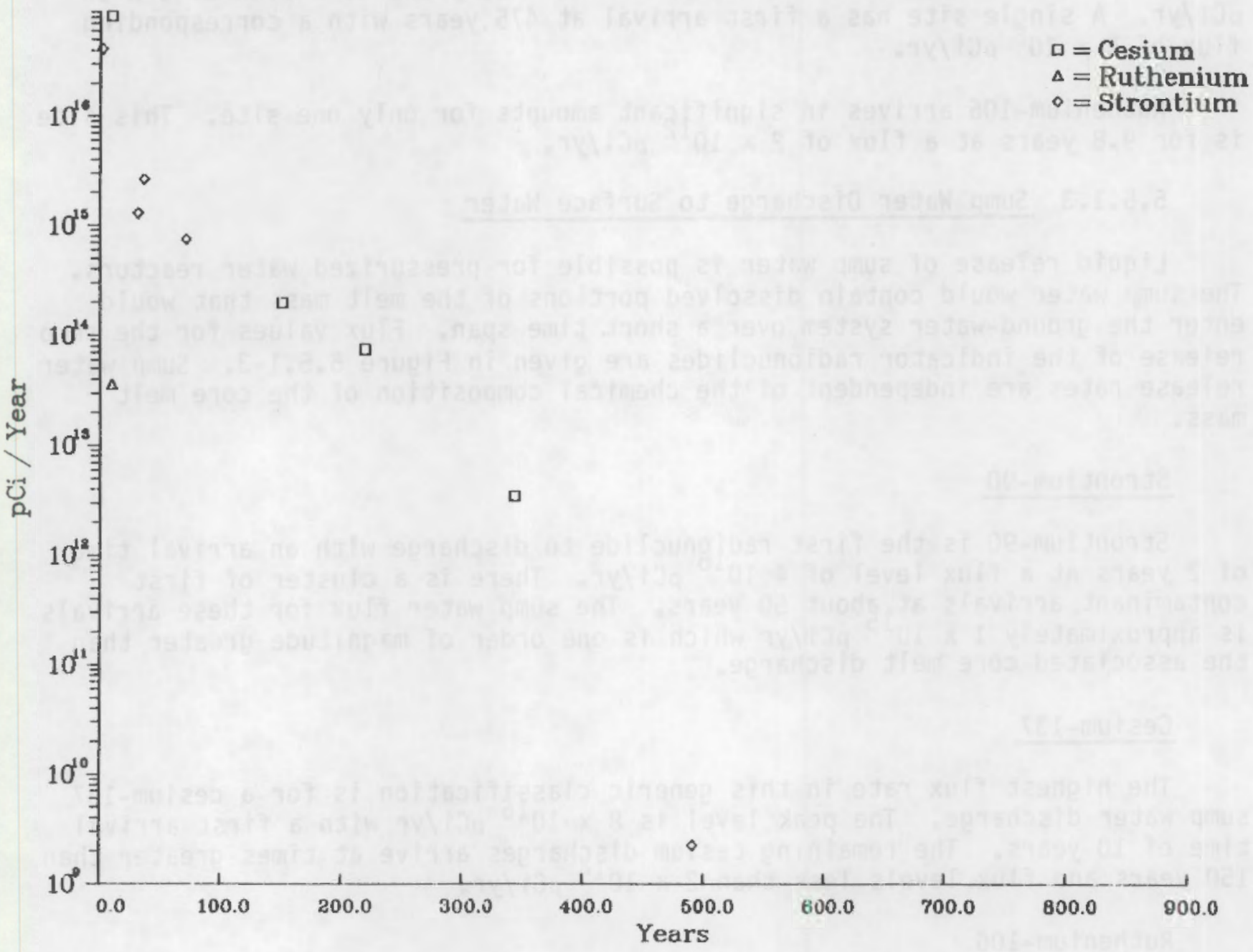

FIGURE 5.5.1-3. Discharge Flux of Reactor Sump Water from Porous Consolidated Silicate Sites to Surface Water for Strontium-90, Cesium-137, and Ruthenium-106 
TABLE 5.5.2-1. Mitigative Techniques for Porous Consolidated Silicates

\section{Mitigative Technique}

1. Grouting:

1a) Particulate/

Cement-based

1b) Non-Particulate/

Chemical
2. Slurry Trenches:

2a) Soil bentonite (S-B)

2b) Cement bentonite ( $C-B)$

2c) Lean concrete $(L-C)$

2d) Vibrating beam (VBT)

3. Steel Sheet Piling

4. Ground-Water Withdrawal for Potentiometric Surface Adjustment:
4a) Prevent discharge to receiving stream.
4b) Prevent water table con- tact $w /$ core melt mass.
4c) Prevent contamination of leaky aquifer.

5. Ground-Water Withdrawal and/or Injection for Contaminant Plume Control:

5a) Withdrawal and injection

5b) Withdrawal without injection

5c) Withdrawal and recharge

5d) Injection

Feasible

Feasible

Feasibility Constraints on Feasibility

Permeation

grouting
Feasibility

limited to

soft,

rippable

competent

rock. VBT

technique is infeasible.
- Host medium permeabilities: $10^{-1}-10^{-3} \mathrm{~cm} / \mathrm{sec}=$ easy, $10^{-3}-10^{-4} \mathrm{~cm} / \mathrm{sec}^{\star}=$ moderate, $10^{-4}-10^{-5} \mathrm{~cm} / \mathrm{sec}=$ marginal,

* Mean values for this classification

- Grain size as low as $0.01 \mathrm{~mm}$ (silt size) can be grouted w/ acrylamide-based grouts.

- Fine granular material as low as $0.10 \mathrm{~mm}$ (fine sand - coarse silt) can be grouted w/lignin grouts.

- Multiple head drills and/or percussion drills can be used to excavate trench in soft, consolidated media.

- Practical limit in consolidated media is $60 \mathrm{~m}$.

- Ground-water velocities less than $5 \mathrm{~cm} / \mathrm{sec}$.

- Host medium permeability greater than $10^{-6} \mathrm{~cm} / \mathrm{sec}$.

Infeasible

- Pilings cannot be hard-driven through consolidated media.

- Proper handling required for contaminated water brought to the surface.

- Filter packing of deep wells may be required.

- Detail hydrogeologic studies required to determine performance.

- Shallow aquifers preferable.

- Significant contaminant plume dispersion, prior to implementation, may limit performance.

- Detailed ground-water flow system simulation required to determine effectiveness.

- Surface handling and treatment of contaminated water must be considered. 
TABLE 5.5.2-1. (contd)

6. Interceptor Trenches

7. Permeable Treatment Beds

8. Ground Freezing

9. Air Injection
Feasibility limited to soft, rippable competent rock.
- Multiple head drills and/or percussion drills can be used to excavate trench in soft consolidated material.

- Significant contaminant plume dispersion, prior to implementation, may limit performance.

- Shallow, water table aquifer required.

- Surface handling and treatment of contaminated water must be considered.

Feasibility limited to soft, rippable competent rock.

- Multiple head drills and/or percussion drills can be used to excavate trench in soft consolidated material.

- Significant contaminant plume dispersion, prior to implementation may limit performance.

- Shallow, water table aquifer preferable.

- Availability of suitable filtration material.

- Proper disposal of spent filtration material.

Feasible

- Very expensive and energy intensive.

- Thermal erosion may preclude implementation.

- 0.9-1.2 $\mathrm{m} /$ day maximum groundwater velocity.

- Surface piping insulation required.

- Host material saturation $>10 \%$.

Marginally feasible
- Little engineering expertise or implementation experience.

- Saturated conditions required.

- Drilling costs may be high.

- Energy intensive.

- Air bleeding of contaminants. 


\subsection{GENERIC SITE: POROUS UNCONSOLIDATED SILICATES}

\section{5:6.1 Pre-Mitigative Contaminant Discharge}

\subsubsection{Significant Radionuclide Discharges}

The percentage of sites where indicator radionuclides are calculated to enter a surface water body prior to 40 half-lives of decay is shown in Figure 5.6.1-1. Strontium-90, cesium-137 and ruthenium-106 would be in the ground-water flow system in significant amounts at $49 \%, 27 \%$ and $5 \%$ of the sites, respectively. About half as many sites have significant cesium-137 discharges as compared to strontium-90 which has a similar half-life. This result is expected since the equilibrium distribution coefficient for cesium-137 is six times greater than strontium-90 in this generic classification. The discharge of ruthenium-106, which has a half-life of 367 days, indicates that $5 \%$ of the sites in this generic classification have short contaminant transport times.

\subsubsection{Core Melt Leachate 0ischarged to Surface Water}

The core melt debris will release radionuclides from a silicic melt at slow rates over long periods of time. The peak value of radionuclide flux is indicated by a line perpendicular to the flux/year curve at the left terminus. The porous unconsolidated silicates classification has the largest number of individual sites and generic trends are readily observable. Figure 5.6.1-2 presents the flux rate with time for the core melt leachate reaching a surface water body at significant levels.

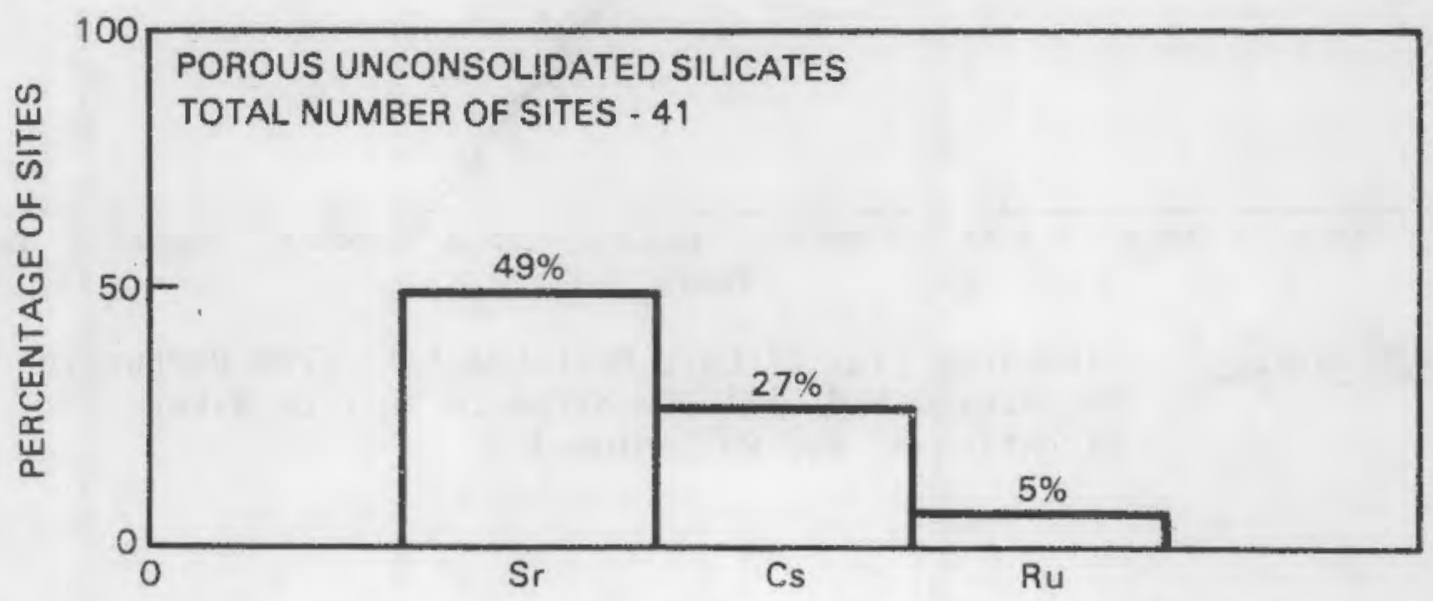

FIGURE 5.6.1-1. Percentage of Porous Unconsolidated Silicate Sites That Would Discharge Each of the Indicator Radionuclides Prior to 40 Half-Lives of Decay 
POROUS UNCONSOLIDATED SILICATE - CORE MELT

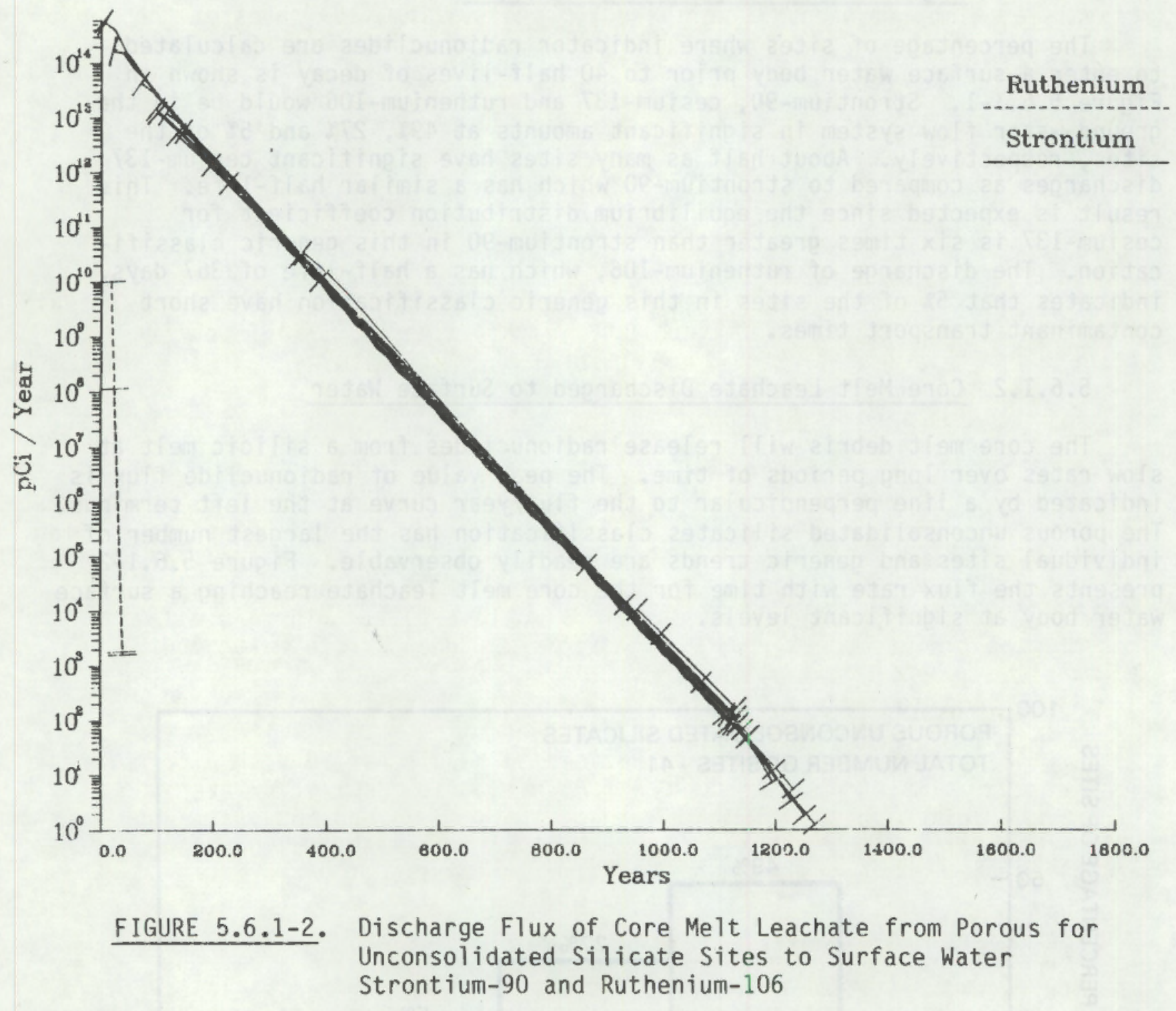




\section{Strontium-90}

The calculated first contaminant arrival time is 4.4 years for two sites. Flux of strontium-90 at $6 \times 10^{14} \rho \mathrm{Ci} / \mathrm{yr}$ for these two sites. Additional discharges are calculated at 25 years with a loose grouping of arrivals at times between 75 years and 250 years. The flux rates of the loose grouping are between $7 \times 10^{12}$ and $1 \times 10^{13} \rho \mathrm{Ci} / \mathrm{yr}$. First arrival of contaminant occurs at about 375 years for three sites and at extreme times of about 950 years for four remaining sites. The flux rates of the radionuclide discharges at times over 375 years are at flux levels less than $1 \times$ $10^{10} \rho \mathrm{Ci} / \mathrm{yr}$.

\section{Ruthenium-106}

The travel times to surface water are sufficiently long to decay ruthenium-106 to insignificant levels for all but two sites. The first arrival of ruthenium contaminant is at 17.6 years with a flux of $1 \times 10^{0} \rho \mathrm{Ci} / \mathrm{yr}$ and the next first arrival time is 25 years at $1 \times 10^{8} \rho \mathrm{Ci} / \mathrm{yr}$.

\subsubsection{Sump Water Discharge to Surface Water}

Sump water can collect in the containment structure during a severe nuclear power plant accident involving a pressurized water reactor. The liquid would be released when the top of the core melt debris cooled below the boiling point of water. Radionuclides contained in the sump water would be released at a rapid rate with high radionuclide concentrations as compared to a leach release. High radionuclide concentrations would result. Figure 5.6.1-3 presents the peak sump water discharge fluxes at the surface water body.

\section{Strontium-90}

Strontium-90 is the first radionuclide to be discharged with a calculated first arrival time of 4.4 years and a flux of $2 \times 10^{16} \mathrm{pCi} / \mathrm{yr}$. Later strontium-90 discharges are loosely grouped between 75 and 250 years with an average flux of $3 \times 10^{13} \mathrm{pCi} / \mathrm{yr}$. The remaining sites exhibit much longer first arrival times and have flux rates below $1 \times 10^{11} \mathrm{pCi} / \mathrm{yr}$.

\section{Cesium-137}

The highest rate for cesium-137 discharges in this generic classification is $2 \times 10^{16}{ }_{0 C \mathrm{i} / \mathrm{yr}}$ occurring at about 24 years. The cesium-137 data do not cluster around a specific time or flux rate.

\section{Ruthenium-106}

The calculated first arrival of ruthenium for this generic classification takes place after that of strontium-90. The contaminant transport time is long enough to decay most of the ruthenium before surface water discharge. The peak ruthenium flux is $1 \times 10^{11} \rho \mathrm{Ci} / \mathrm{yr}$ or about five orders of magnitude less than cesium-137 and strontium-90. 


\section{POROUS UNCONSOLIDATED SILICATE - SUMP WATER}

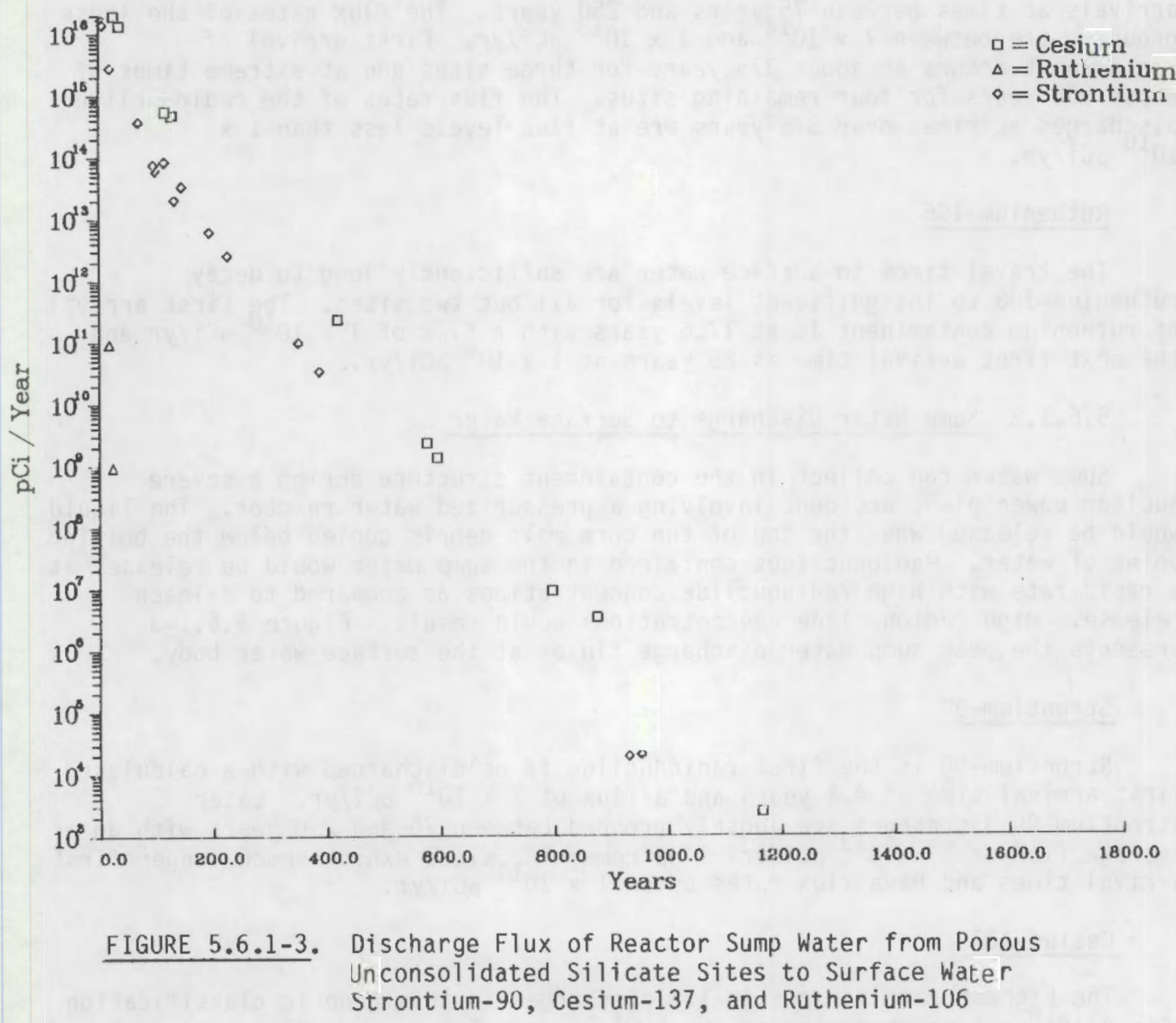

\subsubsection{Mitigative Techniques for Porous Unconsolidated Silicates}

Table 5.6.2-1 presents a matrix of ground-water contaminant mitigative techniques versus feasibility of implementation at porous unconsolidated silicates sites. Constraints on feasibility as they relate to this generic site are also briefly sumarized in the table. 
TABLE 5.6.2-1. Mitigative Techniques for Porous Unconsolidated Silicates

\section{Mitigative Teehnique}

1. Grouting:

1a) Particulate/

Cement-base

2b) Non-particulate/

Chemical

Feasibility
Permeation
grouting
Compaction
grouting

Feasible within depth limitations and with proper key-in integrity.

3. Steel Sheet Piling
2a) Soil bentonite (S-B)
2b) Cement bentonite ( $C-B$ )
2c) Lean concrete ( $L-C)$
2d) Vibrating beam (VBT)

Feasible in
- Host medium permeabilities: $10^{-1}-10^{-3} \mathrm{~cm} / \mathrm{sec}^{\star}=$ easy, $10^{-3}-10^{-4} \mathrm{~cm} / \mathrm{sec}=$ moderate $10^{-4}-10^{-5} \mathrm{~cm} / \mathrm{sec}=$ marginal

* Mean range of values for this classification.

- Grain size as low as $0.01 \mathrm{~mm}$ (silt size) can be grouted w/acrylamide-based grouts.

- Fine granular material as low as $0.10 \mathrm{~mm}$ (fine sand - coarse silt) can be grouted w/lignin grouts.

- Backhoes for excavation to $17 \mathrm{~m}$.

- Oraglines for excavation to $30 \mathrm{~m}$.

- Clamshells for excavation to $85 m$.

- Ground-water velocities less than $5 \mathrm{~cm} / \mathrm{sec}$.

- Soil permeability greater than $10^{-6} \mathrm{~cm} / \mathrm{sec}$.

- VTB method depth limitation is roughly $30 \mathrm{~m}$. Boulders and cobbles may cause limited penetration and/or sealing. loose soils without appreciable cobbles or boulders.
- Difficult to moisture seal piling interlocking systems.

- Must be hard-driven into impervious key-in layer.

- Relatively short (7-40 years) effective life.

- Effect of differential hydrostatic head must be considered. 


\section{TABLE 5.6.2-1. (contd)}

4. Ground-Water Withdrawal for Potentiometric Surface Adjustment:

4a) Prevent discharge to receiving stream

4b) Prevent water table contact $w /$ core melt mass.

4c) Prevent contamination of leaky aquifer

5. Ground-Water Withdrawal and/or Injection for Contaminant Plume Control:

5a) Withdrawal and injection

5b) Withdrawal without injection

5c) Withdrawal and recharge

5d) Injection

6. Interceptor Trenches

7. Permeable Treainent Beds
Feasible

Feasible

- Fine-grained soils with low permeabilities may be prohibitive.

- Proper handling required for contaminated water brought to surface.

- Detailed hydrogeologic studies of complex flow system required to determine effectiveness.

- Significant contaminant plume dispersion, prior to implementation, limit performance.

Feasible

- Shallow, water table aquifer required.

- Significant contaminant plume dispersion, prior to implementation, may limit performance.

- Surface handling and treatment of contaminated water must be considered.

Feasible
- Shallow, water table aquifer preferred.

- Significant contaminant plume dispersion, prior to implementation, may limit performance.

- Availability of suitable filtration material.

- Proper disposal of spent filtration material. 


\section{TABLE 5.6.2-1. (contd)}

8. Ground Freezing Feasible

- Very expensive and energy intensive.

- Thermal erosion may preclude implementation.

- Soil heave may occur in saturated materials.

- 0.9-1.2 m/day maximum groundwater velocity.

- Surface piping insulation required.

- Host material saturation $>10 \%$.

9. Air Injection

Marginally

- Little engineering expertise or

feasible implementation experience.

- Saturated conditions required.

- Energy intensive.

- Air bleeding of contaminants.

\subsection{GENERIC SITE: FRACTURED CONSOLIDATED SILICATES - SHALE}

\subsubsection{Pre-Mitigative Contaminant Discharge}

\subsubsection{Significant Radionuclide Discharge}

The percentage of individual sites that have contaminant travel times to a surface water body of less than 40 half-lives represent the significant radionuclide releases. These values for the indicator radionuclides (i.e., strontium-90, cesium-137 and ruthenium-106) are presented in Figure 5.7.1-1. Strontium-90 and cesium-137 have similar decay rates yet reach the surface water body in significant amounts at $60 \%$ and $20 \%$ percent of the sites, respectively. This is because the equilibrium distribution coefficient of cesium-137 is 33 times greater than that of strontium-90. Consequently, cesium-137 is more strongly retarded. Ruthenium-106 decays to insignificant amounts prior to surface water discharge at all shale sites.

The average travel distance (i.e., 700 meters) is the longest for this generic classification and has a strong influence on the discharge quantities of short-lived radionuclides such as ruthenium-106.

\subsubsection{Core Melt Leachate Discharged to Surface Water}

The core melt debris will slowly release radionuclides to the ground-water flow system as the silicic matrix leaches. The arrival of strontium-90 at the nearest surface water body is presented in Figure 5.7.1-2. The calculated peak flux is $2 \times 10^{14} \mathrm{\rho Ci} / \mathrm{yr}$ at the first arrival time of 32 years. Two other sites which discharge to surface water bodies prior to 40 half-lives of decay have arrival times of 450 and 625 years after initial release. 


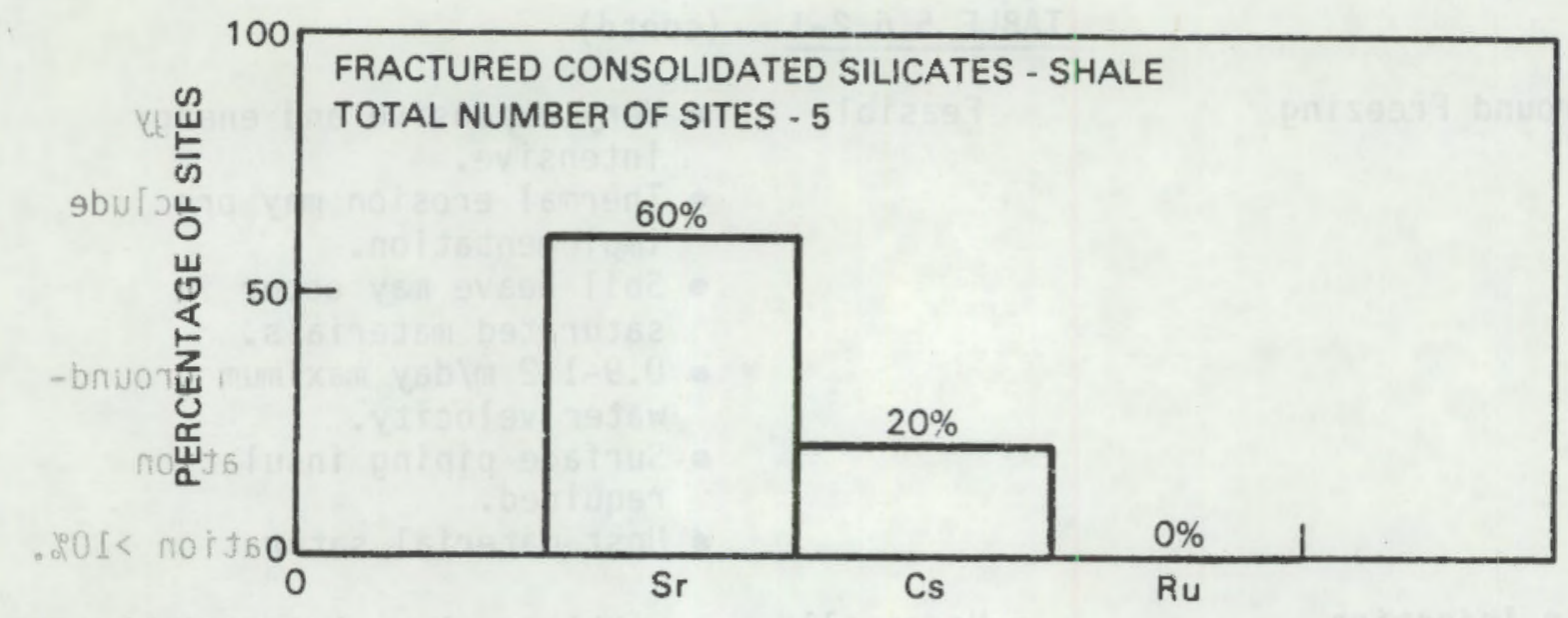

FIGURE $5.7 .1-1$. Percentage of Fractured Consolidated Silicate-Shale Sites

.b97iups7 2no That Would Discharge Each of the Indicator Radionuclides Prior to $40 \mathrm{Half-Lives} \mathrm{of} \mathrm{Decay}$

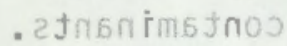

\subsubsection{Sump Water Discharge to Surface Water}

Sump water release is a concern in the event of a core melt accident involving a pressurized water reactor. The liquid used in cooling during the accident could become contaminated with a large percent of the core inventory of certain radionuclides, specifically cesium-137. The sump water release would be much faster than a leach release and would produce a higher activity flux over a shorter period of time (e.g., days to weeks) than the core melt mass.6? The calculated peak sump water discharges are presented in

Figure 5.7.1-3.

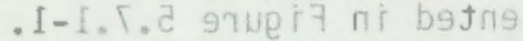

The calculated first arrival time of significant quantities of contaminant would be at 32 yearstafter release for strontium-90. The flux for the first contaminant arrival would be $2 \times 10^{15} \rho \mathrm{Ci} / \mathrm{yr}$. Later arrival times of stgontium-90 far other sites are greater than 450 years and below $1 \times$ $10^{9}$ pCi/yr.eizni of zर6วsb

$$
.52 j i 5
$$

Cesium-137 is more strongly sorbed than strontium-90. Cesium-137 would arrive at the surface water body in significant amounts from only one site. The traved time would be more than 1000 years with a flux of $5 \times 10^{4} \mathrm{pCi} / \mathrm{yr}$.

\subsubsection{Mitigative Techniques for Fractured Shale}

Table 5.7.2-1 presents a matrix of ground-water contaminant mitigation techniques versus feasibility of implementation at shale sites. Constraints on feasibility as they relate to this generic site are also briefly summarized in the table.

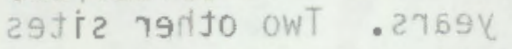

sVbrt k5 


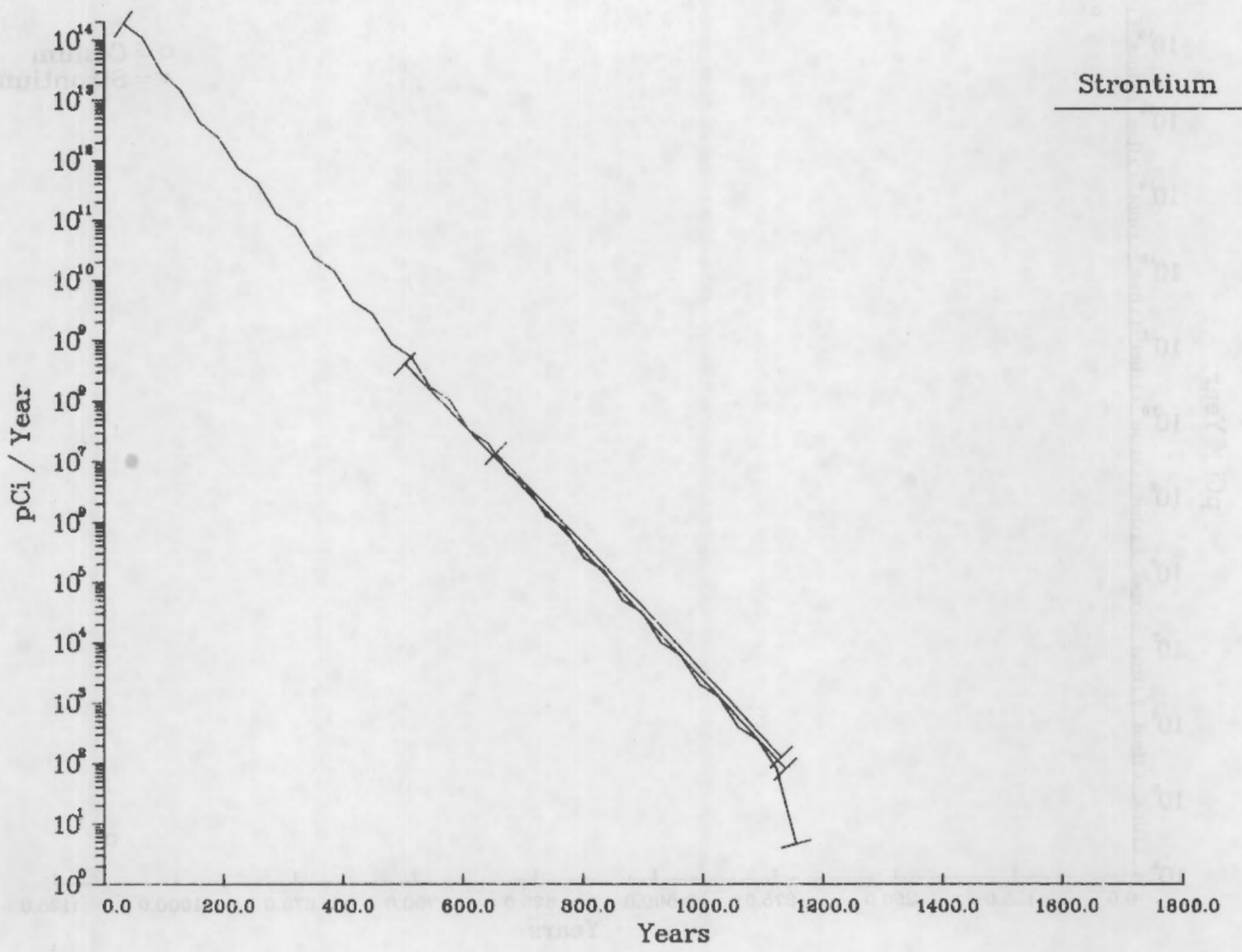

FIGURE 5.7.1-2. Discharge Flux of Core Melt Leachate from Fractured Consolidated Silicate-Shale Sites to Surface Water for Strontium-90 and Ruthenium-106 
FRACTURED COSOLIDATED SILICATE SHALE - SUMP WATER

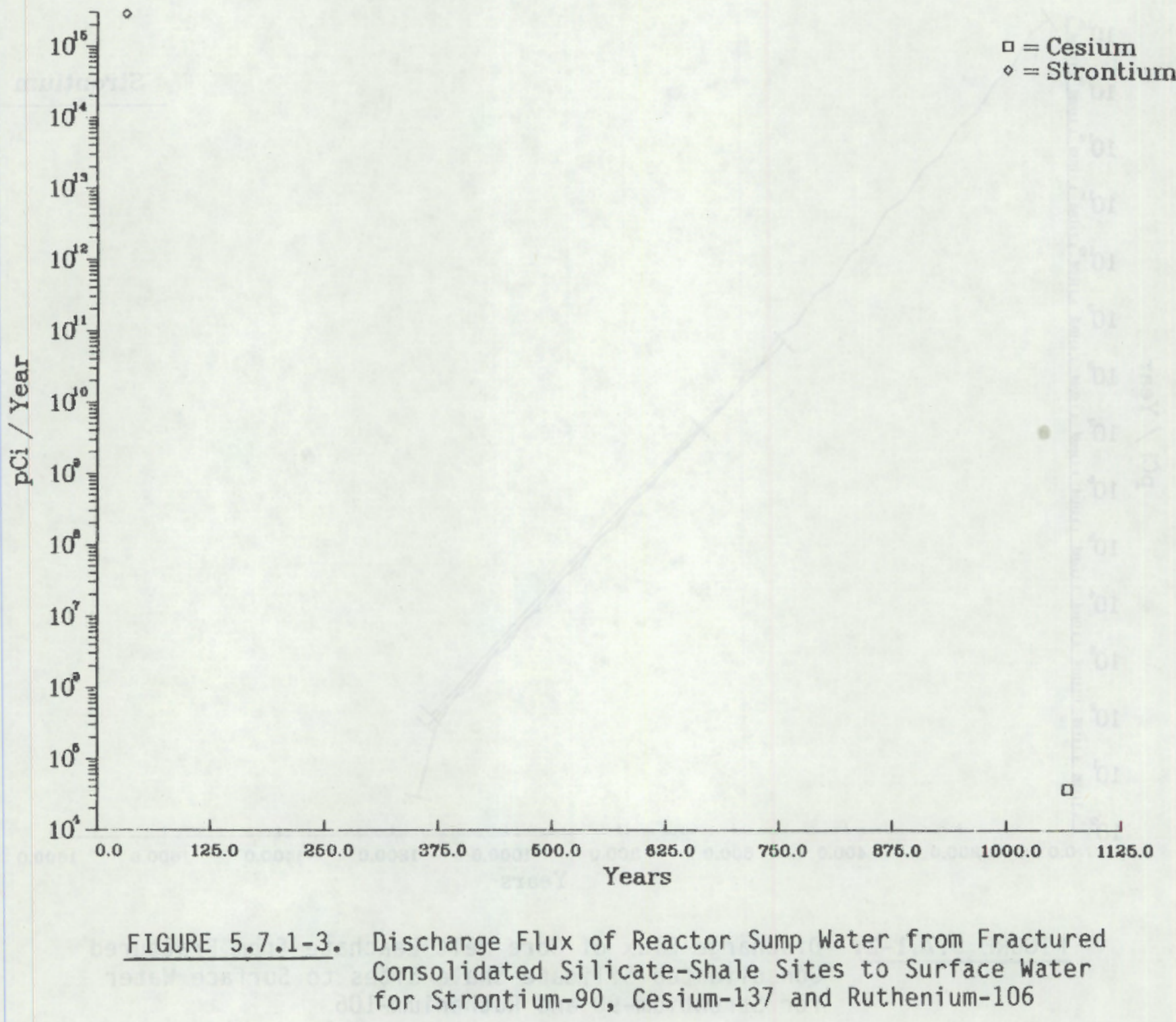




\section{TABLE 5.7.2-1. Mitigative Techniques for Fractured Shale}

Mitigative Technique

1. Grouting:

1a) Particulate/

Cement-based

1b) Non-particulate/ Chemical

2. Slurry Trenches:

2a) Soil bentonite (S-B)

2b) Cement bentonite (C-B)

2c) Lean concrete (L-C)

2d) Vibrating beam (VBT)

3. Steel Sheet Piling

4. Ground-Water Withdrawal for Potentiometric Surface Adjustment:

4a) Prevent discharge to receiving stream

4b) Prevent water table contact $w /$ core melt mass.

4c) Prevent contamination of leaky aquifer
Feasibility

Fissure grouting

Fracture grouting

Infeasible

Infeasible

Marginally feasible
- Joint gaps between $0.5 \mathrm{~mm}$ and $6.0 \mathrm{~mm}$ for cement-based grouts.

- Fissure width up to $10 \mathrm{~cm}$ $15 \mathrm{~cm}$ can be grouted w/acrylamide-based grouts.

- Excavation prohibited by competent rock.
- Pilings cannot be hard-driven through consolidated media.

- Shallow aquifers preferable.

- Definition of fracture system is necessary.

- Detailed hydrogeologic studies required to determine feasibility (i.e., difficulty arises in determining radii of influence of wells in fractured media).

- Ground-water system response may be prohibitively slow due to relatively low hydraulic conductivity.

- Proper handling required for contaminated water brought to the surface. 
TABLE 5.7.2-1. (contd)

5. Ground-Water Withdrawal and/or Injection for Contaminant Plume Control:

5a) Withdrawal and injection

5b) Withdrawal without injection

5c) Withdrawal and recharge

5d) Injection
Feasible

Infeasible

6. Interceptor Trenches

7. Permeable Treatment Beds

8. Ground Freezing

Feasible

9. Air Injection

Infeasible

Marginally
- Definition of fracture system required.

- Ground-water system response may be prohibitively slow due to relatively low hydraulic conductivity.

- Detailed hydrogeologic studies required to determine feasibility.

- Fracture system may enhance performance by concentrating contaminants.

- Proper handling required for contaminated water brought to the surface.

- Excavation prohibited by competent rock.

- Excavation prohibited by competent rock.

- Very expensive and energy intensive.

- Thermal erosion may preclude implementation.

- 0.9-1.2 m/day maximum groundwater velocity.

- Surface piping insulation required.

- Host material saturation $>10 \%$. feasible
- Little engineering expertise or implementation experience.

- Saturated conditions required.

- Energy intensive.

- Air bleeding of contaminants. 


\subsection{COMPARISON OF PRE-MITIGATIVE CONTAMINANT DISCHARGES}

\subsubsection{Significant Discharges to Surface Water Bodies}

Some of the indicator radionuclides are calculated to arrive at the nearest surface water body at insignificant flux rates. The discrimination of these sites is to develop guidelines to which hydrogeologic classifications are sensitive to radioactive discharges and consequently may be of immediate environmental concern. A 40 half-life limit is used to delineate significant radionuclide discharges from those discharges that exhibit very late arrivals with low levels of radioactivity. In all actual severe accidents the site specific pre-mitigative discharge would be determined before deciding upon the necessity and type of mitigation to be implemented. The three radionuclides used as indicators of potential environmental consequences are discussed separately below.

The 28.2 year half-life and low rate of sorbtion of strontium-90 makes it a good environmental indicator since it would not necessarily undergo 40 halflives of decay prior to discharge into a surface water body. The percentage of sites within each generic classification that would exhibit a significant strontium-90 discharge is shown in Figure 5.8.1-1. The hydrogeologic classification numbers are used as a convenience in the figure and are defined in Table 5.8.1-1. Strontium-90 is discharged to surface water prior to 40 halflives at some sites in all generic classifications. 0ischarges are most likely

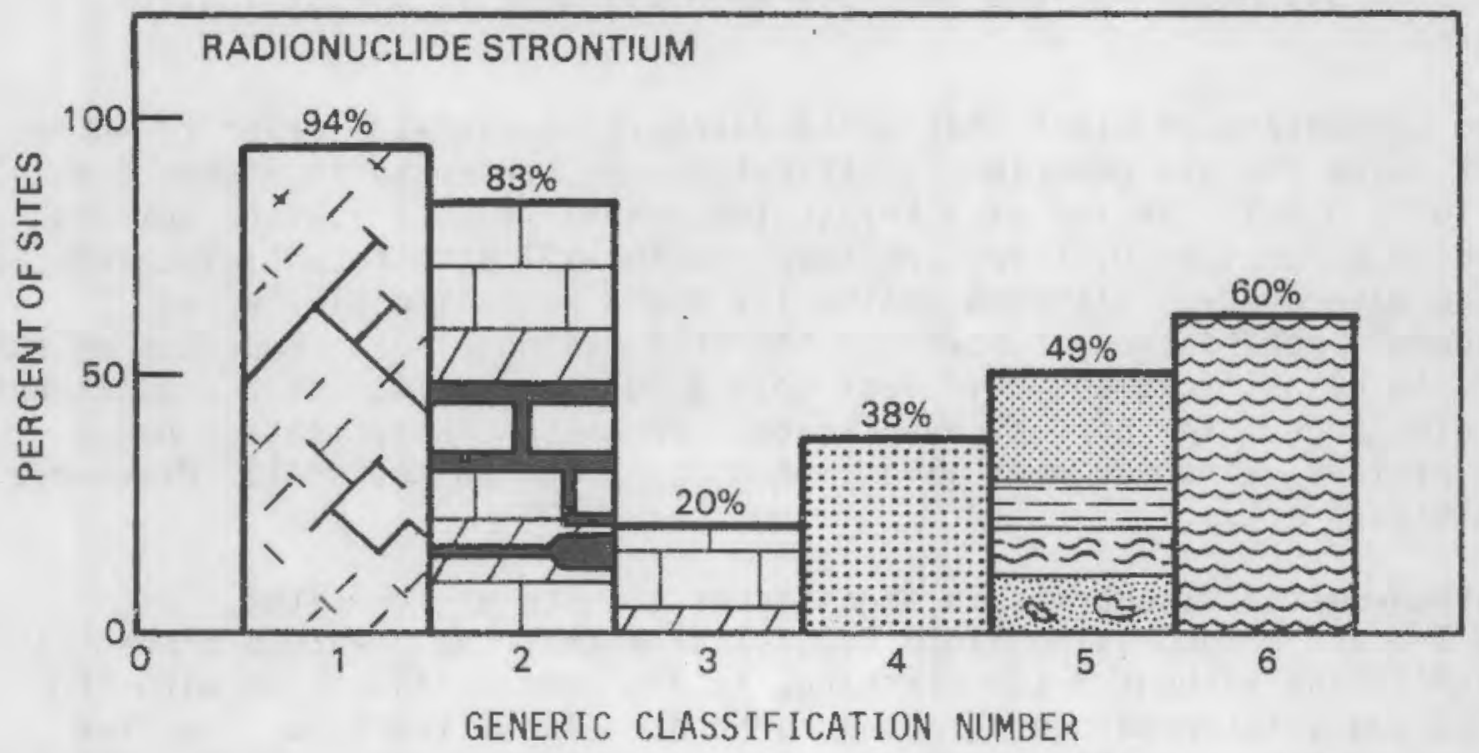

FIGURE 5.8.1-1. Percentage of Nuclear Power Plant Sites in Each Generic Hydrogeologic Classification That Would Discharge Strontium-90 Prior to $40 \mathrm{Half}$-Lives of Decay 
TABLE 5.8.1-1. Generic Classification Numbering Index

Generic Classification

Number As Used in

Figures $5.8 .1-1,2,3$

1

2

3

4

5

6
Generic Classification As Developed in This Report

Fractured Consolidated Silicates-Crystalline

Fractured \& Solutioned Consolidated Carbonates

Porous Consolidated Carbonates

Porous Consolidated Silicates

Porous Unconsolidated Silicates

Fractured Consolidated Silicates - Shale

in fractured consolidated silicates-crystalline (at $94 \%$ of the sites) and fractured and solutioned consolidated carbonates (at $83 \%$ of the sites). Porous geologic materials demonstrate a smaller percentage of significant discharges reaching a minimum of $20 \%$ of the sites in the porous consolidated carbonate classification. The large span of percentages of significant strontium-90 discharges demonstrates that it is a good indicator of the potential for adverse environmental consequences. In three of the six generic classifications significant discharges would occur at an average of less than $35 \%$ of the individual sites. These generic classifications are relatively insensitive to a strontium-90 core melt release. The probability of a significant strontium-90 discharge is less than $50 \%$ when all generic classifications are considered.

The percentage of sites that would discharge cesium-137 prior to 40 halflives of decay for all generic classifications is presented in Figure 5.8.1-2. Again, Table 5.8.1-1 serves as a key to the generic classification numbers. As compared to strontium-90, there are fewer cesium-137 significant discharges to a surface water body. Although cesium-137 has a half-life similar to strontium-9D, retardation is stronger for this radionuclide. Four out of the six generic classifications have less than a $50 \%$ probability of a significant cesium discharge. The porous consolidated carbonate classification has a minimum of 1209 years (40 half lives) of decay prior to cesium-137 discharge at all individual sites.

Ruthenium-106 discharges in significant amounts at few sites. Figure 5.8.1-3 and accompanying Table 5.8.1-1 show that the greatest probability of a significant ruthenium-106 discharge is $33 \%$ and is associated with the fractured and solutioned consolidated carbonate classification. The five remaining generic classifications have significant discharges at $5 \%$ or less of the sites. Clearly, ruthenium-106 is decayed to low levels at most sites while still in the ground-water system. Consequently, ruthenium is not the primary radionuclide of concern at the point of discharge in any generic classification. 


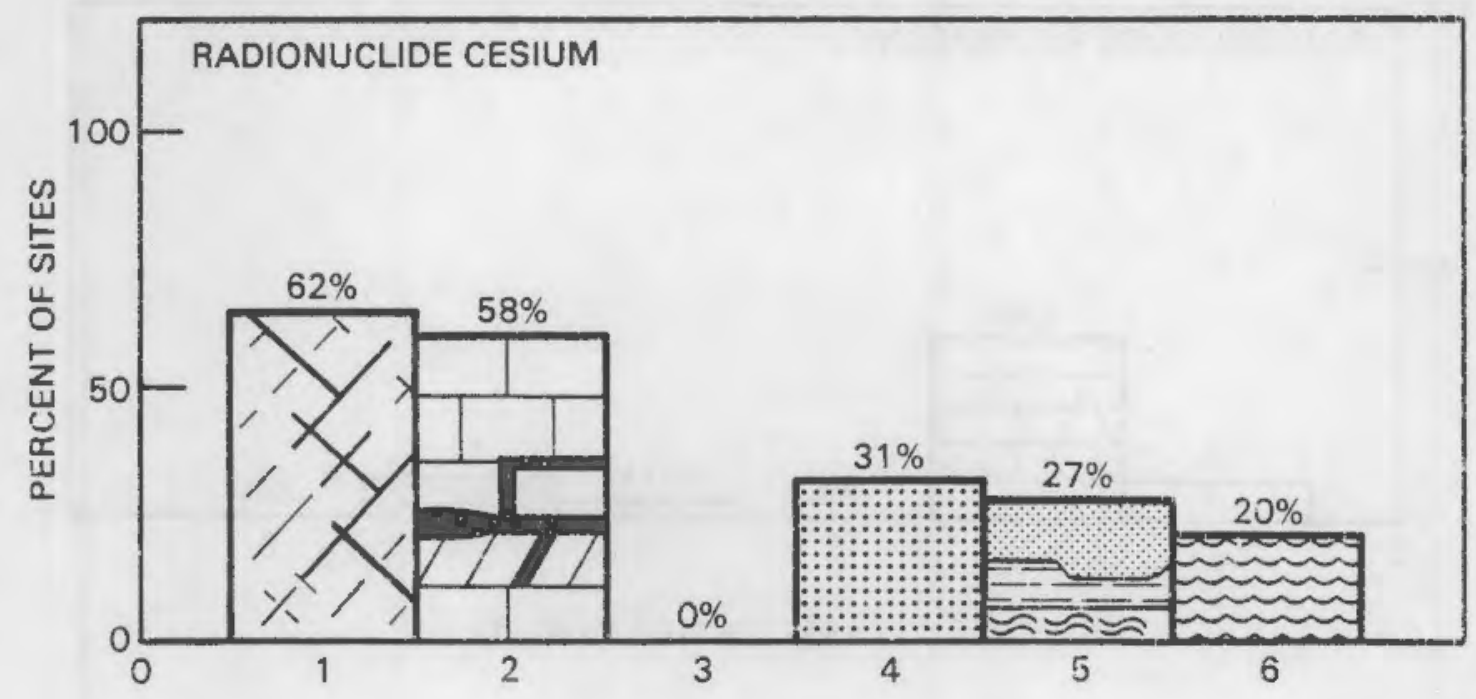

GENERIC CLASSIFICATION NUMBER

FIGURE 5.8.1-2. Percentage of Nuclear Power Plant Sites in Each Generic Hydrogeologic Classification That Would Discharge Cesium-137 Prior to 40 Half-Lives of Decay

The percentage of significant discharges can also be used to rank the generic sites according to the probability that a severe nuclear accident will require mitigative action. For this analysis it was assumed that if any of the indicator radionuclides reached a surface water body in significant amounts, then mitigation would be required. In actuality some sites having a calculated significant discharge would not need mitigation due to site specific characteristics. The dilution factor of the receiving water body, precise contaminant outflow flux and location, or contaminant (i.e., strontium-90) chemically replacing calcite could be important factors in determining the need for mitigation. Therefore, assuming mitigation is required for any discharge above a conservatively defined level of significance is pessimistic. The sensitivity of a generic classification to a core melt accident was determined in this manner. The results are presented in Table 5.8.1-2.

The ranking of generic classifications based on the percent of sites with significant surface water discharges conforms to the basic concepts of contaminant ground-water hydrology. Fractured geologic materials are about twice as likely to have significant radionuclide discharges as their porous counterparts.

These percentages indicate that even under a conservative definition of a significant discharge, $43 \%$ of all nuclear power plant sites fail to produce prominent radionuclide fluxes after a simulated core melt accident. Fractured ground-water systems are more sensitive than porous flow systems. Fractured rock can be expected to produce significant discharges to surface water at $85 \%$ 


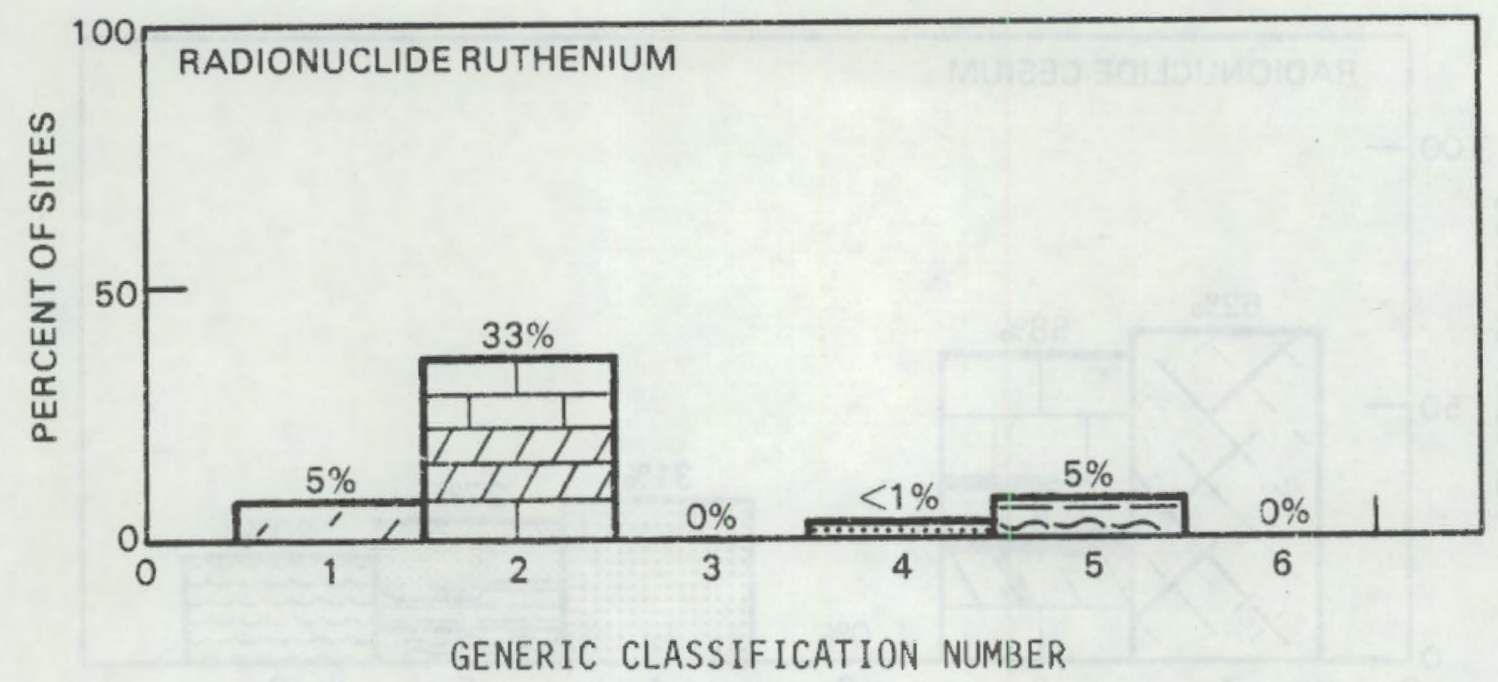

FIGURE 5.8.1-3. Percentage of Nuclear Power Plant Sites in Each Generic Hydrogeologic Classification That Would Discharge Ruthenium-106 Prior to 40 Half-Lives of Decay

TABLE 5.8.1-2. Generic Sensitivity to a Severe Nuclear Accident

\begin{tabular}{|c|c|c|c|}
\hline Rank & Generic Classification & $\begin{array}{c}\text { Percent of Sites } \\
\text { with Significant } \\
\text { Surface Water } \\
\text { Discharges* }\end{array}$ & $\begin{array}{l}\text { Number of Sites } \\
\text { in Generic } \\
\text { Classification }\end{array}$ \\
\hline 1 & $\begin{array}{l}\text { Fractured Consolidated Silicates- } \\
\text { Crystalline }\end{array}$ & $94 \%$ & 16 \\
\hline 2 & $\begin{array}{l}\text { Fractured \& Solutioned Consoli- } \\
\text { dated Carbonates }\end{array}$ & $83 \%$ & 12 \\
\hline 3 & $\begin{array}{l}\text { Fractured Consolidated Silicate- } \\
\text { Shale }\end{array}$ & $60 \%$ & 5 \\
\hline 4 & Porous Unconsolidated Silicates & $49 \%$ & 41 \\
\hline 5 & Porous Consolidated Silicates & $38 \%$ & 13 \\
\hline 6 & Porous Consolidated Carbonates & $20 \%$ & 10 \\
\hline
\end{tabular}

* All three indicator radionuclides considered. 
of the sites. Porous ground-water systems can be expected to produce significant radionuclide discharges at only $42 \%$ of the nuclear power plant sites comprising the porous classifications.

\subsubsection{Core Melt Leachate Discharges to Surface Water}

Variations in the hydrogeologic conditions upon which the generic classifications are based result in large scale differences in contaminant discharges at individual sites. There is a wide range of possible first arrival times and radionuclide activity fluxes even within a single generic classification. Comparison of representative results of extreme values and data trends gives a basis of evaluation of the environmental sensitivity of the generic classifications.

Table 5.8.2-1 presents a summary of core melt leachate entering surface water from each generic classification. The shortest time of first contaminant arrival within each classification is shown in Column 2. The time of first contaminant arrival at the surface water body under the assumptions of the transport analysis is the same for sump water and core debris leachate. The arrival times are in relation to the initiation of contaminant transport, and not the accident. The first contaminant arrival times are the data extremes and hence reflect the worst case in each generic classification. The first arrival times have a constrained range with regard to the wide variations of hydraulic parameters. Generally, the fractured flow systems have the shortest first arrival time of contaminant except for fractured shale media. Porous ground-water flow systems have a first arrival time of about a half an order of magnitude longer than the fractured generic classifications except for shale media as noted above. The data extremes for first contaminant arrivals indicate that this parameter is not strongly generically correlated and may be more of a site specific characteristic. The first arrival time of contaminant by generic classification does show that a minimum contaminant travel time from the core melt to a surface water body is on the order of several months for all power plant sites.

The radionuclide activities flux associated with the first arrival times is shown in Column 3 of Table 5.8.2-1. The flux values show a relationship to generic classification. Strontium-90 is, of the two core melt radionuclides of interest, a better indicator than ruthenium-106 generic characteristics. The flux is much less dependent upon travel time. The analysis of core melt leachate is based on strontium-90 because of its longer half-life. There are two major factors beyond aquifer hydraulics that determine peak flux rate: 1) the leach release rate which is largely a function of rock chemistry 2) and the amount of retardation due to sorption. When these factors favor release and transport simultaneously, as in the case of the fractured and solutioned consolidated carbonate classification, the flux discharge is at its maximum. For this classifjcation strontium-90 and ruthenium-106 have peak discharge fluxes of $1 \times 10^{1 /}$ and $2 \times 10^{10} \rho \mathrm{Ci} / \mathrm{yr}$, respectively.

The generic classification fractured and solutioned carbonates has the maximum flux as expected in consideration of the initial conditions. However, the second greatest flux values for this generic classification are also 
TABLE 5.8.2-1. Summary of Pre-Mitigative Core Melt Discharges to Surface Water

\begin{tabular}{|c|c|c|c|c|c|c|}
\hline $\begin{array}{c}\text { (1) } \\
\text { Generic } \\
\text { Classification } \\
\end{array}$ & $\begin{array}{c}\text { (2) } \\
\text { Time of First } \\
\text { Contapijant } \\
\text { Arrival }(\mathrm{a})(\mathrm{yr}) \\
\end{array}$ & $\begin{array}{c}\text { (3) } \\
\text { Peak } \\
\text { Activity } \\
\text { Flux } \\
(\rho \mathrm{Ci} / \mathrm{yr}) \\
\end{array}$ & 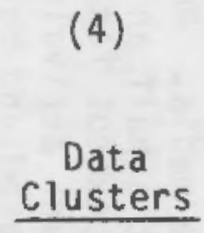 & $\begin{array}{c}(5) \\
\text { Time of } \\
\text { Clustered } \\
\text { Contaminant } \\
\text { Arrival }(y) \text { (yr) } \\
\end{array}$ & $\begin{array}{l}\quad(6) \\
\text { Clustered } \\
\text { Activity } \\
\text { Flux } \\
(\rho \mathrm{Ci} / \mathrm{yr}) \\
\end{array}$ & Radionuclide \\
\hline $\begin{array}{l}\text { Fractured Con- } \\
\text { solidated } \\
\text { Silicates- } \\
\text { Crystalline }\end{array}$ & $\begin{array}{l}0.9 \\
4.6\end{array}$ & $\begin{array}{l}1 \times 10^{15} \\
1 \times 10^{14}\end{array}$ & $\begin{array}{l}\text { Yes } \\
\text { No }\end{array}$ & 10 & $\begin{array}{l}2 \times 10^{14} \\
--\end{array}$ & $\begin{array}{c}90 \mathrm{Sr} \\
106 \mathrm{Ru}\end{array}$ \\
\hline $\begin{array}{l}\text { Fractured and } \\
\text { Solutioned } \\
\text { Consolidated } \\
\text { Carbonates }\end{array}$ & $\begin{array}{l}0.6 \\
2.2\end{array}$ & $\begin{array}{l}1 \times 10^{17} \\
2 \times 10^{16}\end{array}$ & $\begin{array}{l}\text { Y\&es } \\
\text { No }\end{array}$ & $\begin{array}{r}5 \\
--\end{array}$ & $\begin{array}{l}3 \times 10^{16} \\
\ldots\end{array}$ & $\begin{array}{l}{ }^{90} \mathrm{Sr} \\
106_{\mathrm{Ru}}\end{array}$ \\
\hline $\begin{array}{l}\text { Porous } \\
\text { Consolidated } \\
\text { Carbonates }\end{array}$ & $\begin{array}{r}44.0 \\
>40.0\end{array}$ & $4 \times 10^{15}$ & Minor & $\begin{array}{c}<200 \\
--\end{array}$ & $\begin{array}{l}>2 \times 10^{13} \\
-\end{array}$ & $\begin{array}{l}{ }^{90} \mathrm{Sr} \\
{ }^{106} \mathrm{Ru}\end{array}$ \\
\hline $\begin{array}{l}\text { Porous } \\
\text { Consolidated } \\
\text { Silicate }\end{array}$ & $\begin{array}{l}2.0 \\
9.8\end{array}$ & $\begin{array}{l}1 \times 10^{15} \\
3 \times 10^{12}\end{array}$ & $\begin{array}{l}\text { Yes } \\
\text { No }\end{array}$ & 50 & $8 \times 10^{13}$ & $\begin{array}{l}{ }^{90} \mathrm{Sr} \\
106 \mathrm{Ru}\end{array}$ \\
\hline $\begin{array}{l}\text { Porous } \\
\text { Unconsolidated } \\
\text { Silicate }\end{array}$ & $\begin{array}{r}4.4 \\
17.6\end{array}$ & $\begin{array}{l}6 \times 10^{14} \\
1 \times 10^{10}\end{array}$ & Yes & 125 & $5 \times 10^{12}$ & $\begin{array}{l}{ }^{90} \mathrm{Sr} \\
106_{\mathrm{Ru}}\end{array}$ \\
\hline $\begin{array}{l}\text { Fractured } \\
\text { Consolidated } \\
\text { Silicate-Shale }\end{array}$ & $\begin{array}{r}32.0 \\
>40.0\end{array}$ & $2 \times 10^{14}$ & No & -- & - & $\begin{array}{l}{ }^{90} \mathrm{Sr} \\
106_{\mathrm{Ru}}\end{array}$ \\
\hline
\end{tabular}

(a) Times are given from time of release which is assumed to be 1 year after the accident. 
important because they determine what transient feature is more sensitive to a nuclear release; fracture hydraulics or the chemically controlled leach rate? Fractured flow systems have the shortest transport times and carbonate rock types have high leachate rates. Comparison of peak strontium-90 flux values for fractured consolidated crystalline silicates and porous consolidated carbonate classifications shows that the latter has about four times greater flux. This occurs despite of the much longer time to first contaminant arrival for porous consolidated carbonates. The lowest peak flux values are observed in the fractured consolidated silicate-shale classification. Here the effects of a slow silicic leach rate and a long transport time to the surface water body become evjgent. The peak strontiuim-90 flux for this generic classification is $2 \times 10^{14} \rho \mathrm{Ci} / \mathrm{yr}$ and 2.5 is orders of magnitude less than the maximum observed flux.

Generic trends are noteworthy because they indicate the credible characteristics of a significant discharge. The generically characteristic values of arrival time and flux are given in Columns 4 and 5 of Table 5.7.1-3. Again, the time and flux relationships for generic classification are similar to those observed in the first arrival time-peak flux analysis. Ruthenium-106 decay is too rapid for it to be used as an indicator radionuclide at these long travel times of 5 to 125 years. The first arrival activity flux of ruthenium falls quickly with time making data clustering unlikely. In addition, not all generic classifications exhibit data clustering or trends other than that caused by radioactive decay. Data clusters are defined as grouped site arrival times and discharge fluxes. However, the clustering does not always include the majority of sites in a generic classification. Hence the clustered data values do not represent the most likely values. For distribution of times and flux values in a generic classification the reader should consult the individual generic discharge descriptions. Fractured geologic materials except for shale media tend to have characteristic first arrival times of about 5 to 10 years after release. Porous flow systems have much longer characteristic first contaminant arrival times of 50 to greater than 200 years.

Shale is a special case although not one of yreat concern. The long time of contaminant transport in shale coupled with the lack of sites in this classification prevent any observable trends to contaminant discharges. It was concluded that discharge of core melt leachate from shale media will be at long times and at low activity levels. In all generic classifications the clustered arrival times are sufficient to construct mitigative barriers.

The clustered activity fluxes of strontium-90 are presented in Table 5.8.2-1, Column 5. The early contaminant arrivals for the fractured consolidated crystalline silicates and fractured consolidated carbonates produce the highest flux values of $2 \times 10^{14}$ and $3 \times 10^{16} \rho \mathrm{Ci} / \mathrm{yr}$, respectively. Contaminant flustered arrivals 50 years after the release flux values are less than $8 \times 10^{13} \mathrm{\rho Ci} / \mathrm{yr}$ and generic distinctions are not clear. 


\subsubsection{Sump Water Discharges to Surface Water}

A sump water releaswe would contain the remainaing fractions of strontium-90 and ruthenium-106, not incorporated in the core melt mass. The entire inventory of cesium-137 is also assumed to be included in a sump water release. A comparison of first arrival times and peak discharge fluxes is given in Table 5.8.3-1. The first arrival times for strontium-90 and ruthenium-106 are the same as for the core melt release. Cesium-137 is retarded equal to or greater than ruthenium-106 and thus is never the first radionuclide to be discharged into surface water. The analysis of first arrival times of strontium-90 and ruthenium-106 is presented in Section 5.8.2.

of the two types of radionuclide releases following a core melt accident, sump water has the potential of creating the highest activity flux into the accessible environment. The flux rate is dependent upon rate of liquid release (which is a function of pressure head and melt debris permeability) and the travel time to a surface water body. Column 2 of Table 5.8.3-1 gives the maximum activity flux calculated for each generic classification. When travel times are short, cesium-137 has flux rates above the other indicator radionuclides rheaching a peak value of $2.5 \times 10^{1} \mathrm{\rho Ci} / \mathrm{yr}$ in fractured and solutioned consolidated carbonates. In porous ground-water systems, higher rate of sorption for cesium-137 results in discharge activities comparable to that of strontium despite the much larger initial release of cesium-137. Fractured shale media is a special case where cesium-137 is highly sorbed and discharge fluxes are about 11 orders of magnitude less than the other generic classifications. Carbonate also is a sorptive environment for cesium-137 and in the porous classification the first arrival time is long and peak flux is low. The range of significant cesium-137 is somewhat constrained in that there are only a 2.5 orders of magnitude of variation.

Strontium-90 peak fluxes are also relatively high in sump water discharges. Strontium-90 is less sorbed than cesiuim-137 and arrives at the discharge location earlier, thus preserving a high flux rate from the time effects of radioactive decay. The range of peak strontium-90 flux values is $1 \times 10^{15}$ to $2 \times 10^{17} \rho \mathrm{Ci} /$ year yielding about the same range as cesium-137.

Ruthenium-106 (which has the greatest initial release of activity) arrives at the discharge location decayed to flux levels of $2 \times 10^{16}$ to $1 \times$

$10^{11} \mathrm{pCi} /$ year. Fractured shale and porous consolidated carbonates classifications discharge ruthenium-106 at long times and at insignificant levels. In all classifications rutheniuim-106 is discharged to the surface water body at fluxes at least one order of magnitude less than strontium-90 and cesium-137.

First arrival time and peak flux data clusters are given in Columns 4 and 5 of Table 5.8.3-1. The clustered times for strontium-90 are the same as in Section 5.8.2. Strontium-90 characteristics discharge occur in silicates (where sorption is less) and in fractured carbonates (where contaminant transport is more rapid). The characteristic strontium-90 sump water discharge flux levels are one to three orders of magnitude less than the peak flux 
TABLE 5.8.3-1. Summary of Pre-Mitigative Sump Water Discharges to Surface Water

(1)

(2)

Time of First

Time of First Activity
Contaminant

Generic Classification

G

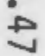

(3)

$$
\text { Peak }
$$

Flux

$1 \times 10^{13}$

$1 \times 10^{15}$
Fractured Con-

solidated

Silicates

Crystalline

Fractured and

Solutioned

Consolidated

0.9

18.4

4.6

$$
\begin{aligned}
& 0.6 \\
& 2.6 \\
& 2.2
\end{aligned}
$$

\section{Porous \\ Consolidated}

Carbonates

\section{Porous \\ Consolidated \\ Silicate}

\section{Porous}

Unconsolidated

Silicate

\section{Fractured}

Consolidated

Silicate-Shale

$>44$
$>520$

$>40$

2.0

9.8

9.8

4.4

26.4

17.6

1066

$>40$ $(\rho \mathrm{Ci} / \mathrm{yr})$

$$
\begin{aligned}
& 6 \times 10^{16} \\
& 1 \times 10^{17}
\end{aligned}
$$

(4)

(5)

Time of

Clustered

\begin{tabular}{|c|c|c|c|}
\hline isters & $\Rightarrow(y)$ & & \\
\hline Yes & 10 & $4 \times 10^{15}$ & ${ }^{90} \mathrm{Sr}$ \\
\hline $\begin{array}{l}\text { No } \\
\text { No }\end{array}$ & $\begin{array}{l}-- \\
--\end{array}$ & -- & $\begin{array}{l}137 \mathrm{Cs} \\
106_{\mathrm{Ru}}\end{array}$ \\
\hline
\end{tabular}

(6)

Clustered

(7)

Data Contamipant Flux

Activity

$$
\begin{array}{r}
2 \times 10^{17} \\
2.5 \times 10^{17} \\
2 \times 10^{16}
\end{array}
$$

Minor
No
No

$<150$

--

No

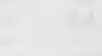

$-$

--

$4 \times 10^{16}$

$8 \times 10^{16}$

Yes

Minor

No

$-$

$2 \times 10^{16}$

$2 \times 10^{16}$

$1 \times 10^{11}$

Yes
No

No

$3 \times 1015$

$4 \times 10^{4}$

No

No

No

$>1 \times 10^{13}$

$--$

$-$

$-$

$-$

$--$

$1 \times 10^{15}$
$5 \times 10^{13}$

$--$

$\begin{array}{lr}5 \times 10^{13} & 90 \mathrm{Sr} \\ -- & 137_{\mathrm{CS}}^{\mathrm{CS}} \\ -- & 10 \mathrm{Ru}_{\mathrm{Ru}}\end{array}$

$$
\begin{array}{r}
{ }^{90} \mathrm{Sr} \\
137 \mathrm{Cs} \\
106 \mathrm{Ru}
\end{array}
$$

(a) Times are given from time of release which is assumed to be 6 months after accident. 
rates. Ruthenium-106 decays at a rapid rate and the discharges cananot be generically characterized. Cesium-137 is retarded by sorption to the extent that this radionuclide also fails to show generic clustering except for porous consolidated silicates. For this classification the generic clustering occurs at 225 years after release and produces a moderate flux rate of $5 \times$ $10^{13} \rho \mathrm{Ci} / \mathrm{yr}$.

\subsection{CONCLUSIONS FOR PRE-MITIGATIVE CONTAMINANT DISCHARGES}

- The lack of clear generic trends in some classifications indicates that there are wide ranges in site specific parameters that outweigh the importance of the geologic transport media. In these cases the key generic trend is indicated by the percentage of sites with significant releases prior to 40 half-lives of decay.

- Generic characteristics that affect the severity of a core melt accident can be ranked in descending importance and are: 1) bedrock chemical type, 2) porosity type (i.e., interstitial or fracture), 3) sorption, and 4) aquifer hydraulics.

- Strontium-90 would be first of the indicator radionuclides to arrive at the discharge location. Cesium-137 which has an initially large sump water release would arrive at a slightly later time at flux levels very close to that of strontium-90. Ruthenium-106 arrives at longer times and lower activity flux than either strontium-90 and cesium-137.

- Strontium-90 is a better indicator of accident severity due to its longer half-life. Ruthenium-106 is decayed to flux levels 1 to 4.6 orders of magnitude less than strontium-90 prior to discharge.

- The time over which the radionuclides in a sump water release would be discharged into the accessible environment is on the order of weeks or months whereas core melt leachate would be discharged for hundreds of years.

- Fractured flow systems are more likely than porous flow systems to discharge contaminant at early times. The shortest arrival time of leachate in fractured silicates and carbonates is between 0.5 and 1.0 years. Shale media is an exception where first arrival times from leachate are on the order of decades.

- Porous flow systems have first arrival times of between 2.0 and 44 years after leach release. The average value is about 15 years which indicates there will be time to implement mitigative measures if needed.

- Carbonate aquifers are more sensitive to a core melt accident than a silicic aquifer. The leachate discharge flux to surface water for carbonates is expected to be 100 times greater than in fractured silicate aquifers and about 4 times greater than in porous silicate 
aquifers. The porous consolidated carbonate classification has a generic characteristic of long contaminant travel times preventing high flux values.

- The release of sump water to a ground-water flow system can create higher flux rates than core melt leaching. The peak discharge rates are about one order of magnitude greater than for coremelt leachate.

- Generic characteristics of sump water releases are best observed in first contaminant arrival times and peak flux values. Clustering of times and fluxes is seen clearly only for the strontium-90 discharges. Ruthenium decays at a rapid rate and cesium is most strongly sorbed making generic trends difficult to discern.

- The maximum flux rates due to sump water releases are for fractured consolidated crystalline silicates and solutioned carbonates are on the order of $1 \times 10^{17} \rho \mathrm{Ci} / \mathrm{yr}$. Minimum arrival times occur in the same classifications and are about 6 months to one year after radionuclide release which may be up to one year after the core melt accident. 



\subsection{CASE STUDY NO. 1}

\subsection{INTRODUCTION}

Chapter 5.0 presents the results of pre-mitigative severe accident radionuclide release and transport analyses for each of the six generic site classifications. In addition, a set of matrices is provided which relate the feasibility of implementing selected mitigative techniques for each of the sites to composite hydrogeologic characteristics and technology constraints. The overall purpose of Chapter 5.0 is to provide a screening tool to determine the relative likelihood of significant radionuclide discharges at a given site by generic classification and to identify a preliminary set of feasible mitigative alternatives for further consideration. Clearly, determination of the "best" mitigative action(s) (in terms of technical feasibility, performance, maintenance requirements, service life and costs) requires a detailed evaluation of pre- and post-mitigative radionuclide transport through the groundwater system to potentially accessible environments. The South Texas Plant(a) (STP) case study described in this chapter is representative of the general methodology for performing such an evaluation. Emphasis is focused on the characterization and evaluation of ground-water flow and contaminant transport phenomena important to the South Texas Plant. The intent of this initial case study is to determine the methods, procedures, and analyses necessary to determine the impact of various mitigative strategies on the ground-water flow regime of a specific site. Subsequent case studies will be more heavily involved with issues related to power plant configuration.

\subsubsection{Case Study Objectives}

The primary objective of the STP case study is to demonstrate a methodology for evaluating mitigative techniques on the basis of site-specific characteristics. In addition, the case study is designed to:

- quantitatively assess achievable mitigation (e.g., reduction in radionuclide concentrations of the geohydrologic unit and receiving water) as a function of site hydrogeology, power plant configuration, accident scenario(s) and basic mitigative technique design characteristics proposed for the STP site, and

- numerically and graphically illustrate the spatial effects of selected mitigative techniques on ground-water potentials, flow velocities and contaminant transport.

6.1.2 Relationship of Case Study No. 1 to Generic Classification - Mitigation Matrix

The hydrogeologic conditions underlying the STP site are representative of the porous unconsolidated silicate classification which is described in Chapter 3.0 and discussed further in Section 5.6. Relative to the other generic hydrogeologic classifications, the porous unconsolidated silicate sites have high hydraulic conductivity, high effective porosity, low hydraulic gradient and slightly greater than average distances (compared to other power

(a) The South Texas Plant was selected solely because of adequate data availability. The case study is strictly hypothetical and is intended only to demonstrate certain analytical procedures. 
plant sites) to surface water. In general these characteristics apply to the STP site. Given this correlation between the STP site and the porous unconsolidated silicate classification, the matrix presented in Table 5.6.2-1 serves as a useful guide for preliminary selection of mitigative techniques for more indepth evaluation. In turn, the results of the case study will provide quantitative verification of the matrix.

\subsubsection{General Methodology for Evaluation of Mitigative Alternatives}

The recommended methodology for the evaluation of selected techniques for mitigation of possible ground-water contamination due to severe accidents at nuclear power plants consists of four main steps:

Step 1. Survey of regional ground-water hydrogeologic characteristics and regional flow analysis to determine local boundary conditions.

Step 2. Pre-mitigative local ground-water flow and transport analysis.

Step 3. Performance evaluation of feasible mitigative techniques based on ground-water and contaminant transport simulation.

Step 4. Sensitivity analyses of contaminant transport to hydrogeologic parameters.

This overall approach is intended to be universally applicable to most nuclear power plant sites. The appropriate means would be selected for analyzing ground-water flow and contaminant transport phenomena, dependent on sitespecific conditions such as the geologic medium (e.g., porous sandstone, porous unconsolidated silicate, etc.), proximity to water users, and accident

scenario. The computational requirements could range from simplified analytical representations to more sophisticated finite-difference or finiteelement modeling depending on site conditions, data availability, and compatibility of computational approach with the objective of assessing the feasibility of mitigative alternatives.

A survey of regional ground-water flow characteristics is conducted in order to establish the general hydrogeologic conditions relevant to the study site. The regional ground-water flow analysis, using appropriate ground-water analytical and/or numerical modeling techniques provides the necessary data for determination of appropriate boundary conditions for the local analysis. The local flow and transport analyses are also performed by employing appropriate modeling techniques. As noted above, the techniques employed will be largely a function of the geologic medium hydraulic properties, data availability and the ability of the technique to determine the performance of particular mitigative method. Generally, the primary measure of relative performance for the mitigative strategies will be contaminant flux at the location of the nearest downgradient surface water body or other accessible environment. Consideration should also be given to the contaminant flux at accessible off-site hydrologic 
units which may be used for water supply. Without some level of ground-water modeling of site-specific characteristics it would be virtually impossible to recommend, with confidence, an appropriate mitigative strategy.

The local flow and transport analyses are first applied to a pre-mitigative accident scenario to determine the baseline contaminant flux. These results provide the basis for subsequent trade-off analyses of the effectiveness of various mitigation approaches. Parametric studies are typically performed to determine possible limits of the effectiveness (i.e., performance) of a mitigative strategy in relation to both uncertainties in hydrogeologic parameters (e.g., hydraulic conductivity) and changes in major design characteristics of individual mitigative strategies (e.g., slurry walls).

The engineering interpretation of case study results will lead to consideration of performance related factors pertinent to the choice of mitigative alternatives used their designs. These factors include construction considerations, cost, durability, and the impact on water table elevations in the immediate vicinity of the plant. The durability issue is particularly important in light of the extended period of acceptable performance that may be required of the selected mitigative strategy. Durability considerations, which are dependent on the configuration of the mitigative strategy, may range from longterm effects of grout exposure to the hydrologic environment to mechanical equipment deterioration (e.g., pumps for well injection).

\subsubsection{Case Study No. 1 Approach and Limitations}

The approach taken for the STP case study is consistent with the general methodology described in Section 6.1.3. Specifically, a regional hydrogeologic analysis to determine local boundary conditions and a local flow and transport analysis are conducted using the TRANS ground-water flow and transport code developed by the Illinois Water Survey Division (Prickett et al. 1981). The criteria followed in the evaluation and selection of TRANS are discussed in Section 6.4 .

For the remainder of this section, the term "model" is used to define a numerical computer code (e.g., TRANS) in conjunction with the data set or the site being studied (STP). In applying a code such as TRANS it is important to realize that a "model", as defined, is a simplification of the real world. However, when properly developed and validated a site specific model does approximate the attributes of the real ground-water system that are important to the objectives of the study. While not a perfect indicator of observed contaminant movement, a hydrologic flow and transport model can provide reconnaissance level (or better) understanding of the transport phenomena for the purpose of evaluating the effectiveness of various mitigative alternatives.

The primary limitation of the STP case study is that, due to the demonstrative nature and scope of this study, only previously published data are used. If required data are sparse or unavailable, hypothesized data are generated based on the best information available and engineering judgment. In reality a field program would be conducted to provide a sufficient level of data to properly characterize the hydrogeologic properties of the site. 
Other limitations of the case study relate to representing the STP aquifer system as a two-dimensional (horizontal) flow system and assuming steady-state simulation of water movement. Use of a two-dimensional model assumes vertically averaged flow and transport over the total aquifer thickness. It also assumes instantaneous mixing in the vertical. In terms of evaluating mitigative alternatives, injection and withdrawal wells and low permeability barriers are assumed to fully penetrate the aquifer. Further, it is assumed that no contaminant leakage occurs between the bottom of impermeable barriers and the aquifer bottom. Though these assumptions represent simplifications of the actual STP flow system, they do not detract significant ly from the ability to realistically evaluate mitigative alternatives at the STP.

\subsection{DEFINITION OF CASE STUDY NO. 1}

\subsubsection{Geographical Location and Physical Setting}

The South Texas Plant (STP) is situated in south-central Matagorda County, Texas approximately $4.9 \mathrm{~km}$ due west of the Colorado River. The STP is located on the Texas Gulf Coastal Plain approximately $17 \mathrm{~km}$ inland from Matagorda Bay and $24 \mathrm{~km}$ inland from the Gulf of Mexico. Figure 6.2.1-1 shows the site location within the State of Texas. The STP site is influenced by the coastal hydrometeorologic regime and tidal effects of the Gulf of Mexico. In summary, these influences result in (Houston Power and Light 1978):

1. high gross natural evapotranspiration rates,

2. high annual rainfall volumes and hourly intensities,

3. high winds,

4. tropical cyclones,

5. high ambient air temperatures,

6. high natural river water temperatures,

7. moisture-laden warm air masses, and

8. brackish surface water.

The geomorphology of Matagorda County (and the STP site) is typical of a slightly eroded coastal plain. The area is characterized by low relief, abandoned river valleys, marshes, and offshore barrier bars. The surface of the STP site is a depositional plain of the last ice age (Hammond 1969).

The STP site is within the humid subtropical region of Texas, and receives average annual precipitation on the order of $100 \mathrm{~cm}$. Rainfall is normally well distributed on an annual basis with maximum rainfall usually occurring in September and minimum rainfall occurring in March (Hammond 1969). The area experiences long, hot summers with temperatures exceeding $32^{\circ} \mathrm{C}\left(90^{\circ} \mathrm{F}\right)$ for about 100 days each year. During the winter, cold fronts occasionally move down from the north which mix with the warm air lying over the Gulf of Mexico and produce cloudy, mild, but drizzly weather. Spring experiences mild days, brisk winds and frequent showers. Strong southeast winds begin in March but diminish in April and May and give way to pleasant sea breezes by mid-June. During late June, July and early August, the sea breeze greatly subsides and occasionally fails completely. The area is subject to tropical disturbances during summer and fall with potentially destructive winds. Thunderstorms are frequent but hail is infrequent and tornadoes are rare (NOAA 1980). 


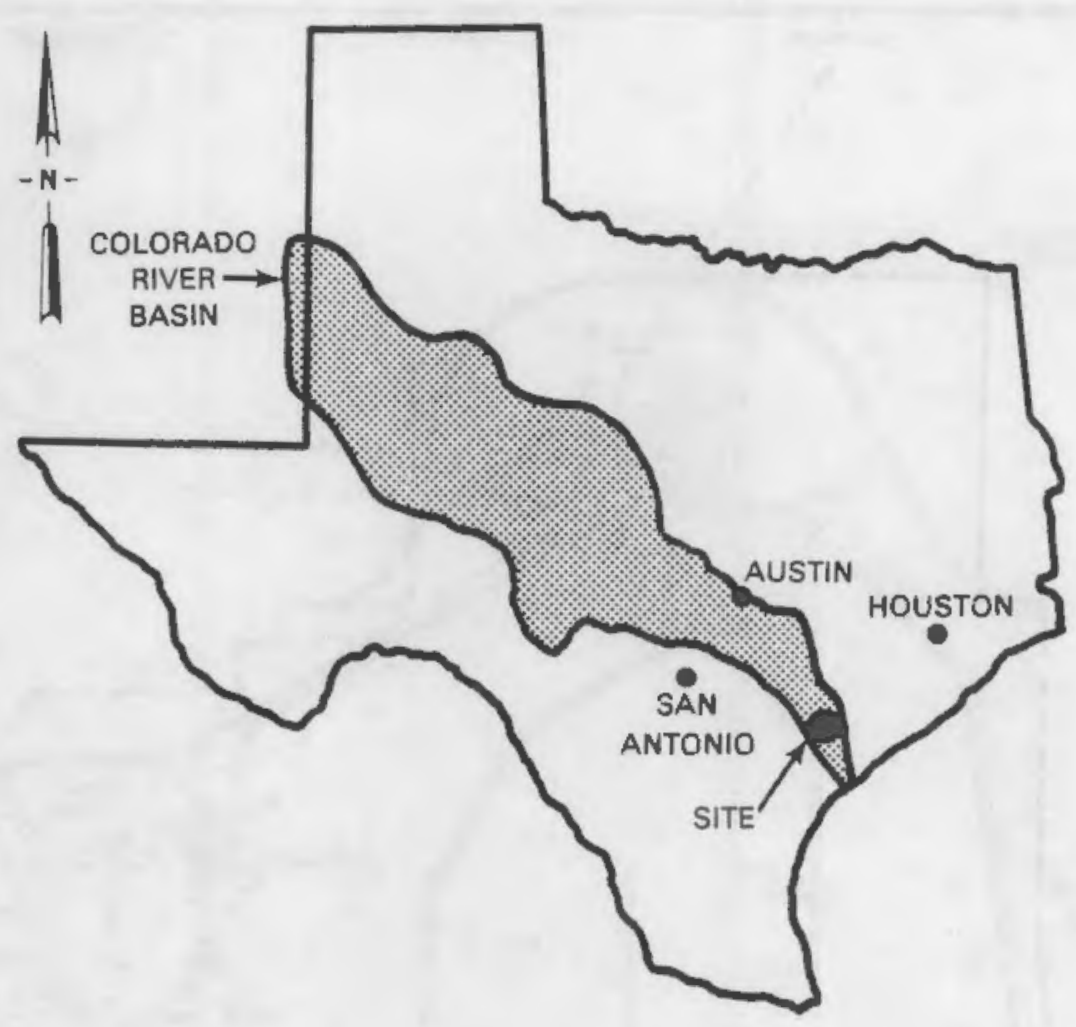

FIGURE 6.2.1-1. STP Site Location Map

\subsubsection{Reactor Design and Plant Configuration}

The South Texas Plant is composed of two units each having identical pressurized water reactors (PWR). The two units are roughly $180 \mathrm{~m}$ apart and use certain shared facilities including the cooling reservoir, spillway and blowdown facilities, and essential cooling pond. The reactor core-rated thermal power is 3,800 Mwt. High pressure light water serves as the coolant, neutron moderator, reflector, and solvent for the neutron absorber (Houston Power and Light 1978). The reactor containment building has a diameter of approximately $45 \mathrm{~m}$ with a concrete basemat roughly $5.5 \mathrm{~m}$ thick. The containment is designed to withstand the internal pressure buildup following a loss of coolant accident.

Figure 6.2.2-1 shows the plant area (i.e., containment buildings, etc.) in relation to other station features. The plant grade is at $8.5 \mathrm{~m} \mathrm{MSL}$. The cooling reservoir is located south of the plant area and covers approximately 2800 ha or a little over half of the site property. The impoundment is supplied by water diverted from the Colorado River. The essential cooling pond, located east of the station, is intended to provide cooling water for safe shutdown of the plant. The essential cooling pond is an offstream impoundment which, under normal conditions is supplied with water from the cooling reservoir but has a backup well with $2000 \mathrm{\ell} / \mathrm{min}$ pumping capacity (Houston Power and Light 1978). The essential cooling pond covers nearly 19 ha. 


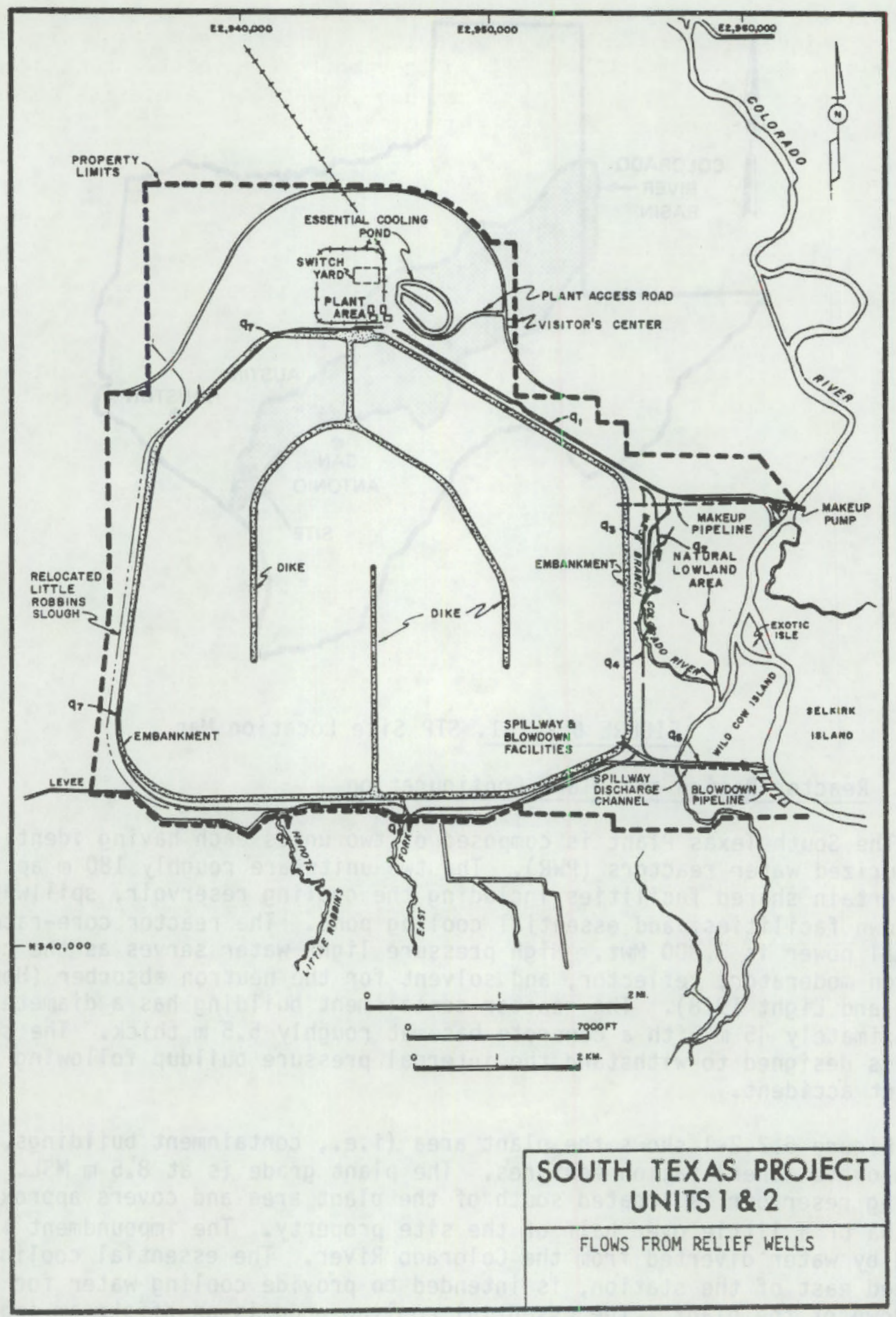

FIGURE 6.2.2-1. STP Plant Area (Source: Houston Power and Light 1978) 
Offsite utility service is important in considering the types of mitigative techniques that may be implementable. There are eight $345 \mathrm{kV}$ transmission circuits from the STP $345 \mathrm{kV}$ switchyard to the interconnecting grids of the STP owners. The transmission system provides reliable of $f$ site power services any time power is unavailable from the station.

\subsubsection{Definition of Accident Scenario}

\subsubsection{Severe Power Plant Accident}

The South Texas Plant is a PWR incorporating a double loop for removal of heat from the reactor core. In a postulated severe accident, insufficient heat is removed from the reactor and the core materials overheat to the point of melting. The molten nuclear fuel and supporting materials could contain sufficient heat to melt through the reactor vessel and drop onto the floor of the containment building. The hot core materials would then thermally decompose and melt the concrete containment basemat (USNRC 1975).

The basemat structure could be penetrated (i.e., melted through) by the core melt mass or severely fractured allowing radioactive debris to enter the geologic materials below the power plant. Once the core debris containing nuclear fuel, steel, and liquified geomaterials entered the substratum, cooling would initiate solidification. The decay heat of the radionuclides in the debris would contain enough energy to prevent ground-water contact for about one year (Niemczyk et a 1. 1981). Ground water flowing through and around the core debris would leach radionuclides from the core melt mass and begin transporting contaminant away from the site. A more complete description of accident sequences and contaminant release is contained in Chapter 2.

In addition to core debris, the cooling water and water used in emergency spray systems could collect in the containment building sump. This water, referred to as "sump water", would become contaminated in the accident process and could be released into the geologic units beneath the plant due to basemat failure. The South Texas Plant is capable of producing both types of contaminant releases in a severe accident.

In a severe nuclear accident, radionuclides of various half-lives, initial quantities, toxicities, and ground-water transport parameters would be released. It is not necessary to determine the ultimate position of all classes of radionuclides. This study focuses on radionuclides that would be released into the ground-water system (as opposed to those that would constitute an atmospheric release). The radionuclides having long half-lives are of concern because they would not decay to low levels very soon after an accident. Radionuclides in large quantities that are not strongly sorbed are also of concern because they have the potential to migrate away from the site more quickly and in high concentrations. 
The experience gained in the generic characterization of all nuclear power sites is used to select radionuclides that can serve as indicators of contamination. In unconsolidated silicates (i.e., sand, silt and clay), the radionuclides which best characterize contamination are strontium-90 and cesium- 137 .

There are several accident scenarios that could result in a nuclear power plant core melt. This study has conservatively assumed that the accident sequence that would release the largest portion of the nuclear inventory has occurred at this site. The amount of radionuclides contained in the core is based on the thermal output of the STP in relation to a theoretical reference reactor described by USNRC (1975). The thermal output and a partial core inventory of the two reactors are listed in Table 6.2.3-1.

The radionuclides contained in the core would be partitioned into the core debris, the sump water and the containment atmosphere. The accident sequence preceeding the core melt determines the percentage of the initial inventory that would reside in each of the above partitions under the assumption of the most likely accident sequence. The radionuclide partitioning for this study assumes that the most severe accident sequence has occurred. The resultant initial amounts of key radionuclides available for release are listed in Table 6.2.3-2. A more complete description of the core melt source term is given in Section 2.2.

\subsubsection{Release of Radionuclides Into the Ground-Water System}

The penetration of the core melt into the earth below the containment structure is a function of the accident sequence, size of the reactor, and the chemical composition of the geologic materials. Clay and sand at the STP would primarily be chemically composed of silicic minerals. The shape of core melt penetration into a silicate material has been calculated by Nienczyk et al. (1981). The geometric configuration of the core debris would be approximately cylindrical with a radius of roughly $9 \mathrm{~m}(29 \mathrm{ft})$ and a depth of approximately $11 \mathrm{~m}$ ( $35 \mathrm{ft}$ ) below the basemat or about $25 \mathrm{~m}$ ( $80 \mathrm{ft}$ below MSL). At this depth, the core debris would reside in the lower unit of the shallow-zone aquifer (see Section 6.3.2 for a detailed characterization of the STP site hydrogeology). The deep aquifer, which is used as a source of fresh water, would be isolated from the core melt by over $45 \mathrm{~m}$ (150 ft) of clay. The shallow aquifer sands are therefore the hydrostratigraphic unit that would transport the majority of radionuclides away from the site.

TABLE 6.2.3-1. Initial Amounts of Indicator Radionuclides

$\begin{array}{lcccc}\text { Radionuclide } & \frac{\begin{array}{c}\text { Half-Life } \\ \text { (days) }\end{array}}{\text { Strontium-90 }} & 10519 & \frac{\begin{array}{c}\text { Reference Reactor PCi } \\ \text { (USNRC 1975) }\end{array}}{3.71 \times 10^{18}} & \begin{array}{c}\text { South Texas Plant pCi } \\ \text { (Single Unit) }\end{array} \\ \text { Cesium-137 } & 11042 & & 4.67 \times 10^{18} & 4.53 \times 10^{18}\end{array}$


TABLE 6.2.3-2. Release Fractions for the Indicator Radionuclides

(Source: Niemczyk et al. 1981)

$\begin{array}{lcc}\text { Radionuclide } & \begin{array}{c}\text { Sump Water } \\ \text { Release, } \%\end{array} & \begin{array}{c}\text { Core Melt Debris } \\ \text { Leach Release, \% }\end{array} \\ { } } & 11 & 89 \\ \text { Cesium-137 } & 100 & 0\end{array}$

The heat contained in the core debris would temporarily vaporize the ground water adjacent to the melt and prevent transport under saturated conditions. It is estimated the top of the core melt in contact with sump water would cool below the boiling point of water in about six months. Similarly, the central portion of the core melt would cool in approximately one year (Niemczyk et al. 1981). The resaturation of the desiccation-alteration zone around the core debris would also delay the transport of contaminant. This study accounts for the temperature of the debris preventing saturation and conservatively does not consider the additional time required for resaturation.

The leach release of silicic materials occurs over a long period of time. Indeed, glass is often used as an isolation medium for radioactive wastes because of its isolation properties and low rate of decomposition. The dominant mechanism for the removal of radionuclides from core debris is matrix corrosion. The silicic leach processes are described more fully in Section 2.4.2. The majority of the radioactivity undergoes decay while still contained in the melt debris and does not enter the ground-water system. However, the leach release does continue for millennia at an exponentially decreasing rate. The leach rate is determined under the same assumptions as used in the generic examination of silicic core melts. The absolute rate is appropriately scaled to represent the thermal size of a single reactor at the STP. Figure $6 \cdot 2 \cdot 3-1$ presents the release flux of strontium-90 over time.

\subsection{REGIONAL ANALYSIS}

\subsubsection{Approach ${ }^{(a)}$}

The regional hydrologic system is important in analyzing the hydrology and contaminant transport of more localized systems. This importance has been demonstrated in a ground-water modeling study of remedial action effectiveness for the La Bounty Landfill in Charles City, Iowa presented by Cole et al. (1983). Their study also shows that boundary conditions for the local system must be determined from the regional system for pre-mitigative and postmitigative flow conditions if reasonable estimates of travel times and groundwater flow rates are to be obtained. On this basis, a two stage modeling approach is developed for the STP site. The first stage consists of

(a) English units of measure are used throughout the analysis because published data pertaining to the hydrogeologic properties of sites in the U.S. are typically in English units. 


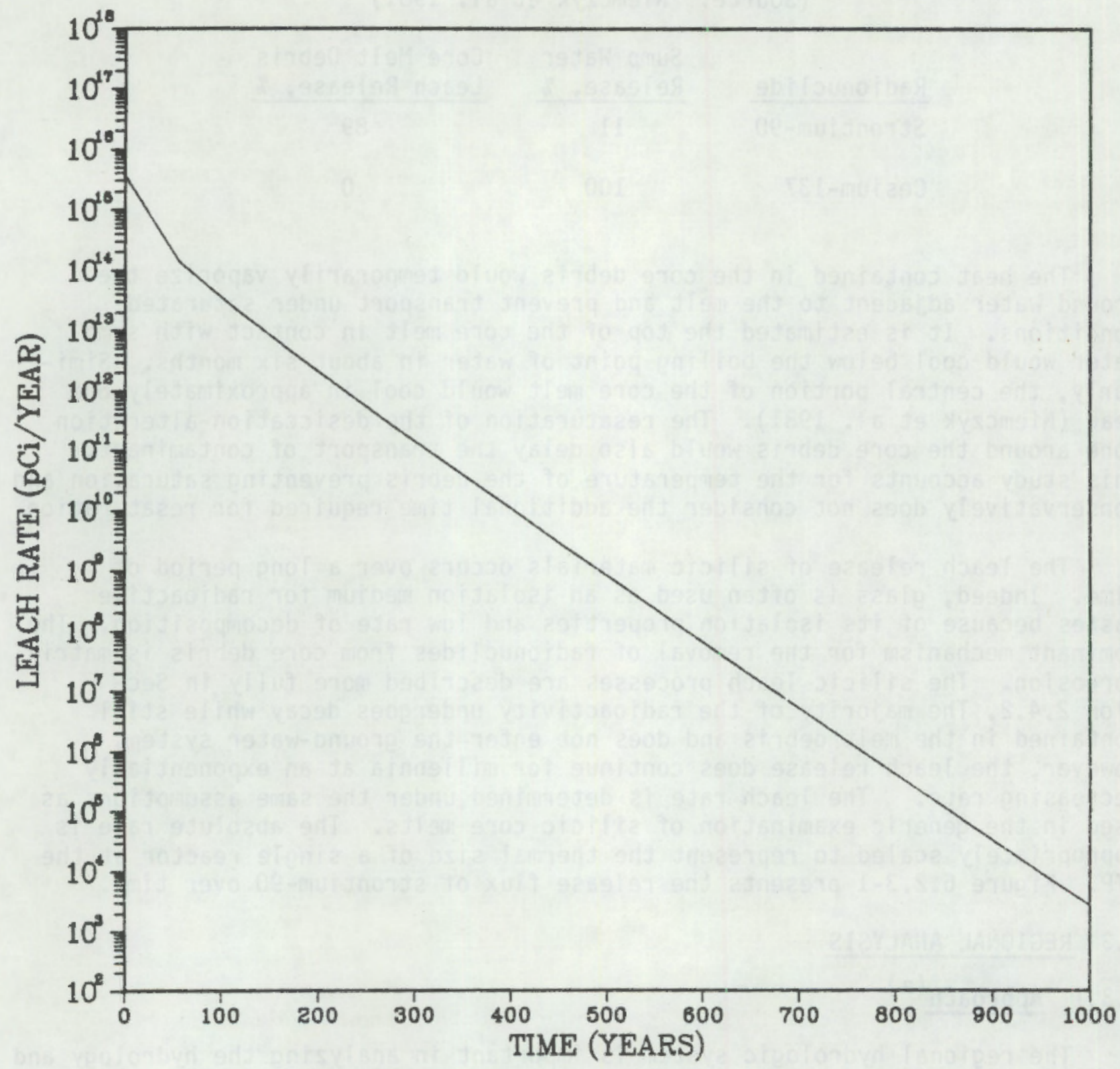

FIGURE 6.2.3-1. Hypothesized South Texas Plant Leach Release of Strontium-90.

development of a coarse grid regional ground-water flow model, while the second stage involves development of ground-water flow and contaminant transport model for the immediate vicinity of the STP site. 
The application of models to investigate ground-water flow and transport involves several areas of effort: data collection, data preparation for the model, history matching and predictive simulation (Mercer and Faust 1980). The interrelationships of these tasks is illustrated in Figure 6.3.1-1. The first phase of a ground-water model study consists of gathering the available geologic and hydrologic data on the ground-water system of interest. Typically this would include information on: surface and subsurface geology, precipitation, evapotranspiration, pumping, surface streamflows, soils, vegetation, irrigation, hydraulic potential, aquifer properties and boundary conditions. If available data are not adequate, a field data collection program may be required. All of the data are then used to develop a conceptual model of the basin.

As discussed by Boonstra and de Ridder (1981) a conceptual model is constructed based on preliminary assumptions regarding study area size, boundary conditions, number of geologic layers, ground-water flow direction, recharge and discharge locations, etc. The first step in developing the conceptual model is to identify the extent and nature of the ground-water system (e.g., does the system consist of a single aquifer or combination of multiple aquifers). Using the preliminary conceptual model, an appropriate computer code can be selected and development of the numerical model can begin. The model is first used to synthesize the various data and then to test the validity of the conceptual model. From this stage, refinement of the conceptual model and calibration of the numerical model involve an iterative process that continues until the two are consistent with each other and the numerical model adequately reproduces observed data. When this is accomplished, the numerical model is ready for predictive simulations.

The implementation of this process to the development of the STP regional model is described below.

\subsubsection{Data Compilation and Conceptual Model Development}

Numerical model development and calibration require a variety of quantitative hydrogeologic data that can be classified into two groups (Boonstra and de Ridder 1981):

1. data that define the physical framework of the ground-water system, and

2. data that describe the system inflow and outflow.

Specific data types within each group are listed in Table 6.3.2-1.

For a particular site there are many sources for the different types of data listed in Table 6.3.2-1. These sources include:

- Preliminary Safety Analysis Report, Final Safety Analysis Reports, Environmental Reports, etc.

- Local water supply districts, well drillers, engineering consulting firms and other firms which deal with water problems.

- Local and regional Soil Conservation Service offices. 


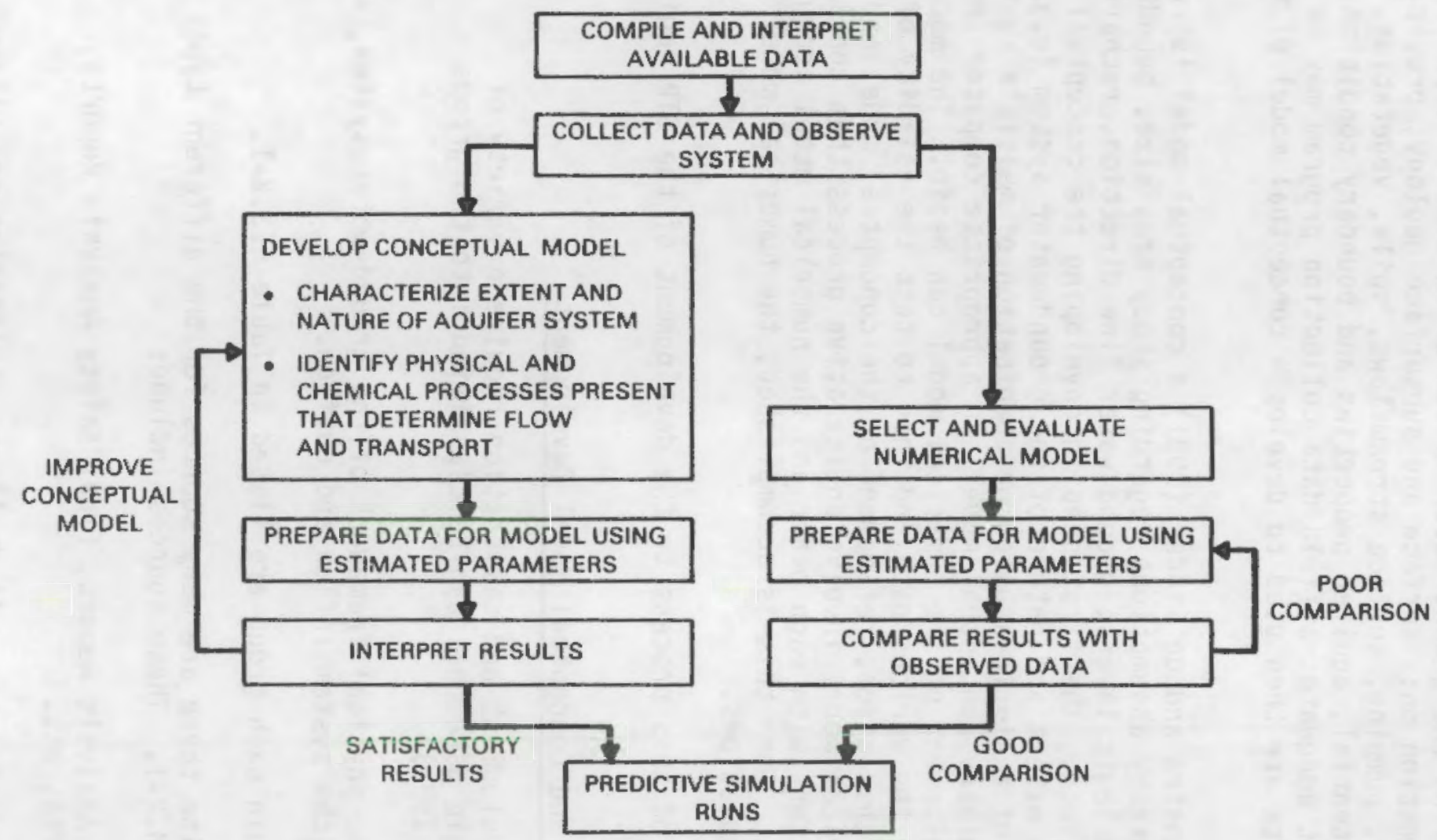

FIGURE 6.3.1-1. Major Steps in Ground-Water Model Applications (Source: Mercer and Faust 1980) 
- State and county offices of natural resources, environment, health, or ecology.

- Local, state, regional and national offices of the U.S. Geological Survey (USGS), the U.S. Corps of Engineers, the U.S. Bureau of Reclamation, and the U.S. Environmental Protection Agency.

- Universities and colleges with programs in geology and hydrology.

- Local libraries.

In compiling data for the STP case study readily accessible sources were used. Selected sections of the STP Final Safety Analysis Report (Houston Power and Light 1978) were relied upon as one of the principal data sources. Other key sources included the USGS and the Texas State Department of Water Resources. The remainder of this section presents the results of the STP hydrogeologic characterization. For each data type listed in Table 6.3.2-1, details of the data sources, analysis and interpretation are provided.

\section{3 .2 .1 Topography}

A basic requirement for conducting a ground-water study is a topographic map delineating surface water bodies, streams, man-made water courses and land surface elevation contours. Maps for the STP site were obtained from the USGS Map Distribution Center in Denver, Colorado. Figure 6.3.2-1 is a reduction of the topographic maps for the vicinity of the STP site. Features identified on the map include the approximate STP property limits and site location, Colorado River, Intracoastal Waterway and the Gulf of Mexico. In general, the topography is characterized by gently sloping terrain to the north of the site and

TABLE 6.3.2-1. Data Required for Ground-Water Modeling

(Source: Boonstra and de Ridder 1981)

Physical Framework.

1. Topography

2. Geology

3. Types of Aquifers

4. Aquifer boundaries

5. Aquifer thickness and lateral extent

6. Porous media material properties
Hydrologic Stress

1. Watertable elevation

2. Rate and extent of recharge areas

3. Rate and extent of point and and areal discharge 


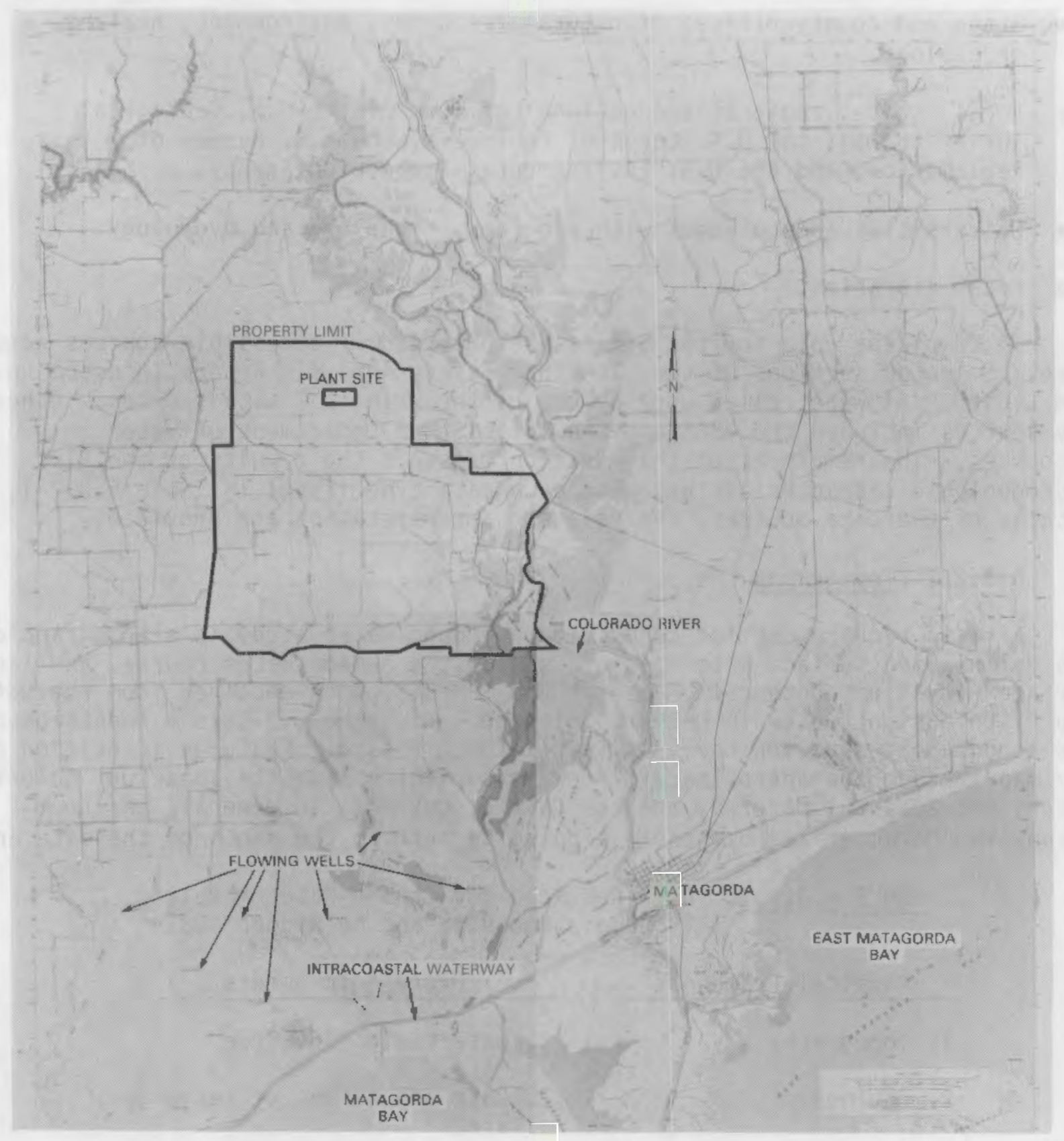

FIGURE 6.3.2-1. USGS Topographic Map for the vicinity of the STP Site

flat swampy areas to the south. There are no structural geologic features discernable at the STP site. Local land-forms are subdued due to the gentle slope of the underlying geologic units, weathering and stream erosion.

\section{3 .2 .2 Geology}

The structural history the of Texas Gulf Coastal Plain on which the STP is located began in the late Jurassic Period. At this time, roughly 145 million 
years ago, the crust of the earth began to downwarp as a large regional feature known as the Gulf Geosyncline (Stokes 1966). Sediments eroded from the continental land mass to the north were transported by rivers and deposited in the geosyncline. These processes have accumulated over 50,000 feet of sedimentary material in the central depression of the geosyncline ranging in age from the cretaceous Period to the present. The regular transportation of sediments in this region has resulted in the formation of the thick sedimentary units forming the Coastal Plain. There are two characteristic features of these geologic units: 1) the sediments are graded, that is, they become finer material (i.e., sand to clay) toward the center of the geosyncline; and 2) the layers of sediments become thicker toward the center of the geosyncline. This depositional formation has created extensive units known as sedimentary wedges that thicken and dip seaward. The southward dip of the older environment is greater than the more recent units because of the continued continental uplift inland and continued downwarp of the Gulf Geosyncline.

Deposition of the more coarse sediments occurred by alluvial processes along rivers and streams. As the rivers altered their channels and deposited additional material, the lateral accretion deposits (i.e., channel lag deposits, channel bar deposits, and point bar deposits) became vertically superimposed. The rivers continually migrated back and forth across the broad low relief depositional plain and created a series of coalescing alluvial and deltaic plains (Houston Power and Light 1978). This process formed geologic units of discontinuous interfingering beds which grade laterally over very short distances from clay to silt to sand to gravel (Hammond 1969). Taken in its entirety, the sediments are referred to as the Gulf Coast Aquifer (Baker and Wall 1976).

The near surface geologic units found in Matagorda County and their hydrologic significance are listed in Table 6.3.2-2. The STP is situated on the Pleistocene Beaumont Formation which extends at least 700 feet below the site. The base of the Beaumont Formation dips to the south at 10 to $20 \mathrm{feet} / \mathrm{mile}$ (Houston Power and Light 1978). The upper surface of the Beaumont Formation constitutes the present land surface. The formation is characterized as layers of clay, sandy clay, and thick sand units. The layers of sand are up to 100 feet thick and produce significant amounts of water for irrigation and mining (Hammond 1969). Clay layers of up to 150 feet thick hydraulically isolate the various sand layers.

The Beaumont Formation has been characterized in detail at the site of the South Texas Plant by drilling, bore hole logging and reflection geophysical profiling between bores. A hydrologic evaluation combining the geological evidence and piezometric data identified three major sand layers that are capable of transmitting large volumes of water. These sand layers are separated into two hydrostratigraphic units; a deep aquifer at depths greater than 300 feet, and a shallow aquifer consisting of an upper and lower unit ranging between 90 and 150 feet below land surface. A hydrostratigraphic unit is defined as a body of rock or series of formations with considerable lateral extent that compose a reasonably distinct hydrologic system. The distinction of the upper and lower units in the shallow aquifer is based on the presence of a 20 feet thick clay layer that locally separates the units and produces 
TABLE 6.3.2-2. Geologic Description and Water-Bearing Properties of Stratigraphic Units Forming the Gulf Coast Aquifer (Source: Hammond 1969)

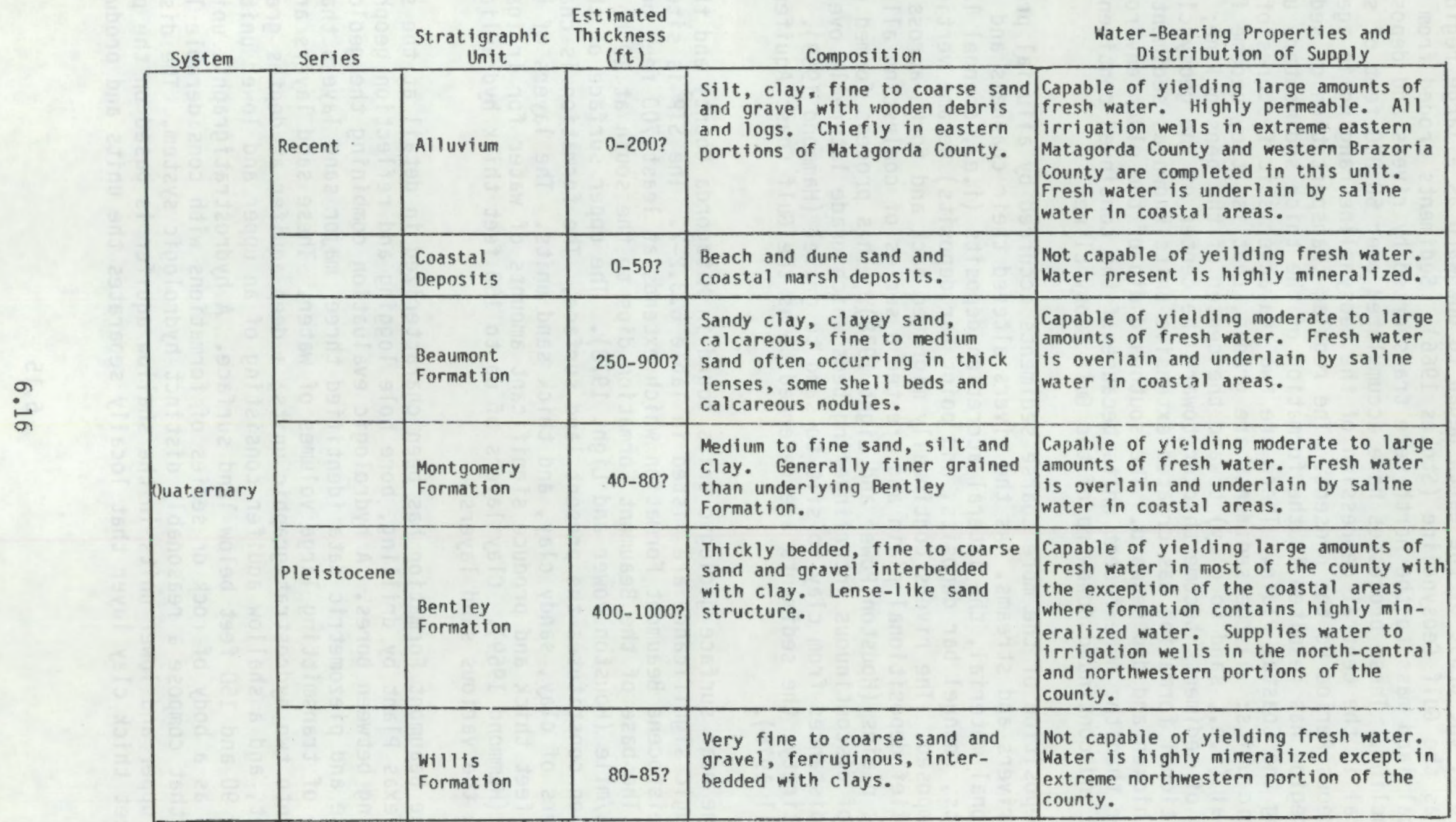


slightly different potentiometric levels. South of the site boundary this clay layer pinches out and the shallow aquifer becomes a single unit.

\subsubsection{Types of Aquifers}

An aquifer is defined as a geologic formation or group of formations that contain sufficient saturated permeable material to yield significant quantities of water (Boonstra and de Ridder 1981). Thus, determination of aquifer type(s) is accomplished by translating the known geologic and hydrologic information into terms of high yield waterbearing formations (aquifers), confining layers (very low permeability) or semi-confining layers (low permeability). Consecutive formations having similar water transmitting properties should be classified as a single aquifer system. For example, consecutive strata of clay, silty clay, sand clay, etc., though different in age and depositional conditions, represent a single layer having similar ground-water hydraulic properties. The three basic types of porous media aquifers; unconfined (watertable), confined (artesian) and semi-confined (leaky) are shown in Figure 6.3.2-2.

The primary sources of information for identifying the aquifer types in the vicinity of the STP site were the STP FSAR (Houston Power and Light 1978) and the Texas Water Development Board Report 91 by Hammond (1969). The aquifers in the site vicinity are found in the lower Gulf Coastal Plain, described as a thick composite of deltaic sediments extending locally to depths of as much as $2000 \mathrm{ft}$. These sediments are discontinuous, interfingering beds of clay, silt, sand and gravel seldom traceable over very appreciable distances. The different stratigraphic units in the Gulf Coastal Plain are described in Table 6.3.2-1. In Matagorda County, the Beaumont Formation supplies most of the usable ground water and extends from the ground surface to depths of about 700 feet in the area of the STP. Ground water in the Beaumont Formation is confined by an overlying zone of predominantly clay materials up to 150 feet thick. The main producing aquifer zone, designated as the deep aquifer zone, lies below depths of 200 to 300 feet in the site area.

Within the Beaumont Formation there is a shallow aquifer zone that occurs above depths ranging from 90 feet to 150 feet in the vicinity of the site. Based on geophysical and hydraulic tests as discussed in the STP FSAR (Houston Power and Light 1978), the upper zone is segmented into lower and upper confined units. Each unit is characterized by a different piezometric surface. The regional geologic configuration in the vicinity of the site is illustrated by the geohydrologic-cross section shown in Figure 6.3.2-3. The cross-section clearly shows the deep aquifer zone overlain by the deep confining zone which ranges in thickness from over 150 feet to almost 250 feet. The shallow aquifer zone is located between the surface confining zone and the deep confining zone. The upper and lower units of the shallow aquifer zone are easily distinguishable, separated by a layer of predominantly impermeable material 25 feet to 50 feet in thickness. The piezometric levels shown on Figure 6.3.2-3 indicate both the shallnw and deep aquifer zones are artesian units. 


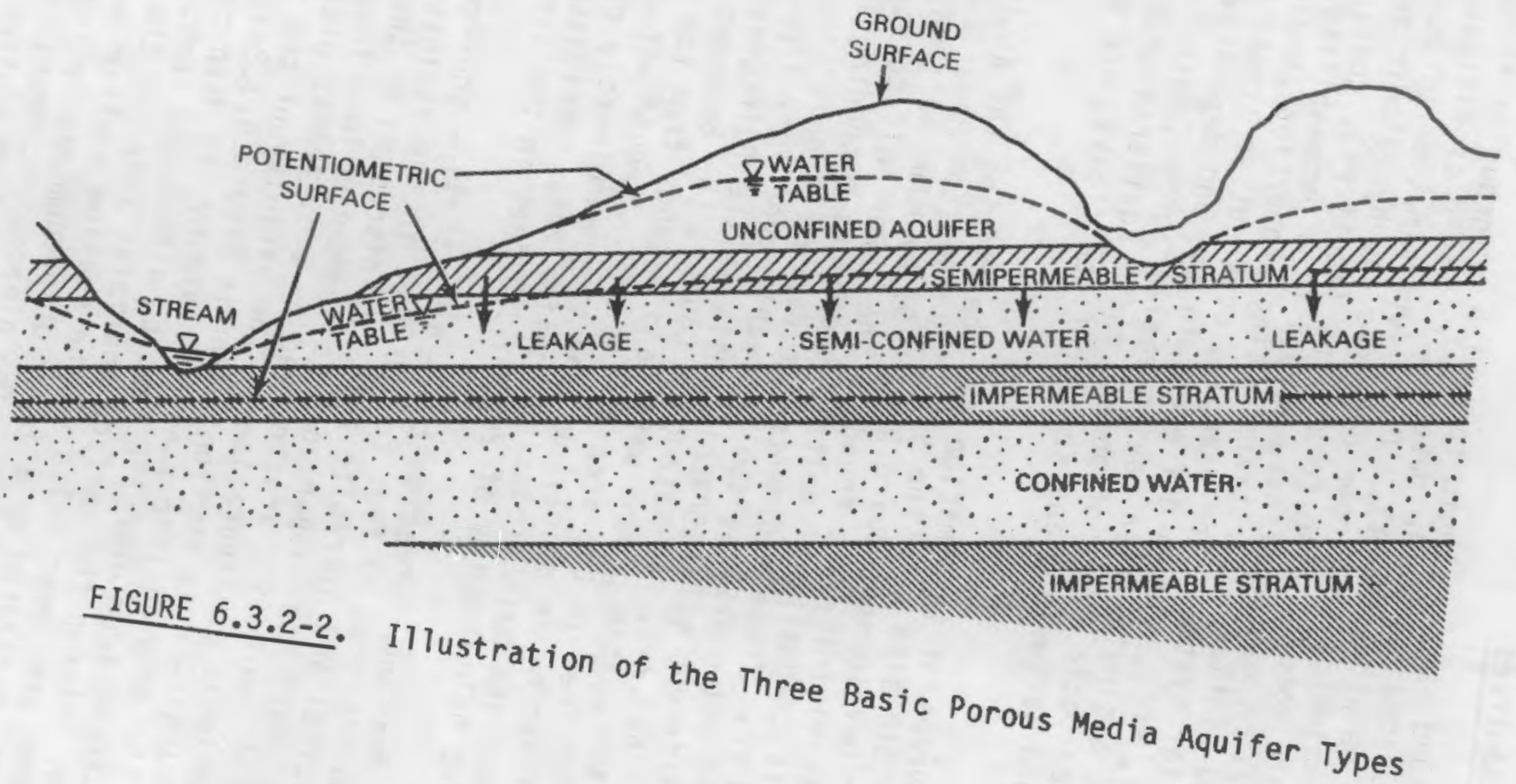


On the basis of the stratigraphy and relative locations of the aquifer units and the discussion of the postulated effects of a severe accident at the STP in Section 6.2.3.2, it is apparent that the molten core mass would penetrate to a depth corresponding to the lower unit of the shallow aquifer zone. Thus, flow and transport would occur under artesian conditions and, in the absence of significant inner-unit transfers, analysis can be limited to the lower unit of the shallow aquifer. This assumption precludes the need to perform detailed study of both the upper and lower units of the upper aquifer. Subsequent data analysis is conducted under this assumption. In an actual assessment of potential accident effects outside the context of a case study, this assumption would be subjected to extensive evaluation before proceeding.

\subsubsection{Aquifer Boundaries}

In addition to describing the thickness and lateral extent of the aquifer in question, the aquifer boundaries must also be properly defined. The different types of boundaries identified by Boonstra and de Ridder (1981) include :

- zero-flow boundaries.

- head-controlled boundaries.

- flow-controlled boundaries.

- free surface boundaries.

Since the free surface boundary is to be determined by the numerical model it will not be discussed here. These types of boundaries are illustrated in Figure 6.3.2-4 and briefly discussed below.

\section{Zero-Flow Boundary}

Conceptually, a zero-flow boundary is one across which flows are insignificant relative to flows in the main aquifer. Zero-flow boundaries can occur as either internal or external boundaries. For example, a massive unfractured crystalline formation along the outer edge of an aquifer or a ground-water divide would produce an external zero-flow boundary. A local outcrop of massive rock and an impermeable aquifer bottom would be representative of internal zero-flow boundaries. In developing a ground-water model of a basin, it is necessary to delineate the zero-flow boundaries on a map. Zero-flow is then achieved in the model by setting the hydraulic conductivity at the boundary equal to zero (Boonstra and de Ridder 1981).

\section{Head-Controlled Boundary}

A head-controlled boundary has a known hydraulic head which is either constant or varies with time and is not affected by potentiometric or permeability changes within the ground-water basin. Examples include large water bodies such as oceans and lakes or water courses with fixed water levels like irrigation canals. Similar to zero-flow boundaries, head-controlled boundaries can occur both internal and external to the aquifer. A stream in 


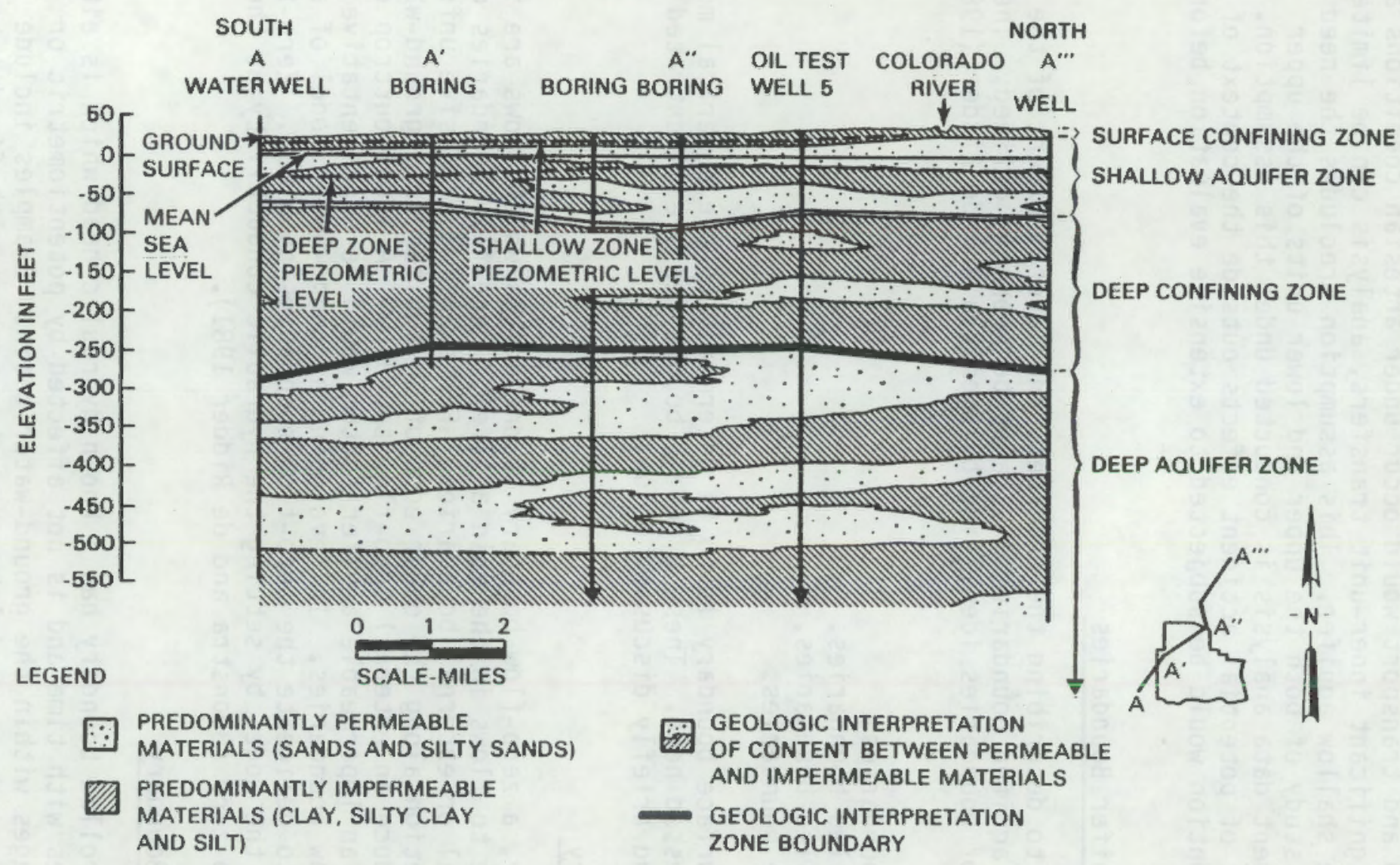

FIGURE 6.3.2-3. Geohydrologic Cross-Section A-A"' for the STP Site (Source: Houston Power and Light 1978) 


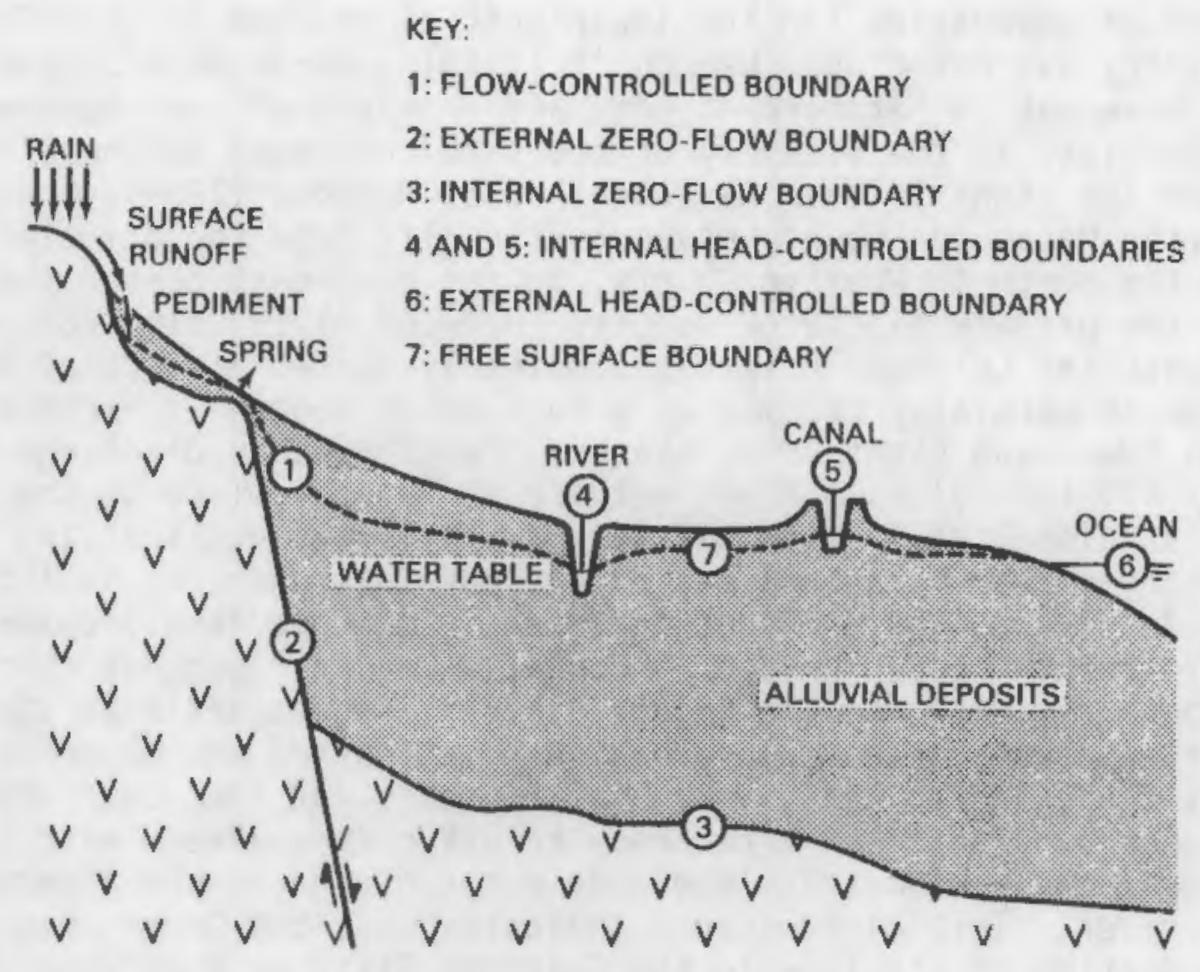

FIGURE 6.3.2-4. Illustration of Different Aquifer Boundary Types (Source: Boonstra and de Ridder 1981)

hydraulic contact with an aquifer inside its boundaries is an internal head controlled boundary while the ocean in direct contact with an aquifer is an external head-controlled boundary (Boonstra and de Ridder 1981).

Flow-Controlled Boundary

A flow-controlled boundary is a boundary through which ground water enters the aquifer at a certain rate from adjacent strata whose hydraulic head is not known. The volume of water transferred in this way is normally estimated by recharge based on rainfall and runoff data. The aquifer boundary may be a zero-flow boundary but a portion of the incident precipitation may percolate into the colluvium and enter the aquifer at the boundary as ground-water flow (Boonstra and de Ridder 1981).

\section{Selection of STP Boundary Conditions}

During development of a ground-water model, it is advantageous in defining boundary conditions to select the external boundaries of the model so they coincide with head-controlled and/or zero-flow boundaries. If the model is being developed for only a portion of the basin, however, it might be necessary to arbitrarily choose a boundary where ground water flows into or out of the basin. In this case, the flow rate must be computed based on the boundary heads and hydraulic conductivity. 
Selection of boundaries for the lower unit of the shallow aquifer in the SṬP site vicinity was based upon Hammond's (1969) general description of ground-water movement in Matagorda County and analysis of the observed hydraulic potentials in the vicinity of the site presented in the STP FSAR (Houston Power and Light 1978). As described by Hammond (1969), the ground water underlying Matagorda County moves continually from the principal areas of recharge, to the north in Wharton County, to the southeast toward the Gulf of Mexico where the primary discharge occurs. Hammond (1969) also points out that at times, though the Colorado River is completely dammed at a point below Bay City, its flow is partially resumed by ground-water seepage. Further, the STP FSAR (Houston Power and Light 1978) states: "shallow-zone discharge is into Matagorda Bay and the Colorado River estuary at least 5 miles to the southeast of the power station area." Thus, it was initially thought that the shallow aquifer discharges into Matagorda Bay except possibly where it is intercepted by the Colorado River. The pre-construction piezometric levels observed on March 14, 1974 for the upper unit of the shallow aquifer suggest this is occurring. The contours, presented in Figure 6.3.2-5, show a definite steepening in gradient as they approach the Colorado River, indicating the upper unit is hydraulically connected to the river. The contours for the lower unit, presented in Figure 6.3.2-6, show a tendency to align themselves with the river. However, the piezometric levels do not converge to the apparent water level of the river. This circumstance indicates that the lower unit only discharges a portion of its flow to the Colorado River as upward seepage through its confining layer.

On the basis of these observations, a regional study area was designed with the $x$-direction roughly parallel to the observed lower unit contours of equal hydraulic head. The rectangular area, partially outlined in Figure 6.3.2-7, superimposed on the site topography maps extends to the south into Matagorda Bay and East Matagorda Bay and to the north beyond the STP property limits. The exact regional boundaries were chosen arbitrarily at a distance far enough away from the STP site so that assigned boundary conditions would not greatly influence the local hydraulic conditions in the immediate vicinity of the STP. The complete grid, approximately $11.4 \mathrm{mi}$. by $13.3 \mathrm{mi}$. (2000 $\mathrm{ft}$ by $2000 \mathrm{ft}$ grid elements) is shown in Figure 6.3.2-8.

For the purposes of constructing the STP conceptual and numerical models it was necessary to determine the type and location of the aquifer boundaries for all four sides of the regional grid. The southern most boundary was assumed to be a head-controlled boundary coinciding with the Intracoastal Waterway. Tide gage records for the Waterway obtained from the USGS(a) indicate the mean tide level in the vicinity of Matagorda, Texas is approximately 1 foot MSL. The actual location of the $1 \mathrm{ft}$ MSL constant head boundary is designated in Figure $6.3 .2-8$ by the heavy grid lines running along the Intracoastal Waterway.

(a) Letter from Robert K. Gabrysch, Chief, Houston Subdistrict, U.S. Geological Survey to Richard Skaggs, PNL. 


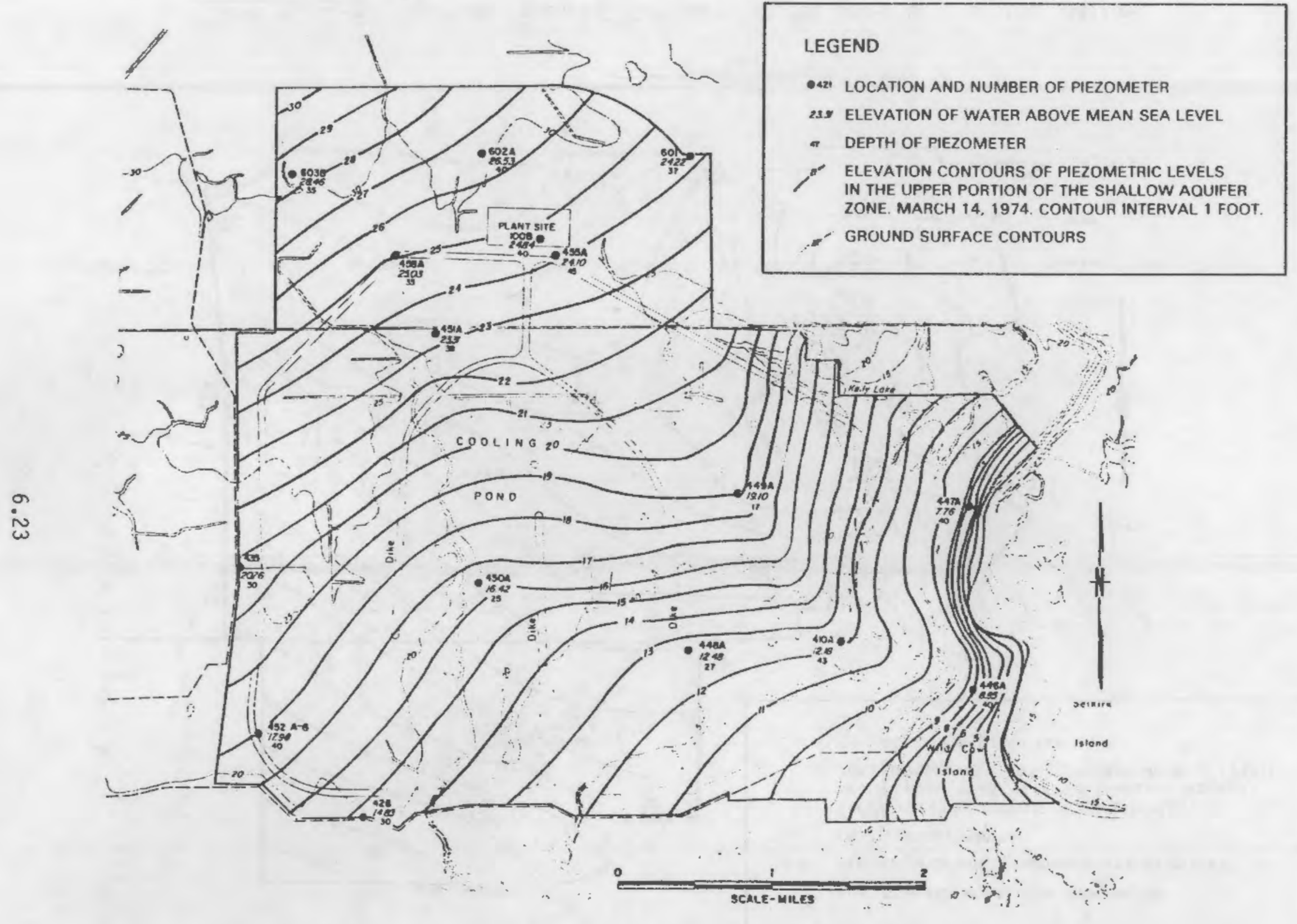

FIGURE 6.3.2-5. Observed Potential Contours for the Upper Unit of the Shallow Aquifer Zone (Source: Houston Power and Light 1978) 


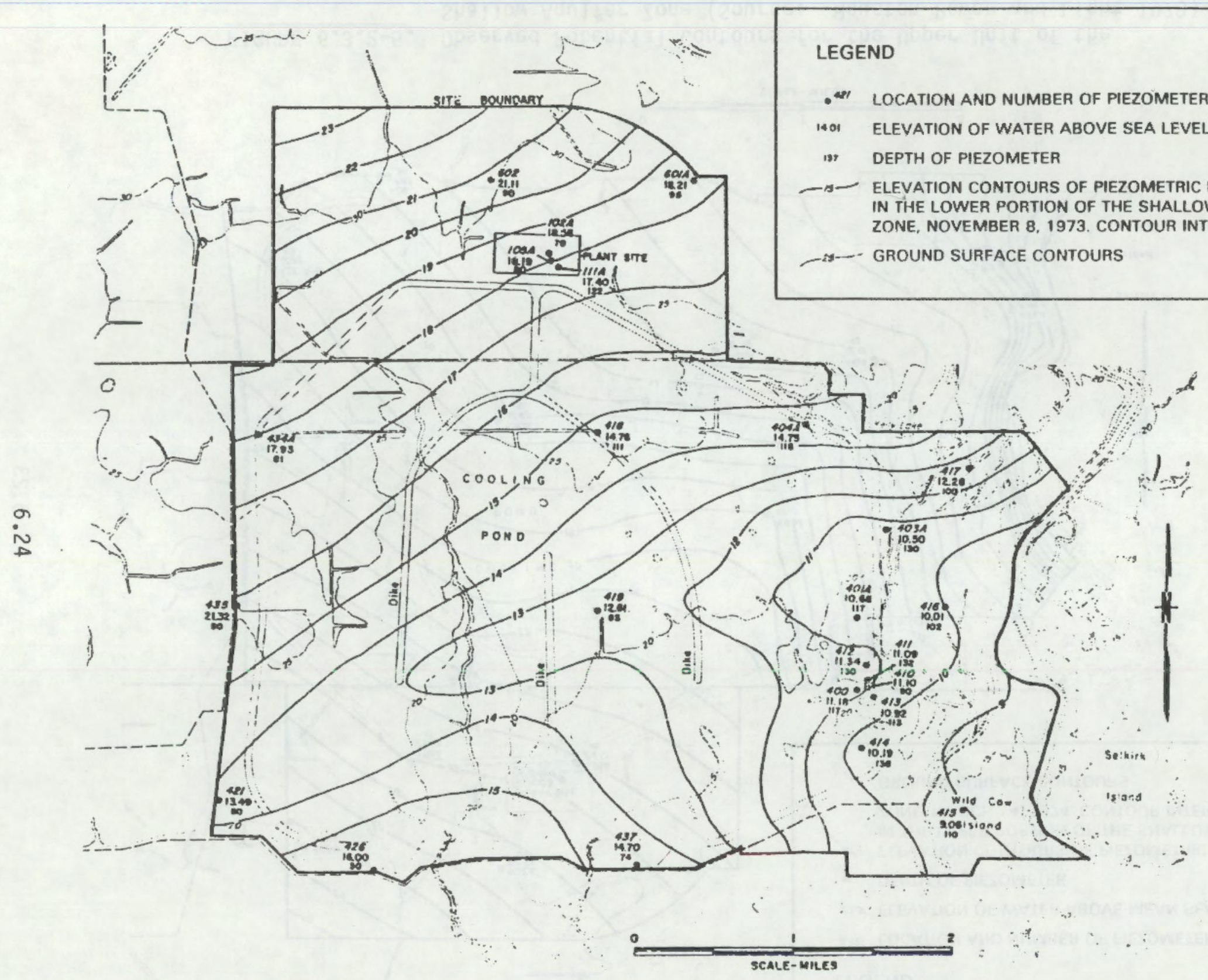

FIGURE 6.3.2-6. Observed Potential Contours for the Lower Unit of the Shallow Aquifer Zone (Source: Houston Power and Light 1978) 


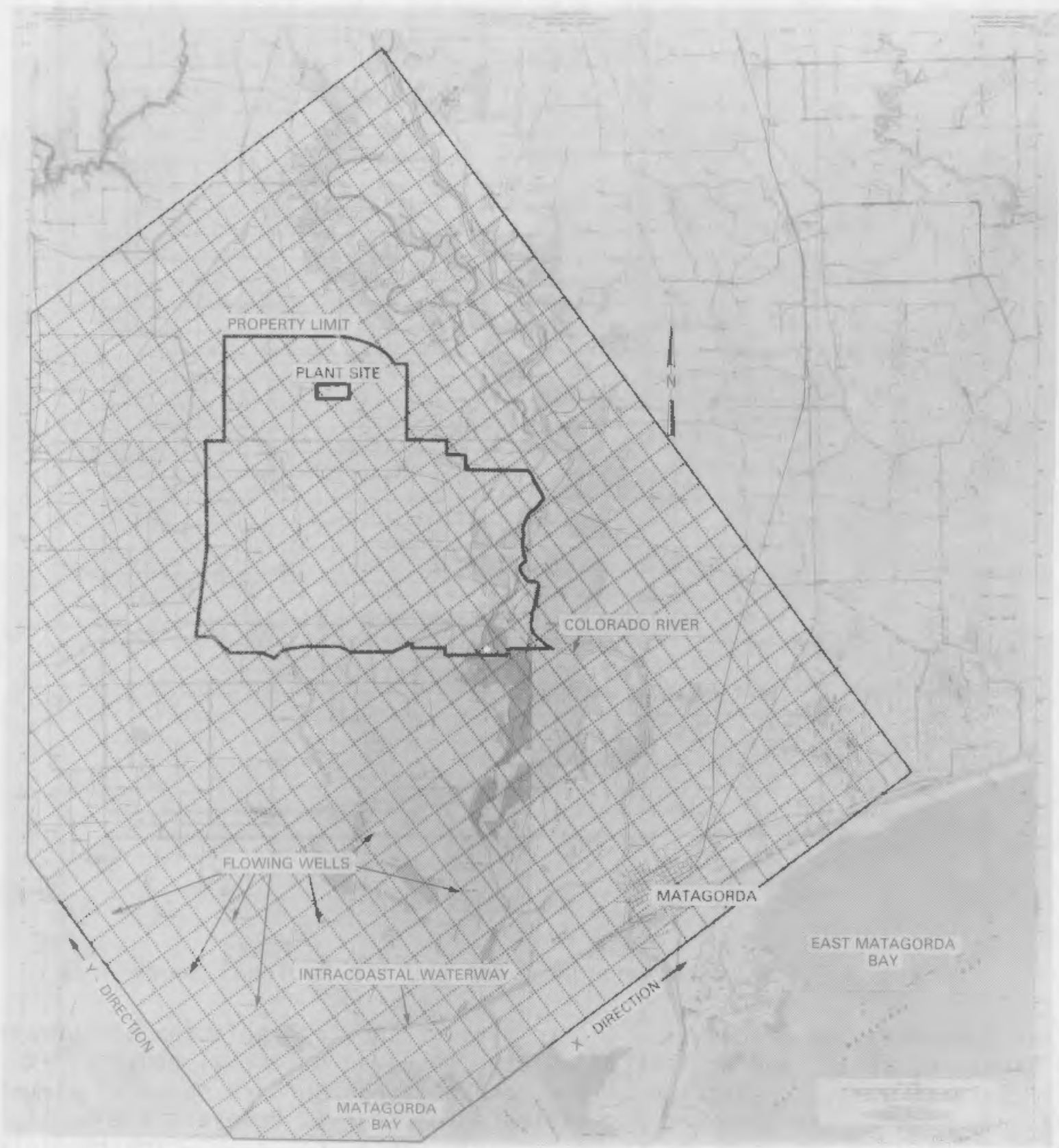

FIGURE 6.2.3-7. Partial Outline of Regional Study Area Superimposed on the STP Topographic Map

Several of the observed contours of equal hydraulic head were extended the breadth of the regional grid. The contour extensions were based primarily on the shape of the observed contours and additional facts such as the existence of a line of flowing wells at an approximate surface elevation of $6 \mathrm{ft}$ MSL and an apparent ground-water mound in the center of the grid. Using the observed and estimated contours shown in Figure 6.3.2-9, hydraulic heads were estimated for each node in the regional grid using a 16-direction, steepest gradient, 


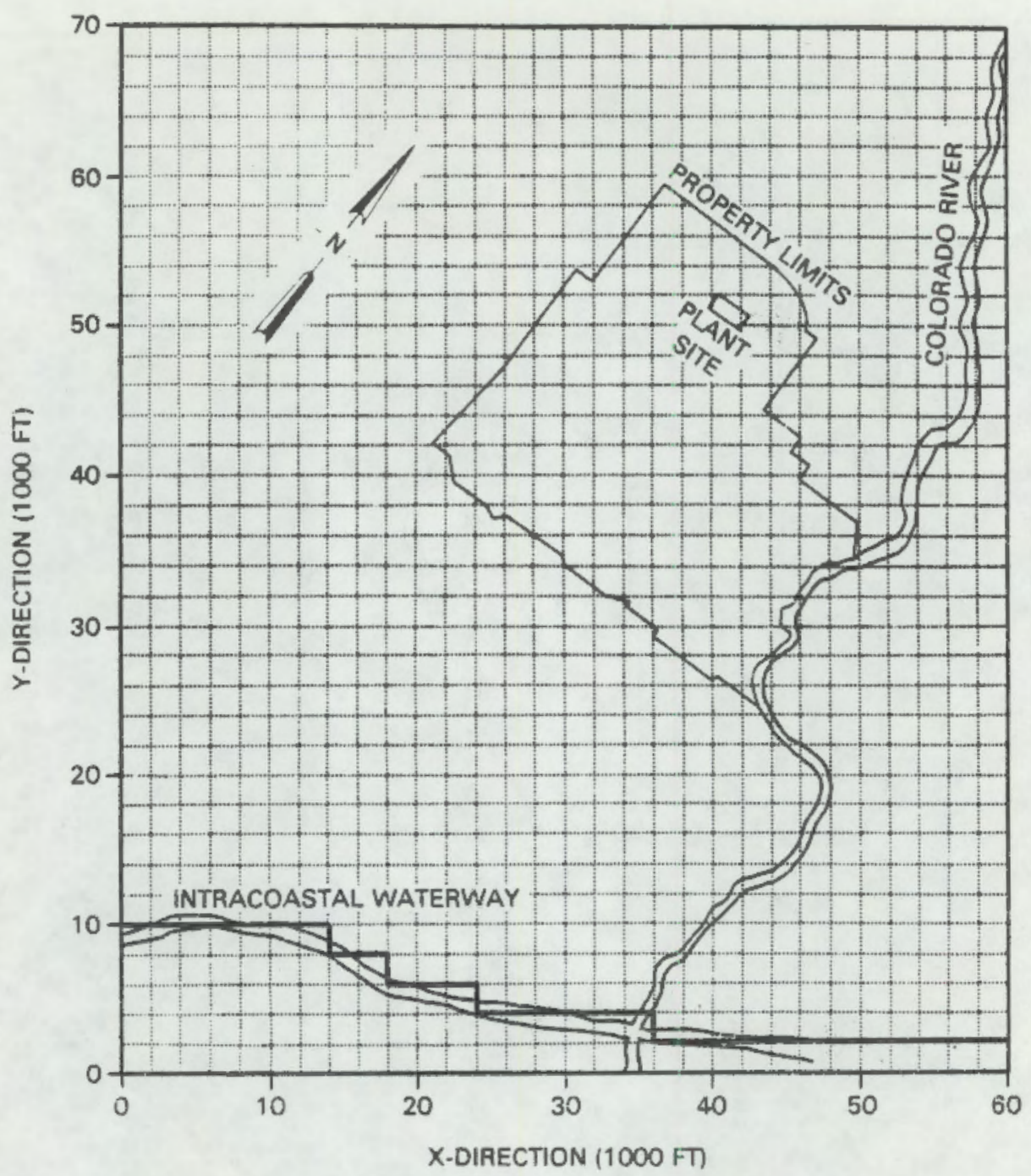

FIGURE 6.3.2-8. Complete Grid for the STP Regional Study Area

liner interpolation procedure. The results of the interpolation are presented in Figure 6.3.2-10, and designated as the "observed potential contours" for the STP regional area. Inspection of the interpolated contours shows an almost exact match with the observed and estimated contours. However, due to the interpolation scheme used and the relatively large area over which the interpolation was made, minor peculiarities were produced. The 24,26 and 28 foot contours appear to be closed indicating a ground-water mound that most likely does not exist. A1so, the 12,14, and 16 foot contours near the western edge of the area incorrectly bend upward. In both instances the net effect on the overall flow field, particularly in the vicinity of the STP site, is insignificant. 


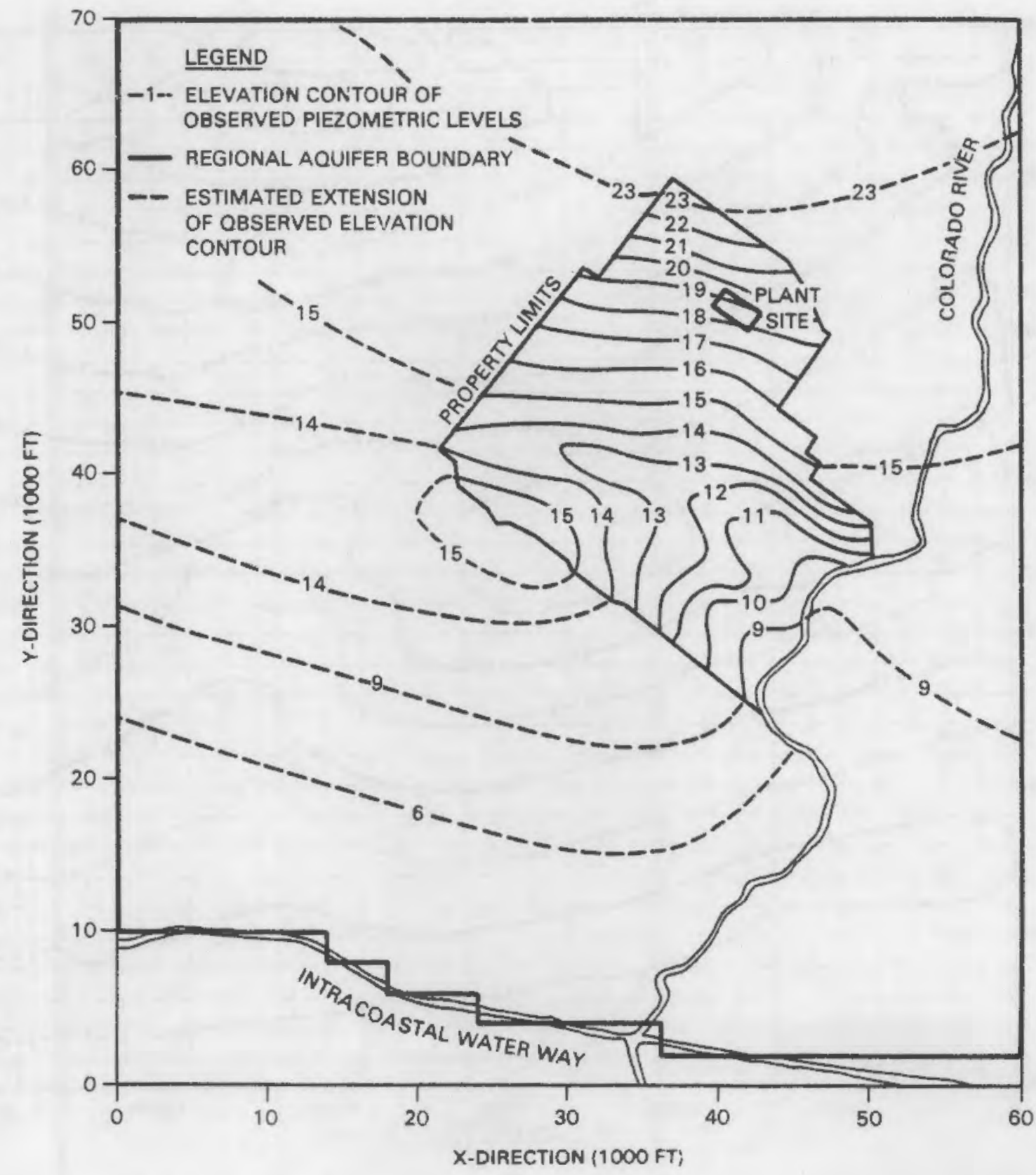

FIGURE 6.3.2-9. Observed and Estimated Potential Contours for STP Regional Study Area

Inspection of the observed potentials shows that near the east and west grid boundaries the contours are approximately perpendicular to the $y$-direction. In the model, these boundaries are assumed to be head-controlled boundaries having constant head values equivalent to those shown in Figure 6.3.2-10.

The northern-most boundary is assumed to be a flow-controlled boundary where the head and flow at the boundary will be determined by the model. 


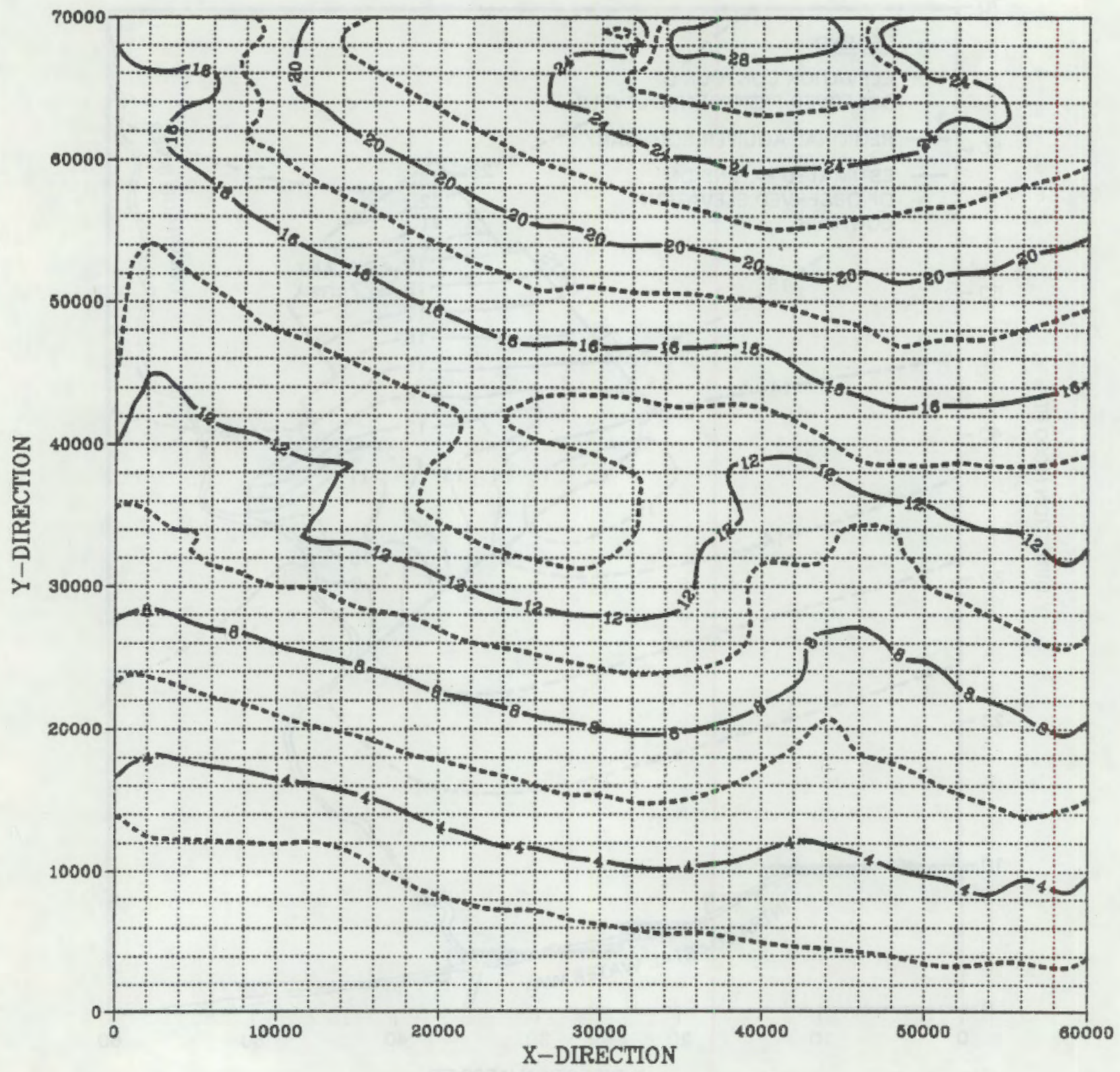

FIGURE 6.3.2-10. Observed Potential Contours for the STP Regional Area 


\subsubsection{Aquifer Thickness and Lateral Extent}

Typically, the lateral extent and thickness of an aquifer vary considerably from one place to another. Fluvial basin aquifers commonly thin toward the rim of the basin while some basins show structural deformation due to downwarping and faulting. The primary sources of data for delineation of aquifer lateral extent are generally well and bore logs, and existing geologic maps. From these data, the aquifer top and bottom elevations are determined and the aquifer thickness calculated as the difference between the two.

The primary sources of information for the STP site were well and bore logging data presented in the STP FSAR (Houston Power and Light 1978). Useful information was also obtained from Hammond (1969). Over 100 oil or gas well electric logs, water well drilling logs, and soil borings were identified in the STP FSAR (Houston Power and Light 1978). Though the actual data from the logs and boring were not available for this study, three geohydrologic crosssections interpreting the data were presented in the STP FSAR (Houston Power and Light 1978). Two cross-sections are shown in Figure 6.3.2-11 while the third is presented in Figure 6.3.2-3 above. The approximate locations of the three cross-sections relative to the STP site are indicated in Figure 6.3.2-12. It is clear from the figure that only a limited portion of the cross-sections extend outside the STP property limits. Therefore, for modeling purposes, it was necessary to infer from the cross-sections the top and bottom elevations of the lower unit for the study area.

The basic approach to accomplishing this is to compute values for the aquifer top and bottom at the node points of the regional grid using a fifthdegree polynomial interpolating function developed by International Mathematical and Statistical Libraries, Inc. (IMSL), (1980). Contour and surface maps showing the interpolated results for the top and bottom elevations are presented in Figures $6.3 .2-13$ and $6.3 .2-14$, respectively. The $(0,0)$ coordinate for both figures corresponds to the lower left hand corner of the study grid.

To summarize data presented thus far, the conceptual model for the STP case study consists of the lower unit of the shallow zone aquifer. The lower unit is a confined or semi-confined aquifer that extends continuously over the study area. The aquifer interfaces at its bottom with the very low permeability deep confining zone and at its top with a zero or low permeability layer segregating the lower unit from the upper unit of the shallow aquifer.

The bottom of the aquifer varies from approximately -60 feet mean sea level (MSL) to -120 feet MSL. Similarly, the top varies from about -30 feet MSL to -60 feet. Both the aquifer top and bottom dip from the northwest to the southeast which is consistent with the slope of the underlying Beaumont Formation as described by Hammond (1969). The thickness of the lower unit varies from about 28 feet to 62 feet. An overlay of the lower unit aquifer top and bottom illustrating the spatial distribution of the thickness is presented in Figure 6.3.2-15. 


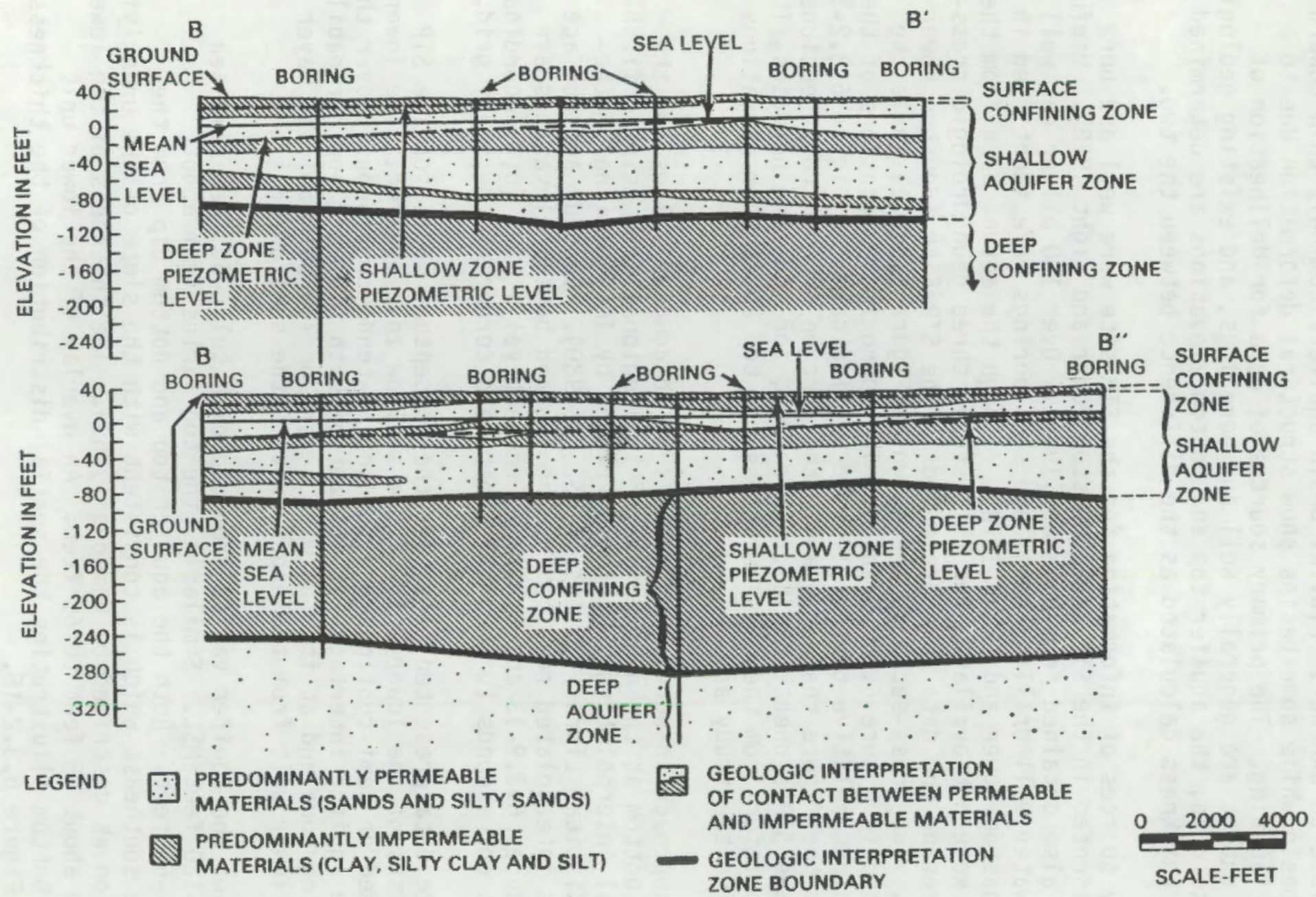

FIGURE 6.3.2-11. Geohydrologic Cross-Sections B-B' and B-B" for the STP Site (Source: Houston Power and Light 1978) 


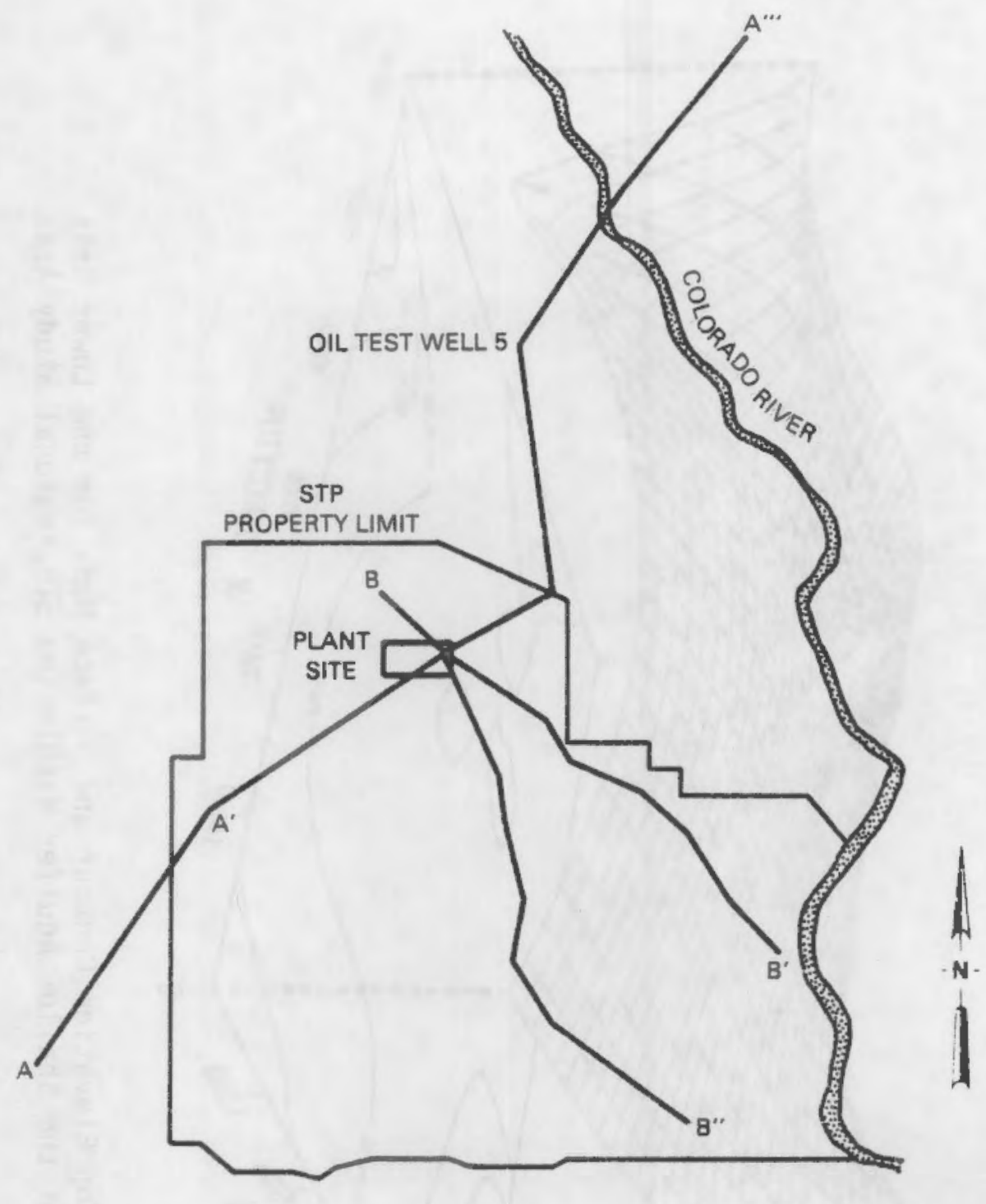

FIGURE 6.3.2-12. Locations of the Geohydrologic Cross-Section $A-A^{\prime \prime \prime}, B-B^{\prime}$ and $B-B^{\prime \prime}$ (Source: Houst on Power and Light 1978)

\subsubsection{Porous Media Hydraulic Properties}

The magnitude and spatial distribution of a number of material properties must be specified for the aquifer under study. Table $6.3 .2-3$ presents some of the required properties for each of the aquifer types (Boonstra and de Ridder 1981). A variety of field, laboratory and numerical methods have been developed to determine the different hydraulic properties. For discussions of the various methods, the reader is referred to Bentall (1963), Krusemand and de Ridder (1970), Of fice of Water Data Coordination (1977) and Boonstra and de Ridder (1981). 


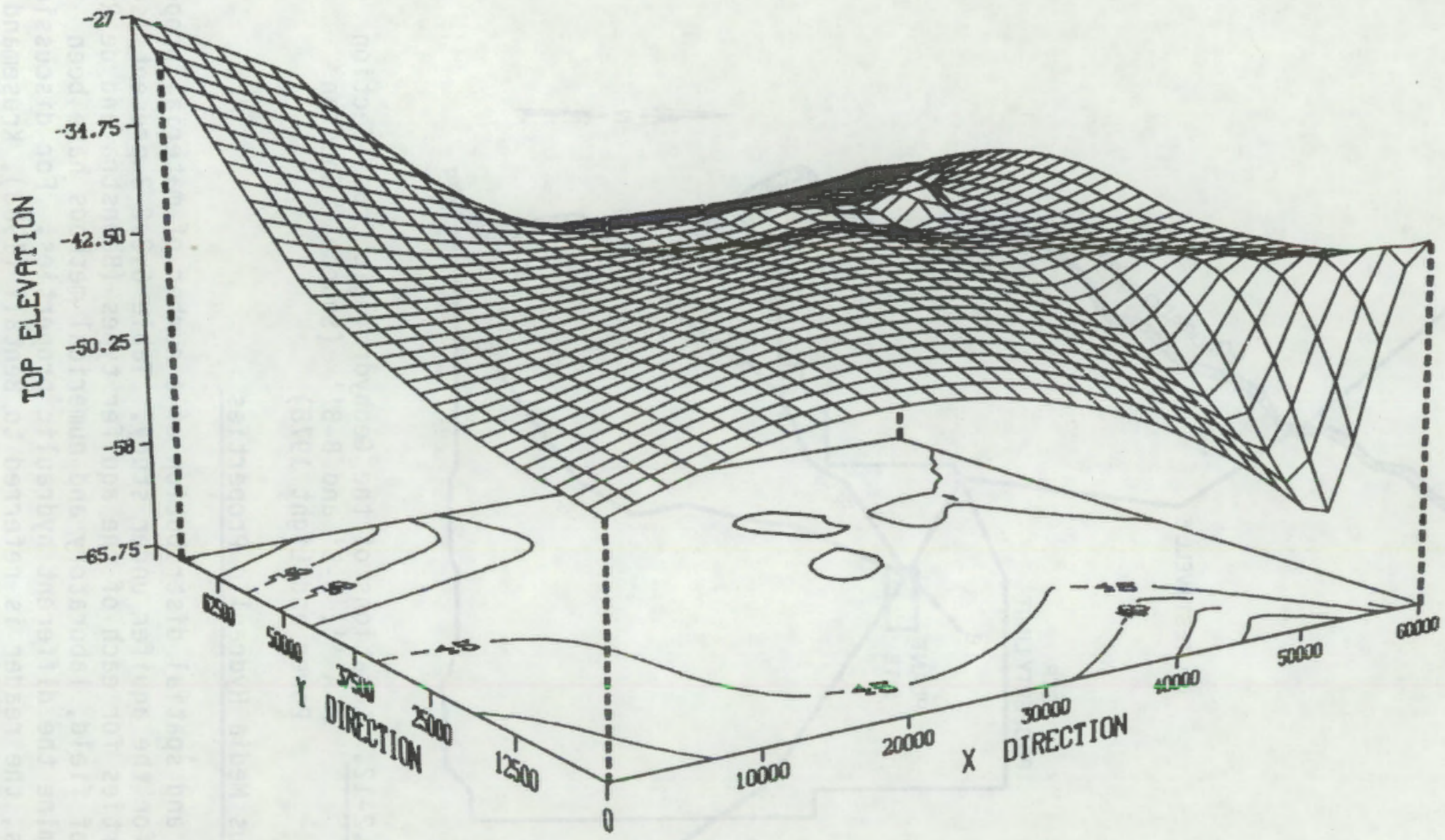

FIGURE 6.3.2-13. Top Elevation Contour and Surface Maps for the Lower Unit of the Shallow Aquifer Within the STP Regional Study Area 


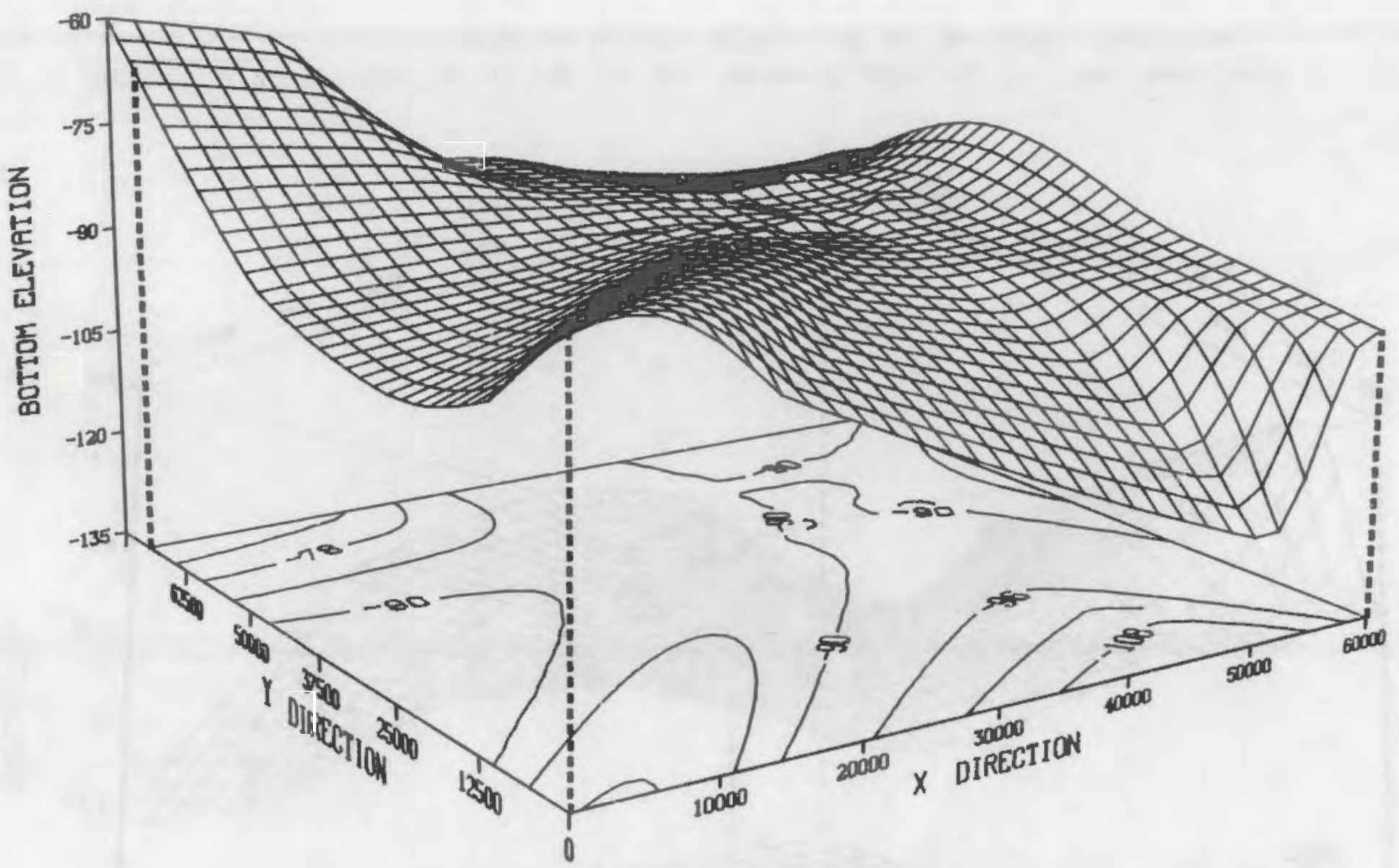

FIGURE 6.3.2-14. Bottom Elevation Contour and Surface Maps for the Upper Unit of the Shallow Aquifer Within the STP Regional Study Area 


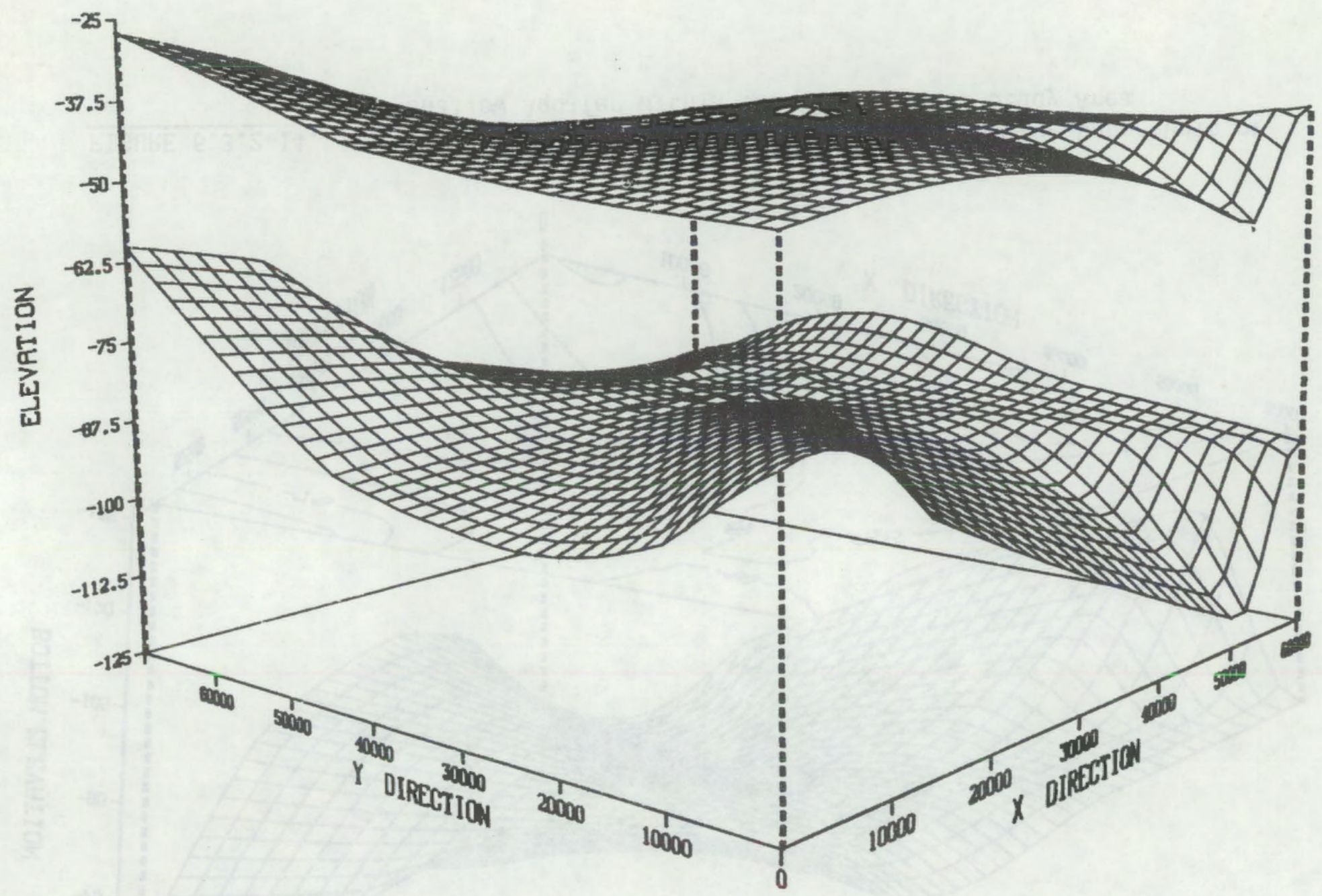

FIGURE 6.3.2-15. Overlay of the Top and Bottom Elevations for the Lower Unit of the Shallow Aquifer Within the STP Regional Study Area 
TABLE 6.3.2-3. Required Porous Media Hydraulic Properties

\begin{tabular}{|c|c|c|c|}
\hline \multirow[b]{2}{*}{ Property } & \multicolumn{3}{|c|}{ Aquifer Type } \\
\hline & Confined & Unconfined & Semi-Confined \\
\hline Hydraulic Conductivity, K & $x$ & $x$ & $x$ \\
\hline $\begin{array}{l}\text { Hydraulic Conductivity } \\
\text { for Overlying Confining } \\
\text { Layer, } K^{\prime}\end{array}$ & & 1 & $x$ \\
\hline $\begin{array}{l}\text { Storage Coefficient, (for } \\
\text { transient simulation } \\
\text { only), S }\end{array}$ & $x$ & & $x$ \\
\hline Specific Yield, $\mu$ & & $x$ & \\
\hline Porosity, $n$ & $x$ & $x$ & $x$ \\
\hline Effective Porosity, $n_{e}$ & $x$ & $x$ & $x$ \\
\hline
\end{tabular}

The data and information concerning the hydraulic properties for the lower unit of the shallow aquifer zone were compiled primarily from the results of four pumping tests conducted in the shallow zone within the STP property limits (Houston Power and Light 1978). The depths of the tests and the test results are summarized in Table 6.3.2-4.

Based on the test depths, pump test 3 most likely measures the conditions in the upper unit while the remaining test depths coincide with the lower unit. Therefore, hydraulic conductivities in the lower unit are in the range of 400 to $600 \mathrm{gpd} / \mathrm{ft}^{2}$ while storage coefficients vary from 0.00045 to 0.0007 .

Additional information regarding hydraulic properties related to analyses of accidental radionuclide releases in the lower aquifer unit is presented in the STP FSAR (Houston Power and Light 1978). For the analysis discussed, the following properties were assumed:

- hydraulic conductivity $635 \mathrm{gal} / \mathrm{day} / \mathrm{ft}^{2}$

- porosity: $37 \%$.

Complementing the information obtained from the STP FSAR, Hammond (1969) describes the hydraulic characteristic of the Gulf Coast aquifer. Though Hammond's discussion emphasizes the heavily pumped deep aquifer zone, the information provides a framework for evaluating the FSAR pumping tests data. Pumping tests in Matagorda County and surrounding areas provide values of hydraulic conduçtivity for the sands of the Gulf Coast aquifer ranging from 103 to $3,950 \mathrm{gpd} / \mathrm{ft}^{2}$ and averaging about $570 \mathrm{gpd} / \mathrm{ft}^{2}$. Generally, the deeper sands, because of increased compaction and cementation, have lower hydraulic 
TABLE 6.3.2-4. Aquifer Test Summary (Source: Houston Power and Light 1978)

Hydraulic

\begin{tabular}{|c|c|c|c|c|}
\hline $\begin{array}{l}\text { Pump Test } \\
\text { Number }\end{array}$ & $\begin{array}{c}\text { Test Depth } \\
(\mathrm{ft})\end{array}$ & $\begin{array}{c}\text { Transmissivity } \\
\text { (gpd/ft) }\end{array}$ & $\begin{array}{c}\text { Conductivity } \\
\left(\mathrm{gpd} / \mathrm{ft}^{2}\right)\end{array}$ & $\begin{array}{c}\text { Storage } \\
\text { Coefficient } \\
\end{array}$ \\
\hline 1 & $60-140$ & 33,000 & 410 & 0.00071 \\
\hline 2 & $59-83$ & 13,000 & $600^{\circ}$ & 0.00045 \\
\hline 3 & $20-43$ & 1,100 & 65 & 0.0017 \\
\hline 4 & $30-45$ & 10,500 & 420 & 0.0007 \\
\hline
\end{tabular}

conductivities. Table 6.3.2-5 presents the results of the pump tests for the two wells in Matagorda County that are partially screened in the lower unit aquifer. The transmissivities for both wells are relatively high compared to $70,000 \mathrm{gpd} / \mathrm{ft}$ average value for the deeper wells.

The hydraulic conductivity value in Table $6.3 .2-5$ is also much higher than the pump test results presented in the FSAR (Table 6.3.2-4). This is explained in part by Hammond's observation that lower permeabilities are generally found near the coast due to finer grain size sediments. The sands away from the coast are part of the Colorado River alluvial deposits and tend to have coarser size distributions.

The storage coefficients of the STP pump tests 1,2 , and 3 were in the neighborhood of $5 \times 10^{-4}$ to $7 \times 10^{-4}$ (Houston Power and Light 1978). The single value for storage coefficient shown in Table 6.3.2-5 is similar in magnitude, having a value of $1.1 \times 10^{-3}$. These values are typical for a confined aquifer and confirm the conceptual model based on bore logs.

TABLE 6.3.2-5. Pump Test Results for Wells in Matagorda County (Source: Hammond 1969)

\begin{tabular}{|c|c|c|c|c|c|}
\hline $\begin{array}{c}\text { Well } \\
\text { Number }\end{array}$ & Date & $\begin{array}{l}\text { Screened } \\
\text { Internal } \\
\text { (ft MSL) } \\
\end{array}$ & $\begin{array}{l}\text { Hydraulic } \\
\text { Conductixity } \\
\text { (gpd/ft } / \mathrm{ft}^{2}\end{array}$ & $\begin{array}{c}\text { Transmissivity } \\
\text { (gpd/ft) }\end{array}$ & $\begin{array}{c}\text { Storage } \\
\text { Coefficient } \\
\end{array}$ \\
\hline$T A-65-58-107$ & $10-04-66$ & $75-202$ & -- & 176,000 & $1.1 \times 10^{-3}$ \\
\hline TA-65-58-803 & $05-01-66$ & $91-215$ & 3,950 & 399,000 & $=-$ \\
\hline
\end{tabular}

The values for porosity provided by Hammond (1969) are representative ranges for sedimentary material. These are presented below in Table 6.3.2-6. On the basis of the values shown, the value for porosity of $37 \%$ assumed in the FSAR (Houston Power and Light 1978) is within the range for medium to coarse mixed sand $(35-40 \%)$ and uniform sand $(30-40 \%)$. The assumed value is slightly outside the $30 \%$ to $35 \%$ range for the fine to medium mixed sand. 
TABLE 6.3.2-6. Representative Porosities for Sedimentary

Material (Source: Hammond 1969)

\begin{tabular}{lr}
\multicolumn{1}{c}{ Material } & Porosity, $\%$ \\
\cline { 1 - 1 } Soils & $50-60$ \\
Clay & $45-55$ \\
Silt & $40-50$ \\
Medium to coarse mixed sand & $35-40$ \\
Uniform sand & $30-40$ \\
Fine to medium mixed sand & $30-35$ \\
Gravel & $30-40$ \\
Gravel and sand & $20-35$ \\
Sandstone & $10-20$ \\
Shale & $1-10$
\end{tabular}

\subsubsection{Hydraulic Head (Ground-Water Potential)}

Generally, a ground-water basin experience a number simultaneously occurring of hydrologic stresses (Boonstra and de Ridder 1981). These stresses include: infiltration of rainfall and/or irrigation water, streambed percolation, evapotranspiration, ground-water discharge by streams or springs and well pumpage. At any given time, the combined effects of the stresses are reflected in the configuration and fluctuation of the basin hydraulic heads. Consequently, the collection and evaluation of watertable data are important parts of ground-water model development (i.e., calibration by history matching). Simulated hydraulic heads are compared with measured values to ensure the ground-water model is representing the various stresses that are being exerted on the basin. The data requirements for quantifying the hydrologic stress and the results obtained for the STP site are discussed below.

The magnitude and distribution of the hydraulic head within a basin and at the boundaries are determined by observation wells and/or piezometers. For confined and unconfined aquifers, only observation wells screened in the aquifer of study are required. In a semi-confined aquifer, however, hydraulic head measurements are required in the study aquifer as well as in the aquifer overlying the permeable confining layer. Though not used directly, the heads for the overlying aquifer are required to compute recharge/discharge through the confining layer. Under normal conditions, the observation wells should be measured periodically (dependent on local conditions) for one to two years to establish temporal hydraulic head level fluctuation trends.

The results of the water level measurements are best presented in the form of maps of equal contours of hydraulic hgeads, hydrographs, and, if applicable, head-difference maps. The necessary map(s) must be generated for the beginning of the study period to establish the initial conditions for the basin. If 
sufficient change in the head contours occurs within the basin over time due to récharge, discharge, pumping, etc., then maps are also needed for each successive time period chosen for modeling. If steady-state conditions are assumed for the basin, the model is calibrated only for the specified initial conditions. For a semi-confined aquifer, two hydraulic head contour maps must be drawn; one for the study aquifer and one for the aquifer above the confining layer.

At the STP site, hydraulic head data are limited to those available in the STP FSAR (Houston Power and Light 1978). Contours of the observed data for the lower and upper units of the shallow aquifer zone are presented in Figures 6.3.2-5 and 6.3.2-6. As discussed in Section 6.3.2.4, the contours were extrapolated over the study region based upon the available information. The results of this process for the lower unit are presented in Figure 6.3.2-10. The same procedure is followed to extrapolate data for the upper unit. Since the available data are limited to measurements taken on a single day (i.e., May 14, 1974 from the upper unit and November 8, 1973 for the lower unit) the following assumptions are made:

1. post-construction potential levels rebounded to those measured,

2. steady-state conditions prevail in the upper and lower unit aquifers, and

3. the measured data are representative of steady-state conditions.

The primary reason for making these assumptions is that the data required to characterize dynamic conditions within the basin and the efforts of construction were unavailable.

The main source of temporal change within the basin is the Colorado River which under normal conditions can experience stage changes of up to 10 feet within a given year. Figure 6.3.2-16 shows the response of the Colorado River to typical rainfall period in 1973 and the associated response of the lower and upper units of the shallow aquifer zone. It can be seen that the response of the lower unit is attenuated significantly compared to that of the upper unit. With regard to the first assumption, the single greatest potential effect is due to construction of the Cooling Reservoir (see Figure 6.2.2-1). As stated in the STP FSAR (Houston Power and Light 1978), the normal maximum operating level for the Cooling Reservoir is 49 feet MSL which is over 20 feet above the surrounding ground surface. Thus, seepage from the Cooling Reservoir will tend to raise local ground-water potentials. However, the reservoir embankment is designed to use compacted fill, to insure that the piezometric levels of the soil in the plant area remain below the ground surface. Since pre-construction levels in the upper aquifer were 2 to 3 feet below the ground surface, this would indicate the ground-water mounding will be less than 2 to 3 feet. Further, since the seepage from the Cooling Reservoir will discharge directly into the upper unit, the effect in the lower unit will be limited to the increased leakage that will occur due to the higher hydraulic head. 

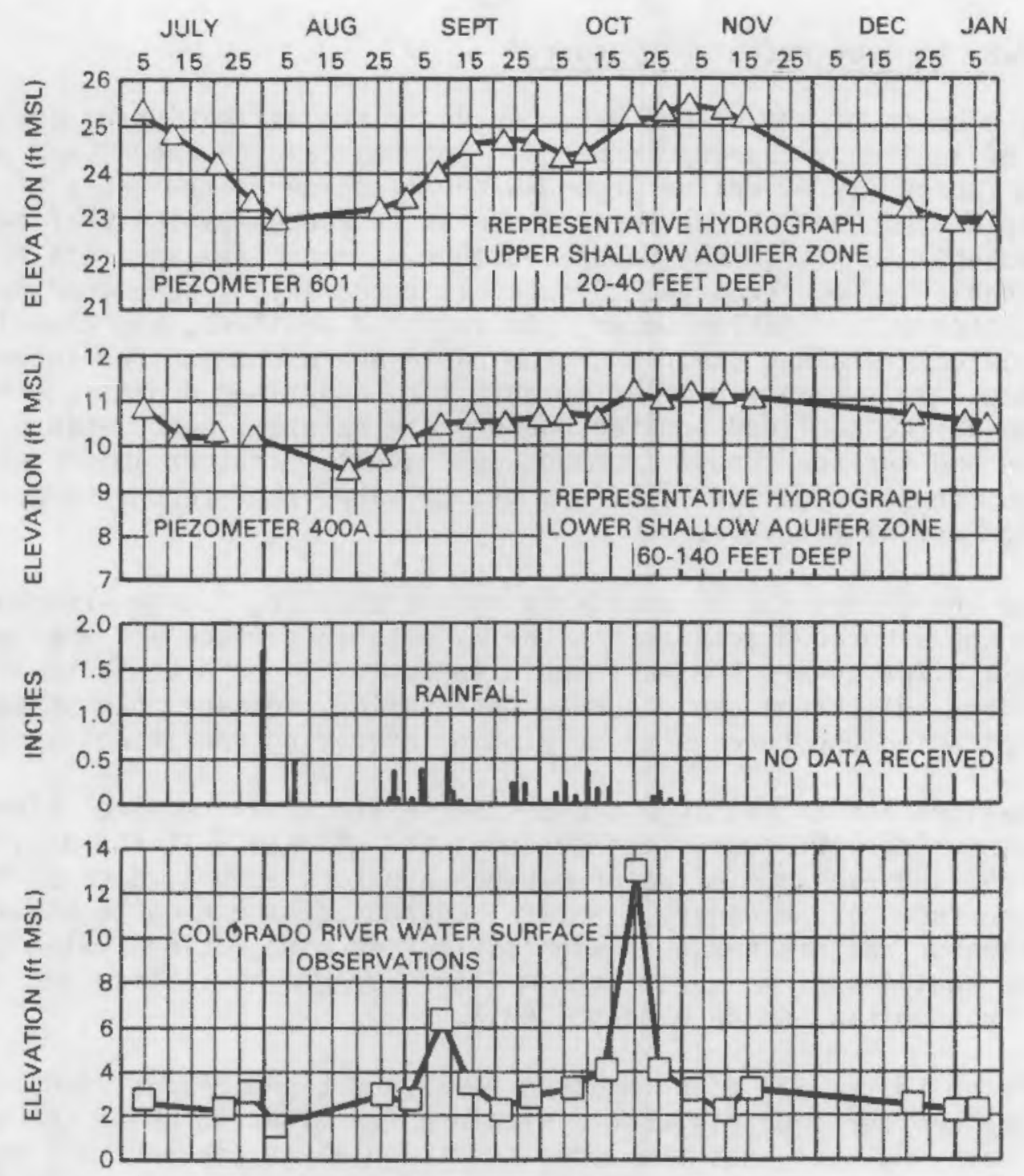

NOTES

1. RIVER LEVEL MEASUREMENTS MADE AT FM ROAD 521 BRIDGE APPROXIMATELY TWO MILES EAST OF SITE.

2. RAINFALL MEASUREMENTS FROM SOUTH TEXAS PROJECT METEOROLOGICAL TOWER.

FIGURE 6.3.2-16. 1973 Water Level Observations in the Vicinity of the STP Site (Source: Houston Power and Light 1978)

From the above discussion, it is apparent that changes in hydrologic stresses with time and changes due to the STP construction will modify the potentials measured for the upper and lower units of the shallow aquifer. However, based on the evidence presented it appears that the effects of these changes are not severe in the lower unit. Therefore, in light of the stated objectives of the case study, the limitations associated with making the stated assumptions regarding the use of available hydraulic head data are considered acceptable by the authors. 


\subsubsection{Aquifer Recharge/Discharge}

A key element of any ground-water study is the estimation of the type and magnitude of aquifer recharge/discharge. For the case of unconfined aquifers Freeze and Cherry (1979) define ground-water recharge as the entry of water into the saturated zone at the water table surface accompanied by flow away from the watertable within the saturated zone. Unconfined aquifers having a deep watertable can be recharged by rainfall percolation, streambed percolation and percolation of irrigation water. In confined aquifers, recharge in the strict sence occurs along the rim of the basin where the aquifer intersects the land surface. In a manner similar to that for unconfined aquifers, the sources of recharge at the confined aquifer outcrop are rainfall percolation, streambed percolation and surface runoff from adjacent areas. Another important source of recharge for semi-confined aquifers may be water flow through over- or under-lying confining layers.

Freeze and Cherry (1979) similarly define discharge as the removal of water from the saturated zone across the watertable surface accompanied by flow within the aquifer toward the watertable surface. In both confined and unconfined aquifers, discharge can occur as spring flow, seepage into streams, evapotranspiration and through underlying or overlying confining layers.

The delineation of recharge and discharge areas may require information on topography, surface and subsurface geology, and climate. If the aquifer is semi-confined and exchange of water between aquifers occurs, data on hydraulic potential surfaces is necessary. Several methods can be used to estimate aquifer recharge and discharge. Examples include computations using Darcy's equation or analysis of measured stream flow hydrographs. These and others are described by Boonstra and de Ridder (1981).

According to the STP FSAR (Houston Power and Light 1978), recharge of the shallow-zone aquifer probably occurs within a few miles north of the site. The available data indicate that the upper confining layer prevents any appreciable recharge within or to the south of the site. Consequently, analysis of recharge for the lower unit of the shallow aquifer is limited to seepage from the upper unit. Discharge from the lower unit, as discussed previously regarding boundary conditions, is assumed to occur at the Intracoastal Waterway and by vertical seepage, particularly at the Colorado River. The recharge and discharge of the lower unit were calculated by applying a form of Darcy's equation (Freeze and Cherry 1979):

$$
Q=-K^{\prime} \frac{\left(h-h^{\prime}\right)}{m^{\prime}} \Delta x \Delta y
$$

where

$Q=$ recharge/discharge rate (gpd)

$K^{\prime}=$ vertical hydraulic conductivity in confining bed (gpd/ft)

$\mathrm{h}=$ hydraulic head in aquifer (ft MSL)

$\mathrm{h}^{\prime}=$ hydraulic head in covering layer ( $\mathrm{ft}$ MSL)

$\mathrm{m}^{\prime}=$ thickness of confining bed ( $\mathrm{ft}$ )

$\Delta x=x$-dimension of regional grid elements $(\mathrm{ft})$

$\Delta y=y$-dimension of regional grid elements $(\mathrm{ft})$. 
A negative value for $\left(h-h^{\prime}\right)$ indicates flow of water into the lower unit. Conversely, a positive value signifies water is being discharged by the lower unit as vertical upward seepage.

The initial evaluations of recharge and discharge were computed at each node of the regional grid based upon an assumed uniform vertical hydraulic conductivity, the previously determined potentials for the upper and lower units of the shallow aquifer, values of the confining layer thickness interpolated from the available geohydrologic cross-sections, and the values of $\Delta x$ and $\Delta y$ determined directly from the regional study grid. The vertical hydraulic conductivity was initially set at $0.005 \mathrm{gpd} / \mathrm{ft}^{2}$ based on the range of $0.01 \mathrm{gpd} / \mathrm{ft}^{2}$ to $0.00001 \mathrm{gpd} / \mathrm{ft}^{2}$ provided by Freeze and Cherry (1979) for unconsolidated, unweathered marine clay. The results of the initial evaluation were a net recharge to the aquifer of $1.6 \times 10^{6} \mathrm{gpd}$ or $3.7 \times 10^{-4} \mathrm{gpd} / \mathrm{ft}^{2}$ of aquifer.

According to Hammond (1969), in some parts of Matagorda County, available data indicate that sands in the deep zone aquifer are replenished by water from overlying shallower sands through the bore holes of idle water wells. Obviously, this is not directly accounted for in the recharge/discharge analyses. If this represents a significant form of water loss which has affected observed potentials, it will ultimately be reflected in the model through the calibration procedure by reducing the recharge from the overlying unit to achieve the necessary water balance. Another possibility not accounted for is downward vertical seepage from the lower unit shallow aquifer to the deep zone aquifer. Though there is significant head differential between the two aquifers, as much as 30 feet, it is believed that the 100 to 200 foot thick deep confining zone would limit the seepage to insignificant levels.

Hammond (1969) reports that most of the irrigation, public supply and industrial wells in Matagorda County produce water from the 200 to 700 foot depth interval. Due to the high salinity of the shallow zone aquifer, only minor pumpage for some domestic and livestock wells produce from shallower depths. A summary of estimated 1973 ground-water usage within a 10-mile radius of the STP site is shown in Table 6.3.2.7 (Houston Power and Light 1978). The total 130 acre-ft/yr withdrawal from the shallow-zone aquifer, equivalent to $1.2 \times 10^{5} \mathrm{gal} /$ day, is less than $7 \%$ of the computed net recharge rate. The pumpage was not directly accounted for in developing the ground-water model of the lower unit of the shallow aquifers.

\subsubsection{Conceptual Model}

The preceding sections describe a majority of the data obtained and analyzed for the STP case study. In the sections following, the numerical model development, calibration and simulations are presented. The bridge linking the two efforts is the conceptual model of the ground-water flow system that determines transport of radionuclide releases due to a postulated severe accident at the STP site. 
TABLE 6.3.2.7. Summary of Estimated 1973 Ground-Water Use in the Vicinity of the STP (Source: Houston Power and Light 1978)

\begin{tabular}{|c|c|c|c|c|}
\hline \multirow[b]{2}{*}{$\begin{array}{c}\text { Ground-Water } \\
\text { Use }\end{array}$} & \multicolumn{2}{|c|}{ Total Wells in Operation } & \multicolumn{2}{|c|}{$(a c r e-f t / y r)$} \\
\hline & $\begin{array}{l}\text { Shallow } \\
\text { Aquifer Zone }\end{array}$ & $\begin{array}{c}\text { Deep } \\
\text { Aquifer Zone }\end{array}$ & $\begin{array}{c}\text { Shallow } \\
\text { Aquifer Zone }\end{array}$ & $\begin{array}{c}\text { Deep } \\
\text { Aquifer Zone }\end{array}$ \\
\hline Irrigation & - & 17 & - & 1,750 \\
\hline Industrial & - & 1 & - & 160 \\
\hline $\begin{array}{l}\text { Public and } \\
\text { Municipal }\end{array}$ & - & 7 & - & 100 \\
\hline $\begin{array}{l}\text { Stock and } \\
\text { Domestic }\end{array}$ & 49 & 69 & 100 & 140 \\
\hline Drilling Supply & 1 & 1 & 30 & 30 \\
\hline TOTAL & 50 & 95 & 130 & 2,180 \\
\hline
\end{tabular}

A conceptual model, defined by Simmons and Cole (1983) is the modeler's perception of the physical behavior of a ground-water system. Conceptual model development is simply the process by which a preliminary description and understanding of a ground-water system is obtained based on available data, experience and fundamental hydrologic principles. The conceptual model thus becomes, a simplified composite picture of what is known about the study area, hydrogeologic boundaries and boundary conditions, geologic and stratigraphic layers, ground-water flow directions and quantities, flow barriers, recharge/discharge areas, time dependencies of the flow system, etc.

A general rule suggested by Simmons and Cole (1983) for developing a conceptual model is: "a model should be made as simple as possible and only the detail necessary to explain the available data and observed phenomena relevant to the study objectives should be included." Further, as depicted in Figure 6.3.1-1, development of the conceptual model is a continuing process that occurs parallel to the numerical model development. As new data and new understanding about the system are gained, the conceptual model is updated as required throughout the study.

The objective of the STP case study requires the development a groundwater model to simulate the transport of radionuclides released by a severe accident. Given the postulated accident scenario, it is assumed the molten reactor core mass would ultimately rest approximately $35 \mathrm{ft}$ below the STP containment building basemat within the lower unit of the shallow-zone aquifer. On the basis of this assumption, development of the conceptual model focused on the lower unit. The key features of the conceptual model are listed below and illustrated in Figure 6.3.2-17: 


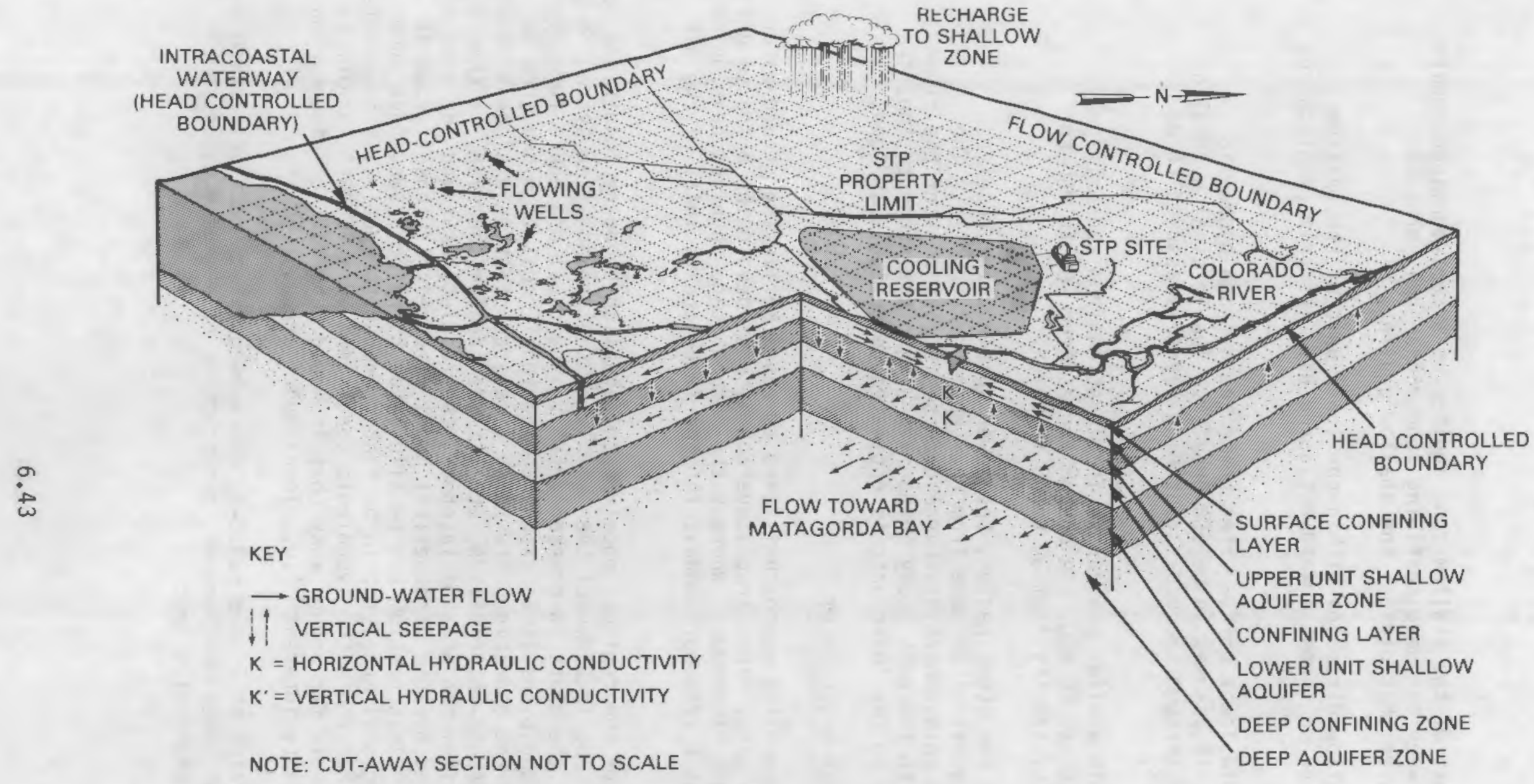

FIGURE 6.3.2-17. Illustration of the Conceptual Model for the STP Site 
- The lower unit of the shallow-zone aquifer is a semi-confined aquifer situated between the deep confining zone and a semi-permeable confining layer that divides the shallow aquifer.

- The general flow direction within the lower unit of the shallow aquifer is the southwest toward Matagorda Bay, its primary discharge point.

- From available lower unit aquifer tests the average hydraulic conductivity is assumed to be $600 \mathrm{gpd} / \mathrm{ft}^{2}$. The vertical hydraulic conductivity through the upper confining layer is assumed to be $0.005 \mathrm{gpd} / \mathrm{ft}^{2}$.

- The lower unit aquifer top ranges in elevation from approximately $-30 \mathrm{ft}$ MSL to $-60 \mathrm{ft}$ MSL, the bottom varies from $-60 \mathrm{ft}$ MSL to -120 feet MSL, and its from 30 to $60 \mathrm{ft}$ thick.

- Over most of the study region, the lower unit aquifer receives recharge as vertical seepage from the upper unit aquifer. The exception to this, where discharge occurs, is just west of the river all the way to the east study boundary. Within the study fegion, the net recharge to the lower unit is estimated to be $1.6 \times 10^{6} \mathrm{gpd}$.

\subsection{REGIONAL MODEL DEVELOPMENT}

A two-stage modeling approach is used to characterize the ground-water system at the STP site. The first stage consists of developing a coarse grid regional hydrologic flow model, whereas the second stage involves developing flow and contaminant transport models for the immediate vicinity of the STP site.

The purpose of the regional model is to establish boundary conditions for the local model. The local model then simulates the ground-water system in the immediate area of the plant in greater detail. The usual procedure for determining boundary conditions is to extend the regional model from the area of interest to where the conditions are known (i.e., constant head along a river, no flow along a ground-water divide, etc.). The problem, however, is that if one goes too far from the area of interest, the resolution around the area of interest is reduced because of numerical model size restrictions (i.e., the number of nodes). This problem can be alleviated by using a two-stage modeling approach. The regional model should be coarse enough to enable its boundaries extend out to either where the hydrologic conditions were "known", and/or to where the boundary is far enough away that it would have little influence on the area of immediate interest (i.e., local model area).

Again, referring to Figure 6.3.1-1, and subsequent to data collection and initial conceptual model development, construction of a ground-water model involves three additional steps: 
1. selection of an appropriate computer code,

2. preparation of data for model using determined parameters (Initial Model Development), and

3. compare results with observed data (Model Calibration).

\subsubsection{Code Selection}

A computer code is the numerical implementation of a set of equations that describe, in simplified form, the important physical processes acting within a ground-water system (Simmons and Cole 1983). Quite often and incorrectly, the computer code is said to be the model and model development is thought to be merely the selection of an appropriate code. However, the two processes are quite distinct. There are a number of different codes that may solve the same equations; but selecting an appropriate code for the analysis of a site specific ground-water flow and transport problem requires analyses of several factors. It is unlikely that there is a "best" code for all study purposes and objectives. For example, a code that is appropriate for flow in a porous medium may be totally inappropriate for similar analyses in a fractured environment. Codes should be selected on the basis of demonstrated numerical accuracy and faithful description of the dominant physical processes. Further, the selected code should have the necessary regional simulation capabilities (e.g., representation of spatial variations in hydraulic conductivity).

Preliminary code selection for the STP case study is based on a study of available ground-water flow and transport code capability summaries (Kincaid et al. 1983). The specific criteria used in the final code selection include:

- Is the theoretical basis of the code technically sound, is it well documented, and has it been previously implemented and verified?

- Does the code simulate the dominant hydrologic and transport processes identified in the preliminary STP conceptual model?

- Does the code provide for varying structure of the hydrologic flow and transport system?

- Will the code accept spatially varying parameters (e.g., hydraulic conductivity, transmissivity, etc.)?

- Can the code accept the appropriate boundary conditions (head-controlled and flow-controlled), interior impermeable boundaries, recharge, and withdrawal/injection?

From the results of the review, the TRANS code was selected for use in the STP case study local and regional modeling. TRANS is an extensively documented, generalized computer code which simulates the effects of convection, dispersion and to a limited extent, chemical reaction. Ground-water flow is computed using a variable grid, finite difference formulation. Solutions are included 
for nonsteady/steady flow problems in heterogeneous aquifers under confined, unconfined or leaky aquifer conditions. The code also accounts for timevarying withdrawal and injection, ground-water recharge and evapotranspiration. The solute transport portion of the code is based on a Lagrangian particle technique for the convective mechanisms and a random-walk technique for the dispersion. With its many features, TRANS provides the means to evaluate the performance of both active and passive interdiction methods that may be implementable at the STP with reasonable accuracy and efficiency. For a detailed description of the code formulations, the reader is referred to Prickett and Lonnquist (1971), and Prickett, Naymik and Lonnquist (1982).

\subsubsection{Initial Regional Model Development}

Development of the initial ground-water model is essentially the process of translating the conceptual model into a discretized form consistent with the input format of the selected code. This process can be streamlined considerably if in the data collection and analysis stage of the study, the need for discretization is anticipated. If so, the data analysis can be done node by node and the results converted directly into the appropriate code format. Such was the case in constructing the conceptual model for the lower unit of the shallow zone aquifer at the STP site. All aquifer system parameters that required spatial discretization were discretized using the previously selected regional grid (Figure 6.3.2-8). The primary TRANS input data requirements and the source of the initial data values used are summarized in Table 6.4.2-1.

The results of the initial model steady-state simulation are presented in Figure 6.4.2-1 which shows the simulated potential contours. Comparison of the simulated potentials to the observed potentials, general slopes are similar and they match at the boundaries, (Figure 6.3.2-10), reveals quite a difference, even though general slopes are similar and they match at the boundaries. The observed ground-water mound just to the left of the grid center is missing in the simulated results. The observed low potential extending from the lower right corner of the grid toward the mound is also not simulated. In general, the simulated potentials on the left half of the grid are too high.

\subsubsection{Regional Model Calibration}

Before the initial model of the study area can be used to predict hydraulic potentials or contaminant concentrations resulting from implementation of various mitigative action alternatives, it must be calibrated. Calibration means that a check is made to determine how well the model can correctly generate the past behavior of hydraulic potentials (hydrologic flow model) and/or contaminant movement (contaminant transport model) as they are established from historical records. Adjustments are then made in model parameters until an acceptable recreation of historical patterns is achieved. 
TABLE 6.4.2-1. TRANS Input Requirements and Source of Data for Initial Regional Model

Parameter

(Required for Each Node)

Aquifer top and bottom

elevations

Hydraulic Conductivity, (K)

Storage Coefficient, (S)

Effective Porosity, $\left(n_{e}\right)$

Actual Porosity, $(n)$

Vertical Hydraulic

Conductivity for

Confining Layer, ( $\left.\mathrm{K}^{\prime}\right)$

Recharge/Discharge Rate

Initial Hydraulic Heads
Source

Interpolated from available geohydrologic cross-sections

Uniform value $\left(600 \mathrm{gpd} / \mathrm{ft}^{2}\right)$ selected from well test results

Uniform value $(0.00045)$ selected from well test results

Uniform value $(0.37)$ from the STP FSAR

Uniform value $(0.37)$; assumed $n_{e}$ equals $n$ for sandy aquifers

Uniform value $\left(0.005 \mathrm{gpd} / \mathrm{ft}^{2}\right)$ from

Freeze and Cherry (1979)

Computed directly from $K^{\prime}$ and aquifer thickness (top elevation minus bottom elevation)

Observed potential contours

The calibration procedure begins by selecting a period of time for which historical records are available. The required modeling information is then input to the model (as discussed in the previous section on initial model development) and an initial potentiometeric surface is calculated. The predicted values are then compared with values observed (measured) in the field for the period of historical record. Typically, there is a discrepancy between the simulated and the observed.

Because geologic and hydrologic information can be interpreted in a number of different ways, and because of inherent measurement errors which are incorporated in historical records or incompleteness in historical records, the input parameters must be adjusted to a certain extent. A re-evaluation of the hydrogeologic information and/or the historical records is required to formulate a new input data set for the model. The historical period is then simulated with the new data set and the results compared to observed potentials. The process is repeated until an adequate fit of simulated results to observed behavior is reached. 


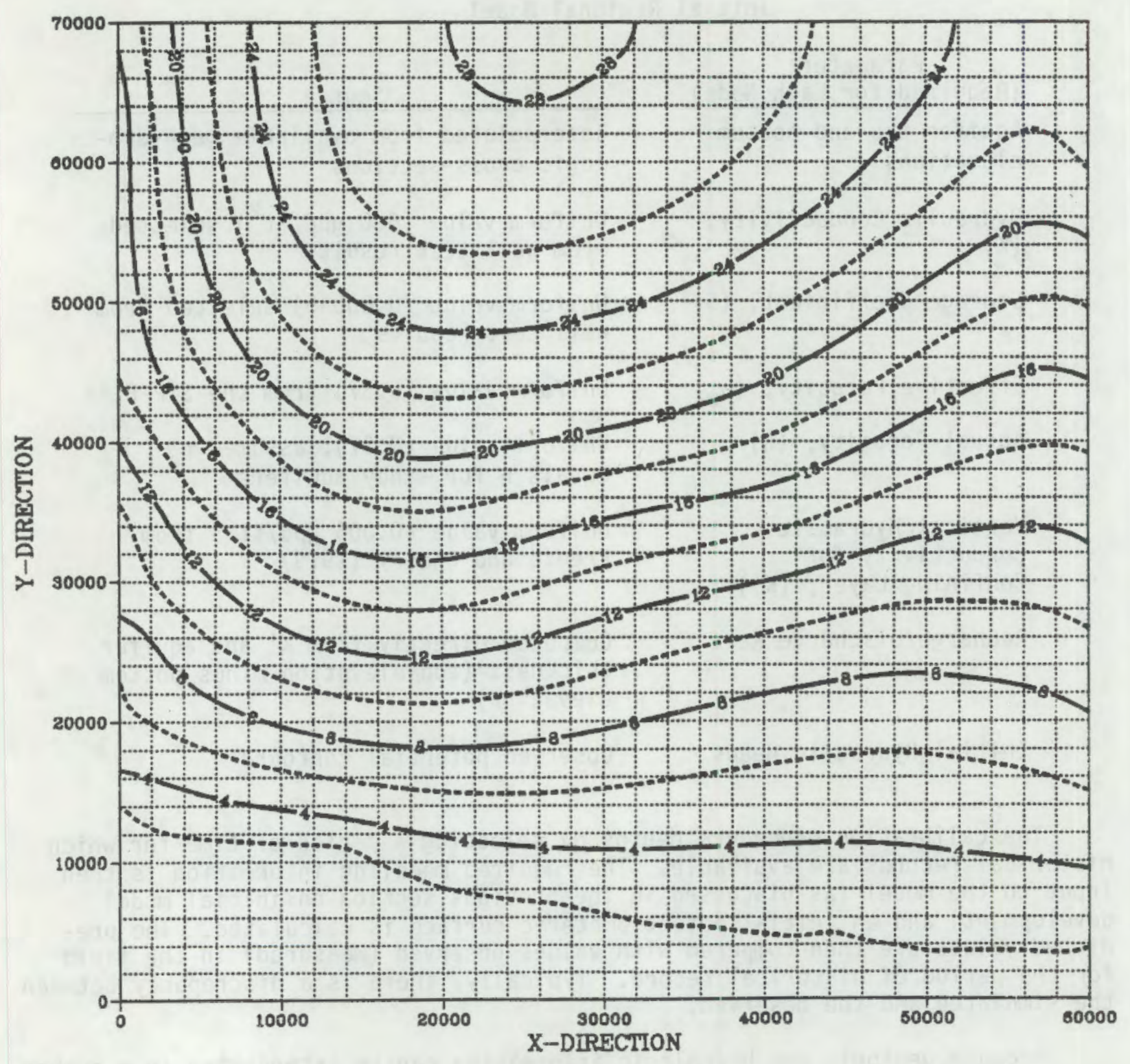

\section{FIGURE 6.4.2-1. Potential Contours Simulated by the Initial STP Region Model}

At the STP site little data were available from available literature regarding the hydraulic potentials or the hydraulic properties of the lower unit of the shallow-zone aquifer. Because of the lack of data and associated uncertainties adjustments must be made in the input data set in order to adequately calibrate the model. Because of these uncertainties the model is helpful in understanding the ground-water flow system. Many changes in parameter values can be made relatively quickly and inexpensively in the model. This facilitates comparison of model response to changes in parameter values 
and appreciation of model sensitivity to these changes. The adjustments made in the calibration process are based on refinements/improvements in the data set and in the understanding of the ground-water flow system. The model only indicates that changes are needed. It does not describe the changes. Arbitrary changes not supported by data or bound by understanding should be avoided.

It is often difficult to define a satisfactory match. 0bviously, the longer the historical record of hydrologic measurements/observations used for calibration, the better the results will be. Since long-term hydrologic records are seldom available, models are usually calibrated with data covering only a relatively short time period. For example, at the STP site, because of data limitations it was necessary to calibrate the model to a single set of hydraulic potential measurements covering a limited portion of the study region.

Calibration is often the most difficult and one of the most time consuming aspects of ground-water modeling. However, calibration is of utmost importance. Depending on the desired accuracy and the difficulties experienced with scarcity of data, tens of runs can be required to obtain a satisfactory match. However, a model becomes a reliable prediction tool on which to base decisions once it is properly calibrated (Boonstra nd de Ridder 1981).

The procedure used to calibrate the STP regional flow model was to run the initial model, compare observed with model-predicted results, make the appropriate changes in the initial data set and rerun the model. This process continued for a number of runs until an acceptable match between simulated hydraulic potentials and observed potentials was achieved. Because the available hydraulic potential data are limited, the focus in the calibration had to be duplication of the hydraulic head within the STP property limits.

The parameters adjusted in the regional model calibration process (i.e., those parameters to which were most sensitive) were the hydraulic conductivity, $(K)$, and the recharge/discharge rates. After several iterations, an acceptable match was achieved between observed and model predicted potentials. The original hydraulic conductivities (i.e., uniformly $600 \mathrm{gpd} / \mathrm{ft}^{2}$ ) were adjusted as shown in the three dimensional plot presented in Figure 6.4.3-1. The relative adjustments made were guided by the differences in the observed potential contours and those simulated by the initial model. For example, simulation of the observed ground-water mound left (or west) of the study area center required relatively low hydraulic conductivities within and down-gradient of the mound ( $540 \mathrm{gpd} / \mathrm{ft}^{2}$ ) and a high hydraulic conductivity immediately up-gradient of the mound (4200 gpd/ft ${ }^{2}$ ). Similarly, the trough (i.e., low potential levels) in the lower right corner (or southeast) of the study area was simulated by increasing hydraulic conductivities to $2340 \mathrm{gpd} / \mathrm{ft}^{2}$.

The recharge/discharge rate adjustments were accomplished by adjusting the vertical hydraulic conductivity $\left(K^{\prime}\right)$. Adjustments were made primarily to simulate the water mound to the left of the grid center which is characteristic of increased recharge, and the trough which is characteristic of decreased recharge. 


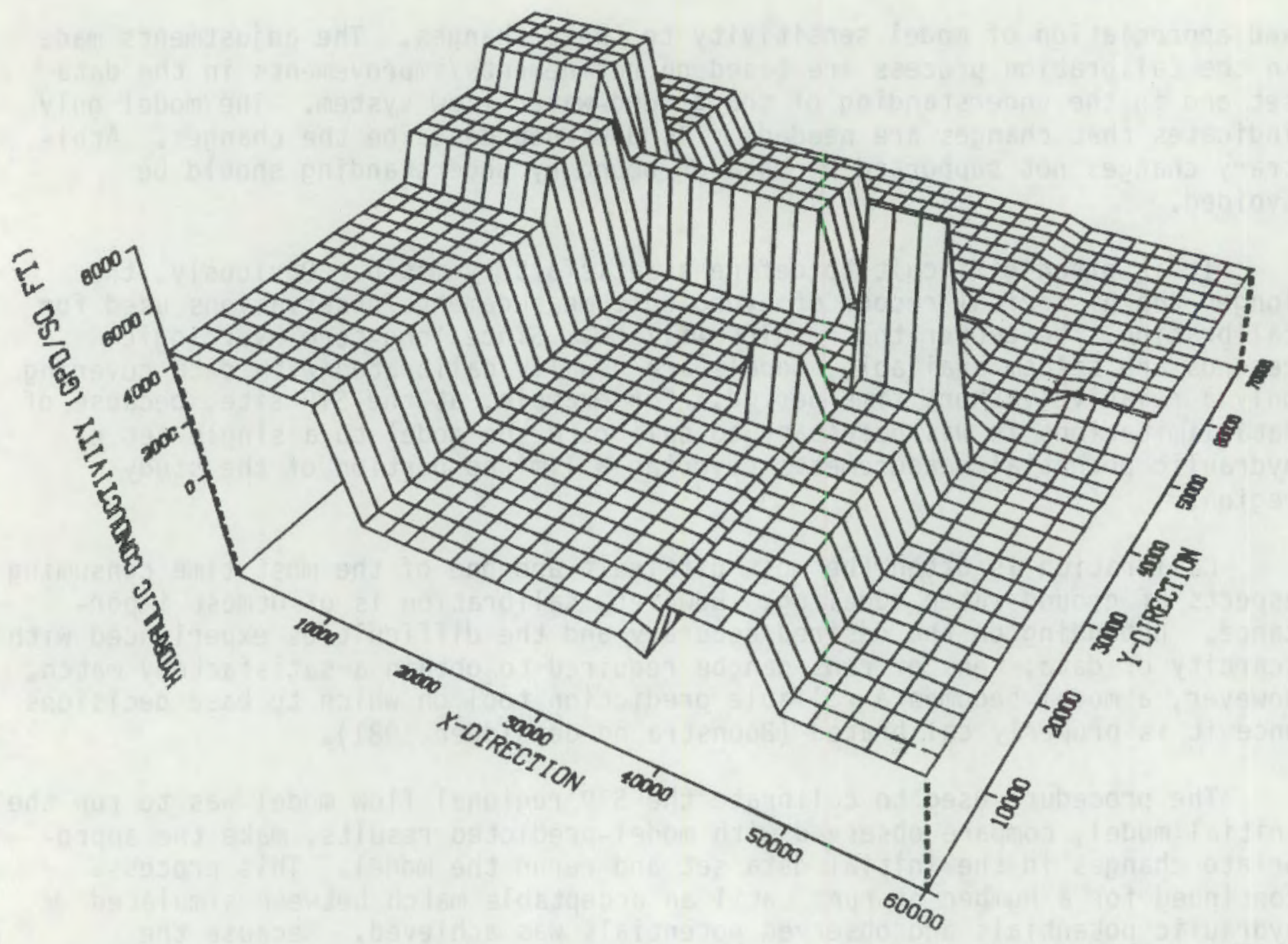

FIGURE 6.4.3-1. Calibrated Hydraulic Conductivities for the STP Final Regional Model

The final recharge/discharge distribution is shown in Figure 6.4.3-2. Overal1, the recharge to the study region was increased above initial estimates by about $70 \%$ to $2.8 \times 10^{7} \mathrm{gpd}$.

Potential contours from the final STP model simulation are presented in Figure 6.4.3-3. Though the match is not exact, the key features which would most effect flow paths and velocities (i.e., general trends in the potential gradient, the ground-water mound and trough) are acceptably reproduced. The similarities are further illustrated in Figures 6.4.3-4 and 6.4.3-5 which are three dimensional plots of the observed and simulated potential surface, respectively. The ground-water mound in the center of the figure is prominant in both plots; as is also the trough. To further verify the reasonableness of the final model results, Figure 6.4.3-6 shows streamlines beginning at the approximate location of the STP (coordinate $42000 \mathrm{ft}, 51000 \mathrm{ft}$ ) based on the observed and the simulated potentials. The streamlines, which closely approximate the contaminant trajectory, are approximately the same. 


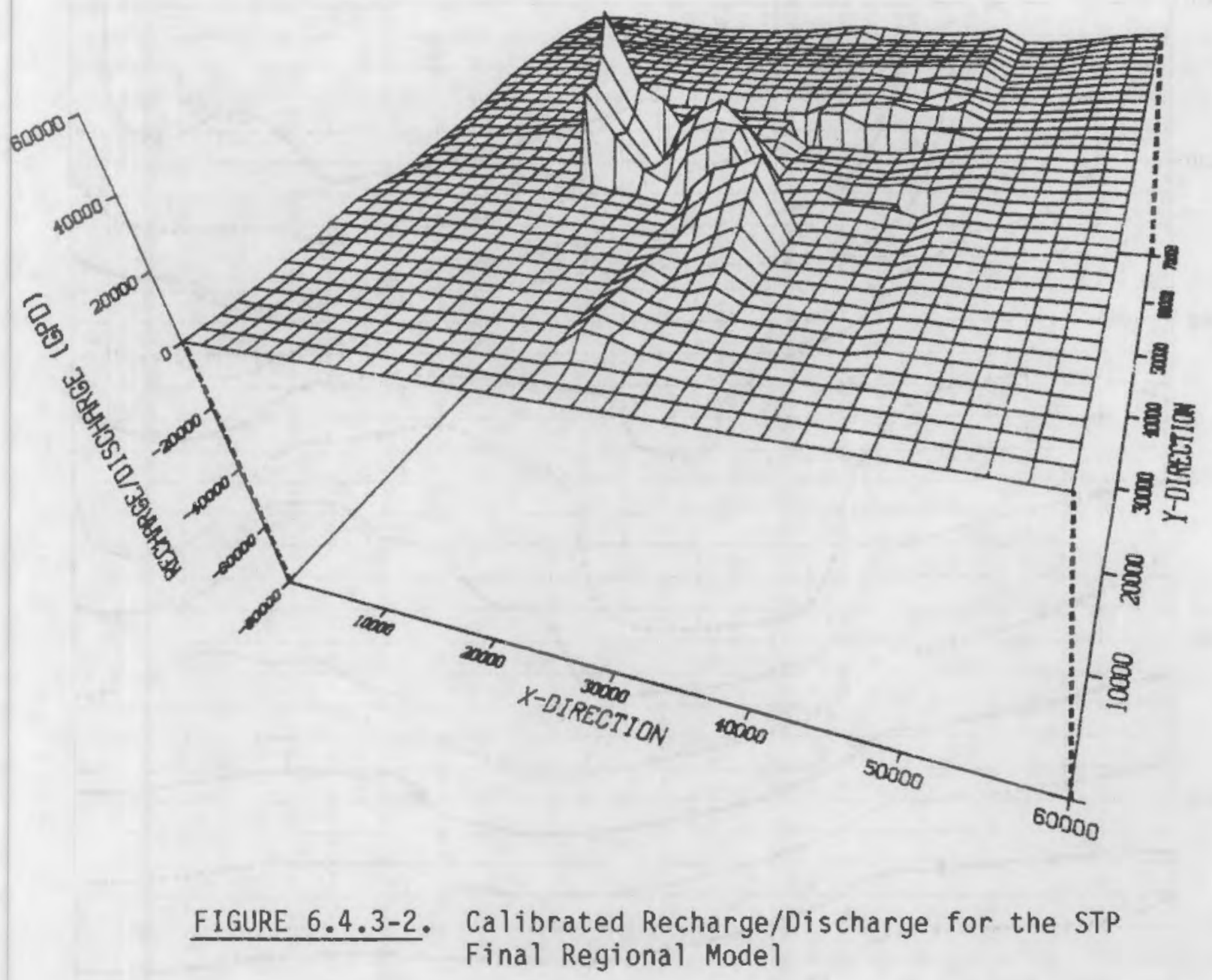




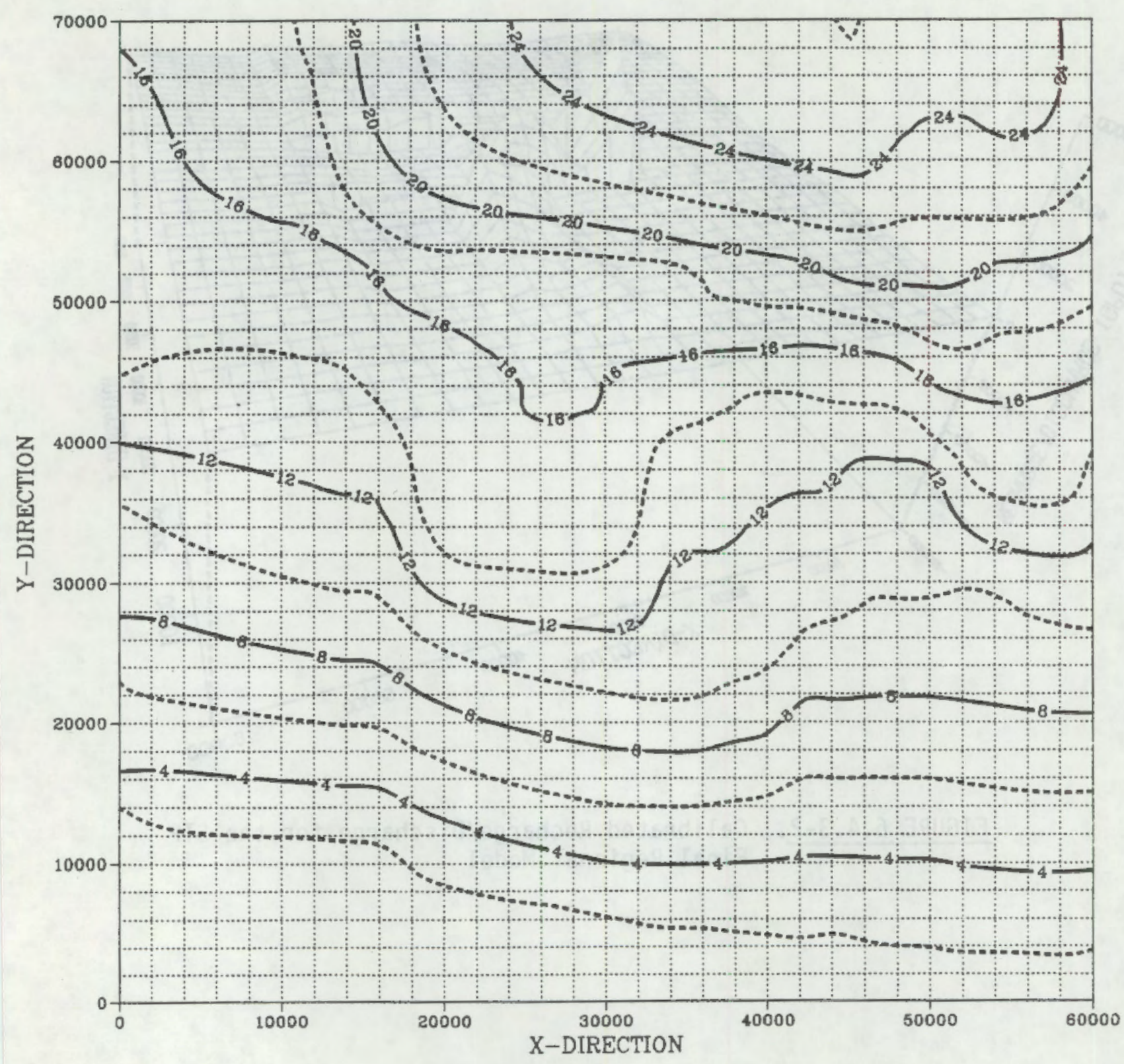

FIGURE 6.4.3-3. Potential Contours Simulated by the Final STP Regional Model 


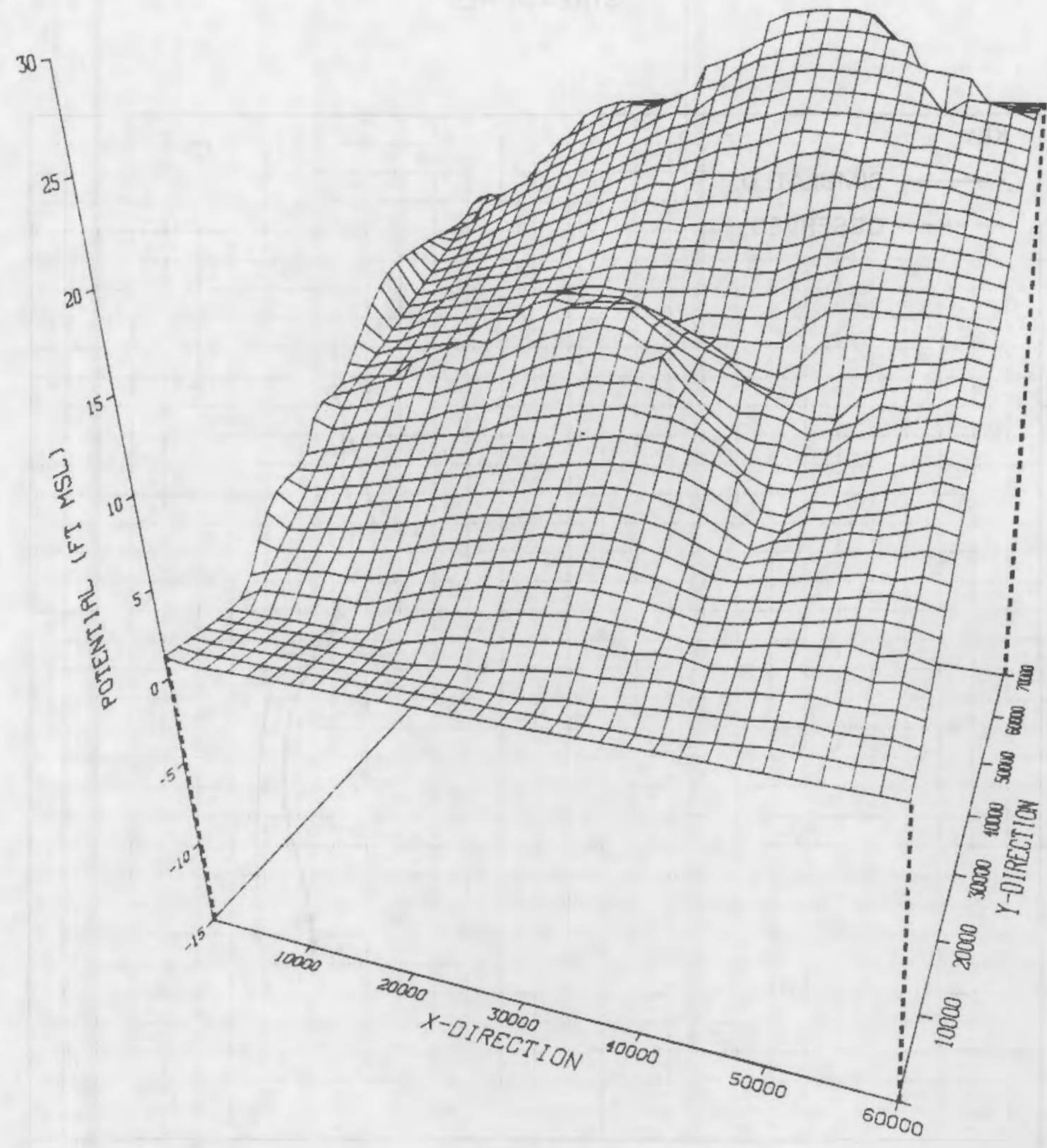

FIGURE 6.4.3-4. Observed Potential Surface for the STP Regional Study Area 


\section{STREAMLINES}

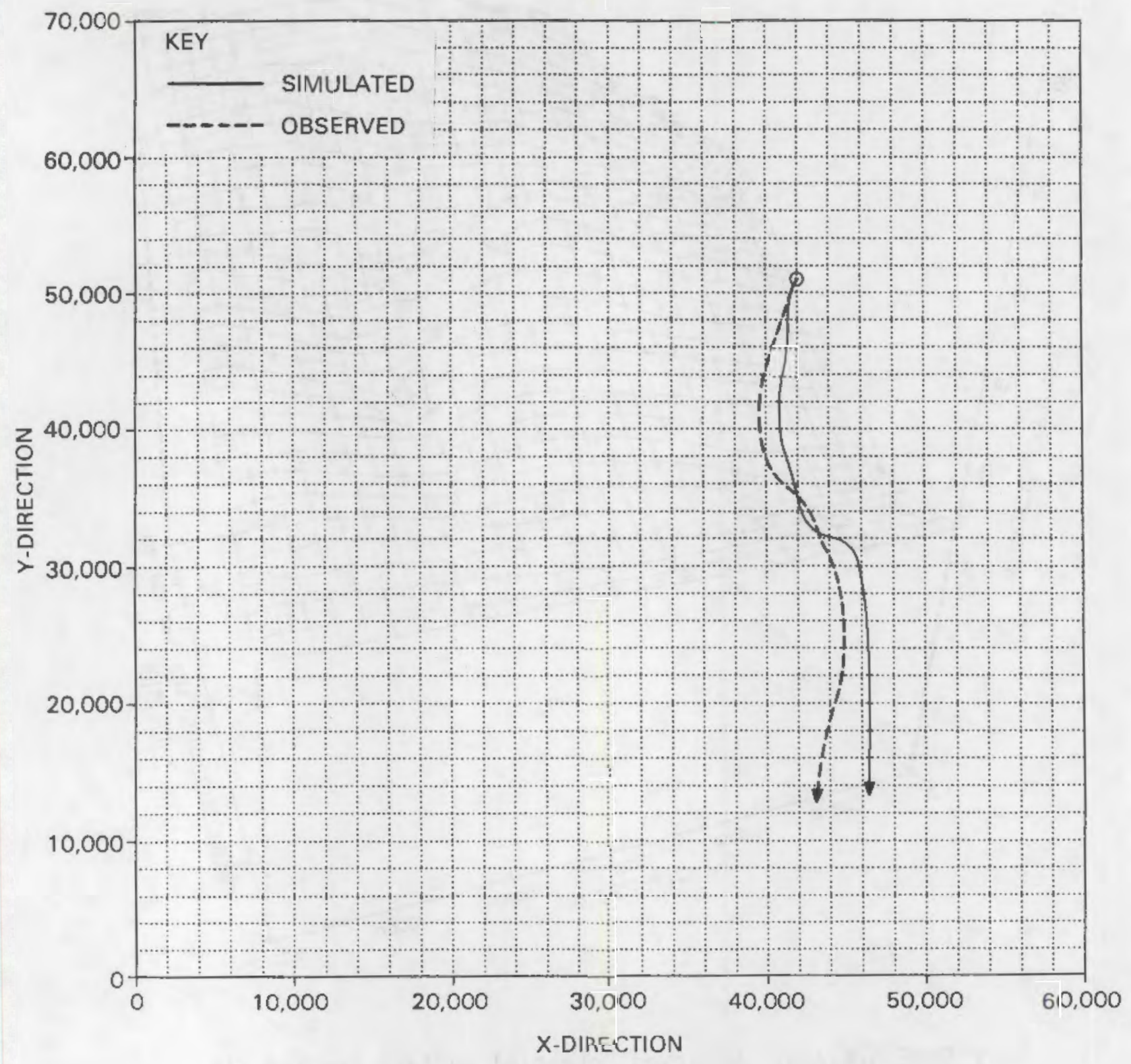

FIGURE 6.4.3-5. Final Regional Model Simulation of the Potential Surface for the STP Regional Study Area 


\subsection{LOCAL MODEL DEVELOPMENT}

\subsubsection{Local Area Size and Boundary Conditions}

The local model covers an area of 11.2 square miles within the regional study area as shown in Figure 6.5.1-1. The model boundaries were chosen to encompass the STP site and the area down-gradient to the Colorado River.

The boundaries of the local model are located far enough away from the plant site such that implementation of the various mitigative strategies in the vicinity of the plant would not greatly affect the flow field at the boundaries. At the same time the local study area was made small enough to allow a detailed look at flow and transport from the plant (i.e., use a fine mesh) without using an excessive number of nodes. The irregular local model grid, was designed to minimize grid cell size around the STP (coordinate $42000 \mathrm{ft}$, $51000 \mathrm{ft}$ ) and have increasing cell size away from the plant. This was done to allow flexibility in locating and sizing barriers and injection/withdrawal wells for the evaluation of the performance of various mitigative strategies.

As previously discussed, the boundary conditions for the local model are determined directly from the regional model. The procedure for implementing the two models (i.e., regional and local) for pre-mitigative and post-mitigative analyses is to first run the regional model, set the local boundary conditions from the regional results, then run the local model. The boundary conditions in the local model are head-controlled for all boundaries.

The structural top and bottom of the lower shallow-zone aquifer were defined the same as in the regional model as were also the hydraulic conductivities and the recharge/discharge rates. The transfer of these properties from the regional model grid to the irregular local grid was accomplished using an IMSL interpolation routine (IMSL 1980).

The observed and simulated potential contours for the local area are presented in Figures $6.5 .1-2$ and $6.5 .1-3$, respectively. It can be seen that the observed trends in the gradient and contour shapes are basically reproduced by the local model. This is particularly true immediately down-gradient of the approximate plant location (i.e., coordinate $42000 \mathrm{ft}, 51000 \mathrm{ft}$ ), indicating an acceptable model calibration.

\subsection{PRE-MITIGATIVE LOCAL FLOW AND TRANSPORT MODELING}

Ideally, development of a transport model parallels that for the flow model. Beginning with the final local flow model, initial values of the transport parameters are estimated from available data and subsequently calibrated to obtain a reasonable match between field-measured and modelpredicted contaminant concentrations. However, when developing a model to evaluate mitigative techniques for the control of radionuclide contaminants due to severe nuclear power plant accidents, radionuclide contaminant field data are not likely to exist. Consequently, one must rely on initial estimates of the transport parameters (e.g., primarily the effective porosity, retardation 


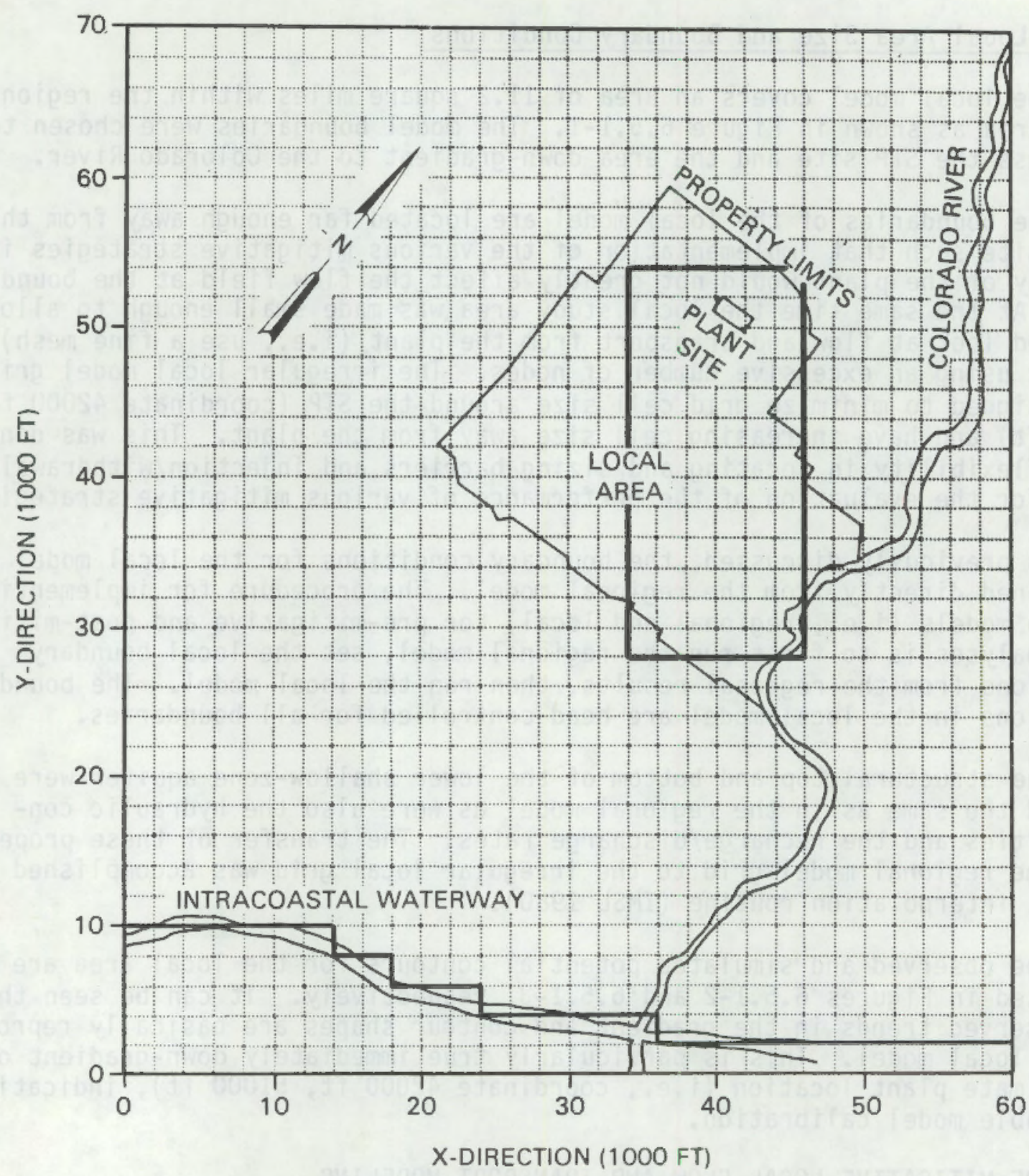

FIGURE 6.5.1-1. STP Local Model Study Area 


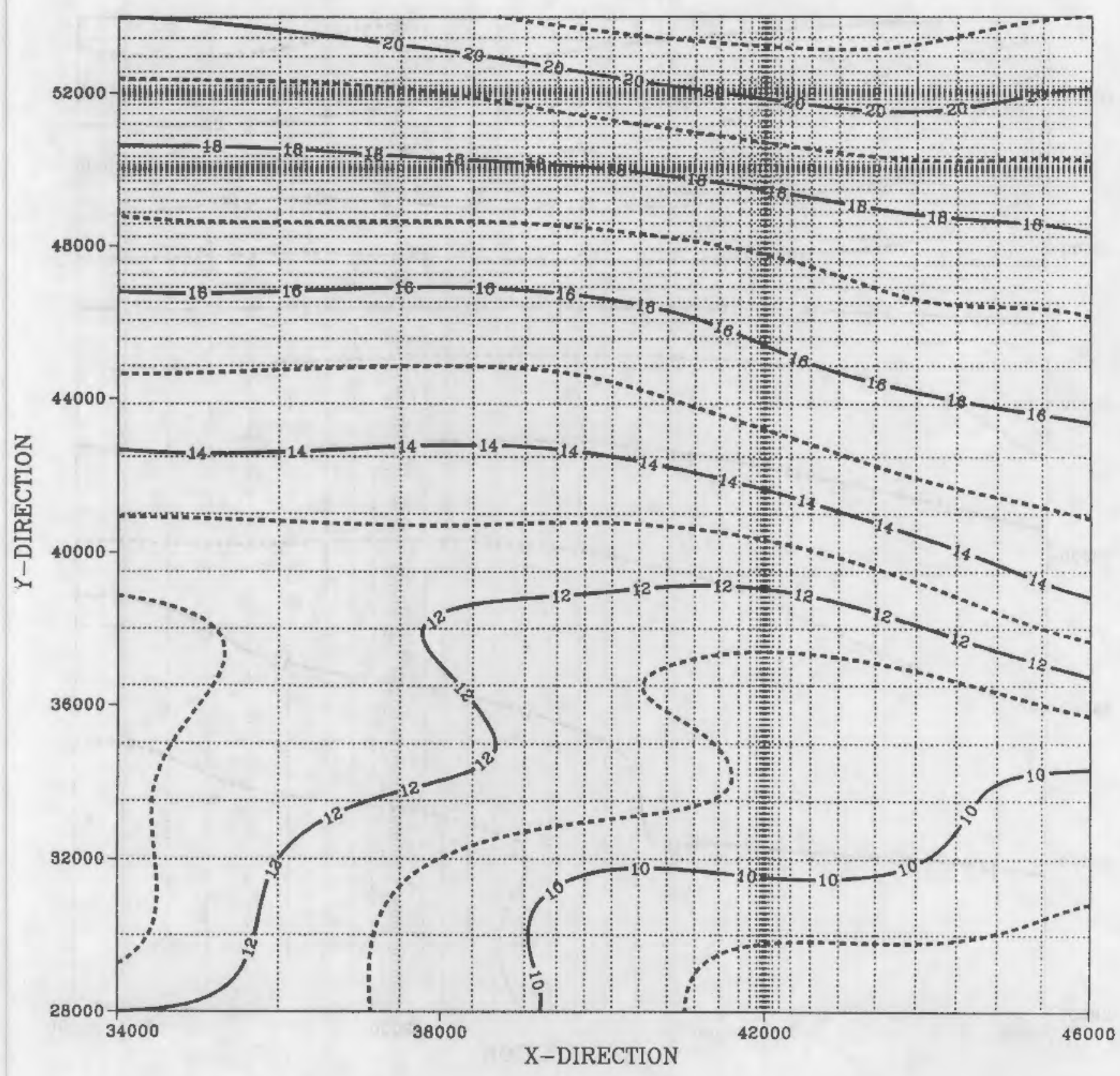

FIGURE 6.5.1-2. STP Local Area Observed Potential Contours 


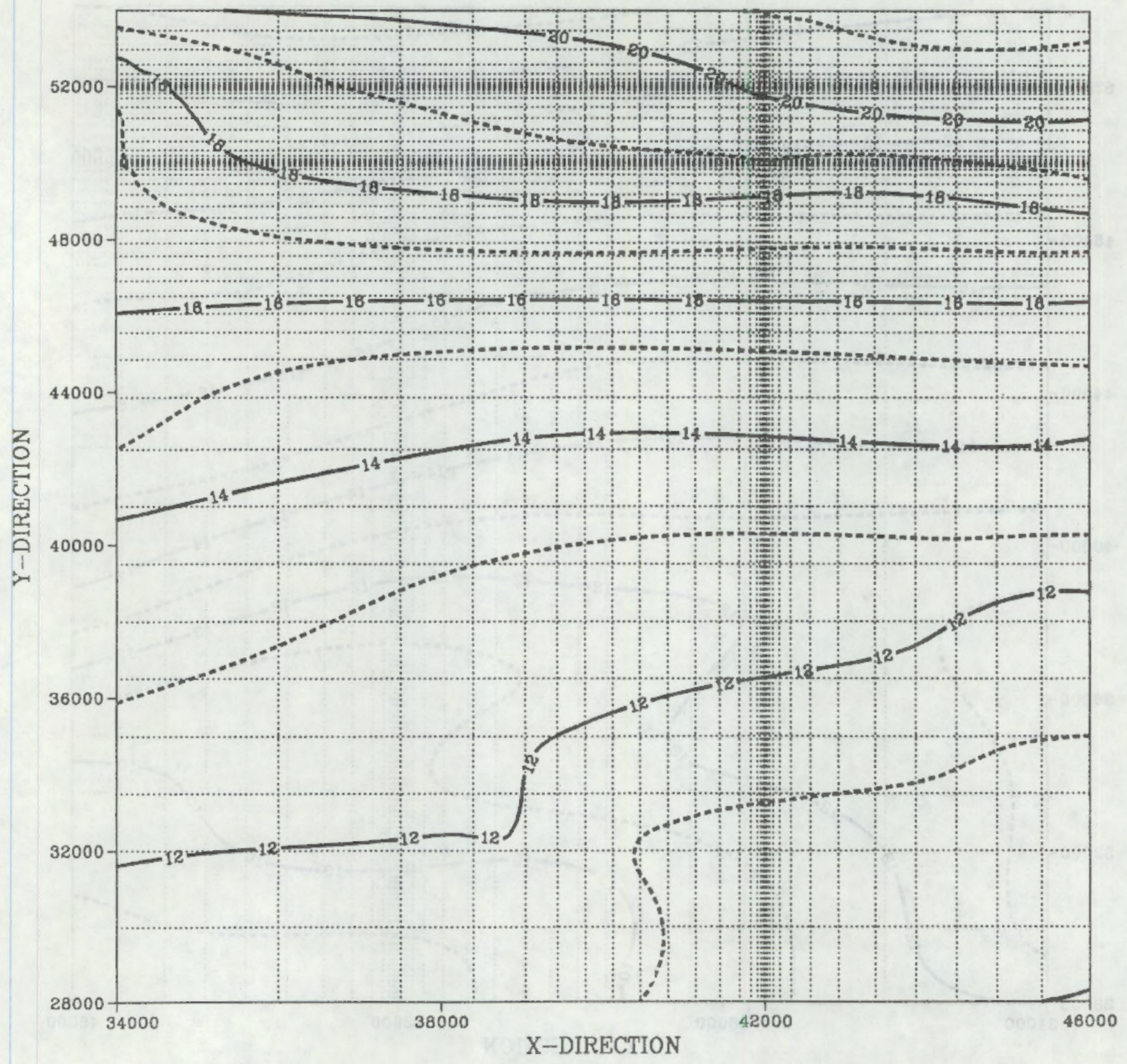

FIGURE 6.5.1-3. STP Local Model Simulated Potential Contours 
factor and dispersivity coefficients), based on available information. Generally, once satisfactory estimates are obtained, these same values are used for the baseline pre-mitigative simulations as well as the post-mitigative performance comparisons.

\subsubsection{Transport Parameter Estimations}

The data and parameters required to simulate transport are:

1. longitudinal and transverse dispersivity coefficients,

2. contaminant source characteristics including leach rate and contaminant decay constant,

3. adsorption data such as distribution coefficient, bulk density and effective porosity.

The determination of the required parameters and data for the pre- and postmitigative transport analysis is discussed below.

\subsubsection{Dispersivity Coefficients}

Simmons and Cole (1983) describe dispersion in a ground-water system as a combination of molecular diffusion, which occurs even under conditions of no flow, and hydrodynamic dispersion. Hydrodynamic dispersion results from variation in the local water velocity within the medium with respect to its average value as described by convection. This variation in velocity exists at any scale, from microscopic (in the pores) to macroscopic (due to uncharacterized heterogeneity of the medium) and even megascopic (due to large scale variations in medium properties like fractures). Dispersion is important because it produces mixing and spreading both longitudinally and transversely with respect to the flow direction of the transported contaminants. Estimation and measurement of hydrodynamic dispersion for field conditions is presently a topic of intensive research (Molz et a1. 1983; Wang and Anderson 1982; Simmons 1982). The problems in dealing with spatial variability of hydrologic properties and field-scale dispersion processes have resulted in questions about the adequacy of the classical convective-dispersive approach with its inherent assumptions regarding dispersion. However, as long as the appropriate cffective dispersion coefficients can be defined the convective-dispersion approach is considered applicable.

In TRANS contaminant transport is computed on the basis that the distribu$t i o n$ of contaminant concentrations in the ground water can be represented by a finite number of discrete particles. Each particle represents a fraction of the total mass of contaminant involved and is assumed to move with the groundwater flow. The technique, designated by Prickett, Naymick and Lonnquist (1981) as the "random-walk" method, is founded on the concept that dispersion in porous media is a random process such that particles move through an aquifer with two types of motion. One motion is that of the mean flow along computed streamlines. The other type is random motion governed by scaled probabilities related to flow length and the longitudinal and transverse dispersion coefficients. The "random-walk" concept is illustrated in Figure 6.6.1-1. 


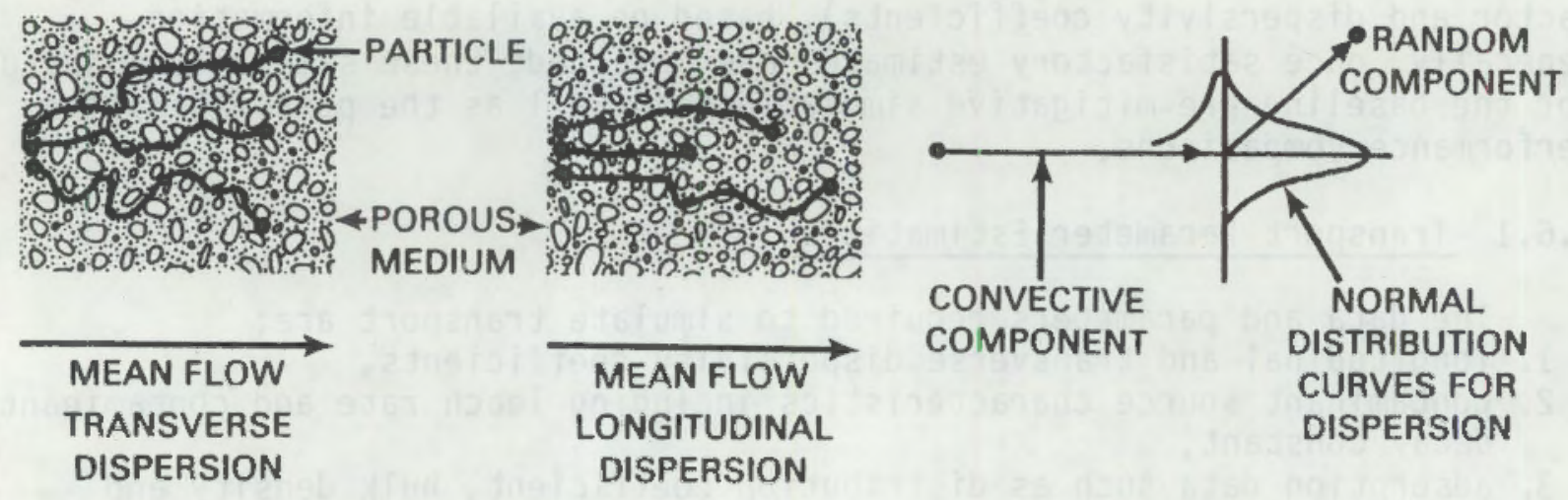

FIGURE 6.6.1-1. Illustration of "Random-Walk" Concept Employed by TRANS (Source: Prickett, Naymik and Lonnquist 1981)

Because of a total lack of data related to dispersivity in the study aquifer, initial estimates of longitudinal $\left(D_{1}\right)$ and transverse $\left(D_{T}\right)$ dispersivity coefficients were made based on information in the literature. One source (Yeh 1981) provided estimates of $D_{L}$ for various materials which are presented in Table 6.6.1-1.

The geologic material in the study aquifer most likely fits in the sandy silt to sand range resulting in a valve equal to $25 \mathrm{~m}$ to $50 \mathrm{~m}$ or approximately $80 \mathrm{ft}$. to $165 \mathrm{ft}$. According to Fried and Combarnous (1971) based on laboratory studies $D_{T}$ is equal to about $1 / 20 D_{L}$. Therefore, the equivalent range for $D_{T}$ is $4 \mathrm{ft}$. to $8 \mathrm{ft}$. Data presented by Gelhar and Axness (1981), shown in Figure $6.6 .1-2$, demonstrate that the value of $D_{L}$ is a function of scale.

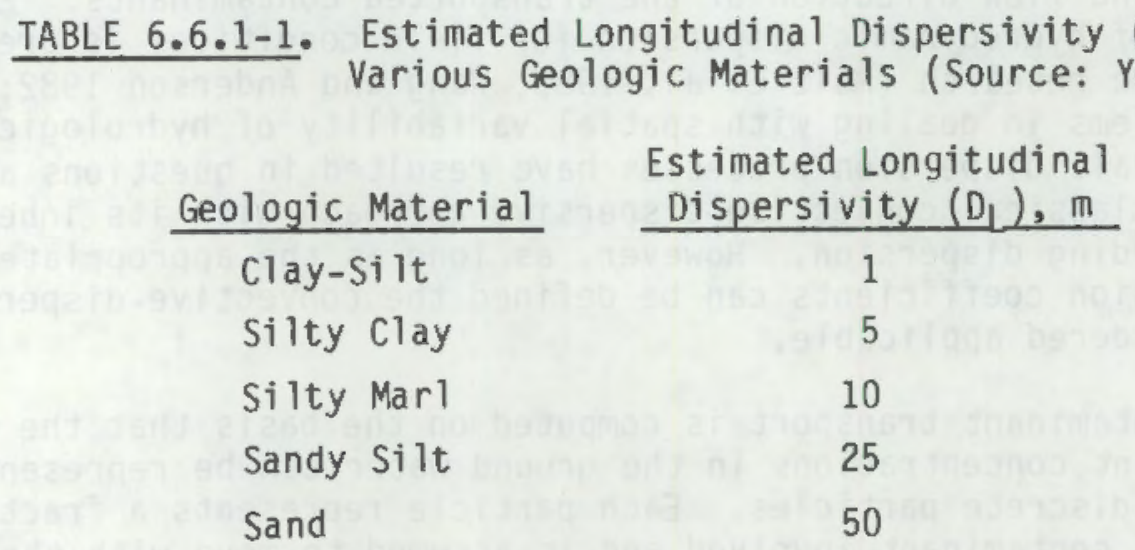

Though there is considerable scatter in the data it shows a distinct increase

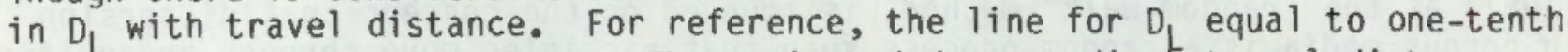
the travel distance is shown. The estimated down-gradient travel distance from the STP to the Colorado River is about $5 \mathrm{miles}(8000 \mathrm{~m})$. For distances of this magnitude measured dispersivities shown in Figure 6.6.1-2 range from about $5 \mathrm{~m}$ to $500 \mathrm{~m}$. The value suggested by Yeh (1981) falls well within this range and would be at about the midpoint on the log-log plot. Consequently, this value is used for the initial transport analysis. 


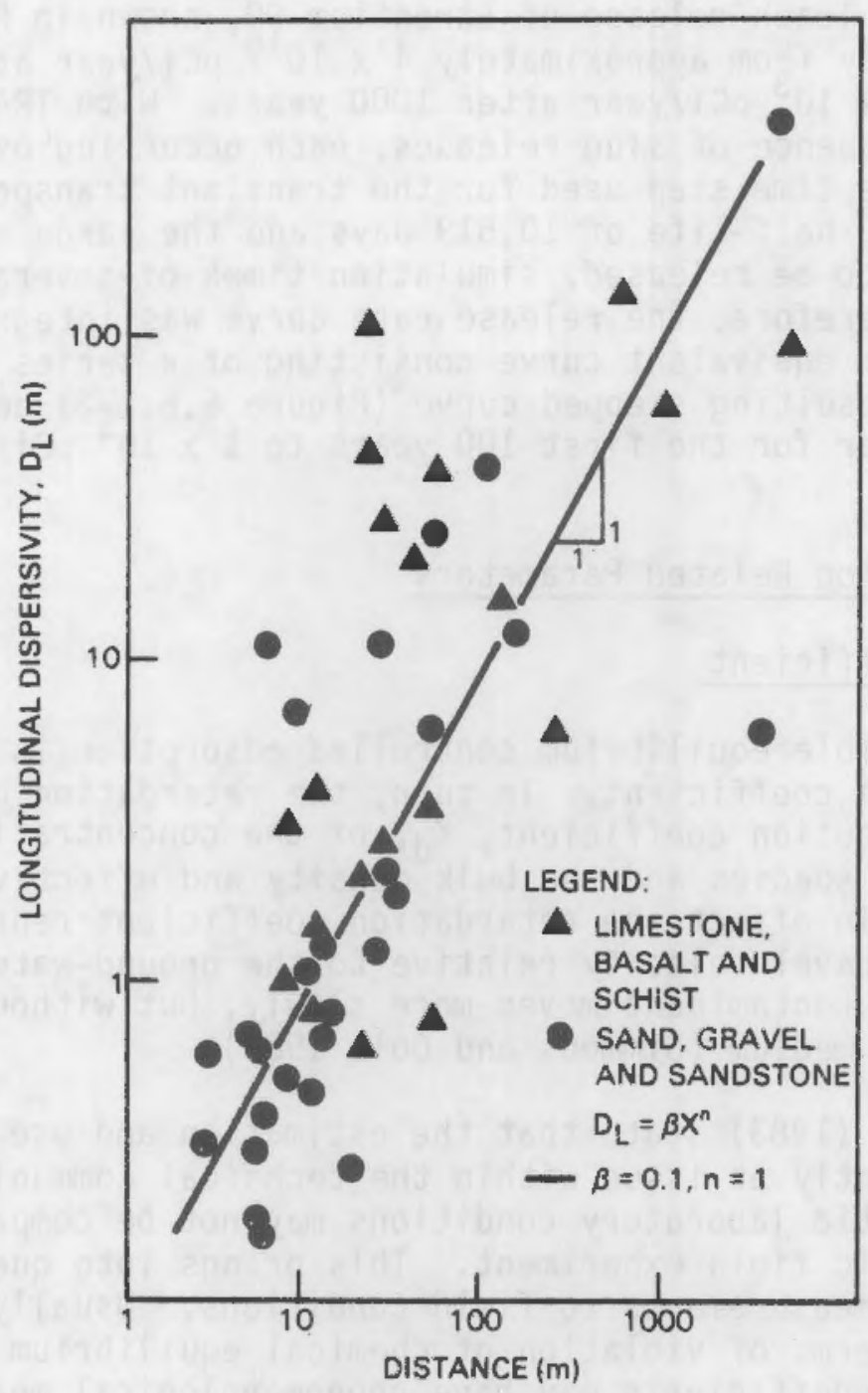

FIGURE 6.6.1-2. Field Observations of Longitudinal Dispersivity (After: Gelhar and Axnes 1981)

\subsubsection{Source Characteristics}

Data requirements for characterization of a radionuclide contaminant source are the source leach rate and decay constants for the radionuclides present. As noted in Section 6.2.3 this case study and methodology demonstration will address the leaching of radionuclides from the core melt debris following a postulated severe reactor accident at the STP. Further, strontium-90 will be used as the indicator radionuclide for the pre-mitigative transport modeling. 
The hypothesized leach release of strontium-90, shown in Figure 6.2.3-1, decreases exponentially from approximately $4 \times 10^{15^{\prime}} \mathrm{pCi} /$ year at the time leaching begins to $2 \times 10^{3} \mathrm{pCi} /$ year after 1000 years. With TRANS, the source must be input as a sequence of slug releases, each occurring over a specified time period (i.e., the time step used for the transient transport simulation). Given the strontium-90 half-life of 10,519 days and the large amounts of radionuclide hypothesized to be released, simulation times of several hundred years were anticipated. Therefore, the release rate curve was integrated in 100-year intervals to obtain an equivalent curve consisting of a series of constant release rates, The resulting stepped curve (Figure 6.6.1-2) decreases from about $4 \times 10^{14} \mathrm{pCi} /$ year for the first 100 years to $1 \times 10^{4} \mathrm{pCi} /$ year at the end of 1000 years.

\subsubsection{Adsorption Related Parameters}

\section{Distribution Coefficient}

In TRANS, reversible equilibrium controlled adsorption is described in terms of a retardation coefficient. In turn, the retardation coefficient is related to the distribution coefficient, $K_{d}$, of the concentration isotherm for a particular chemical species and the bulk density and effective porosity of the aquifer medium. In effect the retardation coefficient represents the reduction in solute travel velocity relative to the ground-water flow velocity such that an adsorbed contaminant moves more slowly, but without being permanently affixed to the medium (Simmons and Cole 1983).

Simmons and Cole (1983) state that the estimation and use of distribution coefficients is currently at issue within the technical community. Measurements of $K_{d}$ under static laboratory conditions may not be comparable to those obtained from a dynamic field experiment. This brings into question transferability of laboratory measurements to field conditions. Usually discrepancies can be explained in terms of violation of chemical equilibrium assumptions. However, retardation coefficients may have phenomenological meaning when estimated inversely to match a field-scale tracer test, even though values may not conform to laboratory conditions. In this light, an estimate of $K_{d}$ for strontium-90 which was obtained from the representative $K_{d}$ 's is presented in Table 3.3.2-2. Values in the table are $10 \mathrm{ml} / \mathrm{g}$ for porous silicate and $50 \mathrm{ml} / \mathrm{g}$ for porous silicate containing clay and silt. Conservatively, a value of $10 \mathrm{ml} / \mathrm{g}$ is selected for the analysis.

\section{Effective Porosity}

The available information regarding effective porosity for the study area was limited to an assumed value of $37 \%$ obtained from the STP FSAR (Houston Power and Light 1978) and the representative porosity values for various sedimentary material shown in Table 6.3.2-6 (Hammond 1969). The ranges given are $30 \%$ to $40 \%$ for uniform sand and $30 \%$ to $35 \%$ for fine to medium mixed sand. The $37 \%$ value assumed in the STP FSAR (Houston Power and Light 1978) falls within or near these ranges and thus appears to be reasonable. 


\section{Bulk Density}

In addition to effective porosity, determination of the retardation factor requires a known bulk mass density which can be determined from the relationship (Freeze and Cherry 1979):

$$
n_{e}=1-\frac{\rho_{b}}{\rho_{m}}
$$

where

$$
\begin{aligned}
& \eta_{e}=\text { effective porosity } \\
& \rho_{m}=\text { particle mass density }\left(2.65 \mathrm{~g} / \mathrm{cm}^{3} \text { for most mineral soils }\right) \text {, and } \\
& \rho_{b}=\text { bulk mass density. }
\end{aligned}
$$

From this relationship, assuming an effective porosity of $37 \%$, the bulk mass density for the lower unit is $1.7 \mathrm{~g} / \mathrm{cm}^{3}$ or $104 \mathrm{lb} / \mathrm{ft}^{3}$.

\subsubsection{Additional TRANS Parameters}

As previously discussed, the total mass of contaminant is represented in TRANS by a discrete number of particles, with the idea that as the number of particles approaches the molecular level the exact solution to the convectivediffusion equation would be obtained. Prickett et al. (1981) suggest that relatively few particles (less than 5000 ) are needed to obtain an acceptable solution for most engineering applications. Measured contaminant data necessary to test their assertion were not available. However, in initial model tests several transport runs were made with different numbers of particles. The results indicated that simulation results did not change appreciably due to increasing the number of particles from 5000 to 7000 , though computer simulation time increased significantly. Consequently, the number of particles was set equal to 5000 for all simulations.

The final parameter values determined for the pre-mitigative transport simulations and their sources are summarized in Table 6.6.1-1.

\subsubsection{Pre-Mitigative Local Transport Results} analysis:

There are two primary objectives in performing a pre-mitigative transport

1. quantitatively assess the need for mitigation following a severe accident release of radionuclides to the ground-water system, and

2. when mitigation is found to be necessary, provide a baseline for evaluating the effectiveness of selected mitigation techniques.

To meet these objectives for the case study, TRANS was used to simulate radionuclide transport from the STP for a 1000-yr period from the time leach releases begin. The transient simulation was made using 100 year time steps and the discretized leach rate curve shown in Figure 6.6.1-3. The radionuclide 
TABLE 6.6.1-1. Summary of TRANS Transport Parameter Values for STP Transport Simulations

\begin{tabular}{|c|c|c|}
\hline Parameter & Value & Source \\
\hline Longitudinal Dispersivity $\left(D_{L}\right)$ & $50 \mathrm{~m}(164 \mathrm{ft})$ & Gelhar and Axness (1981) \\
\hline Transverse Dispersivity $\left(D_{T}\right)$ & $2.5 \mathrm{~m}(8 \mathrm{ft})$ & Computed; $\mathrm{D}_{\mathrm{L}} / 20$ \\
\hline Distribution Coefficient $\left(K_{d}\right)$ & $10 \mathrm{ml} / \mathrm{g}$ & Table 3.3.2-2 \\
\hline Effective Porosity $\left(n_{e}\right)$ & $37 \%$ & $\begin{array}{l}\text { STP FSAR (Houston Power } \\
\text { and Light 1978) }\end{array}$ \\
\hline Bulk Density $\left(\rho_{b}\right)$ & $104 \mathrm{lb} / \mathrm{ft}^{3}$ & Computed \\
\hline Retardation Factor $\left(R_{d}\right)$ & 46 & Computed \\
\hline Number of Particles (NP) ${ }^{\mathrm{a}}$ & 5000 & Prickett et al. (1981) \\
\hline
\end{tabular}

(a) TRANS specific parameter

release is assumed to be a point source at spatial coordinates $42,000 \mathrm{ft}$ in the $x$-direction and $51,000 \mathrm{ft}$ in the $y$-direction.

The results of the pre-mitigative transport simulation indicate that the strontium-90 plume, because of the high retardation, would migrate less than $2400 \mathrm{ft}$ from the STP in 1000 years. Three-dimensional plots of the distribu$t i o n$ of strontium-90 concentrations at 100 years and 1000 years are shown in Figures 6.6.2-1 and 6.6.2-2. At 100 years the maximum concentration is approximately $1 \times 10^{5} \mathrm{pCi} / \mathrm{ml}$ while at 1000 years the maximum has decreased to $2.5 \times 10^{-5} \mathrm{pCi} / \mathrm{ml}$, well below the maximum permissible concentration of strontium-90 of $0.3 \mathrm{pCi} / \mathrm{ml}$ according to $10 \mathrm{CFR} /$ Part 20 (USNRC 1978).

With regard to the first objective of the pre-mitigative transport analysis, based on the simulations using strontium-90 as an index radionuclide, mitigation of radionuclide movement in ground water following a severe accident at the STP clearly would not be necessary.

Though mitigation would not actually be required at the STP, the groundwater model for the site still provides an excellent vehicle for demonstrating site specific evaluation of mitigative techniques. To this end, the following sections describe a detailed analysis of feasible mitigative techniques is described. The analysis is based upon the STP local and regional models and a hypothetical contaminant that is assumed to move only advectively with the ground water (i.e., the distribution coefficient and dispersivities are equal to zero). In Figure 6.6.2-3, the pathline for ground-water flow from the STP to the Colorado River is shown. The estimated time of arrival is 310 years. This value will serve as the baseline for evaluating the effectiveness of mitigation techniques to be considered. 


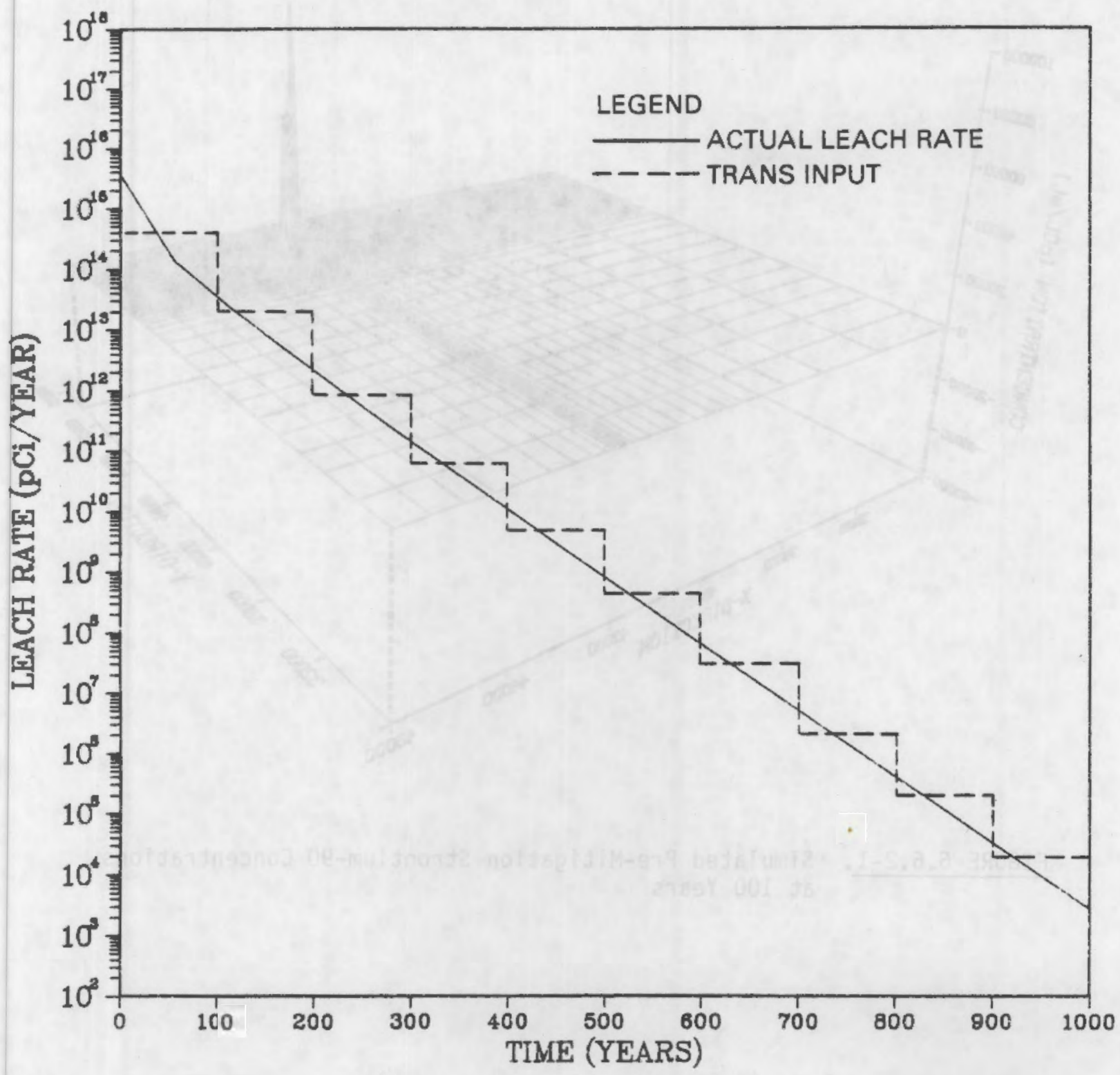

FIGURE 6.6.1-3. Stepped Source Leach Rate Curve for Strontium-90 


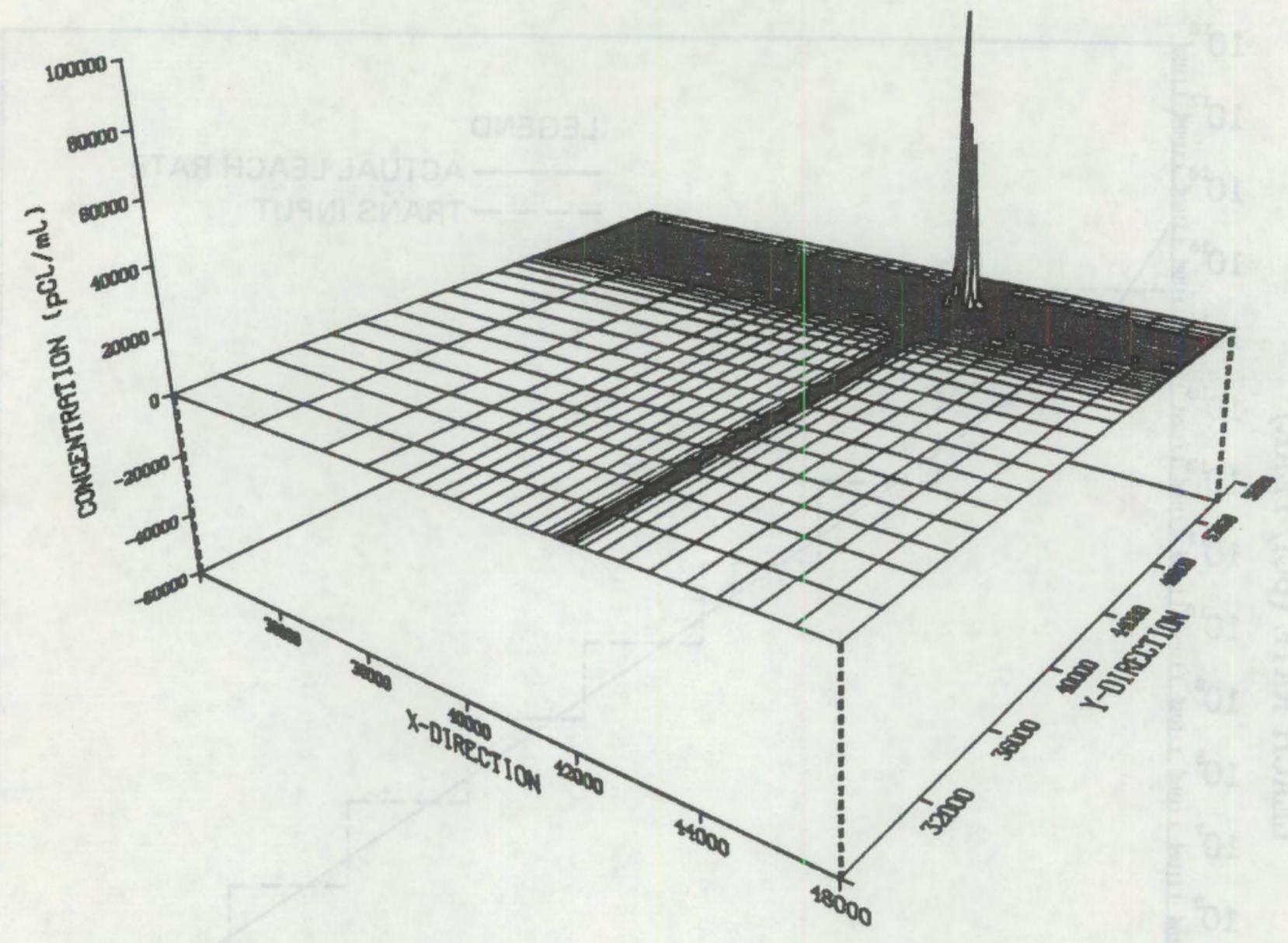

FIGURE 6.6.2-1. Simulated Pre-Mitigation Strontium-90 Concentrations at 100 Years 


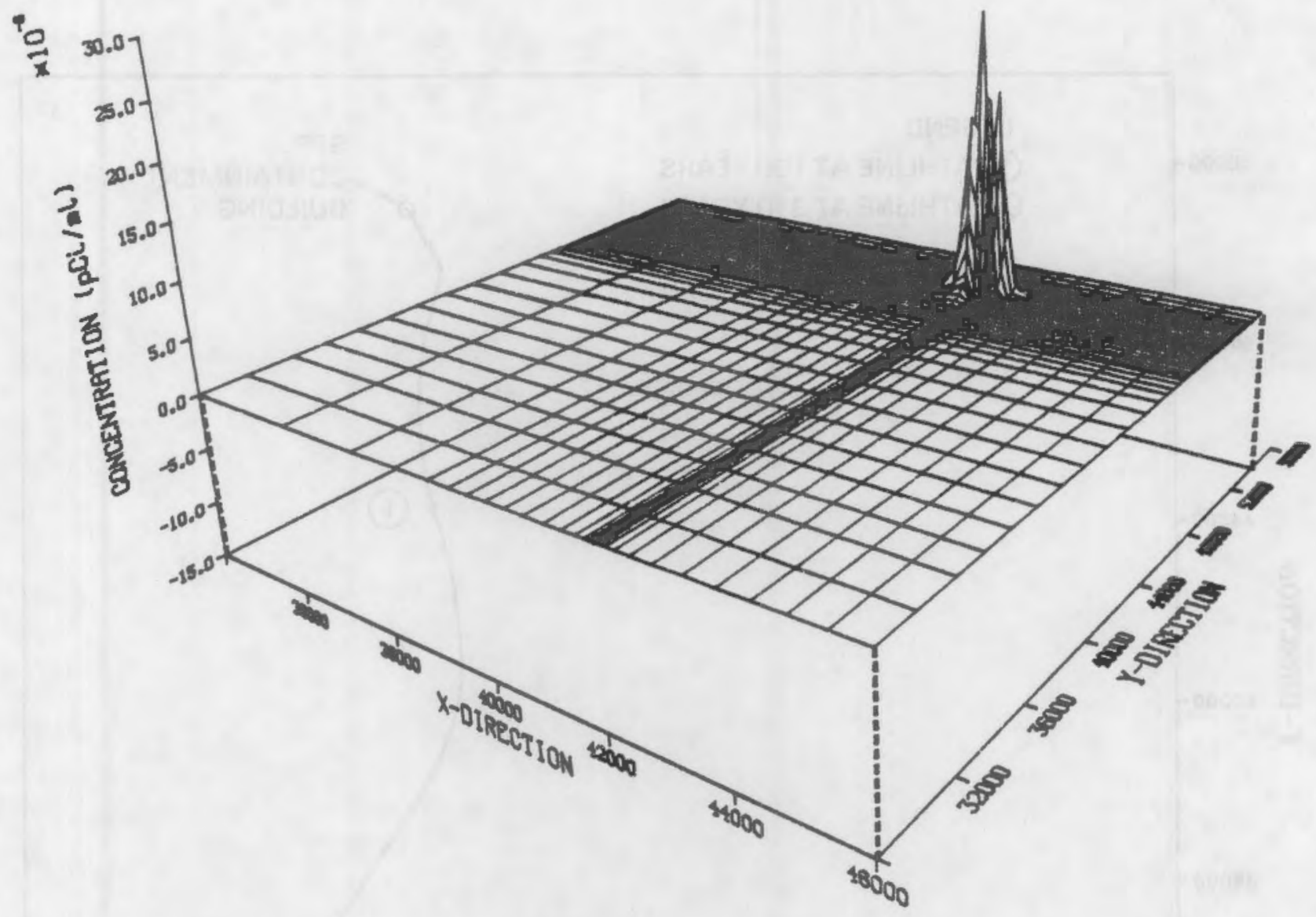

FIGURE 6.6.2-2. Simulated Pre-Mitigation Strontium-90 Concentrations at 1000 Years (Note Vertical Scale Exaggeration as Compared to Figure 6.6.2-1) 


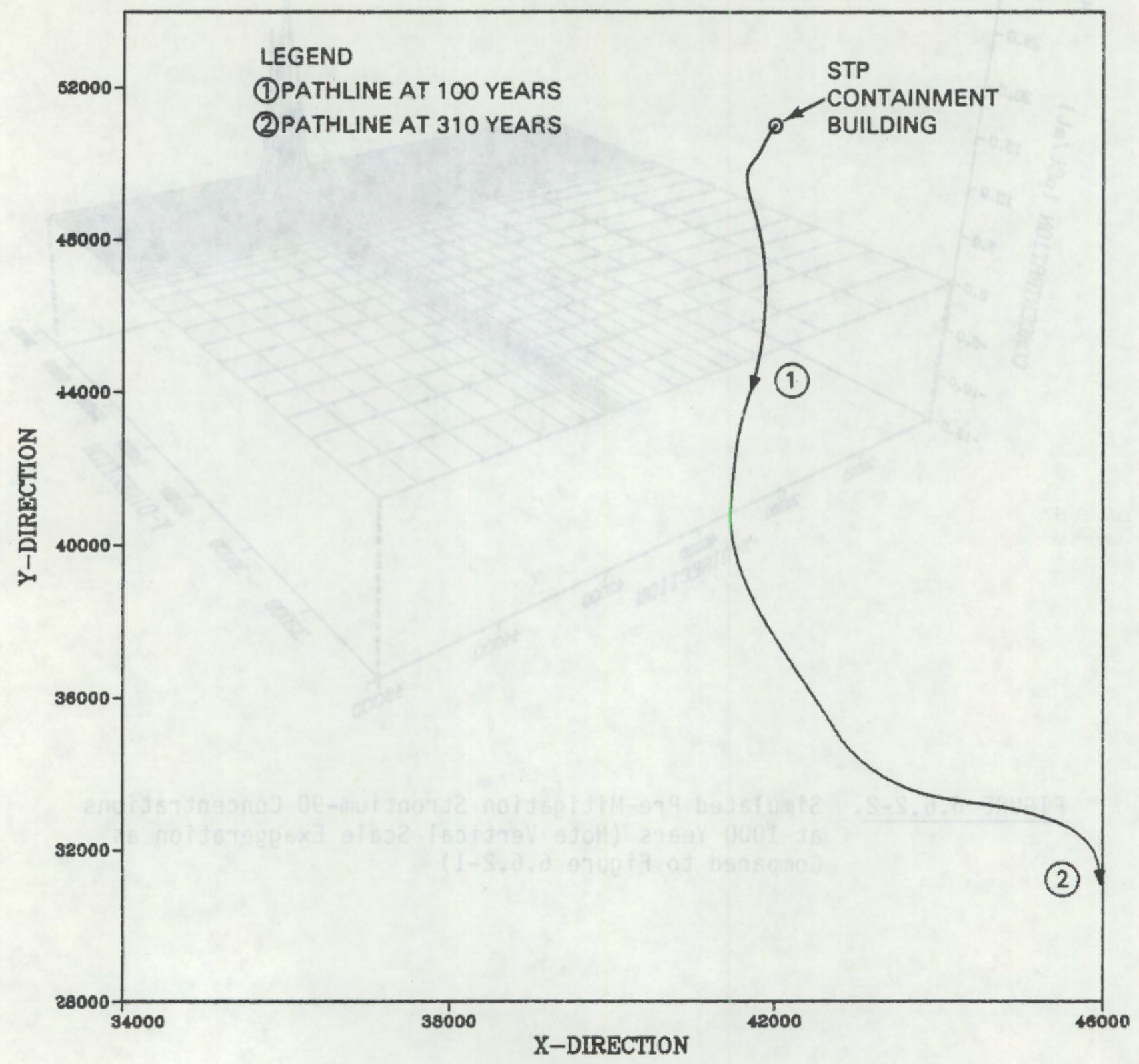

FIGURE 6.6.2-3. Pre-Mitigation Pathline From the STP 


\subsection{EVALUATION OF MITIGATIVE TECHNIQUES}

The previous sections of this chapter discuss the procedures for developing a mathematical model for analysis of flow and contaminant transport at porous media nuclear power plant sites and then demonstrates the procedures by applying them to the STP. This pattern is continued in this section wherein the emphasis is in demonstrating the general approach to evaluate mitigative techniques while giving only limited attention to the specific characteristics and configuration of the STP.

\subsubsection{Approach}

The first step in the evaluation of mitigative techniques involves preliminary screening of those methods that clearly are not feasible given sitespecific hydrogeologic conditions. Engineering judgment and an understanding of the design, construction and performance considerations of the different techniques are usually sufficient to determine those methods most likely to be applicable. The review of mitigation techniques presented in Chapter 4.0 provides information necessary for this screening phase.

Following the initial screening, the remaining mitigative techniques are subjected to a detailed assessment in terms of their effectiveness in achieving the desired level of mitigation and in formulating a their preliminary design. Recent studies by Geologic Testing (1982); Silka and Mercer (1982); and Cole et al. (1983) demonstrate the usefulness of computer modeling in the feasibility study process. While it may be straightforward to determine that grouts are applicable to a relatively porous hydrogeologic unit, mathematical models are required to assess the performance of a grout cutoff as a function of location (i.e., up-gradient or down-gradient and orientation and dimension. The trade-offs in performance lead one to conceptual design specifications for a technique. Once a model is developed for a site, any number of alternatives can be evaluated with minimal additional effort. Further predictions of contaminant concentrations can be obtained for any location of interest such as site boundaries, surface water discharge points, or drinking water wells (Brown et al. 1983).

\subsubsection{Screening of Mitigative Techniques}

Within the generic site classification scheme the STP is categorized as porous unconsolidated silicate. As such, a wide range of mitigative techniques or strategies are potentially feasible (see Table 5.6.2-1). However, due to site specific data obtained from the hydrogeologic characterization and assessment performed on the STP the range of feasible strategies can be narrowed.

Both particulate (i.e., cement-based) and more probably non-particulate (i.e., chemical) grouts may be feasible for construction of ground-water cutoffs to the migration of radionuclides from the STP. The general material properties of the shallow zone aquifer indicate that both the upper and lower shallow zone aquifers could be successfully grouted with the intervening clay layer acting as a key-in and a natural ground-water flow barrier. The average permeability of the host material at the STP is approximately $85 \mathrm{ft} /$ day 
$(0.03 \mathrm{~cm} / \mathrm{sec})$ which falls in the middle of the "easy" to grout range of permeabilities listed in Table 5.6.2-1. The relatively high permeability coupled with the low average ground-water velocity (i.e., roughly $0.3 \mathrm{ft} / \mathrm{day}$ ) facilitates successful chemical grouting of ground-water cutoffs. According to data presented in Table 4.3.1-3 permeation grouting with sodium silicate, lignochrome gel, colloidal solutions, or prepolymer grouts would be recommended. In granular materials, such as those present at the STP, there may be a filtration of cement-based grouts, thus diminishing their suitability for development of a low permeability barrier. However, detailed laboratory analyses would be required to estimate the degree and overall effect of the filtration as a constraint on the feasibility of implementing cement-based grouts. The soil size limitations on grout permeation presented in Figure 4.3.1-1 suggest that silicate grouts may be most suitable for the STP. Silicate grouts may also be somewhat more resistant to the potential prolonged exposure to saltwater that may be possible at the STP depending on the eventual location of the cutoff. Finally, the normal range of $\mathrm{pH}$ (i.e., roughly 6 to 8 ) observed for the groundwater in vicinity of the STP (Hammond 1969) would not prohibit the use of a silicate grout.

Because of the depth to which a constructed barrier would have to be placed to be effective in mitigating the consequences of contamination of the lower shallow zone aquifer, the use of steel sheet piling is infeasible and the construction of slurry trench cutoff walls would be impractical. A realistic value for the depth of cutoff, including key-in to the underlying confining bed, that would be required for the STP is roughly $100 \mathrm{ft}$ below MSL. This depth coupled with a surface elevation of $25 \mathrm{ft}$ would require excavation of over $125 \mathrm{ft}$ of material. The depth of excavation could be reduced by locating the slurry trench in an area where the bottom of lower shallow zone aquifer is closer to the ground surface. However, this approach may result in a grossly non-optimal placement of the cutoff. The alternate-slot method would be recommended for construction of a slurry trench cutoff at depths approaching $125 \mathrm{ft}$. Because of structural integrity, the depth of the wall and the relatively high permeability of the site lean-concrete would most likely be preferred for the construction of the cutoff. Also, because of the depth and looseness of the host material, trench cave-in may prohibit the construction of a slurry trench cutoff.

Creation of a hydraulic barrier to the specific path or trajectory of the contaminant plume resulting from a possible severe accident at the STP would also be a feasible mitigative strategy for the STP site. Due to the conceptual nature of these dynamic strategies, their feasibility, which is directly related to performance, must be addressed via some form of model evaluation of the effects of varying withdrawal and/or injection rates at various locations on ground-water flow and contaminant transport. Since the aquifer for which potential surface modification would be sought is deep (125 ft) and confined, deep wells would most likely be installed that have high pumping capacities. The wells would only be screened in the lower shallow-zone aquifer in order to prevent avoidable contamination of the upper shallow zone aquifer. Strategies that involve injection would be preferable to a significant amount of withdrawal because of the potential for contamination of the surface environment. Readily available sources of injection water could be obtained from the 
Colorado River although filtration would be required for efficient injection. An alternative to filtering Colorado River water would possibly be to locate a high volume discharge well a suitable distance away so that drawdown did not appreciably undermine the creation of a hydraulic barrier. The well discharge would then be used as injection water. Such a scheme would require development of an overland pipeline and small retention storage. The STP cooling reservoir could also be useful as both a source of injection water and/or a storage basin for water withdrawn from the aquifer, depending upon the degree to which it would be contaminated by atmospheric releases of radionuclides. According to Davis and DeWiest (1966) water yields of between 200 and $300 \mathrm{gpm}$ are normally associated with coastal plain aquifers. Therefore, ground-water withdrawal rates should not exceed this limit by any appreciable amount. Acceptable injection rates should be achievable because of the relatively high porosity (i.e., 0.37) and high permeability in the vicinity of the STP.

Interceptor trenches and permeable treatment beds would not be practically feasible at the STP site for two specific reasons. First, the depth limitations on excavation for development of slurry trenches also apply to development of interceptor trenches. Second, the characteristics of ground-water flow and contaminant transport in the shallow zone aquifer prohibit implementation of collection systems. Because of the very flat hydraulic gradient associated with the lower shallow zone aquifer and the relatively high effective porosity ground-water velocities are very low. Consequently, dispersive behavior may contribute to the spread of a contaminant plume much more so than advective transport of radionuclides. Therefore, to be efficient any collection system (i.e., interceptor trenches or permeable treatment beds) would require artificial inducement (possibly through withdrawal and injection) to counter the effect of dispersion in intercepting the contaminant. Because of the depth and confined nature of the lower shallow zone aquifer and the dispersive influence of the hydraulic properties of the aquifer, collection systems would be impractical.

Ground-water freezing would also be impractical for construction of a barrier to ground-water flow because of the obvious limitations of cost and climate. Thermal erosion due to the warm climate and frequent precipitation could continually prohibit closure of a frozen cutoff. Air injection would not be recommended due to the lack of experience in designing and implementing air injection systems as barriers to ground-water flow.

In summary, the ground-water contaminant mitigative techniques that appear most suitable for implementation at the STP based on the reconnaissance level hydrogeologic characterization and the pre-mitigative ground-water flow and contaminant transport analysis are:

1. a fully penetrating and properly keyed grouted cutoff, and

2. a hydraulic barrier to ground-water flow and transport created by withdrawal and injection. 


\subsubsection{Assessment of Feasible Alternatives}

The two basic mitigation techniques identified in the screening phase as most feasible for the STP site are a grouted cutoff wall and the development of a hydraulic barrier by ground-water injection and withdrawal. In reality there are any number of implementable conceptual designs for each of these techniques, either individually or in combination. It is not the purpose of this case study to attempt to evaluate all of these possibilities or even to identify the "best" or most effective design. The intent here is to provide information regarding the use of quantitative methods to make such an evaluation and to demonstrate their use for selected alternatives.

The approach used to assess the above alternatives involves quantifying their effectiveness in increasing ground-water travel time from the STP to the Colorado River and, hence, enhancing natural decay of radionuclides. Selected model parameters and inputs for the local transport model were adjusted to simulate the impact each alternative would have on ground-water flow. Steadystate simulations of ground-water flow were then made and the results were compared with the pre-mitigated results to obtain a measure of effectiveness.

\subsubsection{Cutoff Walls}

Cutoff walls are vertical barriers emplaced to either prevent contaminated ground water from migrating away from the site, or to divert incoming ground water away from the contaminant source. There are several alternative cut-off design configurations including (Brown et al. 1983):

1. an up-gradient cutoff extending to an impermeable layer,

2. a down-gradient cutoff extending to an impermeable layer,

3. both up-gradient and down-gradient cutoffs, and

4. a cutoff that extends completely around the site

For this case study, up-gradient and down-gradient cutoffs having lengths of $2000 \mathrm{ft}, 3000 \mathrm{ft}$ and $4000 \mathrm{ft}$ were considered. The effectiveness of each cutoff was simulated by introducing a line of nodes having zero permeability $1000 \mathrm{ft}$ up-gradient or down-gradient, from the STP. The $2000 \mathrm{ft}$ cutoffs were centered relative to the plant as illustrated in Figure 6.7.3-1 and Figure 6.7.3-2. The $3000 \mathrm{ft}$ and $4000 \mathrm{ft}$ cutoffs were simply increased in length by adding to the west. The results of the simulations show that ground-water travel times are increased from 310 years for the pre-mitigative case to 540 years, 530 years and 525 years for the $2000 \mathrm{ft}, 3000 \mathrm{ft}$, and $4000 \mathrm{ft}$ cut offs, respectively. Figure 6.7.3-3 compares the pathline produced by the $2000 \mathrm{ft}$ cutoff with that for the pre-mitigated case. It can be seen that there is very little difference in the two paths, but due to the lowering of the gradient below the plant, the cutoff reduces the distance traveled in the first 100 years substantially. The pathlines for the longer cutoff designs, not shown, are practically identical to that for the $2000 \mathrm{ft}$ cutoff. From these results, it is apparent that for the flow field at the STP, once the up-gradient cutoff is sufficiently long to divert up-gradient flows and flatten the gradient at the site, there is no advantage to increasing the cutoff length. 


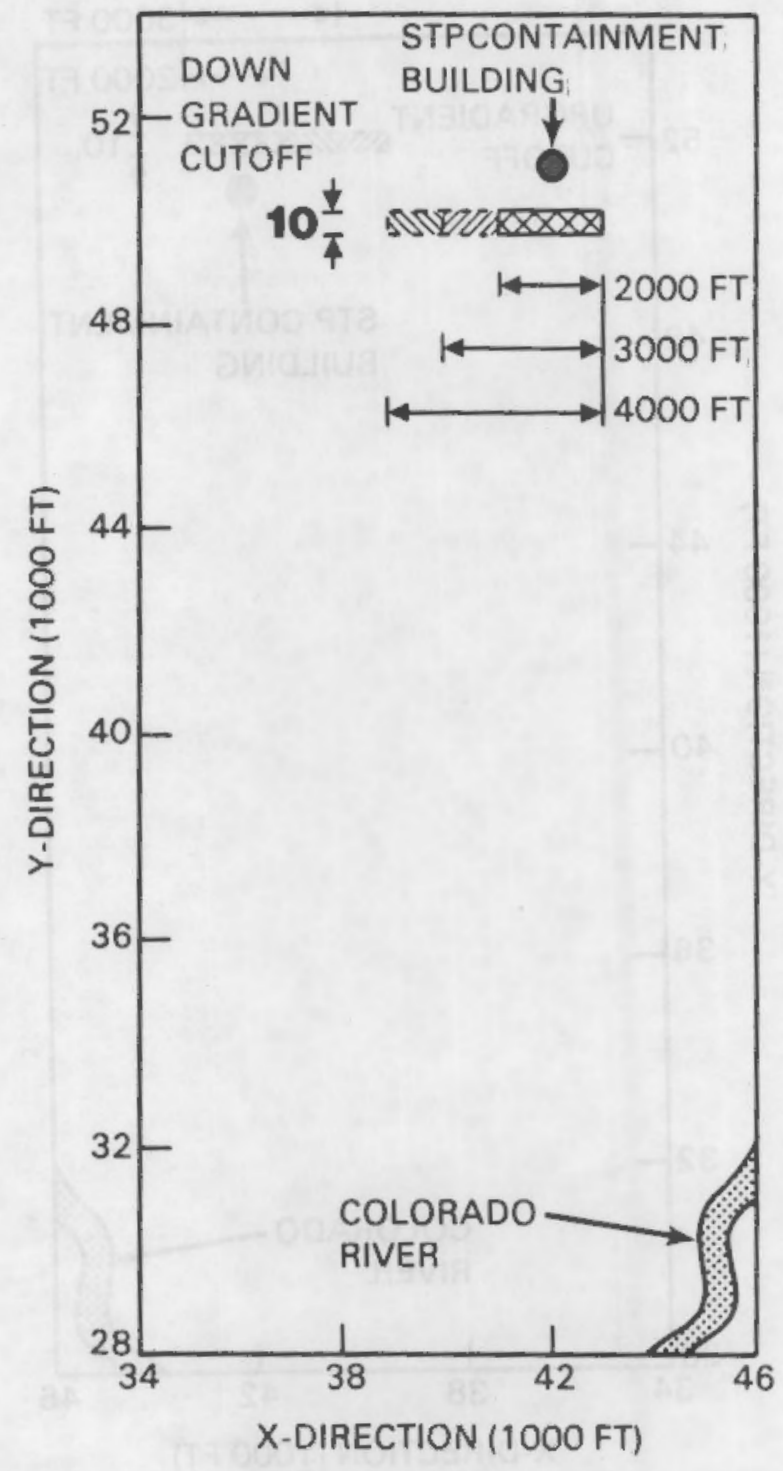

FIGURE 6.7.3-1. Location of Down-Gradient Cutoff Wall 


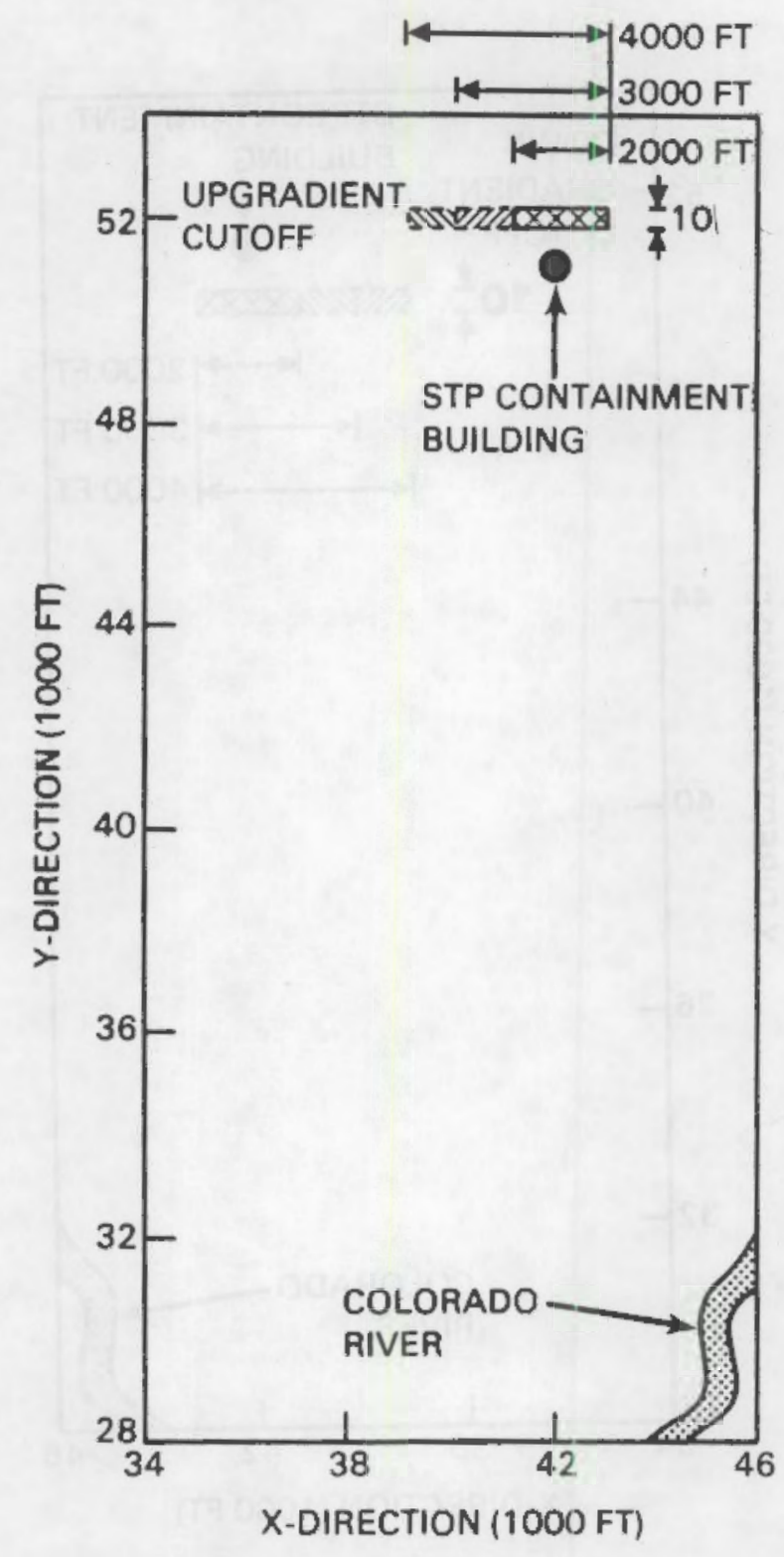

FIGURE $6.7 .3-2$. Location of Up-Gradient Cutoff Wall 


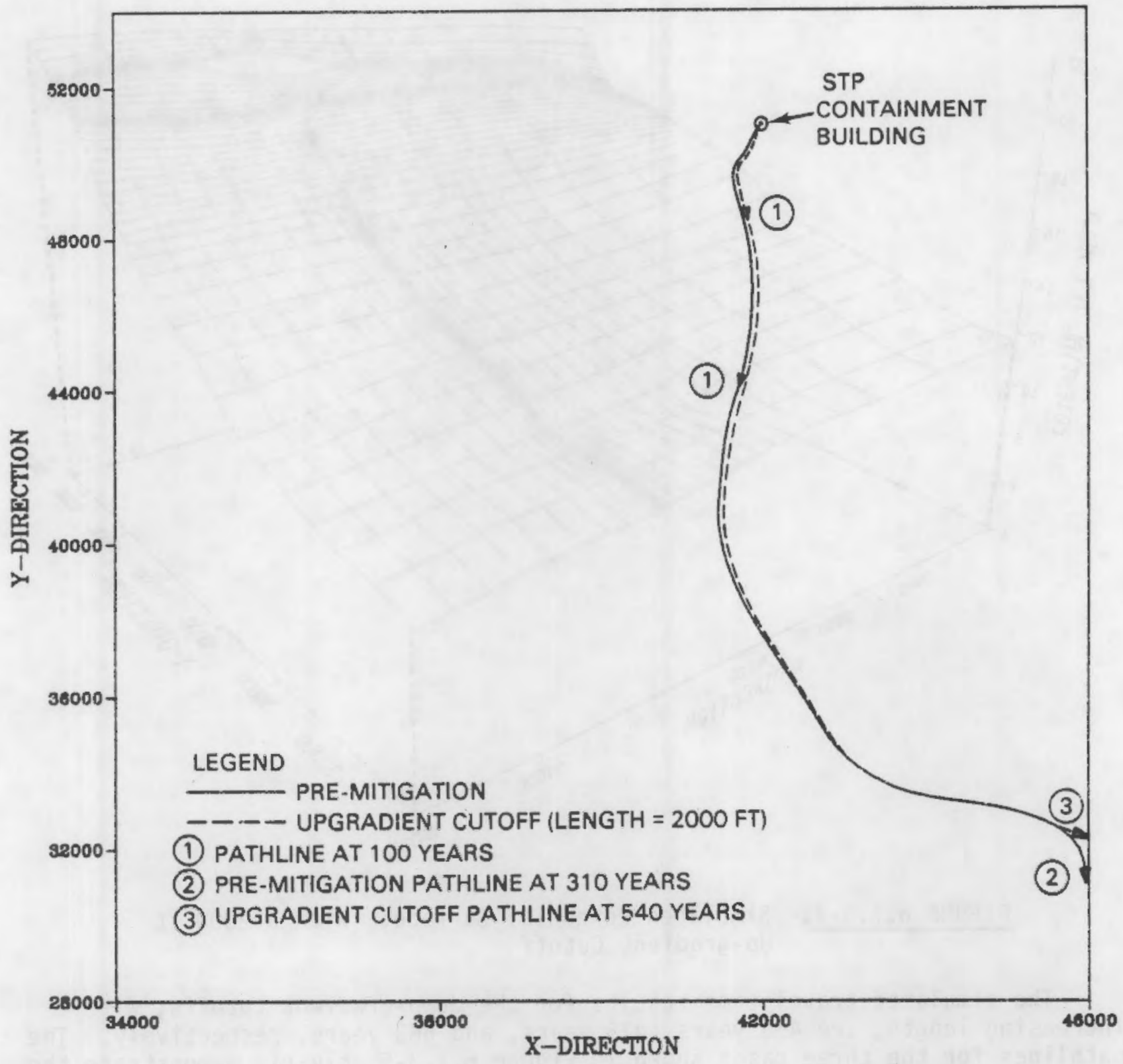

FIGURE 6.7.3-3. Pathline from the STP With $2000 \mathrm{ft}$ Up-gradient Cutoff

The ground-water mounding effects produced by the $2000 \mathrm{ft}$ cutoff are illustrated by the potential surface in Figure 6.7.3-4. The maximum hydraulic head increase behind the cutoff, relative to the pre-mitigated condition, is about $1 \mathrm{ft}$. Thus no significant "bathtub effect" would be evidenced in the confined lower shallow zone aquifer. 


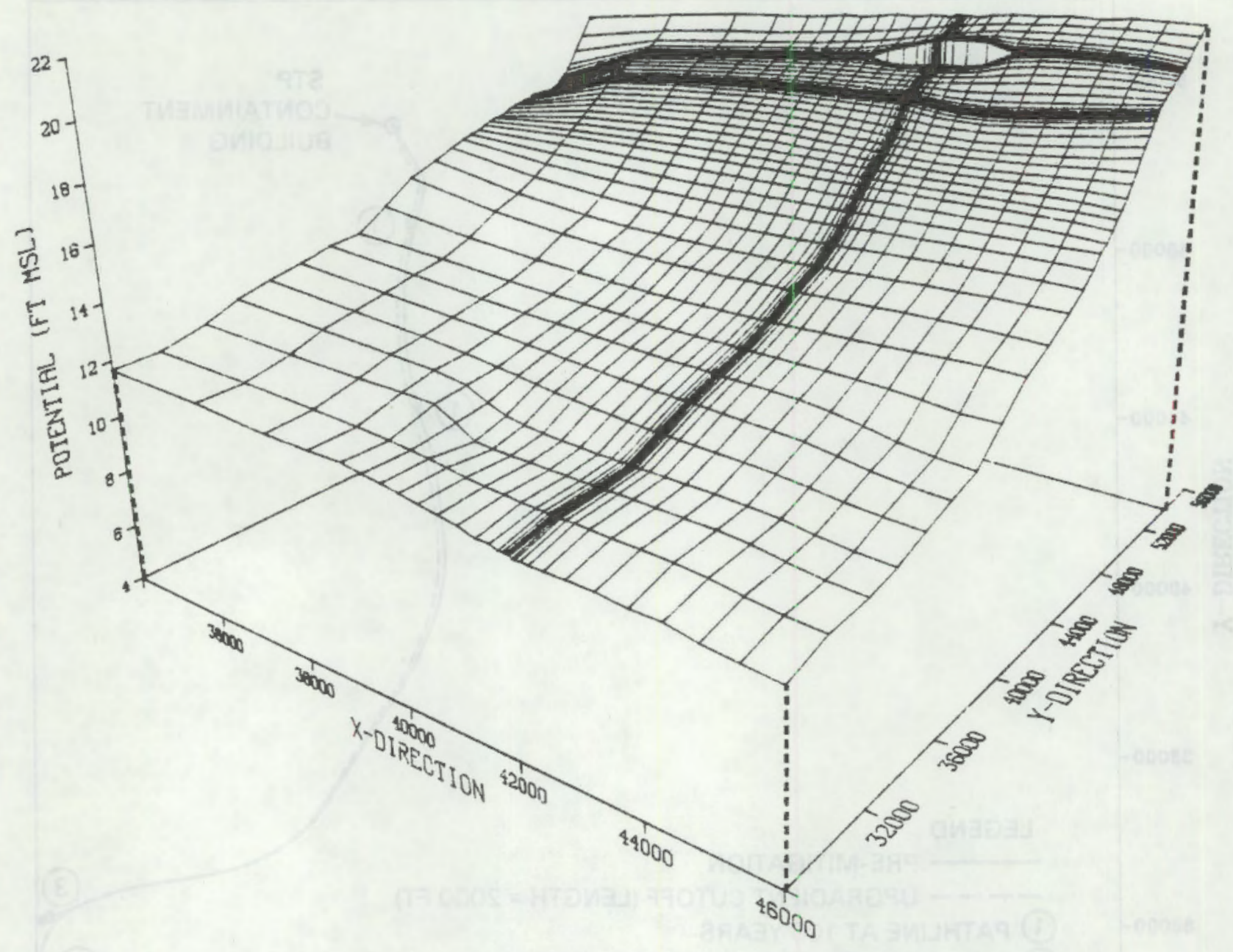

FIGURE 6.7.3-4. Simulated Potential Surface: With a $2000 \mathrm{ft}$ Up-gradient Cutoff

The simulated travel time results for the down-gradient cutoffs, with increasing length, are 450 years, 475 years, and 565 years, respectively. The pathlines for the three cases shown in Figure 6.7.3-5, clearly demonstrate the circuitous routes produced by directly obstructing the pre-mitigative groundwater flow. In contrast to the up-gradient cutoffs, increasing the downgradient cut off length directly increases the path length and, therefore, increases the travel time. However, a $4000 \mathrm{ft}$ down-gradient cutoff is required to surpass the effectiveness of a $2000 \mathrm{ft}$ up-gradient cutoff.

Ground-water mounding effects produced by the $4000 \mathrm{ft}$ down-gradient cutoff well are illustrated by the potential surface presented in Figure 6.7.3-6. The maximum hydraulic head increase behind the cutoff is about $2 \mathrm{ft}$. 


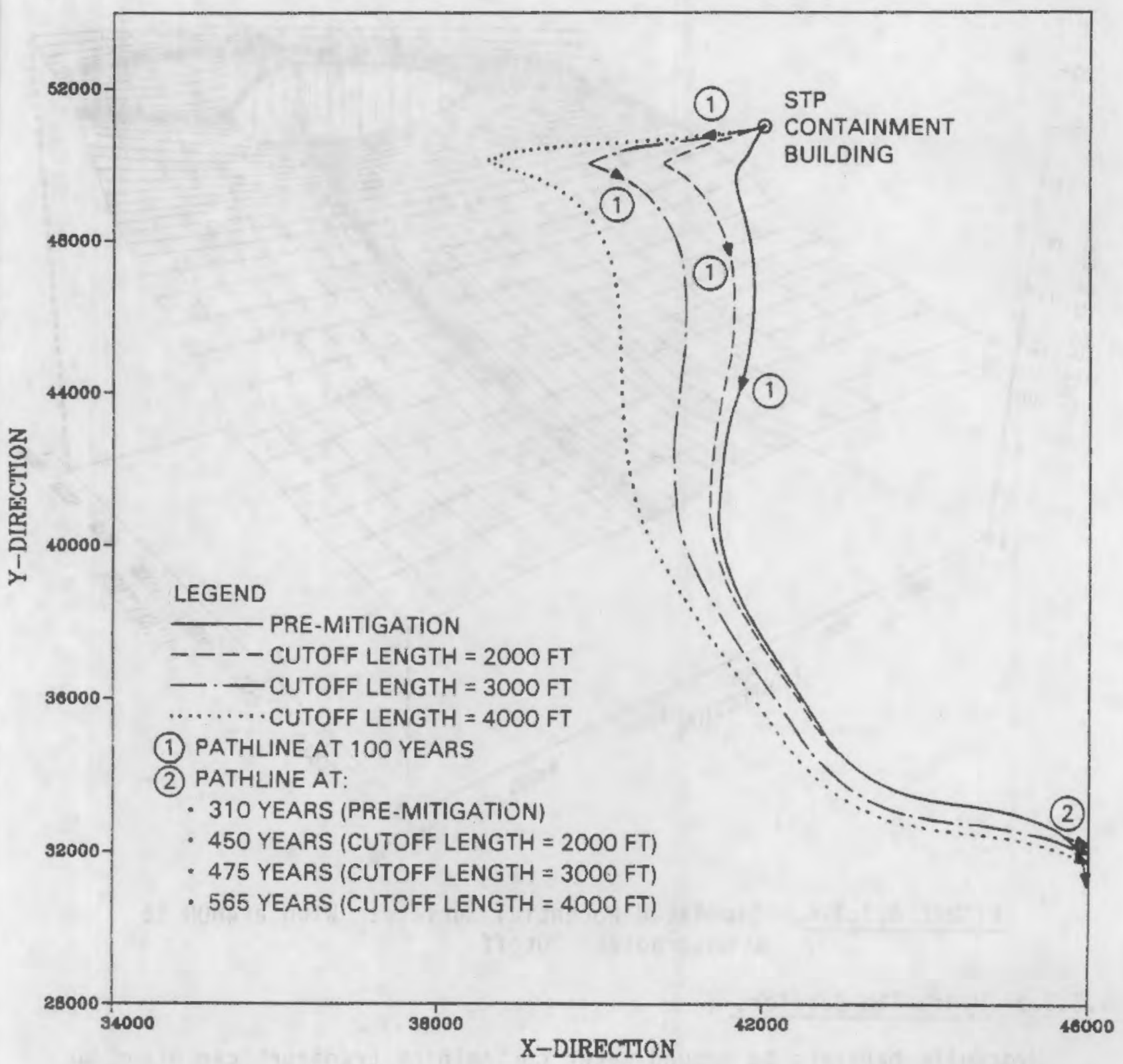

FIGURE 6.7.3-5. Simulated Pathlines from the STP: With Down-gradient Cut offs

A summary of results for the six cutoff design evaluations is presented in Table 6.7.3-1. The table contains the design length, travel time and percentage increase in travel time for each cutoff design. In addition, to provide some perspective on how these designs would effect transport of radionuclides, an estimate is made of the radioactivity remaining in the ground water at the time of a $f^{i v a l}$ at the Colorado River assuming an initial release at time zero of $1 \times 10^{16} \mathrm{pCi}$ of a hypothetical radionuclide having a 10,000 day half-life. In all cases, the increased travel times produced by the cutoffs results in a 2 to 3 orders of magnitude reduction in $\mathrm{pCi}$ remaining at the time of arrival. 


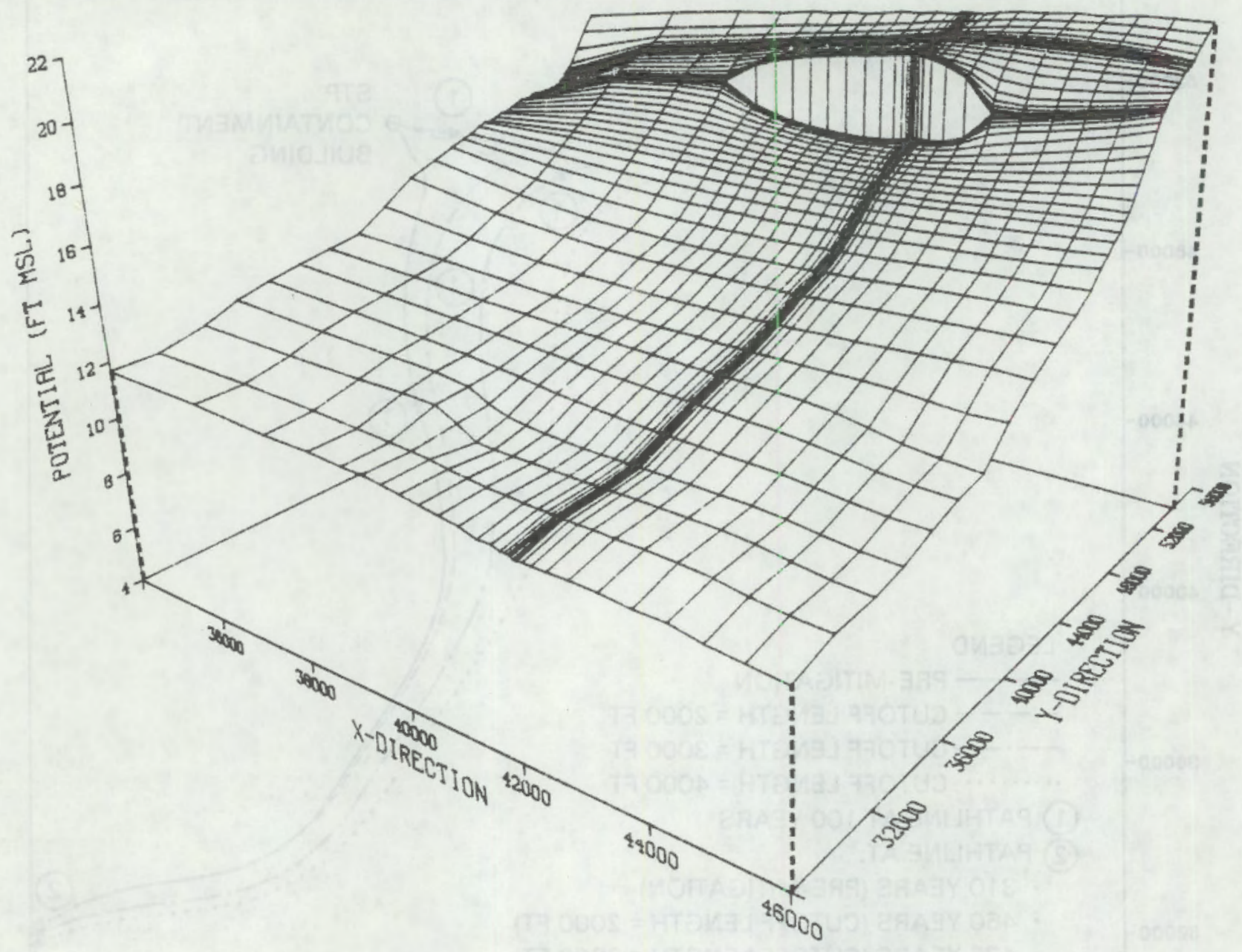

FIGURE 6.7.3-6. Simulated Potential Surface: With a $4000 \mathrm{ft}$ Down-gradient Cutoff

\subsubsection{Hydraulic Barriers}

Hydraulic barriers to ground-water contaminant transport can often be created by ground-water withdrawal and injection which changes the potental surface in some advantageous way. The strategy selected for the STP was development of a hydraulic barrier to divert ground-water flow toward a less potentially hazardous route, that is a longer travel distance (thus greater decay) to the Colorado River. One of the main objectives is to divert the flow without withdrawing contaminated ground water and consequently creating a treatment or disposal problem. 
TABLE 6.7.3-1. Summary of Cutoff Design Evaluations

\begin{tabular}{|c|c|c|c|c|}
\hline Design & $\begin{array}{c}\text { Cutoff } \\
\text { Length, ft } \\
\end{array}$ & $\begin{array}{c}\text { Travel Time } \\
\text { to Colorado } \\
\text { River, yr } \\
\end{array}$ & $\begin{array}{c}\text { Increase } \\
\text { Relative to } \\
\text { Pre-mitigated } \\
\text { Case } \\
\end{array}$ & $\begin{array}{l}\text { Radioactivity (a) } \\
\text { Remaining, } \mathrm{pCi}\end{array}$ \\
\hline Pre-mitigation & - & 310 & -- & $3.9 \times 10^{12}$ \\
\hline \multirow{3}{*}{$\begin{array}{l}\text { Up-gradient } \\
\text { Cutoff }\end{array}$} & 2000 & 540 & $74 \%$ & $1.2 \times 10^{10}$ \\
\hline & 3000 & 530 & $71 \%$ & $1.5 \times 10^{10}$ \\
\hline & 4000 & 525 & $69 \%$ & $1.7 \times 10^{10}$ \\
\hline \multirow{3}{*}{$\begin{array}{l}\text { Down-gradient } \\
\text { Cutoff }\end{array}$} & 2000 & 450 & $45 \%$ & $1.1 \times 10^{11}$ \\
\hline & 3000 & 475 & $53 \%$ & $6.1 \times 10^{10}$ \\
\hline & 4000 & 565 & $82 \%$ & $6.2 \times 10^{9}$ \\
\hline
\end{tabular}

(a) Assumigg an arbitrary half-life of 10,000 days and a release of $1 \times 10^{18} \mathrm{pCi}$ at time zero.

In complicated ground-water flow regimes, where multiple wells may be installed to implement a hydraulic barrier, it can be very difficult to determine pumping rates that achieve the required level of mitigation through control of the trajectory of the contaminant plume. The method used to determine optimum steady-state pumping rates necessary to achieve a specific contaminant control objective once the number and location of the wells have been established is as follows. A nonlinear optimization procedure is coupled with a two-dimensional, steady-state ground-water flow model (similar to TRANS) and a transient, advective contaminant transport model. The optimization algorithm drives the flow modeling component which in turn provides the hydraulic gradient information for the transport analysis. The whole process iterates on pumping rates until the rates that cause the contaminant trajectory and/or travel time to best meet a desired trajectory and/or travel time are determined.

The objective used in the above approach can be any sort of mathematical statement that describes the desired or mitigated contaminant transport. The objective can be in terms of the arrival location of the contaminant travel path and/or the arrival time of a contaminant trajectory, as long as the locations and times can be stated mathematically. This approach can be used to determine the pumping rates necessary to influence the potential surface (which controls contaminant transport) in a manner that will cause the contaminant to be diverted from the unmitigated (and potentially hazardous) travel path into a different and less hazardous trajectory. 
Two general injection/withdrawal schemes for hydraulic barrier development at the STP were evaluated:

1. Near-field injection/withdrawal, and

2. Far-field injection/withdrawal.

The results of the evaluations are discussed below.

Near-field Injection/Withdrawal

Initially, a near-field scheme consisting of 10 wells, located as shown in Figure 6.7.3-7, was input to the optimization procedure. The objective stipulated for the optimization in simple terms was that the flow from the STP be directed away from the Colorado River while minimizing the injection rate. The result of the optimization indicated that only two of the ten injection wells are necessary to satisfactorily divert the contaminant trajectory. The specified injection rates were $34 \mathrm{gpm}$ and $2 \mathrm{gpm}$, respectively. Considering the average yields for irrigation wells in Matagorda County of $1,955 \mathrm{gpm}$, and the high aquifer transmissivities and porosities, this appears to be an easily achievable injection rate. Further, $34 \mathrm{gpm}$ could easily be withdrawn from the colorado River and filtered. In this regard the cooling reservoir could also be used as a settling and/or storage basin.

The pathline for ground-water flow from the STP produced by the near-field scheme is shown in Figure 6.7.3-8. It can be seen that the travel time to the Colorado River is over 1300 years. The potential surface resulting from implementation of the near-field scheme is shown in Figure 6.7.3-9. The spike produced by the scheme represents a maximum increase in potential relative to the pre-mitiqated case of approximately $2 \mathrm{ft}$.

Far-field Injection/Withdrawal

The initial scheme for the far-field case included three wells at the locations shown in Figure 6.7.3-10. Again the target was to divert groundwater flow away from the Colorado River with a minimum combined injection rate. In this case the optimization procedure results stipulated that Well No. 1 pump with a steady-state injection rate of $31 \mathrm{gpm}$. The simulation results show that the travel time to the model boundary is also about 1300 years, a factor of three times the pre-mitigated travel time to the Colorado River. Figure 6.7.3-11 shows the travel path with this scheme which exits the model region along the X-axis. The modified of the potential surface, as illustrated in Figure 6.7.3-12, though more pronounced than that for the other schemes, represents only a $4 \mathrm{ft}$ increase in head relative to the premitigated case. 


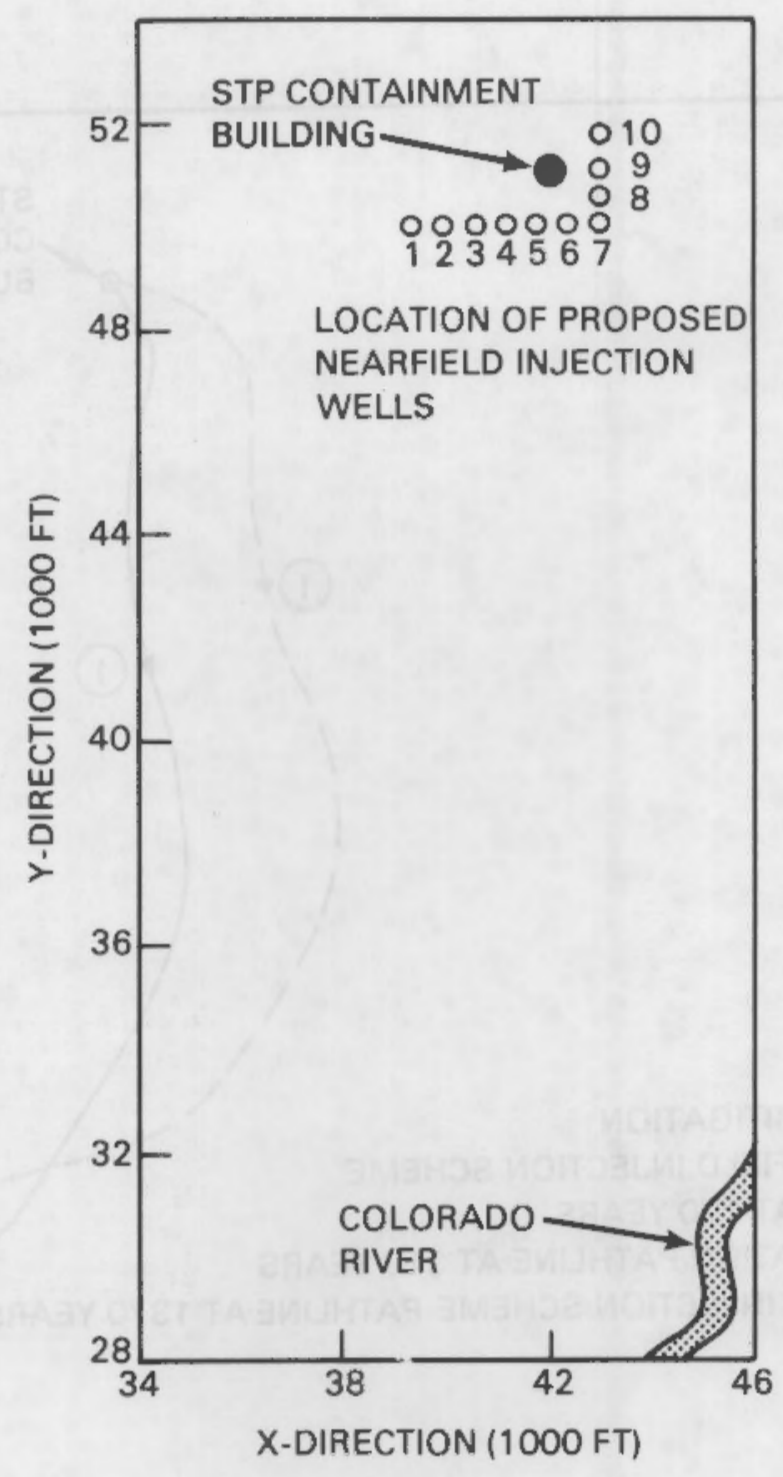

FIGURE 6.7.3-7. Proposed Near-Field Injection Scheme 


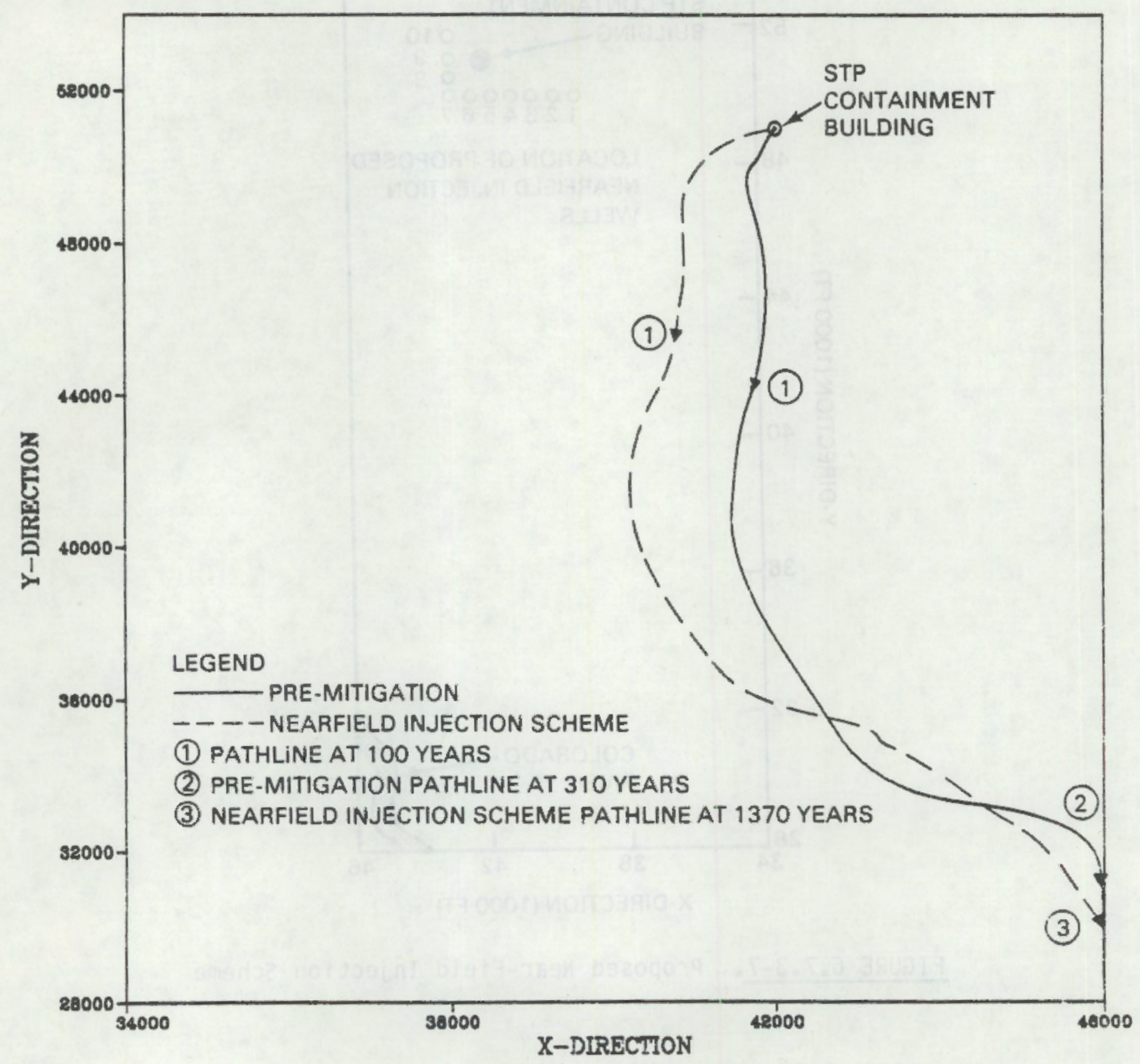

FIGURE 6.7.3-8. Simulated Pathline from the STP: With the Near-Field Injection Scheme 


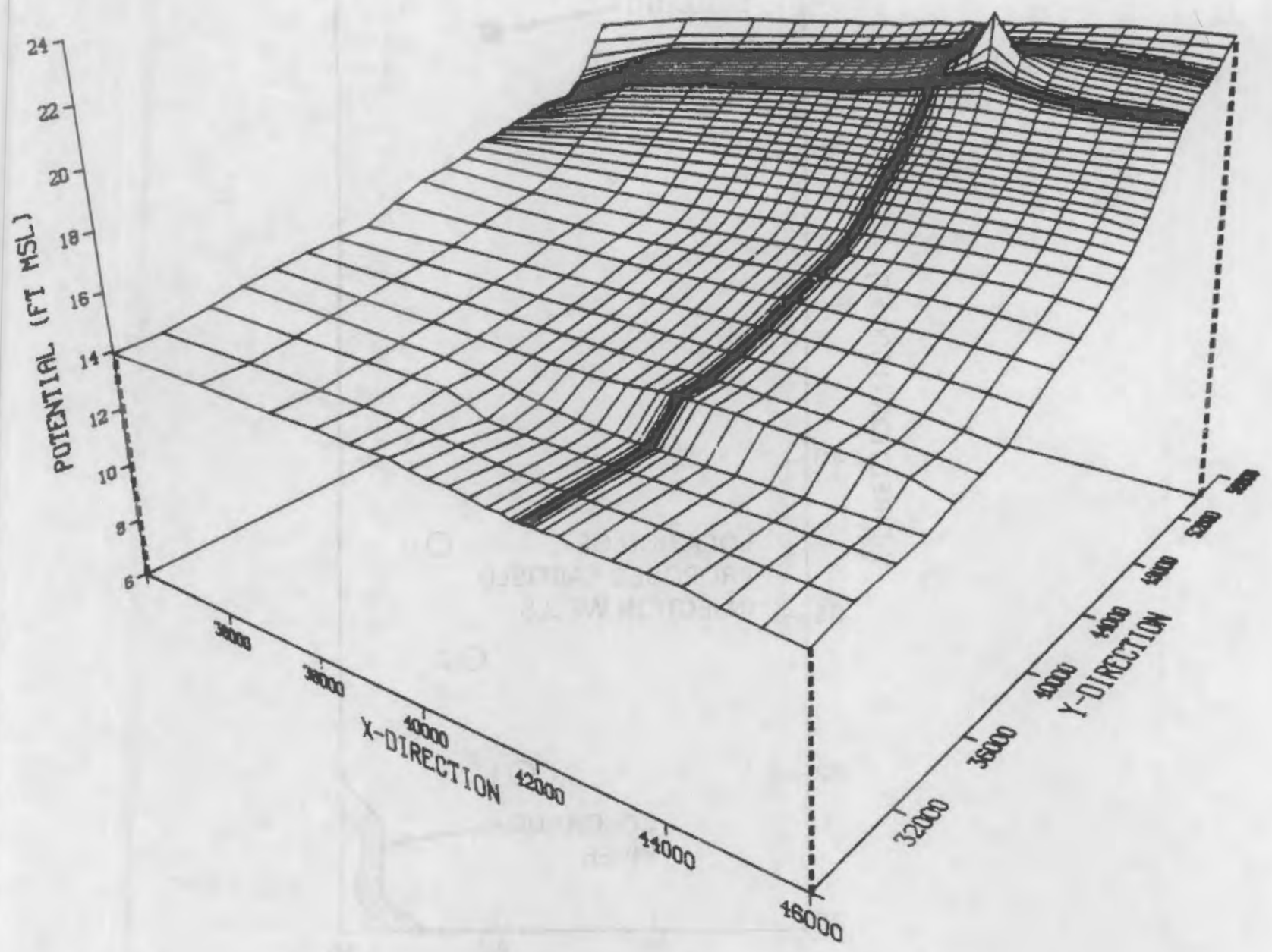

FIGURE 6.7.3-9. Simulated Potential Surface: With the Near-Field Injection Scheme 


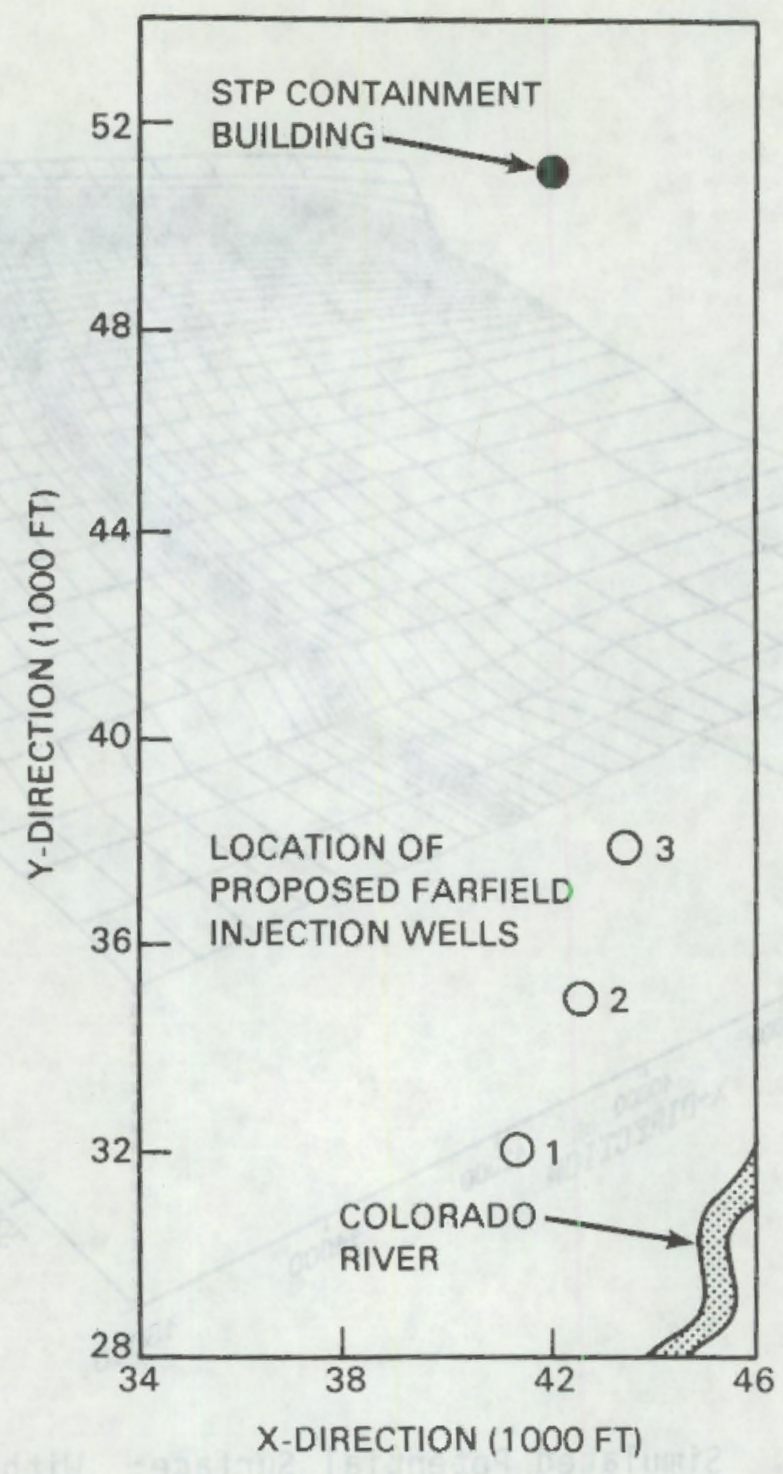

FIGURE 6.7.3-10. Proposed Far-Field Injection Scheme 


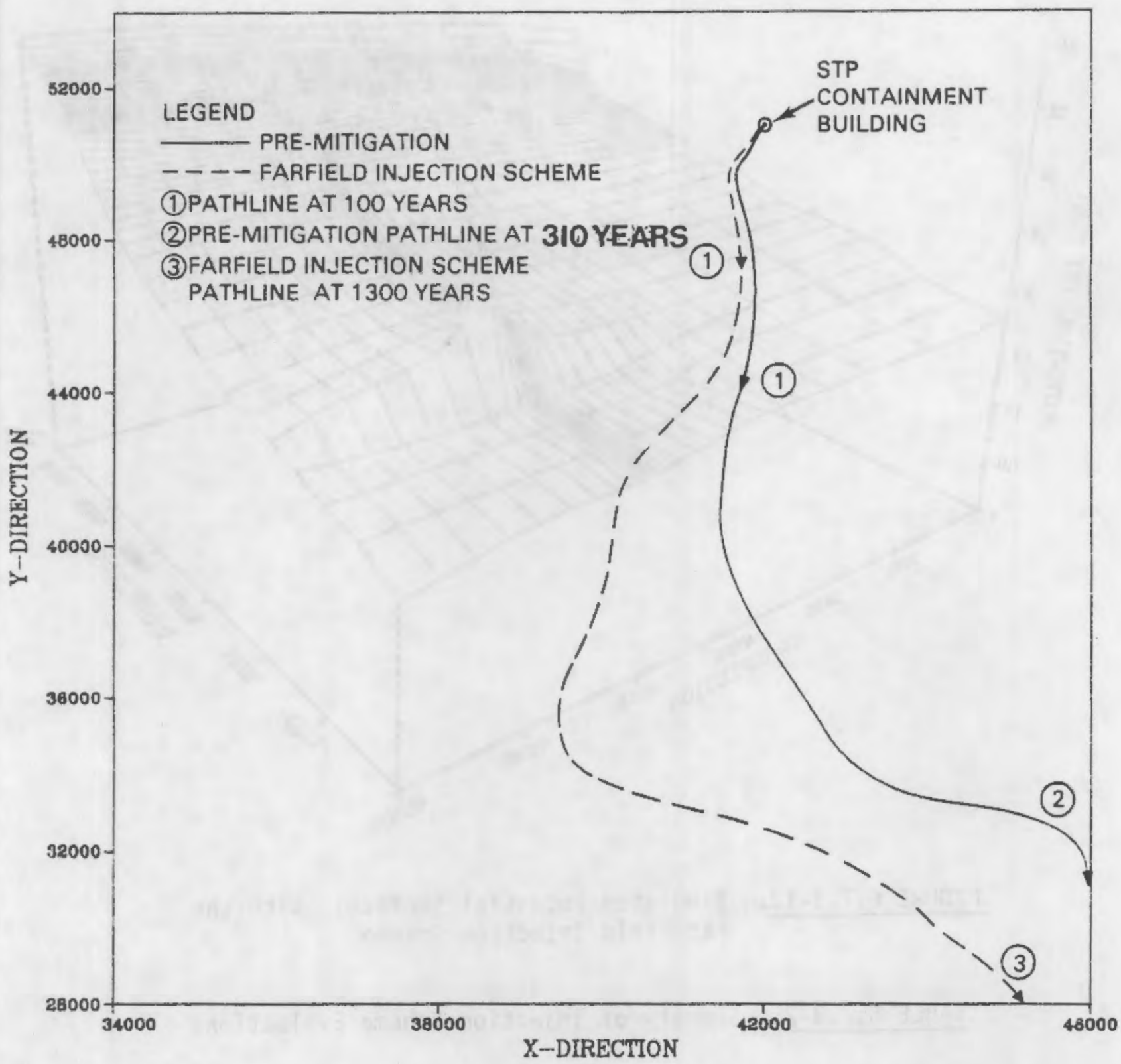

FIGURE 6.7.3-11. Simulated Pathline from the STP: With the Far-Field Injection Scheme

A summary of results for the injection scheme evaluations is presented in Table 6.7.3-2. The table contains the total injection rate, travel time to the Colorado River and percentage increase in travel time relative to the premitigated case. Similar to what was presented for the cutoff designs, an estimate is made of the radioactivity remaining in the ground water at the time of arrival at the Colorado River assuming a hypothetical release of $1 \times 10^{16} \mathrm{pCi}$ of a radionuclide having a 10,000 day half-live. Both schemes produced a greater than three-fold increase in the travel time, reducing the remaining radioactivity by 10 orders of magnitude. 


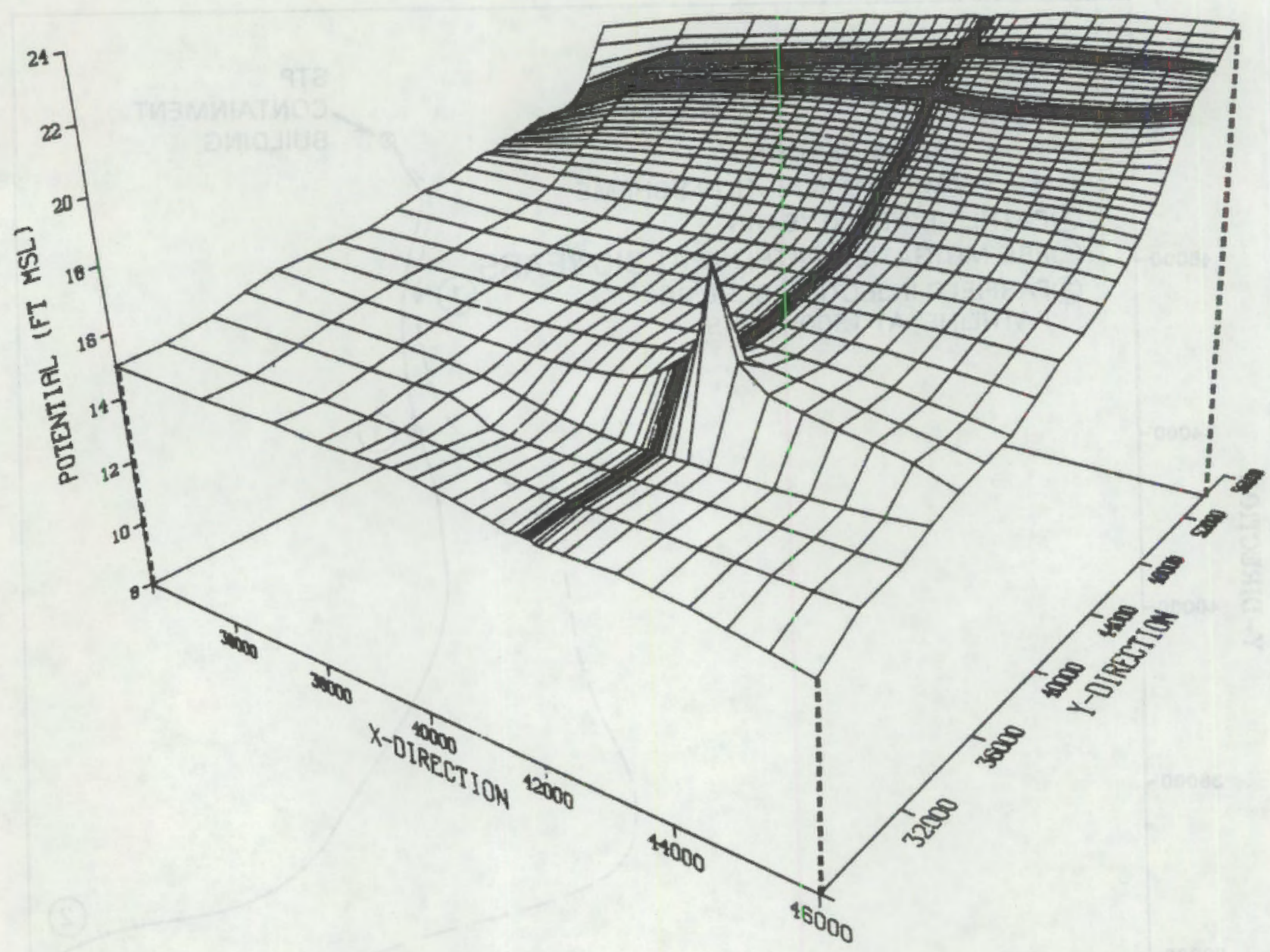

FIGURE 6.7.3-12. Simulated Potential Surface: With the Far-Field Injection Scheme

TABLE 6.7.3-2. Summary of Injection Scheme Evaluations

\begin{tabular}{|c|c|c|c|c|}
\hline Scheme & $\begin{array}{c}\text { Total Injection } \\
\text { Rate, gpm }\end{array}$ & $\begin{array}{l}\text { Travel Time to } \\
\text { Colorado River, yr } \\
\end{array}$ & $\begin{array}{c}\text { Increase Relative } \\
\text { to Pre-Mitigative } \\
\text { Case }\end{array}$ & $\begin{array}{l}\text { Radioactivity (a) } \\
\text { Remaining, } \mathrm{pC} i\end{array}$ \\
\hline Pre-Mitigative & - & 310 & - & $3.9 \times 10^{12}$ \\
\hline Near-field & $36 \mathrm{gpm}$ & 1370 & $342 \%$ & $8.9 \times 10^{0}$ \\
\hline Far-field & $31 \mathrm{gpm}$ & 1300 & $320 \%$ & $5.2 \times 10^{1}$ \\
\hline
\end{tabular}

(a) Assuming an arbitrary half-life of 10,000 days and a release of $1 \times 10^{16} \mathrm{pCi}$ at time zero. 


\subsubsection{Conclusions}

The primary objective of the STP case study is to develop and demonstrate general methodology for evaluating the desirability and feasibility of implementing ground-water contaminant mitigation strategies following a severe nuclear power plant accident. The study was conducted with readily available data sources including the STP Final Safety Analysis Report, regional hydrology reports, and the open literature. The level of technical detail attained in the case study results is commensurate with a reconnaissance or better level of analysis. The STP case study results include:

1. a detailed hydrogeologic characterization of a Texas Gulf Coastal Plain aquifer,

2. a complete idiscussion of data requirements, sources and procedures for the hydrogeologic characterization,

3. a two-dimensional ground-water flow and contaminant transport numerical model development based on the hydrogeologic characterization,

4. a baseline pre-mitigative analysis of radionuclide transport, and

5. an evaluation of the effect of engineered barriers and hydraulic barriers on radionuclide transport.

Major conclusions from the study results are the following:

1. flow and transport model simulation results show that following a severe accident at the STP ground-water radionuclide concentrations would be well below maximum permissible concentrations, therefore, mitigative action would not be necessary,

2. model evaluations of hydraulic and constructed barriers indicate that hydraulic barriers could prove to be much more effective in mitigating radionuclide discharges at the STP,

3. for the STP, all mitigation techniques evaluated significantly increased ground-water and contaminant travel times, and

4. in the case of the STP, up-gradient cutoffs proved to be more effective than down-gradient cut offs of the same length. 


\subsection{REFERENCES}

Baker, E. T., Jr., and J. R. Wall. 1976. "Sumnary Appraisals of the Nations Ground-Water Resources - Texas Gulf Region," U.S. Geological Survey Professional Paper 813-F. U.S. Government Printing office, Washington, D.C.

Bental1, R. 1963. "Methods of Determining Permeability, Transmissivity and Drawdown," Geological Survey Water-Supply Paper 1536-I. U.S. Department of the Interior, U.S. Geological Survey, Arlington, Virginia.

Boonstra, J., and N. A. de Ridder. 1981. Numerical Modeling of Groundwater Basins, International Institute for Land Reclamation and Improvement, Wageningen, The Netherlands.

Brown, S. M., S. H. Boutwell and B. R. Roberts. 1983. "Selection and Use of Models for Remedial Action Evaluation at Uncontrolled Hazardous Waste Sites," (Draft), Anderson-Nichols and Co., Inc., Palo Alto, California.

Cole, C. R., F. W. Bond, S. M. Brown and G. W. Dawson. 1983. "Demonstration/ Application of Ground-Water Modeling Technology for Evaluation of Remedial Action Alternatives," prepared by Pacific Northwest Laboratories, Richland, Washington, for the Municipal Environmental Research Laboratory, Environmental Protection Agency, Cincinati, Ohio.

Espenshade, E. B., Jr., ed. 1970. Goodes World Atlas, Rand McNally and Company, Chicago, Illinois.

Fried, J. J. and M. A. Combarnous. 1971. "Dispersion in Porous Media," in Advances in Hydroscience, Academic Press, New York, pp. 169-282.

Freeze, R. A., and J. A. Cherry. 1979. Groundwater, Prentice-Hall, Inc., Englewood Cliffs, New Jersey.

Gelhar, L. W. and C. J. Axness. 1981. Stochastic Analysis of Macrodispersion in Three-Dimensionally Heterogeneos Aquifers, Report No. H-8, Hydrologic Research Program, New Mexico Institute of Mining and Technology, Socorro, New Mexico.

Geologic Testing Consultants Ltd. 1982. "Gloucester Special Waste Disposal Site: Hydrostratigraphic Interpretation and Remedial Measures Assessment Using Mathematical Modeling Techniques," Draft report prepared by GTC, Ottawa, Ontario for the Department of Supply and Services, Environment Canada .

Hammond, W. W., Jr. 1969. "Ground-Water Resources of Matagorda County, Texas," Report 91, prepared by the Texas Water Development Board in cooperation with the Lower Colorado River Authority and Matagorda County Commissioners Court, Austin, Texas. 
Simmons, C. S. 1982. "A Stochastic-Convective Transport Representation of Dispersion in One-Dimensional Porous Media Systems," Water Resource Res., 18(4) pp. 1193-1214.

Simmons, C. S. and C. R. Cole. 1983. "Groundwater Transport Model Selection and Evaluation Guidelines," (in preparation). Pacific Northwest Laboratory, Richland, Washington.

Stokes, W. L. 1966. Essentials of Earth History, Prentice-Hall, Inc., 2nd Ed., Englewood cliffs, New Jersey.

U.S. Nuclear Regulatory Commission. 1978. "Liquid Pathways Generic Study," NURE G-0440.

U.S. Nuclear Regulatory Commission. 1975. "Reactor Safety Study: An Assessment of Accident Risks in U.S. Commercial Nuclear Power Plants," NUREG-15/014 USNRC, U.S. Government Printing office, Washington, D.C.

Wang, H. S. and M. P. Anderson. 1982. Introduction to Groundwater ModelingFinite Difference and Finite Element Methods, W. H. Freeman and Co., San Francisco.

Yeh, G. T. 1981. "AT123D: Analytical Trans One-, Two-, and Three-Dimensional Simulation of Waste Transport in the Aquifer System," ORNL-5602, Oak Ridge National Laboratory, Oak Ridge, Tennessee. 
Houston Power and Light. 1978. "Final Safety Analysis Report, South Texas Project Units 1 and 2," Houston, Texas.

Hunt, C. B. 1967. Physiography of the United States, W. H. Freeman and Company, San Francisco, California.

International Mathematical and Statistical Libraries, Inc. 1980. "The IMSL Library Reference Manua 1." Edition 8. Houston, Texas.

Kincaid, C. T., J. R. Morrey and J. E. Rogers. 1983. "Geohydrochemical Models for Solute Migration, Volume I, The Selection of Computer Codes and Description of Solute Migration Processes," prepared by Battelle, Pacific Northwest Laboratories, Richland, Washington, for the Electric Power Research Institute, Palo Alto, California.

Kruseman, G. P. and N. A. de Ridder. 1979. "Analysis and Evaluation of Pumping Tests Data," Bulletin 11, ILRI, Wageningen, The Netherlands.

Mercer, J. W., S. D. Thomas and B. Ross. 1982. "Parameters and Variables Appearing in Repository Siting Models," Prepared by Geotrans, Inc. under contract to Teknekron Research, Inc. for the U.S. Nuclear Regulatory Commission, NUREG/CR-3066.

Mercer, J. W. and C. R. Faust. 1980. "Ground-Water Modeling: An Overview," Ground Water, 15(2) pp. 108-115.

Molz, F. J., 0. Guven and J. G. Melville. 1983. "An Examination of Scale Dependent Dispersion Coefficents," Ground Water, 21(6), pp. 715-725.

National Dceanic and Atmospheric Administration. 1980. "Local Climatological Data-Annual Summaries for 1980," National Climatic Center, Asheville, North Carolina.

Niemczyk, S. J., et al. 1981. "The Consequences from Liquid Pathways After a Reactor Meltdown Accident." U.S. Nuclear Regulatory Commission, NUREG/CR-1596.

Office of Water Data Coordination. 1977. "National Handbook of Recommended Methods for Water-Data Acquisition," U.S. Geological Survey, Reston, virginia.

Prickett, T. A., T. G. Naymik and C. G. Lonnquist. 1981. "A Random-Walk Solute Transport Model for Selected Groundwater Quality Evaluations," Bulletin 65, 111 inois State Water Survey Division, Champaign, Illinois.

Prickett, T. A., and C. G. Lonnquist. 1971. "Selected Digital Computer Techniques for Groundwater Resource Evaluation," Illinois State Water Survey Division, Urbana, Illinois. 
NOREG/CR - 3681

PNL-5072

MitheAat SUET "Techniques and Analysis of Generic Site Conditions for Ground-Water Contaminantion Associated witn Severe

Accidents

6. AUTHOA(S)

J. M. Shafer

P. L. Oberlander

R. L. Skaggs

B PEAFORMING ORGANIZATION NAME ANO MAILING ADORESS Ifnclude Zip COde)

Pacific Northwest Laboratory

P.0. Box 999

Richland, WA 99352

2 Lave bionk

4 RECIPIENT'S ACCESSION NUMEER

5. DATE REPOAT COMPLETED

\begin{tabular}{l|l}
\hline MONTH & TEAA \\
January & 1984
\end{tabular}

7 DATE REPOAT ISSUED

MONTH TYEAR

Apri1

1984

9. PAOSECT/TASK WOAK UNIT NUMBEF

PNL -5072

10. FIN NUMTER

B2454

1 SPONSORING ORGANIZATION NAME ANO MAILING ADDRESS IIIClUUO Zio COdE)

Division of Health, Siting, and Waste Management

Office of Nuclear Regulatory Research

U.S. Nuclear Regulatory Commission

Washington, D.C. 20555

12. TYPE OF AEPORT

Technical

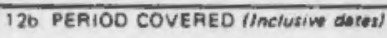

August 1982-January 1984

13. SLPPLEMENTARY NOTES

14 AESTRACT (200 woros or 1 iessi

The purpose of this study is to evaluate the feasibility of using ground-water contaminant mitigation techniques to control radionuclide migration following a severe commercial nuclear power reactor accident. The two types of severe commercial reactor accidents investigated are: 1) containment basemat penetration of core melt debris which slowiy cools and leaches radionuclides to the subsurface environment, and 2) containment basemat penetration of sump water without full penetration of the core mass. Six generic hydrogeologic site classifications are developed from an evaluation of reported data pertaining to the hydrogeologic properties of all existing and proposed commercial reactor sites. One-dimensional radionuclide transport analyses are conducted on each of the individual reactor sites to determine the generic characteristics of a radionuclide discharge to an accessible environment. Ground-water contaminant mitigation techniques that may be suitable, depending on specific site and accident conditions, for severe power plant accidents are identified and evaluated. Feasible mitigative techniques and associated constraints on feasibility are determined for each of the six hydrogeologic site classifications. The first of three case studies is conducted on a site located on the Texas Gulf Coastal Plain. Mitigative strategies are evaluated for their impact on contaminant transport and results show that the techniques evaluated significantly increased ground-water travel times.

15. KEY WOROS AND DOCUMENT ANALYSIS

Ground-Water Contamination

150 DESCAIPTOAS

Core Melt Accident

Mitigative Techniques

Hydrogeologic Site Characterization

Computer Modeling

16 AVAILABILITY STATEMENT

UNL IMI TED

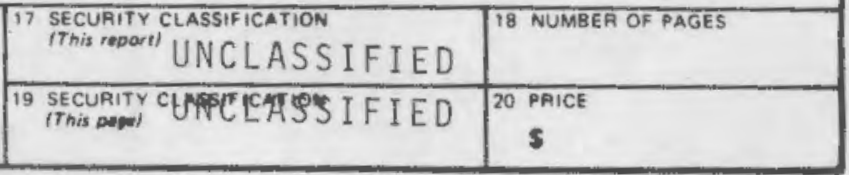

